\title{
Groundwater age in the Wairarapa
}

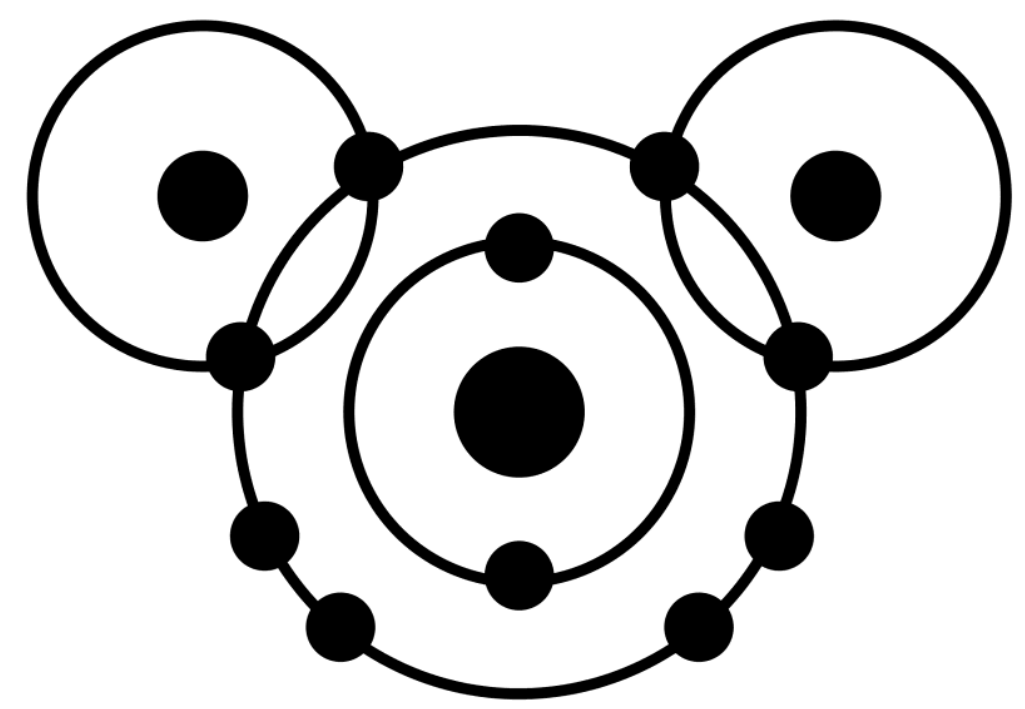

Ryan David Evison

evison.ryan@gmail.com

A thesis submitted to the Victoria University of Wellington in fulfilment of the requirements for the degree of Master of Science

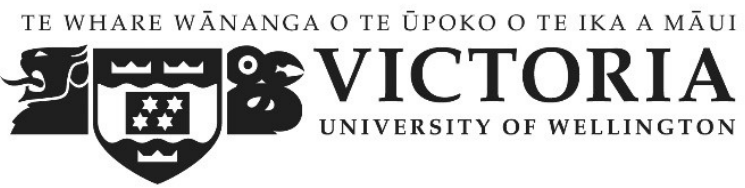

School of Geography, Environment and Earth Sciences

Victoria University of Wellington

November 2014 


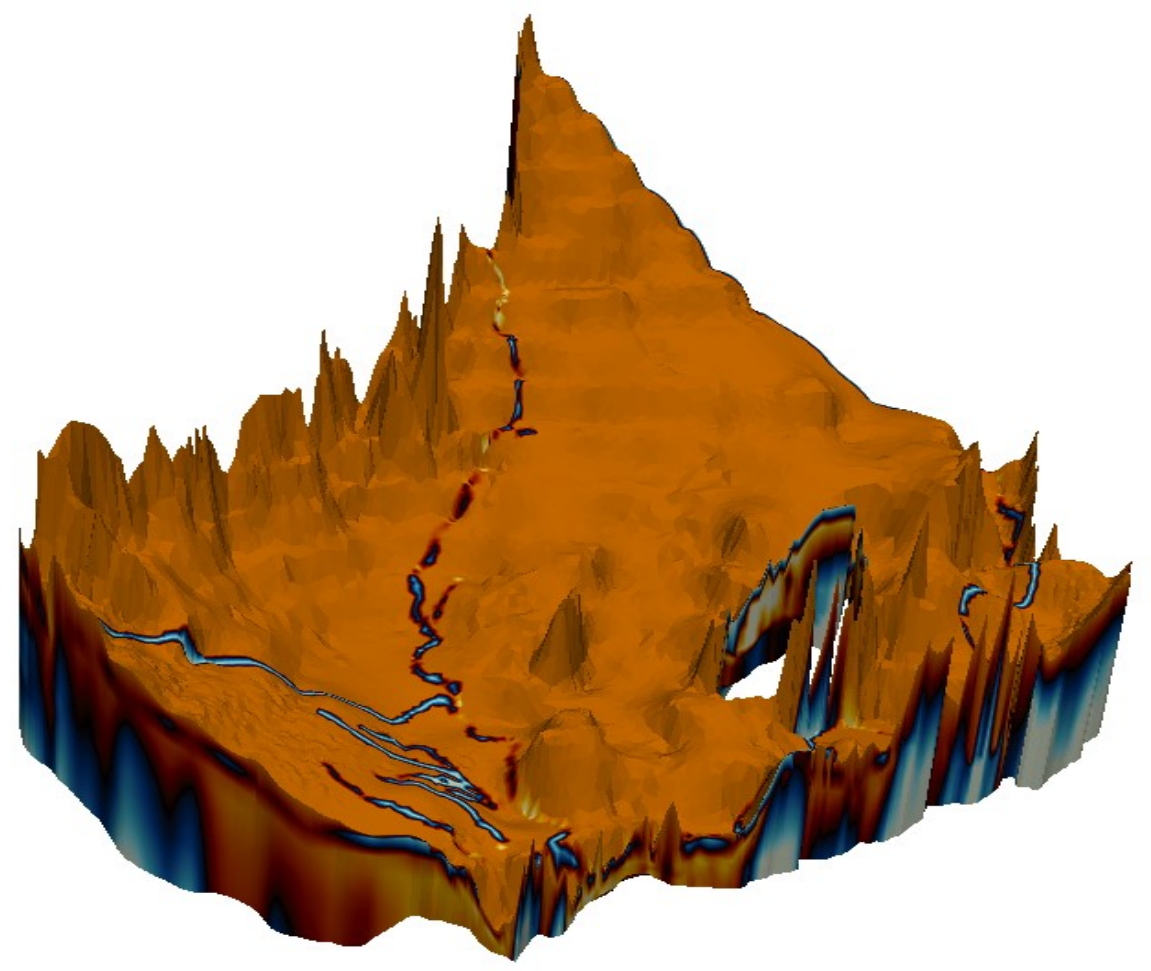

The mystery of the universe, the layer upon layer of new meaning and new discovery, will never be revealed to those who do not look for it.

Veitch (1990) 
This dissertation focuses on the catchment-scale evaluation of groundwater age as a function of space and time in the $270 \mathrm{~km}^{2}$ Middle Wairarapa catchment. The simulation of the mean age and point distribution of ages, contributing to a regional age estimate, is a novel demonstration of the recently developed groundwater software, Cornaton (2012). The Wairarapa is in the southern North Island of New Zealand and is a dynamic water catchment exhibiting complex interactions between its rivers and shallow aquifers. Groundwater has been widely utilized since the 1980s for agriculture, horticulture and drinking water; increasing land use development (i.e. irrigation and nutrient application) requires effective regional management of both the quantity and quality of water resources.

Groundwater age provides insights into groundwater flow and transport processes and thus enables better management of groundwater resources. Subsurface water age information enables the interpretation of recharge influence, zones of sensitivity for sustainable abstraction, as well as contamination risk from land-use intensification to drinking water supplies. It is accepted that groundwater is composed of a mixture of water with different ages, however, until very recently mean age has been the primary indicator for groundwater age assessment. Mean age alone can misrepresent the potential for contamination from young water; for example, a groundwater sample with an old mean age may still contain a significant fraction of young water; therefore, a fuller understanding of the age distribution in both time and space is important for groundwater management. The ability to simulate the full distribution of groundwater age within transient numerical groundwater models has only been very recently enabled, through implementation of the time-marching Laplace transform Galerkin technique (TMLTGT), and is demonstrated in this dissertation.

A transient finite-element groundwater flow model originally developed by Greater Wellington Regional Council was converted to simulate transport of the age tracer tritium and groundwater age using the Ground Water (GW) software. Observed tritium concentrations were utilized in the calibration using the Monte Carlo and Gauss-Marquardt-Levenberg methods. Following the calibration of the transport model the GW software was then used to derive pumping well capture zones and directly simulate age throughout the Middle Wairarapa Valley catchment. The advective dispersive equation and the TMLTGT were used for transient mean-age and transient simulations of the full distribution of groundwater age. The results are presented as maps and graphs of both mean age and age distributions throughout the Middle Valley, covering a 15 year simulation period.

The mean-age simulations indicated the groundwater age in the valley was strongly influenced by seasonal changes and extreme climatic events. Significant variations existed, from high rainfall recharge percolating young water throughout the domain, to dry extended droughts limiting recharge and increasing the age throughout large sections of the Middle Valley. Age distributions were shown to be strongly influenced by abstraction pressures, depth and geology. Abstractions were shown to skew the age distribution, creating both older and younger mean-ages depending on the location of the observation point, and several simulations indicated the potential misrepresentation of young (potentially contaminated) water quantified as old by mean-age assessment. These results show the dynamic nature of the Middle Valley groundwater system and its inherent vulnerabilities. The Wairarapa transient age distributions are one of the first such examples in New Zealand, and they demonstrate the potential of the information interpreted from age estimates to more effectively manage groundwater resources. 


\section{Acknowledgments}

I would like to express my gratitude to GNS Science for providing the scholarship. This dissertation contributes to a tracer validation project aiming to improve groundwater and surface water management in New Zealand. I hope that the project will help provide information for future work, as well as some useful water management options in the Wairarapa. This research has been achieved with the help and previous work done by many people and the project has been immensely rewarding.

- First, I would like to thank my supervisors Bethanna Jackson and Chris Daughney. I was lucky enough to have your guidance, suggestions, and encouragement throughout this project.

- Secondly, Mike Toews, who has within close range throughout the dissertation. Your assistance throughout has been instrumental to the research.

- Many thanks to the developer of the Ground Water (GW) software, Fabian Cornaton. The use of your software and extended support enabled the exciting nature of the project to be achieved.

- I would like to thank the Greater Wellington Regional Council for providing the FEFLOW flow model and data. Mark Gyopari, Doug McAllister, and many others worked for many years on the Wairarapa groundwater investigation.

- John Begg, Andrew Jones, and (again) Chris Daughney for all the hard work on the conceptual groundwater model.

- Karine Petrus for sharing the effort on the Wairarapa. All the best for the future.

- I would like to thank the hydrology and physical geography team at Victoria University. Deborah Maxwell, Martha Trodhall, Monique Beyer, Elizabeth Cairns, Stu Easton, Abby Burdis, and Tapuwa Mharapara; your insights into my work and writing were extremely helpful and I hope I somewhat interested and even taught you something about the dynamic world of groundwater! 
- The team at GNS Science. It has been fantastic working alongside the talented, inspirational, and dedicated hydrogeology team. Special mention to Uwe for the competitive table tennis battles!

- Many thanks to all the people who had insightful comments for the thesis; Mary Roberts, Pete Shand, Tom Shand, Michael Cleary and Roger Shand. Special mention and thanks to the markers, Dr. James Renwick and Dr. Catherine Moore.

- My parents David and Maggie Evison. Thanks for all your insights, assistance and encouragement throughout the research, not that I expected anything less!

- Last but definitely not least, I would like to thank my girlfriend Sally. Without her unbridled support and encouragement, this dissertation would have proved impossible! 


\section{Table of contents}

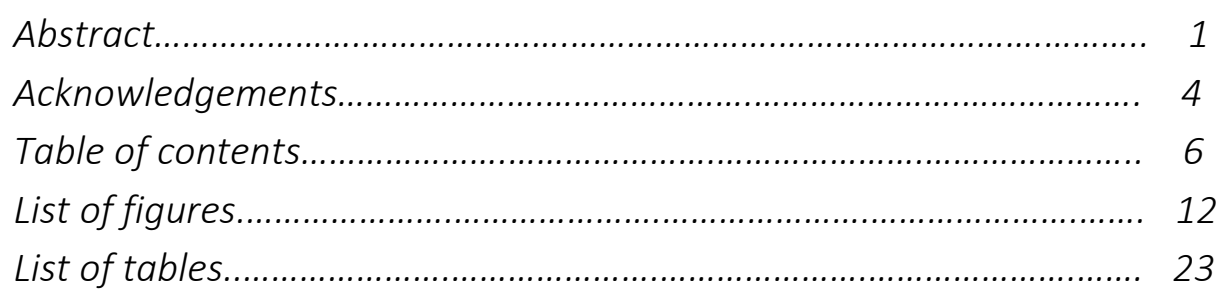

\begin{tabular}{lll} 
Chapter 1 & Introduction & 26 \\
\hline
\end{tabular}

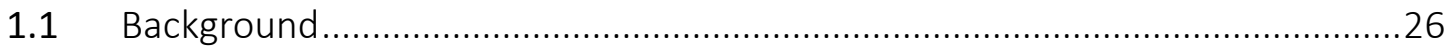

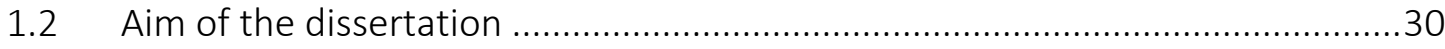

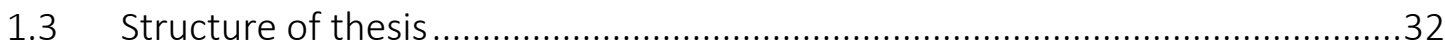

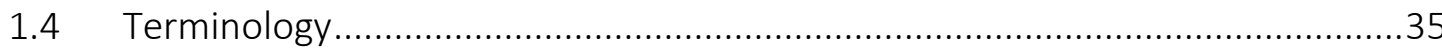

Chapter $2 \quad$ Groundwater flow and transport $\quad 36$

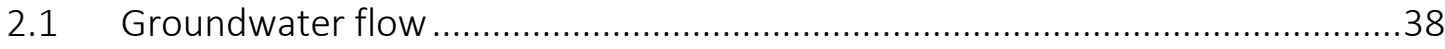

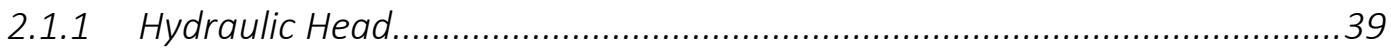

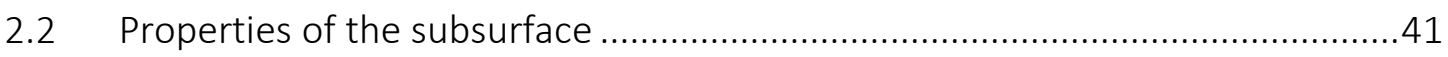

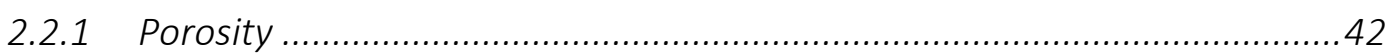

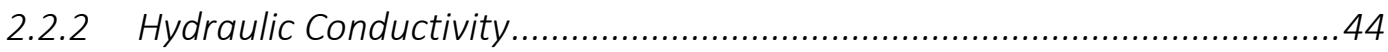

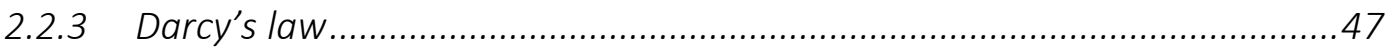

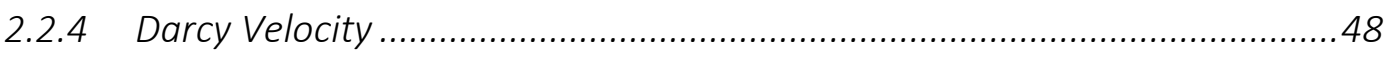

2.2.5 Darcy's law in three-dimensions ................................................................49

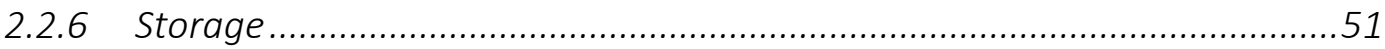

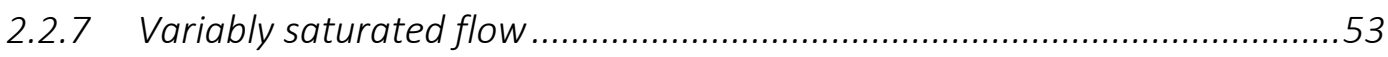

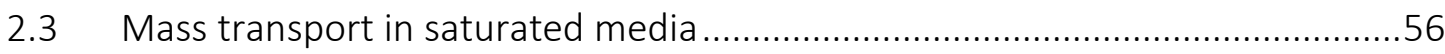

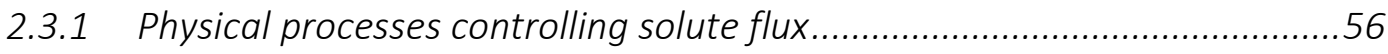

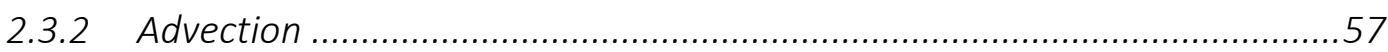

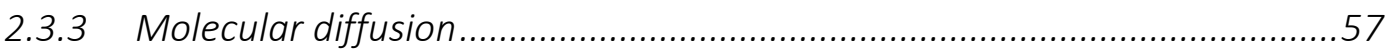

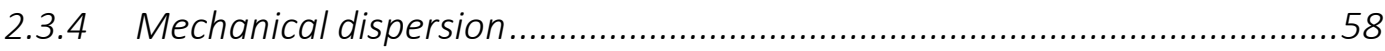

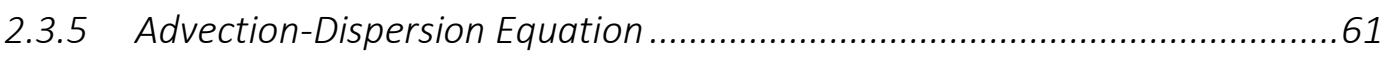

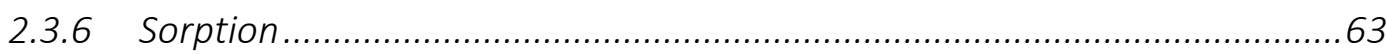

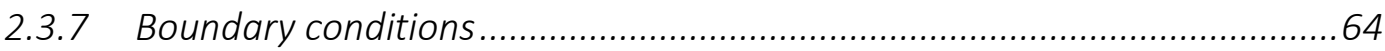




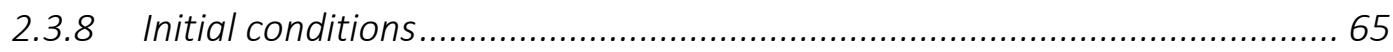

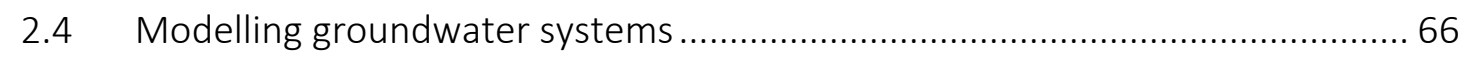

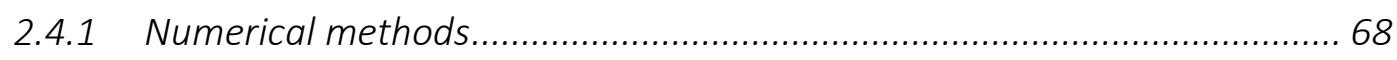

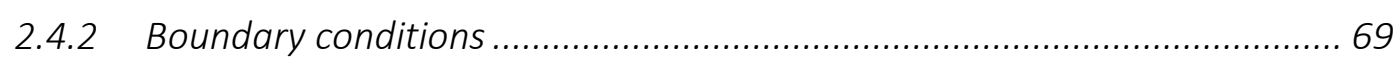

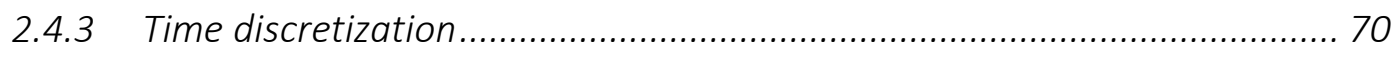

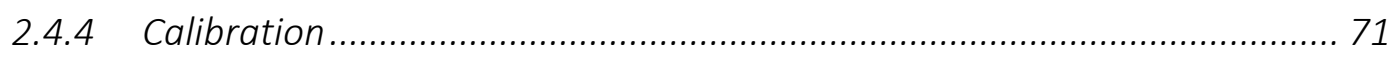

2.4.5 Groundwater modelling Software ........................................................ 73

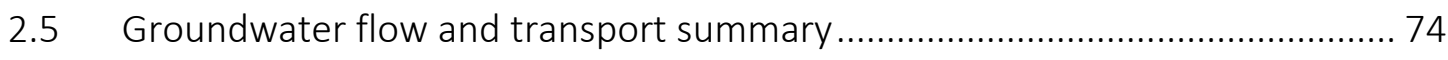

\begin{tabular}{lll} 
Chapter $3 \quad$ Groundwater age & 75 \\
\hline
\end{tabular}

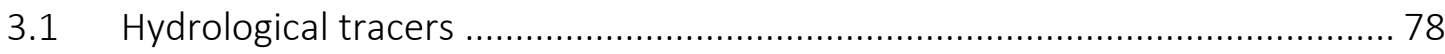

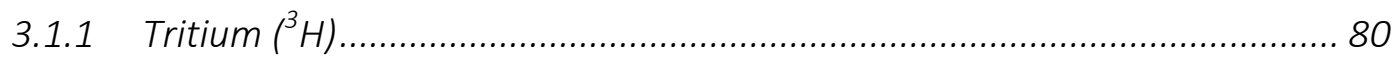

3.1.2 Other tracers and hydrochemistry .................................................. 83

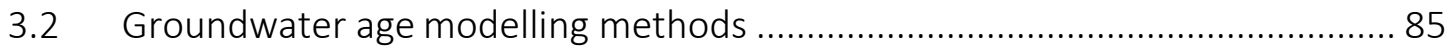

3.2.1 Lumped Parameter Models ............................................................................ 85

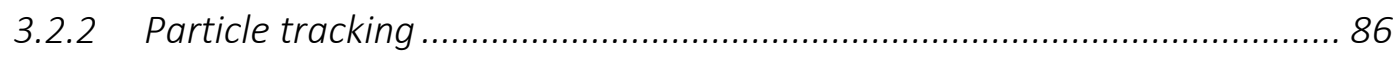

3.2.3 The Direct Age Simulation Method .......................................................... 87

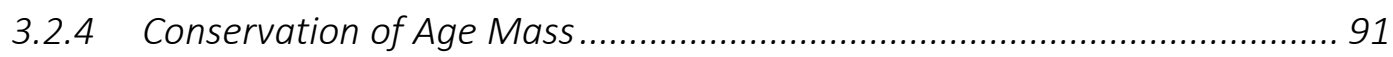

3.2.5 The Time-marching Laplace Transform Galerkin Technique ..................... 95

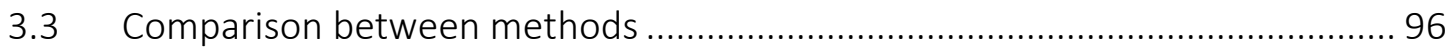

\begin{tabular}{ll} 
Chapter $4 \quad$ The Wairarapa Valley & 101 \\
\hline
\end{tabular}

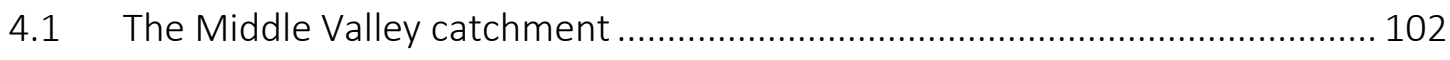

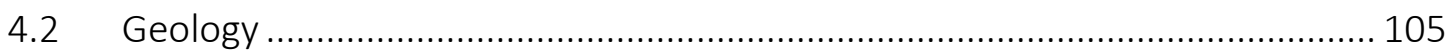

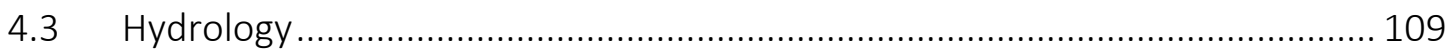

4.3.1 Primary Wairarapa water channels ....................................................... 111

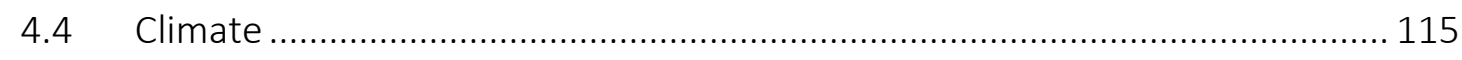

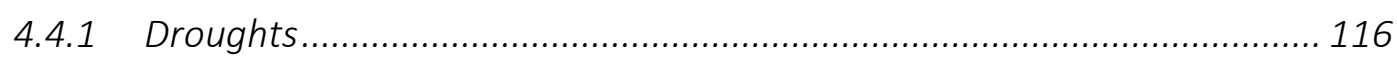

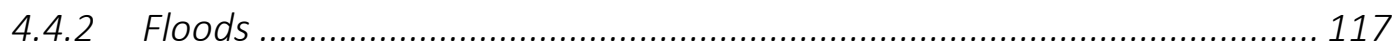

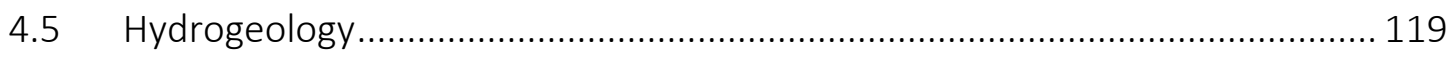

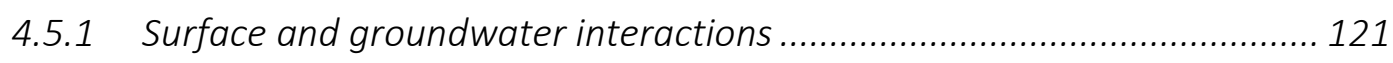

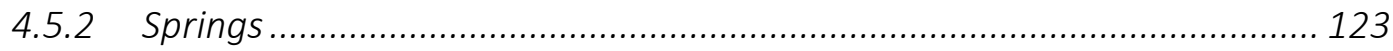

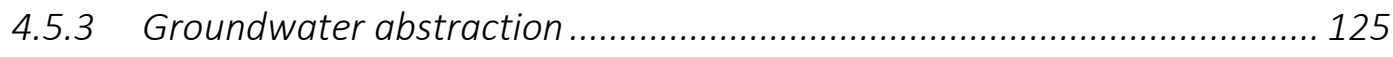

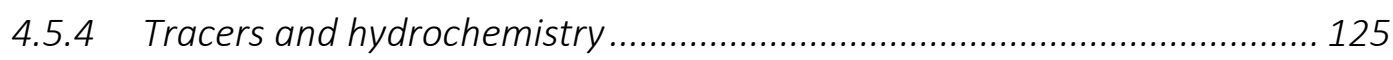

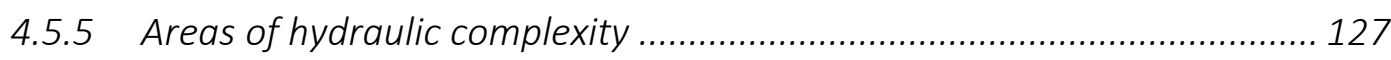




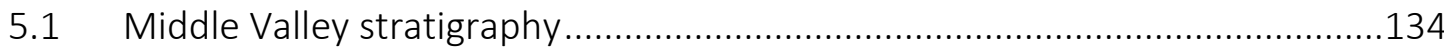

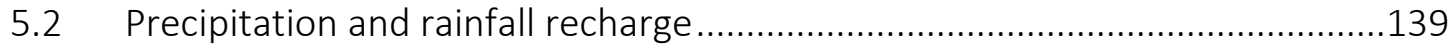

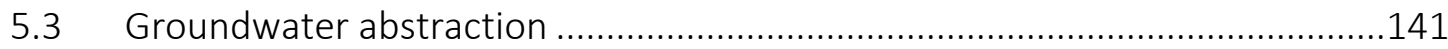

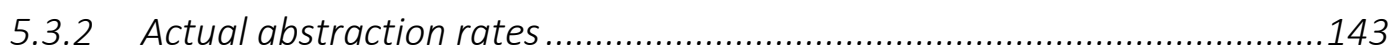

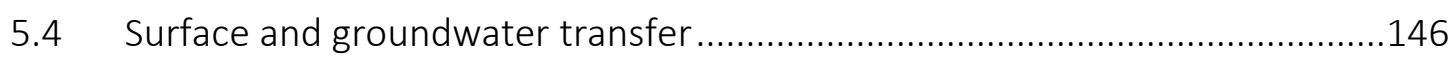

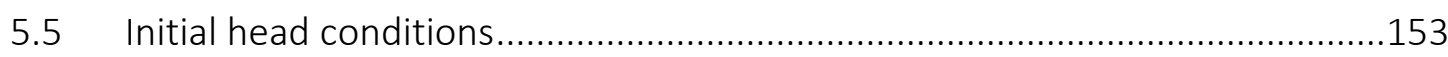

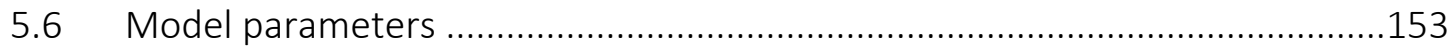

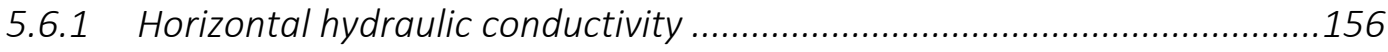

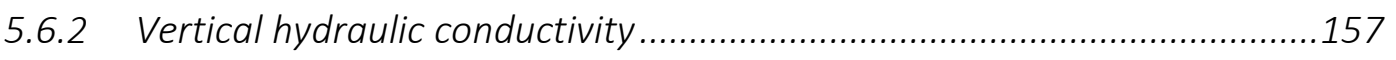

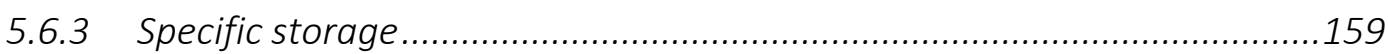

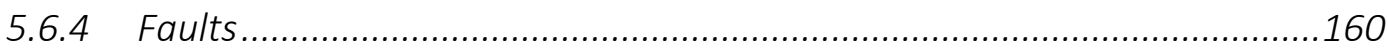

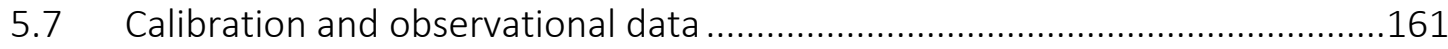

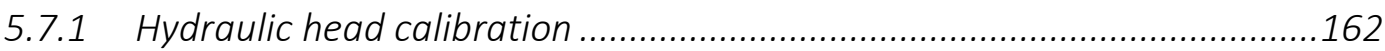

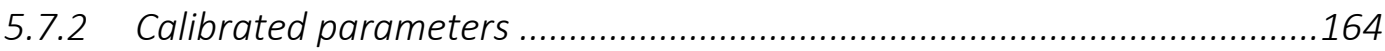

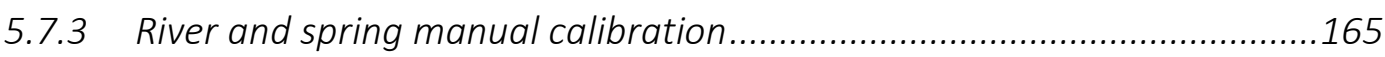

5.7.4 Global water budget calibration ............................................................165

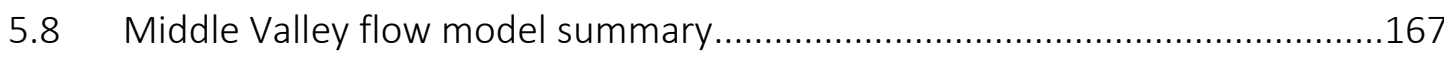

\section{Chapter $6 \quad$ Middle Valley age model methodology 168}

6.1 Middle Valley Ground Water (GW) age model ............................................168

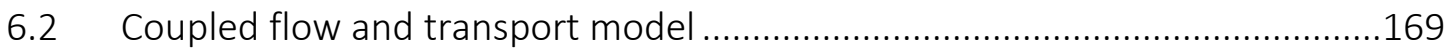

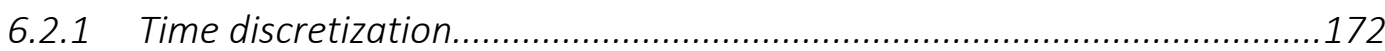

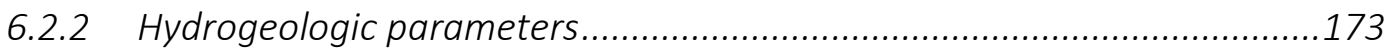

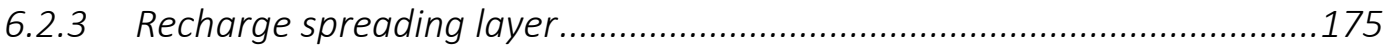

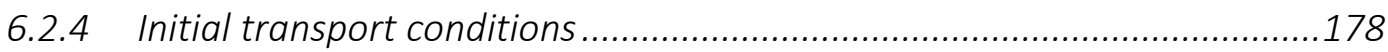

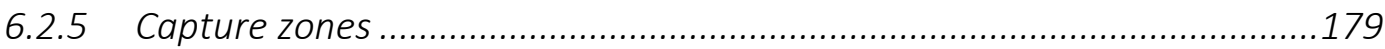

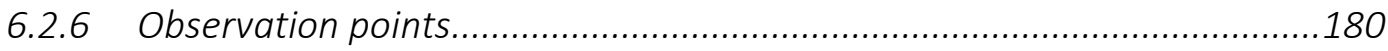

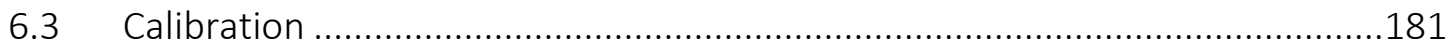

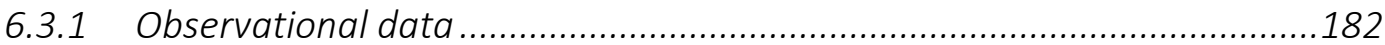

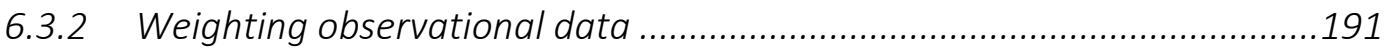

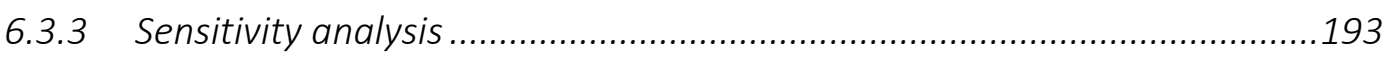

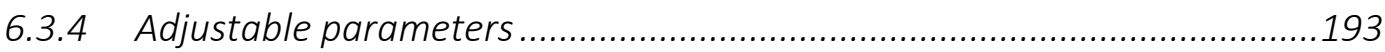


6.3.5 Gauss-Marquardt-Levenberg parameter estimation scheme .................. 195

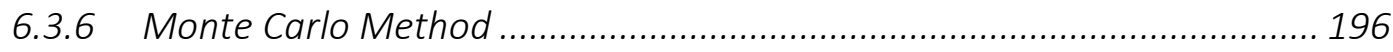

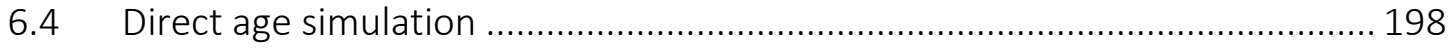

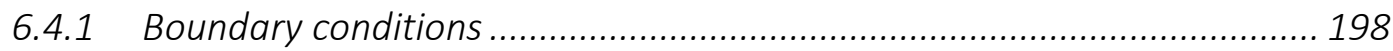

6.4.2 Transient mean-age initial conditions .................................................. 199

6.4.3 Transient groundwater age distributions initial conditions ..................... 199

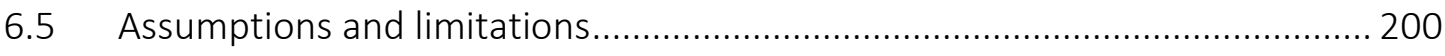

6.6 Middle Valley model methodology summary ................................................ 201

\section{Chapter $7 \quad$ Tritium calibration and directly simulated age results 202}

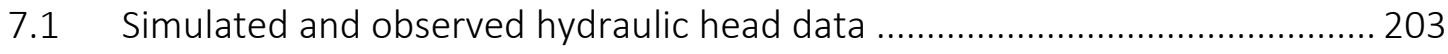

7.1.1 Discrepancies between models ........................................................ 208

7.1.2 Phreatic unconfined aquifer .................................................................. 211

7.1.3 Constraints on type-three boundaries ............................................... 212

7.1.4 Boundary condition modifications .................................................... 212

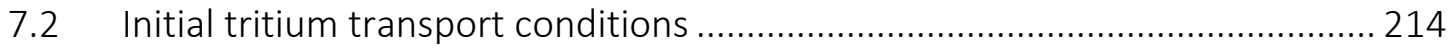

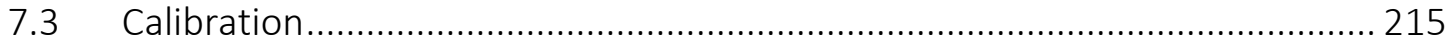

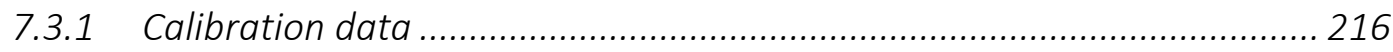

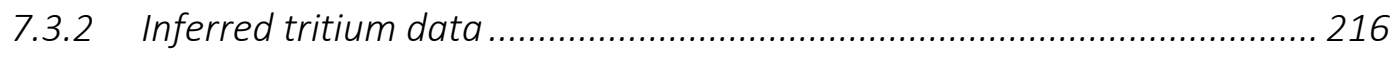

7.3.3 Inferred tritium justification and calibration weighting ........................... 216

7.3.4 Parameter sensitivity analysis .................................................................. 218

7.3.5 Localized Gauss-Marquardt-Levenberg parameter estimation scheme.. 218

7.3.6 Classical Monte Carlo method .................................................................... 220

7.3.7 Porosity sensitivity analysis ..................................................................... 221

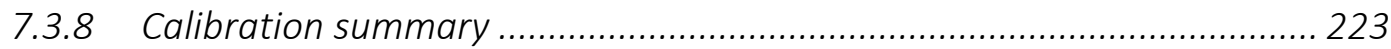

7.4 Middle Valley transient flow and transport model performance .................... 225

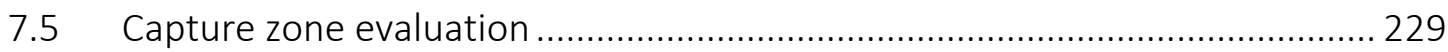

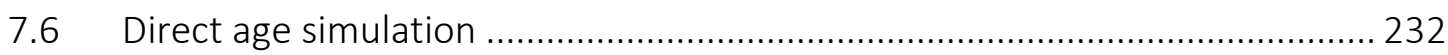

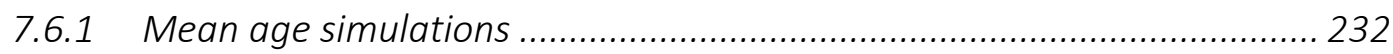

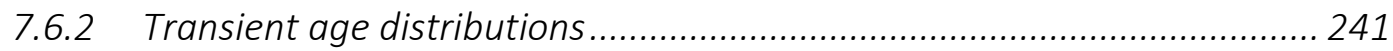

7.6.3 Middle Valley groundwater age summary ........................................... 255

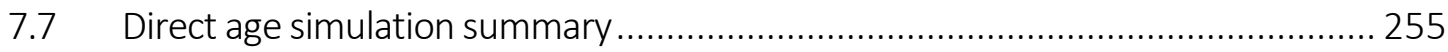




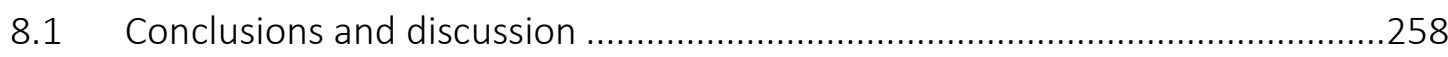

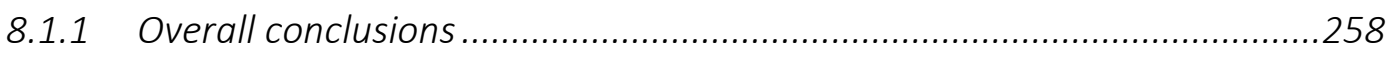

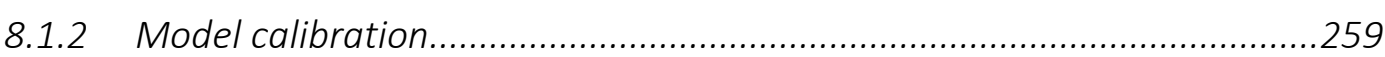

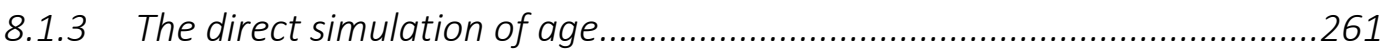

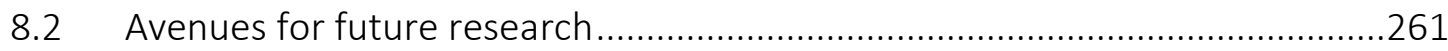

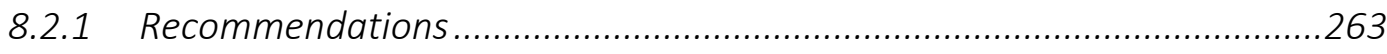

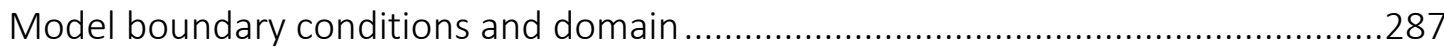

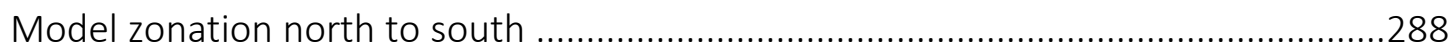

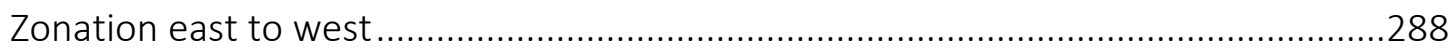

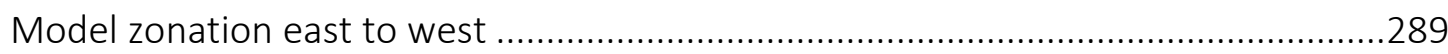

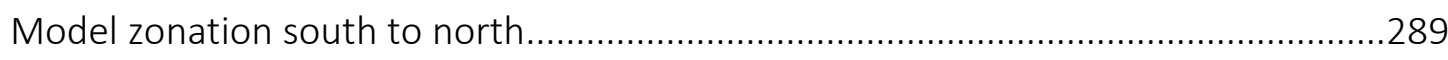

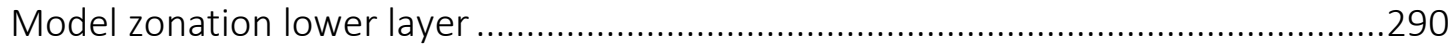

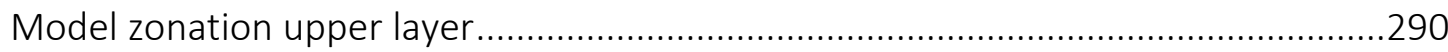

Appendix B Middle Valley model parameters and fluid budget 291

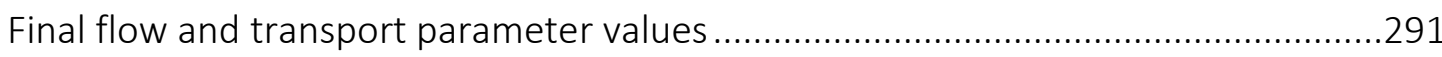

FEFLOW - Ground Water (GW) original conversion with 102 material zones (including

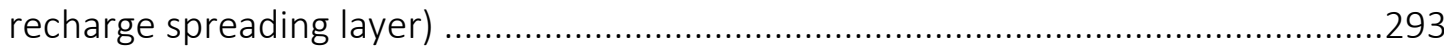

Change in FEFLOW parameters relative to Tritium calibration assigned values.........296

Appendix C Transient FEFLOW flow model figures $\quad 299$

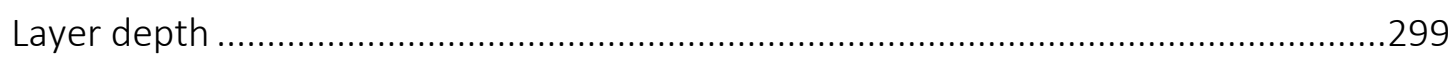

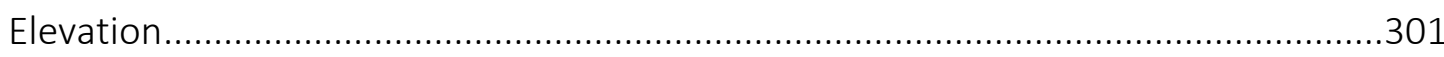

\begin{tabular}{lll} 
Appendix D & Tritium Data & 302 \\
\hline
\end{tabular}

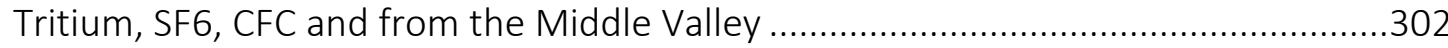

Tritium and silica measurements: Morgenstern (2005) ...............................................302

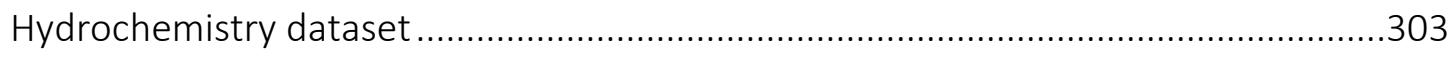

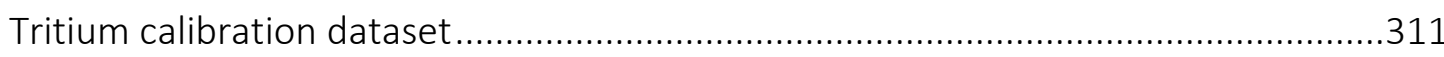


The Exponential Mixing Model...

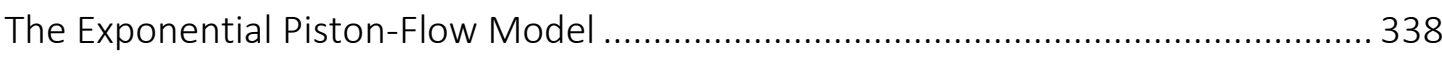

The Dispersion Model

\begin{tabular}{llr} 
Appendix L Additional tracers & 349 \\
\hline
\end{tabular}

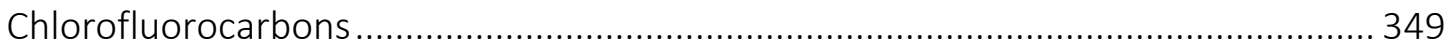

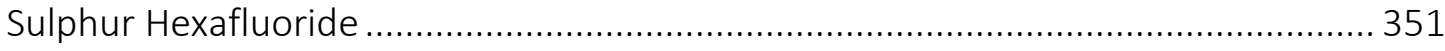

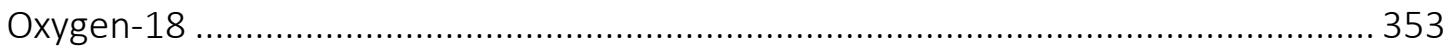

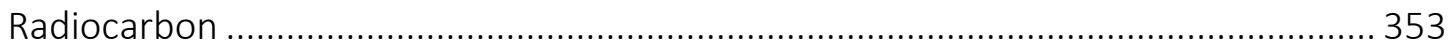

Appendix M Silica-inferred Tritium data statistics $\quad 355$

Appendix N Extended Wairarapa Hydrochemistry Information $\quad 357$

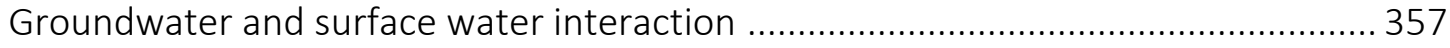

\begin{tabular}{lrr} 
Appendix O Capture Zone Figures & 359 \\
\hline
\end{tabular} 


\section{List of Figures}

Fig. 1.1 Two dimensional cross section of groundwater recharge, discharge, and estimated average residence time (in years). Blue sections represent aquifers, and the grey sections aquitards. Source: Fitts (2002).

Fig. 2.1 Hydrological cycle with numbers representing global fluxes in thousands of $\mathrm{km}^{3}$ /year. Source: Fitts (2002).

Fig. 2.2 Representative groundwater system. Source: Kazemi et al (2006). 38

Fig. 2.3 Typical values of hydraulic conductivity in a range of groundwater yielding media. Source: Fitts (2002) with data compiled by Davis (1969), Freeze and Cherry (1979), and Clay and shale ranges from Neuzil (1994).

Fig. 2.4 Cone of depression example. Modified from Zinn and Konikow (2007)........ 46

Fig. 2.5 Schematic of storage. Source: Ferris et al (1962). 51

Fig. 2.6 Unconfined aquifer schematic showing vadose zone (above water table), aquifer (saturated zone) and aquitard (bedrock/impermeable material). $h=$ hydraulic head, $b=$ fully saturated depth of the aquifer. 53

Fig. 2.7 Groundwater modelling process diagram. Source: Fitts (2002). 68

Fig. 3.1 Initial steady state age distribution in a simplified box model domain, with flow moving left to right, without any pumping influence. Source: Zinn and Konikow (2007).

Fig. 3.2 Resulting age distributions following moderate abstraction rates from the confined aquifer for a five year period. A cone of depression is visible and older water has been drawn down into the confined aquifer. Source: Zinn and Konikow (2007). .... 78

Fig. 3.3 Atmospheric concentrations of tritium, CFC-12, SF 6 , CFC-11 and CFC-113 in the in the Southern Hemisphere 1950-2011. Source: van der Raaji (2013). 79

Fig. 3.4 Tritium in rain at Kaitoke, $40 \mathrm{~km}$ North of Wellington. Tritium samples are taken each month since July 1960. Data between 1955 and 1960 are deduced from 
tritium data from the Hutt River (Kaitoke is in its upper catchment), of Wairakei rain (Taupo), and of South Pole snow pits. The insert shows tritium from 1980 to present with higher resolution. Source: Morgenstern and Taylor (2009).

Fig. 3.5 Age range for tracers used in water age estimation. Source: Beyer et al (2013); Cook and Herzceg (2000); Fitts (2002).

Fig. 4.1 Middle Valley plains looking towards the Tararuas north of Greytown. 103

Fig. 4.2 The Wairarapa Valley, New Zealand, showing the location of bounding mountain ranges, the Middle Valley groundwater catchment, main river channels, and lakes. Circled numbers indicate major geographic features: 1) Ruamahanga River, 2) Waipoua River, 3) Kopuaranga River, 4) Whangaehu River, 5) Taueru River, 6) Waiohine River, 7) Mangatarere Stream, 8) Lake Wairarapa, 9) Tararua Ranges, 10) Mitre Mountain, 11) Rimutaka Ranges, 12) Eastern Uplands, 13) Aorangi Range, 14) Ross Mountain, 15) Tauherenikau River, 16) Tiffen Hill, 17) Featherston, 18) Martinborough, 19) Lake Onoke, 20) Waingawa River.

Fig. 4.3 Middle Valley catchment showing the main towns, Middle Valley boundary, and the primary river channels.

Fig. 4.4 Location of active faults, bounding ranges and Palliser Bay to the South. The geomorphic influence of active faults can be seen in the NE-SW grain of the Wairarapa Valley, with the Wairarapa Fault the most obvious. Source: Begg et al (2005). 106

Fig. 4.5 Alluvial gravels on the floodplain of the Waiohine River. 107

Fig. 4.6 New Zealand 1:250K geological units of the Middle Valley, Wairarapa, New Zealand. Legend explained in Table 4.1. 108

Fig. 4.7 Maximum and minimum flows 1977-2011 in the Ruamahanga River at Wardells. Maximum indicated by horizontal text, minimum by vertical. This site is situated 600 metres upstream of the confluence with the Waingawa River and 95 kilometres from the Ruamahanga River mouth. Source: Gordon (2013).

Fig. 4.8 Ruamahanga River maximum flood discharge at Gladstone Bridge. The site was removed in 2000 and reinstated from 2002. Source: Gordon (2013).

Fig. 4.9 Ruamahanga River upstream from Gladstone Bridge. 
Fig. 4.10 Waiohine River at the State Highway Two Bridge.

Fig. 4.11 Groundwater zones from Greater Wellington Regional Council's 1999

Freshwater Plan, some zones cross between the Lower and Upper Valley catchments.

Source: Gyopari and McAllister (2010).

Fig. 4.12 Groundwater level and river stage data taken in close proximity.

Groundwater level at shallow groundwater monitoring sites on the Ruamahanga River floodplain and stage in the Ruamahanga River (measured and the Wardell's Bridge recorder site). Source: Gyopari and McAllister (2010)......

Fig. 4.13 Surface water and groundwater monitoring sites assigned to the seven hydrochemical clusters in the Wairarapa Valley. Source: Guggenmos et al, (2011) .... 122

Fig. 4.14 Spring distribution in the Middle Valley. 1) Papawai, 2) Tilsons, 3) Muhunoa, 4) Parkvale, 5) Beef Creek, 6) Masterton Fault, and 7) Carterton Fault springs. Shown with the location of rivers, faults; for stratigraphy legend see Fig. 4.6.

Fig. 4.15 Left: Geographic distribution of tritium concentration shown in tritium units (TU). Eight measurements are taken in the Middle Valley. Right: Sampled well depth. Source: Morgenstern (2005). 126

Fig. 4.16 Tiffen Hill geological cross-section. Indicative structure of Carterton, Parkvale, and Ruamahanga valley sub-basins. Source: Gyopari and McAllister (2010). 128

Fig. 5.1 Middle Valley catchment top layer mesh discretization. 21074 elements made up of 10920 nodes. Areas are discretized to a smaller resolution around complex zones, i.e. faults, springs, rivers. 133

Fig. 5.2 Geology of the Middle Valley. Bores and cross section line locations are shown, all of which were used to construct the conceptual hydrogeological model. Source: Gyopari and McAllister (2010).

Fig. 5.3 Percentage of rainfall that recharges the Middle Valley catchment. Source: Gyopari and McAllister (2010).

Fig. 5.4 Estimated annual rainfall recharge across the Middle Valley. Source: Gyopari and McAllister (2010). 
Fig. 5.5 Distribution of the 110 abstraction wells simulated throughout the Middle Valley.

Fig. 5.6 Consented groundwater abstraction and estimated actual groundwater abstraction for the Middle Valley. Source: Gyopari and McAllister (2010).

Fig. 5.7 Simulated Middle Valley groundwater abstractions and rainfall recharge July 1992 - May 2007.

Fig. 5.8 Transfer boundary condition (i.e. Cauchy) distribution throughout the Middle Valley. Orange circles indicate surface water channels assigned transfer rates to simulate surface/groundwater flux. Yellow circles indicate spring sections assigned constraints allowing outflow, but not inflow.

Fig. 5.9 Cauchy transfer boundary nodes locations on slice one and two (Cauchy faces on layer one), slice three and slice four of the Middle Valley model domain. 148

Fig. 5.10 Horizontal areal Cauchy boundary condition assignment of all three of the top nodes. This has been implemented on the Ruamahanga River Cauchy assigned nodes.

Fig. 5.11 Vertical areal Cauchy boundary condition assignment. This has been used to implement Cauchy boundary conditions on the Carterton fault springs.

Fig. 5.12 Schematic of the transfer boundary condition for outflowing ( $\phi=\phi o u t$ and $H>H r$ ) and inflowing hydraulic conditions $(\phi=\phi i n$ and $H<H r$ ). Source: Cornaton (2007).

Fig. 5.13 Zonation of the horizontal hydraulic parameters, longitudinal and transverse directions (i.e. $x$ and $y$ ), of the ten slices. 156

Fig. 5.14 Zonation of the vertical hydraulic parameters of the ten slices. 158

Fig. 5.15 Zonation of the specific storage parameters of the ten slices. 159

Fig. 5.16 Fault locations and visible fine discretization of fault lines in the Middle Valley catchment. 1: Masterton Fault and 2: Carterton Fault running from West to East across the catchment. 160 
Fig. 5.17 Spatial distribution of hydraulic head observational data utilized in the calibration of the flow model. Node depth $(m)$ indicated on left, node slice on right, $\mathrm{n}=14$. 164

Fig. 5.18 Global recharge input for the 15 year simulation. Source: Gyopari and McAllister (2010).

Fig. 5.19 Papawai and Tilsons Creek simulated and (available) observed flow comparison. Source: Gyopari and McAllister (2010).

Fig. 6.1 Middle Valley groundwater system depths. 170

Fig. 6.2 South to North transect and West to East transect, indicating the model (i.e. groundwater system) depth, and hydraulic head on the $1^{\text {st }}$ of July 1992. 171

Fig. 6.3 Middle Valley model domain distinguishing the material zones throughout. 1. Facing south, 2. Facing north, 3. Facing down (above), 4. Facing up (bottom). 175

Fig. 6.4 Nodes on the top layer are assigned Dirichlet boundary conditions, excluding water channels, to simulate the transport of tritium via rainfall recharge.

Fig. 6.5 Tritium concentrations simulated in the Middle Valley catchment from 1977 to 2007. 178

Fig. 6.6 Hypothetical example of the probability of capture method for a single well. Piezometric contours are lines indicating the height of the water table above sea level, analogous to land surface contours. 180

Fig. 6.7 Observation nodes distribution throughout the Middle Valley. Label indicates node depth above sea level. 181

Fig. 6.8 Schematic of localized optimization with an initial estimate moving towards an objective function minimum. Modified from Doherty (2010). 182

Fig. 6.9 Distribution of wells for which GWRC hydraulic head measurements were used for calibration in period 1992-2007. Left text indicates well depth and right indicates the slice which the node is located on..... 184

Fig. 6.10 Observed tritium measurement locations. Six locations showing well identifier and depth (underlined). 186 
Fig. 6.11 Relationship between tritium concentrations and selected hydrochemical parameters in the Middle Valley. It is acknowledged that the lowest tritium value in the Mean Residence Time graph causes significant leverage. Data available in Appendix D. Source: Morgenstern (2005).

Fig. 6.12 Distribution of well for which tritium concentrations in period 1992-2007 could be inferred from $\mathrm{SiO}_{2}$ concentration.

Fig. 6.13 Schematic of PEST optimization process. PEST run will cycle for at least the number of adjustable parameters, until an objective function minimum is achieved. Bold type indicates typical file extension.

Fig. 6.14 Monte Carlo calibration process schematic. Bold type indicates an example of the file extension used. The process runs for a specified number of stochastic model runs, for example, 3000.

Fig. 6.15 Zero age mass transport boundary conditions assigned across the top slice. Blue nodes indicate Dirichlet-type boundary conditions specified as zero.

Fig. 6.16 TMLTG example. Left figure shows age distribution without an initial age distribution, right figure shows age distribution with a supplied initial condition. Scale is not indicated as it is merely an example; however the maximum age and time are 15 years.

Fig. 7.1 Observation nodes to compare hydraulic head differences between models and field data. Node is indicated on the left and well node depth (metres) below ground surface on right.

Fig. 7.2 Head comparison between Ground Water (GW) (brown), FEFLOW (green) simulations and Middle Valley field data (Blue) for nodes one to four.

Fig. 7.3 Head comparison between Ground Water (GW) (brown), FEFLOW (green) simulations and Middle Valley field data (Blue) for nodes five to eight. 206

Fig. 7.4 Comparative heads between confined FEFLOW and confined Ground Water (GW) simulations.

Fig. 7.5 Specific yield (drain fillable porosity) assigned uniformly (layers 1-9) throughout the FEFLOW model. 
Fig. 7.6 Constraints applied to spring nodes in FEFLOW and Ground Water (GW) confined models. Inflow can be seen in the GW spring nodes.

Fig. 7.7 Initial tritium distribution on the $1^{\text {st }}$ July 1992. The (top) clip runs north to south through the middle of the catchment, indicated by the yellow line in the smaller left figure and the bottom concentrations in the right figure.....

Fig. 7.8 Measured tritium concentrations (6) and tritium concentrations inferred from SiO2 concentrations (190) compared against assigned weights.

Fig. 7.9 Final model calibration result showing all observed and simulated data used in the calibration. Final phi of 2480.409 ( $n=4524)$. No significant correlation shown in the right tritium calibration result. 221

Fig. 7.10 Porosity sensitivity analysis for three nodes in the Middle Valley. 222

Fig. 7.11 Upper and Middle Valley catchment geology. Middle Valley is bounded by the Waingawa and Ruamahanga Rivers. Source: Begg et al (2005). 224

Fig. 7.12 Recharge sources and abstraction withdrawals from the Middle Valley catchment. Sources are positive (inputs) and extractions are negative (outputs)........ 225

Fig. 7.13 Fluid budget showing transfer in, sources, transfer out, abstractions and overall change in storage $\left(\mathrm{m}^{3} / \mathrm{d}\right)$.

Fig. 7.14 Capture zone schematic indicating arbitrary capture zone and groundwater travel times the irrigation abstraction well. Modified from the Ministry of Environment (British Columbia) (2004). 229

Fig. 7.15 Capture zone probabilities of all simulated pumping wells in the Middle Valley model. 110 wells in total are simulated with varying pumping rates, well distribution indicated by dark red squares. Individual (larger) figures are located in Appendix O).

Fig. 7.16 Mean-age example, variable recharge over different seasons creates a transient age conditions across the Middle Valley plain, exemplified by directly simulating the mean-age. Top-left is during winter (i.e. consistent rainfall), top-right is a rainfall event during a dry summer, bottom-left and right are during a progressively dry summer, respectively. 
Fig. 7.17 Mean age distribution on the 6/01/1993 during summer and the peak of irrigation season. Figures in clockwise order: 1) top slice, 2) model clipped north-south, and 3) model clipped from west-east

Fig. 7.18 Mean age distribution on the 17/03/1993 at the end of the summer and irrigation season.

Fig. 7.19 Mean age distribution on the 17/08/1994 in the middle of winter with a high amount of rainfall and groundwater recharge.

Fig. 7.20 Mean age distribution on the 06/05/1998. This was following an extended classified drought over the 1997/98 summer months.

Fig. 7.21 Mean age distribution on the 03/04/2002. This was the result of a relatively wet summer with the following year recording above average mean annual rainfall. . 238

Fig. 7.22 Beginning of 2006/07 summer on the 18/10/2006 after significant spring rainfall.

Fig. 7.23 Mean-age distribution on the 20/06/2007 in late summer/autumn. A relatively old water age is spread throughout the domain.

Fig. 7.24 Mean-age on the $11 / 07 / 2007$. The rainfall and subsequent recharge is shown to quickly change the mean-age throughout the upper sections of the domain and lower hydraulically conductive aquifers.

Fig. 7.25 Locations of simulated temporal age evolution. Numbers correspond to nodes and wells within the Middle Valley domain.

Fig. 7.26 First age distribution. Node 43628/Well S26/0223 located at a depth of 5.1 metres in the Northern section of the domain.

Fig. 7.27 Second TMLTG age distribution. Node 14260/Well S26/0298 located at a depth of 1.45 metres in the Northern section of the domain. The age and time units are shown in years

Fig. 7.28 Third TMLTG age distribution. Node 68843 located at a depth of 15.14 metres in the Western section of the domain. The age and time units are shown in years. 
Fig. 7.29 Forth age distribution. Node 90690 located at a depth of 19.64 metres in the Southern section of the domain. The age and time units are shown in years. 247

Fig. 7.30 Fifth age distribution. Node 79786 located at a depth of 21.92 metres in the Eastern section of the domain. The age and time units are shown in years. 248

Fig. 7.31 Sixth age distribution. Node 79766 located at a depth of 28.38 metres in the Eastern section of the domain. The age and time units are shown in years. 249

Fig. 7.32 Seventh age distribution. Node 76597 located at a depth of 13.58 metres in the Southern section of the domain. The age and time units are shown in years. ....... 250

Fig. 7.33 Eighth age distribution: Node 36105 located at a depth of 5.1 metres in the centre of the domain. The age and time units are shown in years. 251

Fig. 7.34 Ninth age distribution. Node 62286 located at a depth of $10.03 \mathrm{~m}$ in the Western section of the domain. The age and time units are shown in years. 252

Fig. 7.35 Tenth TMLTG age distribution: Node 14262, located at a depth of 2.1 metres in the Western section of the domain. The age and time units are shown in years..... 254

Figure A-1 Model boundary conditions and domain. 287

Figure A-2 Zonation of the Middle Valley model domain looking north to south...... 288

Figure A-3 Zonation of the Middle Valley model looking from the southern perspective. 288

Figure A-4 Zonation of the Middle Valley model from east to west from the northern perspective. 289

Figure A-5 Zonation of the Middle Valley model looking south to north.................... 289

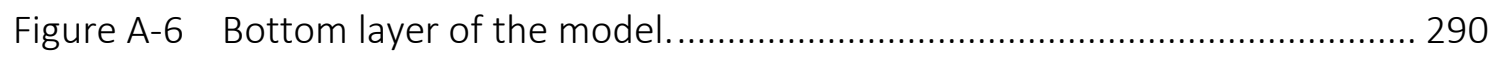

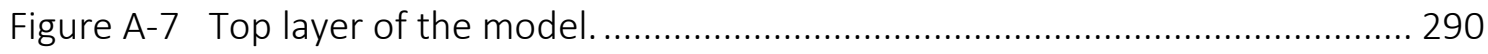

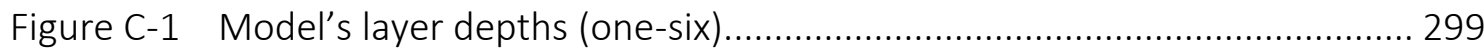

Figure C-2 Model's layer depths (seven-nine). .......................................................... 300

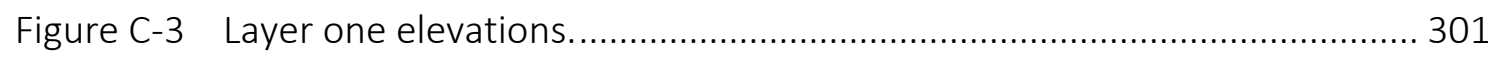


Figure C-4 Layer nine elevations.

Figure J-1 Example figure of where the piston-flow model could be ideally applied. The top left figure shows an unconfined aquifer receiving recharge on top with several wells at shallow depths. The bottom left figure shows a confined aquifer receiving a small amount of recharge, this travels through the system with minimal mixing. Graph shows the sampled age distribution after the tracer travelled along a single travel path exiting with uniform mean age of 25 years at the abstraction point (modified from Jurgens et al, 2012).

Figure J-2 Example figure of where the exponential mixing model could be ideally applied. The left figure shows an unconfined aquifer receiving equal recharge with the sample taken from a well screened throughout the entire aquifer thickness. Any mixing is assumed to occur only in the well, and not in the aquifer, hence a fairly uniform flow speed. The straight down arrows represent recharge, and the arrow bent at a right angle is the sample point. The graph shows the exit-age frequency distribution expected from exponential mixing of the tracer in the well which has a mean age of 25 years (modified from Jurgens et al, 2012).

Figure J-3 Example figure of where the exponential piston-flow model could be ideally applied. The left figure shows a partially confined aquifer with a recharge area $(\mathbf{x})$, a confined section $\left(\mathbf{x}^{*}\right)$, and an abstracting well. The right-angled arrow is where the tracer exits the system (via the well). The graph of the right shows the exit-age distribution expected from the exponential piston-flow tracer transport from the recharge area with an exponential piston-flow ratio of one, and a mean age of 25 years (modified from Jurgens et al, 2012).

Figure J-4 Four groundwater systems where the dispersion model could be applied. Mixing occurs due to fluctuations in flow velocity and a heterogeneous subsurface. Right-angled arrows are sample points and straight arrows represent recharge. The graph (top right) shows the abstracted age frequency distribution with a dispersion parameter of 0.5 and a mean age of 25 years (modified from Jurgens et al, 2012).... 342 
Figure K-1 Finite difference cell showing inflow and outflow components $(x-y-z)$ and the average linear velocity component across each face in cell (i-j-k). Source: Pollock (1994).

Figure L-1 History of Tritium, CFC-12, SF, CFC-11 and CFC-113 concentrations in the atmosphere in the Southern Hemisphere. Source: van der Raaji, 2013.

Figure L-2 Global observations of tropospheric SF6 (parts per trillion) observed in Northern and Southern hemispheres. Source: Levin et al, 2010.

Figure M-1 Plots of the linear regression model showing the measured tritium and silica relationship, observed tritium against predicted tritium, and the residual plot of the predicted tritium. 27 observations were used. 356

Figure N-1 Simplified diagram of the differences between the seven devised

hydrochemical clusters. Source: Guggenmos et al (2011). 358

Figure O-1 Capture zone analysis on the $1^{\text {st }}$ of July 1992. 359

Figure O-2 Capture zone analysis on the $23^{\text {rd }}$ of December 1992. 360

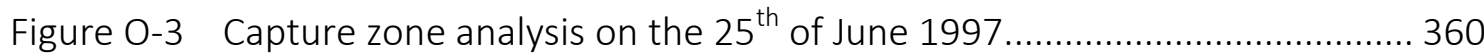

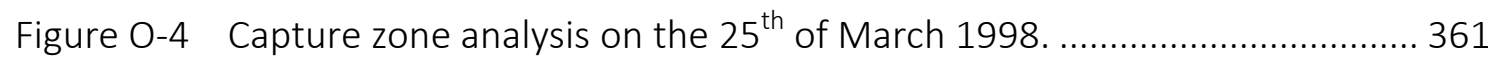

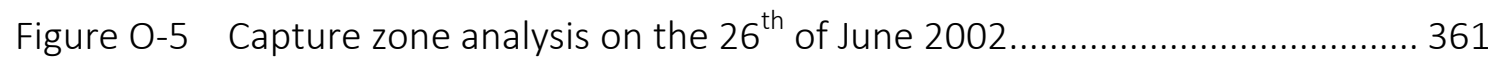

Figure 0-6 Capture zone analysis on the $25^{\text {th }}$ of September $2002 \ldots \ldots \ldots \ldots \ldots \ldots \ldots \ldots . . . . . . . . . . . . . . . .362$

Figure 0-7 Capture zone analysis on the $22^{\text {nd }}$ of December $2004 \ldots \ldots \ldots \ldots \ldots \ldots \ldots \ldots . . . . . . . . . . . . . . . .362$

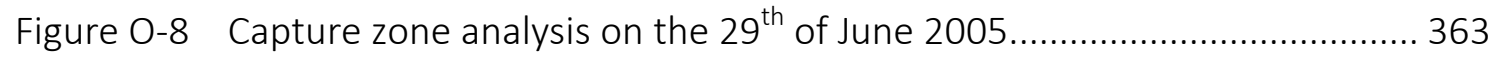




\section{List of Tables}

Table 2.1 Porosity of typical substrate. Source: Fitts (2002)

Table 4.1 Stratigraphy age and description for Middle Valley groundwater system. . 108

Table 4.2 Mean monthly flow for several Wairarapa Rivers, measurements in $\mathrm{m}^{3} / \mathrm{s}$.

Source: Keenan and Gordon (2008).

Table 4.3 Drought history in the Wairarapa 1992-2008

Table 4.4 Flood history in the Upper and Middle Valley catchments from 1991-2007.

Table 4.5 Estimated spring flows in the Middle Valley catchment. The Masterton and Carterton estimates were calculated from limited data. Source: Butcher (2007a) and Keenan (2009).

Table 5.1 FEFLOW finite element Middle Valley model information.

Source:

Gyopari and McAllister (2010).

Table 5.2 Middle Valley model structure and hydrostratigraphic units. The 'Secondary' column is the unit(s) in place when the principal unit is not present. GS: ground surface; AQ: aquifer; AT: aquitard. Source: Gyopari and McAllister (2010).

Table 5.3 Hydrochemical units corresponding to hydrostratigraphic units in the Middle Valley (see Fig. 4.6). Source: Gyopari and McAllister (2010).

Table 5.4 Irrigation abstraction modelling inputs. Modified from Gyopari and McAllister (2010).

Table 5.5 Calibrated transfer rates for Cauchy boundary conditions in the Middle Valley. The transfer rate is calculated by dividing the hydraulic conductivity of the river bed by the thickness of the bed to provide a value in $\mathrm{d}^{-1}$. Source: Gyopari and McAllister (2010). 150

Table 5.6 Estimated transmissivity, hydraulic conductivity and storage parameters.

Source: Gyopari and McAllister (2010)... 
Table 5.7 Middle Valley calibration well information. Source: Gyopari and McAllister (2010) 163

Table 6.1 Middle Valley groundwater catchment elevation and depth. 170

Table 6.2 Manual field measured hydraulic head data. Source: Greater Wellington Regional Council.

Table 6.3 Weekly averaged hydraulic head data information. Source: Greater

Wellington Regional Council.

Table 6.4 Observed tritium dataset from the Middle Valley. Source: Morgenstern (2005)

Table 6.5 Wellington Regional Council measured hydrochemical constituents. 188

Table 6.6 Comparative regression between tritium and hydrochemical constituents throughout the Wairarapa Valley.

Table 6.7 Well information on tritium concentrations inferred from $\mathrm{SiO}_{2}$ concentrations. 190

Table 6.8 95.0\% confidence intervals for tritium estimates derived from silica. 192

Table 6.9 Wellington Regional Council FEFLOW model flow parameter bounds. $\boldsymbol{K}$ is the hydraulic conductivity in the principal $x y z$ directions. Porosity $n e$, and storage coefficient Ss $(\mathrm{m} / \mathrm{s})$. 194

Table 6.10 Ground Water (GW) flow and transport model parameter bounds (m/s).

Table 6.11 Revised Ground Water (GW) flow and transport model parameter bounds $(\mathrm{m} / \mathrm{s})$ 195

Table 7.1 Statistical differences between Ground Water (GW), FEFLOW and field simulations/data. Bold type indicates $>2 \mathrm{~m}$, italic type indicates $<2 \mathrm{~m}$ but $>1 \mathrm{~m}$ difference. 208

Table 7.2 Statistical differences in head relative to boundary condition reassignment: from third-type Cauchy conditions (BC3), to first-type (BC1) and forth-type (BC4)...... 213 Table 7.3 Tritium calibration weighting range. 
Table 7.4 Parameter bounds from best parameter sets of FEFLOW and Ground Water (GW) models.

Table 7.5 Estimated steady state water balance for the Middle Valley catchment.

Source: Gyopari and McAllister (2010a)

Table 7.6 Global fluid budget comparison between transient Ground Water (GW) model and steady state FEFLOW model. 226

Table 7.7 Transient model comparisons.

Table 7.8 Abstraction and climatic events, modelled and historical. 232

Tab. B-1 Final flow parameter values

Tab. B-2 Final transport parameter values.

Tab. B-3 Ground Water (GW) original converted flow parameters, with 102 material zones. 293

Tab. B-4 Flow parameter changes from original FEFLOW values. 296

Tab. D-1 Tritium, sulphur hexaflouride..... 302

Tab. D-2 Tritium and silica measurements 302

Tab. D-3 Hydrochemistry dataset 303

Tab. D-4 Tritium dataset for the calibration of the Middle Valley model

Tab. E-1 Tritium Monthly Measurements 1977-2007

Tab. F-1 Yearly atmospheric tritium measurements from Kaitoke, Upper Hutt, Wellington, New Zealand. 


\section{Chapter 1}

\section{Introduction}

When your work takes you to the frontier, there are no reliable maps and those that exist may be as misleading as they are helpful.

Veitch (1995)

\subsection{Background}

The specific novelty of this dissertation is the ability to evaluate groundwater age in both time and space. This dissertation contributes to a tracer validation project to improve groundwater and surface water management in New Zealand. The project is led by GNS Science with a goal of improving groundwater information for resource managers to effectively apply to (and manage) catchments throughout New Zealand. The project merges two existing methods applied to groundwater systems:

1. Hydrological tracers, which provide information on water source and age; and

2. Numerical groundwater models, the only tools currently available to predict the response of subsurface reservoirs from abstraction pressures, land-use and/or climate change.

The Wellington Regional Council created a transient flow model as part of a regional groundwater investigation into the sustainability of water abstraction pressures in the Wairarapa. This dissertation is an extension of the work done by Greater Wellington Regional Council on the Middle Valley, which includes a conceptual hydrogeological model, to append a transport model and directly simulate groundwater age. Tracer validated numerical models are being developed to enable essential age and transport information to be applied to effective water management. 
The tracer validation project is using the Lake Rotorua catchment in the Bay of Plenty region and Wairarapa catchment in the Greater Wellington region as case studies. This thesis focusses on a case study application within the Wairarapa and uses results and lessons learnt from this research for the wide applicability of tracer validated numerical models.

Management of both the quality and quantity of water is a priority in New Zealand and groundwater accounts for around half of New Zealand's abstractive water needs (White, 2001). Human induced modification of groundwater systems can have a significant impact on the age and distribution of water particles (Zinn and Konikow, 2007). Groundwater provides the base flow to many of New Zealand's rivers and springs, which are a considerable part of New Zealand's tourism industry, as well as bringing various economic, recreational, social, and cultural benefits. Roughly 80 percent of New Zealand's agricultural water requirements are supplied by groundwater, indicating the human influence on, and importance of subsurface reservoirs (White, 2001). In many rural areas, both nationally and in the Wellington region, surface water allocations are at, or reaching, the threshold of supply. Demand on groundwater is projected to increase with the bulk of future water demands predicted to be met by groundwater supplies (Greater Wellington Regional Council, 2012; Hughes and Gyopari, 2011; White, 2001). A negative change in the supply and/or health of groundwater reservoirs could significantly affect these predictions and rural, municipal, and economically important water supplies.

Groundwater age is an effective tool and can reveal important information on the rate of water movement through the subsurface. The age of groundwater is defined as the time water particles have been isolated from the atmosphere in the subsurface environment and it is accepted that groundwater is composed of a mixture of water with different ages. The age in a system is inherently linked to the rates of recharge, flow and geological composition (Fig. 1.1). Generally, an older water age indicates a slower rate of flow and recharge within a system, and vice versa (Bethke and Johnson, 2008). 
Older groundwater tends to contain high amounts of dissolved solids (e.g. silica, fluoride, phosphorus) whilst young ground water, roughly defined as water that has spent less than one year in the subsurface, is more likely to contain pathogenic bacteria and/or viruses ${ }^{1}$. Groundwater older than one year of age generally poses less of a threat due to the natural decay of any pathogens in the subsurface (Stewart and Morgenstern, 2001).

Simulating the age distribution in both time and space is important for groundwater management. For example, a groundwater sample with an old mean age may still contain a fraction of young water; recent contamination is therefore a potential risk that may not be conveyed by consideration of the mean age alone. Simulating both the mean-age and distribution of ages at specific points in both space (i.e. the Middle Valley) and time (i.e. 1992-2007) can inform management of water resources and potentially help abate problems. For example, sustainability issues relating to (excessive) irrigation abstraction and the delineation some potentially vulnerable zones that could also be prone to nutrient and bacterial contamination. Thanks to recent numerical implementation, the groundwater age distribution can now be simulated directly in a hydrogeological model.

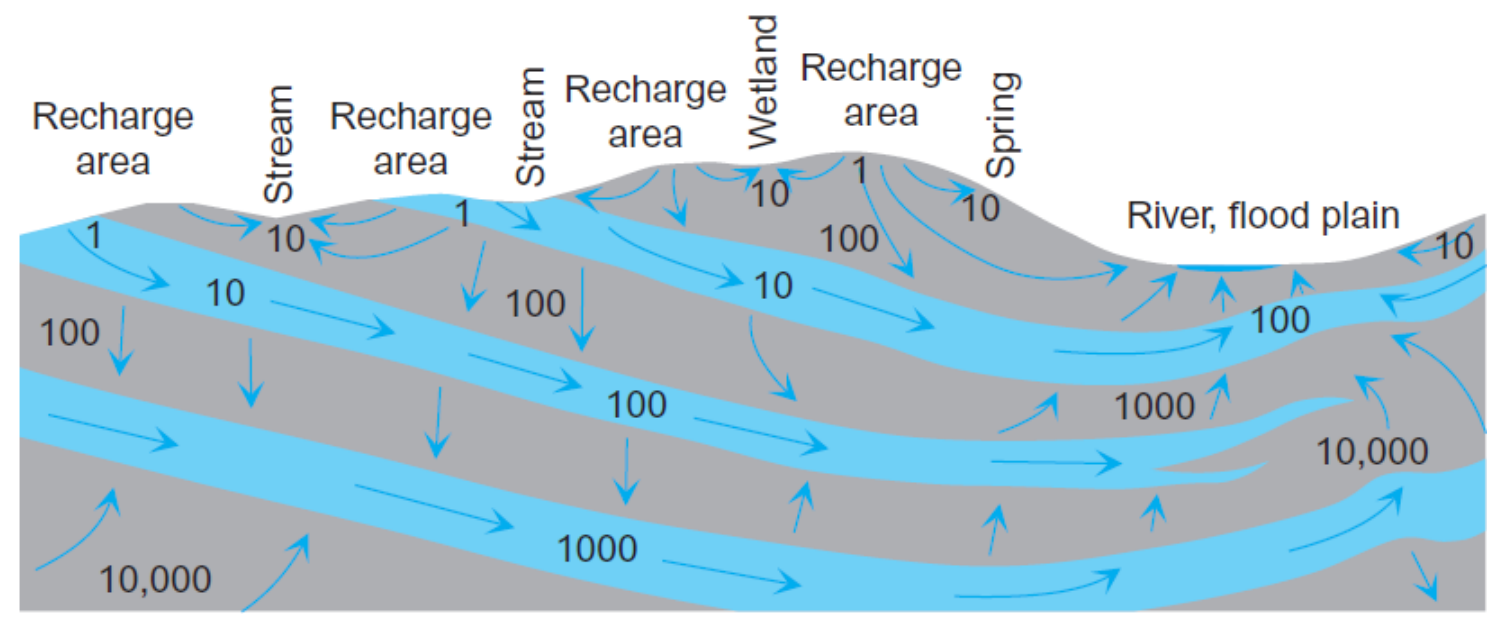

Fig. 1.1 Two dimensional cross-section of groundwater recharge, discharge, and estimated average residence time (in years). Blue sections represent aquifers, and the grey sections aquitards. Source: Fitts (2002).

\footnotetext{
${ }^{1}$ It is acknowledged that all groundwater contains viruses and bacteria, even older groundwater; however pathogens are typically associated with younger groundwater.
} 
The age of groundwater is estimated using observed field measurements of tracers, hydrochemistry, and numerical flow and transport modelling. Groundwater cannot be dated directly because water is a collection of individual particles and only an apparent age can be estimated (Bethke and Johnson, 2008; Kazemi et al, 2006; Sanford, 2011). A groundwater sample is mixture of waters that have generally taken different flow paths, and hence travel times, to reach the sampled observation point. Recent hydrogeological investigations have utilized environmental and anthropogenic tracers to estimate groundwater age through numerical simulations. Studies have focused on the spatial distribution of groundwater age (e.g. Broers, 2004; Cornaton, 2012; Etcheverry and Perrochet, 2000), life expectancy and transit time in aquifers (e.g. Cornaton and Perrochet, 2006), and the statistical estimation of age (e.g. Daughney et al, 2010).

Numerical modelling is a means by which to evaluate and predict responses in the flow and transport within a groundwater system (Gusyev et al, 2012; Gyopari and McAllister, 2010a). Systematic behaviour can be assessed and/or predicted in response to stresses caused by abstractions, land use, and climatic variability. Numerical groundwater flow models solve the advective movement and hydraulic head distributions of flow. Combining the flow solution with a numerical transport model solution solves the distribution of dissolved particle concentrations (i.e. solutes) in water due to advective, dispersive, and chemical reactions throughout a reservoir. Information derived can reveal the quantity and quality of groundwater for assisting appropriate management decisions; however, understanding the behaviour of a groundwater system involves considerable uncertainty. A groundwater model solution is non-unique due to the wide range of hydraulic parameters and fluxes (Fitts, 2002). A solution's uncertainty is compounded by the spatial and temporal variability of recharge through the variably saturated zone to the water table (vadose zone). This is due to the heterogeneous (non-uniform) nature of the subsurface, causing anisotropic groundwater and solute migration, and the natural fluctuations of rainfall and streamflow (Kazemi et al, 2006). Utilizing known parameters values (e.g. bore log information) as well as the integration observed field data is essential in the development of a groundwater model (Lubczynski and Gurwin, 2005). 
The Wairarapa is situated in the southern North Island of New Zealand (see Fig. 4.2). The area is a dynamic and complex hydrogeological system with a warm dry climate, widespread agricultural and horticultural land-use, and several populated areas (e.g. Masterton and Greytown). Rainfall is the main recharge mechanism, replenishing aquifer systems through direct land surface recharge as well as recharge through channel beds hydraulically connected to shallow aquifers (Guggenmos et al, 2011).

The Wairarapa groundwater system has been monitored since the 1980s in response to increased abstraction pressure on groundwater due to limited and over-allocated surface water supplies (O’Dea et al, 1980; Gunn et al, 1987; Annear et al, 1989). Greater Wellington Regional Council has routinely completed annual monitoring reports for regional groundwater management, with a focus on sustainable aquifer abstraction (Butcher, 1997, 2000, 2004). A flow modelling project of the Wairarapa groundwater system was recently completed to address and ensure sustainable groundwater management (Gyopari and McAllister, 2010a, 2010b, 2010c; Hughes and Gyopari, 2011; Jones and Baker, 2005; Jones and Gyopari, 2006).

\subsection{Aim of the dissertation}

One aim of this dissertation and of the tracer validation project in general, is to reduce model uncertainty by employing hydrochemical and tracer data for calibration. This is in addition to hydraulic head and stream/spring/flow observations that are traditionally used in the calibration of groundwater models. This dissertation then uses the calibrated model to directly simulate groundwater age throughout the catchment in both space and time. The aim of this project is to develop a calibrated flow and transport model, utilizing tritium (the only radioactive isotope of hydrogen) and hydrochemistry measurements, to simulate both the transient mean-age and specific point age distributions in the catchment. This is achieved by utilizing an existing flow model and implementing a transport model to form a coupled groundwater model evaluating both flow and transport processes simultaneously. Uncertainty is measured relative to observed and simulated data and the derived age and transport time maps and graphs will assist water management in the Wairarapa. 
This dissertation is informed by and extends the Middle Valley groundwater investigation concluded by Gyopari and McAllister (2010). Model parameters will be extended with the addition of transport parameters, as well as the implementation and application of new groundwater age estimation techniques. The flow and transport parameters are calibrated using both hydraulic heads and tritium concentrations to better characterize the subsurface of the Middle Valley. Following this, age is directly simulated and both transient mean-age and transient age distributions will extrapolate important age information throughout to manage and protect groundwater resources. The radioactive tracer tritium is utilized to calibrate the Middle Valley model parameters. Morgenstern (2005) has collected tritium data used in this dissertation through both the National Groundwater Monitoring Program (NGMP) and a Wairarapa tracer and hydrochemistry study.

Using observed tritium concentrations to calibrate then directly simulate the transport of groundwater age is the focus of this research. Until recently, the direct simulation of age was only achievable for steady state groundwater models, as the mathematics to implement transient cases had not been implemented. Cornaton $(2007,2012)$ provided the theory and numerical implementation to extend direct age simulation to transient models, through the introduction of the time-marching Laplace transform Galerkin technique (TMLTG), which he implemented in the Ground Water (GW) software. As this is a recent development, this is one of the first applications of the direct simulation of transient groundwater age in a real world groundwater catchment. The dataset for the Wairarapa is particularly useful as it has sufficient time-series measurements to enable simulated age distributions derived from the TMLTG technique. The specific modelling objectives of the dissertation determined:

1. If tritium concentrations can be simulated by a transient groundwater flow and transport model, and if simulated tritium concentrations can match measured tritium data; and

2. If field hydrochemistry data, such as silica and phosphorous, can assist in the calibration of a model, and if can they be used in addition to tritium measurements. 
Groundwater age has been estimated throughout New Zealand's water catchments to assess water quality and sustainability. This dissertation provides a thorough assessment of the physical processes controlling the migration of dissolved solutes through the Middle Valley groundwater catchment. Specifically, the spatial and temporal evolution of a groundwater catchment inferred from groundwater age, and the direct simulation of age used to delineate zones of sensitivity in relation to contamination from land use activities (i.e. drinking water contamination).

The transient age distribution throughout a groundwater system has been demonstrated in hypothetical scenarios but not a real-world groundwater system. Additionally, observed measurements of tritium have not been used (to date) to simulate transient flow and age distributions in a New Zealand groundwater catchment (Cornaton, 2007, 2012; Cornaton and Perrochet, 2006; Goode, 1996; Sudicky, 1989; Zinn and Konikow, 2007). Field tritium measurements are used to calibrate the flow and transport parameters of the transient numerical groundwater model. Recently a transient tritium transport model was coupled with a steady state flow model in the Western Taupo catchment (Gusyev et al, 2012); while internationally there is limited, but increasing, application of tracers (i.e. tritium and $\mathrm{SF}_{6}$ ) to calibrate and derive transient age simulations (Gundel et al, 2013).

\subsection{Structure of thesis}

Following on from this introductory section, Chapter Two leads into the specifics of hydrogeological numerical flow and transport modelling. The fundamentals of groundwater flow and transport are described including the substrate properties and the processes involved when modelling groundwater basins. The inherent structure and stratigraphic composition of a groundwater basin is explained, delineating the primary groundwater zones and the important parameters defined within the substrate affecting flow and transport. The groundwater processes cover the dominant processes affecting groundwater flow and solute migration (e.g. advection, dispersion and diffusion), and the governing equations used to simulate groundwater flow and transport in a modelled domain (e.g. Darcy's law and the advective dispersive equation). 
Chapter Three explains the principles of groundwater age and how it is estimated and modelled. Groundwater age is explained with its history, evolution and its increasing importance for the sustainable management of subsurface allocation and pollution prevention. The environmental and anthropogenic tracers are then described with a focus on the conservative age tracer tritium, which is applied in this dissertation, leading into the related principles of the hydrochemical constituents found in groundwater reservoirs.

Chapter Three concludes with the details of the numerical modelling methods used to simulate age in the groundwater environment. These include lumped parameter models, the particle-tracking method, and finally the direct age simulation method, which is utilized for the Middle Valley age simulation. The TMLTGT is then explained. Its application allows the transient groundwater age distributions to be evaluated and used for informed groundwater management. The chapter is concluded with a comparison between the three age simulation methods.

Chapter Four presents an overview of the Wairarapa study area. Current hydrogeological processes are largely governed by the subsurface geology and many studies have contributed to the current knowledge of the Wairarapa groundwater system, specifically, the Middle Valley catchment. The current state of knowledge is presented encompassing the geology, hydrology, hydrogeology, and prevailing climatic conditions in the Wairarapa. This includes the primary geological sub-zones and their relative geological ages, which control the movement and quantity of water in the subsurface aquifers and aquitards. The rivers, streams, and springs are then explained along with the climatic conditions leading to the history of flooding and droughts across the predominantly dry climate. Prior to the summary, the groundwater abstraction pressures are examined and the known areas of hydraulic complexity affecting the accuracy of the numerical model are discussed.

Chapter Five evaluates the specifics of the transient FEFLOW flow model constructed by the Greater Wellington Regional Council (GWRC). The model was completed over a five year period, alongside two others, as part of a regional groundwater investigation into the sustainability of water abstraction pressures in the Wairarapa. The transient 
FEFLOW flow model is derived from the water inputs and outputs including the abstraction/irrigation, rainfall and river flux. The model structure and discretization of the model domain is then covered, explaining the defined model parameters and their relation to the conceptual model, river and rainfall recharge quantification/simulation, the initial flow conditions, the boundary conditions specified for rivers and springs, and the hydraulic head calibration undertaken via the PEST (Model-Independent Parameter Estimation) software. This is concluded with a summary of the transient FEFLOW model leading into the development of the coupled flow and transport model.

Chapter Six describes the methodology of the transient flow and transport model. This section covers all the relevant methods for converting the GWRC flow model, implementing transport parameters, and the simulations based in the Ground Water (GW) software. The model's numerical implementation including the time discretization, transport parameters and transport boundary conditions are then described prior to the initial transport condition assessment and implementation. The calibration process is then worked through starting with the observational tritium data, hydraulic head data, and inferred tritium concentrations from hydrochemistry. The sensitivity analysis is then explained followed by the adjustable hydraulic parameters and the calibration methods which utilized both the localized Gauss-MarquardtLevenberg parameter-estimation scheme and a classical Monte Carlo scheme. The direct age simulation is then described within the Ground Water (GW) software and the chapter is then concluded with a summary of the methodology leading into the results.

Chapter Seven covers the calibration and age simulation results from the Middle Valley model. This covers the main findings including the flow model conversion and resulting flow simulation comparisons between the two software codes (GW and FEFLOW). The time-discretization is then covered and the formulation of the initial transport conditions for the July 1992 simulation starting point. The inferred tritium concentration results are then explained and discussed leading to the implementation of the data in the calibration phase. The resulting calibration parameters and overall calibration process results are then evaluated leading to the calibration summary and specific points of success within the Middle Valley process. 
The direct age simulation results are then covered, including the transient mean age simulations, seasonal age differences, transient age distributions (at specific points), and examination of the effect of historical climatic events on the simulated age of water in the Middle Valley (e.g. flood and drought impact). This followed by chapter eight which contain the concluding remarks, discussion, recommendations, and avenues for future research.

\subsection{Terminology}

- Ground Water (GW): is the software used in the flow and transport simulations. Given the fact this is a groundwater project, the topic: groundwater is distinguished from the software: Ground Water (GW).

- Age: usually implies groundwater age.

- Heterogeneous: non-uniform

- Homogeneous: uniform

- Saturated zone: where pores and fractures are saturated with water (also known as the phreatic zone).

- Variably saturated zone (unsaturated zone): is the part of Earth between the land surface and the top of the saturated zone, where the groundwater is at atmospheric pressure (also known as the vadose zone).

- Aquifer: zone/layer of high hydraulic conductivity (permits relatively fast movement of water through porous media).

- Aquitard: zone/layer of low hydraulic conductivity (permits slow movement of water through porous media).

- Spatio-temporal: of, relating to, or existing in both space and time.

- ${ }^{3} \mathrm{H}$ and Tr: Tritium

- TU: tritium units (one TU represents one tritiated water molecule in $10^{18}$ water molecules)

- $\mathrm{SF}_{6}$ : Sulphur hexafluoride

- CFCs: Chlorofluorocarbons

- TMLTG: Time-marching Laplace Transform Galerkin technique

- PEST: Parameter ESTimation (calibration software) 


\section{Chapter 2}

\section{Groundwater flow and transport}

All is flux, nothing stays still.

Plato

The dissertation combines both the flow and transport of water and particles into a model governed by hydraulic equations. Chapter Two explains the specifics of groundwater flow and transport, specifically the primary groundwater processes and governing fluid and solute transport equations used in numerical models. Subsurface reservoirs are located at varying depths and thickness throughout the world's alluvial basins. Typically meandering river channels carry large amounts of sediment from elevated areas, developing a complex depositional history and forming multiple subsurface reservoirs, over fluctuating glacial and interglacial climate cycles. The supply of sediment is dependent on tectonic forces creating the elevated ranges and climatic conditions, both long-term (e.g. glacial and interglacial) and short-term (e.g. storms and floods), with these processes forming subsurface water systems (i.e. aquifers and aquitards) (Fig. 2.1). Groundwater systems are typically complex with a heterogeneous distribution of media throughout. Some can exhibit a less complex composition, bordering on homogeneous (uniform), however this is arguably never completely true given a groundwater system cannot be completely sampled. Regardless, the inherent complexity and scale of groundwater systems make characterisation of the flow of water and transport of solutes within them challenging. Governing equations for the flow of water and transport of solutes can be used to estimate groundwater processes, often condensed into a model, to inform water resource management. 


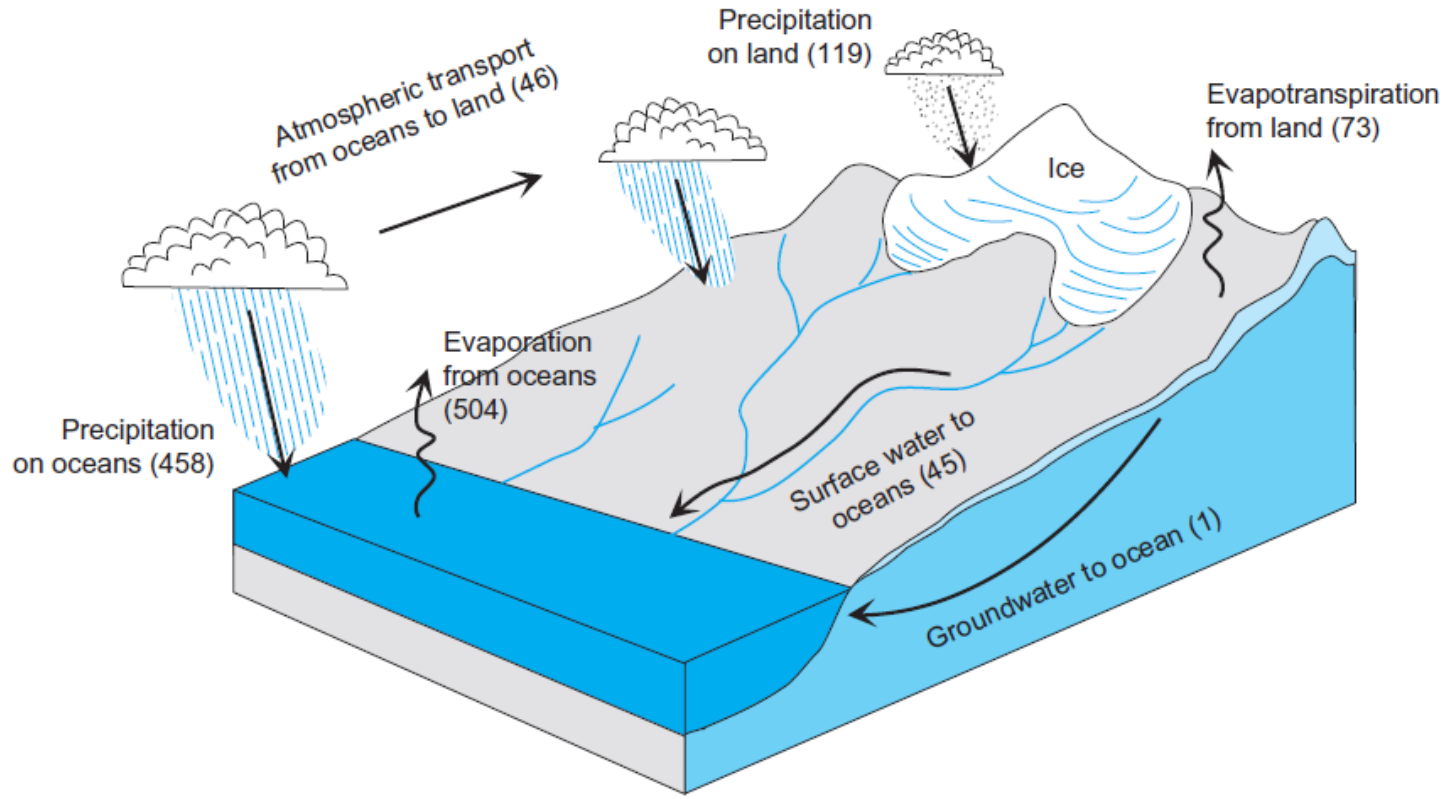

Fig. 2.1 Hydrological cycle with numbers representing global fluxes in thousands of $\mathrm{km}^{3}$ /year. Source: Fitts (2002).

Groundwater is typically located and split into two primary parts, 1) the saturated or phreatic zone and 2) the unsaturated (i.e. variably saturated) or vadose zone (Fitts, 2002). The saturated zone is the area in an aquifer, below the water table, where pores and fractures are saturated with water. The variably saturated zone is the part of Earth between the land surface and the top of the saturated zone, where the groundwater is at atmospheric pressure. The term groundwater is usually referring to water contained in the deeper fully saturated sections of the subsurface, however water is present within the vadose zone. It is important to consider movement of water and solutes through the upper variably saturated sections of the subsurface as these movements can significantly affect the flow and migration of solutes to the saturated zone (Freeze and Cherry, 1977). Groundwater management must also account for surface water processes, given that any recharge to a groundwater system originated from rainfall and/or river flow on the surface (Fig. 2.2). The interactions between shallow aquifers and river channels can significantly affect the water balance of the catchment and subsequently affect the solute transport to groundwater and hence the groundwater age (Daughney et al, 2009a; Guggenmos et al, 2011). 


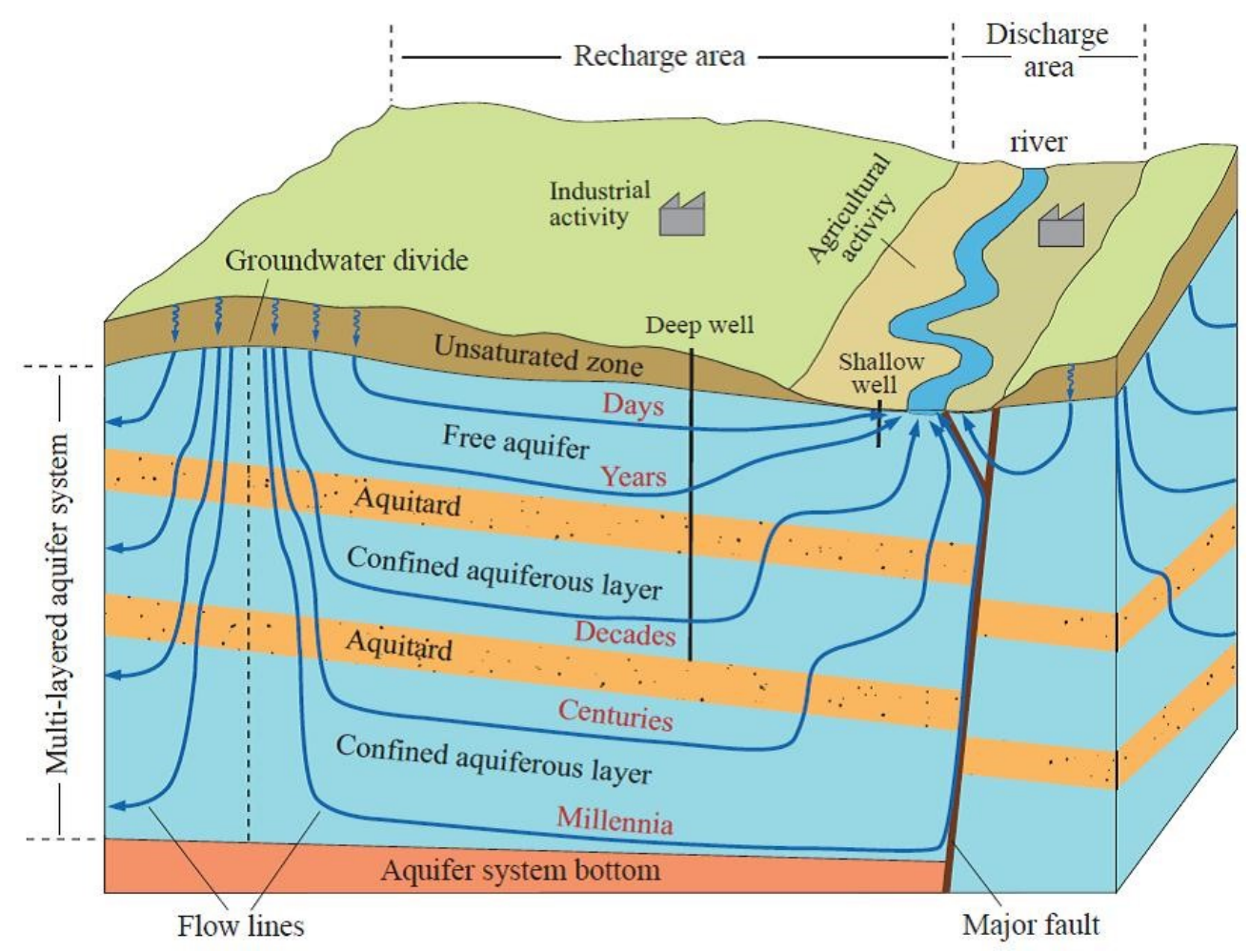

Fig. 2.2 Representative groundwater system. Source: Kazemi et al (2006).

\subsection{Groundwater flow}

Groundwater flow is important to understand and characterize due to increasing utilization of and influence on groundwater resources. Characterization is important in order to sustainably manage current aquifers and accurately simulate water processes in groundwater models. The movement of water in the subsurface is dependent on both the physical properties of water and the material through which it flows. The space in porous media governs the quantity and how fast water moves through the subsurface. The distribution and identification of specific material zones throughout a catchment's subsurface is essential to quantify water and solute flux (Kazemi et al, 2006). The flow variation within a groundwater system has a significant influence on groundwater age and defining the appropriate parameters affects the simulated volumetric flux and age within subsurface systems. Typically, hydraulically conductive gravel aquifers with reliable recharge will exhibit large flow velocities, and therefore will exhibit a younger water age distribution compared to slower, less conductive systems (Fitts, 2002). 


\subsubsection{Hydraulic Head}

The hydraulic head is a measurement of the liquid pressure above a common datum. Hydraulic heads are typically measured and compared relative to their elevation above mean sea level (i.e. the level of the water column above sea level), but can additionally be measured as their elevation above a lake, or the available difference in hydraulic head across a hydroelectric dam to calculate the energy potential. Water flows from one area to another in response to different distributions of mechanical energy within the groundwater (Fitts, 2002). Water always flows from areas of higher mechanical energy to areas with lower mechanical energy. When water flows, it loses some mechanical energy to friction, heating the surrounding material. This heat however is relatively small compared to other heat sources such as geothermal energy. There are three forms of mechanical energy in water:

1. Elastic potential energy, gained by compressing water;

2. Kinetic energy, due to the velocity of water, and

3. Gravitational potential energy, defined by water existing at higher elevations.

These forms of mechanical energy were summarized into the Bernoulli Equation (Bernoulli, 1738). It is a fundamental equation of fluid mechanics and applies to relatively incompressible fluids, such as water, and describes the mechanical energy of water (E) (Fitts, 2002).

$$
E=P V+m g z+\frac{1}{2} m v^{2}
$$

where:

$$
\begin{gathered}
m=\text { mass }(\mathrm{kg}) \\
P=\text { pressure }\left(\mathrm{N} / \mathrm{m}^{2}\right) \\
g=\text { acceleration of gravity }\left(\mathrm{m} / \mathrm{s}^{2}\right) \\
Z=\text { elevation }(\mathrm{m}) \\
V=\text { volume }\left(\mathrm{m}^{3}\right) \\
V=\operatorname{velocity}\left(\mathrm{m} / \mathrm{s}^{2}\right)
\end{gathered}
$$


The Bernoulli Equation assumes that water is near the earth's surface, where the acceleration of gravity $(g)$ can be taken as a constant. The unit of energy is the joule (J), and one joule $=1 \mathrm{~kg} \cdot \mathrm{m}^{2} / \mathrm{sec}^{2}=1 \mathrm{~N} \cdot \mathrm{m}$ (Fitts, 2002). This equation calculates the energy required to compress, elevate, and accelerate a mass $(m)$ of water from one point to another where $P=Z=V=0$. When analysing water flow the most common measurement is hydraulic head $h$, which is the energy per weight of water, calculated by dividing each term of the Bernoulli Equation by the weight of water, $m g$. Water always flows to areas with lower hydraulic head, in the same way heat moves towards areas of lower temperature.

$$
\begin{gathered}
h=\frac{E}{m g} \\
=\frac{P}{\rho_{\omega g}}+z+\frac{v^{2}}{2 g} \\
h=\text { hydraulic head }(\mathrm{m}) \\
E=\text { pressure head }(\mathrm{m}) \\
m=\text { elevation head }(\mathrm{m}) \\
g=\operatorname{velocity} \text { head }(\mathrm{m})
\end{gathered}
$$

$P=$ atmospheric pressure, generally assigned as zero $\left(\mathrm{N} / \mathrm{m}^{2}\right)$

$$
\begin{gathered}
\rho_{\omega g}=\text { weight density }\left(\mathrm{kg} / \mathrm{m}^{3}\right) \\
z=\text { location/elevation }(\mathrm{m}) \\
v=\text { water velocity }(\mathrm{m} / \mathrm{s})
\end{gathered}
$$

Groundwater generally flows at very low velocities, generally less than a few metres per day. The velocity head is one type of head used in calculations and is due to the bulk motion of a fluid. Even in dynamic fast flowing zones the velocity head is considered negligible relative to the hydraulic head. 
Considering this, the hydraulic head equation can be reduced to:

$$
h=\frac{P}{\rho_{\omega g}}+z
$$

Hydraulic heads are determined from water-level measurements in wells and piezometers. Manual water-level measurements are taken using the distance from the ground surface to the water table using a wire probe with two unconnected conductors. The electrical circuit is completed when the water table is reached by the end of the probe, as groundwater has dissolved constituents making it electrically conductive, a small voltage is generated which is amplified in the transistorized circuit contained in the cable reel of the metre. This voltage is read directly on a voltage meter. A piezometer is a device that measures the static pressure (i.e. piezometric head) of groundwater inside a well. The first piezometers in were open wells or standpipes installed into an aquifer (e.g. Casagrande piezometers). These typically have a solid casing and a slotted (or screened) casing sealed into the borehole to prevent groundwater leaking to the surface. In an unconfined aquifer, the water level in the piezometer would be the same as the water table, but in a confined aquifer under artesian conditions, the water level in the piezometer indicates the pressure in the aquifer, but not always the water table. Piezometer wells can be much smaller in diameter than production wells, for example a $5 \mathrm{~cm}$ diameter standpipe is common, compared to $15-30 \mathrm{~cm}$ in diameter for productive irrigation wells. The transducer (pressure gauge) can be pneumatic, vibrating-wire, or strain-gauge, which converts pressure into an electrical signal. These piezometers are cabled to the surface where they can be read by data loggers, allowing more efficient data collection than open standpipe piezometers.

\subsection{Properties of the subsurface}

The properties of the subsurface define the movement of water and solutes in a groundwater basin. There are three primary properties defined in the subsurface including porosity, hydraulic conductivity and storativity. 
A groundwater system is extremely complex and the characterization of its properties involves significant uncertainties. Hence, when analysing modelled results, the assumptions made within the model must be taken into account. Models are assigned parameters based on field stratigraphy measurements which are often subsequently calibrated. Inverse modelling is a calibration method using measured field data and comparing simulated results as a means of deriving and objective function. Field data could be, for example, measured hydraulic heads and tritium concentrations. However, given a heterogeneous three-dimensional groundwater model is (typically) highly parameterized, a large and wide range of assigned parameters can derive similar results. A well-calibrated regional flow and transport model is still a rough representation of the actual water system; given groundwater systems are complex and sparsely characterized (Fitts, 2002).

\subsubsection{Porosity}

The porosity of rock or soil is the percentage of the material volume that is empty pore space inhabitable by a liquid or gas. The porosity and interconnectedness of pores controls the volume of water, and speed with which it transmits through porous media. There are several methods used to measure the porosity of a collection of material and certain grains have known particle sizes (Table 2.1). Direct methods determine the volume of the porous sample and then calculate the volume of the material with no pore spaces, i.e. pore volume $=$ total volume - material volume. Optical methods determine the area of the material compared to the area of the pores under a microscope, where the "areal" and "volumetric" porosities are assumed to be equal for porous media with a random structure (Brun et al, 1977). Imbibition methods immerse a porous sample, under vacuum, in a fluid (typically water) to wet and inhabit the pores (e.g. the water saturation method). The pore volume = total volume of water - volume of water remaining after the sample has been immersed. Other methods include the water evaporation method, gas expansion method, mercury intrusion porosimetry, thermoporosimetry and cryoporometry (see Brun et al, 1977; Mitchell et al, 2008). 
Porosity is defined as:

$$
\begin{gathered}
n=\frac{V_{v}}{V_{t}} \\
\text { where: } \\
n=\text { porosity (dimensionless) } \\
V_{V}=\text { volume of empty pore space }\left(\mathrm{m}^{3}\right) \\
V_{t}=\text { total volume of the material }\left(\mathrm{m}^{3}\right)
\end{gathered}
$$

This is a dimensionless parameter between the range of $0<n<1$, and can be expressed as a percentage by multiplying $n$ by 100. Larger porosities equate to a greater porosity. The effective porosity $n_{e}$ is defined by the above equation, with the exception that $V_{V}$ is the volume of spaces which are connected through which fluid can flow. The total and effective porosity are only significantly different when there are large or multiple areas with pore spaces which are not connected, for example an area (or areas) bounded by solid rock within the flow area.

Table 2.1 Porosity of typical substrate. Source: Fitts (2002).

\begin{tabular}{|lc|}
\hline Material & $n(\%)$ \\
\hline Fine silt, sand, and gravel & $30-50$ \\
Coarse silt, sand, and gravel & $20-35$ \\
Clay, clay-silt & $35-60$ \\
Sandstone & $5-30$ \\
Limestone & $0-40$ \\
Crystalline rock & $0-10$ \\
\hline
\end{tabular}

The grain size of the material is another important variable. The distribution of grain sizes constrains how much water can be stored in pore spaces, and collectively, how productive an aquifer (or unproductive an aquitard) can be in terms of groundwater yield. The primary grain sizes, in order of increasing size, are clay, silt, sand, and gravel. Clay and silt layers create aquitards which store groundwater but transmit water very slowly, as they have a low hydraulic conductivity due to smaller pore spaces and greater surface area. 
These confining layers have a substantial effect on age as they can mix with a bounding confined or unconfined aquifer (Zinn and Konikow, 2007). This creates an older age in the aquifer and a younger age in the aquitard; this is known as the paradox of groundwater age (Bethke and Johnson, 2002).

\subsubsection{Hydraulic Conductivity}

Hydraulic conductivity $(K)$ is the measure of ease by which water passes through media (Freeze and Cherry, 1977). Materials with higher $K$ values transmit water faster than materials exhibiting lower $K$ values. Hydraulic conductivity is related to porosity and exemplified by the fact that large pore spaces are present in materials such as sand and gravel that permit relatively fast water movement. Additionally, larger materials (e.g. gravels) exhibit faster flow due to a smaller surface area, creating less friction, compared to smaller gran sizes such as clay (Fig. 2.3). Materials with a collective large grain size form aquifers while aquitards are small grain size clay or silt matrices, which cause more viscous resistance, with slower water transport (Fitts, 2002).

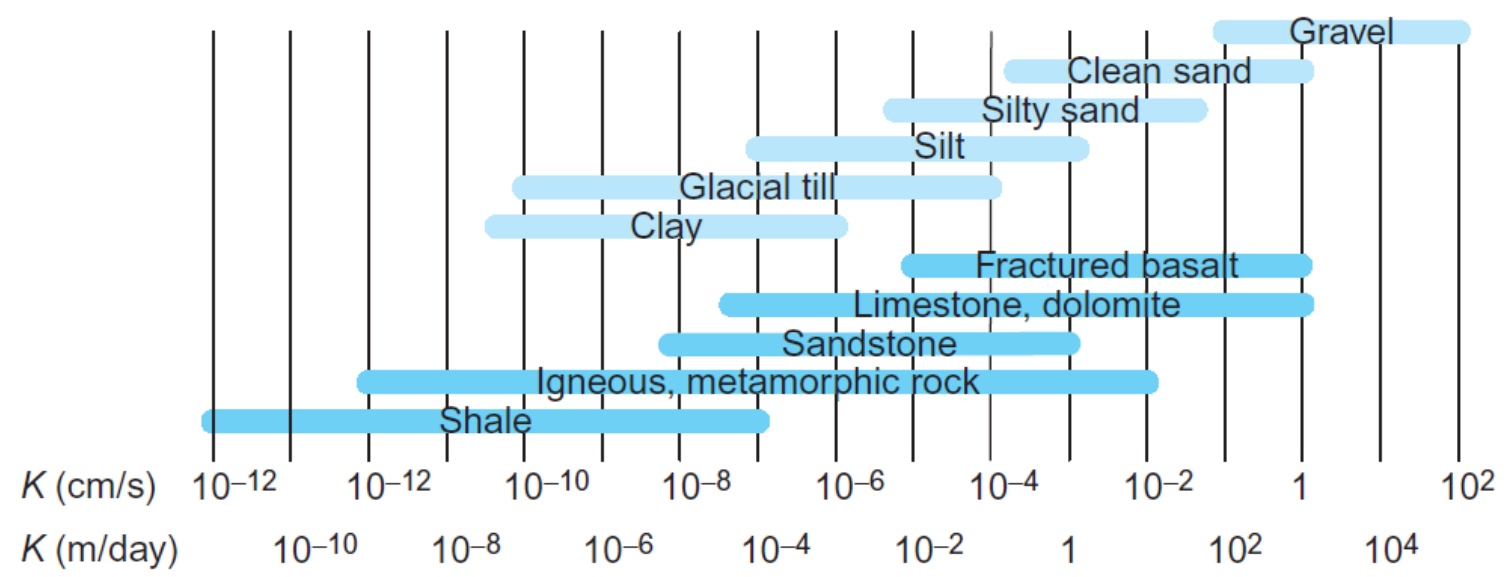

Fig. 2.3 Typical values of hydraulic conductivity in a range of groundwater yielding media. Source: Fitts (2002) with data compiled by Davis (1969), Freeze and Cherry (1979), and Clay and shale ranges from Neuzil (1994).

A groundwater catchment is formed through depositional processes forming a complex network of media. The natural evolution typically results in a range of hydraulic parameters throughout the system. In a heterogeneous system, hydraulic conductivity varies spatially, whereas in a homogeneous system, $K$ is uniform throughout. 
Anisotropy describes the fact that hydraulic conductivity (at a given point) depends on direction. For example, if hydraulic conductivity in the $x$-direction $\left(K_{x}\right)$ does not equal hydraulic conductivity in the $y$-direction $\left(K_{y}\right)$, the material is considered anisotropic as the conductivities are different in perpendicular directions. If the conductivities were equal $\left(K_{x}=K_{y}\right)$ the material would be isotropic. Most groundwater systems are, to some degree, heterogeneous and anisotropic. Estimating hydraulic conductivity is a crucial step in the accurate assessment of groundwater movement and solute transport. Ideally, the entire domain would be sampled in order to generate an ideal set of subsurface parameters, but this is problematic, given the sheer volume and cost of such an investigation. Best estimates are made with the relevant information and data available, which can be subsequently tested against measured heads and concentrations in the calibration phase of a numerical model.

Hydraulic conductivity is determined using empirical and experimental methods. The empirical approach correlates the hydraulic conductivity to soil properties, for example pore and grain size distributions, and soil texture. The experimental approach determines the hydraulic conductivity from hydraulic experiments in saturated media utilizing Darcy's law. Experiments are conducted in laboratories or in situ field tests. Laboratory tests use representative soil/substrate samples in columns subject to water movement through columns (typically in saturated flow). There are several field tests including 1) pump, 2) slug and 3) infiltration tests which cover both large and small scales, and both saturated ( 1 and 2 ) and variably saturated (3) media. A pumping test evaluates the aquifer, from which the well draws from, testing the aquifer through constant pumping and observing the response or drawdown. Typically, a pumping test is performed by pumping water from a well at a steady rate and for at least one day (24 hours) and measuring the water level response in the well and additional monitoring wells in close proximity. As water is abstracted from the pumping well the pressure in the aquifer, which feeds the well, decreases. This reduction in pressure results in a decrease of hydraulic head (known as drawdown) in a well (Fig. 2.4). Drawdown additionally decreases with radial distance from the pumping well (i.e. a cone of depression) and increases with the longer the pumping duration. 

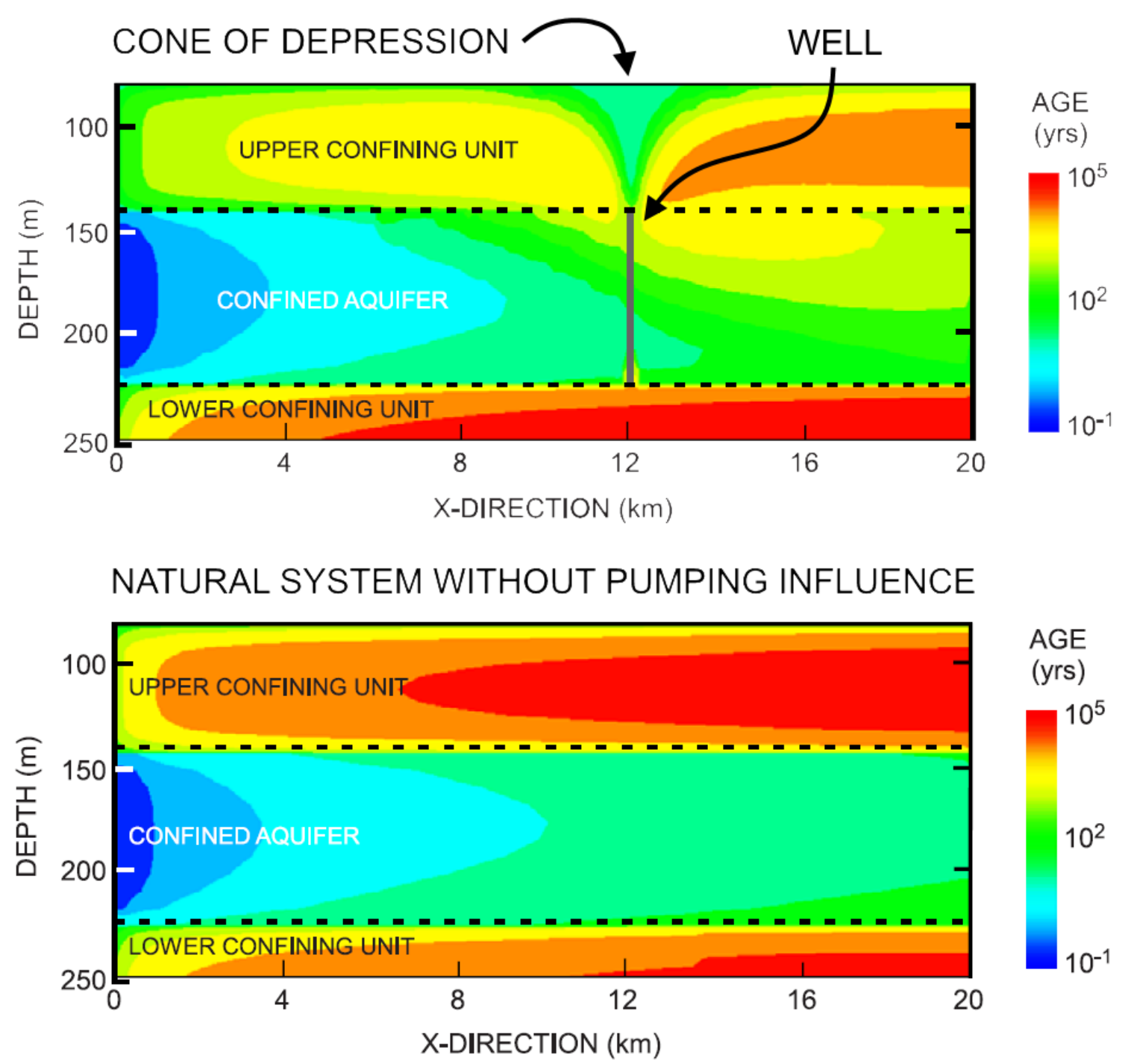

Fig. 2.4 Cone of depression example. Modified from Zinn and Konikow (2007).

A slug test is a variation on the pumping test where an increase or decrease to a single well is executed and the effects observed. It is a smaller scale investigation implemented when estimated aquifer properties are required relatively quickly, minutes instead of days, compared to pumping tests. An infiltration test is a measure of how fast water enters the soil and is measured on soils usually at ground level. Water is placed on a sectioned portion of variably saturated media and the time the water takes to fully infiltrate the media is measured, the test is typically repeated multiple times to assess a representative rate with a partially saturated sample or until an equilibrium is reached. 
Fractured rocks can permit the movement of large volumes of fluids, and hence have a wide range of hydraulic conductivity values. The dissolution of carbonate rock, such as limestone, can lead to large open spaces beneath the ground and can lead to underground rivers and caves, such as the Riwaka Resurgence in the South Island of New Zealand. These formations, including those in basalts, can permit vast water movement much greater than alluvial gravel as large fractures can hold more water and transmit it more directly without the obstruction of gravels, for example, which slow longitudinal fluid movement. These fractured systems are assumed to not exist in the Wairarapa groundwater system and hence not simulated in the Middle Valley.

\subsubsection{Darcy's law}

Darcy's law describes the flow of a fluid through a porous medium. Darcy's law was calculated using an apparatus with a column of sand, saturated with water, with an inlet and an outlet with two manometers (small piezometers) measuring the hydraulic head at two points in the column, $h_{1}$ and $h_{2}$ (Darcy, 1856). Flow is forced through at the top of the column and a steady-flow of water exits at a discharge rate $Q$ from the outlet. Darcy's experiments concluded that $Q$ was proportional to the head difference $\Delta h$ between the two manometers and inversely proportional to the distance between the manometers $\Delta l$. The rate that head changes, $d h / d l$, is known as the hydraulic gradient (Eq. 2-5). $Q$ is also proportional to the cross-sectional area of the column of $A$. Combining these into differential form gives Darcy's law for one-dimensional flow:

$$
Q_{s}=-K_{s} \frac{d h}{d s} A
$$

where:

$$
\begin{gathered}
Q_{s}=\text { discharge in the } s \text { direction }\left(\mathrm{m}^{3} / \mathrm{s}\right) \\
K_{S}=\text { hydraulic conductivity in the } s \text { direction }(\mathrm{m} / \mathrm{s}) \\
d h=\text { difference in head }\left(h_{1}-h_{2}\right) \text { (metres) } \\
d s=\text { length between points at which head is measured }(\mathrm{m}) \\
A=\text { cross-sectional area }\left(\mathrm{m}^{2}\right)
\end{gathered}
$$


Darcy's law can be applied to almost all hydrogeological environments (Freeze and Cherry, 1977). In general, Darcy's law can be applied to:

1. Saturated flow and variably saturated flow;

2. Steady-state and transient flow;

3. Flow through aquifers and aquitards;

4. Flow through isotropic and anisotropic media;

5. Flow in homogeneous and heterogeneous systems, and

6. Flow through rocks and granular substrate.

Darcy's law does not apply to variably saturated flow. It has also been found to be invalid for turbulent flow and some very low-permeability materials, such as clays. A variation of Darcy's law, the Richards equation, is often used with varying degrees of success to describe the flow of water through the variably saturated zone Given the Middle Wairarapa valley is composed of alluvial sand, gravel, silt and clay aquifers, with relatively thin clay sections, Darcy's law is assumed to apply throughout the Middle Valley domain.

\subsubsection{Darcy Velocity}

Darcy's law can be expressed another way in the form of discharge per cross sectional area:

$$
\begin{aligned}
q_{s} & =\frac{Q_{s}}{A} \\
& =-K_{s} \frac{d h}{d s}
\end{aligned}
$$

The $q_{s}$ quantity is the Darcy velocity, also known as the specific discharge. This is the amount of water passing through a given area of the aquifer perpendicular to the $s$ direction. $Q_{S}$ is the flow through the section and $A$ is the area of the section. 
$q_{s}$ is measured in speed, like a velocity, but given water can only flow through a portion of the section due to the space taken up by geologic material, this is known as the Darcy velocity. It is subsequently lower than the average linear velocity. The average linear velocity of water movement is directly proportional to the specific discharge and inversely proportional to the effective porosity. The average linear velocity $\left(\bar{v}_{s}\right)$ is the speed that a conservative tracer, not reacting with the substrate, would travel through the subsurface with the flow of groundwater. It is defined as:

$$
\bar{v}_{s}=\frac{q_{s}}{n_{e}}
$$

where:

$$
\begin{gathered}
\bar{v}_{s}=\text { average linear velocity }(\mathrm{m} / \mathrm{s}) \\
q_{s}=\text { Darcy velocity }(\mathrm{m} / \mathrm{s}) \\
n_{e}=\text { porosity }(\%)
\end{gathered}
$$

\subsubsection{Darcy's law in three-dimensions}

Groundwater in natural porous systems is not limited to one-dimensional flow. In reality, groundwater generally flows in complex three-dimensional paths within heterogeneous systems. Although the assumptions of a homogeneous and isotropic system are often made for initial and/or approximate states when modelling water problems, groundwater systems are rarely homogenous. If the aquifer is heterogeneous, there are flow components in each of the three directions. These are assumed to be described using the Cartesian $x, y, z$ coordinate system, with the $x$ and $y$ forming the horizontal flow and the $z$ component vertical flow. 
The three-dimensional form of Darcy's law has the three vector components as partial differentials (Eq. 2-8) (Bennett, 1976):

$$
\begin{gathered}
q_{x}=-K_{x} \frac{\partial p}{\partial x} \\
q_{y}=-K_{y} \frac{\partial p}{\partial y} \\
q_{z}=-K_{z}\left(\frac{\partial \rho}{\partial z}+\rho_{x, y, z} g\right) \\
\text { where: } \\
q_{x, y, z}=\text { discharge rate }\left(\mathrm{m}^{3} / \mathrm{s}\right) \\
K_{x}, K_{y}, K_{z}=\text { hydraulic conductivity in the } x, y, z \text { direction }(\mathrm{m} / \mathrm{s}) \\
g=\text { acceleration due to gravity }\left(\mathrm{m} / \mathrm{s}^{2}\right)
\end{gathered}
$$

This only satisfies slow laminar flow, but as most groundwater flows demonstrate these prerequisites, it is suitably applied for hydrogeological analysis. Flow is defined by the Reynolds number $\left(R_{e}\right)$ which is a dimensionless parameter and a measure of how laminar or turbulent flow is (Eq. 2-9).

$$
\begin{gathered}
R_{e}=\frac{\rho \bar{v}_{s} d}{\mu} \\
\text { where: } \\
\rho=\text { fluid density }\left(\mathrm{kg} / \mathrm{m}^{3}\right) \\
\bar{v}_{s}=\text { velocity }(\mathrm{m} / \mathrm{s}) \\
\mu=\text { dynamic viscosity }(\mathrm{kg} /(\mathrm{m} \cdot \mathrm{s})) \\
d=\text { mean pore diameter } / \mathrm{mean} \text { grain size }(\mathrm{m})
\end{gathered}
$$


Laminar flow exhibits viscous-like slow velocities with minimal mixing and ripples, whereas turbulent flow is fast with dynamic eddies. For example, any flow with a Reynolds number $>1$ is considered as laminar and hence Darcy's law applies. Flows exhibiting Reynolds numbers between one and 10 have been shown to be Darcian, however, $R_{e}=10$ is a threshold range between laminar and turbulent flow and Darcy's law may not be applicable. Turbulent flows with a Reynolds number of $>10$ occur in fractured flow networks, karst limestone networks, and volcanics which are typically coarse in nature with large pores permitting the high turbulent velocities. Darcy's law is not applicable in turbulent flow conditions (Bear, 1972; Fitts, 2002).

\subsubsection{Storage}

The amount of water stored in the subsurface changes with stress and differences in the pore water pressure (Fig. 2.5) (Fitts, 2002).

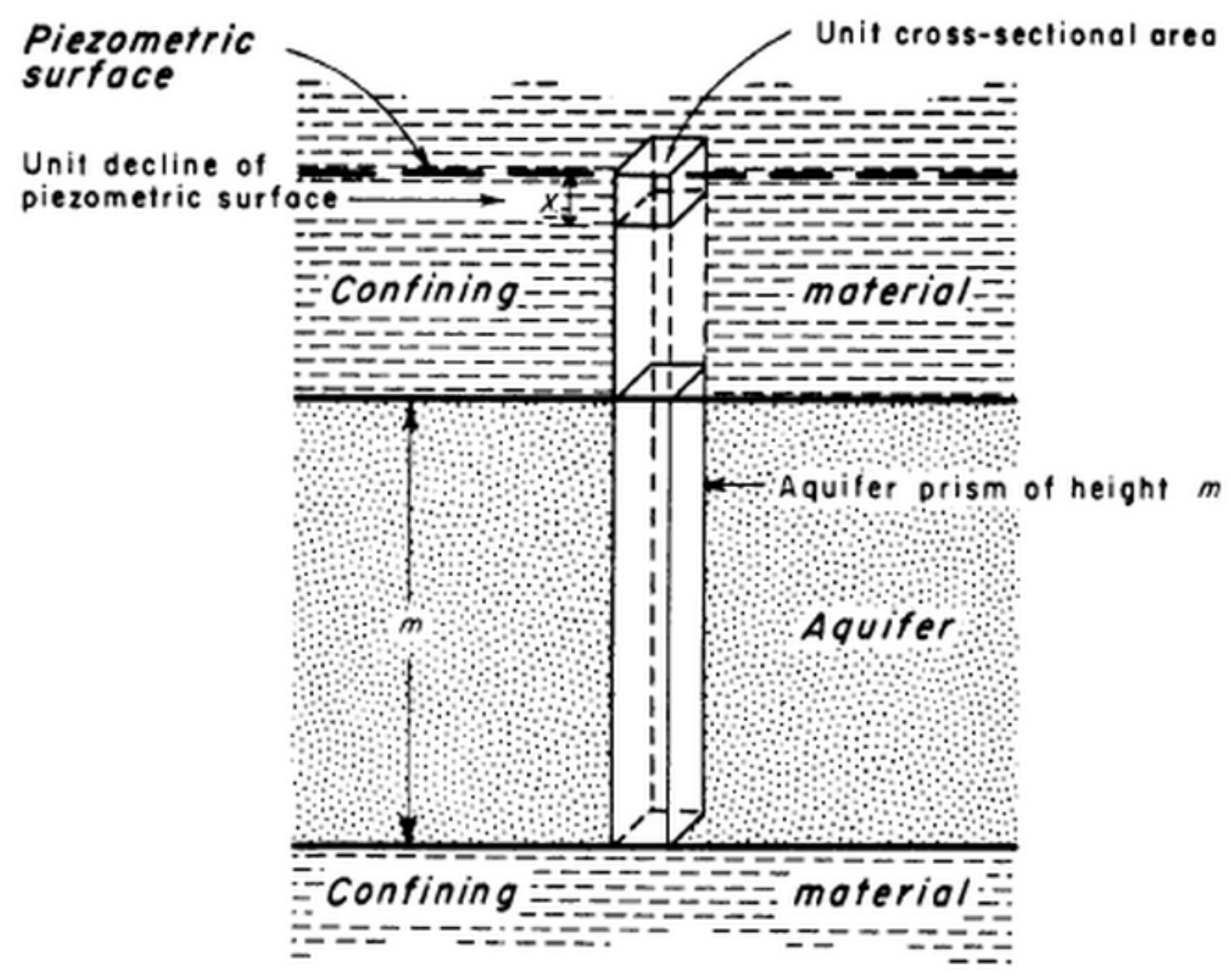

Fig. 2.5 Schematic of storage. Source: Ferris et al (1962). 
For example, if a random area within the saturated zone is examined, the water and the aquifer material matrix are free to expand and contract. Water storage changes over time due to changes in water pressure and/or the shape of the aquifer material matrix. The pressure change causes water to compress or expand in the pore water spaces, and the matrix can contract or expand, changing the amount of available water storage. These processes both occur in transient flow conditions due to head and pressure fluctuations. In a confined aquifer, the storativity is defined as the volume of water released from storage per unit $\left(\mathrm{m}^{3}\right)$ surface area per unit $(\mathrm{L})$ decline in hydraulic head.

A storage parameter used when analysing two-dimensional aquifers integrates storage over the height of the aquifer. This is known as the storativity $(S)$ and typical values in confined aquifers are $10^{-4}$, ranging between $10^{-5}$ and $10^{-3}$ (Freeze and Cherry, 1977). Thick, uncompressed aquifers have high storativities while thin compressed aquifers/aquitards have low storativities. $S$ is dimensionless given the word definition implies: volume/area/length (Fitts, 2002).

$$
\begin{gathered}
S=S_{S} b \\
\text { where: } \\
S=\text { storativity (dimensionless) } \\
S_{S}=\text { specific storage }\left(\mathrm{m}^{2}\right) \\
b=\text { aquifer/aquitard thickness }(\mathrm{m})
\end{gathered}
$$

Specific storage $\left(S_{s}\right)$ is the amount of water output from a unit volume of saturated aquifer material when the (pore) water is changed due to a unit decline in hydraulic head (Freeze and Cherry, 1977). When the hydraulic head lowers, water is forced from the volume as the water expands and the aquifer matrix compresses. This is typically known as elastic storage and it is assumed that the water and matrix expand and contract elastically. The amount of water extractable from a subsurface material is directly proportional to the storativity. 
Specific storage is defined as:

$$
\begin{gathered}
S_{s}=-\frac{d V_{w}}{V_{t}} \frac{1}{d h} \\
\text { where: } \\
S_{s}=\text { specific storage }\left(\mathrm{m}^{2}\right) \\
d V_{w}=\text { volume of water output }\left(\mathrm{m}^{3}\right) \\
V_{t}=\text { aquifer volume }\left(\mathrm{m}^{3}\right) \\
d h \text { = head change }(\mathrm{m})
\end{gathered}
$$

\subsubsection{Variably saturated flow}

The variably saturated zone is one of the major challenges in hydrogeology, specifically for three-dimensional catchment-scale modelling (Fig. 2.6). The focus has largely concentrated on the flow and transport through saturated media, however; variably saturated sections are present in most, if not all, porous material. The pore spaces of this section are partially saturated with water and the remaining free pore space is taken up by air. This relationship is expressed by the volumetric water content $(\theta)$.

\section{Ground surface}

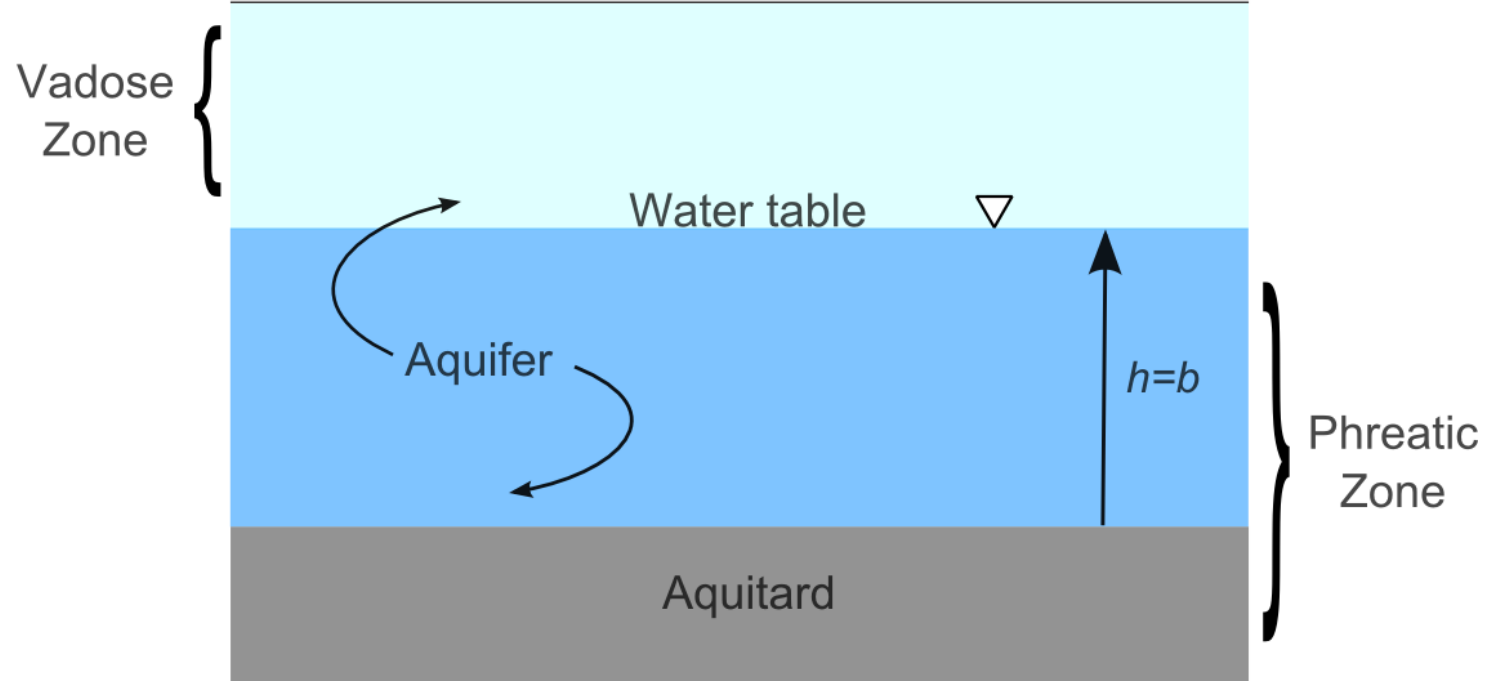

Fig. 2.6 Unconfined aquifer schematic showing vadose zone (above water table), aquifer (saturated zone) and aquitard (bedrock/impermeable material). $h=$ hydraulic head, $b=$ fully saturated depth of the aquifer. 
The major controls on flow in the variably saturated zone are volumetric water content $(\theta)$ and pore water pressure $(P)$. In saturated flow the flow is driven by pore-water pressure and elevation above a reference datum (Fetter, 1993). In unsaturated flow the pore water pressure changes with volumetric water content (Fitts, 2002). This relative proportion of water and air in pore spaces can substantially vary due to the close proximity to the surface (i.e. recharge processes). This has a major effect on the hydraulic properties of the media in the variably saturated zone (Fetter, 1993). The variably saturated zone can influence the flow of water and transport of solutes significantly, particularly the timing between the water and/or solutes migration between the surface and saturated zone.

Although the concepts of Darcy's law and hydraulic head are the same as in the saturated zone, in the variably saturated zone, the hydraulic conductivity $(K)$ is no longer a material constant. It is instead a variable depending on the volumetric water content $(\theta)$, therefore the transient storage term is different in the variably saturated flow equation (Fitts, 2002). The storage term (i.e. rate of change in a mass of water stored) in a saturated element is expressed by:

$$
\frac{\partial m}{\partial t}=\rho_{\omega} S_{s} \frac{\partial h}{\partial t} \Delta x \Delta y \Delta z
$$

$$
\begin{gathered}
\text { where: } \\
m=\text { mass }\left(\mathrm{m}^{3}\right) \\
t=\text { time }(\mathrm{sec}) \\
\rho_{\omega}=\text { water density }\left(\mathrm{kg} / \mathrm{m}^{3}\right) \\
S_{S}=\text { specific storage }\left(\mathrm{m}^{2}\right)
\end{gathered}
$$


However, a variably saturated element's storage term would incorporate the change in water content $(\theta)$ :

$$
\begin{gathered}
\frac{\partial m}{\partial t}=\rho_{\omega} \frac{\partial \theta}{\partial t} \Delta x \Delta y \Delta z \\
\text { where: } \\
\theta=\text { volumetric water content (\%) }
\end{gathered}
$$

The variably saturated flow equation is known as the Richards equation (Eq. 2-14) (Richards, 1931). The equation is written as a function of pressure, utilizing the head definition: $h=\frac{P}{\rho \omega g}+z$ :

$$
\begin{array}{r}
\frac{\partial}{\partial x}\left(K_{x}(P) \frac{\partial\left(\frac{P}{\rho \omega g}\right)}{\partial x}\right)+\frac{\partial}{\partial y}\left(K_{y}(P) \frac{\partial\left(\frac{P}{\rho \omega g}\right)}{\partial y}\right) \\
+\frac{\partial}{\partial z}\left(K_{z}(P)\left[\frac{\partial\left(\frac{P}{\rho \omega g}\right)}{\partial z}+1\right]\right)=\frac{\partial \theta}{\partial P} \frac{\partial P}{\partial t}
\end{array}
$$

where:

$$
\begin{gathered}
K_{y}, K_{y}, K_{y}=\text { hydraulic conductivity }(\mathrm{m} / \mathrm{s}) \\
P=\text { pore water pressure }\left(\mathrm{kg} \cdot \mathrm{m} / \mathrm{s}^{2}\right) \\
\rho \omega=\text { density of water }\left(\mathrm{kg} / \mathrm{m}^{3}\right) \\
g=\text { acceleration due to gravity }\left(\mathrm{m} / \mathrm{s}^{2}\right) \\
\theta=\text { water content }(\%) \\
t=\text { time }(\text { e.g. second) }
\end{gathered}
$$

Modelling variably saturated flow requires additional models of the $K(P)$ and $\theta(P)$ relationships, for example, the Van Genuchten model, the Exponential model, the Brooks-Corey model, the Haverkamp model and the Linear model of saturation (Brooks and Corey, 1966; Haverkamp et al, 1977; Van Genuchten, 1980, 1982). 
Simulating variably saturated water and solute movement is complex and computationally demanding, much more so than saturated modelling, and becomes increasingly complex moving up from one-dimensional to three-dimensional processes.

\subsection{Mass transport in saturated media}

Various solutes migrate within groundwater systems and transport models simulate the evolutionary migration of a dissolved solute or the age of groundwater. The equations used to simulate subsurface transport are similar to those quantifying subsurface flow, partial differential equations, simulating hydrodynamic dispersion in groundwater reservoirs (see Bear, 1972). We can describe the transport of solutes through porous media quantifying the flux of a solute into and out of a fixed groundwater domain using the conservation of mass:

$$
\left[\begin{array}{c}
\text { total rate of } \\
\text { a solute's } \\
\text { change of mass } \\
\text { within the domain }
\end{array}\right]=\left[\begin{array}{c}
\text { postive flux } \\
\text { of a solute into } \\
\text { the domain }
\end{array}\right]-\left[\begin{array}{c}
\text { negative flux } \\
\text { of a solute out } \\
\text { of the domain }
\end{array}\right] \pm\left[\begin{array}{c}
\text { loss or gain } \\
\text { of the } \\
\text { solutes mass } \\
\text { due to } \\
\text { reactions }
\end{array}\right]
$$

The fundamental controls on the flux of the mass in and out of the domain are advection and hydrodynamic dispersion. Mass can also be lost due to biochemical or chemical reactions (e.g. denitrification), or radioactive decay (e.g. tritium). Advection is the transport of particles due to the bulk mass movement and velocity of the groundwater flow, while hydrodynamic dispersion happens because of mechanical mixing and molecular diffusion (Freeze and Cherry, 1977).

\subsubsection{Physical processes controlling solute flux}

I. Advection: solutes carried along by the bulk groundwater flow

II. Hydrodynamic dispersion:

i. Diffusion: transport by molecular diffusion

ii. Dispersion: transport by mechanical mixing 


\subsubsection{Advection}

Advection is simply the movement of solute mass within the bulk fluid flow. The mass flux of a solute due to advection is:

$$
\begin{gathered}
F_{a x}=q_{x} \mathrm{c} \\
F_{a x}=\text { advective flux of the solute mass }\left(\mathrm{kg} / \mathrm{m}^{2}\right) \\
q_{x}=\text { specific discharge in the } x \text { direction }\left(\mathrm{m}^{3} / \mathrm{s}\right) \\
\mathrm{c}=\text { solute concentration }\left(\mathrm{kg} / \mathrm{m}^{3}\right)
\end{gathered}
$$

The average rate of solute movement is equal to the average linear velocity (Freeze and Cherry, 1977). However, this balance does not hold when the solute reacts with the medium it is passing through. Depending on the reaction and or retardation of the solute and substrate, the solute typically decreases in concentration due to reactions in the medium.

\subsubsection{Molecular diffusion}

Diffusive transport will occur via the movement of a solute from an area of high to low concentration (Fetter, 1993). This is known as molecular diffusion, or more simply diffusion, where particles are spread evenly throughout a space over time. Diffusion will occur when a concentration gradient exists. Molecular diffusion is proportional to the concentration gradient and can be expressed using Fick's first law (Fitts, 2002). Diffusion in the $x$ direction is expressed as:

$$
\begin{gathered}
F_{d x}=-n T_{x}^{*} D \frac{\partial c}{\partial x} \\
F_{d x}=\text { diffusive mass flux per unit area per unit time }\left(\mathrm{kg} / \mathrm{m}^{2}\right) \\
n=\text { porosity of the medium (\%) }
\end{gathered}
$$

$T_{x}^{*}=$ tortuosity of the liquid phase in the $\mathrm{x}$ direction (length of curve/distance between

$$
\begin{gathered}
\text { ends: e.g. } \mathrm{m} / \mathrm{m}) \\
D=\text { diffusion coefficient }\left(\mathrm{m}^{2} / \mathrm{s}\right) \\
c=\text { solute concentration }\left(\mathrm{kg} / \mathrm{m}^{3}\right) \\
\frac{\partial c}{\partial x}=\text { concentration gradient }\left(\mathrm{kg} / \mathrm{m}^{4}\right)
\end{gathered}
$$


The negative, as in Darcy's law, indicates the movement of solutes from areas of higher to lower concentration. Diffusion in water through porous media is slower than diffusion in an unobstructed domain as the water only occupies a percentage of the space in a network of interconnected paths (Fitts, 2002). Tortuosity is a measure of how winding the path is of which the solute takes, but can be applied to many things including meandering rivers, for example. It is a dimensionless parameter, which is always less than one in porous media. Typical values range from 0.7 for sands and 0.1 for clays, however; it is not easily measured, and often assumed to one for simplicity (De Marsily, 1986). Diffusion $(D)$ coefficients are well constrained and range vary from $1 \times 10^{-9}$ to $2 \times 10^{-9} \mathrm{~m}^{2} / \mathrm{s}$ at $25^{\circ} \mathrm{C}$ (Fitts. 2002); they do not vary as much with concentration as they do with temperature, at $5^{\circ} \mathrm{C}$ they are around $50 \%$ less (Freeze and Cherry, 1979). If the diffusive transport flux is steady-state, then mass transport by diffusion can be described by Fick's first law, however, where solute concentrations are dependent upon time (i.e. transient systems) Fick's second law is used (Eq. 2-18) (Fetter 1993). Fick's second law (in the $x$ direction):

$$
\begin{gathered}
\frac{\partial c}{\partial t}=-n T_{x}^{*} D \frac{\partial^{2} c}{\partial x^{2}} \\
\frac{\partial c}{\partial t}=\text { change in concentration over time }\left(\mathrm{kg} / \mathrm{m}^{3} / \mathrm{s}\right)
\end{gathered}
$$

\subsubsection{Mechanical dispersion}

Advection is a mass movement process. However, given the movement of water is not uniform, advective flow often dilutes and disperses dissolved solutes from the initial entry/concentration source. This movement of mass from one place to another varies due to the distribution of water velocity not being uniform. This is a result of the pore spacing and velocity changes causing longitudinal and transverse dispersion. Longitudinal dispersion is the primary direction of mass movement and under pure laminar flow conditions, no transverse dispersion would occur (Fetter, 1993). Transverse dispersion is caused by temporal variations in velocity and molecular diffusion, processes that commonly occur in dynamic heterogeneous groundwater basins. 
Hence, transverse dispersion is an important process to include, given its potential impact on the robustness of a solution if not included (Fitts, 2002). There are three primary causes for the variation in flow velocities:

1. As in river channels, the water moves faster in the centre of the pore spaces than on the sides in closer proximity to the media;

2. Some particles of water will travel along less direct, longer pathways than others due to obstructing media, and

3. Pore spaces vary in size and larger pore spaces permit faster movement of water than smaller spaces.

Divergence and convergence disperses solutes as they travel through the subsurface. This process is known as mechanical dispersion. Transverse dispersivities are movements perpendicular to the primary flow direction and are often much lower than longitudinal dispersivities moving in the direction of the bulk flow. In anisotropic media, the longitudinal and transverse dispersivities may not adequately quantify dispersive transport alone (Cornaton, 2007). Transverse dispersivity is measured in both the horizontal and vertical directions, and needs to be distinguished as such in any simulation, given that the vertical dispersivity has been shown to be an order of magnitude smaller than horizontal dispersivity (Gelhar et al, 1992). Even though the dominant transport direction of a solute is often longitudinal, variations in the flow velocity over time increase transverse spreading in both the horizontal and vertical direction, and are important for age and solute transport (Fitts, 2002).

There is no proven model of mass flux to quantify mechanical dispersion. This is due to the fact it depends on the nature of spatial and temporal velocity variations, which are controlled by the subsurface structure and the transient flow conditions. These combined processes are too complex to be described by a single (simple) law in a three-dimensional flow model, but the spread of dispersion is comparable to that of diffusion, therefore it is approximated by Fick's first law (Fitts, 2002). These two processes are combined and known as macrodispersion (Eq. 2-19). 
A form of Fick's first law, shown in the $x$ direction, can govern the one-dimensional macrodispersive flux:

$$
\begin{gathered}
F_{m x}=-n D_{m x} \frac{\partial c}{\partial x} \\
\text { where: } \\
D=\text { diffusion coefficient }\left(\mathrm{m}^{2} / \mathrm{s}\right) \\
D_{m x}=\text { macrodispersion coefficient in the } \mathrm{x} \text { direction }(\mathrm{m}) \\
n=\text { porosity of the medium }(\%) \\
c=\text { solute concentration }\left(\mathrm{kg} / \mathrm{m}^{3}\right) \\
\frac{\partial c}{\partial x}=\text { concentration gradient }\left(\mathrm{kg} / \mathrm{m}^{4}\right)
\end{gathered}
$$

The macrodispersion coefficient is a combination of two terms lumping mechanical dispersion and molecular diffusion:

$$
\begin{gathered}
D_{m x}=\alpha_{x}|\bar{v}|+T_{x}^{*} D \\
\alpha_{x}=\text { dispersivity in the x-direction }(\mathrm{m}) \\
|\bar{v}|=\text { magnitude of the average linear velocity of flow }(\mathrm{m} / \mathrm{s}) \\
T_{x}^{*}=\text { tortuosity in the } x \text { direction }(\mathrm{m} / \mathrm{m}) \\
D=\text { diffusion coefficient }\left(\mathrm{m}^{2} / \mathrm{s}\right)
\end{gathered}
$$

The diffusion term can be removed from Eq. 2-20 in advection-dominated systems as diffusion only occurs over longer periods, in substrates of lower hydraulic conductivity. Strata containing, for example, clay and loess layers with relatively low hydraulic conductivities would typically exhibit diffusion processes. Models simulating transport in more than one spatial direction define the macrodispersion parameters in orthogonal directions, one in the direction of flow, and the others in the opposite directions. For example, $D_{m x}$ and $\alpha_{x}$ could apply to the direction of flow, and $D_{m y}, \alpha_{y}$, $D_{m z}$, and $\alpha_{z}$ would be applied to the transverse vertical and horizontal directions of flow (Fitts, 2002). 


\subsubsection{Advection-Dispersion Equation}

Conservation of mass is assumed when a solute migrates through a closed groundwater catchment. The transient solute flux is modelled and governed by the advection-dispersion equation (Eq. 2-21) which is used to quantify solute transport in groundwater systems. Essentially, it calculates solute concentration flux using the principle of mass balance. Mass balance for a given domain equates to the total change of solute mass through the boundary of the domain, which is equal to the time rate of change of solute mass within the domain. The two types of flux considered are 1) advective flux (Eq. 2-16), and 2) macrodispersive flux (Eq. 2-19) (Fitts, 2002).

A three-dimensional advection-dispersion equation for calculating the flux of a nonreactive solute would be:

$$
\begin{gathered}
D_{m x}\left[\frac{\partial^{2} c}{\partial x^{2}}-\frac{\partial}{\partial x}\right]\left(\bar{v}_{x} c\right)+ \\
D_{m y}\left[\frac{\partial^{2} c}{\partial y^{2}}-\frac{\partial}{\partial y}\right]\left(\bar{v}_{y} c\right)+ \\
D_{m z}\left[\frac{\partial^{2} c}{\partial z^{2}}-\frac{\partial}{\partial z}\right]\left(\bar{v}_{z} c\right)=\frac{\partial c}{\partial t} \\
\text { where: } \\
D_{m(x, y, z)}=\text { macrodispersion coefficient }\left(\mathrm{m}^{2} / \mathrm{s}\right) \\
c=\text { solute concentration }\left(\mathrm{kg} / \mathrm{m}^{3}\right) \\
\left.\bar{v}_{x, y, z}=\text { average velocity (of fluid } / \text { water }\right)(\mathrm{m} / \mathrm{s})
\end{gathered}
$$

The $\boldsymbol{D}_{\boldsymbol{m}(\boldsymbol{x}, \boldsymbol{y}, \mathbf{z})}$ describes macrodispersion (i.e. diffusion and dispersion) of the concentration of solute $\boldsymbol{c}$. For example, when a concentration is low in surrounding areas compared to the area where the concentration is high, the concentration will diffuse out and the concentration will decrease. Conversely, if the concentration is high, then the concentration will diffuse out and the concentration will increase in surrounding areas. 
The second part describes advection $\overline{\boldsymbol{v}}_{\boldsymbol{x}, \boldsymbol{y}, \mathbf{z}}$ and its influence on concentration. For example, if a mass of diesel contaminated a groundwater aquifer, the concentration would be high at the point of entry and decrease as it passes through a single location.

This can be simplified using the Nabla operator $\nabla=\left(\begin{array}{c}\frac{\partial}{\partial x} \\ \frac{\partial}{\partial y} \\ \frac{\partial}{\partial z}\end{array}\right), D_{m i}$ as the macrodispersion coefficients, and $\overline{\boldsymbol{v}}_{\boldsymbol{i}}$ as the flow field reducing Eq. 2-21 to:

$$
\begin{gathered}
D_{m i} \nabla^{2} c-\nabla\left(\bar{v}_{i} c\right)=\frac{\partial c}{\partial t} \\
\text { where: } \\
D_{m i}=\left(D_{m x}, D_{m y}, D_{m z}\right)=\text { macrodispersion coefficient }\left(\mathrm{m}^{2} / \mathrm{s}\right) \\
\bar{v}_{i}=\left(\bar{v}_{x}, \bar{v}_{y}, \bar{v}_{z}\right)=\text { average velocity }(\mathrm{m} / \mathrm{s})
\end{gathered}
$$

This is the general advection dispersion equation for three dimensions. The porosity and macrodispersivities are assumed constant in both space and time, and the solute is assumed to be non-reactive. Variations exist including the following forms (applying to):

1. Steady flow - where the flow field is at a steady state, making $\nabla \bar{v}_{i}=0$;

2. Steady state flow and concentration - where the solute concentration field is at a steady state (in addition to the flow field) making $\partial \mathrm{t} / \partial \mathrm{c}=0$;

3. No flow in the system - this is where $\bar{v}=0$, reducing Eq. 2-22 to the diffusion equation $D_{m i} \nabla^{2} c=\frac{\partial c}{\partial t}$

A variation is needed however to account for the decay of a reactive solute. Tritium for example is radioactive and decays at a constant rate. 
Decay is assumed to be governed by the first-order rate law:

$$
\begin{gathered}
\frac{d c}{d t}=-\lambda c \\
\text { where: } \\
\lambda=\text { decay constant }(1 / \mathrm{s}) \\
c=\text { solute concentration }\left(\mathrm{kg} / \mathrm{m}^{3}\right) \\
t=\text { time }(\mathrm{s})
\end{gathered}
$$

Accounting for this, the equation becomes:

$$
\begin{gathered}
D_{m i} \nabla^{2} c-\nabla\left(\bar{v}_{i} c\right)-\lambda c=\frac{\partial c}{\partial t} \\
\text { where: } \\
D_{m i}=\left(D_{m x}, D_{m y}, D_{m z}\right)=\text { macrodispersion coefficient }\left(\mathrm{m}^{2} / \mathrm{s}\right) \\
\bar{v}_{i}=\left(\bar{v}_{x}, \bar{v}_{y}, \bar{v}_{z}\right)=\text { average velocity }(\mathrm{m} / \mathrm{s}) \\
\lambda=\text { decay constant }(1 / \mathrm{s}) \\
c=\text { solute concentration }\left(\mathrm{kg} / \mathrm{m}^{3}\right)
\end{gathered}
$$

A first-order reaction depends on the concentration of only one reactant (Fitts, 2002). $\lambda$ is the decay constant with dimensions of $(1 / T)$. This is often applied and assumed in numerical models in order to simulate the response of water resources to contaminants. This reaction will be applied to the mass transport of tritium throughout the model domain in our study of the Middle Valley in the Wairarapa (Morgenstern, 2005).

\subsubsection{Sorption}

A dissolved solute can travel through the subsurface with or without reacting to porous media. Sorption is a process whereby a solute becomes bound to the surface of or incorporated into a solid particle. 
Sorption processes can significantly affect a solute's migration from its source to its sampled, predicted, or final destination. If a solute does not sorb to the aquifer media, the transport rate can be directly estimated from the average linear velocity of groundwater flow. However, when a solute reacts with another solute or the aquifer material, the travel time is different (typically slower) than the linear flow velocity. Such reactions are important when modelling the effects of, for example, iron (i.e. heavy metals) and various organic compounds. The reader is directed to Fetter (1993) and Fitts (2002) for further information.

\subsubsection{Boundary conditions}

The governing equations and boundary conditions define the model. Boundary conditions define part of the mass distribution and changes within the domain. There are several boundary conditions including:

1. Specified mass flux at a boundary (applies throughout the simulation time);

2. Specified concentration at a boundary (applies throughout the simulation time);

The first mass flux boundary condition is the total fixed flux. This is the advective as well as dispersive flux. The specified flux boundary condition equation is a combination of the advective flux and macrodispersive flux equations, Eq. 2-16 and Eq. 2-19, respectively (Fitts, 2002). The equation applies at the domain boundary:

$$
\begin{gathered}
q_{b} c-n D_{m b} \frac{\partial c}{\partial x}=F_{b} \\
\text { where: } \\
q_{b}=\text { specific discharge normal to the boundary }(\mathrm{m} / \mathrm{s}) \\
n=\text { porosity }(\%) \\
c=\text { solute concentration }\left(\mathrm{kg} / \mathrm{m}^{3}\right) \\
\partial \mathrm{c} / \partial \mathrm{x}=\text { concentration gradient normal to boundary }\left(\mathrm{kg} / \mathrm{m}^{4}\right) \\
\left.F_{b}=\text { specified flux across boundary (mass } / \text { time } / \mathrm{area}\right) \\
\text { note: for a no flux boundary } F_{b}=0
\end{gathered}
$$


The second mass boundary type requires a specified fixed concentration at the boundary. The concentration is typically applied and constant over time. This is expressed simply as:

$$
\begin{gathered}
c c=c_{b} \\
\text { where: } \\
c=\text { solute concentration }\left(\mathrm{kg} / \mathrm{m}^{3}\right) \\
c_{b}=\text { solute concentration on boundary }\left(\mathrm{kg} / \mathrm{m}^{3}\right)
\end{gathered}
$$

\subsubsection{Initial conditions}

Initial conditions are required to begin a simulation with a representative spatial distribution of information at the point in time that simulation is representing. Initial conditions are required given the assumption that any real world system would not have an initial state (e.g. hydraulic head distribution) at any given point in time, is unrealistic and therefore, not representative. For example, assuming an initial groundwater age of zero throughout a system is unrealistic given the only water with a groundwater age of zero would be recharge starting on the surface. An initial "spin-up" can be generated from a steady state or transient model to simulate flow and/or transport conditions at a specific point in time. Initial flow conditions often incorporate abstractions, river water flux, rainfall recharge, and hydraulic head. Initial solute concentrations use a known input to generate a representative initial state and/or the use of measured solute concentrations.

The initial concentration is applied throughout or in a specific region in the model at a point in time. This is usually the initial concentration representative of a systems concentration distributed throughout the domain or specific region:

$$
\begin{gathered}
c c=c_{i} \\
\text { where: } \\
c=\text { solute concentration }\left(\mathrm{kg} / \mathrm{m}^{3}\right) \\
c_{i}=\text { initial solute concentration }\left(\mathrm{kg} / \mathrm{m}^{3}\right)
\end{gathered}
$$




\subsection{Modelling groundwater systems}

Mathematical models are used to simulate complex natural fluid flow and solute transport problems. Commonly boundary-value problems are used which take the form of mathematical models based on the physics of flow to solve a physical problem. This is usually a four stage process:

1. Outlining the physical problem;

2. Modifying it in the form of a mathematical problem;

3. Solving the problem, and

4. Analysing the results and assumptions made to gain an insight into the physical system.

This was pioneered by the developers of potential field theory and was applied to problems involving the conduction of heat in solids (Carslaw and Jaeger, 1959; Freeze and Cherry, 1977). To simulate a catchment with a coupled transient flow and transport boundary-value problem, the inputs required are:

1. The size and structure of the natural system;

2. The equations of flow and transport within the system;

3. The boundary conditions applied to the system;

4. The initial conditions for the flow and transport problem (not required for a steady state system);

5. The spatial distribution of the hydraulic parameters controlling the flow and transport within the system;

6. Numerical implementation to solve the flow and transport problems.

A groundwater model simulates both surface and subsurface processes. Results can be used to predict and remediate problems associated with, for example, increases in applied nutrients and animal effluent, and decreases in recharge and reservoir volumes (Fitts, 2002; Gusyev et al, 2012). In a numerical transport model the parameters (i.e. effective porosity, dispersivity, decay and/or reaction) control solute movement within the model in conjunction with the dominant flow parameters. 
Representative parameters are required to reach a defendable solution. Calibration utilizes field measurements to estimate the system's actual state.

The accuracy of the numerical model solution is dependent on several factors. These include the:

1. Code and/or program selection;

2. The underlying assumptions in the conceptual and numerical models;

3. Grid and size of the domain;

4. The quality and availability of observed field data;

5. The parameter values and their application to various parts of the model domain.

A system can be modelled at a steady or transient state (Fitts, 2002). A steady state implies the flow and transport fields are unchanging with time, whereas transient systems have flow or transport fields changing with time (i.e. the real world). Anything somewhat connected to atmospheric and/or subsurface processes exhibits a transient state. Dynamic heterogeneous groundwater systems, such as the Middle Valley, exhibit variable recharge to, and discharge from, the system. Dynamic groundwater basins are (usually) transient in nature and require modelling in a transient state. The time in a transient model is required to be discretized whereby each iteration/timestep is solved for a specific time during the simulation period. This is performed for numerical accuracy and convergence, ensuring the time steps (adaptive or constant) is not too long or short, in addition to the spatial domain discretization. There are various time discretization options available for numerical fluid modelling including the explicit, Crank-Nicholson, and fully-implicit schemes (Cornaton, 2007).

A numerical model is typically tested in four steps:

1. Initial simulation;

2. Analysis;

3. Calibration of parameters, and

4. Results. 
The first three steps (simulation-analysis-calibration) are usually run through several times to achieve the desired results, compared to observed field data (Fig. 2.7).

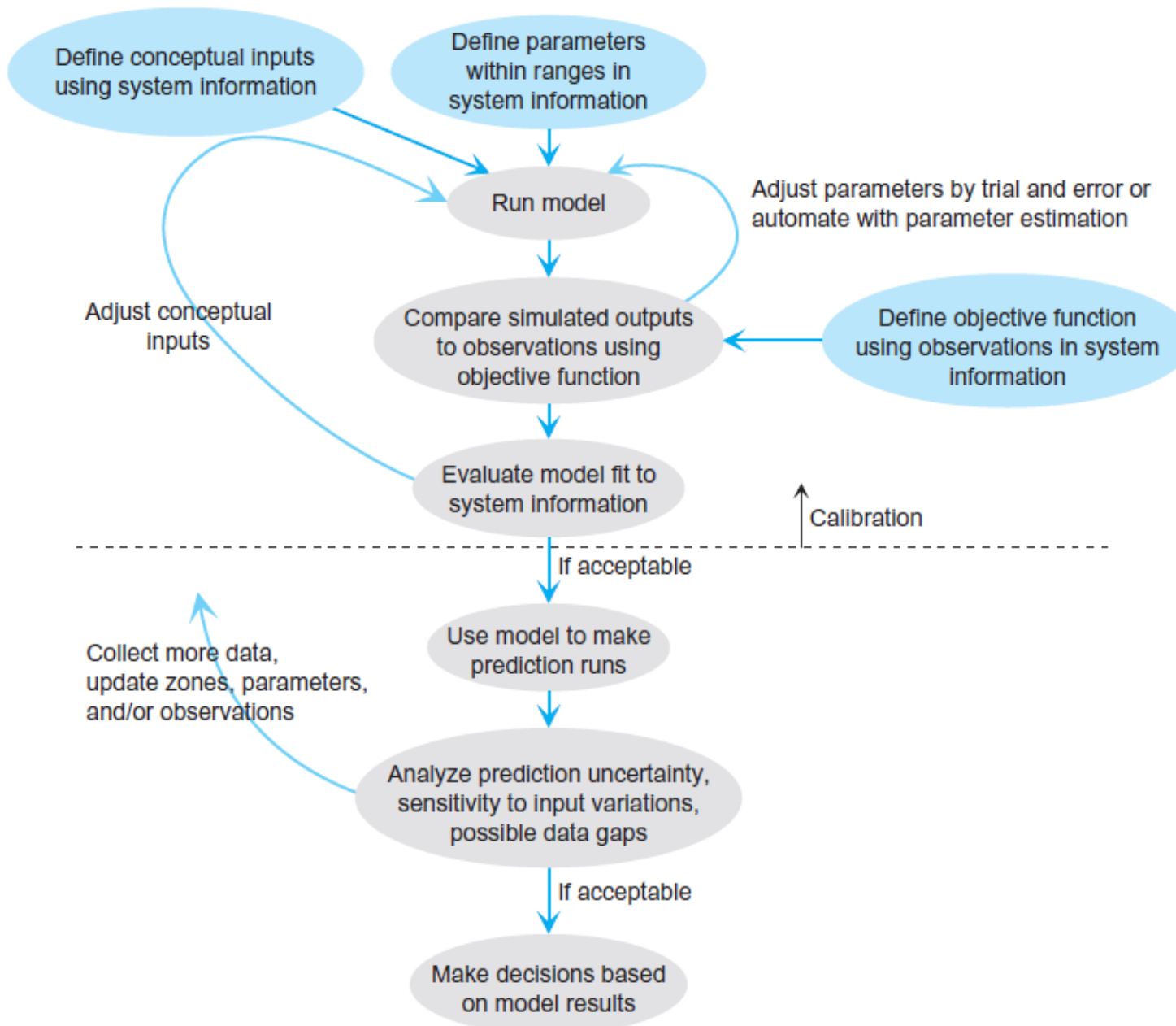

Fig. 2.7 Groundwater modelling process diagram. Source: Fitts (2002).

\subsubsection{Numerical methods}

Groundwater modelling is based on governing equations for the flow of water and transport of solutes. Flow models are based on Darcy's law for the advective flow in saturated media and (often coupled with) transport model which are simulated using the combined advection-dispersion equation (Fitts, 2002; Freeze and Cherry, 1979). The conservation of mass applies to both flow and transport in groundwater models. 
There are several numerical methods used to simulate groundwater systems. Common spatial methods are the:

1. Finite difference method;

2. Finite element method;

3. Analytical element method, and

4. Finite volume method.

These are differentiated by the way in which the flow and transport variables are approximated, and the discretization of the modelled domain into discrete elements and nodes. The finite difference method involves the use of algebraic equations to solve the general flow equation, whereas analytic solutions are utilized for the finite element method. In terms of discretization, the finite element method utilizes triangles and trapezoids for two-dimensional flow, and triangular and trapezoidal prisms for three-dimensional flow; finite difference domains use rectangles for twodimensional flow and cuboids for three-dimensional flow (Diersch, 2002; Harbaugh et $a l, 2000)$. The analytic element method does not discretize the entire domain into grids and elements, only surface water components are discretized, and used by the model as the initial and input data. These components, for example a river section or lake, are represented by closed form analytic solutions (analytic elements) and the model solution is achieved by the superposition of all the analytic elements throughout the model. The groundwater flow is determined by discharge potentials, which are required to be appropriately placed, instead of (the traditional) piezometric heads (Haitjema, 1981; Strack and Haitjema, 1981). The finite volume similar to the analytical element method and it supports structured and unstructured grids, allowing the model to concentrate on rivers and wells (i.e. inputs and outputs), and sub discretization can be applied to different components and hydrostratigraphic units (Panday et al, 2013).

\subsubsection{Boundary conditions}

Any given general equation has many potential solutions, the appropriate solution for a groundwater model, is one that corresponds with specified boundary conditions of the conceptual system (Fitts, 2002). 
Boundary conditions include hydraulic head, recharge, pumping wells and solute concentrations. They control the flow and transport regime of the model and can be located throughout a domain across multiple layers. The external boundaries of the model domain match the defined conceptual model boundaries (i.e. physical system in a regional model) and are all of 'no-flow' type (i.e. no water flux (in or out) around the model boundary, unless specified with a boundary condition).

There are three broad types of boundary conditions typically used in groundwater modelling (Todd and Mays, 2005):

1. The Dirichlet, also known as first-type and fixed, boundary condition. When the value of the dependent variable is specified on the boundary, or when imposed on an ordinary or a partial differential equation, it specifies the values that a solution needs to take along the boundary of the domain;

2. A Neumann, or second-type boundary condition is defined when the normal derivative of the dependent variable is specified on the boundary. For this, the boundary must be somewhat uncomplicated for the normal derivative to exist. For example, at edges or corners of the boundary the normal vector is not well defined;

3. A Cauchy, also known as a third-type boundary condition. This is where both the value and the normal derivative of the dependant variable are specified on the boundary, or where it extends an ordinary or partial differential equation to completely determine the solution. This means that both the function value and normal derivative are specified on the boundary. The third-type condition is a combination of both Dirichlet and Neumann boundary conditions.

\subsubsection{Time discretization}

A steady state model is only discretized spatially while a transient model is additionally discretized as the model progresses forward through time. 
The three time-stepping schemes used in the Middle Valley Groundwater (GW) simulations were (Cornaton, 2007):

1. the Explicit scheme;

2. the Crank-Nicholson scheme (implicit), and

3. the Fully-Implicit scheme.

The time discretization schemes are not explored in any depth here, however the reader is directed to Cornaton (2007) and Todd and Mays (2005) for more detail.

\subsubsection{Calibration}

The calibration of a model involves adjusting the parameters and potentially the conceptual model to achieve a reasonable match between observed environmental data and the modelled output. This can be a simple process, with simple models, whereby the calibration adjustments are done through a trial and error process, comparing the output to measured data. However complex regional models often require this to be automated. A feature of an automated calibration is the definition of a numerical measure of the difference between simulated and observed data, which is known as an objective function. Additionally, linear regression methods are used to calculate a set, or sets, of parameters that generate a good fit, using the objective function as a measure of model performance. PEST (Doherty, 2010) and UCODE (Poeter et al., 2005) are widely used parameter estimation software codes which have been designed to link together with groundwater modelling software, with several algorithms, the default being the Gauss- Marquardt-Levenberg parameter estimation scheme $^{2}$ (Fitts, 2002).

Observed measurements, such as hydraulic heads, are commonly measured as part of environmental management, as well as stream discharges. Concentrations are used to calibrate both the flow and the transport model, as in this dissertation where the conservative solute tritium is utilized.

\footnotetext{
${ }^{2}$ The Levenberg-Marquardt algorithm is typically applied to least squares curve fitting problems. A set of independent and dependent variables is used to optimize the parameters of a model curve, in order to minimise the objective function (i.e. the sum of the squares of the deviations).
} 
The prior parameter estimates could be hydraulic conductivity $(K)$ as measured from well slug and/or aquifer pumping tests, or porosity $(n e)$ based on the typical values of known or estimated aquifer.

An objective function example $O$ is defined as a weighted least-squares function which includes weighted observations of head and solute concentrations as well as initial estimates of the parameters:

$$
O=\sum_{i=1}^{N_{h}} w_{i}\left(h_{i}-\hat{h}_{i}\right)^{2}+\sum_{j=1}^{N_{q}} w_{j}\left(q_{j}-\hat{q}_{j}\right)^{2}+\sum_{k=1}^{N_{p}} w_{k}\left(p_{k}-\hat{p}_{k}\right)^{2}
$$

where:

$$
\begin{gathered}
O=\text { weighted least-squares function } \\
N_{h}=\text { number of observed heads } \\
h_{i}=i \text { th observed head }
\end{gathered}
$$

$\hat{h}_{i}=$ simulated head corresponding to the $i$ th observed head

$$
w_{i}=\text { weight } \text { of } i \text { th observed head }
$$

$N_{q}=$ number of observed concentrations

$$
q_{j}=i \text { th observed concentration }
$$

$\hat{q}_{j}=$ simulated concentration corresponding to the $i$ th observed concentration

$$
\begin{gathered}
w_{j}=\text { weight of } i \text { th observed concentration } \\
N_{p}=\text { number of observed prior estimates of parameters } \\
p_{k}=k \text { th prior parameter estimate }
\end{gathered}
$$

$-\hat{p}_{k}=$ simulated parameter value corresponding to the $k$ th prior parameter estimate

$$
w_{k}=\text { weight of the } k \text { th prior parameter }
$$

The weights $\left(w_{i}, w_{j}, w_{k}\right)$ in the objective function are calculated (to varying degrees of subjectivity) taking into account the observed data and parameter estimates quality, as well as importance and confidence in the values. The simplification of a natural system to a condensed simplified form (i.e. a numerical model) involves error, as well as the observed data (which is used to constrain the estimates of the parameter values), which contains inherent noise, as no measurement is perfect. 
To constrain observational error, it is subjectively calculated and corrected to some extent by weighting each observed data value in the calibration dataset. This is done as a means by which to inform the calibration process of the accuracy of the data it uses, to estimate parameters, and achieve better model output (Doherty and Hunt, 2010). Following the definition of an objective function the model can be calibrated through many model runs (either manually or automatically using software or scripts) to find the "best" set of parameter values which minimize $O$ (the objective function).

\subsubsection{Groundwater modelling Software}

Commercial software is often used when modelling groundwater systems. The codes can perform one $\left({ }^{1}\right)$, two $\left({ }^{2}\right)$ and three-dimensional $\left({ }^{3}\right)$ simulations of flow $\left({ }^{F}\right)$, solute transport $\left({ }^{\top}\right)$ and energy $\left({ }^{H}\right)$. They typically use either the finite difference $\left({ }^{\mathrm{FD}}\right)$, finite element $\left({ }^{\mathrm{FE}}\right)$, finite volume $\left({ }^{\mathrm{FV}}\right)$ or analytical element $\left({ }^{\mathrm{AE}}\right)$ methods ${ }^{3}$. Examples include FEFLOW $^{3, F, T, H, F E}$ (Diersch, 2009), GFLOW ${ }^{3, F, A E}$ (Haitjema and Kelson, 1994),

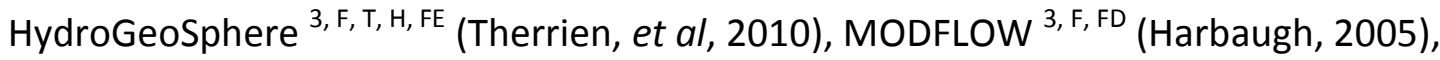
MODFLOW-USG ${ }^{3, F, F V}$ (Panday et al, 2013). MODFLOW is developed by the United States Geological Survey (USGS) and has various transport simulation codes, to incorporate particle tracking (e.g. MODPATH ${ }^{3, T, F D}$ ) and solute transport/direct age simulation (e.g. MT3DMS ${ }^{3, T, F D}$ ), using a MODFLOW derived flow simulation. MODFLOW-USG is a recent release opting for an unstructured grid format using the finite volume method, instead of the finite difference method associated with MODFLOW.

\subsubsection{MT3DMS}

A MODFLOW flow model is widely used in addition to the MT3DMS (formerly MT3D) transport model to simulate age and tracer transport (Engelhardt et al, 2013; Gusyev et al, 2014; Wallis et al, 2014; Zheng, 1992; Zheng and Wang, 1999). It utilises the finite difference method, alongside MODFLOW. Gusyev et al, (2014) used MT3DMS to calibrate the age transport model of the Western Lake Taupo catchment.

\footnotetext{
${ }^{3}$ Letters and numbers represent the various capabilities and methods of the individual software codes.
} 
This used a set of measured tritium concentrations taken in the river channels of the catchment to calibrate the model, which was used to simulate groundwater ages and the groundwater age distributions in the river catchments. The estimates of age indicated recharge patterns, identifying potential contamination risks, and management options for the Western Lake Taupo catchment.

The Wairarapa Middle Valley model was constructed using FEFLOW, which utilizes the finite element method, and hence, MT3DMS was inapplicable in this case.

\subsection{Groundwater flow and transport summary}

The governing equations allow the quantification and simulation of groundwater processes to be assessed and important information derived for the informed management of groundwater resources. The inherent properties of the catchment define the speed and migration of water and solutes, for example, younger alluvial river sediments permit a relatively fast movement of water and solutes compared to less permeable compact sediments such as silt and clay. Due to the complexity of subsurface and hydrogeological processes, assumptions are made on the distribution of subsurface media zones, a uniform water temperature and density, and the transport of single solute negating the reality of a complex collection of dissolved constituents. The characterization of the boundary conditions ensures a representation of the river and spring flux within a simulation, in the same way the initial conditions provide the assumed hydraulic head distribution and/or solute concentration throughout the domain.

The main aim of this research was to create a transient flow and transport modelsimulating age throughout the Middle Valley catchment. The Middle Valley model was initially developed as a transient flow model. Transport processes are coupled using a transport model to solve both the groundwater flow and transport processes to characterize the age distribution over a 15-year period. Transport processes can help to better define the parameters within a model utilizing additional observational data gathered from the catchment of interest. Groundwater age is important to characterize for groundwater management and water resource sustainability. 


\title{
Chapter 3
}

\section{Groundwater age}

\begin{abstract}
Measurement is fundamental to the growth and application of
science. But making a measurement is not enough. When we come to use the result we must know if it is good enough for our
\end{abstract} purposes.

Barford (1985)

Groundwater age is defined as the time expired since a single water particle last had contact with the atmosphere. This dissertation focuses on modelling groundwater age, as it is a valuable management tool in the wake of increasing groundwater utilization and development. Chapter Three explains the specifics of groundwater age, how it is estimated and how it is modelled for environmental assessment. Utilizing age for groundwater monitoring and management provides critical information on reservoir s! ustainability and environmental risk (Cornaton and Perrochet, 2006; Stewart et al, 2002). Numerical modelling of groundwater is commonly implemented to represent a groundwater basin or zone, as widespread field sampling is prohibitive considering the scale of a subsurface basin and the subsequent cost. Environmental and anthropogenic tracers, as well as hydrochemical solutes, are used to estimate age through laboratory analysis as well as providing accuracy and calibration measures for numerical groundwater models (Kazemi et al, 2006).

A key concept of groundwater age is that water is a collection of individual molecules, with each individual particle assigned a specific age (Ginn, 1999). For example, an arbitrary sample has a distribution of ages within it, and collectively, they form a representative mean age. Water is a collection of individual particles and a sample of water from an aquifer will have a mixture or distribution of ages given that each water particle has taken different path lines and times to reach the sample point. 
Hydrodynamic dispersion combines water molecules that all have individual ages and a representative sample suggests an apparent age of the aquifer.

Groundwater has an assigned age just like every living and non-living entity, for example a flower, rock or cat; age can imply various things, typically health and continued wellbeing. For example, humans typically set their age from the moment of birth, not including the time in the womb. Groundwater systems are recharged by rainfall which has a groundwater age of zero on the surface and which increases as it travels through the sub-surface (Bethke and Johnson, 2008; Zuber et al. 2011).

Stagnant slow-moving systems typically have more evenly distributed ages due to slow uniform advective processes, minimal abstraction pressures, and the lengthy effects of molecular diffusion. A dynamic groundwater system exhibits variable recharge (e.g. large winter rainfall) with variable abstraction pressures, hydraulic interactions between surface and groundwater, and a heterogeneous subsurface. These factors create a dynamic environment where water particles flow along different path lines due to variations in advective flow, thus creating a mixture of ages (Zuber and Małoszewski, 2001). Recent efforts have focused on the determination of groundwater age, specifically the spatial distribution of ages due to aquifer heterogeneity (Bethke and Johnson, 2008; Cornaton, 2012; Cornaton and Perrochet, 2006).

It is important to measure groundwater age to:

1. Ensure the sustainable allocation of groundwater, for example, preventing over allocation of slowly recharged systems (exhibiting old ages);

2. Manage the contamination of groundwater (both prevention and remediation);

3. Constrain aquifer permeability and vulnerability, and

4. Assist in the calibration of groundwater models using measured environmental and anthropogenic dissolved solutes and tracers, for example, tritium and sulphur hexafluoride.

Young groundwater is roughly defined as water that has been recharged within the last 50 years. Any water exhibiting an age of between $0-50$ years is considered more at risk from surface and bacterial contamination, however, groundwater $>50$ years of age can 
contain natural toxic contaminants from surrounding geological formations (e.g. arsenic) (Meharg, 2005). Groundwater older than one year of age is considered safe because it has endured the required decay time for bacteria and viruses to no longer be a considerable threat to health (Stewart and Morgenstern, 2001). Many rural domestic water supplies come from shallow bores in dynamic groundwater zones where abstracted water is used for both water supply and irrigation. Shallow aquifers have contamination risks and groundwater age is a means by which to assess the systems and identify any potential risks. A simulated transient mean-age and age distribution provides an assessment of potential water contamination.

Human water abstractions from pumping wells are modifications to a previously natural system (Fig. 3.1). An apparent age sample can be somewhat misleading due to older water entering the system from upper or lower confining layers (low yielding layers composed of silts, clays, and/or rock) (e.g. in Fig. 3.2, the upper and lower confining units) (Zinn and Konikow, 2007). The age of groundwater from a spring can be considered representative or the average of water in an aquifer; however widespread modification to water systems requires caution when suggesting mean ages for entire aquifers due to mixing from abstraction pressures and confining layers. Typically aquifers are composed of a mixture of both old and young water (Bethke and Johnson, 2002; Zinn and Konikow, 2007). The evolution of groundwater age can reveal important changes in the system, and can help define an aquifer's properties, recharge ‘conditions, and vulnerabilities (Kazemi et al, 2006).

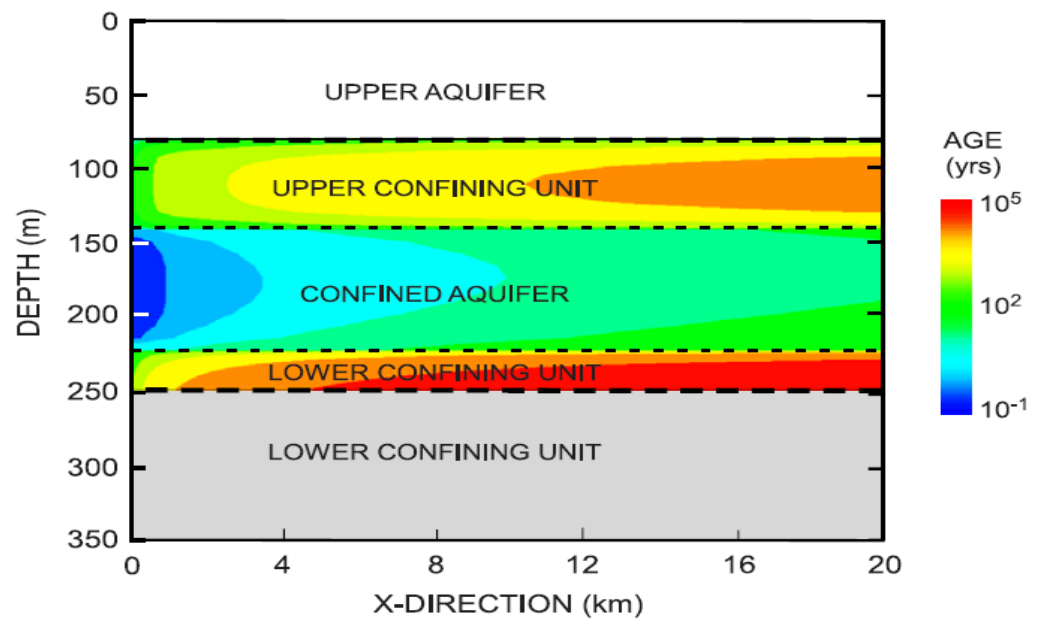

Fig. 3.1 Initial steady state age distribution in a simplified box model domain, with flow moving left to right, without any pumping influence. Source: Zinn and Konikow (2007). 


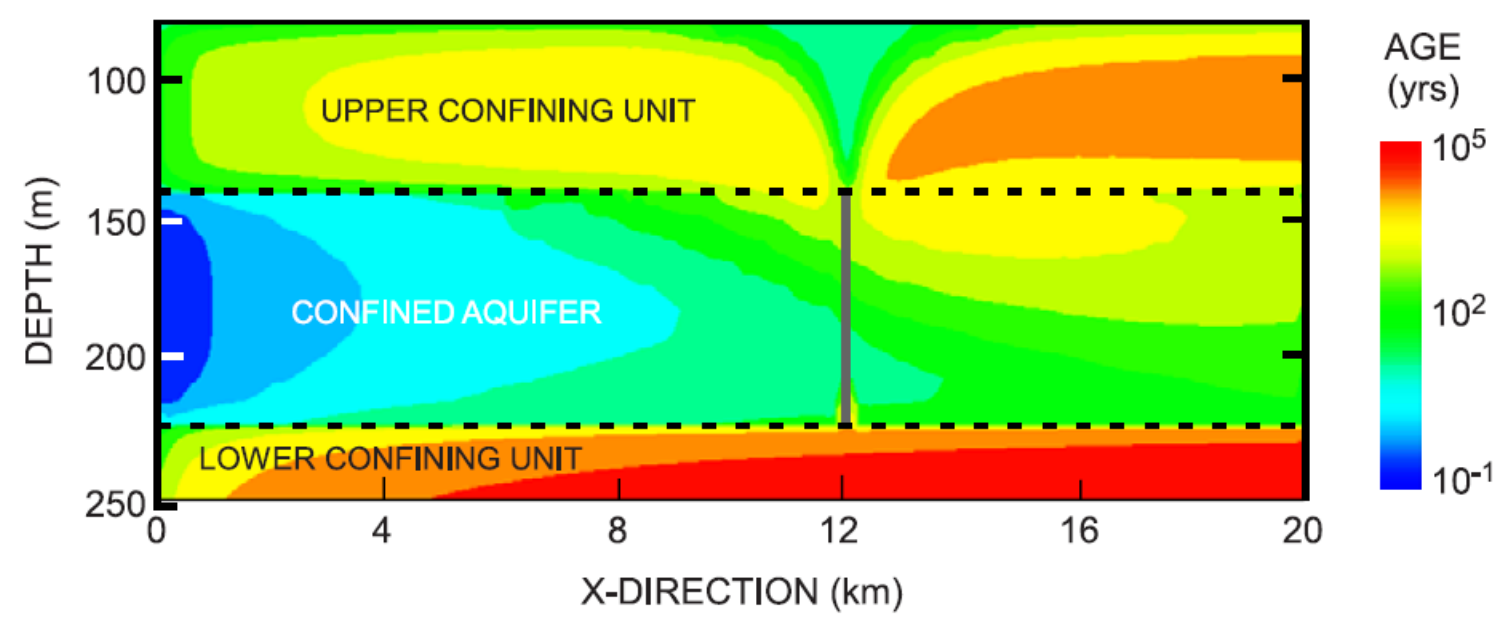

Fig. 3.2 Resulting age distributions following moderate abstraction rates from the confined aquifer for a five year period. A cone of depression is visible and older water has been drawn down into the confined aquifer. Source: Zinn and Konikow (2007).

\subsection{Hydrological tracers}

Groundwater age is commonly measured and modelled using environmental and anthropogenic tracers (Bethke and Johnson, 2008; Daughney, 2007; Kazemi et al, 2006; Morgenstern, 2005). A tracer is a property of or within water that can be measured and provides information on the age, processes affecting, and source of the water. Radioactive isotopes and anthropogenic compounds are common tracers used to analyse groundwater age (e.g. Morgenstern, 2005; Stewart and Morgenstern, 2001; Van der Raaij, 2003). Environmental tracers are those that are naturally released into the hydrological system, for example, oxygen-18 $\left({ }^{18} \mathrm{O}\right)$ and radiocarbon-14 $\left({ }^{14} \mathrm{C}\right)$. Anthropogenic tracers have predominately been introduced to the global system (relatively recently) by human industrial processes, for example, chlorofluorocarbons (CFCs) and sulphur hexafluoride ( $\mathrm{SF}_{6}$ ) (Fig. 3.3). Some tracers are produced naturally with additional amounts introduced by human processes, for example, tritium and $\mathrm{SF}_{6}$. Practically, tracers are used to infer the contamination risk of municipal water supplies, to provide environmental risk assessments, and to calibrate flow and transport parameters within a model. Defining the model parameters utilizes observed tracer concentrations in the calibration phase and gives a groundwater model, and its simulated results, a measure of confidence and comparison to the field data. 


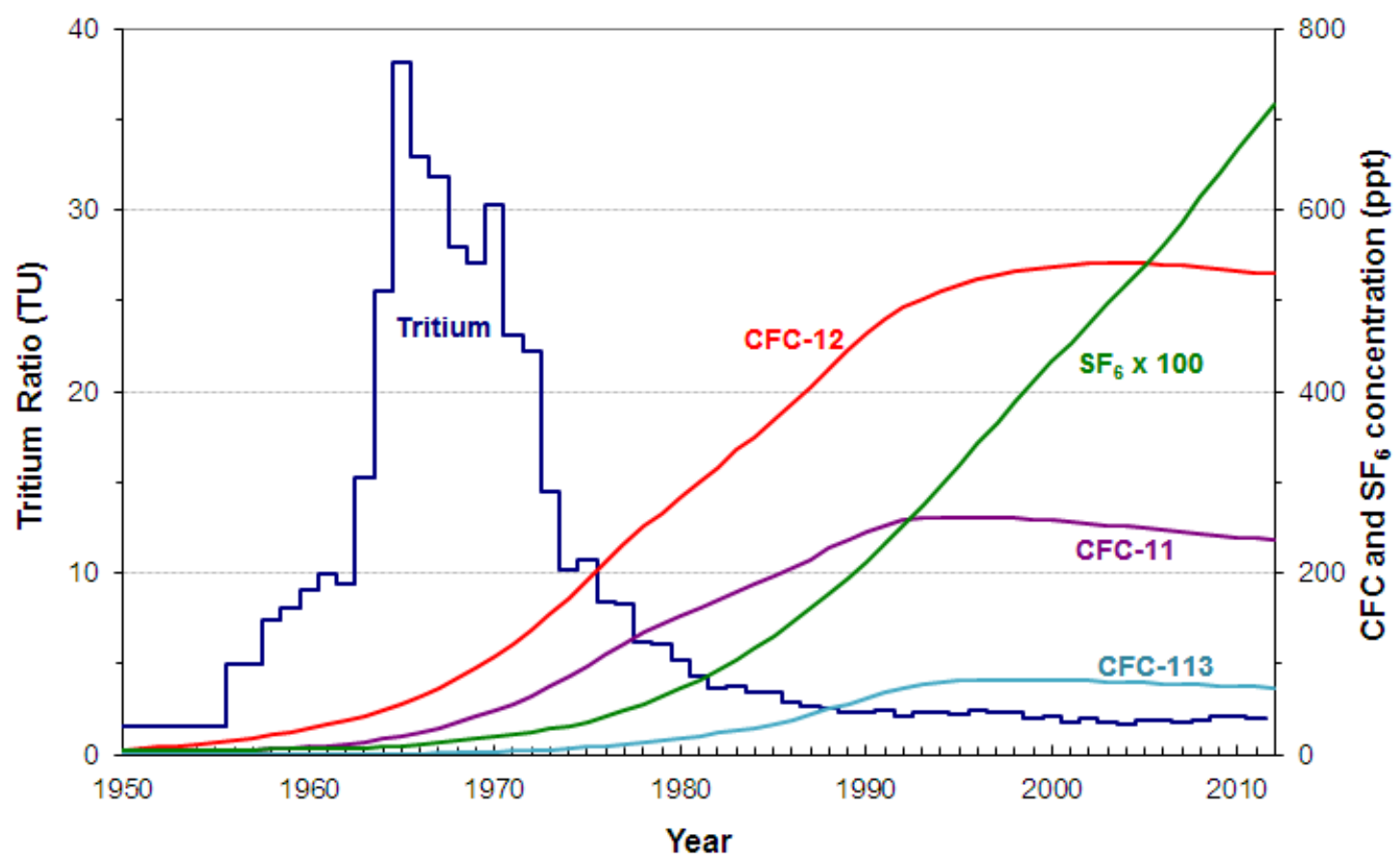

Fig. 3.3 Atmospheric concentrations of tritium, CFC-12, $\mathrm{SF}_{6}, \mathrm{CFC}-11$ and CFC-113 in the in the Southern Hemisphere 1950-2011. Source: van der Raaji (2013).

Measureable amounts of tracers have been released into the environment over the last 60 years (Cook and Herczeg, 2000; Daughney et al, 2010; Morgenstern, 2005; Stewart and Morgenstern, 2001). Dating methods are based on the assumption that input functions (human or atmospheric) and factors affecting tracer concentration in the subsurface are understood and quantifiable (Zuber et al, 2011). The comparison of groundwater ages derived from several different well-established water dating tracers, such as sulphur hexafluoride $\left(\mathrm{SF}_{6}\right), \mathrm{CFCs}$ and tritium, can resolve abnormalities and uncertainties in analyses (Van der Raaij, 2003). It must be noted that concentrations differ globally due to the atmospheric input source, atmospheric processes, and population distribution between the northern and southern hemispheres. Measurements are taken worldwide to obtain spatial variability of tracer concentrations in rainfall (Cook and Herczeg, 2000; Van der Raaij, 2003).

Groundwater dating using tracers often results in different tracer ages from the bulk water age (Kazemi et al, 2006). Different tracer ages can result from heterogeneous aquifer configurations. For example, diffusion between stagnant and mobile water zones (Zinn and Konikow, 2007). 
In thin aquifers or fractured rock zones this may lead to vast differences between advective and tracer ages; this could also imply variability between the advective and tracer velocities (Zuber et al, 2011).

\subsubsection{Tritium $\left({ }^{3} \mathrm{H}\right)$}

Tritium is the only radioactive isotope of hydrogen. It is a tracer with relatively low natural production caused by cosmic ray spallation in the atmosphere and neutron radiation of rocks on the surface (Cook and Herczeg, 2000). Tritium is the only tracer that is incorporated as part of the water molecule, as all other tracers are solutes, dissolved in, and travelling within the water (Kazemi et al, 2006). The tritium content of water in a sample is expressed in TU (tritium units), where one TU represents one tritiated water molecule in $10^{18}$ water molecules. When water becomes separated from the atmosphere, the tritium source is isolated and the tritium concentration decreases over time due to radioactive decay. The half-life of the tritium isotope is approximately 12.32 years (Kazemi et al, 2006; Morgenstern and Taylor, 2009). It is an ideal groundwater age indicator as it is a conservative tracer not affected by chemical or microbial processes, or reactions between the groundwater, soil sediment and substrate; in part due to tritium being a component of the water molecule (Morgenstern, 2005; Morgenstern and Taylor, 2009).

Tritium concentrations in New Zealand rain have varied substantially in the past 60 years. Thermonuclear weapons testing beginning in the 1950s was a significant source of anthropogenic tritium well above naturally produced rates. The highest TU detected in a sample from Kaitoke in Wellington was 78 TU in 1966, and the natural background atmospheric concentration is roughly 1.9 TU (Fig. 3.4). This anthropogenic input initially made tritium difficult to use for water age-calibration (Morgenstern, 2005). It has taken fifty years to reduce to naturally produced levels in the southern hemisphere and this has restored tritium as an effective tracer for groundwater dating. Because of the improved accuracy of tritium measurements in low-tritium environments, it is now possible to utilize tritium for age estimation in the Southern Hemisphere as the tritium-bomb peak naturally decays (Morgenstern and Daughney, 2012; Morgenstern and Taylor, 2009). 
The situation is improving in the Northern Hemisphere and tritium dating will become as effective, as it is presently in the Southern hemisphere, over the next decade (Morgenstern and Daughney, 2012). Tritium concentrations in precipitation are taken in monthly measurements at Kaitoke, near Wellington, and adjusted by a scale factor for different areas of New Zealand (Stewart and Thomas, 2007). The scale factor adjusts precipitation data for 15 well-known latitudinal and altitudinal variations over New Zealand with a scale factor of 1.0 at Kaitoke's (Wellington) latitude, 0.8 in Kaitaia, 1.2 in Invercargill, and 1.3 in the Southern Alps (Stewart and Taylor, 1981).

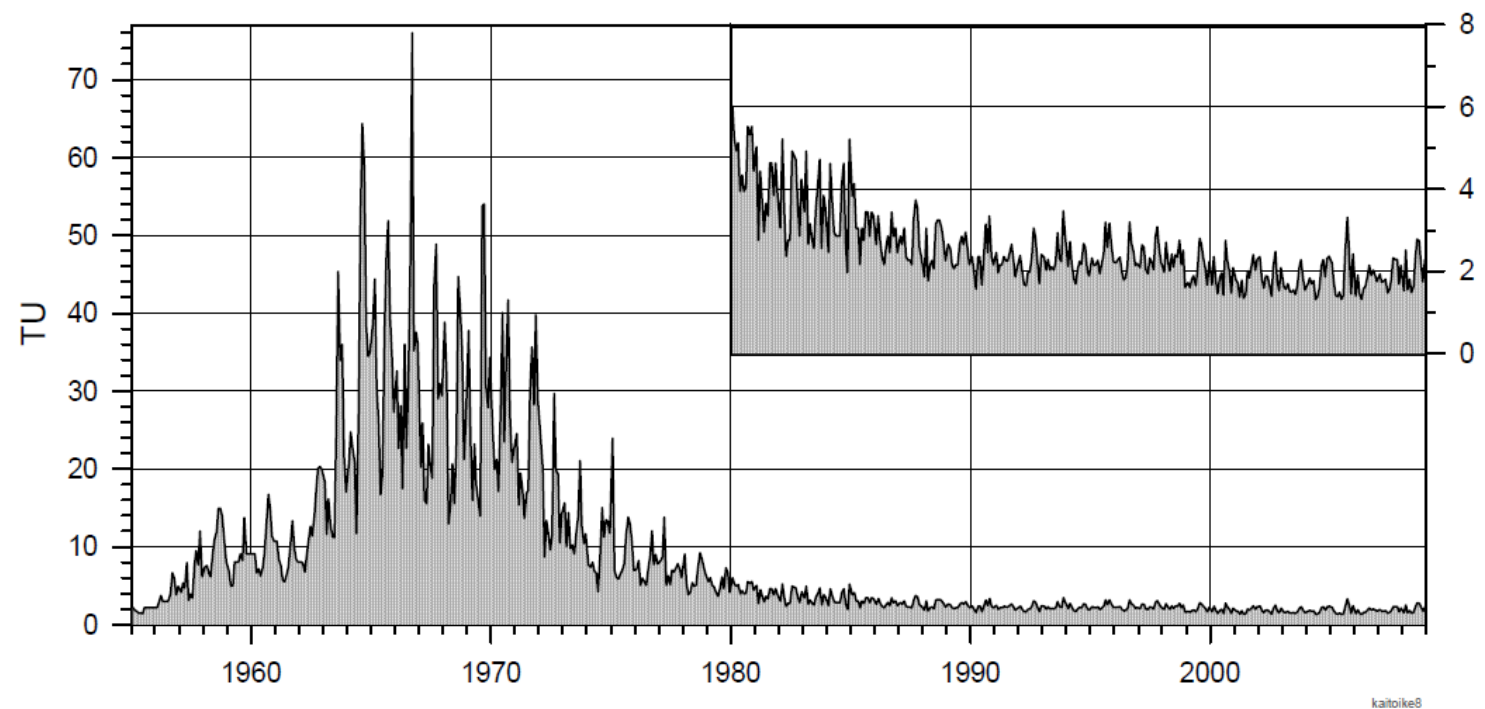

Fig. 3.4 Tritium in rain at Kaitoke, $40 \mathrm{~km}$ North of Wellington. Tritium samples are taken each month since July 1960. Data between 1955 and 1960 are deduced from tritium data from the Hutt River (Kaitoke is in its upper catchment), of Wairakei rain (Taupo), and of South Pole snow pits. The insert shows tritium from 1980 to present with higher resolution. Source: Morgenstern and Taylor (2009).

Tritium has been widely used to infer groundwater flow rates and various aquifer parameters. Using the known atmospheric input, decay rate and the enriched tritium within a sample indicates the time a sample of water has elapsed underground (Morgenstern and Taylor, 2009; Daughney et al, 2010). Examples of studies utilizing tritium include:

- Stewart et al (2003) which used isotopic measurements, including tritium, to estimate mean residence times in the Upper Motueka groundwater catchment in Nelson, New Zealand. The groundwater investigation revealed relatively short mean residence times (0-12 months), and estimated that rainfall recharge 
was frequent enough to force a reservoir turnover every 2.5 years on average. The study was part of the Motueka River Integrated Catchment Management (ICM) project to improve the management of land and water resources in dynamic zones with potentially conflicting land uses. Tritium measurements provided initial estimates, with additional measurements planned in the future, to better understand and manage the catchment's land use and water resources.

- Morgenstern (2005) used observed tritium and hydrochemistry from bores in the Wairarapa to estimate residence times, flow patterns, and hydrochemistry trends. Tritium measurements indicated shallow groundwater in the Upper and Middle Valley catchments was relatively young ( 2 years) aerobic (oxygenated) water, while zones in the deep wells and central Lower Valley housed older (>100 years) anaerobic (de-oxygenated) water. Recharge was also inferred from the south-eastern hills by small tritium concentrations in water (45-80 years) from south-eastern sections of the Wairarapa Valley.

- Stewart et al (2005) investigated groundwater contribution to the Pukemanga Stream near Hamilton using variations in oxygen-18, tritium, chlorofluorocarbons, and $\mathrm{SF}_{6}$ concentrations over time to determine a large percentage ( $87 \%$ of the total drainage) was sourced from groundwater.

- Stewart and Thomas (2007) investigated karst springs supplied by an upland aquifer in the Takaka Valley, South Island, New Zealand. A conceptual flow model was developed using tritium, hydraulic head, chlorofluorocarbons, oxygen-18, and chloride measurements. The tracer inputs were tritium and chlorofluorocarbon concentrations, and temporal oxygen-18 variations in the rainfall recharge, which were simulated through the groundwater system. The study found that groundwater ages estimated using CFC-11 and tritium often match, whereas ages estimated using CFC-12, are generally several years younger (Stewart and Morgenstern, 2001; Stewart and Thomas, 2007).

- Daughney et al (2010) conducted a national survey using concentrations of tritium, chlorofluorocarbons and sulphur hexafluoride. Concentrations were measured at $>100$ groundwater monitoring sites across New Zealand which 
were used to infer groundwater age distributions using the exponential-piston flow model (see Appendix J). Mean residence times ranged from $<1$ year to $>100$ years, with four mean residence time age groups: approximately 0-10, 11$40,41-100$ and $>100$ years. Age was classified using discriminant analysis and based on nine input variables: well depth, electrical conductivity and the concentrations of the ions sodium, potassium, calcium, magnesium, bicarbonate, chlorine and sulphate.

- Gusyev et al (2012) calibrated the transport model of the Western Lake Taupo catchment to measured tritium concentrations in the river channels. The calibrated model was then used to simulate groundwater ages and the groundwater age distributions in the river catchments. In this case, tritium enabled estimates of age, and valuable model calibration data to validate simulated output.

\subsubsection{Other tracers and hydrochemistry}

Many other tracers exist, including radioactive isotopes, gases, and hydrochemistry measurements that can be used for groundwater age assessment (Fig. 3.5). Young groundwater has been dated using the Tritium-Helium method $\left({ }^{3} \mathrm{H} /{ }^{3} \mathrm{He}\right)$, and with chlorofluorocarbons (CFCs: CFC-12 $\left(\mathrm{CF}_{2} \mathrm{Cl}_{2}\right), \mathrm{CFC}-11\left(\mathrm{CFCl}_{3}\right), \mathrm{CFC}-113\left(\mathrm{CF}_{2} \mathrm{ClCFCL}_{2}\right)$ ), Sulphur hexafluoride $\left(\mathrm{SF}_{6}\right)$, Helium-3 $\left({ }^{3} \mathrm{He}\right)$, Oxygen-18 $\left({ }^{18} \mathrm{O}\right)$, Helium-4 $\left({ }^{4} \mathrm{He}\right)$, Chloride$36\left({ }^{36} \mathrm{Cl}\right)$, and Krypton-81 $\left({ }^{81} \mathrm{Kr}\right)$. Successful older groundwater tracers include Radiocarbon $\left({ }^{14} \mathrm{C}\right)$, Silicon-32 $\left({ }^{32} \mathrm{Si}\right)$, and Argon-39 $\left({ }^{39} \mathrm{Ar}\right)$ (Kazemi et al, 2006). New tracers are discovered, proven, and used as they enable more confident results, and improved tracer techniques. Artificial anthropogenic tracers such as hydrocarbons, and dyes have been also been used (Broers, 2004; Kazemi et al, 2006).

Hydrochemistry data can help characterize the quality of groundwater resources and identify negative impacts on groundwater. The New Zealand National Groundwater Monitoring Program (NGMP) involves ongoing quarterly nation-wide sampling and hydrochemistry analysis of 17 parameters (e.g. major ions, nutrients, metals, arsenic) from over 100 groundwater monitoring sites around New Zealand (Daughney et al, 2012; Morgenstern and Daughney, 2012). 
The NGMP also involves two- to three-yearly measurements of tracers (e.g. tritium, chlorofluorocarbons and $\mathrm{SF}_{6}$ ) to determine the groundwater age distribution in important aquifers (Daughney et al, 2009b, 2011; Gusyev et al, 2011). The Wairarapa Valley's hydrochemistry is monitored and studies have utilized statistical hierarchal cluster analysis and discriminant analysis to delineate groundwater zones and identify groundwater and surface water interactions in the region (Daughney, 2007; Daughney et al, 2009a; Guggenmos, 2010; Guggenmos et al, 2011; Morgenstern, 2005).

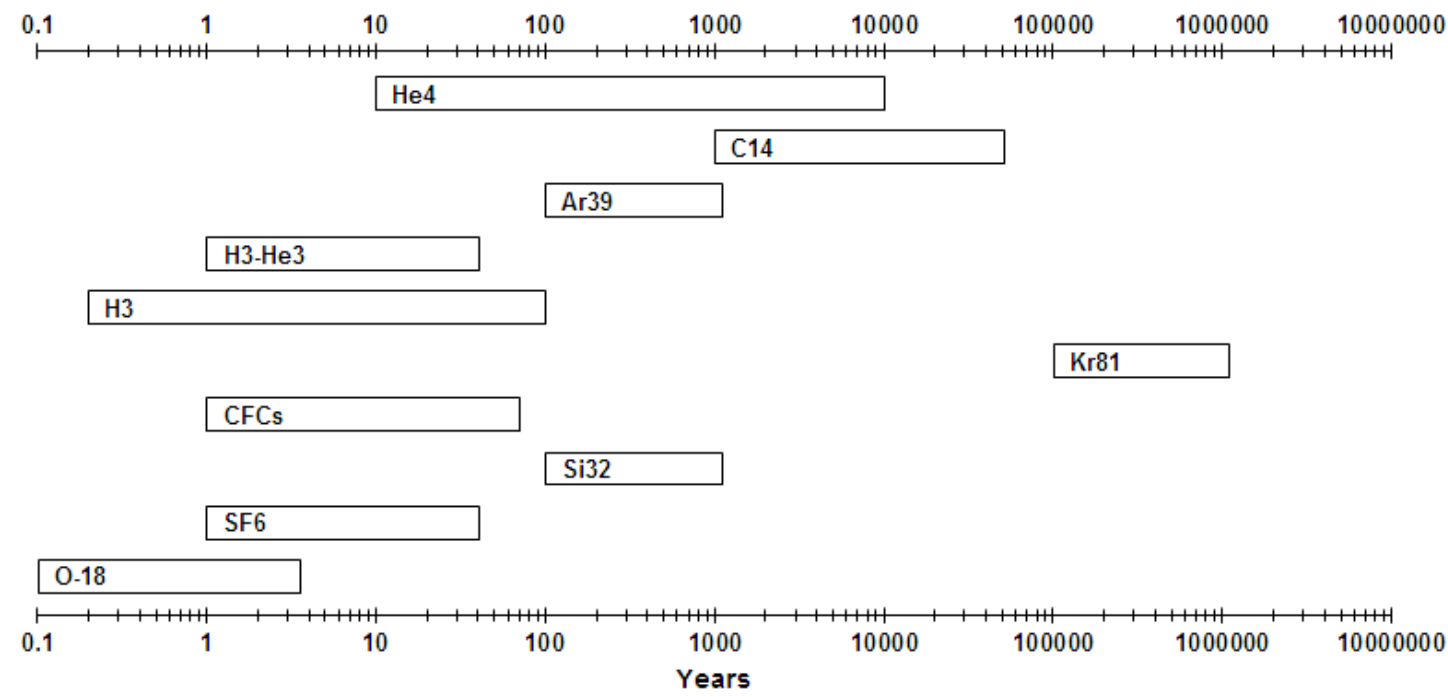

Fig. 3.5 Age range for tracers used in water age estimation. Source: Beyer et al (2013); Cook and Herzceg (2000); Fitts (2002).

Major dissolved constituents within groundwater can be used for dating. Major constituents include the cations calcium (Ca), magnesium (Mg), sodium ( $\mathrm{Na}$ ), and potassium $(\mathrm{K})$; anions bicarbonate $\left(\mathrm{HCO}_{3}\right)$, sulphate $\left(\mathrm{SO}_{4}\right)$, chloride $(\mathrm{Cl})$; and other constituents' silica $\left(\mathrm{SiO}_{2}\right)$ and dissolved carbon dioxide $\left(\mathrm{H}_{2} \mathrm{CO}_{3}\right)$. Major constituents dissolve into groundwater from porous media that it filters though. Typically, groundwater increases in concentration the longer it is subjected to the subsurface environment (Fitts, 2002). Correlations can be made between major dissolved constituents and measured age tracers such as tritium, chlorofluorocarbons, and $\mathrm{SF}_{6}$. Any relationship can provide additional estimates of age tracers where constituents like $\mathrm{Ca}, \mathrm{Mg}, \mathrm{Na}, \mathrm{K}, \mathrm{HCO}_{3}, \mathrm{Cl}$, and $\mathrm{SiO}_{2}$ have been measured, but where age tracers have not. Local and regional water authorities routinely measure constituents as part of annual environmental monitoring, however, age tracers are often not routinely measured primarily due to cost and time constraints (Rosen, 2001). 
Estimated age tracer data can be used to constrain and calibrate model parameters, such as porosity and hydraulic conductivity.

Tritium and hydrochemistry measurements provided information on the flow system and the hydrochemical evolution of the reservoirs in the Wairarapa. Tritium dating has been widely used to infer groundwater processes across New Zealand, for example, in Canterbury (Stewart et al, 2002; Taylor et al, 1989; Taylor and Fox, 1996), Marlborough (Morgenstern, 2007; Taylor et al, 1992), Hawkes Bay (Baalousha, 2012), Nelson (Stewart et al, 2011), Rotorua (Morgenstern et al, 2004, 2005), and Taupo (Gusyev et al, 2012; Hadfield, 2007; Hedenquist et al, 1990; Reeves and Rosen, 2002).

\subsection{Groundwater age modelling methods}

Groundwater age can be simulated in models to characterize subsurface processes. Flow and transport are characterized in one-, two-, or three-dimensional models and age is often simulated in a transport model following the calibration of parameters using observed data (Kazemi et al, 2006). The reliability of simulated output is dependent on the accuracy of the approximations made to replicate the groundwater system. A conceptual model is an initial representation of the groundwater system, condensing the geological structure and parameters defining the basin's subsurface flow and transport processes. A numerical model is used to simulate the response of inputs and changes of concentrations and/or age within the system. There are three primary modelling techniques used to model age in groundwater catchments, (1) lumped parameter models, (2) the particle tracking method, and 3) the direct age simulation method.

\subsubsection{Lumped Parameter Models}

Lumped parameter models use observed tracer data to match and estimate the flow and age of groundwater (Jurgens et al, 2012; Małoszewski and Zuber, 1982). Age can be inferred from tracer concentration samples analysed from an abstraction point in the system. These are related back to the input of the tracer through recharge processes and travel time through the subsurface to the abstraction point. 
When modelling the flow and transport of water and solutes, hydrogeological systems are often simplified to approximate behaviour under certain assumptions; for example, steady state and/or isotropic conditions. A lumped-parameter model ignores spatial variations of parameters (such as rainfall) and the system is described by adjustable (fitted) parameters (Zuber and Małoszewski, 2001). The models correspond to different assumed and simplified configurations of groundwater flow from an input source in the aquifer (recharge area) to the output point(s) in the aquifer (often a well or spring). These are represented mathematically as transit-time distribution functions or exit-age distribution functions [ $\boldsymbol{g}(\boldsymbol{t})]$ (Małoszewski and Zuber, 1982). Lumped parameter models were developed in the 1950s and have been widely applied to the interpretation of environmental tracer data (Małoszewski and Zuber, 1982; Vogel, 1967).

Lumped parameter models assume that tracers are injected and present in the fluid flux where they behave conservatively (except for known decay or degradation) and travel with the water. This implies that the mean age estimated by tracer concentrations is equal to the mean age of water exiting the system (Małoszewski and Zuber, 1982). In some cases the tracer travel time and water travel time may differ and this can cause inaccurate estimates of the age distribution and mean age of a sample $\left(\tau_{s}\right)$. This is because some tracers are affected by diffusion, sorption, and geochemical exchange and these factors are most-likely when using the tracers which are not part of the water molecule (e.g. CFCs and $\mathrm{SF}_{6}$ ). In these such cases, significant differences can occur between the simulated water age and tracer age (Jurgens et al, 2012). Lumped parameter models are based on a simplified flow regime. If the actual system does not match the assumptions within the lumped parameter model, the age output will be unrealistic, even if the lumped parameter model curve matches the tracer data from the observation well. Further reading and numerical implementation of several lumped parameter models is covered in Appendix J.

\subsubsection{Particle tracking}

The particle tracking method is based on transport equations which are solved by particle-tracking algorithms. 
A flow velocity field is used alongside particle tracking algorithms to gain a purely advective age solution within a groundwater system (Kazemi et al, 2006; Pollock, 1994). Essentially, the advective flow field is used to simulate transport of a specified number of particles through the system, and the path lines can be assessed as the time (i.e. age) taken to reach a given boundary or sink/source (e.g. well or lake).

The decay or degradation of a given solute can be accounted for in the particle tracking simulation. The resulting concentration (often volume-averaged) can be tested against field hydrochemistry measurements to confirm the accuracy of the model. Path lines can be run forwards, in the direction of flow, or backwards following the flow lines upstream to the recharge source. The forward simulation is useful when the solute source (e.g. a toxic contaminant) is known and a prediction of future dispersal is required. Conversely, the backwards simulation can estimate the potential source(s) of the solute following concentration detection at a sampling point (Kazemi et al, 2006).

Particle tracking methods are useful when simulating the transport of solutes in porous media. They are especially applicable in heterogeneous layered material, due to their inherent ability to adapt to the flow velocity, and simulate advection-controlled transport. It should be noted however that hydrodynamic mixing processes are neglected which is often an unrealistic assumption in dynamic environments, such as the Wairarapa (Herrera and Beckie, 2012). Further reading and numerical implementation is explained in Appendix $\mathrm{K}$.

\subsubsection{The Direct Age Simulation Method}

The direct age method simulates groundwater age throughout an entire domain. Direct age simulation also incorporates the effects of dispersion, diffusion, and mixing. The method is a combination of (1) the residence-time distribution and (2) the conservation of age mass. The residence time distribution is the probability distribution function that describes the amount of time a given fluid element has spent inside an area. This approach has been widely used in chemical reaction systems and is applicable to physical groundwater systems (Etcheverry and Perrochet, 2000; Eriksson, 1958; Goode, 1996). 
Essentially it describes the statistical lifetime of components within a system and is used because groundwater molecules are affected by mixing, diffusion, and variable flow velocities. These processes result in a range of different paths and residence times for different molecules within a sample of water (Goode, 1996). The connection between the residence time distribution and the transport of a tracer (e.g. tritium) can be used to obtain residence time distributions corresponding to solutions of the advection-dispersion transport equation (Goode, 1996; Zuber, 1986). The direct simulation of groundwater age describes transport by volume-averaged field equations of the advective-dispersive type (Goode, 1996; Kazemi et al, 2006). The direct simulation method can assess an entire groundwater system and simulated age information can be extrapolated from multiple wells across an entire groundwater system.

\subsubsection{Transient mean age}

The characterization of groundwater particle age is simulated in relation to the travel time within a groundwater system. The age is dependent on the amount of rainfall recharge and channel recharge to the modelled system. Groundwater age is defined as a relative quantity with respect to a starting location (i.e. the ground of model surface) where age is assumed to be zero, and measured as the time elapsed between the particles entering the system (Cornaton, 2007). The mean age is continuously generated during groundwater flow and is the average age of water particles located in a specific point in the system, at a specific point in time in a transient simulation. The simulation of transient mean age transport was derived by Goode (1996) including the governing equation (Eq. 3-8).

\subsubsection{Transient age distributions}

Accounting for hydrodynamic dispersion is critical in dynamic, mixed aquifer systems and should therefore produce more realistic results. The direct simulation of groundwater age was established by Goode (1996) and is achieved via a uniform zeroorder source term assigned to the advection-dispersion equation, which enables the simulation of age directly, as the dependent variable (Sanford, 2011). 
This method has also been termed the "age-mass" method because age is simulated as a chemical mass in the mass-balance equation (Bethke and Johnson, 2002; Sanford, 2011).

The direct simulation of groundwater age is achieved through the use of an initial conceptual model of the hydrogeological system, after which, a numerical model is used to simulate the movement of groundwater flow and transport of particles within the system. This method is useful given the simulated groundwater ages can be assessed with the subsurface effects of diffusion, dispersion, and mixing throughout the groundwater system (Goode, 1996).

Once the model has been calibrated to match observed tritium and head data the direct age simulation can be run to simulate age throughout the model domain. The mean residence time in a steady state flow system can be determined from the concentration of a tracer input as an impulse at time zero as defined by Goode (1996):

$$
\begin{gathered}
A=\frac{\int_{0}^{x} t c d t}{\int_{0}^{x} c d t}=\frac{E}{M} \\
\text { where: } \\
A=\text { mean residence time/age of molecules (years) } \\
E=\text { concentration weighted average time } \\
M=\text { probability density function } \\
c=\text { concentration flux }\left(\mathrm{kg} / \mathrm{m}^{3}\right)
\end{gathered}
$$

The numerator form is similar to the expectation of a random variable $t$ with probability density function $\boldsymbol{c}$. The denominator normalizes the numerator such that $\boldsymbol{c}$ divided by the time integral of $\boldsymbol{c}$ has the properties of a probability density function. This integral is constant and uniform for steady flow (Goode, 1996; Spalding, 1958). 
For transport by advection and dispersion (assuming a constant density fluid) the concentration is as defined by Goode (1996):

$$
\begin{gathered}
\frac{\partial c \theta}{\partial t}=\nabla \cdot \theta \mathrm{D} \cdot \nabla c-\nabla \cdot \mathrm{q} c \\
\text { where: } \\
\theta=\text { moisture content/porosity }(\%) \\
\mathrm{D}=\text { dispersion tensor }\left(\mathrm{m}^{2} / \mathrm{s}\right) \\
\mathrm{q}=\text { specific discharge vector }\left(\mathrm{m}^{3} / \mathrm{s}\right) \\
c=\text { solute concentration }\left(\mathrm{kg} / \mathrm{m}^{3}\right)
\end{gathered}
$$

A standard model of dispersion is assumed whereby the product of moisture content and the dispersion tensor, $D$, is given by:

$$
\begin{gathered}
\theta D_{j}=\left(\theta D_{m}+\alpha_{T} q\right) \delta_{i j}+\left(\alpha_{L}-\alpha_{T}\right) \frac{q_{i} q_{j}}{q} \\
\text { where: } \\
D_{m}=\text { diffusion coefficient }\left(\mathrm{m}^{2} / \mathrm{s}\right)
\end{gathered}
$$

The Kronecker delta: $\delta_{i j}=1$ if $i=j$ and $\delta_{i j}=0$ if $i \neq j$

$$
\begin{aligned}
& \alpha_{L}=\text { longitudinal dispersivity }(\mathrm{m}) \\
& \alpha_{T}=\text { transverse dispersivity }(\mathrm{m})
\end{aligned}
$$

$q_{i}$ and $q_{j}=$ components of the specific discharge vector $\left(\mathrm{m}^{3} / \mathrm{s}\right)$

$$
q=\text { magnitude of specific discharge }\left(\mathrm{m}^{3} / \mathrm{s}\right)
$$

Multiplying Eq. 3-2 by time and integrating through all time gives (Spalding, 1958)

$$
-\theta=\nabla \cdot \theta \mathrm{D} \cdot \nabla \mathrm{E}-\nabla \cdot \mathrm{q} E
$$


The left side of Eq. 3-4 is gained through integration by parts of the time derivative term. Dividing by $M$ (which is uniform and can be taken inside the spatial derivatives) and assuming porosity is also constant, gives:

$$
\nabla \cdot D \cdot \nabla A-\frac{1}{\theta} \nabla \cdot \mathrm{qA}+1=0
$$

Where the defined mean age $\boldsymbol{A}=\boldsymbol{E} / \boldsymbol{M}$ has been substituted. Therefore, the mean age at a point within the domain satisfies a steady state advection-dispersion transport equation with an internal source of unit $(\boldsymbol{A}=E / \boldsymbol{M})$ strength (Goode, 1996). To complete the mathematics, boundary conditions are needed and will be defined in the following section.

\subsubsection{Conservation of Age Mass}

A more general form of the age transport equation can be derived from massconservation principles. Assuming that the mean age of a mixture of water is a mass weighted average, the mean age is equivalent to a conservative solute concentration (Goode, 1996). As age cannot be measured directly as a physical property, and confirmed through sample verification, it is assumed that when two water volumes mix their mean age is the mass-weighted average age of the two volumes combined. Hydrochemical analysis of tracers can help confirm assumptions on mixing (Stewart and Morgenstern, 2001). A mass of water with a mean age of $\boldsymbol{A}$ is assumed to have an age mass of the product of the mean age and water mass, $A p V$, where $\boldsymbol{p}$ is density (kg $\mathrm{m}^{-3}$ ) and $\boldsymbol{V}$ is water volume $\left(\mathrm{m}^{3}\right)$. Age is not conserved during transport as it is does not include a source term; however, density and volume are conserved (Bethke and Johnson, 2002). Goode (1996) termed $\boldsymbol{A p} \boldsymbol{V}$ the age mass (kg/s or kg/yr), the mean age of mixture with two components is a volume weighted average:

$$
A=\frac{A_{1} V_{1}+A_{2} V_{2}}{V_{1}+V_{2}}
$$

For example if $1 \mathrm{~kg}$ of 20 year old water was mixed with $1 \mathrm{~kg}$ of 40 year old water it would result in $60 \mathrm{~kg} \mathrm{yr}$ of age mass, or $2 \mathrm{~kg}$ of 30 year old water. 
This equation is the same as a conservative solute mixing in constant density water and this can be used to derive a governing transport equation for mean age (Goode, 1996).

A governing equation for age mass transport can be derived from a box model balance example. The net mass of a solute entering or exiting a specified volume of an aquifer, over a given time period, must equal the gain or loss of mass stored in the volume over the period (Konikow and Grove, 1977). The age mass is the solute and is represented within a simple box volume (with dimensions: $\Delta \boldsymbol{x}$ by $\Delta \boldsymbol{y}$ by $\Delta \boldsymbol{z}$ ) as a simulated portion of an aquifer's volume. The age mass within this volume is the product of the age $(\boldsymbol{A})$ and the water mass $(\theta p \Delta x \Delta y \Delta z)$. The age mass flux across the boundaries of the box volume, $\boldsymbol{G}$, has three components $\boldsymbol{G}_{\boldsymbol{x}} \boldsymbol{G}_{\boldsymbol{y}}$, and $\boldsymbol{G}_{\boldsymbol{z}}$, which incorporates advective flow as well as dispersive flux. Over a time period $(\Delta t)$ the age mass within the water of the box volume changes by the product of $\Delta t$ and the water mass. To account for total exchange of age mass with separate phases an internal net source of age mass of rate $\boldsymbol{H}$ is included, as shown below (Goode, 1996; Konikow and Grove, 1977). The assumption is made that the age mass is conserved and quantified by the source term $\boldsymbol{( H ) .}$ A difference form of a conservation equation is:

$$
\begin{aligned}
& A(t+\Delta t) \theta p \Delta x \Delta y \Delta z \\
= & A(t) \theta p \Delta x \Delta y \Delta z+\Delta t \theta p \Delta x \Delta y \Delta z \\
+ & \Delta t\left\{\Delta y \Delta z\left[G_{x}\left(-\frac{\Delta x}{2}\right)-G_{x}\left(+\frac{\Delta x}{2}\right)\right]\right. \\
+ & {\left[G_{y}\left(-\frac{\Delta y}{2}\right)-G_{y}\left(+\frac{\Delta y}{2}\right)\right] } \\
+ & {\left.\left[G_{z}\left(-\frac{\Delta z}{2}\right)-G_{z}\left(+\frac{\Delta z}{2}\right)\right]\right\}+H \Delta t \Delta x \Delta y \Delta z . }
\end{aligned}
$$

Dividing by the volume and the time-step period, as well as allowing the size of the control volume and the time step length to go to zero in the limit, leads to the governing partial differential equation for mean age transport (Goode, 1996; Konikow and Grove, 1977). 


$$
\begin{gathered}
\frac{\partial A \theta p}{\partial t}=\theta p-\frac{\partial G_{x}}{\partial x}-\frac{\partial G_{y}}{\partial y}-\frac{\partial G_{z}}{\partial z}+H \\
\frac{\partial A \theta p}{\partial t}=\theta p-\nabla \cdot G+H
\end{gathered}
$$

In this equation the water density is allowed to vary, the model of dispersive flux is not specified, and the equation is transient (Goode, 1996). Mean age can be determined for transient flow conditions, as long as the flow history is known (i.e. initial conditions). This is especially relevant for simulating age in large aquifer systems to assess human and climate change impact(s).

Equation 3-8 requires a description of dispersive age mass flux, in terms of age, to complete the governing equation. Goode (1996) adopted the standard model of mass flux such that $\mathbf{G}$ is comprised of advection, dispersion, and diffusion modelled as Fickian diffusion (i.e. a process following Fick's laws); in the equation above $\mathbf{G}$ is replaced by:

$$
\mathrm{G} \approx A p \mathrm{q}-\theta p \mathrm{D} \cdot \nabla A
$$

$D$ is the dispersion tensor and includes a diffusion term; by substitution, the governing equation becomes:

$$
\frac{\partial A \theta p}{\partial t}=\theta p-\nabla \cdot A p q+\nabla \cdot \theta p \mathrm{D} \cdot \nabla A+H
$$

If the porosity and density are constant over time and uniform in space then the above equation becomes:

$$
\frac{\partial A}{\partial t}=1-\nabla \cdot A \frac{\mathrm{q}}{\theta}+\nabla \cdot \mathrm{D} \cdot \nabla A+\frac{H}{\theta p}
$$

If the system is at a steady-flow, the time derivative $(\partial t)$ can be zero to gain a mean age steady-state distribution; however, a distribution will not exist if $\mathbf{q}$ and $\mathbf{D}$ are both zero, as the ages will not disperse and change/create a distribution of ages. 
The age of groundwater is defined by when the water entered the subsurface as recharge at an age of zero. Initial and boundary conditions for the mean age transport equation can be gained from the box model balance. The age mass flux (the product of age and water mass flux) is zero across all inflow boundaries, as well as zero at the noflow boundaries (i.e. age is only influenced by recharge or river/stream boundaries):

$$
\begin{gathered}
\mathrm{G} \mid r_{1} \cdot n=0 \\
\text { where: } \\
r_{1}=\text { inflow or outflow boundary } \\
n=\text { unit outward normal } \\
\mathrm{G}=\text { total age mass age flux. }
\end{gathered}
$$

$\mathrm{G}$ includes dispersion and advection and no dispersion is assumed to occur upstream over the inflow boundary. The outflow boundary condition depends on the system, but it is assumed that any mass flux across the outflow boundary occurs only by advection. The condition of no dispersion across the outflow boundary is:

$$
\mathrm{D} \Delta A \mid r_{2} \cdot n=0
$$

where:

$r_{2}$ is an inflow or outflow boundary

This assumed condition is most appropriately used when the aquifer discharges to surface water bodies, such as a lake or river, and another condition would potentially work better when transfer between aquifers or aquitards occurs (Bethke and Johnson, 2002; Goode, 1996). The general form of the governing equation for mean age transport is transient and requires the initial mean age distribution throughout the system to yield a solution. For steady state systems the general equation drops the time derivative (Goode, 1996).

The direct simulation of groundwater age utilizes the governing advective-dispersive equation to solve the spatial distribution of the transient mean age of groundwater. 
The method attempts to account for the naturally occurring hydrodynamic processes (e.g. dispersion, diffusion and mixing) within subsurface reservoirs and complements existing techniques. Simulated ages can be compared between different methods, for example, lumped parameters models. This complements the TMLTGT which allows the distribution of age in the transient case. These two age modelling techniques allow additional important information for water resource management to be extrapolated from a calibrated numerical model.

\subsubsection{The Time-marching Laplace Transform Galerkin Technique}

The TMLTGT is a numerical scheme for solving the water age distribution problem in a transient flow domain. Water age is modelled given the fact that age is defined in the three spatial dimensions, at a specified location, and the fact the age changes over time (i.e. the time coordinate). Hence, the temporal evolution of groundwater age is a five-dimensional problem. The TMLTG technique enables the evolution of a given location's groundwater age distribution to be evaluated for environmental risk assessment. The Laplace Transform Galerkin technique was originally applied to the subsurface water transport of solutes by Sudicky (1989). He proposed that the nature of the Laplace transformation, the LTG method, was suited to transient groundwater flow and solute transport in fractured and multiple aquifer systems.

When modelling transient groundwater simulations, it involves an extended transport operator, which incorporates an extra coordinate for water age (Eq. 3-14). The technique is an algorithm which combines the Laplace Transform technique applied to the age coordinate with standard time-marching schemes. The basic principal relies on the fact that age and time are completely independent quantities, and hence the rate of aging, does not depend on time since it is always one per unit time. It must be noted that transient age simulations rely on the evaluation (and implementation) of realistic initial conditions for age mass transport problems. Moreover, a steady state is not necessarily a proper representation of an initial state for systems exhibiting a transient state (Cornaton, 2012). 
The primary characteristic of the TMLTG is the reduction in the problem dimension. This is achieved via the mathematical transformation of the age dimension using the Laplace transform operator. A standard time-marching procedure is then applied to the Laplace transformed age distributions, to simulate their evolution over time. The TMLTG numerical solution uses the Crank-Nicholson scheme for the time-discretization, with a constant step-size of 0.5 days (Cornaton, 2007, 2012). The age distribution can be solved regardless of the numerical and/or hydrogeological complexity.

$$
\begin{gathered}
\frac{\partial \theta f_{A}}{\partial t}=-\nabla \cdot \mathbf{q} f_{A}+\nabla \cdot \theta \mathbf{D} \nabla f_{A}-\frac{\partial \theta f_{A}}{\partial \tau}+r_{A} \\
\text { where: } \\
f_{A}=f_{A}(\boldsymbol{x}, t, \tau) \text { is the transient age distribution } \\
r_{A} \text { is the age increase or decrease term }
\end{gathered}
$$

The direct simulation of groundwater age provides useful age information for groundwater management (Cornaton, 2012; Cornaton and Perrochet, 2006; Sudicky, 1989). Until recently, direct simulation was only achievable for steady state models. By implementing the TMLTGT in the Ground Water software, Cornaton (2012) provided the theory and numerical implementation to extend direct age simulation to transient models. However, practical application of the TMLTGT, for direct simulation of age in a transient model, has never been demonstrated for a real catchment. This is primarily due to few catchments having sufficient time-series measurements of tracer concentrations to enable accurate modelled age distributions derived from the TMLTGT. The reader is recommended the following for in-depth breakdown of the technique and implementation: Cornaton (2007), Cornaton (2012), Cornaton and Perrochet (2006), and Sudicky (1989).

\subsection{Comparison between methods}

There are several numerical methods which simulate age within a groundwater system. The first, lumped parameter models, quantify both the groundwater flow and age distributions within aquifer systems. 
Several modelling methods have been extensively developed over several decades to suit a wide range of different aquifer configurations. The limitations of lumped parameter models are obvious, given their inherent assumptions (Małoszewski and Zuber, 1982). For example, piston flow age reflects only advection in one dimension, whereas in reality the age of a groundwater depends on transport mixing processes in three dimensions (Etcheverry and Perrochet, 2000; Goode, 1996). A second disadvantage of lumped parameter models is the inherent inability to model both the solute concentration and flow variation simultaneously (Małoszewski and Zuber, 1993). Additionally, significantly simplifying the subsurface structure, not accounting for natural spatial recharge/infiltration variability, and neglecting the aquifer flow and transport processes are several factors which arguably make several lumped parameter models (i.e. the piston flow and exponential flow model) unsuitable in many dynamic groundwater systems (Kazemi et al, 2006). The exponential piston-flow and dispersion lumped parameter models are the most suitably applied to groundwater systems exhibiting mixing processes. This is due to the addition of an extra fitting parameter within the models (Małoszewski and Zuber, 1982). The dispersion model estimates mixing with a dispersion parameter which provides a measure of the relative importance of dispersion to advection (Jurgens et al, 2012; Zuber and Małoszewski, 2001). Lumped parameter models are especially suited to karst and fractured systems where many other methods are unable to achieve accurate and realistic transport simulations.

Lumped parameter model assumptions and simplifications can be significant compared to direct simulation and particle tracking methods (Kazemi et al, 2006; Małoszewski and Zuber, 1982, 1991). These simplifications may indeed significantly impact the simulated age and/or simulated solute concentration. Lumped parameter models usually only simulate a small portion of the system, for example the recharge area to a well abstraction point, and use observed measurements to estimate processes affecting the area in-between. An appropriate lumped parameter model is suited to a given groundwater zone based on known subsurface water processes. 
If no knowledge exists, an estimate with uncertainty will be constructed to represent the hydrogeologic reality (Etcheverry and Perrochet, 2000). The system is fitted to measured tracer concentrations through the adjustment of the model parameters.

The piston-flow and exponential-mixing lumped parameter models are the least applicable in many groundwater systems due to their lack of error characterization for any hydrodynamic dispersion and mixing in the aquifer, however they are applicable in confined groundwater systems and unconfined systems with uniform recharge. The dispersion lumped parameter model incorporates dispersion and is therefore more robust in dynamic systems. The diversity and development of different models shows the versatility of lumped parameter models and given the (currently) impossible task of accurately assessing all subsurface parameters and processes, the best estimation is made for the system evaluated, in a relatively simple manner.

Information on the age distribution can be gained through the evaluation of lumped parameter models with measured tracer concentrations, and lumped parameter models have an advantage seeing as they do not require the construction of a large three-dimensional flow and transport model (Eberts et al, 2012). Lumped parameter models are also useful when compared to other methods (e.g. direct simulation) as they account for tracer processes such as sorption and chemical exchange that do not affect the advective flow (Goode, 1996). Lumped parameter models have been shown to give similar age distributions to the particle-tracking method, for bores with different ages of water, when based on similar conceptual models and calibrated to similar tracer data, and they have also yielded good simulated results from measured tracer measurements in New Zealand (Eberts et al, 2012; Stewart, 2012).

The particle tracking method has been widely used in hydrogeological investigations to simulate advective transport in groundwater systems (Gusyev et al, 2012; Lindgren et al, 2011; Weissmann et al, 2002). The method is useful given its abilities to track particles both forwards to an abstraction point, and backwards to the recharge point which can help delineate capture zones for wells. The method can also run particle simulations both forwards and backwards in steady state and transient simulations (Gusyev et al, 2012). 
However, a purely advective age simulation is unrealistic if any dilution, mixing, or dispersion has occurred in the subsurface basin. These hydrodynamic processes have significant impacts on the age distribution, especially complex heterogeneous aquifer systems with abstraction pressures (Małoszewski and Zuber, 1982, 1991).

Moreover, the particle tracking method does not allow the calculation of residence time distributions, as the dynamic groundwater masses are not associated to the simulated ages (Kazemi et al, 2006). Depending on the situation, scale, and properties of the area under evaluation, the particle tracking method can yield useful information on groundwater age and solute transport. The method can at the very least provide additional validation of other dating methods, such as isotopic methods, using the disintegration of radioactive isotopes as the age index (Kazemi et al, 2006).

Groundwater age estimates that do not account for the effects of dispersion and mixing can be inaccurate, to varying degrees depending on the heterogeneity of the system. Mixing must be accounted for given environmental tracers inherent qualities as solutes traveling with the bulk water mass, and dispersion and mixing are usually, if not always, processes occurring in dynamic groundwater catchments. Incorporating these processes enables additional age and transport information to be inferred from tracer concentrations. The method falls between those which solely simulate transport by advection, through a particle tracking model and, others that simulate transport in a solute transport model. The direct simulation of age incorporates the effects of dispersion, diffusion, and mixing on groundwater age for a robust age solution (Goode, 1996).

The direct simulation of groundwater age describes transport by volume averaged field equations of the advective-dispersive type (Goode, 1996; Kazemi et al, 2006). Where a piston-flow lumped parameter model would only cover a single well, the direct simulation method can assess an entire groundwater system and the simulated age information can be gained from multiple wells, points and zones. The method accounts for the naturally occurring dispersion, diffusion, mixing and exchange processes within groundwater systems. 
It is useful given the fact it does not require separate models for different tracers, however separate model runs must be performed on each tracer within the same model domain (Engesgaard and Molson, 2005; Goode, 1996). The method complements existing modelling techniques and fits between particle tracking methods and specified solute transport models (e.g. lumped parameters models).

Engesgaard and Molson (2005) concluded that the direct simulation of groundwater age was the most accurate technique when assessed against (1) a tritium transport equation with decay, and (2) an analytical age solution. Castro and Goblet (2005) also found direct simulation of the mean age field yielded the best results when compared to (1) an advective age solution, and (2) a carbon-14 $\left({ }^{14} \mathrm{C}\right)$ age simulation (with decay). Both studies concluded that direct simulation achieved better results due to (1.) the transport of a single component, (2.) the effects of dispersion were included, and (3.) that it can be applied in dynamic heterogeneous systems where mixing processes cannot be ignored and where water velocities vary over several orders of magnitude within an aquifer (Castro and Goblet, 2005; Engesgaard and Molson, 2005).

The governing advective-dispersive equation can derive results for mean age; however one must stress the risks of relying solely on the calculation of the mean age, given at a specified time many different age distributions exist at points within an aquifer which can have the same mean and variance. The advantage of assessing both (1) the mean age and (2) distribution of ages is that young water particles shown in the simulated age distribution indicate potential contamination risks. Coupling the advective dispersive equation to the reservoir theory can allow simulations of the distribution of ages and show the temporal evolution of groundwater age throughout a large heterogeneous groundwater system (Cornaton, 2012; Cornaton and Perrochet, 2006). 


\title{
Chapter 4
}

\section{The Wairarapa Valley}

\begin{abstract}
"Nature creates ever new forms; what is, has never yet been; what has been, comes not again - everything is new and yet always old".
\end{abstract}

Goethe: Essay on Nature

This dissertation focuses on the Middle Valley catchment in the Wairarapa Valley. The Wairarapa is a geographic region in the south-eastern corner of the North Island of New Zealand (Fig. 4.1). The Wairarapa encompasses elevated bounding ranges and a valley basin which has formed and evolved due to various geomorphic processes (e.g. glacial and interglacial periods) and tectonic movements of multiple faults (e.g. the Wairarapa and Carterton faults) (Begg et al, 2005). The region is split between the Tararua Ranges on the west and the Aorangi Ranges and Eastern Uplands to the east (Fig. 4.2) (Morgan and Hughes, 2001). The highest point in the Tararuas is Mitre Mountain at a height of 1,571 metres $(5,154 \text { feet })^{4}$. The highest point to the east is Ross Mountain in the southern Aorangi Range, at 981 metres (3,219 feet). The Wairarapa is sparsely populated with a predominant land-use economy base with agricultural and horticultural production scattered throughout the valley (Boffa Miskell Ltd, 2010; Noble, 1985). There are five main towns: Masterton, Carterton, Greytown, Featherston, and Martinborough (Fig. 4.3). The latter two are located in the lower valley section, to the north east and east of Lake Wairarapa, respectively (see Fig. 4.2).

The area is named after Lake Wairarapa, the third largest lake in the North Island, and $12^{\text {th }}$ largest in New Zealand by surface-area (Viner, 1987).

\footnotetext{
${ }^{4}$ Mitre Mountain is in the North Island, not to be confused with the South Island's Mitre Peak in Fiordland.
} 
The Ruamahanga River is the largest water channel running through the valley, with its headwaters located in the Tararua Ranges, northwest of Masterton. The Wairarapa basin occupies an estimated area of $1073 \mathrm{~km}^{2}$ with three groundwater catchments designated by the Wellington Regional Council; the Upper $\left(160 \mathrm{~km}^{2}\right)$, Middle $\left(270 \mathrm{~km}^{2}\right)$, and Lower $\left(643 \mathrm{~km}^{2}\right)$ Valley catchments. These areas were assigned in the 2005-2010 Wairarapa Valley groundwater catchment investigation (Gyopari and McAlister, 2010). The Wairarapa exhibits similar hydrological and hydrogeological characteristics to other groundwater catchments across New Zealand, and like many environmental systems, is dependent on accurate environmental monitoring and management for continued productivity.

\subsection{The Middle Valley catchment}

The Middle Valley houses Carterton and Greytown within its boundary, contains no lakes, but several spring systems and rivers including the Ruamahanga and Waiohine Rivers, and the Mangatarere Stream. The Waingawa River forms the northern boundary of the Middle Valley and flows into the Ruamahanga River. There are several spring systems including the Greytown springs (Papawai, Tilsons, and Muhunoa), Masterton and Carterton fault springs, Parkvale, Beef Creek, Enaki springs, and the Kaipaitangata diffuse springs. The Masterton and Carterton faults are two major active faults branching eastwards from the primary Wairarapa Fault. These both cut across the Mangatarere Stream and the Waingawa River and their alluvial fan sediments. These have folded and compressed porous aquifer material creating barriers to groundwater flow, but have also created several of the aforementioned Fault spring systems that transfer groundwater to the surface. The influence of surface water on groundwater is considerable and various sections indicate water transfer between the river bed and shallow underlying aquifers (Guggenmos et al, 2011). This is important due to the reliance on aquifer influx from river recharge in persistent westerly weather systems and groundwater outflow providing the base flow to river channels in dry climatic conditions.

The Middle Valley is an expansive groundwater catchment with complex hydrological interactions (Guggenmos et al, 2011). 
This complexity, combined with the availability of environmental data, make the valley an ideal environment to investigate temporal evolution of groundwater age. Aquifers have been increasingly monitored since surface water resources exhibited signs of stress due to the increasing municipal and land-use water demands (Annear et al, 1989; Jones and Baker; 2005; O'Dea et al, 1980). In recent years, regional management has focused on the connections between water channel beds and subsurface aquifers, the sustainable allocation of groundwater, and tracer/hydrochemistry analysis to infer the influence of anthropogenic land-use (Morgenstern and Daughney, 2012; Guggenmos et al, 2011; Hughes and Gyopari, 2011, Morgenstern, 2005). The Middle Valley groundwater resource investigation conducted by the Wellington Regional Council focused on the hydrogeology and modelling the transient flow over a 15 year period, providing information on the groundwater movements, and the response to increasing abstraction pressures (Gyopari and McAllister, 2010a).

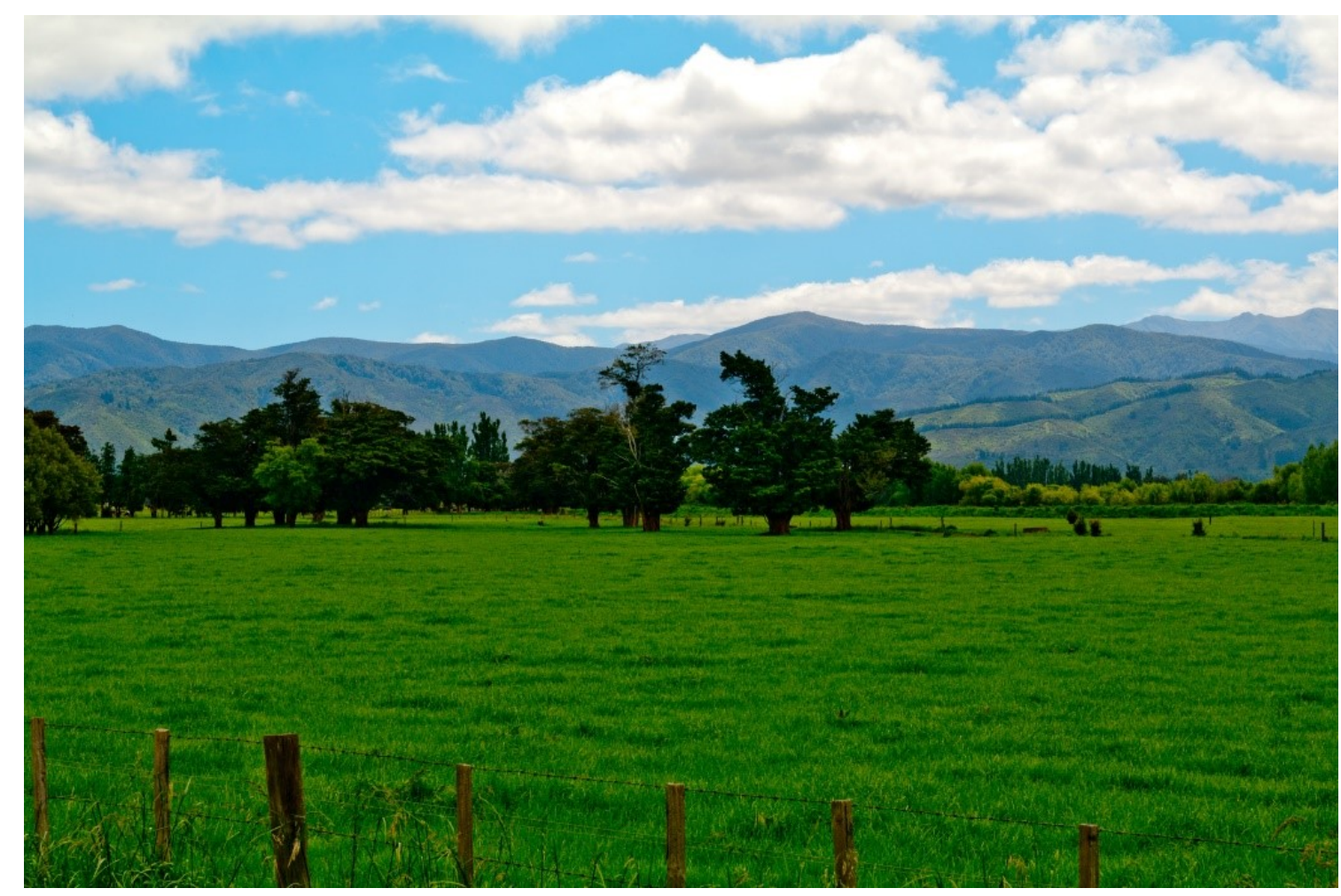

Fig. 4.1 Middle Valley plains looking towards the Tararuas north of Greytown. 


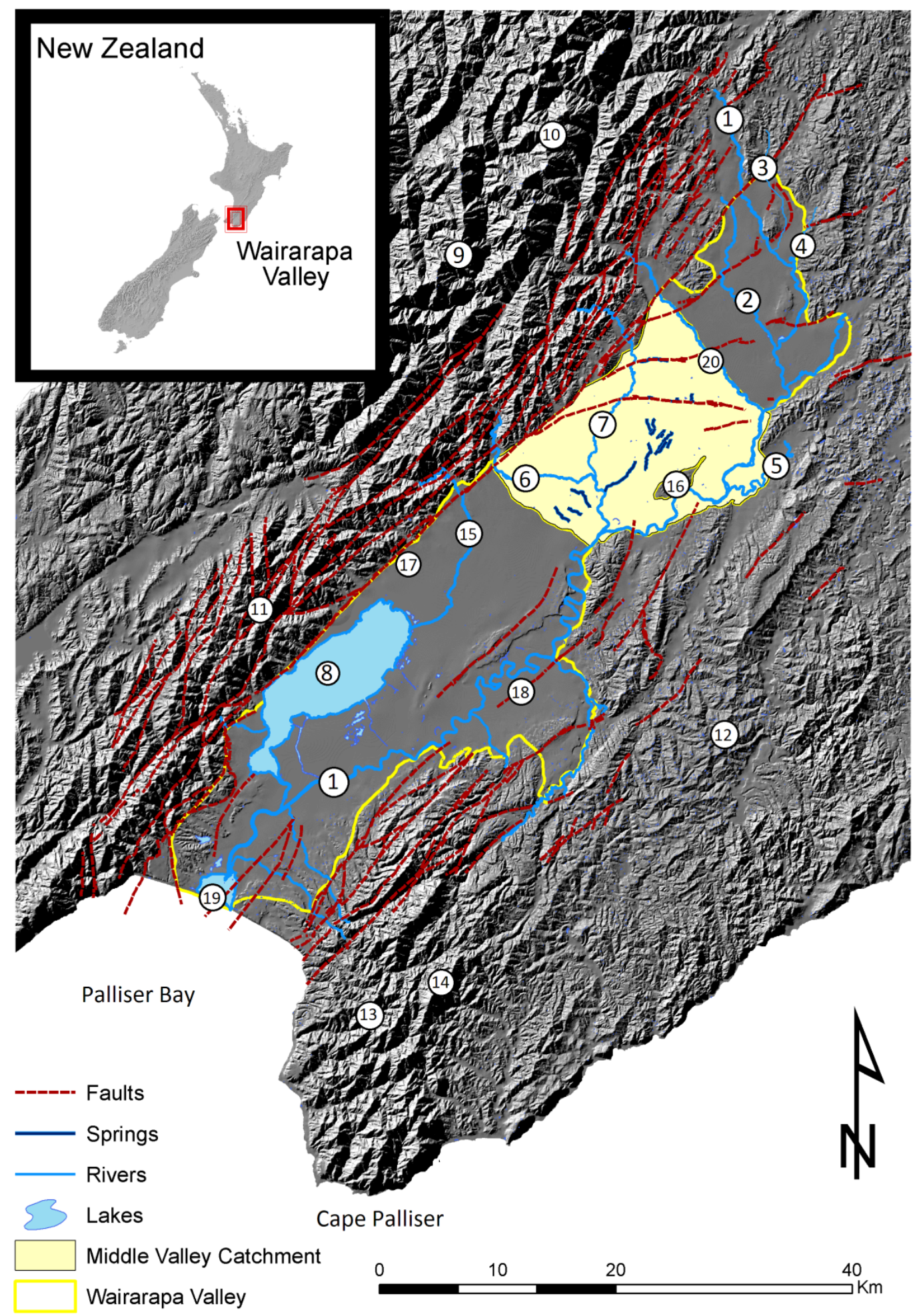

Fig. 4.2 The Wairarapa Valley, New Zealand, showing the location of bounding mountain ranges, the Middle Valley groundwater catchment, main river channels, and lakes. Circled numbers indicate major geographic features: 1) Ruamahanga River, 2) Waipoua River, 3) Kopuaranga River, 4) Whangaehu River, 5) Taueru River, 6) Waiohine River, 7) Mangatarere Stream, 8) Lake Wairarapa, 9) Tararua Ranges, 10) Mitre Mountain, 11) Rimutaka Ranges, 12) Eastern Uplands, 13) Aorangi Range, 14) Ross Mountain, 15) Tauherenikau River, 16) Tiffen Hill, 17) Featherston, 18) Martinborough, 19) Lake Onoke, 20) Waingawa River. 


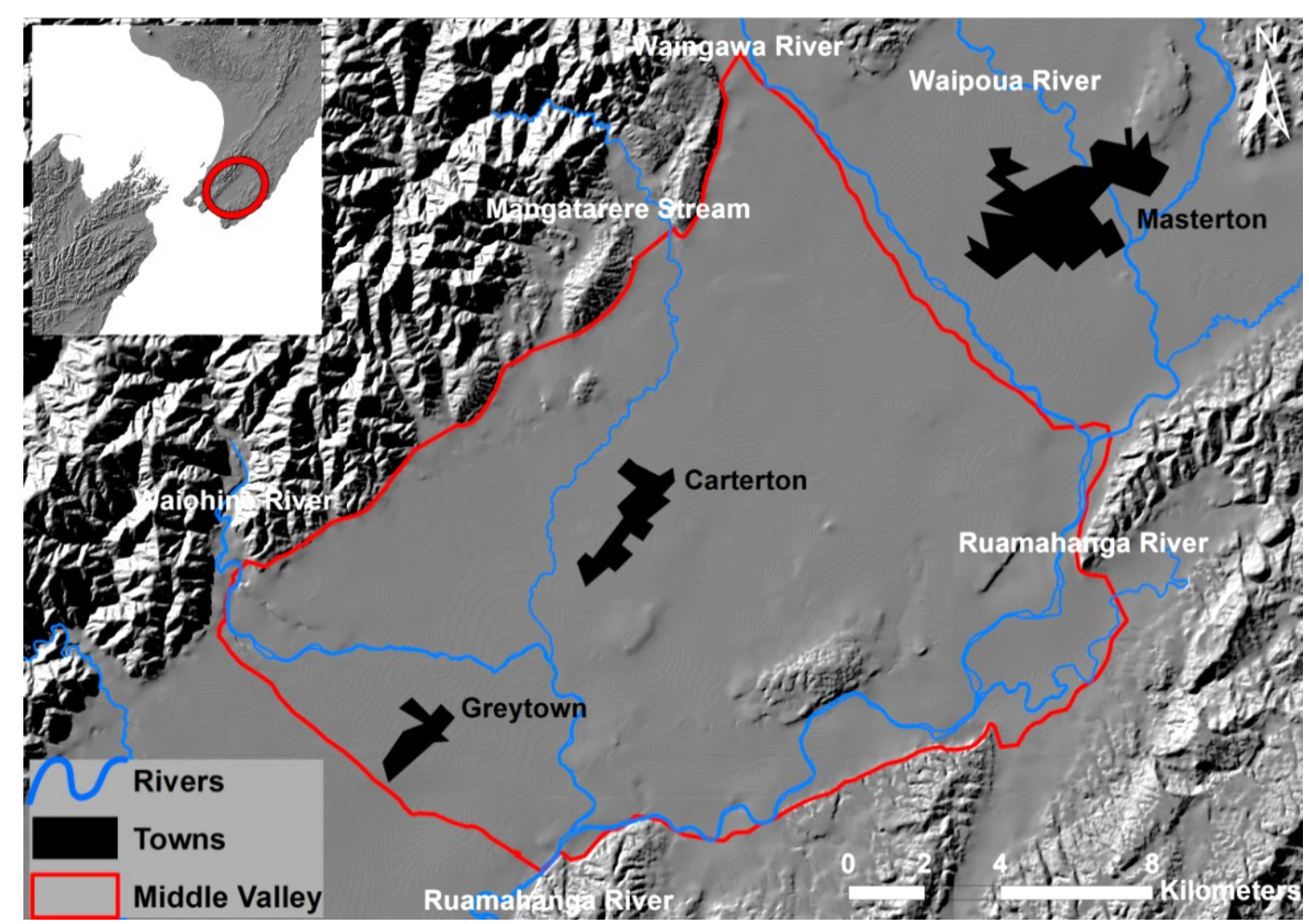

Fig. 4.3 Middle Valley catchment showing the main towns, Middle Valley boundary, and the primary river channels.

\subsection{Geology}

The substrate type and distribution throughout the Wairarapa has a profound effect on water and solute movement. The Wairarapa Valley is a structural depression 110 km long, running NE-SW into Palliser Bay with a maximum width of 15 km (Fig. 4.4). These bounding ranges supply the sand and gravel which have collectively formed the water-bearing aquifers. The evolution of the Wairarapa involves a combination of sea level changes, tectonic faulting, and geomorphic processes constructing a complex heterogeneous subsurface (Heath, 1979; Leach, 1981). Glacial, fluvial, and marine deposits have collectively formed outwash and alluvial plains with water amassing in the porous layers of the subsurface. During glacial periods, erosion increased and led to the deposit of poorly sorted sand and gravel alluvial fans around the foothills of the ranges. The valley subsided in interglacial periods when the sea level increased and fine-grained sediments were deposited in the lower valley, forming confining aquitards (Morgan and Hughes, 2001). 


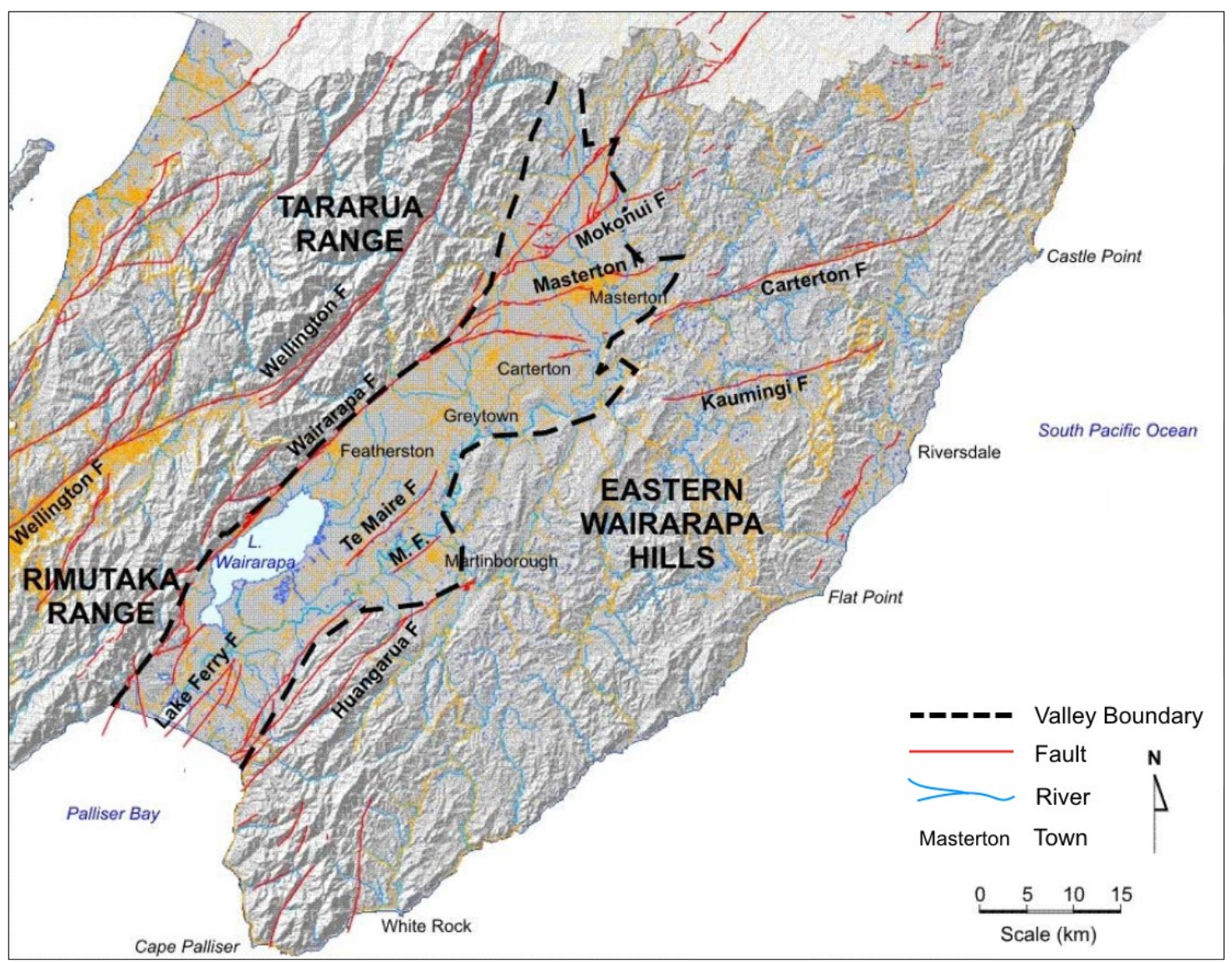

Fig. 4.4 Location of active faults, bounding ranges and Palliser Bay to the South. The geomorphic influence of active faults can be seen in the NE-SW grain of the Wairarapa Valley, with the Wairarapa Fault the most obvious. Source: Begg et al (2005).

The valley is filled with Tertiary and Quaternary marine and alluvial deposits (Fig. 4.5)

(Cape et al, 1990). The western side of the Wairarapa Valley is defined by the

Wairarapa Fault, with uplifted greywacke basement rocks to the northwest, and Neogene and impermeable Early Quaternary marine deposits and permeable

Quaternary valley-fill deposits to the southeast. On the eastern side of the valley, marine Late Cretaceous to Early Quaternary deposits are faulted against, or overlie, the greywacke basement. Within the Valley, Middle Quaternary to Holocene nonmarine and small marine deposits are the predominant substrate, faulted against, or overlying, scattered areas of older aged Neogene and greywacke basement deposits. There are five major rock unit groups in the Wairarapa Valley: (1) Torlesse composite terrane and Pahaoa Group (230 - 120 Ma), (2) Mangapurupuru Group, Glenburn Formation, Tinui Group, Mangatu Group (100 - 25 Ma), (3) Palliser Group, Onoke Group (25 - 2.3 Ma), (4) Early to Middle Quaternary (2.3 Ma - $128 \mathrm{ka}$ ), and (5) Late Quaternary ( $<128 \mathrm{ka})$ as defined by Begg et al, 2005. 
The younger two of the five geological units are the most significant for groundwater resources. Detailed geologic and hydrogeological information is available from Begg et al (2005).

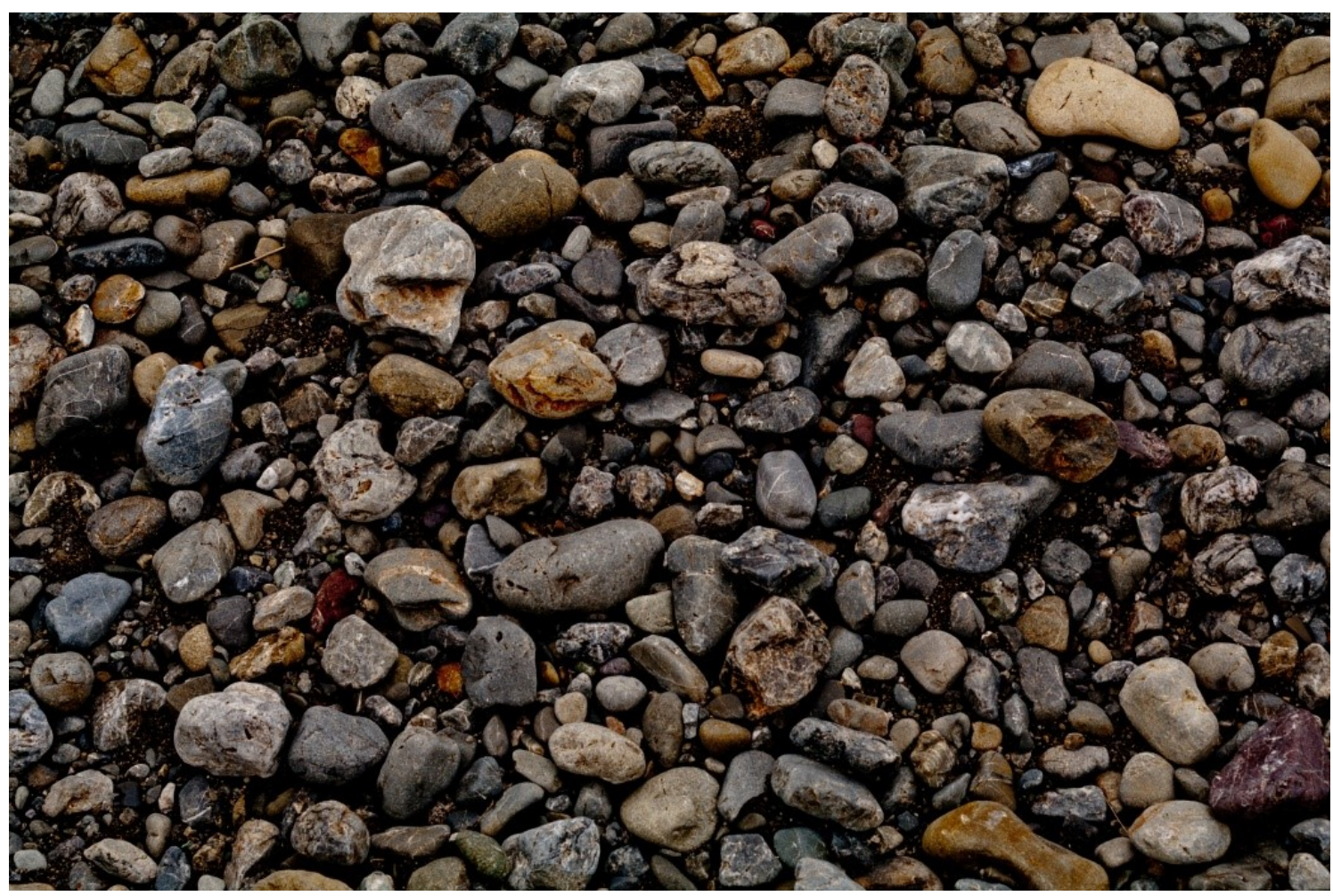

Fig. 4.5 Alluvial gravels on the floodplain of the Waiohine River.

The Wairarapa has several faults and has been extensively affected by tectonic movements; the bounding Wairarapa Fault and other faults and folds are found in the valley (e.g. the Masterton and Carterton faults) (Fig. 4.6). Movement of these has resulted in elevated basement and early Quaternary sediments such as Te Maire Ridge (e.g. Q1 and Q14+ in Table 4.1), and localised depressions such as the Te Ore Ore area (Jones and Baker, 2005). Greywacke and old alluvial sediment have moved up through the substrate to the surface. These faults may have significant impact on groundwater flow and age depending on their location and degree of permeability, with the potential to increase ages in aquifers, and decrease ages in faulted sections and aquitards (Bethke and Johnson, 2002; Castro and Goblet, 2005). Tiffen Hill is an example of an uplifted greywacke block in the east of the Middle Valley and several spring systems exist due to fault movements on the Masterton and Carterton Faults (Fig. 4.6) (Gyopari and McAllister, 2010a). 


\subsubsection{Middle Valley geological units}

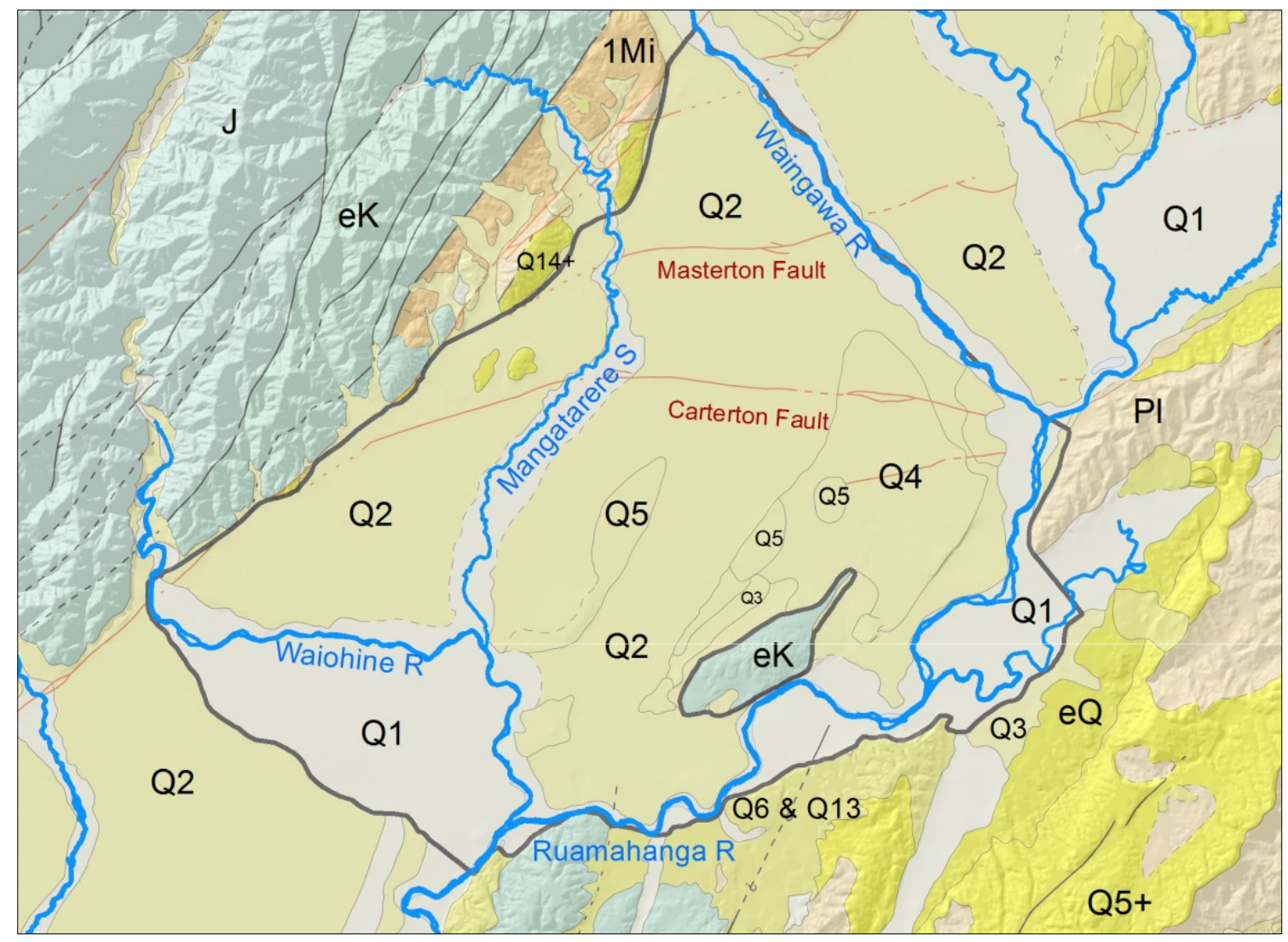

Fig. 4.6 New Zealand 1:250K geological units of the Middle Valley, Wairarapa, New Zealand. Legend explained in Table 4.1.

Table 4.1 Stratigraphy age and description for Middle Valley groundwater system.

\begin{tabular}{|c|c|}
\hline Age & Description \\
\hline Q1 & OIS 1 (Holocene) river deposits. Well sorted floodplain gravels ${ }^{5}$. \\
\hline Q14+ & $\begin{array}{c}\text { Early Pleistocene river deposits. Weathered; poorly sorted loess } \\
\text { covered fan gravel; alluvial gravel and lacustrine silt deposits; } \\
\text { including Te Muna Formation. }\end{array}$ \\
\hline Q2 & $\begin{array}{c}\text { OIS } 2 \text { (Late Pleistocene) river deposits. Poorly to moderately } \\
\text { sorted gravel with minor sand or silt underlying terraces; includes } \\
\text { minor fan gravel. }\end{array}$ \\
\hline Q3 & $\begin{array}{c}\text { OIS } 3 \text { (Late Pleistocene) river deposits. Weathered; poorly sorted } \\
\text { to moderately sorted gravel underlying loess covered; commonly } \\
\text { eroded aggradational surfaces. }\end{array}$ \\
\hline Q4 & $\begin{array}{c}\text { OIS } 4 \text { (Late Pleistocene) river deposits. Weathered, poorly to } \\
\text { moderately sorted gravel with loess, sand and silt. }\end{array}$ \\
\hline
\end{tabular}

\footnotetext{
${ }^{5}$ Oxygen isotope stages (OIS) are alternating climate (warm and cool) periods in the Earth's paleoclimate and their isotope signatures enable the relative ages of strata throughout geologic basins to be inferred. OIS 1: 11,000 years before present (ybp), OIS 2: 24,000 ybp, OIS3: 60,000 ybp, OIS 4: 71,000 ybp, OIS 5: 130,000 ybp, OIS 6-21: 190,000 - 865,000 ybp (Bassinot et al, 1994).
} 


\begin{tabular}{|c|c|}
\hline Age & Description \\
\hline Q5 & $\begin{array}{c}\text { OIS } 5 \text { (Late Pleistocene) river, lake and swamp deposits. } \\
\text { Weathered alluvial gravel; blue grey silty clay; and peat of alluvial; } \\
\text { swamp and possibly lacustrine origin. }\end{array}$ \\
\hline Q5+ & $\begin{array}{l}\text { Late Pliocene Totaranui Limestone, Otope Limestone, Pori } \\
\text { Limestone, Ngaruru Limestone, Kumeroa Limestone (Mangamaire } \\
\text { Group), Pukenui Limestone (Onoke Group), Neogene sedimentary } \\
\text { rocks, coquina. }\end{array}$ \\
\hline Q6, Q13 & $\begin{array}{l}\text { Middle Pleistocene fan, river and lake deposits. Weathered; poorly } \\
\text { sorted loess covered fan gravel; alluvial gravel and lacustrine silt } \\
\text { deposits; including Ahiaruhe Formation. }\end{array}$ \\
\hline eK & $\begin{array}{c}\text { Undifferentiated Pahau terrane sandstone. Basement (Eastern } \\
\text { Province, Tiffen Hill) sedimentary rocks. Thick; poorly bedded } \\
\text { sandstone; well bedded; commonly graded sandstone and } \\
\text { mudstone; minor volcanic rocks. }\end{array}$ \\
\hline eQ & $\begin{array}{l}\text { Early Pleistocene river deposits. Alternating gravel, loess and } \\
\text { mudstone. }\end{array}$ \\
\hline $\mathrm{J}$ & $\begin{array}{l}\text { Esk Head sandstone and mudstone. Basement (Eastern Province) } \\
\text { sedimentary rocks. Deformed sandstone and/or mudstone } \\
\text { dominated sequence with blocks of chert; basalt and limestone; } \\
\text { locally melange. }\end{array}$ \\
\hline $\mathrm{PI}$ & $\begin{array}{l}\text { Pliocene mudstone (Mangamaire Group, Mangahea Group, Te } \\
\text { Aute Group, Hurupi Group, Eketahuna Group, Moa Group, Makuri } \\
\text { Group, Onoke Group), Neogene sedimentary rocks. Massive, } \\
\text { poorly bedded mudstone and minor alternating sandstone and } \\
\text { mudstone. }\end{array}$ \\
\hline IMi & $\begin{array}{l}\text { Late Miocene mudstone (Palliser Group, Hurupi Group, Soren } \\
\text { Group and Onoke Group), Neogene sedimentary rocks. Massive } \\
\text { blue grey calcareous mudstone with sparse fossils and } \\
\text { discontinuous limestone lenses and sparse tuff beds. }\end{array}$ \\
\hline
\end{tabular}

\subsection{Hydrology}

Water can be both abundant and scarce in the Wairarapa. The climate is strongly influenced by the bounding ranges with prevailing north-westerly winds forcing regular fronts from the Tasman Sea over the path of the eastern Tararua and Rimutaka Ranges (Tait et al, 2002). This creates heavy orographic precipitation, due to the height, size, and position of the mountains. The rain collects in the headwaters of river catchments which flow and drain out through the Wairarapa Valley. Flow from the ranges into the valley plains is often rapid, delivering a substantial proportion of the mountainous rainfall to the valley due to the predominantly bedrock incised water channels in the ranges (Begg et al, 2005). 
A rain shadow zone exists between the western and eastern elevated areas of the valley due to the prevailing westerly wind, although southerly winds bring rain off Palliser Bay and Cook Strait. The Eastern Uplands and Aorangi Ranges experience relatively rare heavy rain from easterly weather systems, and minor precipitation from westerly systems after advancing over the western ranges and valley plains (Begg et al, 2005). Rainfall is more frequent in the winter months, with summer months experiencing less frequent and less heavy rainfall events.

Rainfall is a primary groundwater recharge process in the valley. Average annual rainfall peaks at a maximum of $7000 \mathrm{~mm}$, high in the Tararua Ranges, decreasing to an average of $1600 \mathrm{~mm}$ on the western side of the Wairarapa Plains, and $800 \mathrm{~mm}$ in the eastern section boundary (Morgan and Hughes, 2001). This indicates a steep rainfall gradient across the valley, from the Tararua Ranges to the eastern hills, creating spatial variation in rainfall and recharge throughout the valley (Tait et al, 2002). Shallow aquifers, at known reaches, connect with surface water channels and recharge shallow groundwater adjacent to the Waipoua, Waingawa, Waiohine and Ruamahanga Rivers. Rainfall is the groundwater recharge source in valley zones not in close proximity to any rivers, streams, springs or water races (Gyopari and McAllister, 2010a). A maximum of $1800-1900 \mathrm{~mm}$ of annual rainfall can be expected on the western flank of the Middle Valley zone, while on the eastern side this reduces to around $800-900 \mathrm{~mm}$. Soil type and thickness significantly affect the speed and timing of recharge, as well the depth to the water table.

Maintaining river flows and river water quality are primary objectives of water management in the Wairarapa. Rivers are critical for drinking water supplies and irrigation but also pose risks due to their ability to transport excessive volumes of water in flood conditions. The main rivers of the Wairarapa experience seasonal flooding and have the ability to amass significant flows from heavy rainfall in the bounding ranges. The valley also exhibits strong connections between the rivers and shallow aquifers which can have significant impacts on the groundwater flux (Guggenmos et al, 2011). Water quality is considered good in surface waters in and near the bounding ranges; however the reaches of the Waipoua and Ruamahanga Rivers in the Valley have been periodically observed to be unsafe for swimming due to 
faecal contamination (Greater Wellington Regional Council, 2012). To manage and detect water problems, the Wairarapa has 18 rainfall, 26 river flow and/or water level, 77 groundwater level (35 automated), and 48 groundwater quality sites. As for water allocations, most rivers are currently classified as being fully allocated for water use, and some groundwater zones are exhibiting pressure from current abstraction rates (Greater Wellington Regional Council, 2012).

\subsubsection{Primary Wairarapa water channels}

\subsubsection{Ruamahanga River}

The Ruamahanga River is the main river channel draining the Wairarapa Valley (Fig.

4.2). The river drains from its source in the north eastern Tararua Range with a length of approximately $162 \mathrm{~km}$ with a catchment of approximately 3,430 $\mathrm{km}^{2}$ (Gyopari and McAllister, 2010a). As it flows south through the Wairarapa Valley it is joined by the Waipoua, Waingawa, and Waiohine rivers (Fig. 4.3), which also drain from the Tararua Ranges, and the Kopuaranga, Whangaehu, and Taueru rivers that drain from the adjacent eastern ranges (Heslop, 1995).

Table 4.2 Mean monthly flow for several Wairarapa Rivers, measurements in $\mathrm{m}^{3} / \mathrm{s}$. Source: Keenan and Gordon (2008).

\begin{tabular}{|c|c|c|c|c|c|c|c|c|c|c|c|c|c|}
\hline $\begin{array}{l}\text { Site location and } \\
\text { date range }\end{array}$ & Jan & Feb & Mar & Apr & May & Jun & Jul & Aug & Sep & Oct & Nov & Dec & $\begin{array}{c}\text { Mean } \\
\text { annual } \\
\text { flow }\end{array}$ \\
\hline $\begin{array}{l}\text { Ruamahanga at } \\
\text { Wardells (1977- } \\
\text { 2008) }\end{array}$ & 11.4 & 13.1 & 13.1 & 15.5 & 21.5 & 31.4 & 39.2 & 35.5 & 27.8 & 32.3 & 21.6 & 18.5 & 23.4 \\
\hline $\begin{array}{c}\text { Waiohine at } \\
\text { Gorge (1979- } \\
\text { 2008) }\end{array}$ & 17.2 & 16.8 & 17.3 & 18.0 & 22.6 & 27.6 & 30.6 & 29.0 & 27.5 & 34.2 & 27.6 & 26.5 & 24.6 \\
\hline $\begin{array}{l}\text { Mangatarere } \\
\text { Stream at Gorge } \\
(1999-2008)\end{array}$ & 0.9 & 1.1 & 1.0 & 0.9 & 1.8 & 2.6 & 2.9 & 2.8 & 1.6 & 3.0 & 1.7 & 1.4 & 1.8 \\
\hline $\begin{array}{l}\text { Whangaehu } \\
\text { River at Waihi } \\
(1967-2008)\end{array}$ & 0.1 & 0.2 & 0.6 & 0.3 & 0.5 & 1.0 & 1.2 & 1.1 & 0.8 & 0.6 & 0.3 & 0.2 & 0.6 \\
\hline $\begin{array}{l}\text { Waingawa River } \\
\text { at Kaituna } \\
(1976-2008)\end{array}$ & 6.8 & 6.8 & 2.7 & 7.8 & 9.8 & 12.1 & 13.3 & 13.0 & 12.2 & 13.3 & 10.7 & 10.2 & 9.9 \\
\hline $\begin{array}{c}\text { Tauherenikau } \\
\text { River at Gorge } \\
(1976-2008)\end{array}$ & 5.3 & 5.1 & 6.0 & 6.6 & 9.1 & 11.8 & 13.4 & 12.1 & 10.7 & 12.0 & 8.5 & 8.6 & 9.1 \\
\hline
\end{tabular}


From its source in the Tararua Ranges it runs south and emerges on the Wairarapa Valley plains at Mt Bruce, 21 kilometres north of Masterton. In the 25 kilometre section between the Waingawa River and Waiohine River confluence, the river changes several times between braided and meandering (single channel) river forms. After the Waiohine confluence the river flows southwest through the valley, past Martinborough, to Lake Onoke which discharges directly into Palliser Bay (Heslop, 1995). In its lower reaches, the river meanders across a large floodplain, and was modified extensively since the late 1960s. The river once flowed into Lake Wairarapa, but in 1968 was diverted into Lake Onoke in the Lower Valley Development Scheme (Airey et al, 2000). The river now drains at Palliser Bay ten kilometres further south than its original discharge point. The flow history can be seen at two different points in the below figures (Fig. 4.7 and Fig. 4.8), with Gladstone (Fig. 4.9) recording a maximum of 1255 cumecs in 1998 (1992 - 2011).

\section{Ruamahunga River at Wardells}

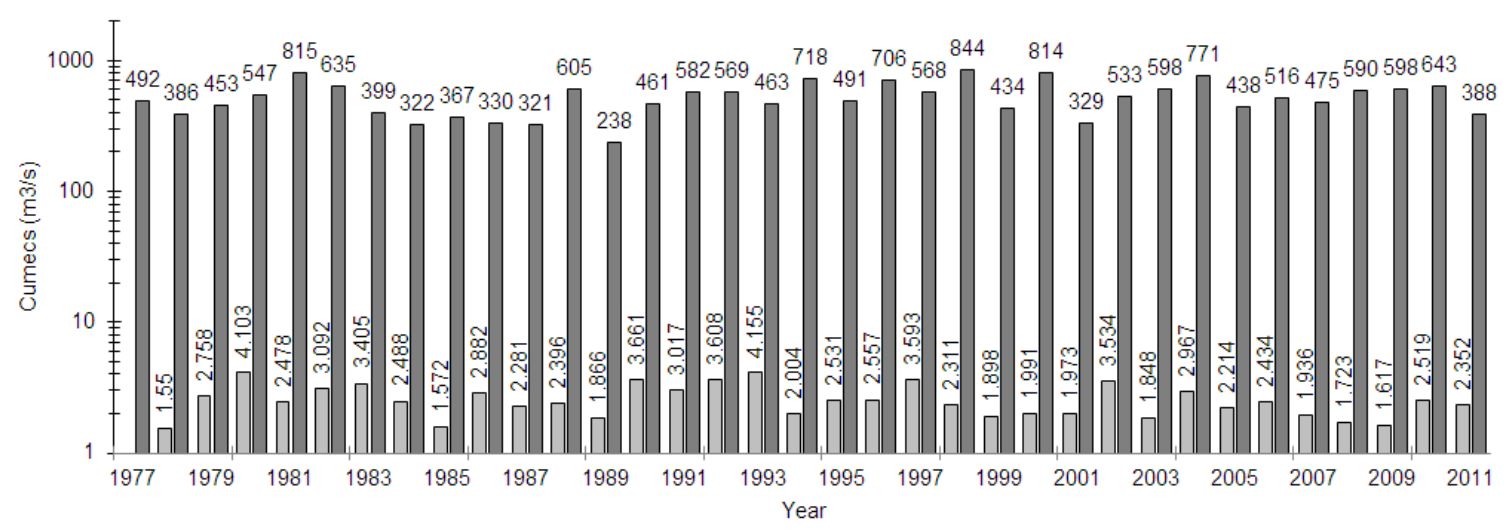

Fig. 4.7 Maximum and minimum flows 1977-2011 in the Ruamahanga River at Wardells. Maximum indicated by horizontal text, minimum by vertical. This site is situated 600 metres upstream of the confluence with the Waingawa River and 95 kilometres from the Ruamahanga River mouth. Source: Gordon (2013). 


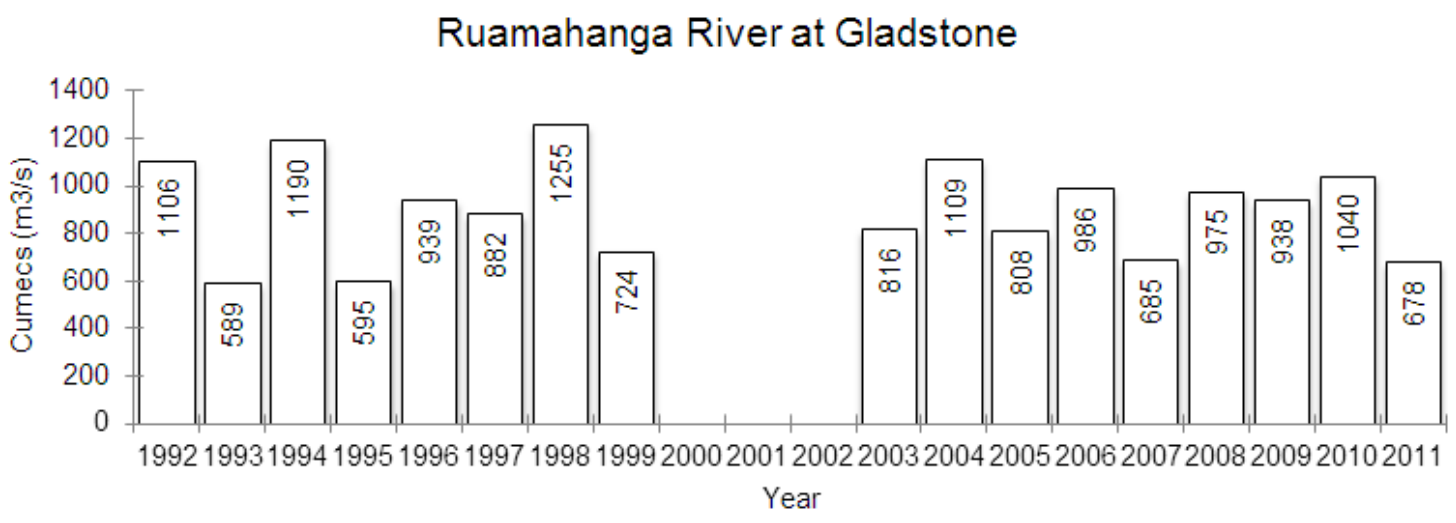

Fig. 4.8 Ruamahanga River maximum flood discharge at Gladstone Bridge. The site was removed in 2000 and reinstated from 2002. Source: Gordon (2013).

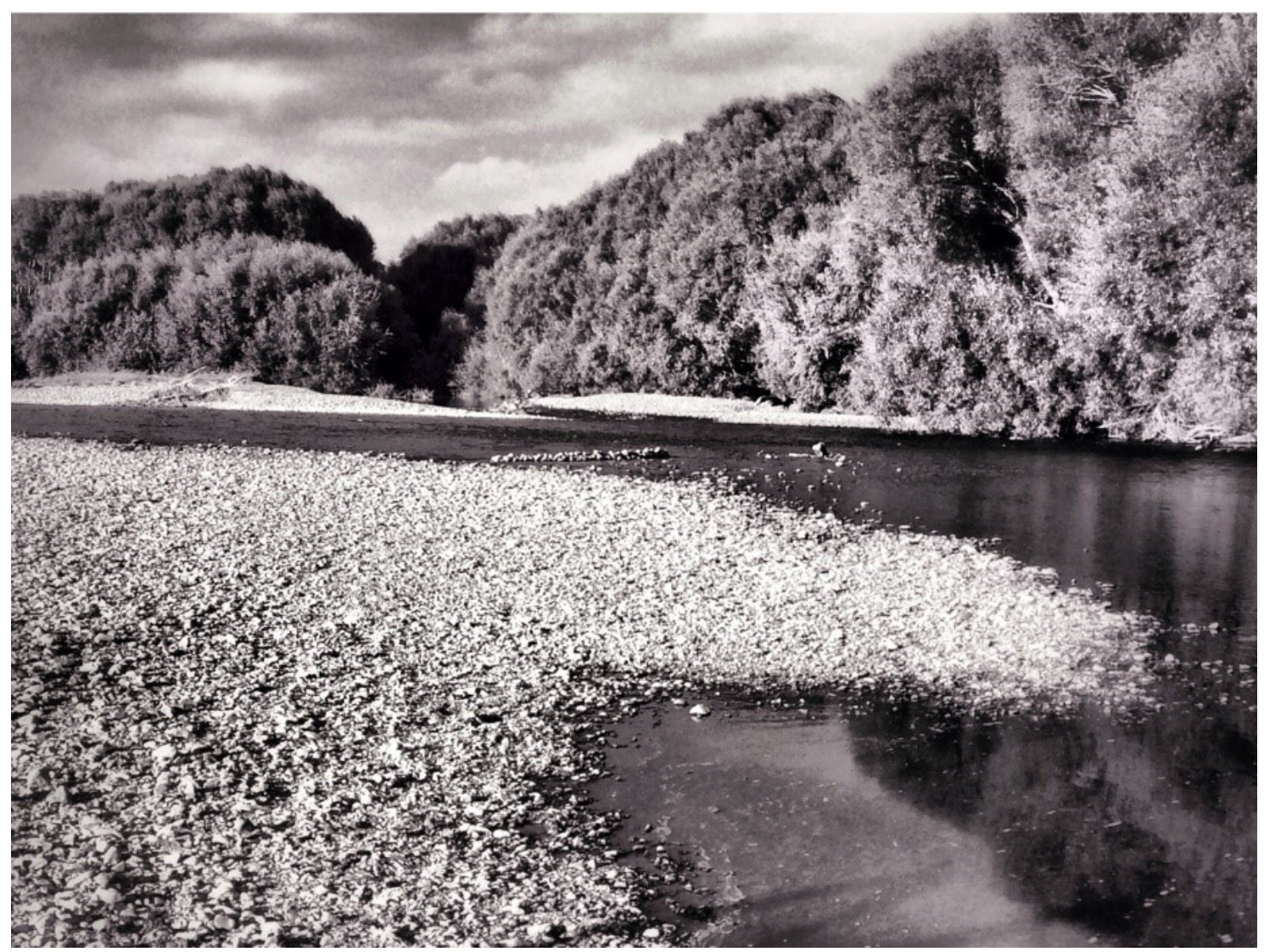

Fig. 4.9 Ruamahanga River upstream from Gladstone Bridge.

\subsubsection{Waingawa River}

The Waingawa River forms the northern boundary of the Middle Valley catchment (Fig. 4.3). The river flows from the Tararua Range for a distance of 36 kilometres where it joins the Ruamahanga River on the eastern side of the valley. The river has a catchment area of $146 \mathrm{~km}^{2}, 81.5 \%$ of it located in the Tararua Ranges. 
The mean annual flow is roughly 10 cumecs with significant monthly and seasonal variation (Table 4.2). The Waingawa River is a significant source of coarse sediment from the Tararua Ranges. The river flows down a steep gradient which permits the fast movement of gravels, which is evident in the wide semi-braided sections of the channel. Faults cutting under the river have had a significant impact on the river channel's evolutionary migration and evidence suggests that the river may have once joined the Waipoua River after flowing through the Masterton area (Gyopari and McAllister, 2010a).

\subsubsection{Waiohine River}

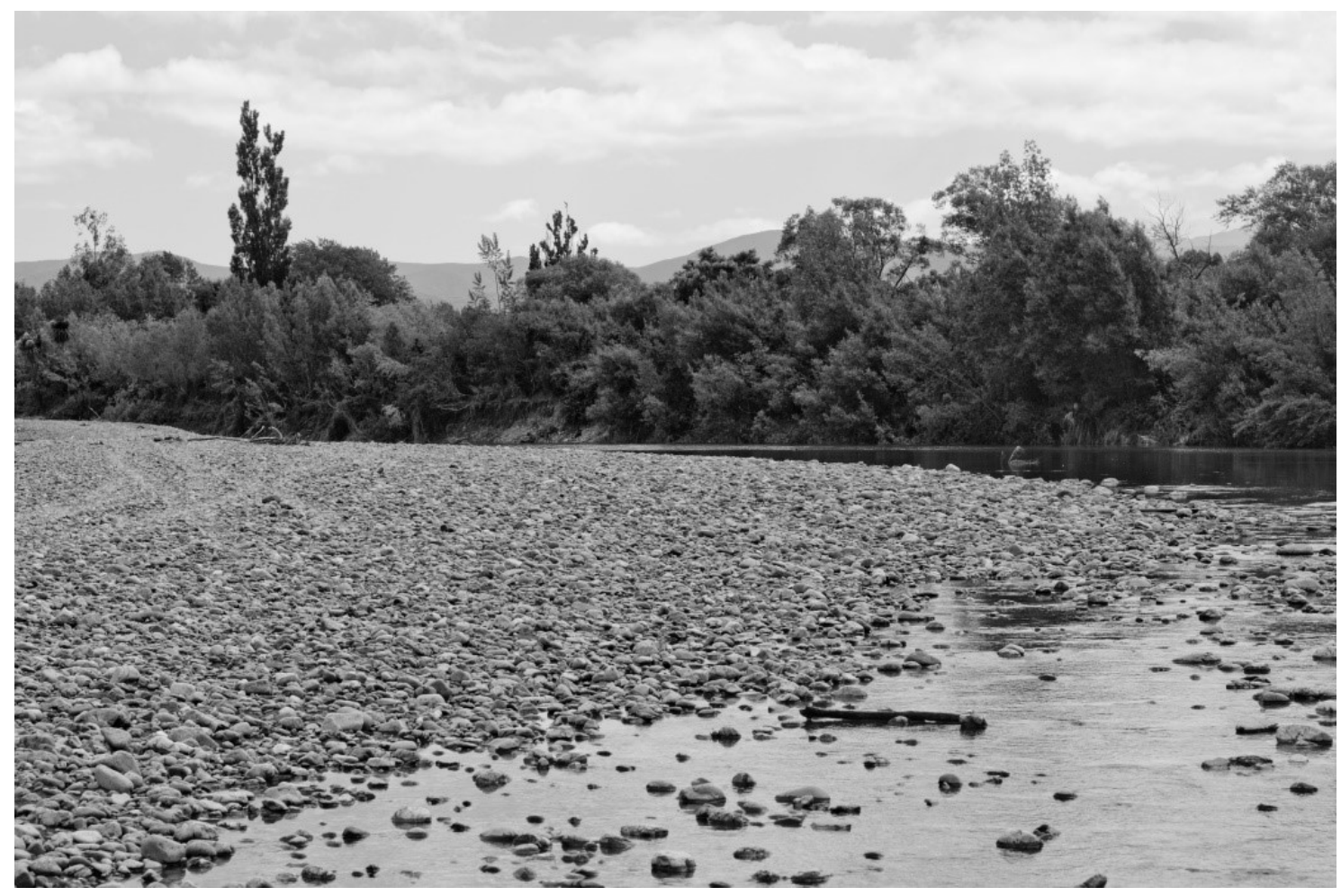

Fig. 4.10 Waiohine River at the State Highway Two Bridge.

The Waiohine River also drains out from the Tararua Ranges and has a $379 \mathrm{~km}^{2}$ catchment area (Fig. 4.3). Flowing from steep mountainous headwaters near the Tararua drainage divide, the river emerges from the foothills at the Waiohine Gorge where it flows $14 \mathrm{~km}$ down an easterly path to join with the smaller Mangatarere Stream. After this point the Waiohine River travels southeast and merges with the Ruamahanga River in the south of the Middle Valley catchment. 
The Waiohine River differs from the Waingawa River as it is not significantly braided and has a dominant single meandering channel due to the lesser grade of the river length, making it unable to transport larger and more numerous amounts of gravels from its elevated headwaters (Fig. 4.5 and Fig. 4.10).

\subsubsection{Mangatarere Stream}

The Mangatarere Stream is a small gravel bed single channel with a catchment of 90 $\mathrm{km}^{2}$ (Fig. 4.3). The stream cuts through the inner western section of the Middle Valley and is the main tributary of the larger Waiohine River. With $62 \%$ of its catchment in the Tararua Ranges the stream can swell significantly, relative to its small channel, in large rainfall events. Its mean annual flow is $1.8 \mathrm{~m}^{3} / \mathrm{s}$ (Table 4.2 ).

\subsection{Climate}

Weather patterns that occur periodically across the Pacific Ocean significantly increase the chance of a drought. El Niño and La Niña are the two most common weather patterns and are both characterized by variable levels of winds and rainfall in different parts of New Zealand. Both La Niña and El Niño can initiate low seasonal rainfall in the Wairarapa but overall El Niño has a greater effect due to the positive feedback of westerly conditions. In the Wairarapa an El Niño event generally increases the possibility of low summer rainfall; whereas, if a La Niña event occurs, the possibility of low autumn rainfall increases (Harkness, 2000). Most of the severe droughts of the last few decades in the Wairarapa (e.g. 1977/78 and 2002/03) occurred during El Niño episodes; although during La Niña and the positive phase of the Southern Annular Mode, there have been several recent droughts (e.g. 2000/01 and 2007/08) (Gyopari and McAllister, 2010a).

The Southern Annular Model (SAM) is a climatic phenomenon present in the South Pole with a variable tendency to extend over New Zealand (Kidston et al, 2009). Wind and storm frequency and intensity change in the middle $\left(40^{\circ}-50^{\circ} \mathrm{S}\right)$ and high $\left(50^{\circ}-70^{\circ}\right.$ S) latitudes depending on the positive or negative phases: 
1. Positive SAM: light winds and relatively calm weather over New Zealand latitudes and stronger westerly winds and storm activity in the southern oceans;

2. Negative SAM: westerly winds increase with more intense stormy weather throughout New Zealand and calmer weather predominates in the southern oceans.

The Southern Annular Mode can be associated with La Niña and may have contributed to the extended drought over 1997/98 (Table 4.3).

\subsubsection{Droughts}

The Wairarapa is prone to prolonged dry climatic conditions causing droughts and low flows in water channels. Meteorologically, floods are caused by shorter weather events (e.g. storms), whereas droughts are a result of a prevailing dry climate (e.g. months of dry warm weather). Droughts typically occur over the summer months with extreme low flows recorded during these extended dry periods (Harding et al, 2004). Droughts are defined and classified due to a combination of their cultural and economic effects (e.g. agricultural, horticultural, ecological, and drinking water supply) and/or their hydrological effects (e.g. groundwater, river flow, rainfall, and soil moisture rates). Low flows often occur over a large area (regional and/or national) as part of a drought, through minimal rainfall over a sustained period (Fig. 4.7 and Fig. 4.8) (Pearson and Henderson, 2004). During El Niño, drought is more pronounced in the Wairarapa than the Kapiti Coast or the Hutt Valley, while during La Niña's regions west of the Tararua Ranges can experience extended periods of drought (Tait et al, 2002). 
Table 4.3 Drought history in the Wairarapa 1992-2008.

\begin{tabular}{|c|c|}
\hline Year & Details \\
\hline 1992 & $\begin{array}{l}\text { Severe droughts affected the entire country in the winter months (Pearson, } \\
\text { 1992). }\end{array}$ \\
\hline $1997-98$ & $\begin{array}{l}68 \text { days with severe soil moisture deficit at Masterton, } 74 \text { days at East } \\
\text { Taratahi. (Tait et al, 2002). Water levels are low with some dams only half } \\
\text { full, compared to wet/overflowing condition at this time in past years } \\
\text { (TWTDRC, 2008). }\end{array}$ \\
\hline $2000 / 01$ & $\begin{array}{l}\text { Prolonged dry period during the } 2001 \text { summer (Knowles et al, 2003). } 23 \\
\text { days with severe soil moisture deficit at Masterton, } 12 \text { days at East Taratah } \\
\text { (Tait et al, 2002). }\end{array}$ \\
\hline $2002 / 03$ & $\begin{array}{l}\text { Many regions across New Zealand (including the Wairarapa) were affected } \\
\text { by a prolonged drought during the summer of 2002-2003 (Gyopari and } \\
\text { McAllister, 2010a; Pearson and Henderson, 2004). }\end{array}$ \\
\hline $2007 / 08$ & $\begin{array}{l}\text { Minimal rain for a three month period (Black, 2007). Affecting most of the } \\
\text { North Islands East Coast regions (Gyopari and McAllister, 2010a). }\end{array}$ \\
\hline
\end{tabular}

\subsubsection{Floods}

Flooding is a common occurrence across the Wairarapa (Greater Wellington Regional Council, 2007) (Table 4.4). Floods usually occur over a small spatial scale, compared to droughts, in response to single or multiple heavy rainfall events in neighbouring catchments (Pearson and Henderson, 2004). Due to the valley's long gradient from the northern foothills to the sea, and large steep bounding ranges, floods have caused widespread landslips, erosion, stock losses, as well as residential and infrastructure damage. The Ruamahanga River is prone to large flood events and the large-scale modification of the river was partially due to the flood risk. Approximately $300 \mathrm{~mm}$ of rain fell in the Tararua Ranges in October 1998; the Ruamahanga River swelled to a 50 year record near Masterton, and 4.4 metres was recorded at the Martinborough Bridge (Greater Wellington Regional Council, 2007). On the $10^{\text {th }}$ of October 2000 $300 \mathrm{~mm}$ of rain was recorded in the Tararua Ranges over 24 hours causing many landslides and closing many roads, including State Highway Two. The flooding cost the region an estimated 1.1 million dollars with widespread damage to homes, roads, bridges, and widespread stock losses. Severe flooding occurred in February 2004, at Angle Knob in the Tararua Ranges $394.5 \mathrm{~mm}$ of rain was recorded in 24 hours causing the Ruamahanga, Waipoua and most other channels to swell. 
Table 4.4 Flood history in the Upper and Middle Valley catchments from 1991-2007.

\begin{tabular}{|c|c|c|c|}
\hline Date & River & Flow & Information \\
\hline 1991 & $\begin{array}{l}\text { Whangaehu } \\
\text { River }\end{array}$ & $80 \mathrm{~m}^{3} / \mathrm{s}$ & $\begin{array}{l}\text { Wairarapa Engineering Lifelines Association, } \\
\text { (2003); Watts, (2005). }\end{array}$ \\
\hline 1992 & Taueru River & $488 \mathrm{~m}^{3} / \mathrm{s}$ & $\begin{array}{l}\text { Wairarapa Engineering Lifelines Association, } \\
\text { (2003); Watts, (2005). }\end{array}$ \\
\hline $\begin{array}{l}\text { 7-9 March } \\
1994\end{array}$ & $\begin{array}{l}\text { Ruamahanga } \\
\text { River }\end{array}$ & $1800 \mathrm{~m}^{3} / \mathrm{s}$ & Greater Wellington Regional Council, (2007). \\
\hline 1994 & Waipoua River & $326 \mathrm{~m}^{3} / \mathrm{s}$ & $\begin{array}{l}\text { Wairarapa Engineering Lifelines Association, } \\
\text { (2003); Watts, (2005). }\end{array}$ \\
\hline 1998 & $\begin{array}{l}\text { Kopuaranga } \\
\text { River }\end{array}$ & $56 \mathrm{~m}^{3} / \mathrm{s}$ & $\begin{array}{l}\text { Wairarapa Engineering Lifelines Association, } \\
\text { (2003); Watts, (2005). }\end{array}$ \\
\hline $\begin{array}{c}\text { October } \\
1998\end{array}$ & $\begin{array}{l}\text { Ruamahanga } \\
\text { River at } \\
\text { Wardells }\end{array}$ & $1500 \mathrm{~m}^{3} / \mathrm{s}$ & $\begin{array}{l}\text { Large volumes of rain falling in the Tararua Ranges } \\
\text { led to rising rivers on the western side of the } \\
\text { catchment. The Ruamahanga River peaked at } 4.4 \\
\text { m at the Martinborough Bridge (Greater } \\
\text { Wellington Regional Council, 2007). }\end{array}$ \\
\hline 2000 & $\begin{array}{l}\text { Ruamahanga } \\
\text { River at } \\
\text { Wardells }\end{array}$ & $814 \mathrm{~m}^{3} / \mathrm{s}$ & $\begin{array}{l}\text { Wairarapa Engineering Lifelines Association, } \\
\text { (2003); Watts, (2005). }\end{array}$ \\
\hline $\begin{array}{l}\text { October } \\
2000\end{array}$ & $\begin{array}{l}\text { Ruamahanga } \\
\text { River }\end{array}$ & $1500 \mathrm{~m}^{3} / \mathrm{s}$ & $\begin{array}{l}\text { Similar volumes of rain fell as in Oct 1998, resulting } \\
\text { in record river flows in most of the rivers, } \\
\text { damaging infrastructure and causing stock losses } \\
\text { Greater Wellington Regional Council, (2007). }\end{array}$ \\
\hline 2004 & Taueru River & $465 \mathrm{~m}^{3} / \mathrm{s}$ & Watts, (2005). \\
\hline 2004 & Waipoua River & $425 \mathrm{~m}^{3} / \mathrm{s}$ & Watts, (2005). \\
\hline 2004 & Waingawa River & $317 \mathrm{~m}^{3} / \mathrm{s}$ & Watts, (2005). \\
\hline $\begin{array}{l}12 \\
\text { February } \\
2004\end{array}$ & $\begin{array}{l}\text { Waiohine River } \\
\text { at Gorge }\end{array}$ & $1362 \mathrm{~m}^{3} / \mathrm{s}$ & $\begin{array}{l}\text { Northern Wairarapa Tararua fed rivers (Watts, } \\
\text { 2005). }\end{array}$ \\
\hline $\begin{array}{l}15-16 \\
\text { February } \\
2004\end{array}$ & $\begin{array}{l}\text { Ruamahanga at } \\
\text { Waihenga }\end{array}$ & $1950 \mathrm{~m}^{3} / \mathrm{s}$ & $\begin{array}{c}\text { Significant flows in many of the Rivers including the } \\
\text { Ruamahanga, Kopuaranga and Huangarua. Lake } \\
\text { Wairarapa reached } 225 \text { high water levels (Watts, } \\
\text { 2004). }\end{array}$ \\
\hline $\begin{array}{l}\text { March } \\
2005\end{array}$ & $\begin{array}{l}\text { Ruamahanga at } \\
\text { Waihenga }\end{array}$ & $1530 \mathrm{~m}^{3} / \mathrm{s}$ & $\begin{array}{l}\text { Significant rainfall in the } \\
\text { central Wairarapa Valley (Watts and } \\
\text { Gordon, 2006). }\end{array}$ \\
\hline $\begin{array}{l}\text { 4-7 July } \\
2006\end{array}$ & $\begin{array}{l}\text { Ruamahanga } \\
\text { River at } \\
\text { Waihenga }\end{array}$ & $1501 \mathrm{~m}^{3} / \mathrm{s}$ & $\begin{array}{l}\text { This flood event was characterised by large } \\
\text { volumes of water: surface flooding, and record- } \\
\text { high volumes of water passing through the } \\
\text { Wairarapa floodways' into Lake Wairarapa (Watts } \\
\text { and Gordon, 2006). }\end{array}$ \\
\hline
\end{tabular}




\subsection{Hydrogeology}

The groundwater system in the Wairarapa Valley has been studied over the past four decades (O'Dea et al, 1980; Gunn et al, 1987; Annear et al, 1989; Butcher, 1996a, 1996b, 1996c; Jones and Baker; 2005). Annual monitoring reports have been produced on important groundwater subzones including the Te Ore Ore and Parkvale subzones (Butcher: 1996a, 1996b, 1996c, 1997, 2000, 2001a, 2001b, 2001c, 2004; Jones and Baker, 2005; McAlister and Tidswell 2007). The hydrogeology of the area is defined by a depositional history from glacial, alluvial and marine cycles. The overall thickness is relatively thin with approximate aquifer depths averaging around 30 metres and a maximum depth of 100 metres (Cape et al, 1990; Morgan and Hughes, 2001). The depth to the basement greywacke under the valley could be up to three kilometres in places (Hicks and Woodward, 1978). The Wairarapa basin is an unconsolidated sequence of greywacke sand and gravel sediments eroded from the Tararua Range with significantly thick fine-grained sediment layers, or aquitards, composed mainly of clay. Aquifer transmissivities are reasonably high due to the sand and gravel composition. Material has been deposited by the south-east flowing rivers including the Ruamahanga and Waingawa Rivers and their alluvial fans which, in the western part of the valley, tend to have low transmissivities. Many of the Wairarapa's aquifers are heterogeneous with thin bands of significantly higher hydraulic conductivity (Begg et al, 2005; Morgan and Hughes, 2001). Deep groundwater resources do exist in the Wairarapa, however these tend to yield smaller amounts of water, due to thick low permeability aquitard sequences at greater depths. Primary aquifers are shallow with relatively high hydraulic conductivity which exhibit connections to surface channels (Guggenmos, 2010; Morgenstern, 2005).

Management of the groundwater resources has led to the establishment of allocation zones throughout the valley. Greater Wellington Regional Council's 1999 Freshwater Plan designated several groundwater zones across the Middle Valley (Fig. 4.11). In 2005 the Middle Valley groundwater resource investigation was initiated including a review of the geology (Begg et al, 2005; Jones and Gyopari, 2006). The conceptual hydrogeological model focused on the hydrostratigraphy of the valley and geological structure which incorporates the reservoirs' layering processes and groundwater flow. 
Three areas (Upper, Middle and Lower) were designated from the conceptual study. A more comprehensive Phase 2 was initiated to construct three numerical models for the valley simulating the groundwater movement. This involved extensive field investigations including (1) stratigraphic drilling and bores for groundwater monitoring; (2) water metre surveys, (3) hydrochemical sampling and analysis; (4) low flow river concurrent gauging; (5) spring surveys; (6) piezometric surveys, (7) installation of low flow stream gauges, (8) wetland level monitoring, (9) differential GPS surveying, and (10) seismic reflection surveying. A three-dimensional model was constructed using all the available stratigraphic information.

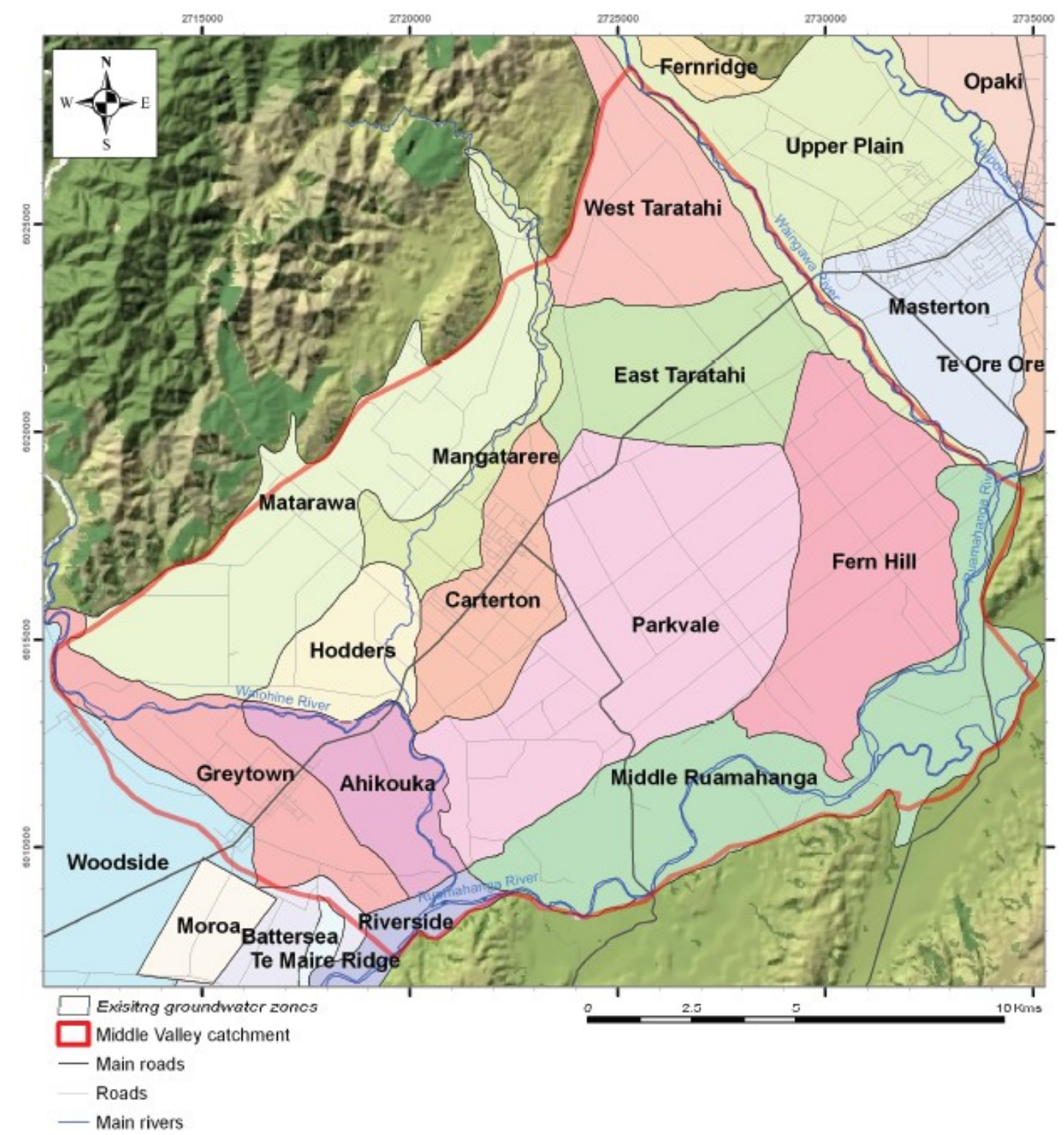

Fig. 4.11 Groundwater zones from Greater Wellington Regional Council's 1999 Freshwater Plan, some zones cross between the Lower and Upper Valley catchments. Source: Gyopari and McAllister (2010). 


\subsubsection{Surface and groundwater interactions}

River channel beds exhibit water exchange with shallow aquifers throughout the valley (Begg et al, 2005; Guggenmos et al, 2011; Gyopari and McAllister, 2010a). Unconfined aquifers are present at the water table over much of the Middle Valley and exist in former river gravel strata. Groundwater in the unconfined systems is derived from local rainfall recharge infiltration and losing river sections with hydraulically conductive connections to the shallow aquifers. Zones in close proximity to the main water channels (e.g. Ruamahanga in the Eastern Middle Valley) are former river braids with highly conductive gravels (Fig. 4.12). These unconfined aquifers provide a means for water to infiltrate between the unconfined and confined aquifers of the groundwater system, allowing recharge into the deeper aquifer layers, as well as flow discharge to the surface water systems.

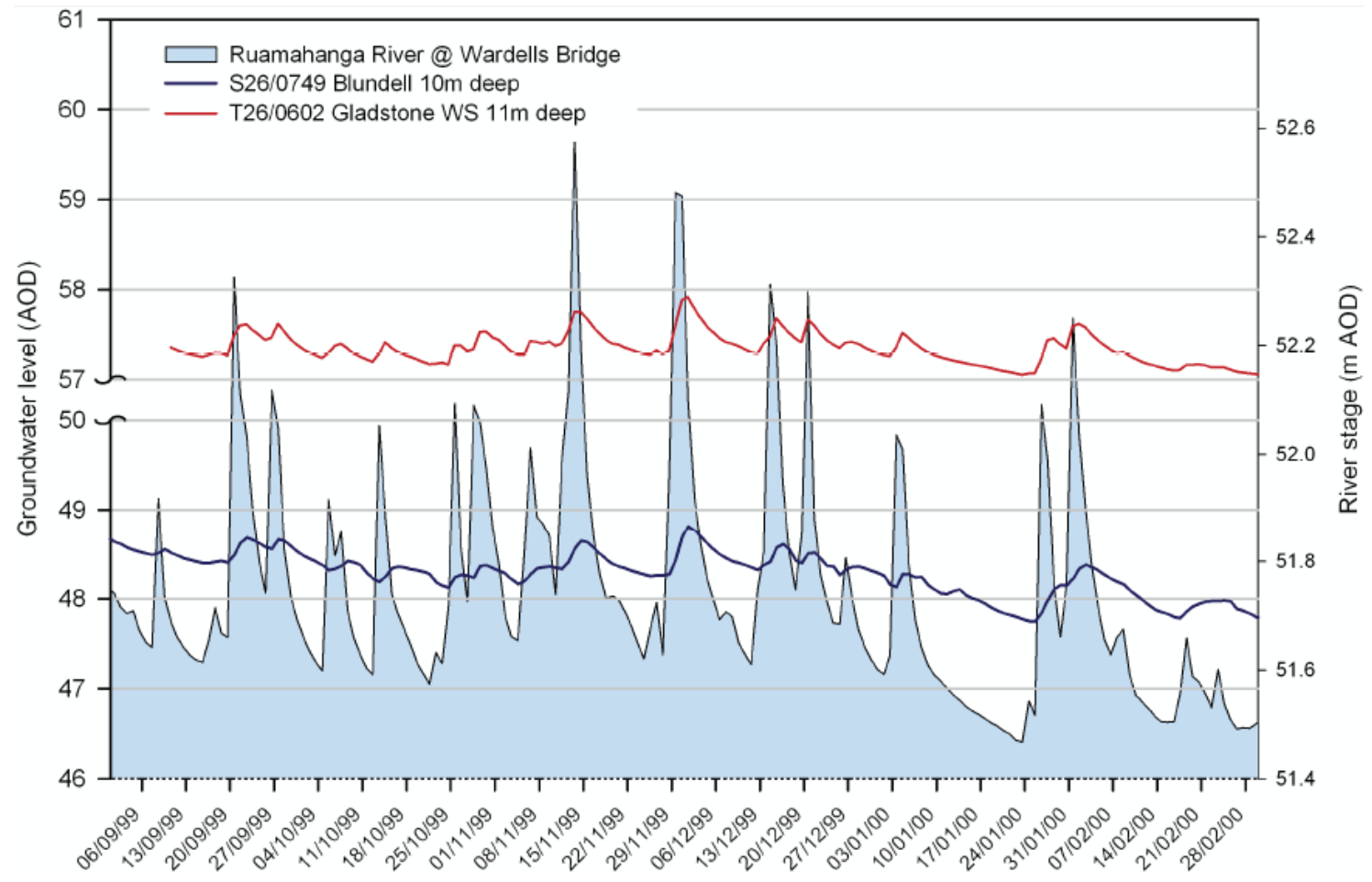

Fig. 4.12 Groundwater level and river stage data taken in close proximity. Groundwater level at shallow groundwater monitoring sites on the Ruamahanga River floodplain and stage in the Ruamahanga River (measured and the Wardell's Bridge recorder site). Source: Gyopari and McAllister (2010).

Further interactions between surface and groundwater were investigated by Guggenmos et al (2011). This study identified groundwater-surface water interaction over a large area using existing hydrochemical datasets, adding to existing knowledge 
of the region, and helping with future studies quantifying the quality and quantity of surface water and groundwater (Guggenmos, 2010). Hierarchal cluster analysis and hydrochemical medians from the entire Wairarapa Valley were utilized, linking and separating, groundwater and surface water bodies (Fig. 4.13). Seven hydrochemical clusters were identified from both surface water and groundwater monitoring site information. These interactions are important for regional scale modelling, estimating potential flux boundaries within the model domain, in an attempt to appropriately represent the field setting in the Wairarapa.

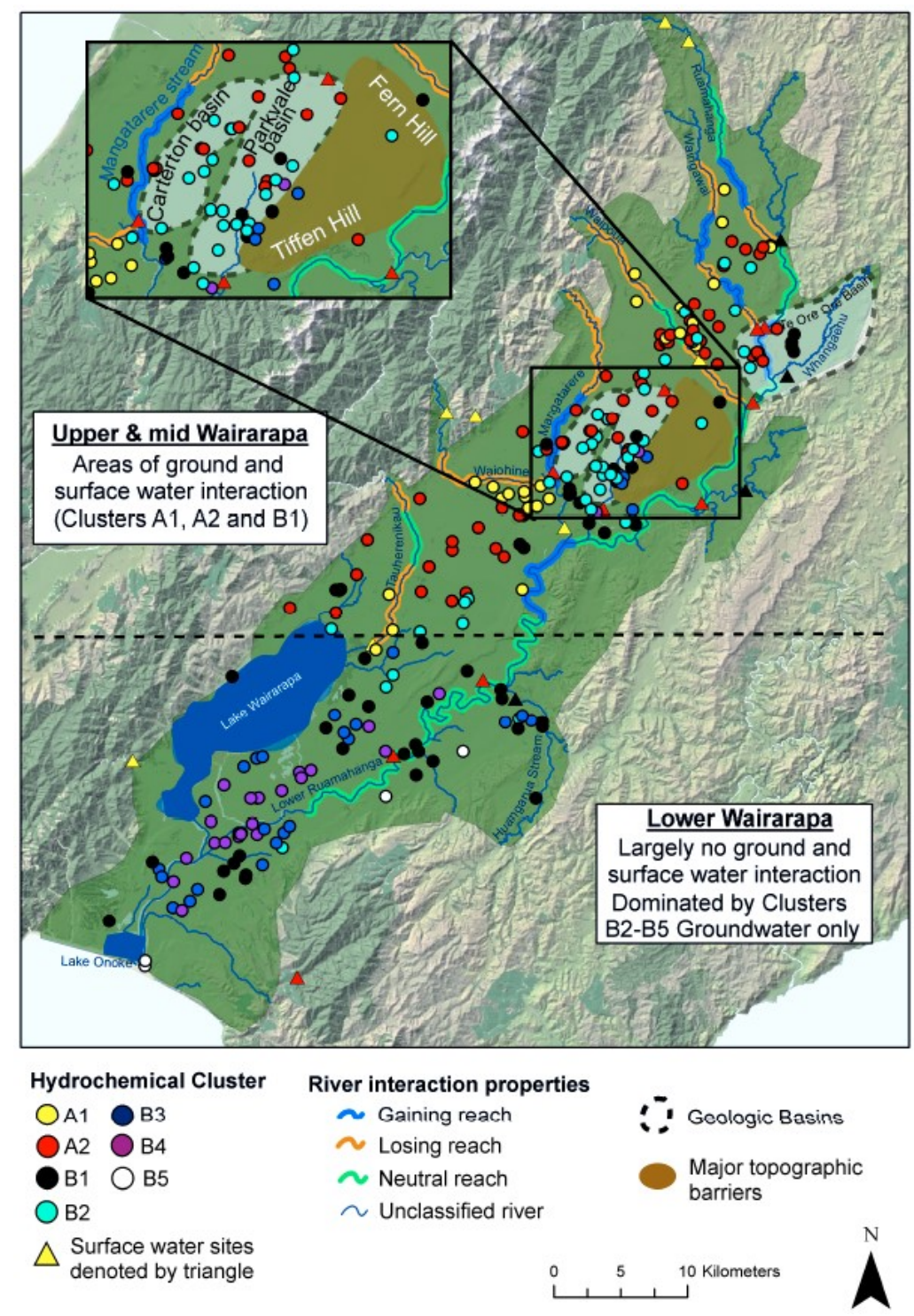

Fig. 4.13 Surface water and groundwater monitoring sites assigned to the seven hydrochemical clusters in the Wairarapa Valley. Source: Guggenmos et al, (2011). 
Surface water systems which exhibit interactions with groundwater aquifers are the Ruamahanga, Waiohine and Waingawa rivers, the Mangatarere stream, spring systems (Parkvale, Papawai-Tilsons, Beef Creek/Enaki, and fault line springs), and water races which may receive from and discharge to the valley aquifers.

\subsubsection{Springs}

A spring is a place where groundwater naturally discharges up to the ground surface due to artesian pressure. At any spring, the water table is present at the ground surface, forming a visible water resource. They are often located at foothills near the slope of a bounding range, and/or where a fault or the base of an aquifer intersects the slope (Fitts, 2002). Springs discharge groundwater to the surface throughout the Middle Valley (Fig. 4.14). This form of groundwater discharge can provide a significant proportion of the baseflow to wetlands, streams, and river channels.

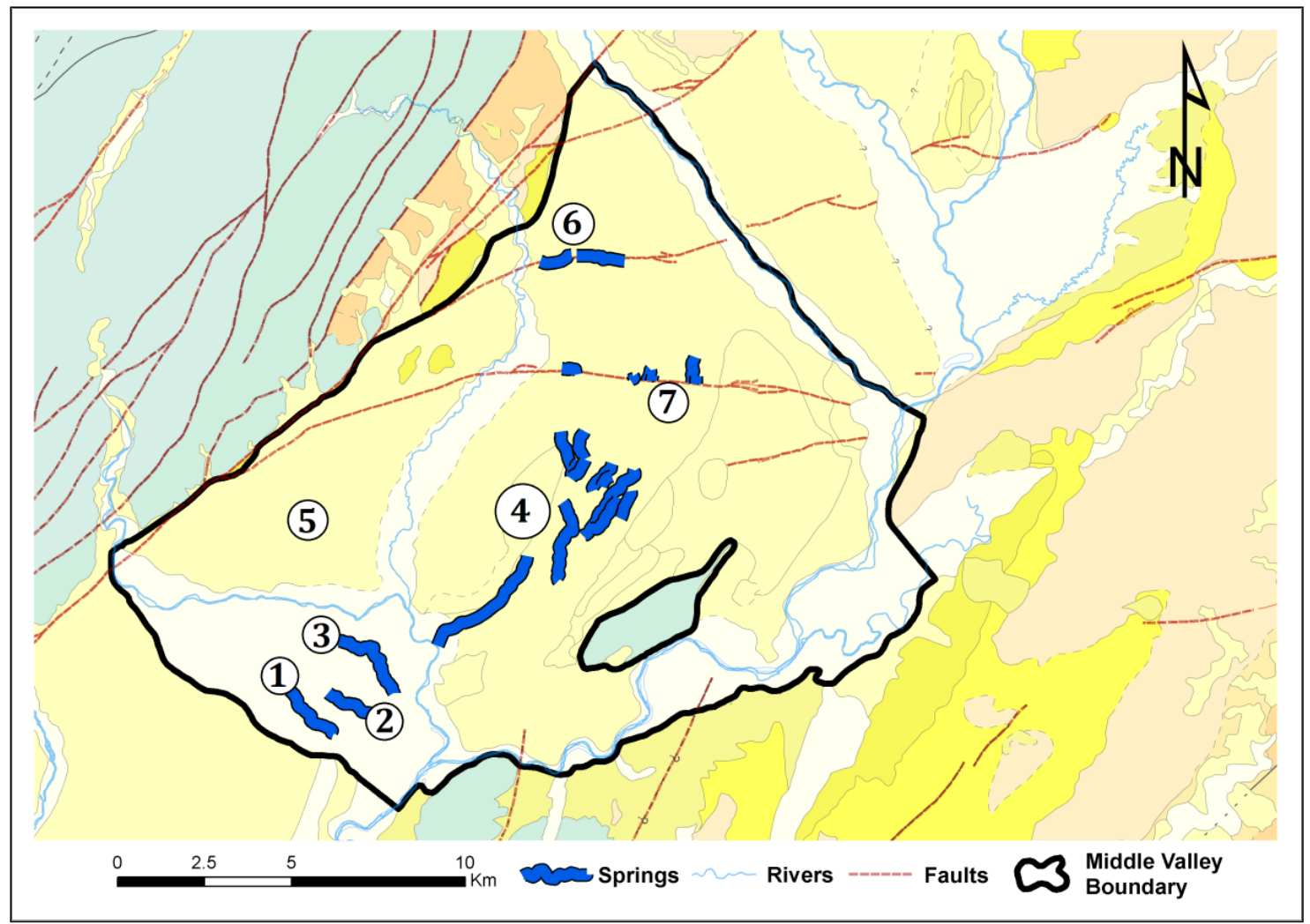

Fig. 4.14 Spring distribution in the Middle Valley. 1) Papawai, 2) Tilsons, 3) Muhunoa, 4) Parkvale, 5) Beef Creek, 6) Masterton Fault, and 7) Carterton Fault springs. Shown with the location of rivers, faults; for stratigraphy legend see Fig. 4.6. 
There are several main springs including the Greytown (Papapwai, Tilsons, and Muhunoa), Parkvale, Beef Creek, and the Masterton and Carterton fault springs. The roughly parallel Papapwai, Tilsons, and Muhunoa spring systems discharge comes from the shallow aquifers of the Greytown/Waiohine plain. The combined mean annual discharge is estimated at $1.42 \mathrm{~m}^{3} / \mathrm{s}$ for these three systems, with the springs flowing towards the southeast, into the Waiohine (Muhunoa) and Ruamahanga Rivers (Tilsons and Papawai) (Table 4.5). Groundwater discharge in the Parkvale area occurs along drainage systems from the Tararua Ranges rather than as discrete spring points. The mean flow for the entire Parkvale spring system has been estimated to be about 150 L/s (Butcher, 2007a). The Beef Creek system exhibits widespread, diffuse spring discharges along the base of the Tararua Ranges (Waiohine-Mangatarere fan system) to the west of Carterton. This system is base-fed by aquifers and discharges in its lower reaches into the Mangatarere Stream. Flow in Beef Creek at State Highway Two was measured at $60 \mathrm{~L} / \mathrm{s}$ and 1,880 L/s for March and August 2008 respectively (Keenan, 2009). Another gauging at State Highway Two in February 2005 indicated a flow of 97 L/s. Under winter conditions Beef Creek gains significantly by over $1 \mathrm{~m}^{3} / \mathrm{s}$ (Butcher, 2007a). The Masterton and Carterton springs occur due to faults and their associated movement creating flow barriers with the exception of the springs along the fault traces. The Carterton system is estimated to discharge around twice that of the Masterton system, however spring discharge quantification is challenging due to connections between water races and wetlands (Gyopari and McAllister, 2010a).

Table 4.5 Estimated spring flows in the Middle Valley catchment. The Masterton and Carterton estimates were calculated from limited data. Source: Butcher (2007a) and Keenan (2009).

\begin{tabular}{ccc}
\hline Spring system & Mean annual flow (L/s) & Mean annual low flow (L/s) \\
\hline Papawai Stream & 380 & 200 \\
\hline Tilsons Creek & 235 & 140 \\
Muhunoa Stream & 800 & 550 \\
Masterton Fault Springs & 120 & 30 \\
Carterton Fault Springs & 230 & 110 \\
\hline Parkvale Springs & 150 & 70 \\
Beef Creek & 1,900 & 60 \\
\hline
\end{tabular}




\subsubsection{Groundwater abstraction}

Groundwater abstractions in the Middle Valley have increased significantly over the past two decades, and have doubled over the past 12 years mainly due to increases in dairy production (Gyopari and McAllister, 2010a). Over the past 15 years groundwater abstraction rates have significantly increased in the Wairarapa, from 48 million $\mathrm{m}^{3}$ per year in 1999, to 270.3 million $\mathrm{m}^{3}$ per year in 2010 (Greater Wellington Regional Council, 2012; Morgan and Hughes, 2001). The most heavily abstracted zones in the Middle Valley are Parkvale, Greytown, Carterton, and Middle Ruamahanga (see Fig. 4.11). When the Greater Wellington numerical model investigation began in 2007, there were 126 bores in the Middle Valley with a maximum combined consented abstraction of $155,000 \mathrm{~m}^{3} /$ day $\left(56,612,510 \mathrm{~m}^{3} /\right.$ year $)$. The majority of the high yielding bores are in the Q1 unconfined aquifers and hence excessive abstraction can affect river flows due to the hydraulic connections.

\subsubsection{Tracers and hydrochemistry}

Morgenstern (2005) produced a comprehensive report using water dating and chemistry time trend analysis. Analysis of the hydrochemistry indicated that shallow groundwater contained mostly young aerobic waters (approximately 2 years mean residence time) in the Upper Valley, intermediate mean residence times (approximately 40 years mean residence time) in the Middle Valley, and old (greater than 100 years mean residence time) groundwater in the deep wells sampled throughout and primarily in the central Lower Valley. Only nitrate, sulphate, and possibly lead show anthropogenic influence on groundwater quality (Morgenstern, 2005). The Middle Valley was sampled and tested for tritium at seven locations in 2005 (Fig. 4.15).

Morgenstern (2005) grouped groundwater into three recharge source distinctions: (1) river recharge, (2) rain recharge, and (3) a combination of (1) and (2). In the Middle Valley, analysis of deuterium and oxygen-18 revealed river derived groundwater between the Waiohine River and Waingawa River to the west of Masterton, as well as the Ruamahanga River supplying a significant amount of groundwater recharge. 
In the Upper Valley, oxygen-18, nitrate, and excess air indicated the recharge source of groundwater came from a combination of river and rainfall recharge.
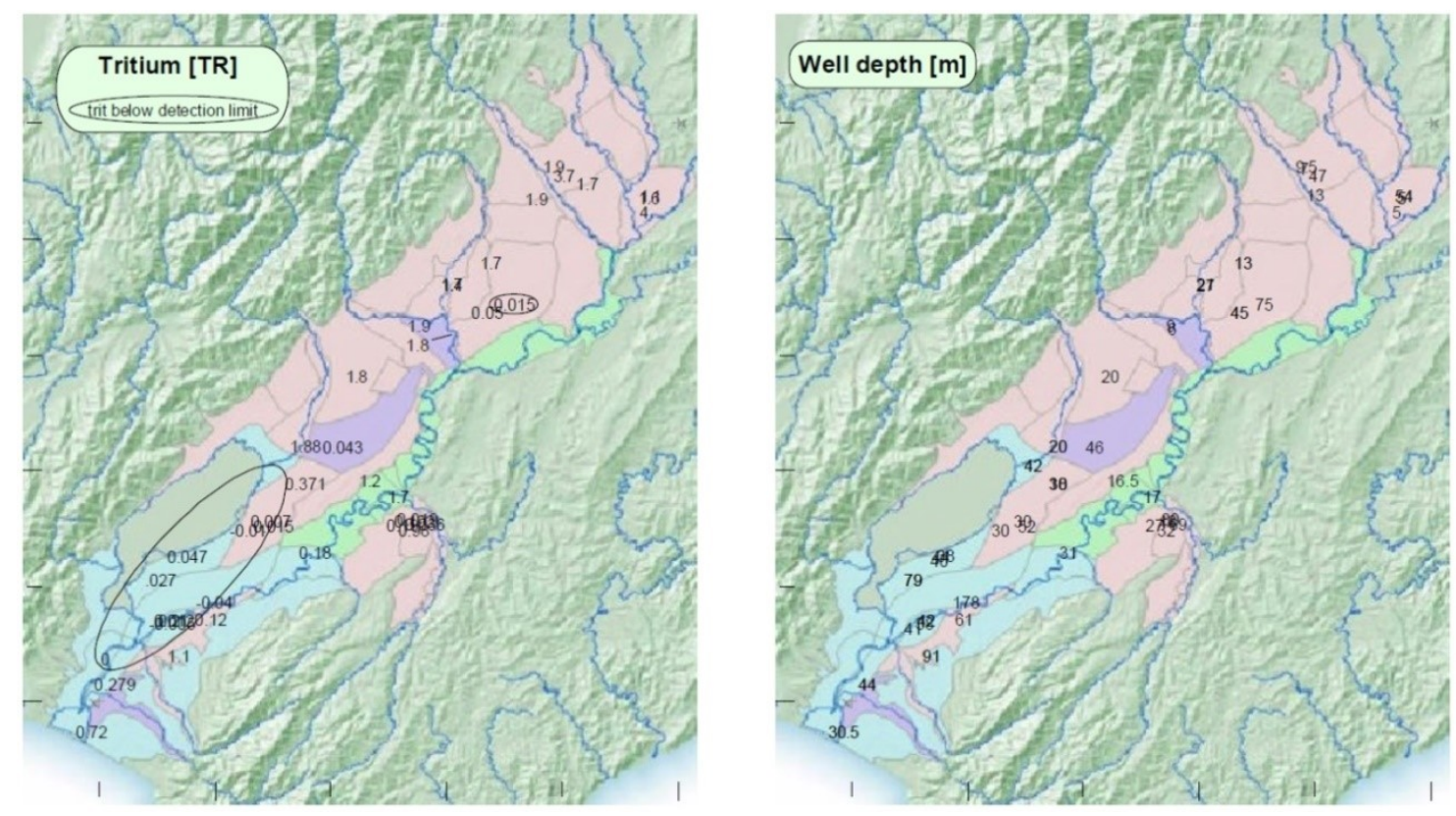

Fig. 4.15 Left: Geographic distribution of tritium concentration shown in tritium units (TU). Eight measurements are taken in the Middle Valley. Right: Sampled well depth. Source: Morgenstern (2005).

Water dating, utilizing hydrochemistry and stable isotopes, provides information on the groundwater system in the Wairarapa. Water dating indicated relatively young (two year old) water in the Upper and Middle Valleys. In the Upper Wairarapa Valley all the groundwater analysed for tritium is relatively young apart from a sample from a 45 metre deep well (Wellington Regional Council well number 4H/1/45) near Carterton (Begg et al, 2005; Morgenstern, 2005). Hydrochemistry trends show consistent increases with groundwater age, which is expected, and can provide information on the groundwater flow path and temporal evolution. The hydrochemistry and groundwater residence time indicate a continuous groundwater system exists throughout the Wairarapa (Morgenstern, 2005). The tracer analysis also indicated significant mixing and potential contamination risks. Several water samples contained unambiguous old tritium ages, with the same sample containing high concentrations of $\mathrm{CFC}$ and $\mathrm{SF}_{6}$. This indicates mixing within the system as the tritium samples indicated relatively old water which should theoretically not contain the high concentrations of chlorofluorocarbons or $\mathrm{SF}_{6}$. 
This could indicate contamination risk (mixing), or potential gas exchange processes in the variably saturated zone and/or unconfined aquifers (Morgenstern, 2005).

\subsubsection{Areas of hydraulic complexity}

There are specific geological areas with complex groundwater behaviour. These areas are often formed due to tectonic movement/faulting of the substrate, creating barriers for groundwater flow and the various sub-basins. In the Middle Valley the major flow barriers are Tiffen Hill and Te Marie Ridge, in the mid-west and south of the catchment respectively. The sub-basins are the Carterton and Parkvale zones, both located adjacent to each other in in the middle of the catchment (see Fig. 4.11), and separated by the Brickworks anticline (Fig. 4.16).

\subsubsection{Parkvale sub-basin}

The Parkvale sub-basin is a large area located in the middle, eastern, and southern areas of the Middle Valley (Fig. 4.16). The zone has high allocation rates of groundwater, and new abstraction consents/permits are regularly suspended until new yield assessments are performed to confirm subsurface water sustainability. Pumping has been interpreted as having an effect on the groundwater levels, and acceptable amounts of decline have been proposed to ensure sustainability (Jones and Baker, 2005). Groundwater level variation is a natural process caused by the natural flux of recharge; however, significant abstraction pressures have been attributed to observed groundwater level reductions in the Parkvale zone. It became apparent during the numerical model calibration process that the eastern side of Parkvale subbasin is far more complex structurally than is shown in the cross sections (Gyopari and McAllister, 2010a). A seismic reflection survey was conducted to resolve ambiguities and concluded the zone was significantly faulted creating a complex basement at depth. The younger sequences in the zone were confirmed and validated the conceptual interpretation, however the survey did not provide any useful information on the upper 50 metres of the seismic profile, and hence nothing on the distribution of aquifers in this zone. 


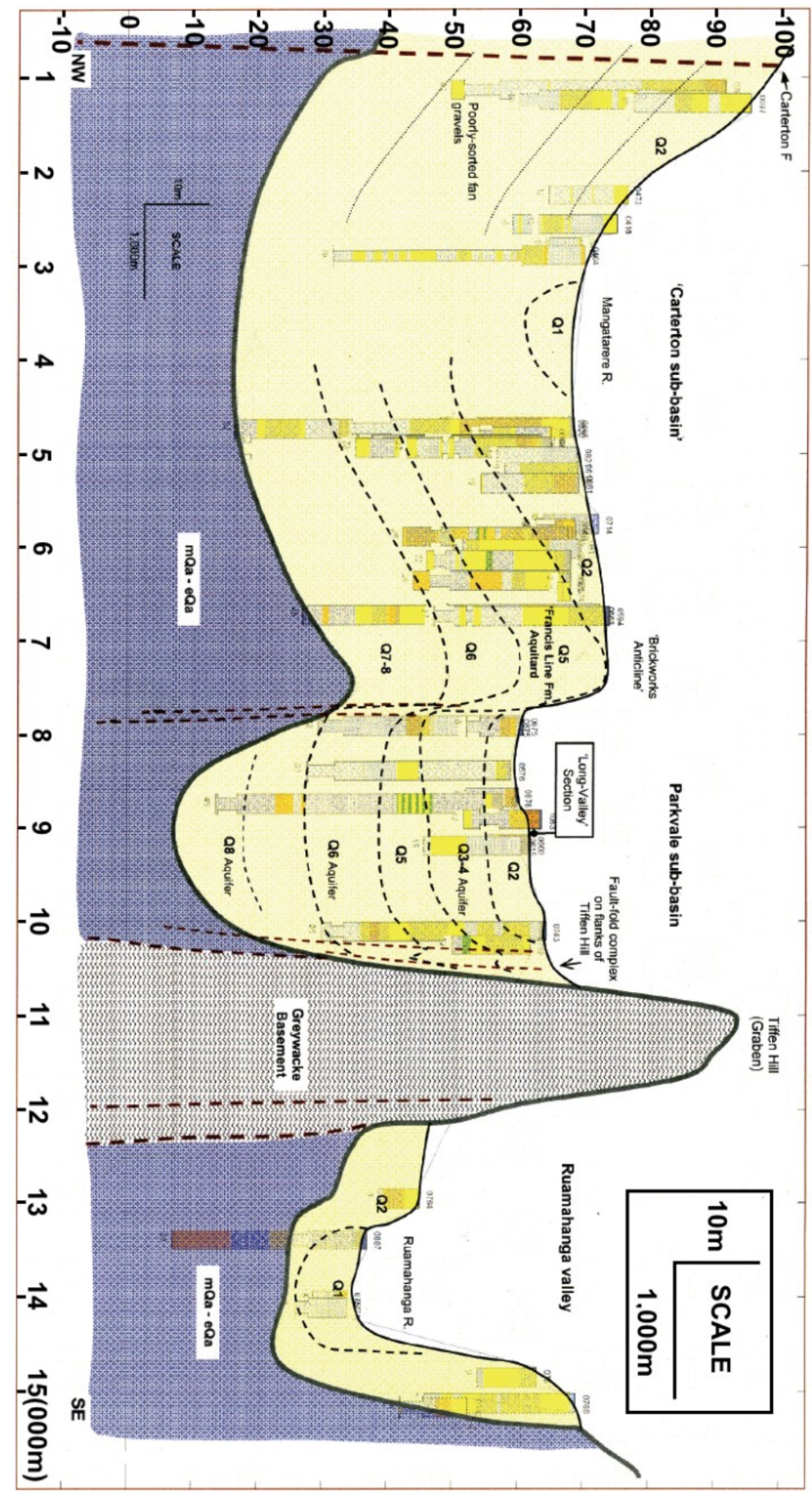

Fig. 4.16 Tiffen Hill geological cross-section. Indicative structure of Carterton, Parkvale, and Ruamahanga valley sub-basins. Source: Gyopari and McAllister (2010). 
The Parkvale sub-basin is strongly affected by pumping (Gyopari and McAllister, 2010a). This human-induced variation also occurs in the Lower valley at Martinborough and Kahutara. Groundwater level fluctuations across the rest of the valley are largely due to natural variations in recharge from rivers and rainfall, making Parkvale a complex zone requiring caution and appropriate management of water resources. In 2006 the deeper confined aquifers (Q6 and Q8) of Parkvale exhibited below average groundwater levels for a sustained period of time. Water quality problems have been identified and show evidence of anthropogenic impacts of elevated nitrate-nitrogen and/or sulphate (Jones and Baker, 2005). The relationship between land use and elevated solute concentrations has been highlighted in recent Greater Wellington Regional Council technical reports (McAlister and Tidswell, 2007). The apparent relationship between land use and elevated solute concentrations (e.g. nitrate) requires confirmation. Assessing these impacts was a priority in the Regional Plan for discharges to land, and highlighted by Jones and Baker (2005). Accurately determining the effect on groundwater required an intensive monitoring network to assess current processes and their effect on the water resources/effectiveness of the current plan.

\subsubsection{Carterton sub-basin}

The Carterton sub-basin is a similar area running parallel to the Parkvale sub-basin and separated from it by the Brickworks anticline (Fig. 4.16). The surface and subsurface layers dip westwards from the anticline towards Carterton and the Mangatarere Stream, which is the lowest and diving point in the basin. Moving further westwards towards the Tararua Ranges the sub-basin is complex and not well-defined, partially due to the Carterton Fault in the north, and it eventually merges with the prograding alluvial fan deposits from the Mangatarere Stream and Waiohine River (Gyopari and McAllister, 2010a).

\subsubsection{Tiffen Hill}

Tiffen hill is an up-faulted block of greywacke bedrock. Tiffen hill is a flow barrier within the groundwater system. 
This block has limited capability of housing any significant groundwater resource, given its greywacke composition, and has been excluded from the Middle Valley groundwater domain in the Greater Wellington Regional Council flow model (Gyopari and McAllister, 2010a).

\subsection{Wairarapa hydrogeology summary}

The Wairarapa Valley is a complex heterogeneous groundwater system. A large valley plain has been formed from sediment eroded off the surround ranges, buckled and uplifted by the underlying faults, leading to the current layered geological system with significant groundwater volume beneath. The area experiences high and low rainfall with many river channels running from the mountains and through the valley plains. The area is widely farmed and sparsely populated, with significant reliance on the agriculture and horticultural industries spread throughout the valley. The simulated period should ideally contain a range of hydrological phenomena that the catchment will experience naturally including normal, wet, and dry climatic conditions. In the Middle Valley of the Wairarapa there was a range of climatic and hydrological events at both ends of the water 'spectrum' between 1992 and 2007. Several high precipitation events occurred and concentrated significant water volumes into the primary water channels (see Section 4.4) with additional water recharge percolating through the shallow aquifer connected river bed sections decreasing water age in the shallow, and perhaps deeper reservoirs. Several dry, and prolonged, climatic droughts also occurred (see Section 4.4.1) with sparse rainfall over both summer and winter months. This lack of rainfall and river recharge would have subsequently affected the water age mass in the catchment, and placed significant strain on both surface and groundwater resources (Black, 2007; Harkness, 2000).

Water quality in the Middle Valley is a concern. Wastewater discharges and contaminants can have a significant impact on groundwater quality. For example, a shallow unconfined/semi-confined aquifer in the Carterton sub-zone is at risk to contamination from land use and contaminated discharge (e.g. wastewater, septic tanks). A nitrogen survey undertaken over the 2006-2007 summer analysed 48 boreholes in the Carterton, Matarawa and South Featherston areas. 
Results indicated elevated nitrate concentrations above natural levels, but only one result exceeded the Ministry of Health national drinking water standard of $11.3 \mathrm{mg} / \mathrm{L}$ (McAlister and Tidswell, 2007). This area will be assessed through groundwater age sensitivity analysis from modelled age output. If the sub-basin exhibited a low mean age, or significant (e.g. >10\%) young groundwater age particles across the transient age distribution, it would indicate a significant contamination risk to river and subsurface water in the Valley. Caution must be exercised when dealing with a dynamic and complex system, such as the Wairarapa, and groundwater age can be used in part to fully recognize and protect the water resources. 


\section{Chapter 5}

\section{Middle Valley Transient Flow Model}

It is astonishing and incredible to us, but not to nature; for she performs with the utmost ease and simplicity things, which are ever infinitely puzzling to our minds, and what, is very difficult for us to comprehend is quite easy for her to perform.

Galileo Galilei

Chapter Five explains how Wellington Regional Council developed the transient Middle Valley groundwater model, specifically data quantification, input, initial conditions, parameters, boundary conditions and calibration. The model was formulated using the finite element method within the FEFLOW groundwater modelling software (Diersch, 2002). The duration simulated was between the $1^{\text {st }}$ July 1992 to the $1^{\text {st }}$ May 2007 using a weekly time step, and abstraction, river, and rainfall data was incorporated to simulate groundwater age. The numerical model domain was defined using geological and hydrogeological information, including cross-sections and stratigraphy data points (Fig. 5.1) (Begg et al, 2005; Daughney, 2007; Jones and Gyopari, 2006). The model domain is approximately $13 \mathrm{~km}$ wide between the Tararua Ranges foothills and the Ruamahanga River (Northwest-Southwest), and approximately $19.5 \mathrm{~km}$ in length between the Waingawa River and the edge of the Greytown/Waiohine plains (Northeast-Southwest). The depth of the model a variable thickness to the assumed bedrock specified as 71.5 metres in the north (187.8m to $116.4 \mathrm{~m}$ elevation), 42.2 metres in the east ( $79.8 \mathrm{~m}$ to $37.5 \mathrm{~m}), 57.8$ metres in the west ( $104.8 \mathrm{~m}$ to $47 \mathrm{~m})$ and 29 metres in the south ( $46.1 \mathrm{~m}$ to $17 \mathrm{~m}$ ) (N., E., W., and S. in Fig. 5.1). Tiffen Hill is an uplifted greywacke block to the near the Parkvale sub-basin. This zone is absent from the model domain as any flow is considered negligible, and justifiably removed given its inherent inability to transmit any considerable volume of water. 


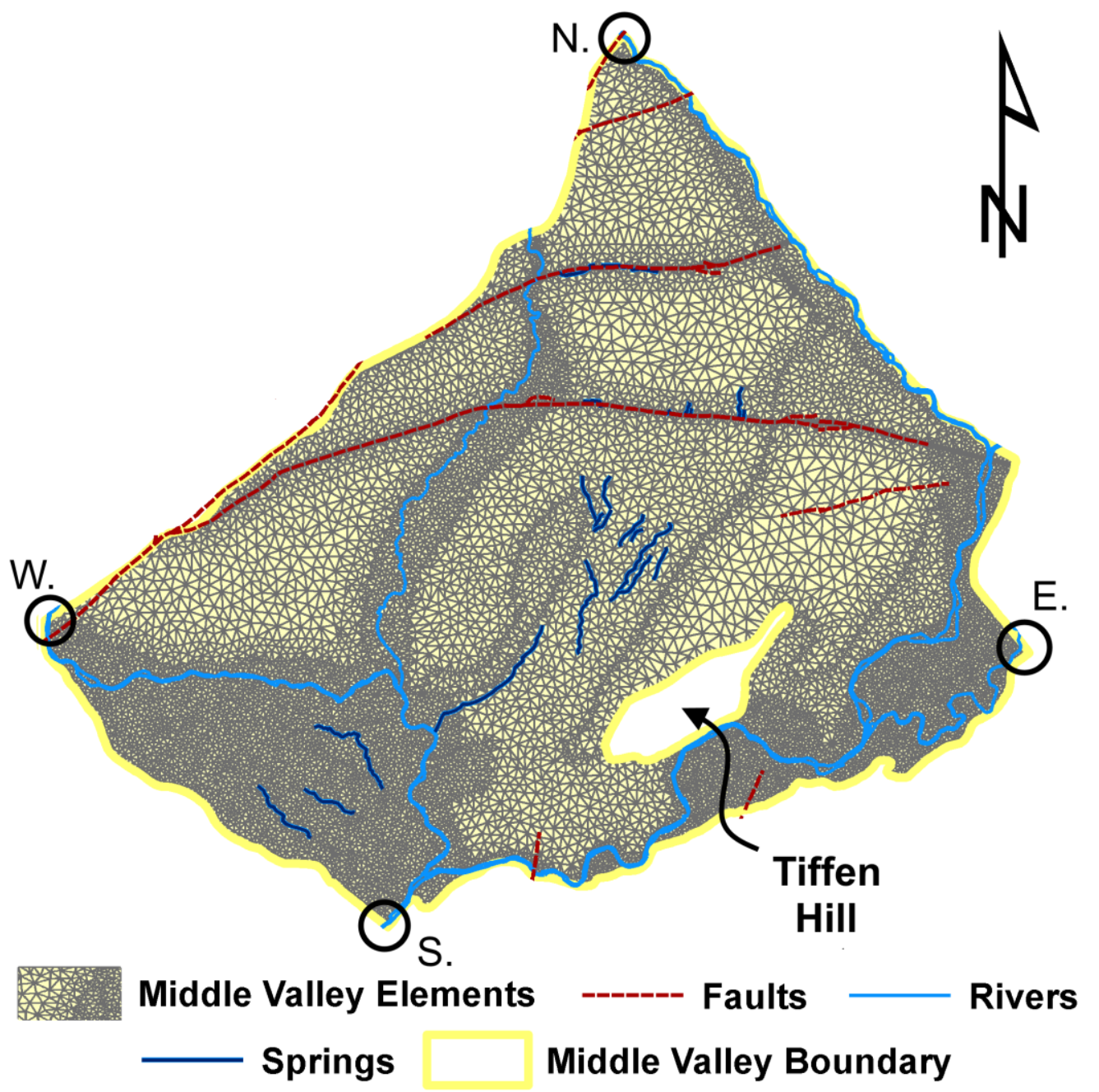

Fig. 5.1 Middle Valley catchment top layer mesh discretization. 21074 elements made up of 10920 nodes. Areas are discretized to a smaller resolution around complex zones, i.e. faults, springs, rivers.

The Middle Valley FEFLOW finite element model consists of nine layers and ten slices (Table 5.1). The distance between the nodes varies between $500 \mathrm{~m}$ on the alluvial fan areas and Fernhill, reducing to $100 \mathrm{~m}$ near faults, rivers and young (e.g. Q1) gravels.

The Wairarapa groundwater system is characterized by a complex depositional history. The Middle Valley model domain is therefore discretized into multiple layers of discrete elements (shapes) and nodes (points). In the Middle Valley model the individual triangular prisms collectively form a finite element mesh. Dividing the catchment model into discrete (triangular) parts enables a numerical simulation to solve flow and transport processes within the modelled domain. The discretization is done to reduce the amount of error, which is inherent, to an amount considered acceptable for the modelling output. 
FEFLOW requires a tabulated mesh, which is a three-dimensional model domain constructed from the initial two-dimensional mesh, i.e. a stratigraphic mesh which is discretized identically on each layer (Diersch, 2002; Gyopari and McAllister, 2010a). Fine mesh sizes are overlain where there are dynamic permeable areas (i.e. Q1 aquifers and river channels) and a coarse mesh is overlain in low permeability areas (i.e. part of Parkvale, and West and East Taratahi) (see Fig. 4.11). The main Carterton and Masterton faults in the north of the catchment have been discretized into narrow strips of $100 \mathrm{~m}$ width. Any surface water channels and springs are also finely discretized. There are 109200 nodes in the mesh forming 210740 elements with a maximum number of 6 nodes per element. The model domain contains 101 different material classes (see Appendix B). Different classes were selected based on differences in the subsurface parameters: drainage porosity (ne), hydraulic conductivity $\left(K_{x x}, K_{y y}, K_{z z}\right)$, and the storage coefficient (Ss).

Table 5.1 FEFLOW finite element Middle Valley model information. Source: Gyopari and McAllister (2010).

\begin{tabular}{cc}
\hline Type of model & 3-D saturated flow \\
\hline Type of aquifer & Unconfined top layer with phreatic surface \\
Model layers & Nine layers (10 slices) \\
Type of simulation & Steady state and transient flow \\
Type of elements & 6-node, triangular prisms \\
Number of elements & 189,666 \\
Number of nodes & 109,200 \\
\hline
\end{tabular}

\subsection{Middle Valley stratigraphy}

Stratigraphic data from bores was used as well as five geological cross sections to representatively construct the three-dimensional hydrogeological model. Four cross sections run across the valley northwest to southeast and one aligned along the valley northeast to southwest (Fig. 5.2) (Gyopari and McAllister, 2010a). Five broad hydrostratigraphic units have been characterized for the Middle Valley sub-zone on the basis of formation lithology, well abstractions, stratigraphic data and aquifer characteristics. 
I. The Q1 (youngest Quaternary sediments) unconfined aquifer is present in the main river channels and Waiohine and Ruamahanga floodplains. These are reworked shallow Holocene age gravels of $<15$ metres depth which exhibit a strong interaction with surface water channels (Daughney, 2007; Guggenmos et al, 2011; Gyopari and McAllister, 2010a);

II. The Q2, Q3, Q4, Q6, and Q8 aquifers consist of layered gravel, sand and silts. These have medium to low hydraulic conductivities and are located at the surface of the Valley or below Q1 deposits;

III. The least productive aquifers are the alluvial fan gravels (Q2-Q8) from the Waiohine, Mangatarere Stream, and Waingawa rivers. These are generally poor aquifers with low hydraulic conductivities and poor water yields;

IV. Q5 and Q7 aquitards are silt and clay swamp deposits. These silt and clay sections are located in the Parkvale, Carterton, Ruamahanga, and Fernhill zones;

V. Uplifted blocks of aquitards have low to very low hydraulic conductivities and can significantly restrict flow passing near these sections. These blocks are located at Tiffen Hill and Fernhill.

Each of the layer surfaces (slices) was developed using the cross sections as a control while modifying the slices to match both the conceptual model and the geological information of the Middle Valley (Table 5.3 and Table 5.2). Layers one and two consist of Q1 gravels, which are not uniformly distributed throughout the upper sections of the Middle Valley. FEFLOW requires layers to extend across the entire model domain (a tabulated mesh), so where Q1 gravels were absent, layers one and two were both fixed at $0.1 \mathrm{~m}$ thickness below slice one and became dry during simulations. This occurred due to the water table being set as 'unconstrained'; the residual water depth does not affect the mass balance for the model or control heads in the unconfined aquifer. In areas without bore log data, surfaces were interpolated to maintain consistency with the conceptual hydrogeological model (Gyopari and McAllister, 2010a). The base of the model consists of Q8 alluvial sediments and is the assumed maximum depth of the Middle Valley groundwater system. 
The elevation of the model varies throughout the domain, for example, the groundwater system is located at higher elevations along the alluvial fan areas of the foothills of the Tararua Ranges, and lower through river reaches. This variability is in line with the natural heterogeneous system in the Wairarapa Valley and the regional groundwater flow roughly follows this downslope gradient.

Table 5.2 Middle Valley model structure and hydrostratigraphic units. The 'Secondary' column is the unit(s) in place when the principal unit is not present. GS: ground surface; AQ: aquifer; AT: aquitard. Source: Gyopari and McAllister (2010).

\begin{tabular}{|c|c|c|c|}
\hline $\begin{array}{l}\text { Slice and layer } \\
\text { sequence }\end{array}$ & $\begin{array}{l}\text { Main layer } \\
\text { composition }\end{array}$ & $\begin{array}{l}\text { Secondary layer } \\
\text { composition }\end{array}$ & $\begin{array}{c}\text { Slice } \\
\text { information }\end{array}$ \\
\hline Slice One (GS) & & & $\begin{array}{c}\text { Phreatic } \\
\text { (unconstrained) }\end{array}$ \\
\hline Layer One & Q1 Gravels & Dry/inactive & \\
\hline Slice Two & & & Unspecified \\
\hline Layer Two & Q1 Gravels & Dry/inactive & \\
\hline Slice Three & & & Unspecified \\
\hline Layer Three & $\begin{array}{c}\text { Q2-4 Gravels } \\
\text { (AQ/AT) }\end{array}$ & Fan gravels & \\
\hline Slice Four & & & Unspecified \\
\hline Layer Four & $\begin{array}{l}\text { Q2-4 Gravels } \\
\text { (AQ/AT) }\end{array}$ & Fan gravels & \\
\hline Slice Five & & & Unspecified \\
\hline Layer Five & Q5 Aquitard & Fan gravels & \\
\hline Slice Six & & & Unspecified \\
\hline Layer Six & Q5 Aquitard & Fan gravels /Q6 & \\
\hline Slice Seven & & & Unspecified \\
\hline Layer Seven & Q6 Gravels (AQ) & Fan gravels & \\
\hline Slice Eight & & & Unspecified \\
\hline Layer Eight & Q6 Gravels (AQ) & Fan gravels & \\
\hline Slice Nine & & & Unspecified \\
\hline Layer Nine & $\begin{array}{c}\text { Q7-8 Gravels } \\
\text { (AQ/AT) }\end{array}$ & Fan gravels & \\
\hline Slice 10 & & & Fixed \\
\hline
\end{tabular}




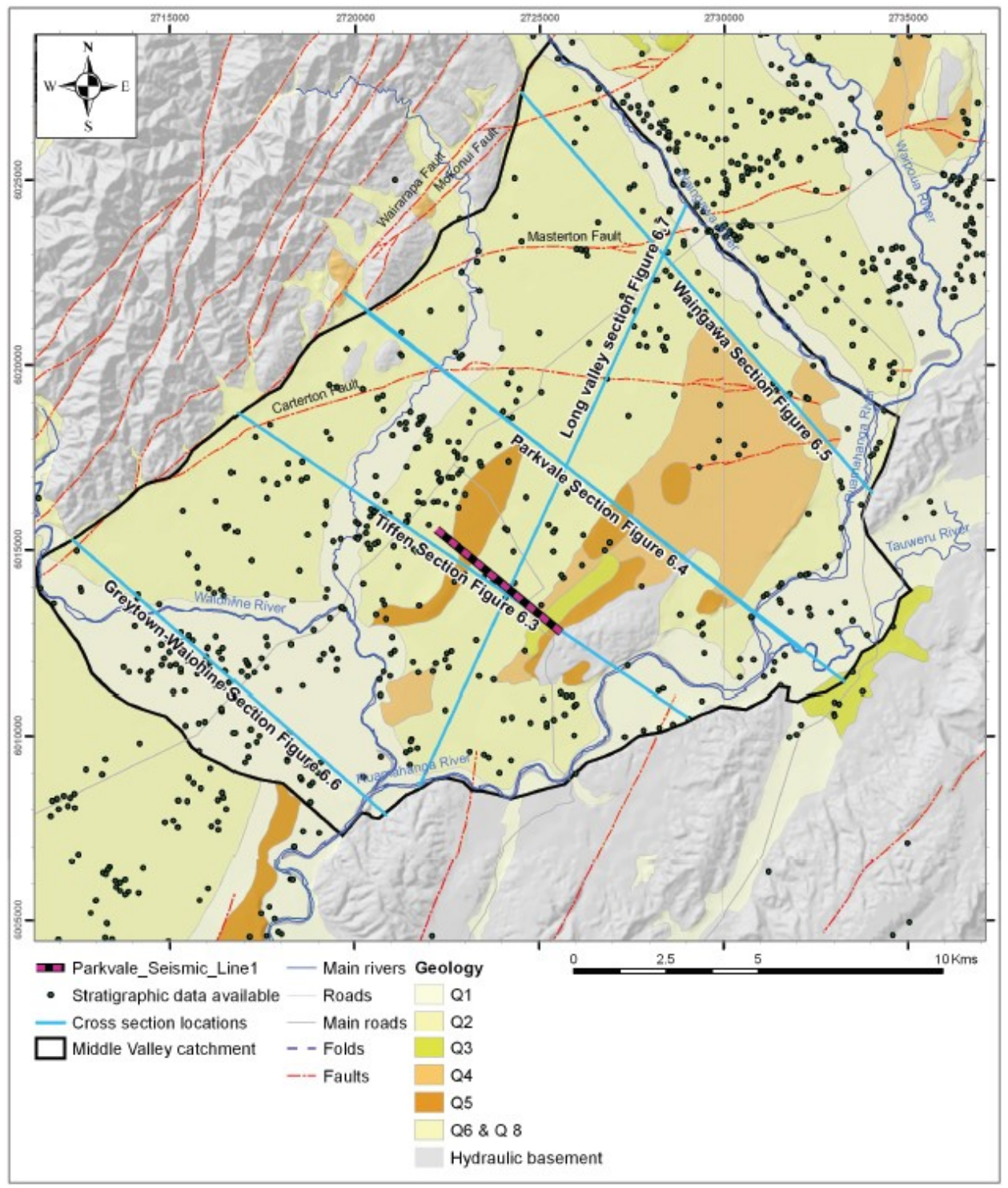

Fig. 5.2 Geology of the Middle Valley. Bores and cross section line locations are shown, all of which were used to construct the conceptual hydrogeological model. Source: Gyopari and McAllister (2010).

A multivariate statistical analysis of the surface and groundwater chemistry was done by Daughney (2007) to confirm the accuracy of the hydrostratigraphic units within Greater Wellington's Middle Valley model (Gyopari and McAllister, 2010a). The sampled wells were located between and near the Waingawa and Waiohine Rivers in the Middle Valley catchment boundary. The geologic parameters in Greater Wellington's conceptual model were assessed for validity via statistical methods using groundwater chemistry to distinguish the hydrochemical signatures that are associated with each of the seven hydrostratigraphic units (Table 5.3). 
Table 5.3 Hydrochemical units corresponding to hydrostratigraphic units in the Middle Valley (see Fig. 4.6). Source: Gyopari and McAllister (2010).

\begin{tabular}{cc}
\hline Hydrostratigraphic unit & Hydrochemistry study unit \\
\hline Alluvial fan gravels & Unit 6 (Q2 - Q8 fan gravels) \\
(Q2 - Q8) & Unit One (Q1 Alluvium) \\
Q1 Unconfined aquifer -4, Q6, Q8 Aquifers & Unit Two (Q2 - 4: Parkvale sub-basin) \\
& $\begin{array}{r}\text { Unit Three (Q2 - 4: Ruamahanga valley) } \\
\text { Unit Four (Q6 Parkvale sub-basin) } \\
\end{array}$ \\
Unit Five (Q8 Parkvale sub-basin) \\
Q5 and Q7 Silt/clay aquitards & Unit Seven (older than Q8) \\
\hline
\end{tabular}

The first stage involved evaluating the unique groundwater chemistry for each hydrostratigraphic unit based on all the wells that were assumed to abstract from each unit. Differences in each unit's hydrochemistry were apparent but subtle. The chemistry signals from Unit 1 indicated a proportionally larger amount of river recharge, while Units 2 and 6 showed a higher proportion of rainfall recharge. Units 2 , 4 and 5 all have similar chemistry suggesting that recharge falls from Unit 2, to Unit 4, to Unit 5. Reduction of oxygen levels is apparent between Unit 4 to Unit 5, and Unit 7 has the least oxygen content as well as the most chemically evolved water indicating that Unit 7 is the oldest. Chemistry analysis confirms the assumptions (by Wellington Regional Council) that recharge moves down through the overlying layers. The Greater Wellington Regional Council conceptual model was confirmed to be generally consistent through the measured hydrochemistry (Daughney, 2007).

The second stage used hierarchal cluster analysis to obtain an independent comparison to Wellington Regional Council's conceptual hydrostratigraphy. Hierarchal cluster analysis restructured the monitoring wells based on major ion concentrations without any consideration of the well or assumed geologic unit. The two major hydrochemical categories ( $A$ and $B$ ) and nine subcategories defined by hierarchal cluster analysis were again generally consistent with the original Wellington Regional Council conceptual hydrostratigraphy (Daughney, 2007). 
The final third stage used discriminant analysis to assess the likelihood that a well taps into each Wellington Regional Council defined unit, based on ion concentration and well depth. Again this generally agreed with the Wellington Regional Council conceptual hydrostratigraphy with discriminant analysis prediction matching the assumed unit for $75 \%$ of the monitoring wells $(n=99)$. Discriminant analysis failed to classify correctly in several areas (Daughney, 2007):

1. Near the confluence of the Mangatere and Waiohine Rivers, suggesting older sediments are closer to the surface.

2. Along a line almost parallel to the Tararua Ranges, the edges of the Q2 to Q4 fan gravels are closer to the Tararua Ranges.

3. A few shallow sites in the Parkvale sub-region thought to be caused by local land influence, not subsurface processes.

\subsection{Precipitation and rainfall recharge}

Groundwater recharge is dependent on the volume and distribution of rainfall. Around $21-40 \%$ of the total precipitation recharges aquifers on the north and western side of the catchment, depending on the specific rainfall distribution, intensity and stratigraphy. Rainfall recharge dramatically decreases on the eastern side of the valley where less than $10 \%$ of the groundwater recharge was attributable to direct rainfall. The remaining $90 \%$ of recharge on the eastern side is from surface and groundwater connected river sections, including the Ruamahanga River. This reduction is caused by low annual rainfall on the eastern side of the Wairarapa (i.e. $<100 \mathrm{~mm}$ ), drier soil and climatic conditions increasing evapotranspiration (Fig. 5.3). This decrease is also due to the geology underlying eastern areas, for example, thick loess layers are present around Fernhill contributing to sections of poorly drained soils (Gyopari and McAllister, 2010a). Rainfall input was simulated using time-varying rainfall recharge data via a recharge grid. Time-series of rainfall data were interpolated corresponding to each element of the rectangular polygon grid, 1160 single $500 \mathrm{~m}^{2}$ elements, which have unique averaged weekly rates for the simulation. 


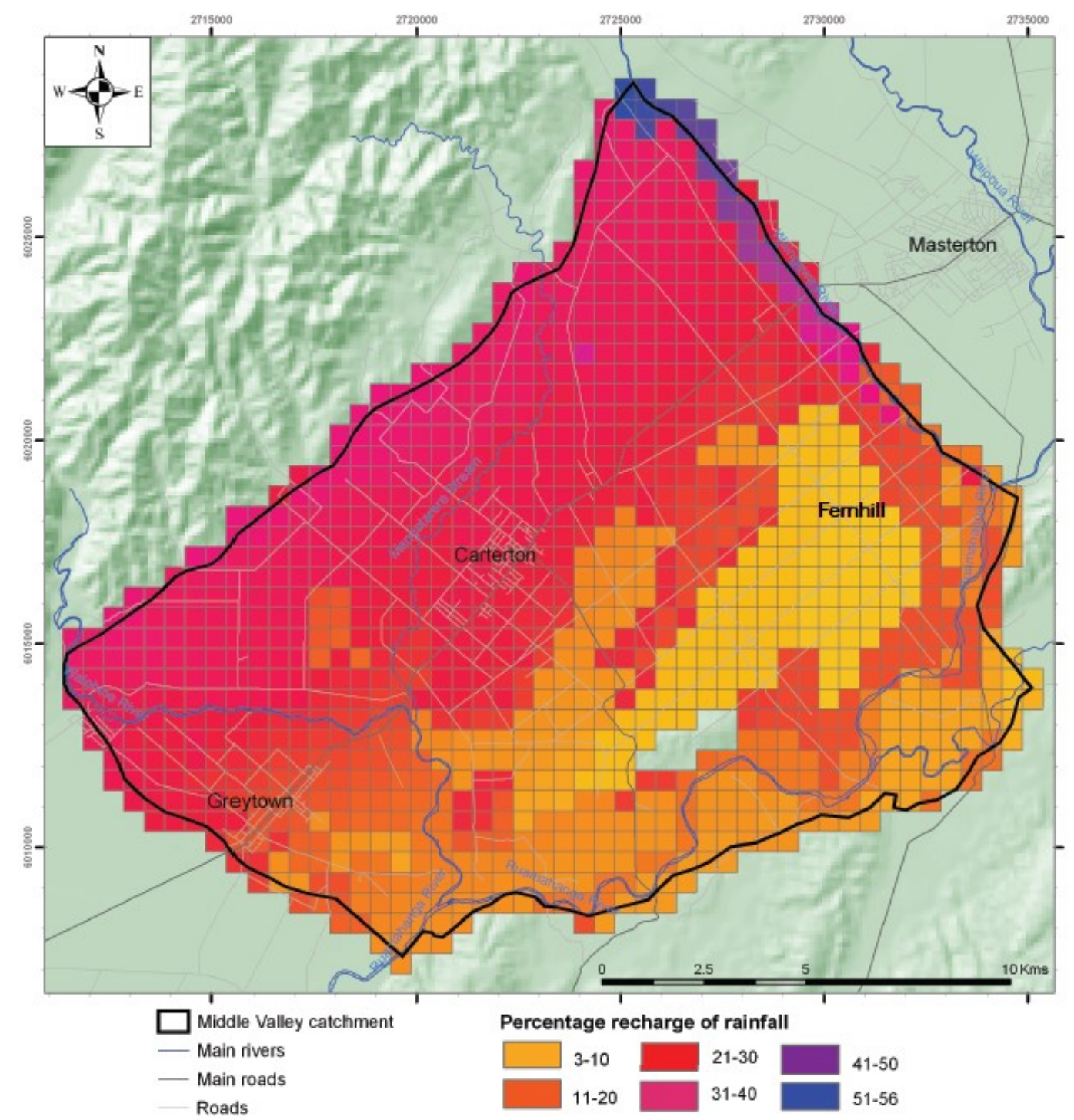

Fig. 5.3 Percentage of rainfall that recharges the Middle Valley catchment. Source: Gyopari and McAllister (2010).

Distributed soil moisture balance modelling was used to estimate rainfall recharge. It is based on a soil moisture balance technique by Rushton et al. (2006) which calculates recharge on $500 \mathrm{~m}^{2}$ grids. Input parameters were provided by a spatial interpolation of daily rainfall and potential evapotranspiration using a spline model by Tait and Woods (2007). This was used in the recharge grid and implemented by NIWA using all relevant data from NIWA and Greater Wellington databases. Soil property mapping was conducted by Landcare Research which incorporated spatial mapping data and soil hydraulic parameters (Webb, 2008). The recharge model was verified by comparing lysimeter data, and basic saturated aquifer mass balance (Gyopari and McAllister, 2010a). 
Daily recharge is simulated as a weekly average and combined to form the total recharge for the 15 year simulation period (July 1992 - May 2007). Extreme weather and climatic conditions have a significant influence on the surface and subsurface environment, for example, the years 1993 and 2001 experienced low rainfall and drought conditions (see Section 4.4); whereas flooding and above average groundwater recharge occurred in 1992, 1995, 1996, 2004, and 2006 (see Section 4.4). The average annual recharge for the 15 year period is $68.2 \times 10^{6} \mathrm{~m}^{3}$ and the average daily recharge across the Middle Valley is estimated at 190,000 $\mathrm{m}^{3}$ (Fig. 5.3 and Fig. 5.4) (Gyopari and McAllister, 2010a). Further extensive information on the recharge model can be found in Rushton et al (2006), Tait and Woods (2007), and Webb (2008).

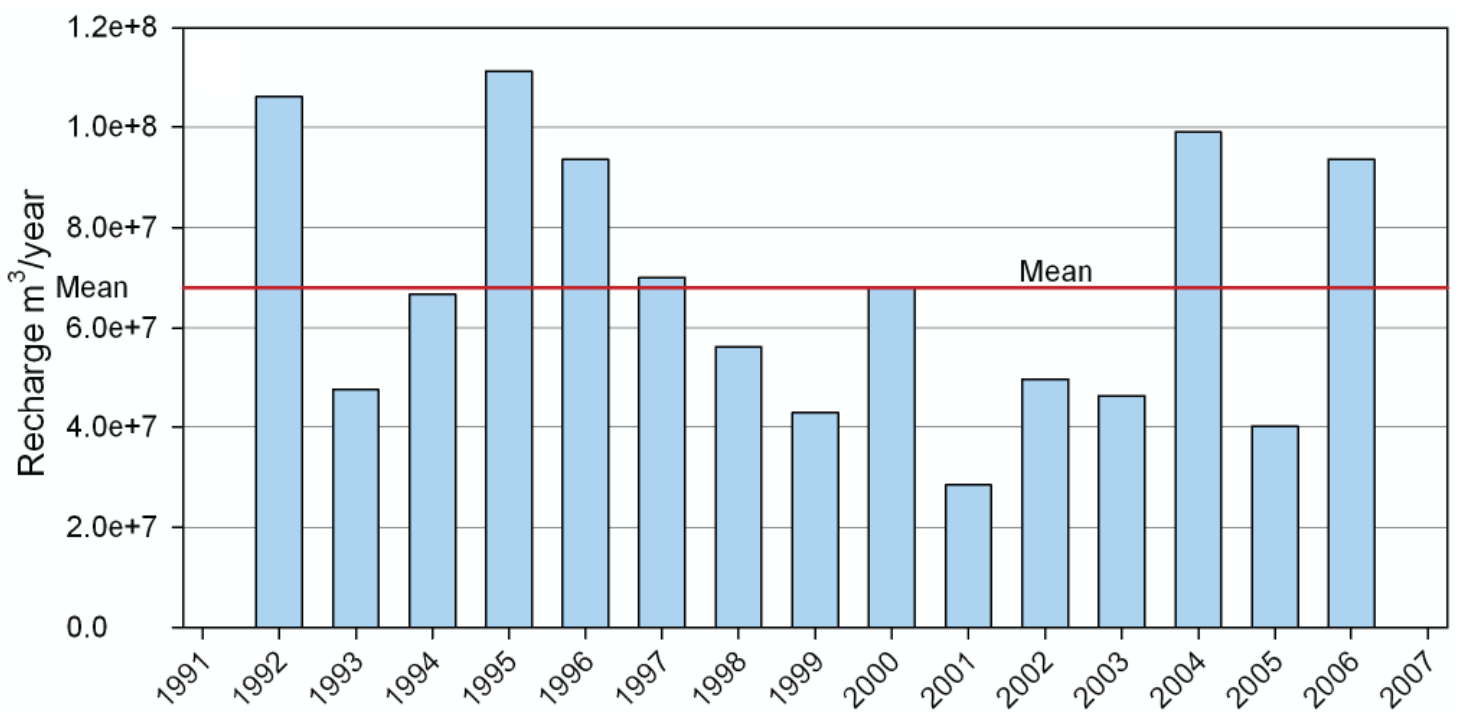

Fig. 5.4 Estimated annual rainfall recharge across the Middle Valley. Source: Gyopari and McAllister (2010).

\subsection{Groundwater abstraction}

Groundwater abstraction was simulated using 110 pumping wells. Abstraction rates were only available from a limited percentage of bores from 2002. Subsequently, seasonal groundwater abstraction estimates were required for the simulation period and developed using: 1 ) soil moisture balance modelling, and 2) a combination of annual water metering data and weekly meter readings (Gyopari and McAllister, 2010a). The wells were specified with well boundary conditions that apply a specified abstraction rate to a node representing the pumping wells location, or alternatively, a collection of nodes if the well is screened across multiple layers. 
For the well conditions, inflows are implemented as negative and outflow as positive; all 110 wells in the Middle Valley flow model are positive and simulated as pumping wells (Fig. 5.5).

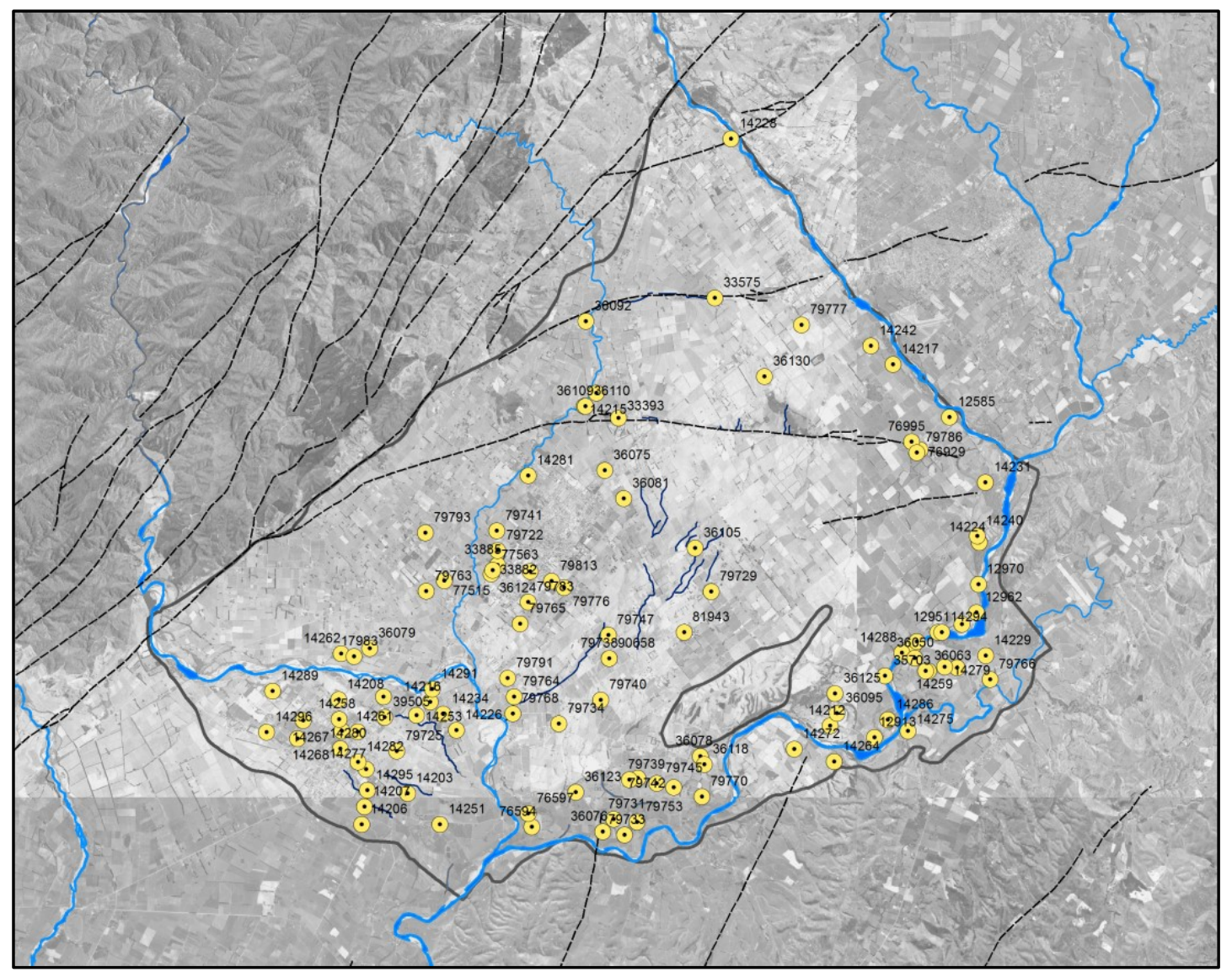

Fig. 5.5 Distribution of the 110 abstraction wells simulated throughout the Middle Valley.

\subsubsection{Annual irrigation period}

A soil moisture deficit trigger (SMD) was used as an estimate for the average irrigation season (Table 5.4). The irrigation period was estimated from the historic irrigation season commencement and duration. An initial study was conducted in the $2006-07$ irrigation season, followed by a thorough investigation conducted in the 2007-08 season. An area close to the confluence of the Mangatarere Stream and Waiohine River was used as an indicative portion of the Middle Valley catchment. Daily soil moisture was initially modelled in the same way groundwater recharge was estimated (i.e. Rushton et al, 2006; Tait and Woods, 2007). Rainfall and potential evapotranspiration data were used to simulate the $1992-2007$ period at daily timesteps. 
Results indicated the weekly average soil moisture deficit was within a range of 0-25 $\mathrm{mm} /$ day, therefore it was assumed that irrigation commenced when the soil moisture deficit reached $20 \mathrm{~mm}$ per day. This rate was confirmed by comparing simulated soil moisture deficit and irrigation commencement (Gyopari and McAllister, 2010a).

Table 5.4 Irrigation abstraction modelling inputs. Modified from Gyopari and McAllister (2010).

\begin{tabular}{ccccc}
\hline $\begin{array}{c}\text { Irrigation } \\
\text { season }\end{array}$ & $\begin{array}{c}\text { Number of } \\
\text { weeks irrigation } \\
\text { SMD }>20 \\
\text { mm/day }\end{array}$ & $\begin{array}{c}\text { Season } \\
\text { length } \\
\text { (weeks) }\end{array}$ & $\begin{array}{c}\text { Season } \\
\text { length } \\
\text { (days) }\end{array}$ & $\begin{array}{c}\text { Annual } \\
\text { percentage of } \\
\text { allocation used } \\
\text { (\%) }\end{array}$ \\
\hline $1992 / 93$ & 10 & 15 & 105 & 25 \\
\hline $1993 / 94$ & 22 & 27 & 189 & 35 \\
\hline $1994 / 95$ & 13 & 16 & 112 & 25 \\
\hline $1995 / 96$ & 10 & 14 & 98 & 25 \\
\hline $1996 / 97$ & 10 & 21 & 147 & 25 \\
\hline $1997 / 98$ & 22 & 22 & 154 & 40 \\
\hline $1998 / 99$ & 10 & 16 & 112 & 25 \\
\hline $1999 / 00$ & 6 & 9 & 63 & 15 \\
\hline $2000 / 01$ & 22 & 25 & 175 & 40 \\
\hline $2001 / 02$ & 10 & 24 & 168 & 25 \\
\hline $2002 / 03$ & 20 & 25 & 175 & 35 \\
\hline $2003 / 04$ & 10 & 23 & 161 & 20 \\
\hline $2004 / 05$ & 13 & 18 & 126 & 25 \\
\hline $2005 / 06$ & 16 & 20 & 140 & 35 \\
\hline $2006 / 07$ & 15 & 15 & 105 & 30 \\
\hline
\end{tabular}

\subsubsection{Actual abstraction rates}

Actual abstractions are often much less than maximum allocated abstraction rates (Fig. 5.6). A review of irrigation meter readings from 2002-2008 indicated very few water takes $>50 \%$ of the allocated maximum, and the majority of rates were only $10-30 \%$ of their allocated amount, on an annual basis. An estimate of actual irrigation use was required to simulate groundwater abstraction in the model. 
The percentage of days where soil moisture deficit $>20 \mathrm{~mm} /$ day over a typical 30 week irrigation season was plotted against the metered annual abstraction amount. This was used to estimate the amount of actual irrigation used, and results indicated it was between $15-35 \%$ of consented abstraction (Gyopari and McAllister, 2010a).

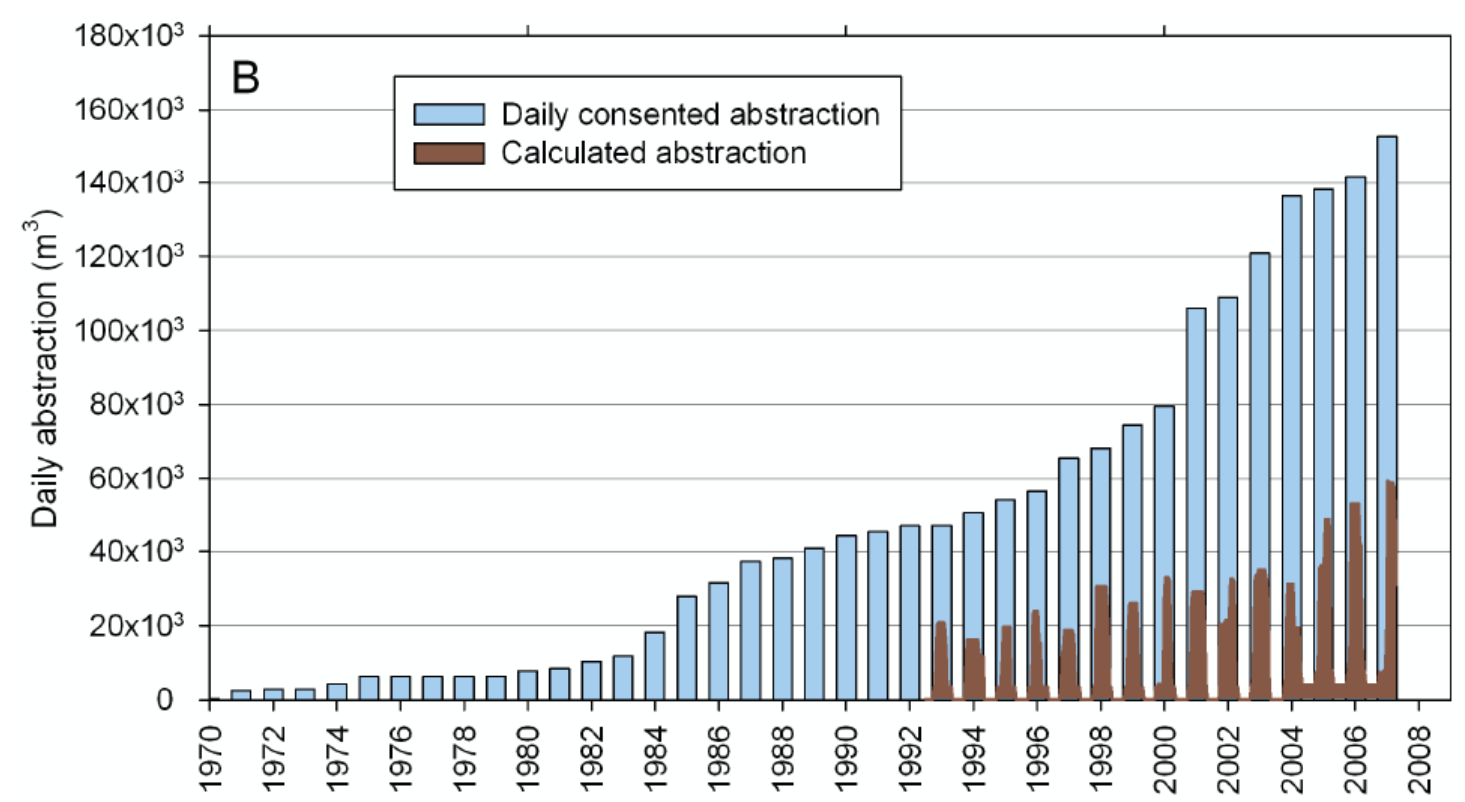

Fig. 5.6 Consented groundwater abstraction and estimated actual groundwater abstraction for the Middle Valley. Source: Gyopari and McAllister (2010).

Time-varying model abstraction was estimated from available field data. The bores were assessed using the consent commencement date, calculated soil moisture deficit at a reference site, and the percentage exceeded over the trigger of $20 \mathrm{~mm} /$ day. It was assumed that abstraction was spread over the irrigation season, and not specific to the period(s) where the trigger soil moisture deficit (>20 mm/day) occurred (Gyopari and McAllister, 2010a). In reality, this may be somewhat unrealistic given irrigation is instigated when a lack of soil moisture inhibits pasture growth. However a percentage of irrigators constantly irrigate, regardless of climatic fluctuations, over the irrigation season to maintain a "constant" soil moisture balance. The Middle Valley model assumes there is not a significant effect on the flow and transport (i.e. tritium movement, mean-age and point age distributions) caused by variable pumping rates. Given the relative insignificance of water abstraction on the model's global water budget, it is assumed to have minimal impact on the modelled output (Fig. 5.7). 


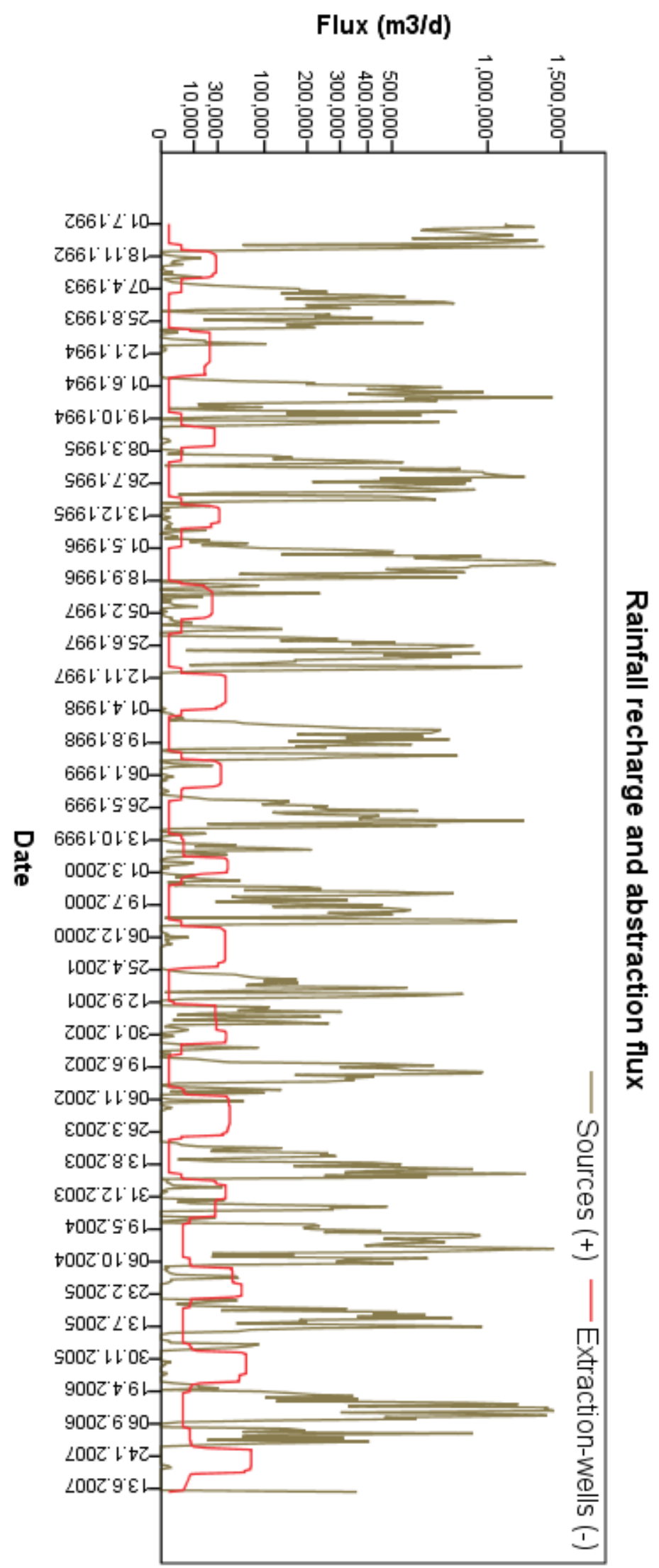

Fig. 5.7 Simulated Middle Valley groundwater abstractions and rainfall recharge July $1992-$ May 2007. 


\subsection{Surface and groundwater transfer}

A significant component of the water balance in the Middle Valley catchment is the transfer between river beds and shallow unconfined aquifers (Begg et al, 2005;

Daughney, 2007; Guggenmos et al, 2011).

Such interactions have been confirmed through statistical hydrochemical analysis (see Section 4.5.1) and observed where bores are in close proximity to river reaches, for example, the Waiohine River (see Fig. 4.12). This water transfer is simulated in the model, both from and to aquifers, using transfer boundary conditions, i.e. Cauchy or type-three (Fig. 5.8 and Fig. 5.9). The surface water sections which exhibit transfer between and/or to shallow groundwater are the:

- Waingawa River;

- Ruamahanga River;

- Mangatarere Stream;

- Waiohine River; and

- Springs (Carterton and Masterton Fault, Papawai, Tilsons, Muhunoa, Beef Creek and Parkvale springs). 


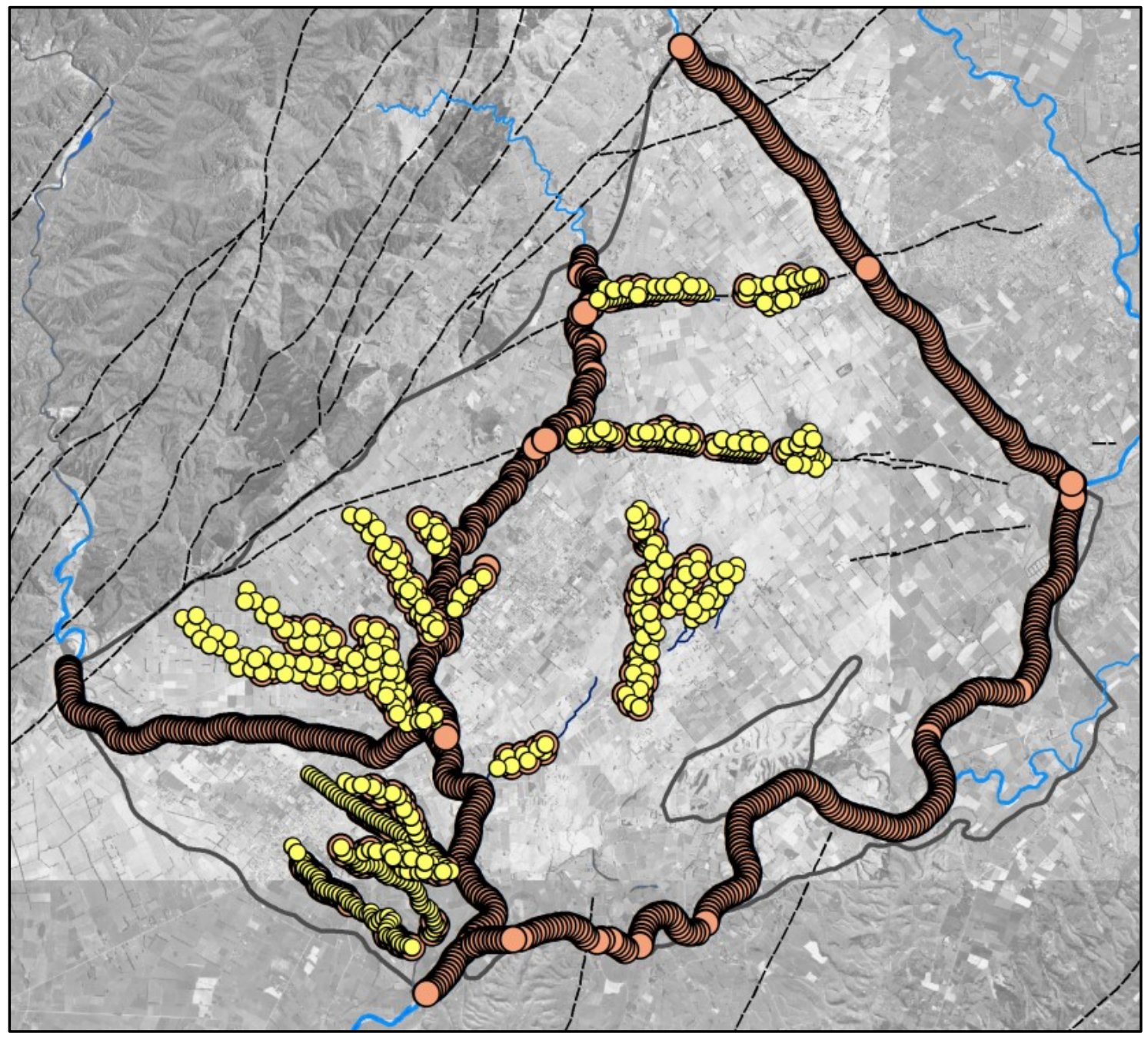

Fig. 5.8 Transfer boundary condition (i.e. Cauchy) distribution throughout the Middle Valley. Orange circles indicate surface water channels assigned transfer rates to simulate surface/groundwater flux. Yellow circles indicate spring sections assigned constraints allowing outflow, but not inflow. 


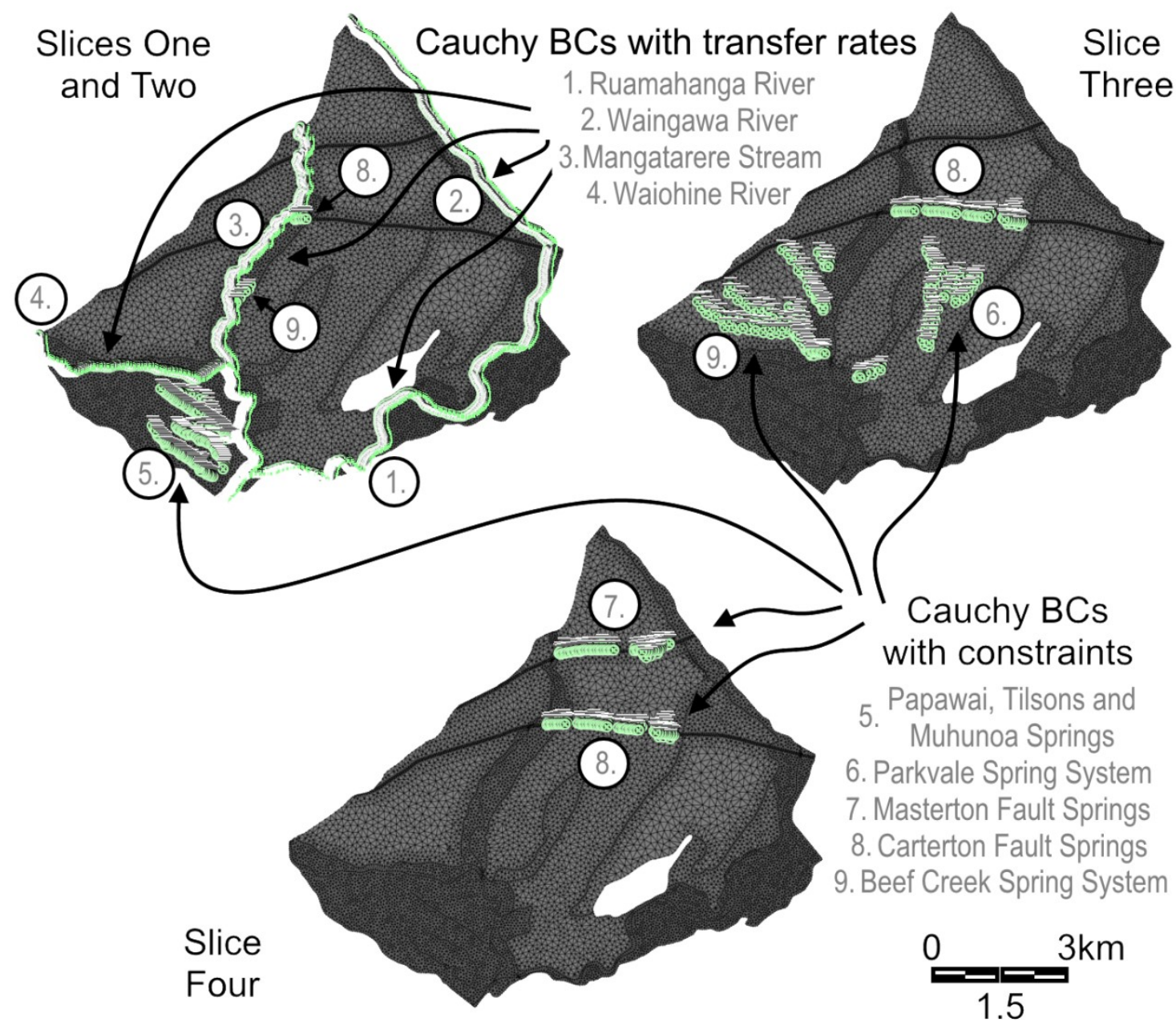

Fig. 5.9 Cauchy transfer boundary nodes locations on slice one and two (Cauchy faces on layer one), slice three and slice four of the Middle Valley model domain.

The water transfer between the assigned Cauchy boundary conditions is controlled by specified transfer rates and specified constraints. Nodes assigned Cauchy boundary conditions also have to enclose entire faces of discretised elements, to define the transfer area:

1. For an inflow at one slice (anywhere in the model domain) all the nodes of an element in one slice (three nodes) have to be assigned the condition (Fig. 5.10).

2. For an inflow at a vertical element face (e.g. a river) two nodes of an element in one slice and the same two nodes in a slice directly above or below have to be assigned the condition (four nodes) (Fig. 5.11). 


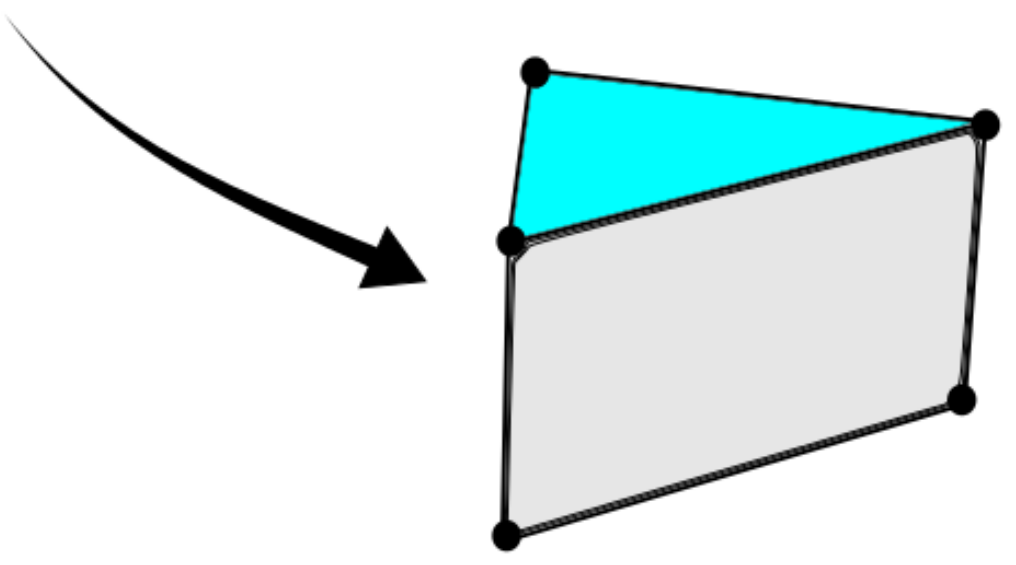

Fig. 5.10 Horizontal areal Cauchy boundary condition assignment of all three of the top nodes. This has been implemented on the Ruamahanga River Cauchy assigned nodes.
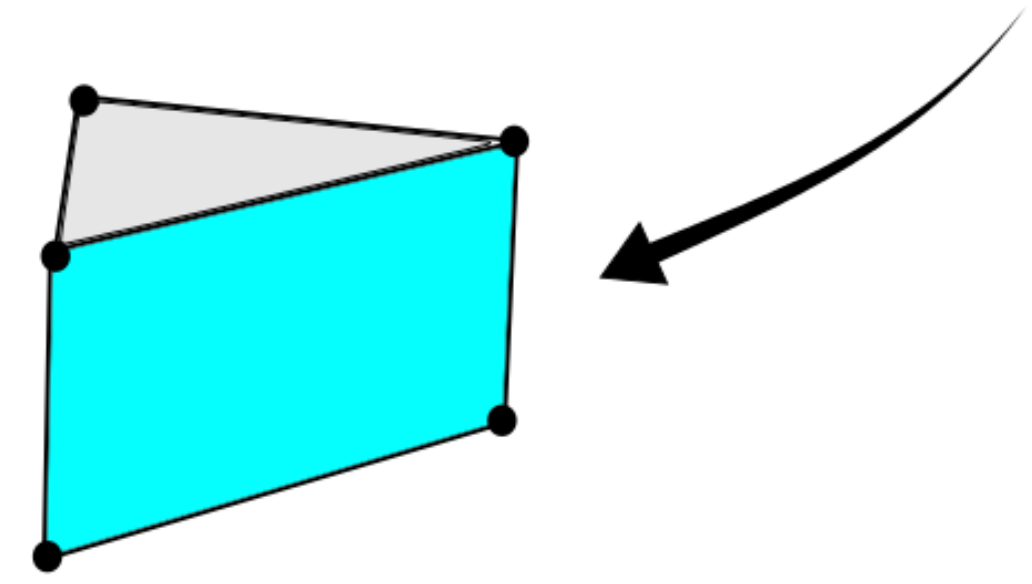

Fig. 5.11 Vertical areal Cauchy boundary condition assignment. This has been used to implement Cauchy boundary conditions on the Carterton fault springs.

Cauchy boundary conditions in the Middle Valley domain hold time-varying river stage data (hydraulic head) where the surface water has partial contact with the groundwater system. The boundary condition of the transfer type describes a timevarying reference to the river stage (head) which has an imperfect hydraulic connection to the groundwater system (Fig. 5.12). The river stage time-series data and transfer rate (a proportionality constant) need to be assigned to each boundary node. Transfer rates were assigned an equal amount for both inflowing and outflowing hydraulic conditions in order to control the flow on the nodes/sections (Table 5.5). For the sections which did exhibit significant flux, constraints were assigned. 
Table 5.5 Calibrated transfer rates for Cauchy boundary conditions in the Middle Valley. The transfer rate is calculated by dividing the hydraulic conductivity of the river bed by the thickness of the bed to provide a value in $\mathrm{d}^{-1}$. Source: Gyopari and McAllister (2010).

\begin{tabular}{cc}
\hline Water system (river, steam, spring) & Transfer rate (1/d) \\
\hline Upper Waiohine & 5 \\
Lower Waiohine & 8 \\
Waingawa and Mangatarere & 3 \\
Ruamahanga & 2 \\
Papawai and Tilsons & 5 \\
Muhunoa & 8 \\
Parkvale & 8 \\
Beef Creek & 8 \\
\hline Masterton and Carterton fault springs & 8 \\
\hline
\end{tabular}

The Cauchy boundary condition for fluid flow is based on a general transfer relationship between the river stage boundary $\left(H_{r}\right)$ and the hydraulic head $(H)$ at the same point (Eq. 5-1). The third-kind transfer condition boundary is expressed as a form of Darcy's equation on the river bed boundary:

$$
q_{t}(x, t)=-\phi(x, t)\left(H_{r}(x, t)-H(x, t)\right)
$$

$\phi$ is the transfer (conductance) parameter constraining flow across the riverbed boundary. This $\phi$ coefficient is a river bed constraining coefficient with both infiltration and discharge conditions, for example, to and from the river, respectively (Fig. 5.12). A space-integrated transfer rate for a constrained node may be quantified using the thickness $(e b)$ and hydraulic conductivity $(K b)$ of the river bed, the river width $(\omega r)$ and length $(L r)$. The transfer coefficient may be directional and differ between inflowing $\left(H_{2}\right)$ and outflowing $\left(H_{1}\right)$ (Cornaton, 2007) 


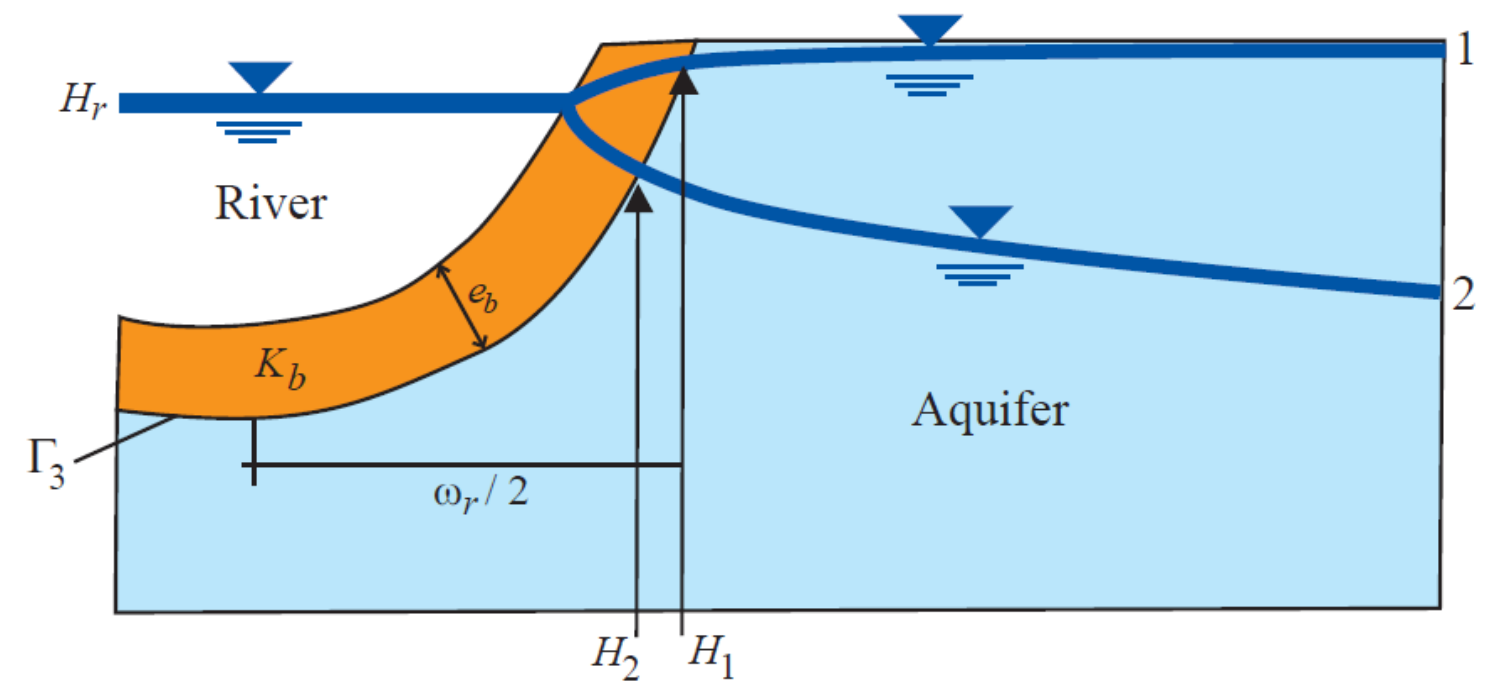

Fig. 5.12 Schematic of the transfer boundary condition for outflowing ( $\phi=\phi_{\text {out }}$ and $H>H_{r}$ ) and inflowing hydraulic conditions $\left(\phi=\phi_{\text {in }}\right.$ and $H<H_{r}$ ). Source: Cornaton (2007).

Constraints are set as limitations to validate boundary conditions (Eq. 5-2). When defining constraint conditions in a groundwater system, inflows are considered positive and outflows as negative. For example, a constraint of a maximum flow rate of zero $\mathrm{m}^{3} / \mathrm{s}$ means that no inflow is allowed at the assigned boundary condition $\left(Q^{\max }\right)$, and conversely, a minimum flow rate of zero $\mathrm{m}^{3} / \mathrm{s}$ restricts any outflow from the assigned boundary condition ( $Q^{\mathrm{min}}$ ) (Diersch, 2002). Constraints within the Middle Valley model are set to allow water to exit the river systems along the points where it was assumed flow entered the aquifers from the river to the groundwater reservoirs (Gyopari and McAllister, 2010a). Constraints are set using minimum and maximum bounds which restricts the flux to within the specified range of minimum and maximum bounds (Cornaton, 2007). Without limiting constraints on a fluid-transfer condition (Cauchy/ $3^{\text {rd }}$ type boundary) the infiltration of surface water would increase and raise the groundwater table. This would be unrealistic as infiltration would cease when the groundwater hydraulic head reached a point just below the river bed elevation. This ensures that infiltration will stay at a constant rate when the groundwater table is below the elevation of the river bed. Due to the fact that constraints were applied to Cauchy boundaries in the FEFLOW model, constraints are applied to the Middle Valley Ground Water (GW) transient flow and transport model. 


$$
\begin{gathered}
h_{r}^{*}(t) \text { if }\left\{\begin{array}{l}
\operatorname{Max}: Q^{\text {calc }}<Q^{\min }(t) \text { else } Q^{\text {calc }}=Q^{\max }(t) \\
\operatorname{Min}: Q^{\text {calc }}>Q^{\min }(t) \text { else } Q^{\text {calc }}=Q^{\min }(t)
\end{array}\right. \\
\text { where: } \\
h_{r}^{*}(t) \text { is the assigned transfer boundary condition } \\
Q^{\text {calc }} \text { is the flowrate }
\end{gathered}
$$

Simulated water balances indicated that groundwater provided the base flow to rivers and springs in the catchment year-round. This baseflow is critically important during summer when the base flow to rivers and springs dominates the catchment water balance. Simulated spring discharges in the GWRC model show a long-term decline which could be attributable to increased groundwater abstraction. Several spring sections exist in the Middle Valley catchment, but prior to 2010, there was limited data available on their distribution and discharge (Gyopari and McAllister, 2010a). Work was conducted to locate and quantify the various spring systems (Butcher, 2007a, 2007b):

1. Greytown springs including the Papawai Stream, Tilsons Creek and Muhunoa Stream:

2. Carterton and Masterton fault springs;

3. Parkvale springs. Areas where the Parkvale Stream gains from groundwater discharge in the central Parkvale plain;

4. Beef Creek system: gaining sections of the lower reaches were located west of Carterton.

To simulate the diffuse spring discharge systems of Parkvale, Beef Creek and the fault line springs (i.e. Carterton and Masterton), the springs were assigned Cauchy boundary conditions on slice three spring nodes to create a horizontal exchange area. The largest spring discharge occurs on the Greytown-Waiohine plains which have a summer base flow of about 50,000 to $70,000 \mathrm{~m}^{3} /$ day, which is a combined flow from the Papawai, Tilsons and Muhunoa springs. The spring discharge from this area appears to be declining post-2004, possibly as a result of increasing groundwater abstraction. 
During summer, groundwater abstraction represents about $13 \%$ of the total water balance for the catchment, significantly more than winter (Gyopari and McAllister, 2010a).

In summary, the entire length of the Ruamahanga, Waiohine, Mangatarere, and, Waingawa rivers were assigned Cauchy boundary conditions to simulate the exchange between the shallow aquifers and river systems. Spring-fed channels were also simulated under the Cauchy type condition, including the Papawai, Muhunoa streams, and Tilsons Creek in the Greytown zone. The Waingawa river boundary runs along, and represents, the northern boundary of the Middle Valley domain. Boundary conditions are combined with time-varying constraints to enable different specific boundary properties; in this case, fluctuating rivers with fluid transfer from aquifers to rivers.

\subsection{Initial head conditions}

Initial head conditions are required to simulate transient flow representative of the catchment. Initial heads were used from flow simulations from Greater Wellington Regional Council, incorporating abstractions, river water flux, rainfall recharge, and hydraulic head. Steady-state model solutions are often used as initial conditions for transient models. The transient flow model's initial conditions were derived from the heads generated from a steady state model run; however, these were not consistent with the specified boundary conditions of the transient model. The head outputs at the end of the 15 year semi-calibrated transient run closely matched the starting heads at the beginning of the simulation and this was implemented as the initial head conditions (Gyopari and McAllister, 2010a).

\subsection{Model parameters}

A model's hydraulic parameters define the movement of water throughout the domain. The hydraulic zonation and properties of each layer and/or material zone are specified from geologic data condensed in the conceptual model to the numerical flow domain (i.e. Begg et al, 2005). Assigned flow parameters are then tested with measured observational data from the Middle Valley catchment, and calibrated accordingly to derive a solution representative of the observed flow data. 
There are nine model layers in the Middle Valley model with each of the layers containing unique sets of parameter zones. There are two layers to represent each geological formation. This is implemented in order to simulate vertical flow within each formation, if there was only a single layer, the simulation of vertical flow would not be possible. The specific zones are differentiated by their assigned hydraulic conductivities, porosities, and storage coefficients (Table 5.6). Layers one and two are distinct hydrogeological units with unique material zones within each layer, for example, Q1 and Q2 gravels of the Ruamahanga River. The characterization of layers one and two was more detailed given their proximity to the surface. Layers three and four are a broad representation of the deeper heterogeneous Middle Valley substrate. The interface between these layers is a control on the vertical flow in the aquifer system (Gyopari and McAllister, 2010a).

Table 5.6 Estimated transmissivity, hydraulic conductivity and storage parameters. Source: Gyopari and McAllister (2010).

\begin{tabular}{|c|c|c|c|}
\hline $\begin{array}{c}\text { Hydrostratigraphic } \\
\text { unit }\end{array}$ & $\begin{array}{l}\text { Representative (bulk) } \\
\text { transmissivity } \\
\left(\mathrm{m}^{2} / \text { day }\right)\end{array}$ & $\begin{array}{l}\text { Representative } \\
\text { hydraulic } \\
\text { conductivity } \\
(\mathrm{m} / \mathrm{d}) \&(\mathrm{~m} / \mathrm{s})\end{array}$ & $\begin{array}{l}\text { Storage } \\
\text { (S or St) }\end{array}$ \\
\hline $\begin{array}{l}\text { Alluvial fan gravels } \\
\text { - Tararua-sourced } \\
\text { (Q2 +) }\end{array}$ & $\begin{array}{l}\text { Waingawa and Mangatarere } \\
\text { fans: } \\
100-500\end{array}$ & $10-50$ & $\begin{array}{c}\text { St: } 5- \\
1 \backslash 50 \% \\
\text { S: } 1-5 E-4\end{array}$ \\
\hline $\begin{array}{c}\text { Q1 Holocene } \\
\text { alluvium (Tararua sourced) } \\
\text { Unconfined aquifers }\end{array}$ & $\begin{array}{c}\text { Waiohine: } 4,000-6,000 \\
\text { Ruamahanga: } 3,000-4,000 \\
\text { Mangatarere: } 1,500-2,000 \\
\text { Waingawa: } 2,000-3,000\end{array}$ & $\begin{array}{c}300-600 \\
300-400 \\
200-300 \\
200-300\end{array}$ & St: $5-15 \%$ \\
\hline $\begin{array}{l}\text { Q6 + Q8 Aquifers } \\
\text { Parkvale/Carterton } \\
\text { basin fill alluvium }\end{array}$ & Parkvale sub-basin: $500-1,000$ & $50-150$ & S: $1-5 \mathrm{E}-4$ \\
\hline
\end{tabular}

Hydraulic parameters of the hydrostratigraphic units were estimated from pump test data in the Greater Wellington Regional Council well database. Estimates were done in bulk from a synthesis of groundwater pump test data and reasonable ranges conforming to the hydrogeologic reality of distinctive units and known groundwater yield. 
Given pumping tests are typically performed on high yielding zones; it is acknowledged there is a (or a potential for) bias in the hydraulic parameter data estimation, towards higher yielding bores. Consideration of this fact was made regarding this bias in the parameter estimation (Gyopari and McAllister, 2010a). Collated data estimated the following information throughout the Middle Valley catchment:

- Q1 unconfined gravel aquifers in the Greytown area (<15 metres deep);

- Q1 unconfined gravel aquifers of the Ruamahanga River (<15 metres deep);

- Q6-Q8 deep Parkvale and Carterton confined gravel aquifers (>15 metres);

- Alluvial fan gravels (<15 metres deep). 
5.6.1 Horizontal hydraulic conductivity
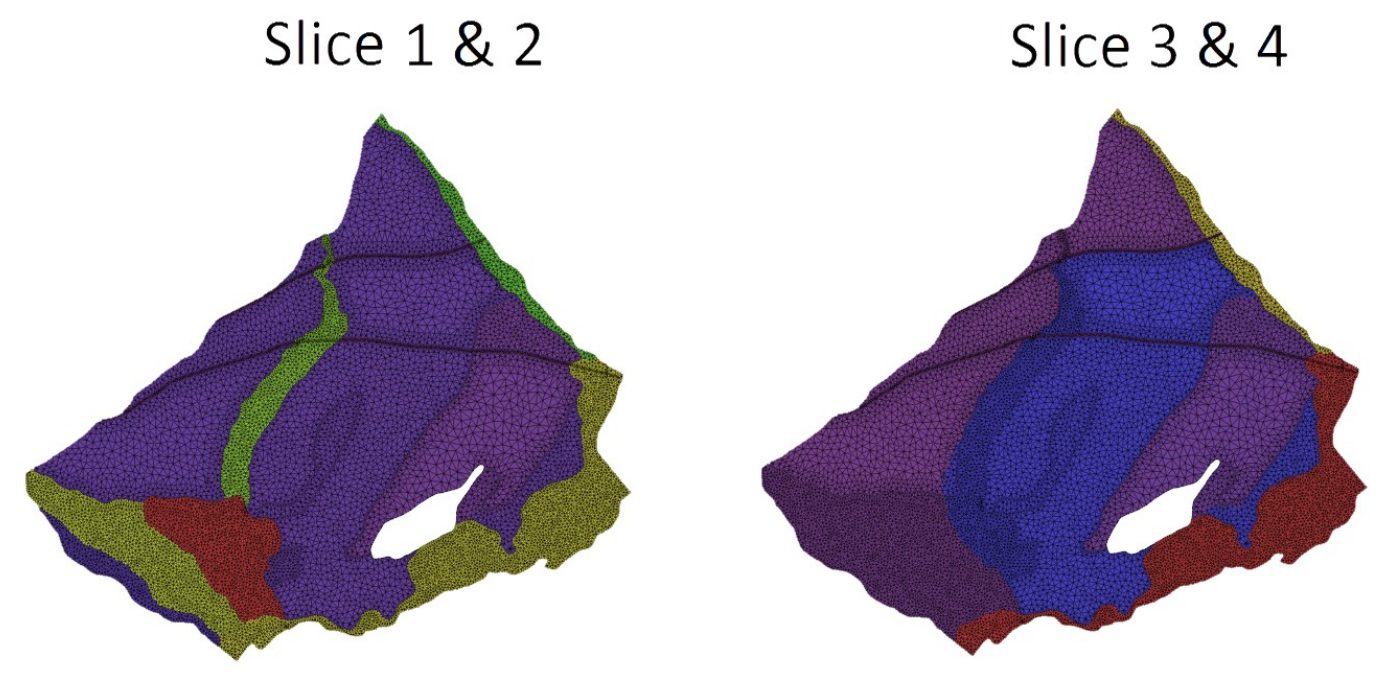

Slice $5 \& 6$

Slice $7 \& 8$
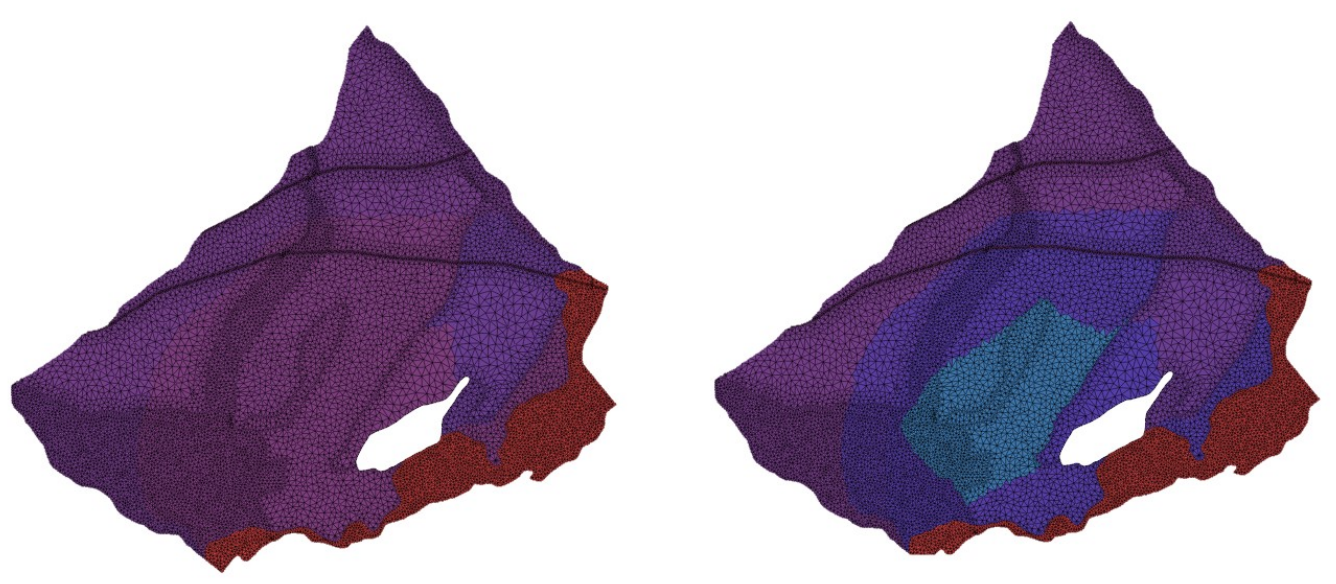

Conductivity

- Patches -

Slice $9 \& 10$

\begin{tabular}{c}
{$[10-4 \mathrm{~m} / \mathrm{s}]$} \\
47.3332 \\
42.6038 \\
37.8744 \\
33.1449 \\
28.4155 \\
23.6861 \\
18.9567 \\
14.2273 \\
9.49784 \\
4.76842 \\
\hline 0.0389966
\end{tabular}

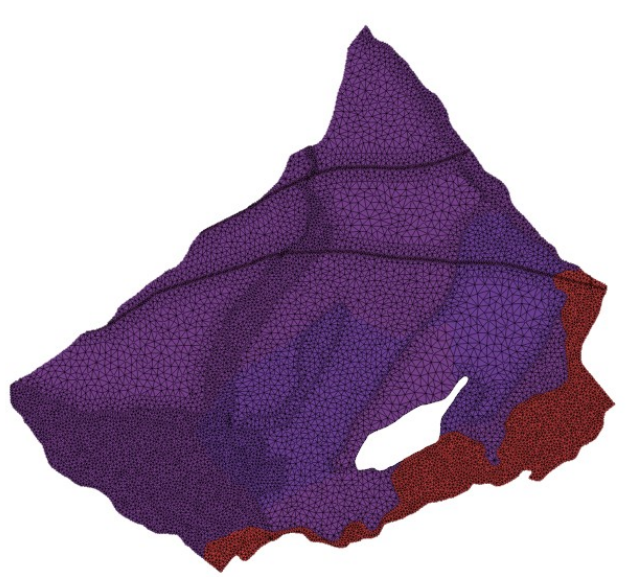

Fig. 5.13 Zonation of the horizontal hydraulic parameters, longitudinal and transverse directions (i.e. $x$ and $y$ ), of the ten slices. 
- Layers one and two

These layers exist only where Q1 gravel aquifers have been distributed by recent outwash (i.e. Quaternary sediments). Individual rivers can have either one or several material property zones (parameters) given the inherent variability of aquifer formation (Fig. 5.13).

- Layers three and four

Where Q1 alluvium is not present, layer three is the top layer in the model. Layer three is partially saturated across most of the model domain. Layers three and four are a combination of sediments of Q2-4 age from the last glaciation and provide a broad representation of the deeper subsurface. These two layers have identical parameter zones.

- Layers five and six

These layers are sediments derived from an interglacial period. They represent a large aquitard layer across much of the middle section of the model in the Parkvale sub-basin.

- Layers seven and eight

These alluvial sediments are of Q6 age and form productive aquifers in the Parkvale and Carterton sub-basins. Three zones form the Q6 aquifer which gradually increases in hydraulic conductivity from the outer valley alluvial fans to the centre of the Parkvale sub-basin.

- Layer nine

Layer nine is the lowest layer and represents Q7-8 age sediments. This includes a large zone which contains older low permeability fan gravels, and an inner zone centred on Parkvale representing a higher yielding section.

\subsubsection{Vertical hydraulic conductivity}

The vertical hydraulic conductivity allows vertical exchange between layers and zones and is often lower than horizontal conductivity (Fig. 5.14). The zones in the FEFLOW flow model are identical to the horizontal conductivity zonation, with different assigned parameters distinguishing slower vertical migration (see Appendix B). 

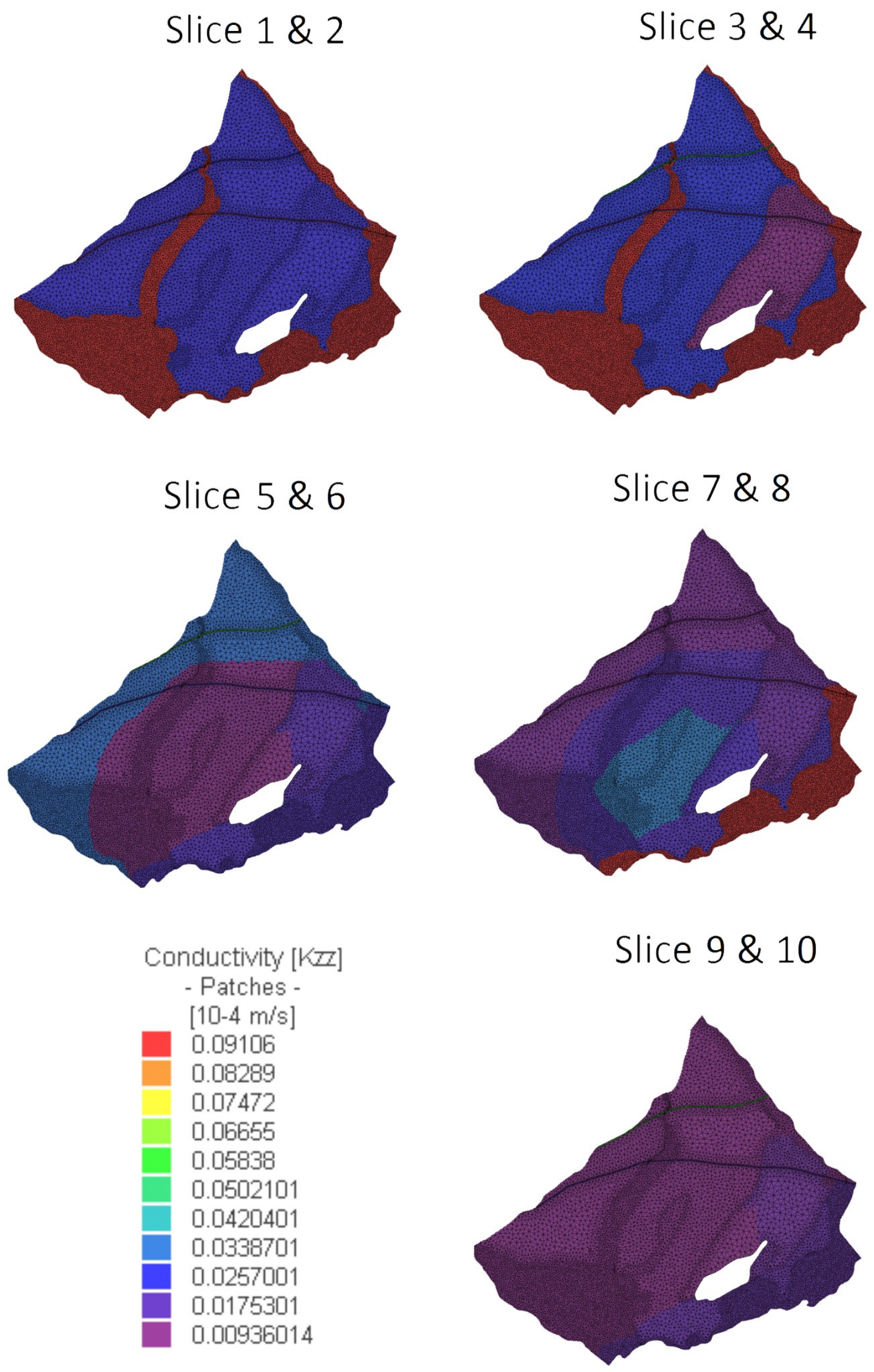

Fig. 5.14 Zonation of the vertical hydraulic parameters of the ten slices. 


\subsubsection{Specific storage}

One specific storage parameter was assigned for layers one to six (Fig. 5.15). It is assumed the storage coefficient is a relatively high and uniform value through these layers to the base of the Q5 aquitard in layers five and six. Deeper layers (e.g. seven, eight, and nine) have a more complex storage zonation with lower values, which decrease towards the centre of the Parkvale sub-basin. Four specific storage zones are distinguished in the lower layer storage system, from pumping test data, as detailed in Section 5.6.

\section{Slices 1-6}

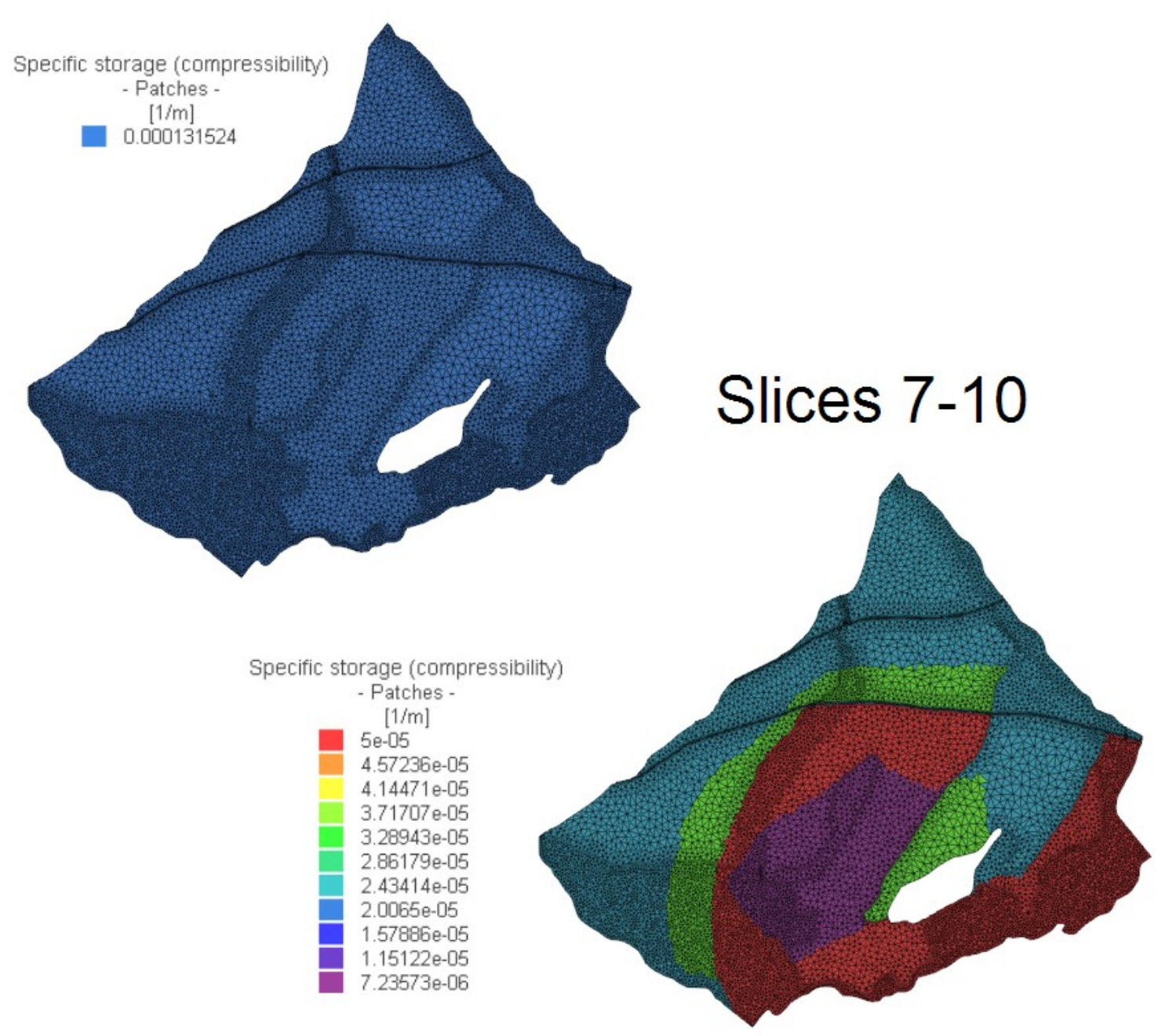

Fig. 5.15 Zonation of the specific storage parameters of the ten slices. 


\subsubsection{Faults}

The faults in the Wairarapa have an influence on regional groundwater flow (Fig. 5.16).

This is exemplified by the numerous fault springs throughout the Middle Valley. To simulate the effect of these fault lines, they are finely discretised into $100 \mathrm{~m}$ wide areas. The two faults have been assigned four separate hydraulic conductivity zones (i.e. two each).

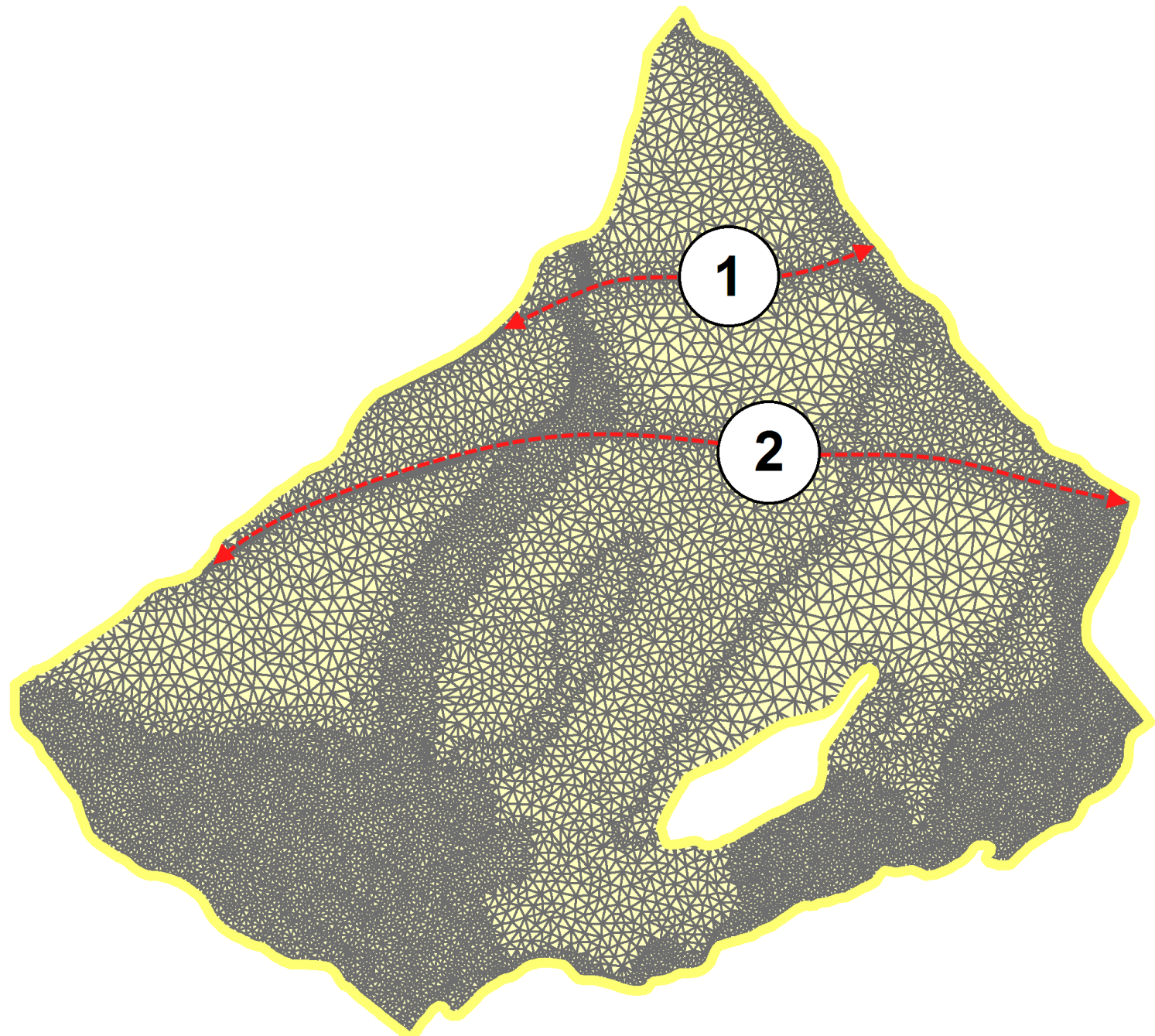

Fig. 5.16 Fault locations and visible fine discretization of fault lines in the Middle Valley catchment. 1: Masterton Fault and 2: Carterton Fault running from West to East across the catchment. 


\subsection{Calibration and observational data}

Calibration was performed to estimate the hydrogeological reality and increase the reliability of the simulated results used for regional water allocation and management. Calibration of the transient model was undertaken by Wellington Regional Council using the Parameter ESTimation software (PEST) inverse model in parameter estimation mode using the Gauss-Marquardt-Levenberg method. The method is an inverse approach, to simulate, compare and adjust flow and transport parameters to measured field data. The parameters calibrated within the model are:

1. Horizontal hydraulic conductivity $-\mathrm{K}_{\mathrm{x}}(\mathrm{m} /$ day);

2. Vertical hydraulic conductivity - $\mathrm{K}_{\mathrm{x}}(\mathrm{m} /$ day);

3. Specific yield - $S_{t}(\%)$;

4. Specific storage $-S_{s}(1 / m)$;

5. Transfer rate in $-\mathrm{I}_{\mathrm{T}}(1 / \mathrm{d})$;

6. Transfer rate out $-\mathrm{O}_{\mathrm{t}}(1 / \mathrm{d})$.

The parameters are calibrated to measured groundwater level, river stage, spring data and water balance estimates (Gyopari and McAllister, 2010a).

Calibration can be performed manually or with automated estimation algorithms. The manual calibration follows a trial and error procedure where simulated results are compared with observed field data. Parameters are adjusted based on known and/or estimated bounds, to match the observed data. Manual calibration adjustment can be time consuming, but can achieve good results. Manual calibration was initiated under steady state conditions to adjust and validate the conceptual model (Begg et al, 2005). A manual transient flow calibration was then performed to assess the model sensitivities and the accuracy of the conceptual model, assigned boundary conditions and hydraulic parameters. After the manual phase, PEST was used to provide flow parameter estimates, head simulated values, and flow; as well as significantly reducing processing time. Initially calibration was performed using a four-year simulation of variable recharge and system stresses applied. The final stage was a run performed over the 15 year simulation to again test robustness of the simulated results. 
The transient model validation run had 771 seven-day stress periods and duration of 5,400 days (Gyopari and McAllister, 2010a).

\subsubsection{Hydraulic head calibration}

Long-term monitoring wells were used in the model calibration (Fig. 5.17). The bore data sites are distributed throughout the Middle Valley, along surface water reaches and heavily irrigated zones such as the Parkvale sub-basin. Measured groundwater level data are taken at various depths, ranging from the ground surface to 50 metre depths (Table 5.7). The data for the 21 monitoring sites formed 10,205 weekly data values. Data from automatic recorders were averaged to form weekly data and raw manual data was implemented unchanged (Gyopari and McAllister, 2010a).

Weighting is an important factor when calibrating a model. Weights are assigned to data to inform the calibration processes of the specific significance of the individual observations. This is an attempt to influence the calibration process and focus the optimization on the important (and less-important) observations within the calibration dataset. Observation nodes were set on specific slices dependent upon the actual bore depth. A calibration weighting regime was developed for the monitoring bore data based on the estimated reliability of the data. Bores which are specified as dedicated monitoring bores, and are either continuously or manually operated, were given a weighting of one ( $25.6 \%$ of the head data). Sites which are pumping bores or that have unreliable drilling stratigraphic information were assigned a weighting of 0.75 (62.7\% of the head data), 0.5 for poor information ( $6.1 \%$ of the head data), or 0.25 for significantly poor information ( $0.3 \%$ of the head data). Given the complexity of a heterogeneous subsurface, some locations exhibit significant differences between simulated and observed values and some measurements were assigned a weight of 0 . These data had no effect on the calibration (5.29\%). These areas indicate zones of hydraulic complexity where additional data and/or model refinement is needed. 
Table 5.7 Middle Valley calibration well information. Source: Gyopari and McAllister (2010)

\begin{tabular}{|c|c|c|c|c|c|}
\hline Monitoring bore & Consent Info & Depth (m) & Pumping* & $\begin{array}{c}\text { Geological } \\
\text { unit }\end{array}$ & Weighting \\
\hline \multicolumn{6}{|c|}{ Area One: Greytown-Waiohine plains } \\
\hline S26/0490 & (Perry) & 5 & $M / D$ & Q1 & 1 \\
\hline$S 26 / 0500$ & (Rogan) & 3.4 & $M / D$ & Q1 & 1 \\
\hline S27/0225 & (Hammond) & 4.6 & $C / D$ & Q1 & 1 \\
\hline S26/0547 & (Craig) & 4.3 & $\mathrm{M} / \mathrm{P}$ & Q1 & 0.75 \\
\hline S26/0545 & (Craig) & 18 & $M / D$ & Q2-4 & 0.75 \\
\hline \multicolumn{6}{|c|}{ Area Two: Parkvale-Carterton sub-basins } \\
\hline S26/0675 & (McNamara) & 31.5 & $M / D$ & Q8 & 1 \\
\hline $\mathrm{S} 26 / 0568$ & (Denbee) & 45 & $\mathrm{M} / \mathrm{P}$ & Q6 & 0.5 \\
\hline S26/0743 & (Baring) & 33 & $\mathrm{C} / \mathrm{P}$ & Q6 & 1 \\
\hline S26/0738 & (Towgood) & 5.4 & C/P15 & Q2-4 & 1 \\
\hline S26/0155 & (Tulloch) & 13.4 & $\mathrm{M} / \mathrm{P}$ & Q2-4 & 0.75 \\
\hline S26/0656 & (WCB Tulloch) & 78.05 & M/D16 & Q8\# & 0.5 \\
\hline S26/0658 & (Craig) & 8 & $\mathrm{M} / \mathrm{P}$ & Q2-4 & 0.5 \\
\hline \multicolumn{6}{|c|}{ Area Three: Upper Waiohine Fan } \\
\hline S26/0223 & (Nicolson) & 9.9 & $\mathrm{M} / \mathrm{P}$ & Q2-4 & 0.5 \\
\hline S26/0242 & (E Coast Fert) & 7.5 & $M / D$ & Q2-4 & 1 \\
\hline S26/0229 & (E Coast Fert) & 23.8 & $M / D$ & Q2-4 & 1 \\
\hline S26/0236 & $\begin{array}{l}\text { (WCB } \\
\text { Oldfield) }\end{array}$ & 41.4 & $M / D$ & Q6 & 1 \\
\hline \multicolumn{6}{|c|}{ Area Four: Waingawa floodplain } \\
\hline S26/0308 & (Oldfield) & 5.5 & $C / D$ & Q1 & 1 \\
\hline S26/0298 & (Oldfield) & 7 & $\mathrm{C} / \mathrm{P}$ & Q1 & 0.5 \\
\hline \multicolumn{6}{|c|}{ Area Five: Fernhill } \\
\hline T26/0326 & (McKay) & 10 & $\mathrm{M} / \mathrm{P}$ & Q2-4 & 0.75 \\
\hline \multicolumn{6}{|c|}{ Area Six: Middle Ruamahanga Valley } \\
\hline S26/0749 & (Blundell) & 10 & $C / D$ & Q2-4 & 1 \\
\hline S27/0248 & (Morrison) & 7.9 & $\mathrm{M} / \mathrm{P}$ & Q2-4 & 0.75 \\
\hline
\end{tabular}

* Continuous or Manual data / Dedicated observation or Pumping well 


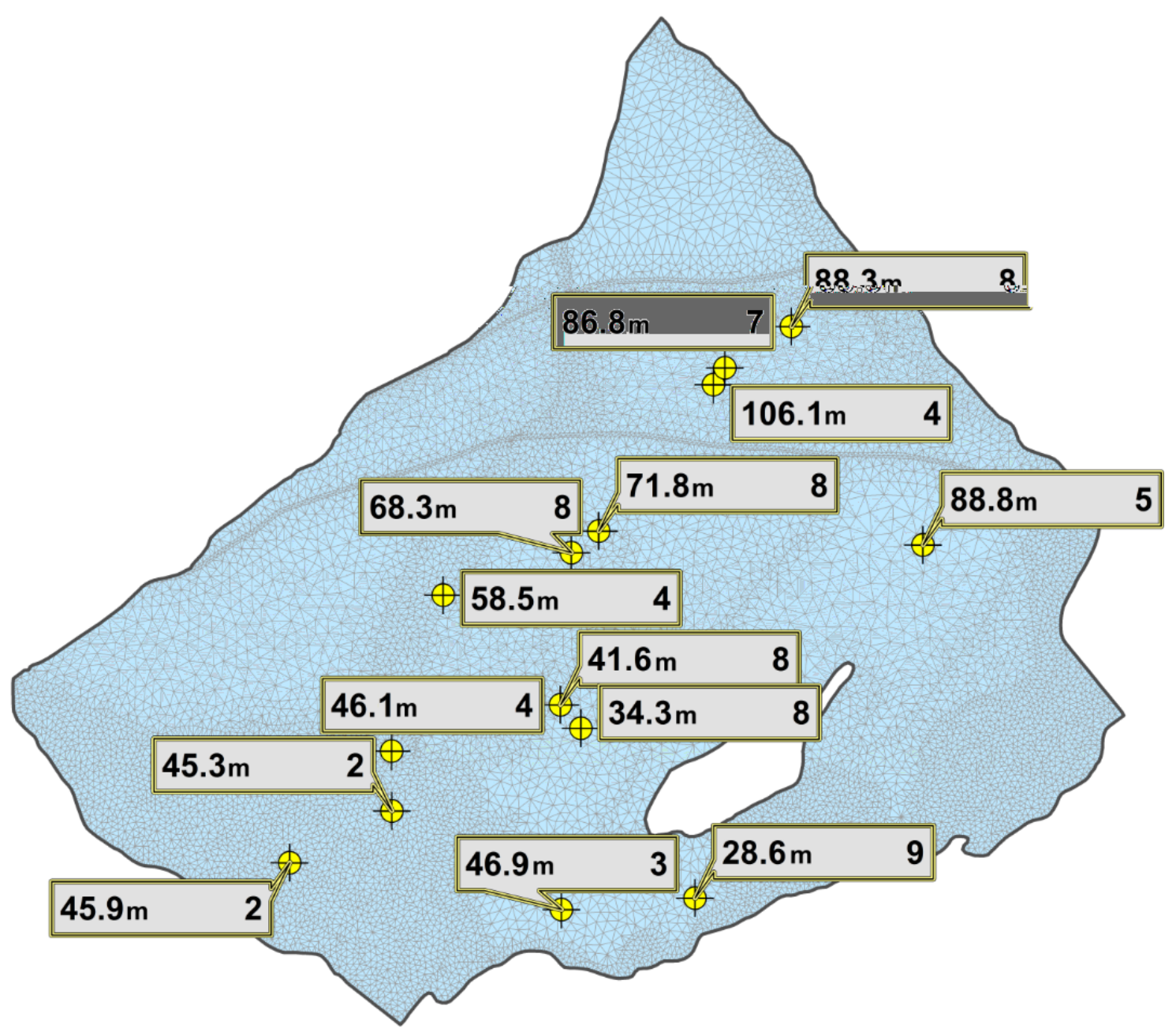

Fig. 5.17 Spatial distribution of hydraulic head observational data utilized in the calibration of the flow model. Node depth $(m)$ indicated on left, node slice on right, $n=14$.

\subsubsection{Calibrated parameters}

Twenty-nine adjustable hydraulic conductivity (horizontal and vertical) and unconfined and confined storage parameters were initially used for estimation. The adjustable parameters were optimized within upper and lower bounds relative to the variation in the objective function (see Sections 2.4.3 and 2.4.3). The parameter bounds were prescribed on the basis of groundwater pump test data as well as estimated ranges for the material contained within each zone, for example, Q1 gravels (Kx01 parameter) were given a calibrated value of $320.9 \mathrm{~m} / \mathrm{d}$ using $282.3 \mathrm{~m} / \mathrm{d}$ as the lower and 364.7 $\mathrm{m} / \mathrm{d}$ as the upper bounds at the $95 \%$ confidence limit. As parameters reached their respective bounds, or where parameter values became highly correlated and insensitive, they were changed to fixed parameters. 
At the final calibration run 17 adjustable hydraulic conductivity parameters were estimated and 42 zones were fixed, including river boundary transfer rate zones (Gyopari and McAllister, 2010a).

The aim of the optimization is to reduce the objective function to a minimum value which is the sum of the squared weighted residuals (i.e. head error). The estimation runs in the Regional Council calibration were able to reduce the overall objective function from 17,114 to 4,057 (76 \% reduction) during the PEST optimisation procedure (Gyopari and McAllister, 2010a). The calibration dataset was used in the extended development and implementation of the coupled flow and transport age model, as described in Chapter Six.

\subsubsection{River and spring manual calibration}

River flow data was also used in the calibration. This provided important information on the flux between surface and groundwater. Specific reaches were identified as gaining from, losing to or neutral in respect to groundwater movement. Spring discharge also indicated the amount of groundwater discharge to the many spring sections throughout the Middle Valley (see Fig. 4.14). These surface water interactions were not implemented in the automatic calibration procedure; instead, hydraulic parameters influencing surface water interactions were manually assessed and modified relative to water balance targets (Gyopari and McAllister, 2010a).

\subsubsection{Global water budget calibration}

Catchment water balances were used in the Middle Valley calibration. Rainfall recharge, transfer to rivers from groundwater, transfer from surface water to groundwater and irrigation wells were evaluated for their simulated and estimated field output for accuracy assessment and model validation. Rainfall recharge is highly seasonal, an average of $190,000 \mathrm{~m}^{3} /$ day (equivalent to the average total discharge to surface water), with peak rainfall typically over the winter months (Fig. 5.18). During these heavy precipitation periods, the groundwater table gradually rises causing the peak flux from groundwater to river channels. 
This reverses in the drier summer months with around $30 \%$ of the recharge (from rainfall and rivers) contributing to the storage replenishment. Groundwater abstraction (primarily for irrigation) represents about $13 \%$ of the total water balance for the catchment.

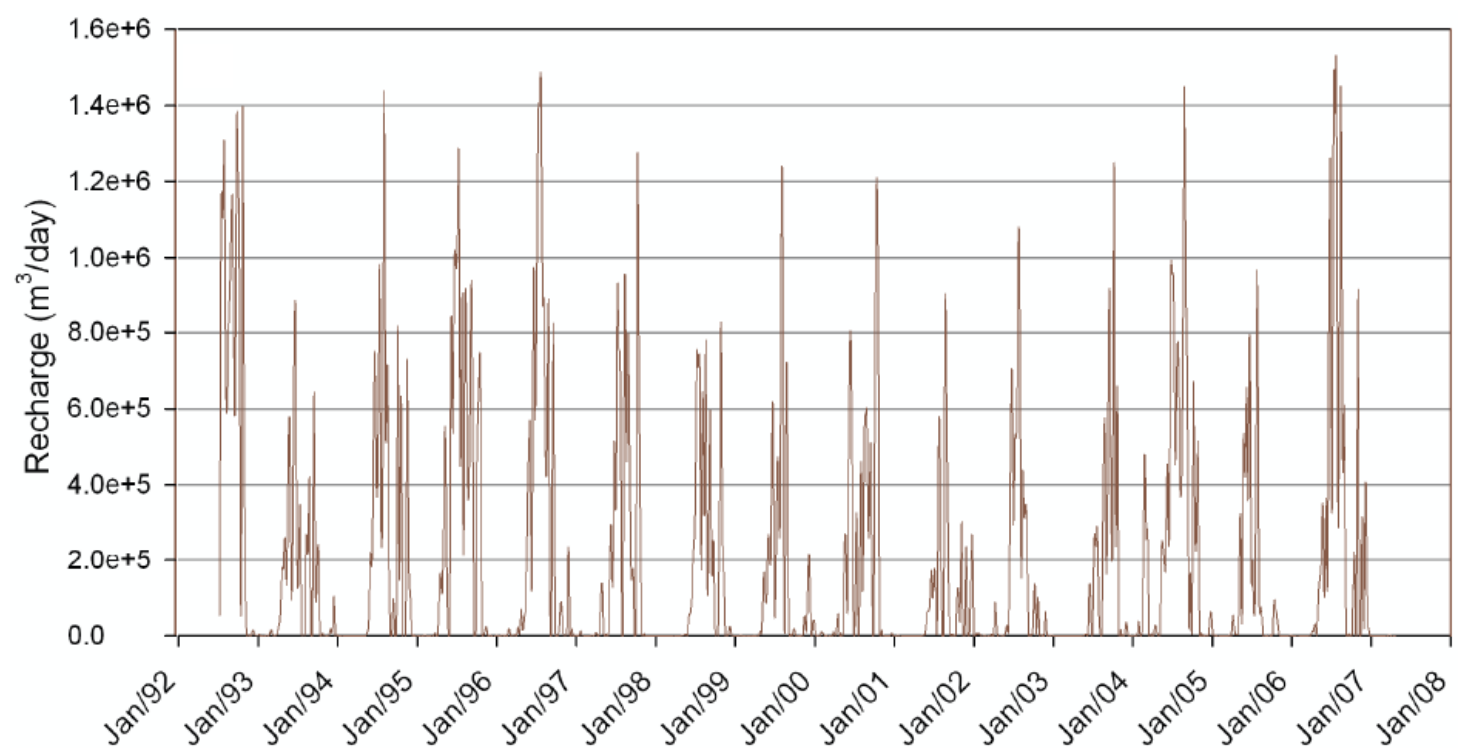

Fig. 5.18 Global recharge input for the 15 year simulation. Source: Gyopari and McAllister (2010).

\subsubsection{Springs}

The simulated spring flows exhibited acceptable error against the limited observational data. The monitoring data are subject to additional surface runoff, including storm water from Greytown, and therefore exhibits a more 'peaky' record compared to the simulated flows (Fig. 5.19). Papawai Stream (spring fed stream from Papawai spring) has a simulated mean annual flow of $250 \mathrm{~L} / \mathrm{s}$ and a mean summer low of about $200 \mathrm{~L} / \mathrm{s}$. Tilsons Creek has a modelled mean flow of about $100 \mathrm{~L} / \mathrm{s}$ and a summer base flow of about $70 \mathrm{~L} / \mathrm{s}$. These flows compare favourably to the flows estimated by Butcher (2007a) as well as actual monitoring data. Butcher (2007b) estimated a mean annual flow for the Parkvale spring system of $150 \mathrm{~L} / \mathrm{s}$ and a mean annual low flow of $70 \mathrm{~L} / \mathrm{s}$ on the basis of limited gauging data. The model simulates a mean flow of $150 \mathrm{~L} / \mathrm{s}$ and summer low flow of around 50-70 L/s. The simulated base flows on the Masterton and Carterton fault spring systems were in the order of $100 \mathrm{~L} / \mathrm{s}$ and $50 \mathrm{~L} / \mathrm{s}$ for the Carterton and Masterton fault spring systems respectively. These simulated in close agreement with estimated and measured spring flows reported by Butcher (2007a). 
The model indicates that flow drops to about $50 \%$ of the mean flow during summer, consistent with available observation data.

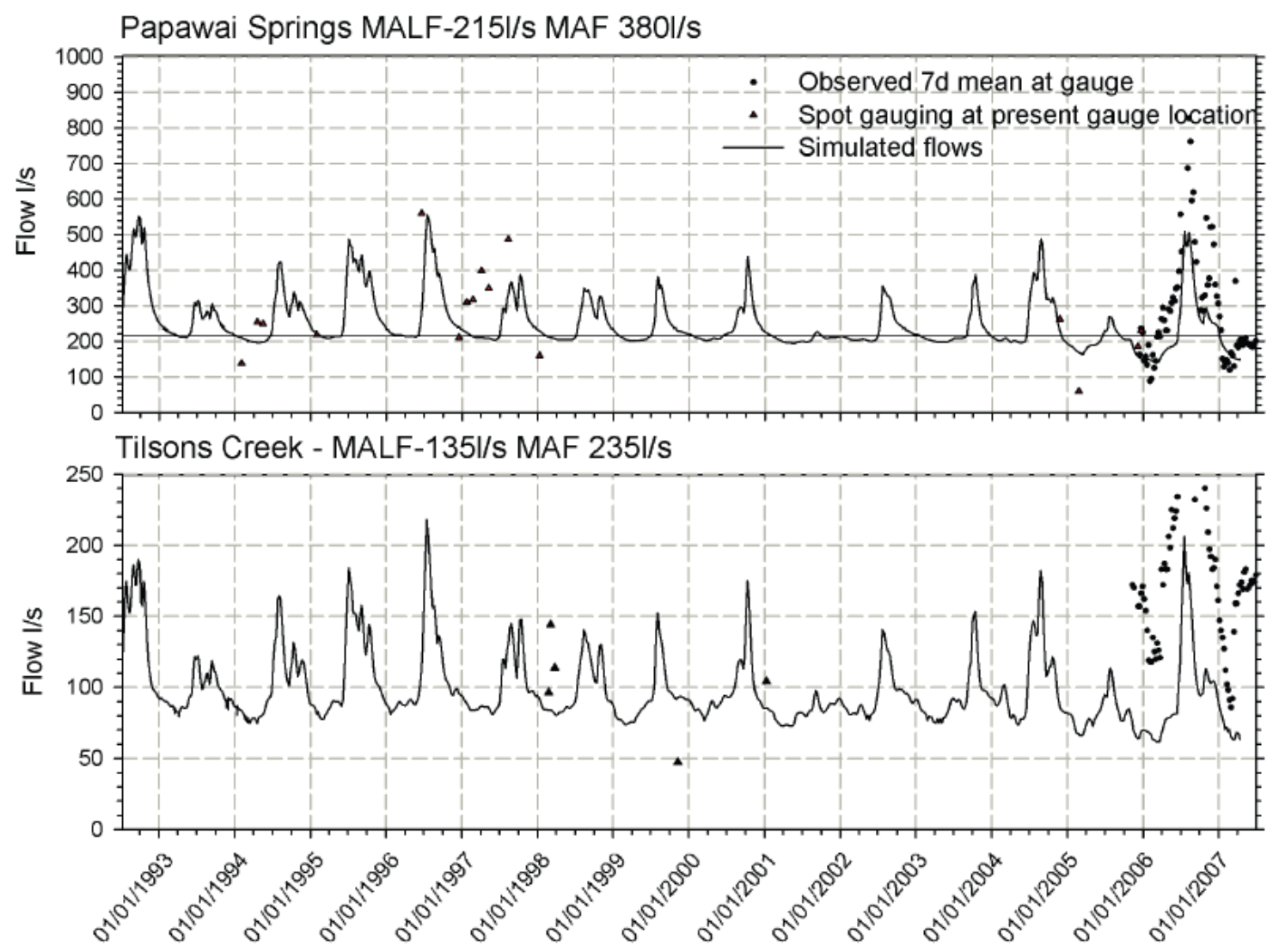

Fig. 5.19 Papawai and Tilsons Creek simulated and (available) observed flow comparison. Source: Gyopari and McAllister (2010).

\subsection{Middle Valley flow model summary}

The Greater Wellington Regional Council investigation developed the Middle Valley transient flow model for the regional groundwater management of the Wairarapa. The model was formulated using the finite element method within the FEFLOW

groundwater modelling software, simulating groundwater movements between the $1^{\text {st }}$ July 1992 and the $1^{\text {st }}$ May 2007 on a weekly time step. The project combined extensive prior hydrological, hydrochemical, and geological information of the Wairarapa Valley basin and utilized groundwater abstraction, river, and rainfall data in the calibration phase to estimate the hydrogeologic parameters (Begg et al, 2005; Daughney, 2007; Jones and Baker, 2005; Jones and Gyopari, 2006; Morgenstern, 2005; Tait et al, 2002). The model was constructed to assist with the development of new groundwater allocation policy. 


\section{Chapter 6}

\section{Middle Valley age model methodology}

All truth passes through three stages. First, it is ridiculed. Second, it is violently opposed. Third, it is accepted as being self-evident.

Arthur Schopenhauer

Flow models are widely developed for abstraction and sensitivity assessment. These existing models can be modified to simulate age, providing a relatively quick and potentially effective groundwater age simulation. The flow and transport in the Middle Valley model was simulated using the Ground Water (GW) software developed by Cornaton (2007). Ground Water (GW) was used to model age as FEFLOW did not have the capabilities to determine age at the time when the analysis was carried out ${ }^{6}$. The existing Wellington Regional Council FEFLOW model was modified to couple transport. First tritium migration was simulated using known tritium concentrations in rainfall to calibrate the flow and transport parameters (in addition to observed hydraulic heads) after which, age could be directly simulated in the catchment.

\subsection{Middle Valley Ground Water (GW) age model}

The FEFLOW model was modified to the run using the Ground Water (GW) software. This change was implemented due to the latter code's flexibility, finite element base, and the numerical implementation of the TMLTGT, which enables simulated transient age distributions (not available in FEFLOW). The conversion uses the feflow2gw plugin which converts a FEFLOW input file into the Ground Water (GW) input files (Cornaton, 2007). Several separate files are required to run Ground Water (GW) in a command line environment which is flexible with both DOS and Linux operating systems.

\footnotetext{
${ }^{6}$ A recent release of FEFLOW, 6.2, has mean lifetime expectancy and exit probability capabilities as of late-2013.
} 
These files define the simulation run time, mesh, solvers, numerical techniques, timeseries data, and model output. Ground Water (GW) allows the simulation of one, two, and three-dimensional water and mass transport in a fully-integrated mode. For example, water starting the hydrological cycle as rainfall can migrate to the various hydrological surface and subsurface features, and is simulated as it would behave in the actual catchment. This fully-coupled numerical solution integration also allows dissolved solute transport to be simulated through surface and subsurface domains.

Utilizing an existing flow model relies on comparable model output between software if patched between different software, in this case, the FEFLOW and Ground Water (GW) codes. Simulations should show similar patterns and be within an appropriate range. Flow comparisons are assessed between identical nodes within the FEFLOW model and Ground Water (GW) model.

\subsection{Coupled flow and transport model}

The flow model initially consisted of all the parameters and data from the calibrated Wellington Regional Council FEFLOW model (see Chapter 5). The first objective was to transfer the model between the different software codes and assess the apparent changes between the simulations within the different codes. The Ground Water (GW) and FEFLOW Middle Valley models each have identical node zonation. Several observation nodes throughout the Middle Valley domain will be identified and assessed relative to their difference in hydraulic heads over the simulation period. The time periods simulated were: 1 ) the $2^{\text {nd }}$ of July 1977 to $31^{\text {st }}$ June 1992 to generate the models initial transport conditions, and 2 ) the primary simulation period from the $1^{\text {st }}$ July 1992 to the $1^{\text {st }}$ May 2007. The Middle Valley model contains the productive groundwater reservoirs, as well as several aquitards, to a maximum depth of 72 metres (Fig. 6.1, Fig. 6.2 and Table 6.1). 
Table 6.1 Middle Valley groundwater catchment elevation and depth.

\begin{tabular}{cccc}
\hline Boundary & $\begin{array}{c}\text { Surface elevation } \\
\left(\text { asl }{ }^{*}\right)\end{array}$ & $\begin{array}{c}\text { Groundwater basement } \\
\left(\text { asl }{ }^{*}\right)\end{array}$ & $\begin{array}{c}\text { System depth } \\
(\mathrm{m})\end{array}$ \\
\hline Northern & 187.94 & 116.41 & 71.53 \\
Western & 104.89 & 47.05 & 57.84 \\
Middle & 79.74 & 39.82 & 39.93 \\
Eastern & 79.84 & 37.59 & 42.25 \\
Southern & 46.14 & 17.07 & 29.06 \\
\hline
\end{tabular}

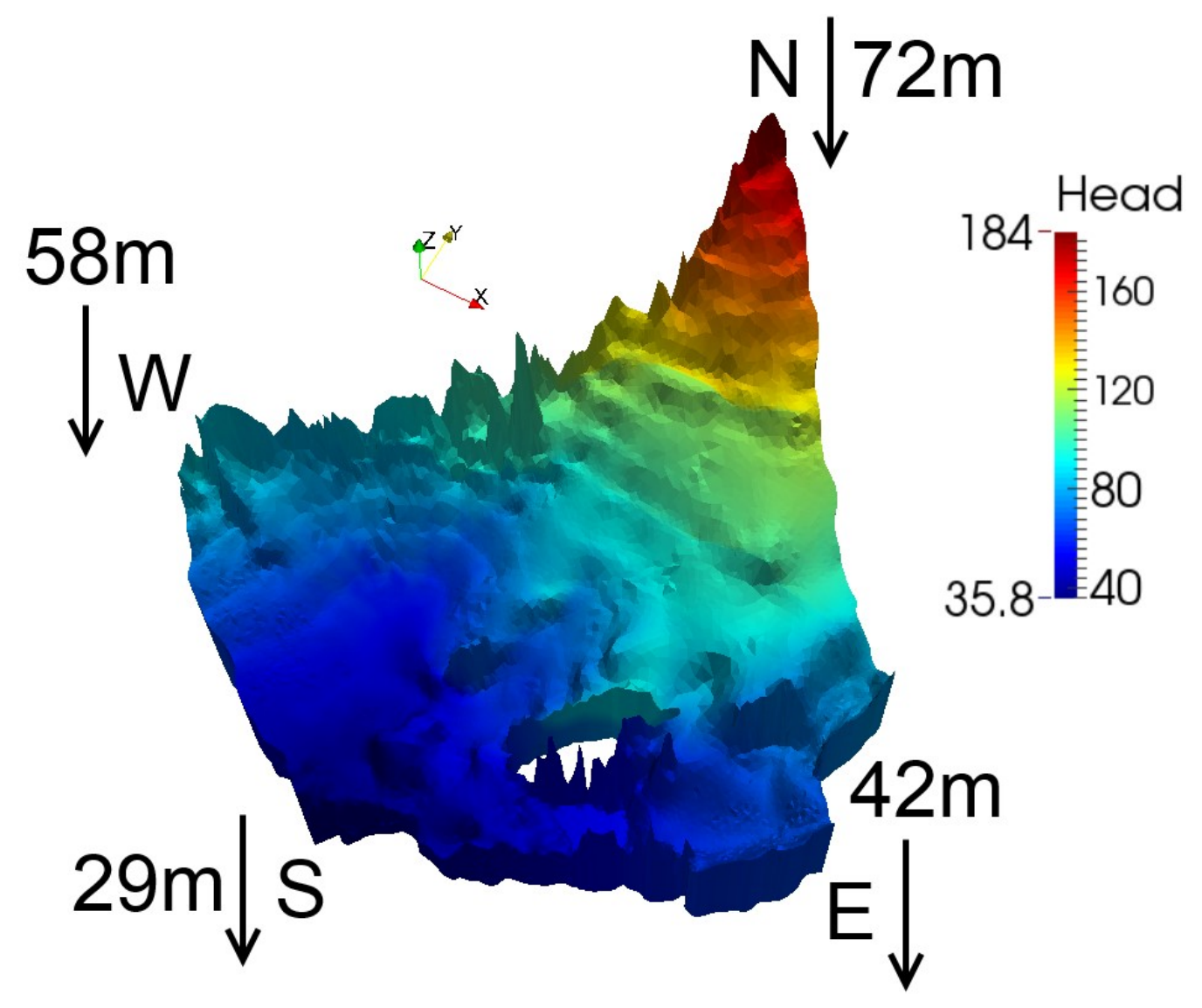

Fig. 6.1 Middle Valley groundwater system depths. 

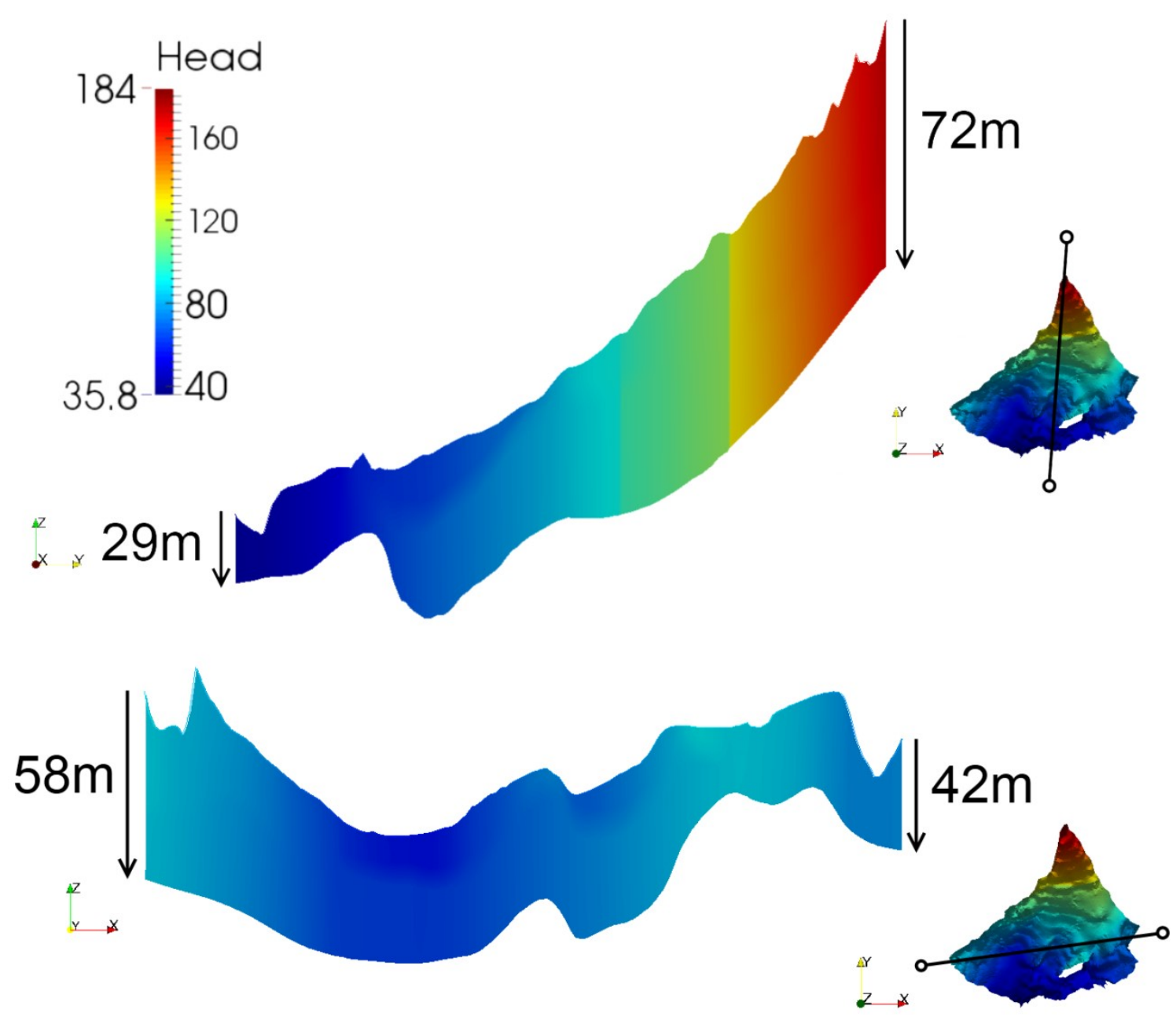

Fig. 6.2 South to North transect and West to East transect, indicating the model (i.e. groundwater system) depth, and hydraulic head on the $1^{\text {st }}$ of July 1992.

Solute transport is the movement of dissolved molecules in flowing groundwater (Fitts, 2002). This involves both physical and chemical processes, for example, advection, dispersion, adsorption, biodegradation, and chemical reactions. Age is simulated as a transport process with the groundwater particles ageing relative to rainfall recharge. As tritium is the only tracer that is incorporated as part of the water molecule, advection and dispersion are the only processes affecting its movement through the subsurface (Cook and Herczeg, 2000). 
The following steps were followed in the implementation of the coupled flow and transport model:

- The flow parameters, mesh, initial head condition, and transfer conditions taken from the calibrated FEFLOW flow model were used in the coupled Ground Water (GW) model (initially) without change;

- Recharge was implemented separately (as required) as an appended recharge spreading layer on the top slice of the Ground Water (GW) model. Time-varying rainfall input was used from the FEFLOW flow model, aside from the conversion to $\mathrm{m}^{3} / \mathrm{s}$;

- Boundary conditions were applied in the transport model for the simulation of tritium. As tritium is a component of the water molecule this was applied as a specified input implemented as Dirichlet (type-one) boundary conditions across the top slice of the model relative to the rainfall and measured concentrations in rainfall (Morgenstern, 2005; Stewart and Taylor, 1981);

- Conservative transport parameters were applied for longitudinal vertical and horizontal transverse dispersivity and diffusion. The known decay constant for tritium was specified as $1.78 \times 10^{-9}$ per second.

The transient Middle Valley Ground Water (GW) model takes around 1.5 to 2.5 hours to complete a single 15 year run with Crank-Nicholson fixed time-stepping. The model was run on two platforms:

1. A 16 core $1.99 \mathrm{GHz}$ Linux server with $62.86 \mathrm{~GB}$ RAM (using 2-4 threads per simulation) running Red Hat 4.4.6-4 OS;

2. A 64-bit PC Intel Quad Core i7-2600 CPU $3.4 \mathrm{GHz}$ with 8GB RAM running Windows 7 OS.

\subsubsection{Time discretization}

Temporal discretization can be either set to adaptively generate the required timesteps controlled within a variable range throughout the simulation, or set to automatically generate specified time-steps. 
This pre-defined time-stepping strategy has a maximum step size and a bias/multiplier to increase the step size, or a constant time step if set to 1.0. The adaptive regime is controlled by setting a maximum time step and both minimum and maximum step size scaling factors.

This results in the discretization starting with small increments, gradually increasing to the maximum, whereas the pre-defined strategy progresses in constant increasing steps from the start (e.g. 0-7-14-21-28 days). In terms of simulation time, an adaptive Crank-Nicholson scheme completed in roughly twice the amount of time compared to the fixed Crank-Nicholson time-stepping regime (i.e. 1561 steps instead of 783). The Crank-Nicholson and fully-implicit schemes were used throughout the modelling process as they proved to yield the "realistic" results, offering the best compromise between stability and efficiency (i.e. run times). The explicit scheme resulted in obvious simulation errors.

\subsubsection{Hydrogeologic parameters}

Flow parameters were initially unmodified from the FEFLOW model conversion. The converted Ground Water (GW) model had 101 unique material classes (102 including the recharge spreading layer) with flow parameters derived from the inverse calibration procedure to measured hydraulic heads (see Appendix B). In order to increase computational efficiency the number of material classes was reduced. This was achieved by setting a conservative universal porosity value of 0.2 in the FEFLOW model, then exporting the model run files across into the Ground Water (GW) software format. This reduced the number of material classes from 102 to 56 (including the recharge spreading layer, effectively 101 to 55). This reduced simulation run times and significantly enhanced the calibration process. Flow parameters are discussed in Section 5.6. 
Transport parameters define how a solute migrates and reacts in the subsurface. There are seven elemental mass transport parameters implemented in the Middle Valley Ground Water (GW) model:

1. The material class identifier (MatID);

2. Porosity (poro);

The three coefficients of dispersivity:

3. Longitudinal dispersivity $(a L)$;

4. Transverse horizontal dispersivity (aTh);

5. Transverse vertical dispersivity $(a T V)$;

6. Molecular diffusion $(D m)$;

7. The decay constant (Lambda).

The assigned transport parameters were chosen considering a conservative value based on recommendations in Cornaton (2007) and Freeze and Cherry (1977). Porosity does not affect a flow simulation and this is an important consideration for the coupled transport and flow model. Hydraulic conductivity parameters however affect both flow and transport simulations, as well as the storativity of the media; subsequently mass transport is affected by any parameter governing advection, such as horizontal hydraulic conductivity. Each unique material zone can have a unique value for each of the above listed parameters (Fig. 6.3). In the implementation of the model, it is assumed that within each unique material zone, the parameters are homogeneous and isotropic within each zone (see Appendix A for extended model zonation). 


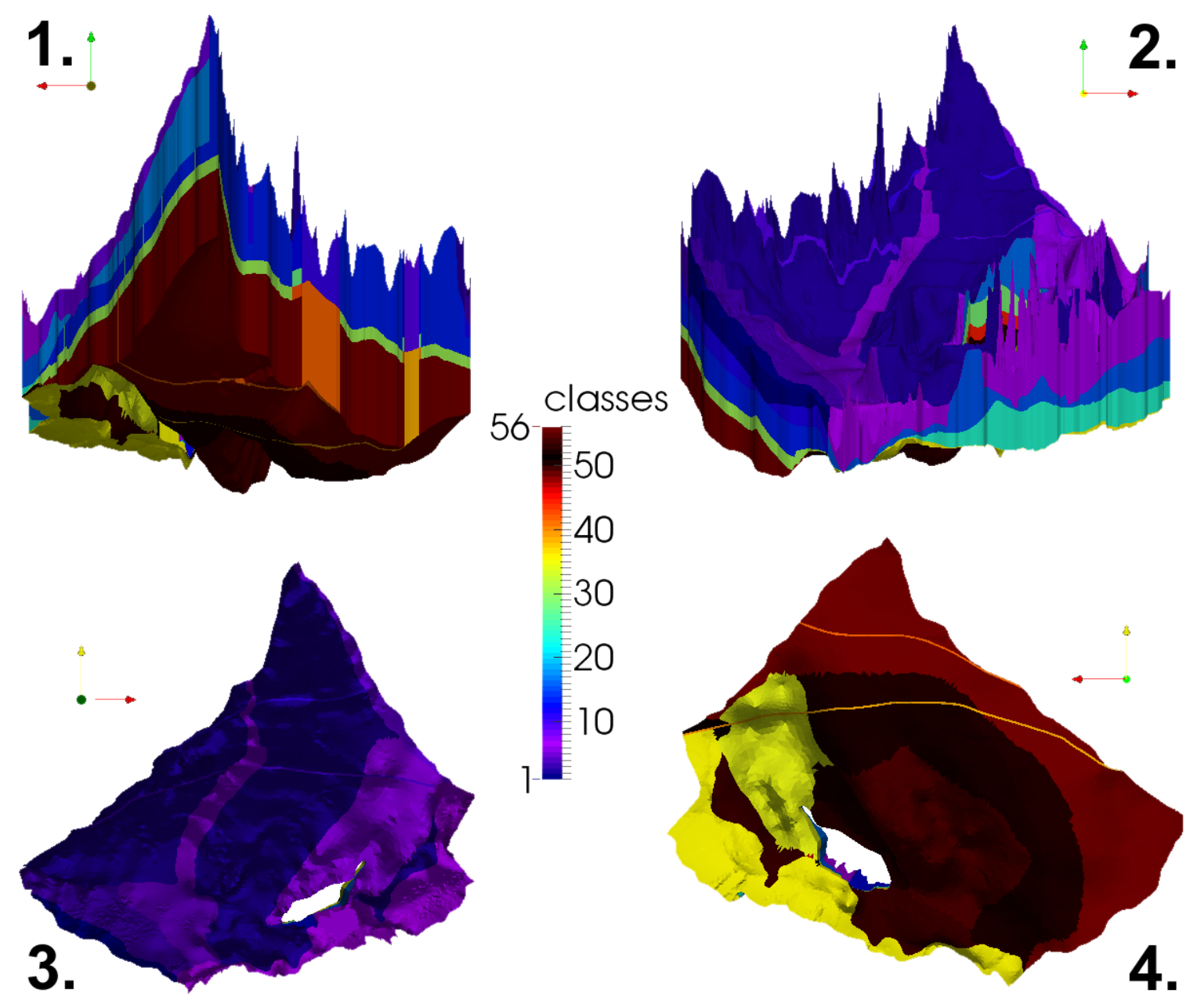

Fig. 6.3 Middle Valley model domain distinguishing the material zones throughout. 1. Facing south, 2. Facing north, 3. Facing down (above), 4. Facing up (bottom).

\subsubsection{Recharge spreading layer}

Rainfall recharge is a primary groundwater source in the Middle Valley. The implementation of the simulated rainfall infiltration can be implemented using a boundary condition, such as a Neumann (second-type) condition, or a recharge spreading layer. A recharge spreading layer corresponds to a set of two-dimensional elements with no assigned hydraulic parameters as a specific material class where the flow sources are specified. Recharge entering the surface nodes is proportional to their surface of influence (Cornaton, 2007). The recharge spreading layer has been implemented on the top slice of the Middle Valley domain and as the last material identifier. It is implemented as the last material identifier to avoid any confusion between the two models in their respective codes. 
Recharge can be simulated without the requirement of any boundary conditions and the model is informed of the existence of the layer in the model run code. Typically, a Neumann type-two boundary condition is used for rainfall simulation with a fixed flux (e.g. Darcy flux) across a model boundary (Diersch, 2009).

Time-varying rainfall recharge data is used as the source input. Rainfall was estimated throughout the domain from rainfall data and interpolated across the Middle Valley elements. The collation of observed rainfall data and modelled rainfall recharge input was completed by NIWA and Wellington Regional Council (see Section 5.2).

Groundwater recharge is simulated through precipitation on the top nodes of the catchment, as well as groundwater flux via river channel beds in close proximity to shallow aquifers.

A custom python code modifies the existing code and appends a slice to the top of the model (see Appendix $\mathrm{H}$ ). This is required as the conversion from FEFLOW does not transfer recharge sources and needs to be manually implemented. Surface water channels are excluded from the rainfall recharge input. These sections include the primary river channels (Ruamahanga, Waiohine, and Waingawa), streams (Mangatarere), and springs (Papawai, Tilsons, Muhunoa, Parkvale, Beef Creek, Masterton Fault and Carterton Fault). The custom python code performs the following actions:

- Converts recharge data from $\mathrm{m} / \mathrm{d}$ (FEFLOW) into $\mathrm{m} / \mathrm{s}$ (GW);

- Copies the top elements and nodes;

- Adds the source for recharge/flow;

- Offsets elements to insert recharge spreading layer;

- Creates a new time-varying input data file;

- Writes model input: elements and nodes for the recharge spreading layer, and recharge source linking the time-varying rainfall recharge data. Transport boundary conditions.

The input of tritium and groundwater age is simulated through rainfall recharge on the top slice of the model. 
The nodes across the top slice have been assigned transport boundary conditions (Fig. 6.4). River, stream, and spring sections within the Middle Valley have been assigned Cauchy flux conditions, and are excluded from receiving Dirichlet transport boundary conditions. A Dirichlet boundary condition specifies the concentration of tritium on the upper surface of the Middle Valley model, or for age simulation, an age of zero across the top slice of the first layer.

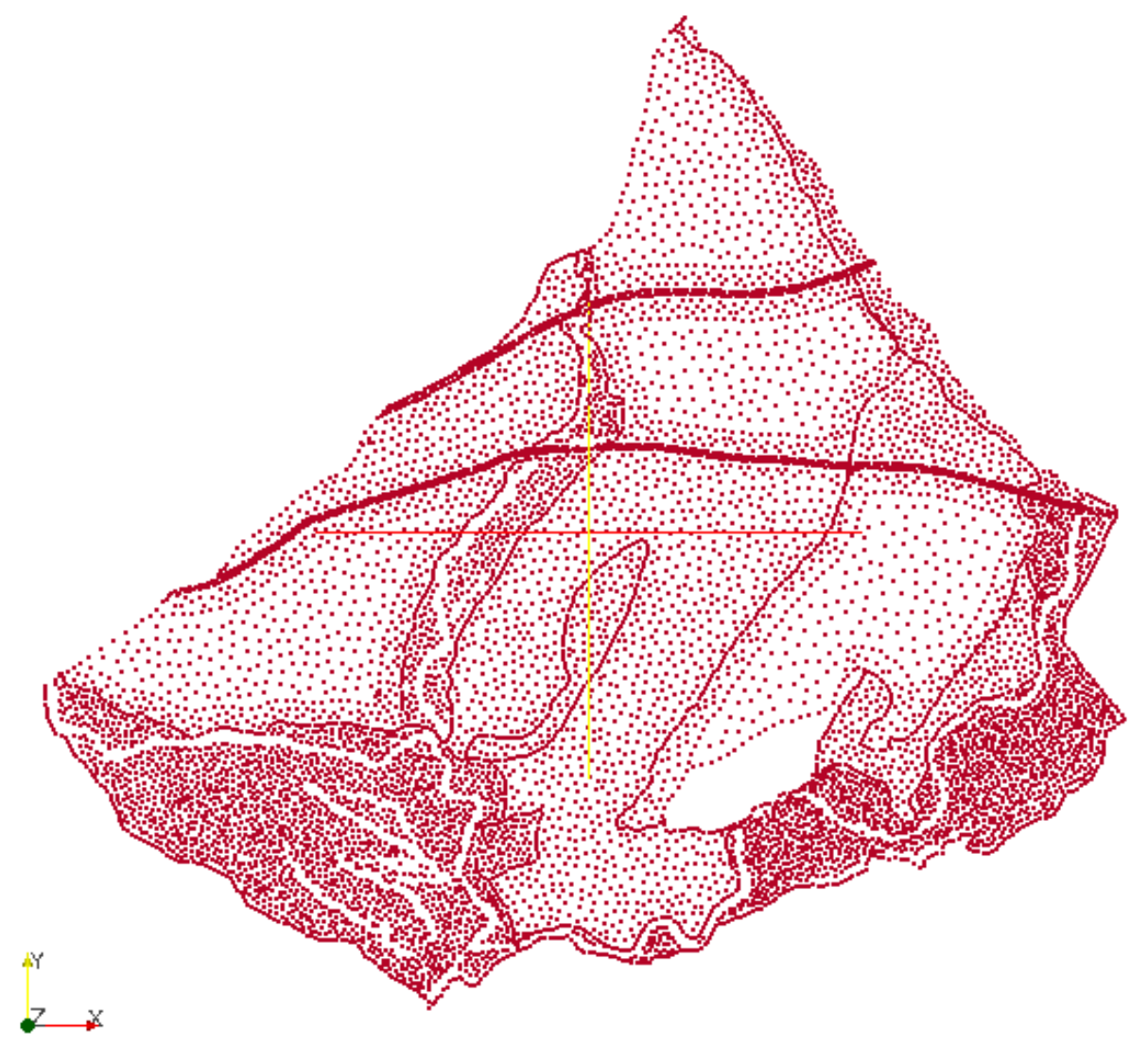

Fig. 6.4 Nodes on the top layer are assigned Dirichlet boundary conditions, excluding water channels, to simulate the transport of tritium via rainfall recharge.

Measured tritium data have a scale factor depending on the latitude and elevation of the area in relation to where tritium concentrations are measured. The base tritium rainfall measurements are taken at Kaitoke, north of Wellington. Tritium concentrations vary with latitude and Kaitoke is located at roughly the same latitude and elevation as the Wairarapa Valley, therefore, there is no scale factor required (or a scale factor of 1.0) for the tritium rainfall data applied to the Middle Valley (Cook and Herczeg, 2000; Stewart and Morgenstern, 2001). Observed tritium data was measured in the Wairarapa between 1983 and 2008 (Morgenstern, 2005). 


\subsubsection{Initial transport conditions}

Tritium was initially simulated through the model for the pre-conditioning and calibration of the model. Simulating tritium through the domain is done using known time-varying atmospheric tritium $\left({ }^{3} \mathrm{H}\right)$ concentrations and these are assigned (as transport and solute input) to the rainfall recharge rates (Fig. 6.5) (see Appendix E and Appendix F). The distribution of rainfall, and hence tritium, varies both spatially and temporally across the Middle Valley catchment. Initial transport conditions specify the concentration of tritium at all points throughout the model at the beginning of the 15 year simulation period. These conditions are assigned to nodes throughout the Middle Valley model domain. Defining these initial transport conditions is required for a representative starting state and set by pre-conditioning the model with a steady state, semi-transient or full-transient simulation.

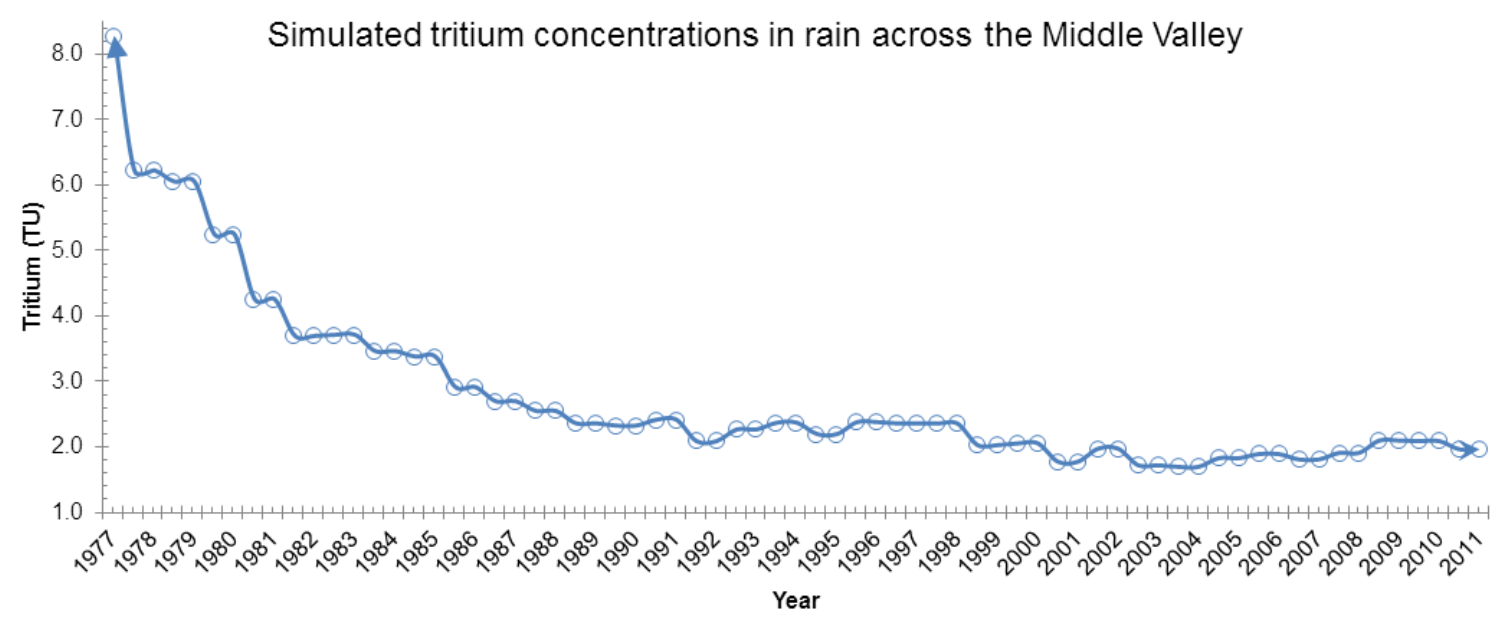

Fig. 6.5 Tritium concentrations simulated in the Middle Valley catchment from 1977 to 2007.

Initial tritium concentrations for the $1^{\text {st }}$ of July 1992 were estimated by simulating known tritium concentrations in rainfall over a 15 year period, from $2^{\text {nd }}$ of July 1977 to $31^{\text {st }}$ June 1992. The period 1977-1992 included the tail end of the bomb peak caused by nuclear testing and widespread anthropogenic tritium release in the atmosphere (see Fig. 3.4) (Cook and Herczeg, 2000). The initial transport conditions are important to accurately simulate tritium transport in the Middle Valley, as tritium concentrations are used in the calibration of the hydraulic parameters, and have an initial concentration throughout the basin. 
Transport conditions for tritium were evaluated using calibrated porosity parameter values and conservative estimates of longitudinal and transverse dispersivities (see Appendix B). The pre-conditioning process assumed the following:

- Rainfall recharge data was used from the 1992-2007 dataset. This was utilized as it contained a wide range of climatic conditions which would have occurred during the period between 1977 and 1992;

- Surface channel transfer rates and constraints were used unchanged from the 1992-2007 dataset. Again, this was done as it was assumed the conditions would have been somewhat representative of what occurred from 1977 to 1992 , as it was a lengthy period encapsulating a range of river conditions;

- Groundwater abstractions (i.e. wells) were removed from the pre-conditioning simulations. These were excluded due to the fact groundwater abstraction was limited prior to 1992, and very limited in 1977 as surface water was largely utilized for water needs (Annear et al, 1989; Morgan and Hughes, 2001). This is a reasonable assumption for water conditions during the pre-conditioning simulations.

\subsubsection{Capture zones}

Capture zones indicate the probability a water particle will exit the system from abstracting wells within the domain (Fig. 6.6). The probability, from a specific point or points, can be calculated to assess, for example, the likelihood that wells within the Middle Valley will capture water and the specific zones from which they capture this water over time. Ground Water (GW) solves the backward probability of an exit boundary value problem and identifies the outlet zones assigning homogeneous conditions to the specific points (i.e. abstracting wells) (Cornaton, 2007). This variable exit probability (due to the transient nature of the model) is important to consider and evaluate for contamination, pollution, and land-use management. For the scope of this dissertation, wells (observation nodes) are assessed for the probability that their simulated age is affected by any adjacent abstraction pressures. Capture zones are useful to delineate sensitive areas, such as buffer/protection zones where wells are utilized for drinking water supplies, and evaluation of abstraction effects on age. 
Determining well capture zones are therefore useful for both environmental (i.e. land use activities) and public health concerns (i.e. drinking water supplies) (Neupauer and Wilson, 2001; van Leeuwen et al, 1998).

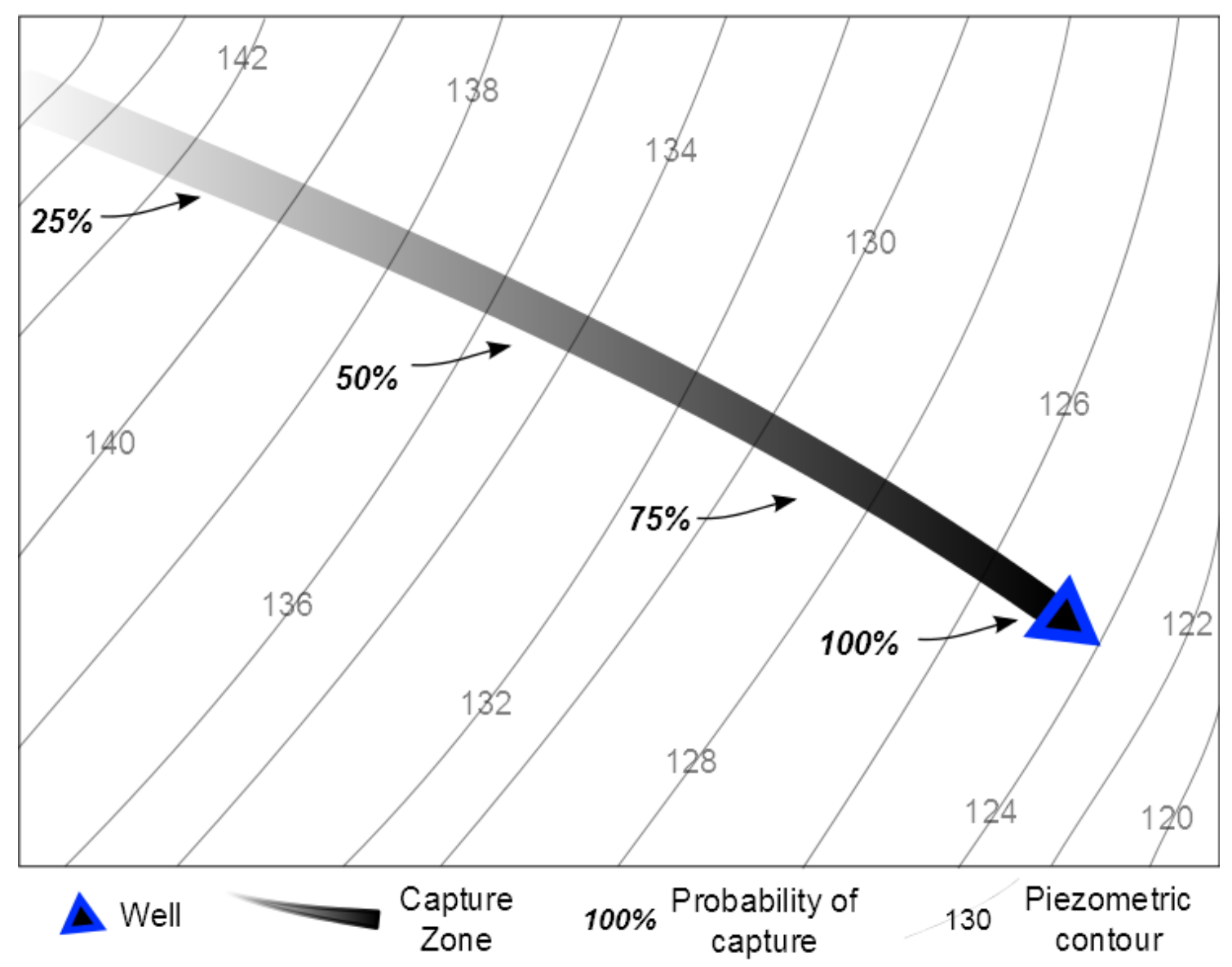

Fig. 6.6 Hypothetical example of the probability of capture method for a single well. Piezometric contours are lines indicating the height of the water table above sea level, analogous to land surface contours.

\subsubsection{Observation points}

Points of interest were selected throughout the Middle Valley catchment to match measured observational data (Fig. 6.7). Observation nodes correspond to several wells used for domestic water supply, irrigation, regional groundwater management and bores which have measured time-series of hydraulic head, and/or observed tritium concentrations, and/or measured hydrochemistry data. These points serve as a means by which to compare the accuracy of the simulated flow and transport to field measurements. 
Observational data were available for tritium, hydrochemistry and hydraulic heads which provided calibration constraint for the flow and transport parameters.

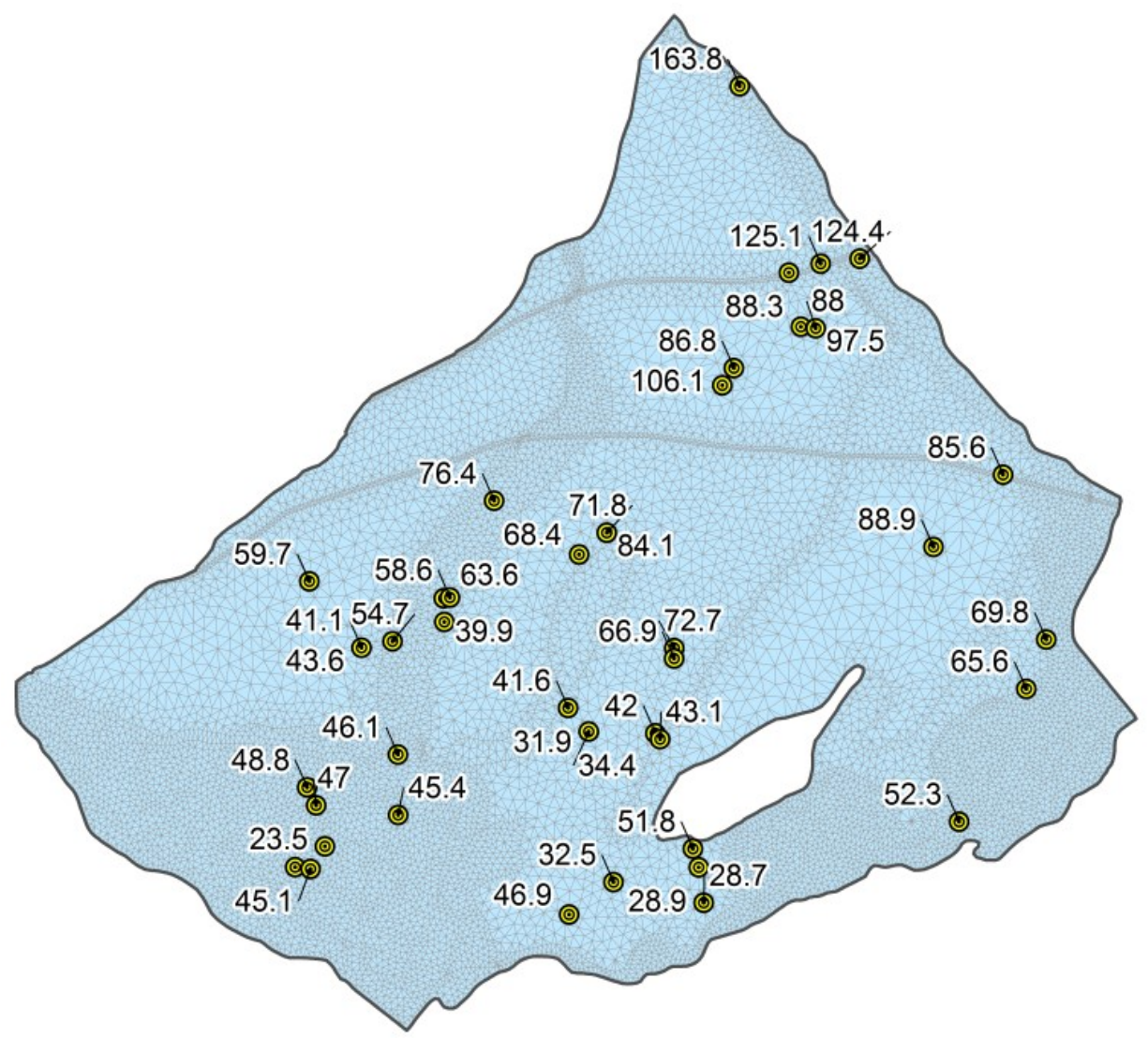

Fig. 6.7 Observation nodes distribution throughout the Middle Valley. Label indicates node depth above sea level.

\subsection{Calibration}

In this study calibration was performed on the transient flow and transport model using an inverse approach with observed and inferred data to constrain and validate the Middle Valley model output. A combination of observational data, hydraulic heads, tritium concentrations and inferred tritium concentrations were used. Given the limited spatial and temporal range of the measured tritium data, inferred data was derived from measured silica data (incorporating the inferred error) as an attempt to better calibrate and achieve more robust model output. Three-dimensional groundwater models are often highly parameterized and this inherent complexity means parameters cannot be uniquely estimated to observed calibration data.

Essentially, the large number of parameters gives way to the situation whereby several unique configurations can produce similar results, i.e. an over-determined system. 
In this study a variant of the Gauss-Marquardt-Levenberg method was utilized to calibrate the model, using the PEST software (Doherty, 2010). The Gauss-MarquardtLevenberg method solves a least-squares minimization problem, it is however susceptible to localized optimization. For example, a different initial estimate could potentially achieve a lower objective function, taking a different "route" during calibration (Fig. 6.8). This results in a calibrated parameter set derived from a local minimum of the objective function, which sometimes is significantly higher than the global minimum (Gallagher \& Doherty, 2007).

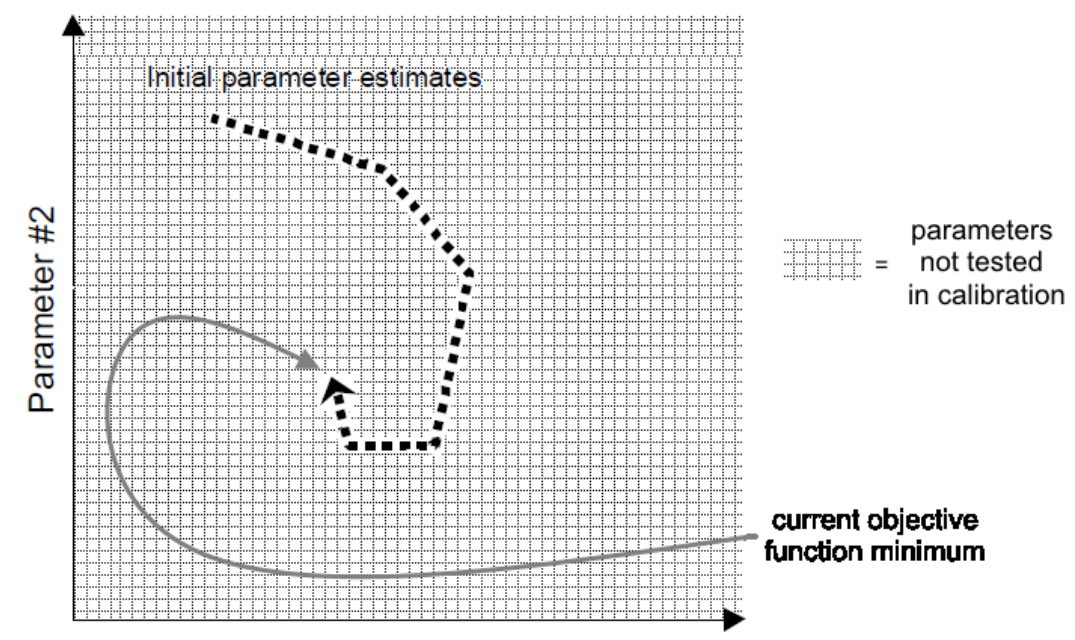

Parameter \#1

Fig. 6.8 Schematic of localized optimization with an initial estimate moving towards an objective function minimum. Modified from Doherty (2010).

To overcome this, a classic Monte Carlo method was also used to sample the domain's global range of flow and transport parameters. This provided an increased measure of confidence in the calibration, as a stochastic global range of parameter values could be tested against the more localized Gauss-Marquardt-Levenberg parameter estimation scheme. Both methods were calibrated and compared to observed and inferred tritium concentrations in addition to observed hydraulic heads.

\subsubsection{Observational data}

\subsubsection{Hydraulic head}

The hydraulic head dataset was used from the Wellington Regional Council transient FEFLOW flow model calibration. 
Hydraulic head data provides a measure of the relative change and sensitivity within a groundwater system, for example, pump and slug tests that observe an aquifer's response to pumping (also known as drawdown) or injection in observation wells. The water flow is controlled by the system's inherent subsurface parameters and given hydraulic head data is widely measured and available, it is often utilized in the calibration phase of a groundwater model. Hydraulic head observational data is utilized as a part of the objective function for the simulated model output.

\subsection{Manual field measurements}

The hydraulic head dataset was provided by Greater Wellington Regional Council (Gyopari and McAllister, 2010a). 14 long-term monitoring wells were used for the Middle Valley Ground Water (GW) model calibration (Fig. 6.9 and Table 6.2).

Table 6.2 Manual field measured hydraulic head data. Source: Greater Wellington Regional Council.

\begin{tabular}{|c|c|c|c|c|c|c|}
\hline Well ID & $\begin{array}{l}\text { Observations } \\
\text { (n) }\end{array}$ & $\begin{array}{l}\text { Weight } \\
\text { (PEST) }\end{array}$ & Depth & $\begin{array}{l}\text { Well info } \\
\left({ }^{*}\right)\end{array}$ & $\begin{array}{c}\text { Geologic } \\
\text { age }\end{array}$ & $\begin{array}{l}\text { Weight } \\
\text { (GWRC) }\end{array}$ \\
\hline S26/0155 & 171 & 0.75 & 13.4 & $M / P$ & Q2-4 & 0.75 \\
\hline S26/0223 & 72 & 0.75 & 9.9 & $M / P$ & Q2-4 & 0.5 \\
\hline S26/0229 & 172 & 0.75 & 23.8 & $M / D$ & Q2-4 & 1 \\
\hline S26/0236 & 172 & 0.75 & 41.4 & $M / D$ & Q6 & 1 \\
\hline S26/0500 & 66 & 0.75 & 3.4 & $M / D$ & Q1 & 1 \\
\hline S26/0545 & 172 & 0.75 & 18 & $M / D$ & Q2-4 & 0.75 \\
\hline S26/0547 & 170 & 0.75 & 4.3 & $\mathrm{M} / \mathrm{P}$ & Q1 & 0.75 \\
\hline S26/0568 & 170 & 0.5 & 45 & $M / P$ & Q6 & 0.5 \\
\hline S26/0656 & 171 & 0 & 78.05 & $M / D$ & Q8 & 0.5 \\
\hline S26/0658 & 172 & 0.75 & 8 & $M / P$ & Q2-4 & 0.5 \\
\hline S26/0675 & 120 & 1 & 31.5 & $M / D$ & Q8 & 1 \\
\hline S26/0756 & 89 & 0.75 & & - & - & - \\
\hline S27/0248 & 171 & 0.75 & 7.9 & $M / P$ & Q2-4 & 0.75 \\
\hline T26/0326 & 172 & 0.75 & 10 & $M / P$ & Q2-4 & 0.75 \\
\hline Sum $=14$ & \multicolumn{6}{|l|}{ Sum $=2060$} \\
\hline \multicolumn{7}{|c|}{ * Continuous or Manual data / Dedicated observation or Pumping well } \\
\hline
\end{tabular}




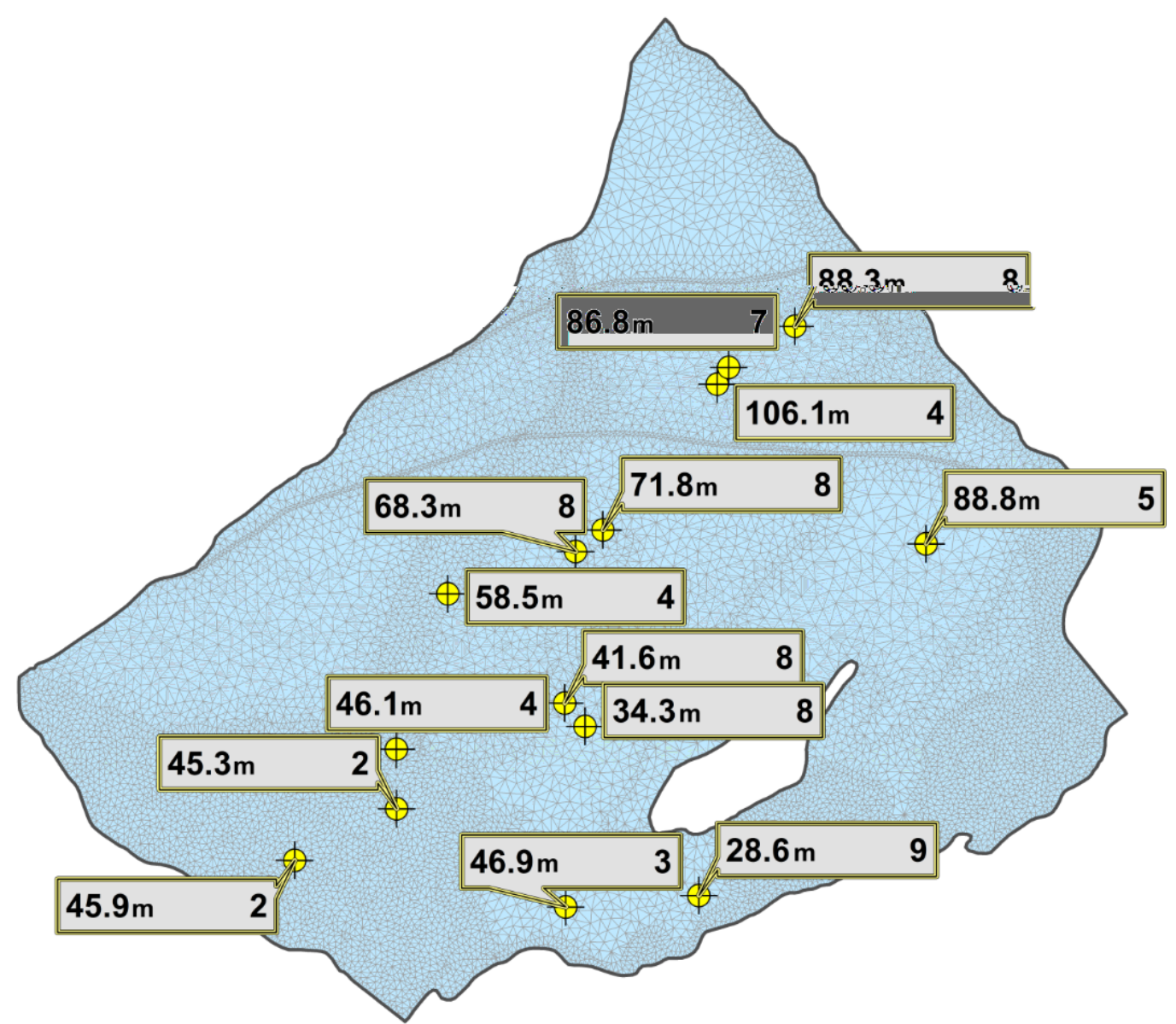

Fig. 6.9 Distribution of wells for which GWRC hydraulic head measurements were used for calibration in period 1992-2007. Left text indicates well depth and right indicates the slice which the node is located on.

\subsection{Weekly averaged measurements}

Manual head measurements were used by GWRC to infer weekly hydraulic head measurements for 22 monitoring wells. Twenty-two monitoring sites and 2060 manual field measurements were used to form 13,872 weekly inferred head measurements (Table 6.3). These were not used in the calibration as the manual measurements were assumed to provide enough constraint and reduce calibration time. 
Table 6.3 Weekly averaged hydraulic head data information. Source: Greater Wellington Regional Council.

\begin{tabular}{|c|c|c|c|c|c|}
\hline Well ID & Observations (n) & Weight & Area & Well Depth & Geologic age \\
\hline S26/0490 & 775 & 1 & 1 & 5 & Q1 \\
\hline S26/0500 & 262 & 1 & 1 & 3.4 & Q1 \\
\hline S27/0225 & 646 & 1 & 1 & 4.6 & Q1 \\
\hline S26/0547 & 767 & 0.75 & 1 & 4.3 & Q1 \\
\hline S26/0545 & 775 & 0.75 & 1 & 18 & Q2-4 \\
\hline S26/0675 & 548 & 1 & 2 & 31.5 & Q8 \\
\hline S26/0568 & 775 & 0.5 & 2 & 45 & Q6 \\
\hline S26/0743 & 731 & 1 & 2 & 33 & Q6 \\
\hline S26/0738 & 754 & 1 & 2 & 5.4 & Q2-4 \\
\hline S26/0155 & 764 & 0.75 & 2 & 13.4 & Q2-4 \\
\hline S26/0656 & 775 & 0.5 & 2 & 78.05 & Q8 \\
\hline S26/0658 & 775 & 0.5 & 2 & 8 & Q2-4 \\
\hline S26/0223 & 329 & 0.5 & 3 & 9.9 & Q2-4 \\
\hline S26/0242 & 723 & 1 & 3 & 7.5 & Q2-4 \\
\hline S26/0229 & 775 & 1 & 3 & 23.8 & Q2-4 \\
\hline S26/0236 & 775 & 1 & 3 & 41.4 & Q6 \\
\hline S26/0298 & 404 & 0.5 & 4 & 7 & Q1 \\
\hline T26/0326 & 775 & 0.75 & 5 & 10 & Q2-4 \\
\hline S26/0749 & 480 & 1 & 6 & 10 & Q2-4 \\
\hline S27/0248 & 775 & 0.75 & 6 & 7.9 & Q2-4 \\
\hline S26/0756 & 429 & - & - & - & - \\
\hline T26/0602 & 60 & - & - & - & - \\
\hline Sum $=22$ & Sum $=13872$ & & & & \\
\hline
\end{tabular}

\subsubsection{Tritium concentrations}

Tritium measurements are available throughout the Wairarapa Valley. Observed concentrations have been taken as part of the National Groundwater Monitoring Programme (NGMP) (Morgenstern and Daughney, 2012), and a regional Wairarapa groundwater study by Morgenstern (2005). The tritium dataset consisted of 73 observed tritium measurements in the Wairarapa taken between the $1^{\text {st }}$ of April 1983 and the $26^{\text {th }}$ of June 2008 ( 25.25 years). Unfortunately, the dataset for the Middle 
Valley was restricted to six measurements within the required simulated period, between 1992 and 2007 (Fig. 6.10 and Table 6.4).

Table 6.4 Observed tritium dataset from the Middle Valley. Source: Morgenstern (2005).

\begin{tabular}{cccccc}
\hline Well ID & $\begin{array}{c}\text { Well } \\
\text { depth }(\mathrm{m})\end{array}$ & Date & $\begin{array}{c}\text { Tritium } \\
(\mathrm{TU})\end{array}$ & $\begin{array}{c}\text { Standard } \\
\text { deviation * }\end{array}$ & $\begin{array}{c}\text { Weight } \\
(1 / \mathrm{SD})\end{array}$ \\
\hline $\mathrm{S} 26 / 0155$ & 13 & $3 / 05 / 2005$ & 1.74 & 0.06 & 16.66667 \\
$\mathrm{~S} 26 / 0244$ & 0 & $3 / 05 / 2005$ & 1.91 & 0.05 & 20 \\
$\mathrm{~S} 26 / 0395$ & 0 & $3 / 05 / 2005$ & 1.81 & 0.05 & 20 \\
$\mathrm{~S} 26 / 0705$ & 27 & $12 / 05 / 2005$ & 1.41 & 0.06 & 16.66667 \\
$\mathrm{~S} 26 / 0824$ & 21 & $12 / 05 / 2005$ & 1.74 & 0.04 & 25 \\
$\mathrm{~S} 26 / 0911$ & 9 & $3 / 05 / 2005$ & 1.85 & 0.05 & 20 \\
$\mathrm{~S} 26 / 0793$ & 75 & $12 / 05 / 2005$ & -0.015 & 0.019 & 52.63158 \\
\hline \multicolumn{5}{c}{$*$} \\
\end{tabular}

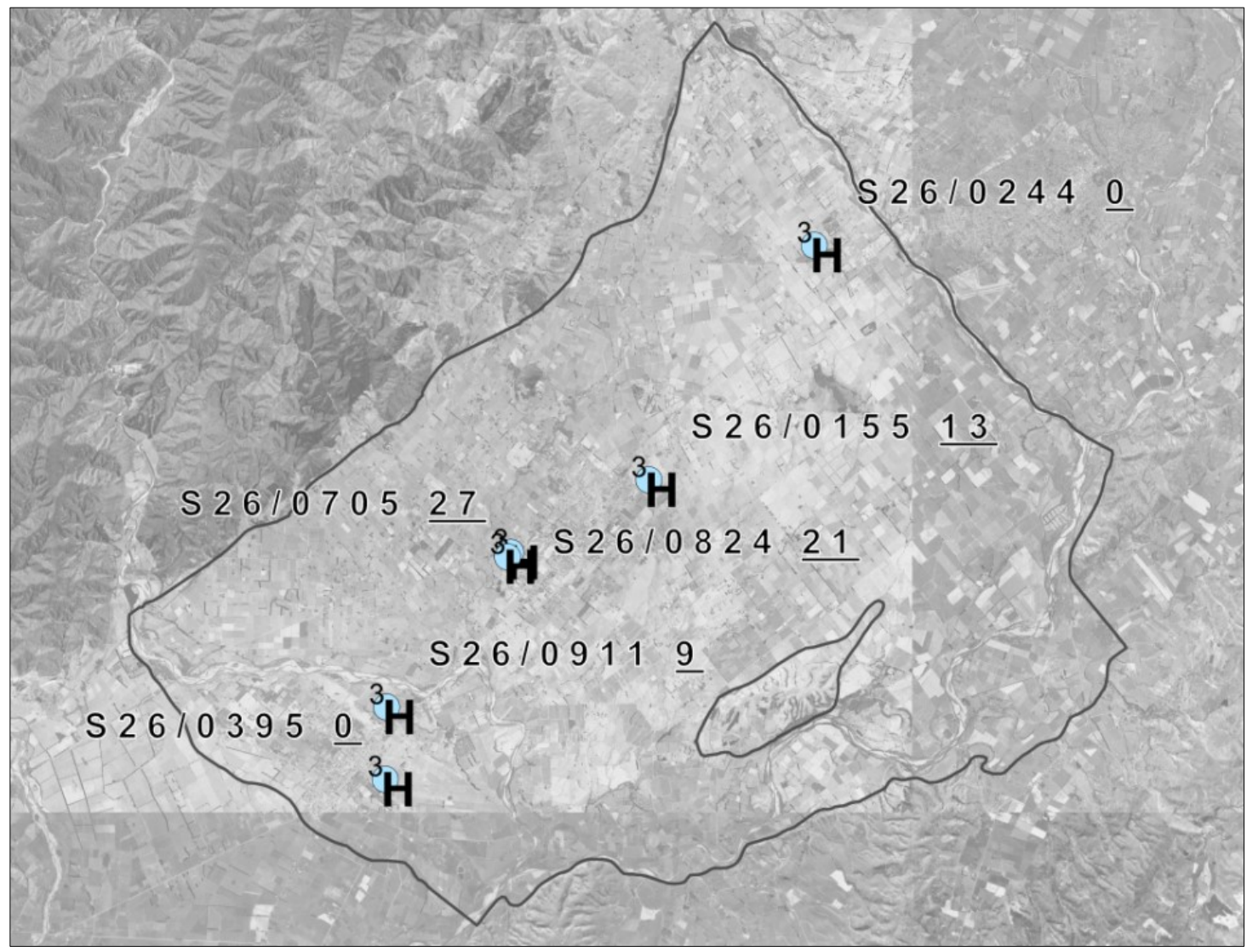

Fig. 6.10 Observed tritium measurement locations. Six locations showing well identifier and depth (underlined). 


\subsubsection{Inferred tritium concentrations}

Tritium can be inferred from a relationship between routinely measured hydrochemical constituents (Fig. 6.11). Inferred tritium data provides additional parameter constraint during calibration. The distribution of measured tritium concentrations in the 15 year simulation period was not ideal given the limited locations and spread over time. Therefore, estimated concentrations were weighted significantly lower than the measured tritium data. The hydrochemical constituents' silica $\left(\mathrm{SiO}_{2}\right)$, potassium $(\mathrm{K})$, bicarbonate $(\mathrm{HCO}-)$, sulphate $\left(\mathrm{SO}_{4}{ }^{2-}\right)$, as well as the $\mathrm{pH}$ measure and total dissolved solids (TDS) were investigated for their relationship to tritium concentration. Regression analysis was used to infer tritium concentrations from measured hydrochemistry data, for example, fluoride, nitrate and iron (Daughney et al, 2010; Morgenstern, 2005).
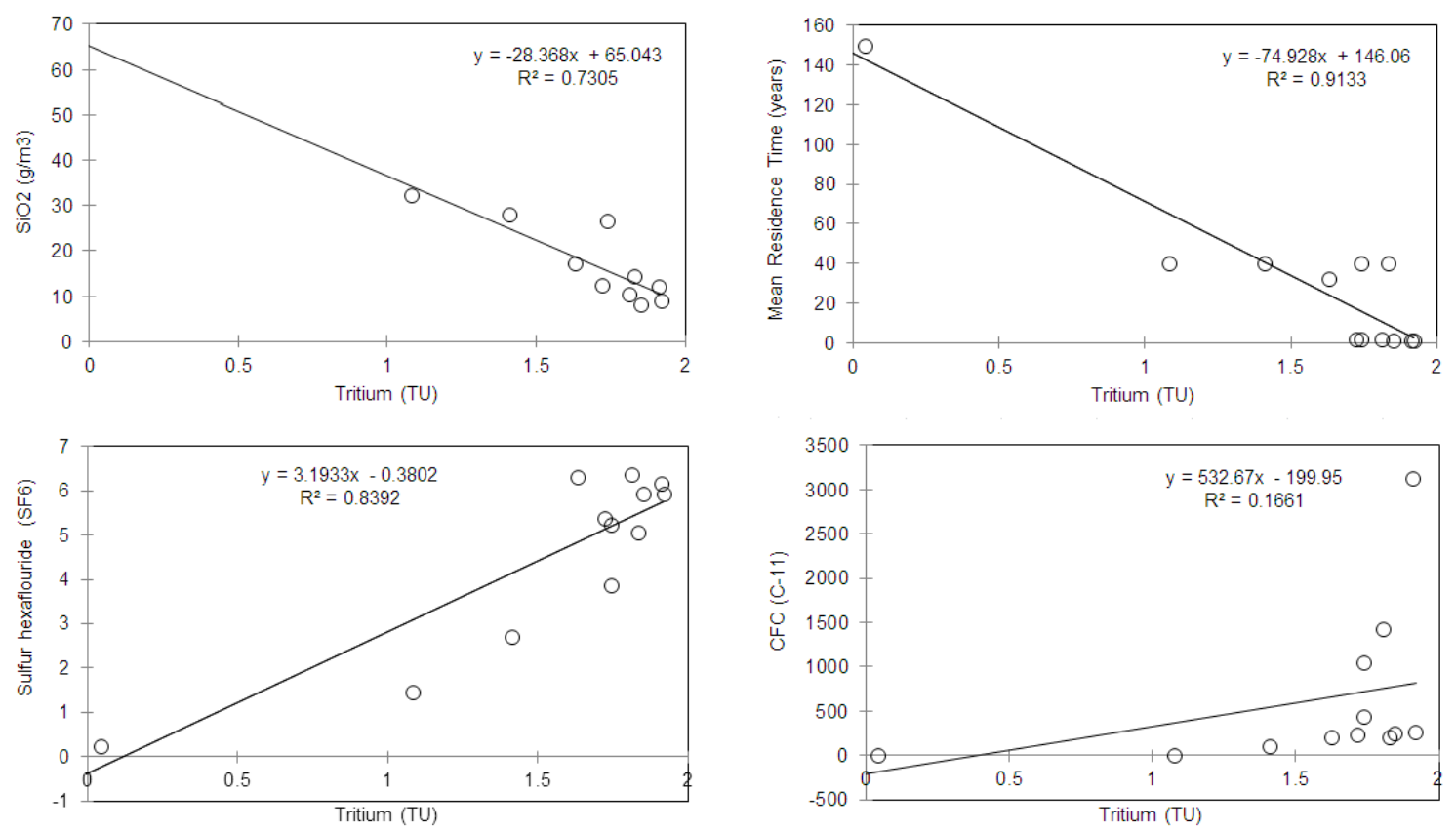

Fig. 6.11 Relationship between tritium concentrations and selected hydrochemical parameters in the Middle Valley. It is acknowledged that the lowest tritium value in the Mean Residence Time graph causes significant leverage. Data available in Appendix D. Source: Morgenstern (2005).

Hydrochemistry is routinely measured by regional councils and various water authorities. A large hydrochemical dataset was available for the Wairarapa and provided by the Wellington Regional Council and GNS Science (Morgenstern, 2005). 
The hydrochemistry data was taken throughout the Wairarapa and Middle Valley over the period $1992-2007$ (Table 6.5). A comparison of the relationship of observed tritium measurements in the Middle Valley to several other measured hydrochemical and tracer variables indicated several strong correlations.

Table 6.5 Wellington Regional Council measured hydrochemical constituents.

\begin{tabular}{|c|c|c|c|c|}
\hline Temperature & Conductivity & E-Coli & Alkalinity & Chloride \\
\hline $\begin{array}{c}\text { Other } \\
\text { Bacteria }\end{array}$ & $\mathrm{pH}$ & $\begin{array}{c}\text { Total } \\
\text { Oxidized } \\
\text { Nitrogen }\end{array}$ & $\begin{array}{c}\text { Total Organic } \\
\text { Carbon }\end{array}$ & Nitrite \\
\hline Nitrate & Phosphorus & Alkalinity & Bicarbonate & $\begin{array}{c}\text { Bicarbonate } \\
\text { Calcium }\end{array}$ \\
\hline Bromide & Fluoride & Conductivity & $\begin{array}{l}\text { Reactive } \\
\text { Sulphate }\end{array}$ & Calcium \\
\hline Hardness & Arsenic & $\begin{array}{c}\text { Ammoniacal } \\
\text { Nitrogen }\end{array}$ & $\begin{array}{c}\text { Total } \\
\text { Dissolved } \\
\text { Solids }\end{array}$ & Manganese \\
\hline Zinc & $\begin{array}{c}\text { Faecal } \\
\text { Coliforms }\end{array}$ & $\begin{array}{c}\text { Total } \\
\text { Coliforms }\end{array}$ & $\begin{array}{c}\text { Presumptive } \\
\text { Coliforms }\end{array}$ & $\begin{array}{c}\text { Total } \\
\text { Hardness }\end{array}$ \\
\hline Silica & $\begin{array}{l}\text { Dissolved } \\
\text { Oxygen }\end{array}$ & Total Cations & Total Anions & Free $\mathrm{CO} 2$ \\
\hline Boron & Potassium & Magnesium & Iron & Nitrogen \\
\hline
\end{tabular}

Tritium and hydrochemistry data was used from 52 different sites in the Wairarapa provided by Morgenstern (2005). All available hydrochemistry parameters were tested for statistically significant correlation to tritium concentration. Daughney et al (2009a), Guggenmos et al (2011) and Morgenstern (2005) divided the well hydrochemistry data into smaller datasets of different domains relative to location, geology, well depth, groundwater age, and the hydrochemistry classification. Table 6.6 indicates the comparative regression between observed tritium and various constituents throughout the entire Wairarapa Valley (i.e. Upper, Middle and Lower catchments). 
Tritium was inferred from fitting a linear regression model to describe the best fit between tritium and silica (Fig. 6.12). Silica was selected due to its relatively strong relationship with tritium and the availability of measured silica data for comparison. Acidity/basicity $(\mathrm{pH})$ also had a relatively strong relationship with tritium (Table 6.6). The equation of the fitted model enabled an inferred tritium concentration from 190 measured silica concentrations from 18 different wells scattered across the Middle Valley (Table 6.7).

Table 6.6 Comparative regression between tritium and hydrochemical constituents throughout the Wairarapa Valley.

\begin{tabular}{ccccc}
\hline & Abbreviation & Constituent & $\begin{array}{c}\text { Observations } \\
(\mathrm{n})\end{array}$ & $\begin{array}{c}\mathrm{R}^{2} \\
(\%)\end{array}$ \\
\hline 1 & $\mathrm{SiO}^{2}$ & Silica & 35 & 69.0 \\
\hline 2 & $\mathrm{pH}$ & acidity/basicity & 37 & 67.1 \\
\hline 3 & $\mathrm{HCO}_{3}$ & Bicarbonate & 37 & 60.0 \\
\hline 4 & $\mathrm{DO}$ & Dissolved oxygen & 40 & 58.5 \\
\hline 5 & $\mathrm{TDS}$ & Total dissolved solids & 34 & 52.2 \\
\hline 6 & $\mathrm{P}$ & Phosphorous & 35 & 50.9 \\
\hline 7 & $\mathrm{NH}_{4}-\mathrm{N}$ & Ammoniacal nitrogen & 37 & 38.9 \\
\hline 8 & $\mathrm{Mn}$ & Manganese & 37 & 37.9 \\
\hline 9 & $\mathrm{~K}$ & Potassium & 37 & 36.0 \\
\hline 10 & $\mathrm{Mg}$ & Magnesium & 37 & 33.3 \\
\hline 11 & $\mathrm{Fe}$ & Iron & 25 & 33.1 \\
\hline 12 & $\mathrm{DRP}$ & Dissolved reactive & 37 & 28.0 \\
& & phosphorous & & \\
\hline 13 & $\mathrm{Na}$ & Sodium & 37 & 20.5 \\
\hline 14 & $\mathrm{SO}_{4}{ }^{2-}$ & Sulphate & 38 & 16.6 \\
\hline 15 & $\mathrm{NO}_{3}-\mathrm{N}$ & Nitrate & 53 & 12.5 \\
\hline 16 & $\mathrm{Cl}$ & Chlorine & 58 & 8.7 \\
\hline 17 & $\mathrm{~Pb}$ & Lead & 37 & 0.6 \\
\hline 18 & $\mathrm{NO}_{2}-\mathrm{N}$ & Nitrite & 39 & 0.3 \\
\hline & & & & \\
\hline
\end{tabular}




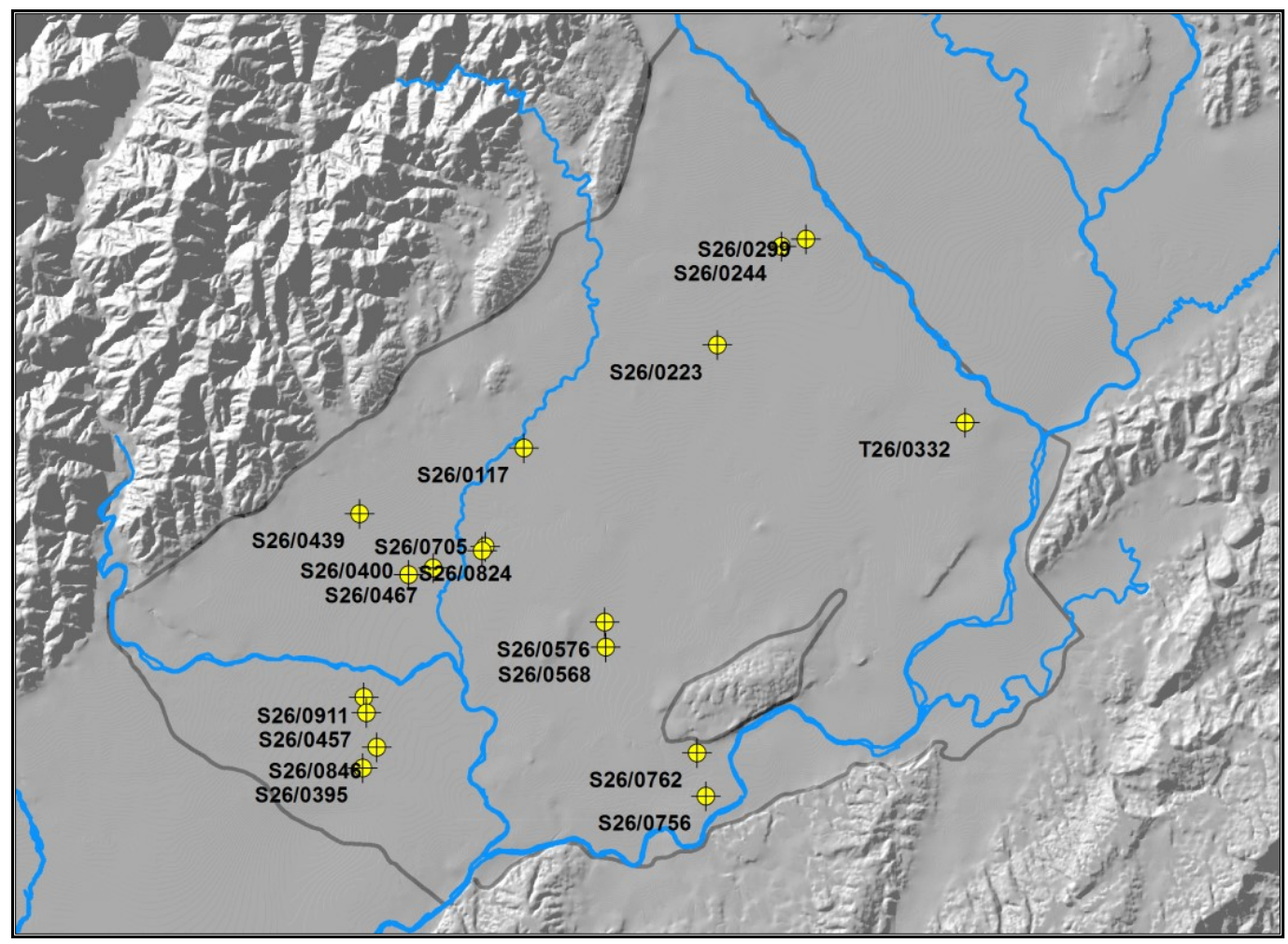

Fig. 6.12 Distribution of well for which tritium concentrations in period 1992-2007 could be inferred from $\mathrm{SiO}_{2}$ concentration.

Table 6.7 Well information on tritium concentrations inferred from $\mathrm{SiO}_{2}$ concentrations.

\begin{tabular}{cccc}
\hline Well ID & $\begin{array}{c}\text { Inferred }{ }^{3} \mathrm{H} \\
\text { measurements }\end{array}$ & Depth & Well Use \\
\hline $\mathrm{S} 26 / 0155$ & 1 & 13 & Irrigation \\
$\mathrm{S} 26 / 0117$ & 11 & 5 & - \\
$\mathrm{S} 26 / 0223$ & 12 & 9.92 & Domestic Supply \\
$\mathrm{S} 26 / 0244$ & 2 & 0 & Not Used \\
$\mathrm{S} 26 / 0299$ & 15 & 8.1 & Domestic Supply \\
$\mathrm{S} 26 / 0395$ & 2 & 0 & Not Used \\
$\mathrm{S} 26 / 0400$ & 1 & 16 & Irrigation \\
$\mathrm{S} 26 / 0439$ & 11 & 11.5 & Domestic Supply \\
$\mathrm{S} 26 / 0457$ & 13 & 6.06 & Domestic Supply \\
$\mathrm{S} 26 / 0467$ & 11 & 6.2 & Domestic Supply \\
$\mathrm{S} 26 / 0568$ & 15 & 45 & Irrigation \\
$\mathrm{S} 26 / 0576$ & 13 & 31 & Irrigation \\
$\mathrm{S} 26 / 0705$ & 17 & 27.4 & Public Supply \\
\hline $\mathrm{S} 26 / 0756$ & 15 & 19 & Irrigation \\
$\mathrm{S} 26 / 0762$ & 15 & 9.5 & Domestic Supply \\
\hline $\mathrm{S} 26 / 0824$ & 17 & 20.6 & Public Supply \\
$\mathrm{S} 26 / 0846$ & 11 & 39.3 & Not Used \\
\hline $\mathrm{S} 26 / 0911$ & 2 & 8.8 & Domestic Supply \\
\hline $\mathrm{T} 26 / 0332$ & 12 & 13.4 & Domestic Supply \\
\hline $\mathrm{S} 4 \mathrm{~m}: 19$ & Sum: 196 & & \\
\hline
\end{tabular}




\subsubsection{Weighting observational data}

The weighting of observational data is often implemented as part of the calibration process. There is no universal technique for achieving a robust weighting regime (Doherty and Hunt, 2010). The consensus is that each measurement should be assigned a weight relative to the inverse of the known error associated with the measurement. Any observations that are known to have significant measurement error or uncertainty should be given low weights to prevent any significant detrimental effect on the calibration procedure. However, given the complexity of a groundwater model, caution is required when weighting observational data solely on measurement uncertainty. A large group of observations of one type (e.g. tritium) may monopolize the objective function leading to an unbalanced calibration. Conversely, if the weight does not account for the relative importance of a given observation in a specific zone of interest, instead calculated solely by measurement error, the calibration may not achieve the desired focus and accuracy (Doherty and Hunt, 2010). Due to these, and other complicating factors, there are a range of (subjective) observational weighting approaches for calibrating highly parameterized models.

\subsubsection{Measured tritium data}

The measured tritium data were weighted according to the relative error in the measured concentrations $\left(W_{T r}\right)$. Data were provided by Morgenstern (2005) and, given the data were measured in the GNS Science water dating laboratory, the relative measurement error was known and provided as the standard deviation(s) $(\sigma)$. This was used for the calibration dataset and weighted accordingly using inverse of the standard deviation (see Appendix D).

$$
\frac{1}{\sigma}=W_{T r}
$$

\subsubsection{Inferred tritium data}

The inferred tritium data were estimated from the relationship between measured tritium and hydrochemical data. 
Greater Wellington Regional Council and GNS Science provided the silica datasets (see Appendix D). Inferred tritium concentrations were derived by fitting a linear regression model to describe the relationship between concentrations of tritium and silica.

Weights were calculated from the $95.0 \%$ confidence intervals of measured concentrations of tritium and silica (Table 6.8).

$$
\begin{gathered}
d=\left(\mathrm{Tr}_{1}+\mathrm{Si}_{1} \times \mathrm{SiO}_{2}\right)-\left(\mathrm{Tr}_{2}+\mathrm{Si}_{2} \times \mathrm{SiO}_{2}\right) \\
\text { where: } \\
d=\text { difference between tritium upper and lower limits } \\
\mathrm{Tr}_{1}=\text { tritium } 95.0 \% \text { confidence interval upper limit } \\
\mathrm{Tr}_{2}=\text { tritium 95.0\% confidence interval lower limit } \\
\mathrm{Si}_{1}=\text { silica } 95.0 \% \text { confidence interval upper limit } \\
\mathrm{Si}_{2}=\text { silica } 95.0 \% \text { confidence interval lower limit } \\
\mathrm{SiO}_{2}=\text { measured silica concentration }
\end{gathered}
$$

Table 6.8 95.0\% confidence intervals for tritium estimates derived from silica.

\begin{tabular}{ccc}
\hline Parameter & Lower Limit & Upper Limit \\
\hline Tritium & 2.007 & 2.686 \\
$\mathrm{SiO} 2$ & -0.065 & -0.033 \\
\hline
\end{tabular}

The inverse of the difference is calculated, giving the unique weighting of the inferred tritium observational data $\left(W_{i T r}\right)$, an estimated confidence in the data used to inform the automated calibration process.

$$
\frac{1}{d}=W_{i T r}
$$

\subsubsection{Hydraulic head data}

A dataset containing 2060 hydraulic head measurements was used. The same weighting regime was used from the FEFLOW calibration according to an estimated reliability of the data. 


\subsubsection{Sensitivity analysis}

A Jacobian matrix was calculated as part of the Middle Valley calibration. The Jacobian matrix consists of the sensitivities of all specified model outputs to all adjustable model parameters; each column of the Jacobian matrix contains the sensitivity of all model outputs for a single adjustable parameter (Doherty, 2005; Doherty and Randall, 2010). This is done to identify any parameters which have little effect on the model output, or specifically identifying the parameters which are most sensitive to change. Parameters which have little influence on the model output can be fixed, speeding up the calibration, as there are fewer adjustable parameters. Parameters are automatically modified in PEST, between estimated bounds, and the relative change in model output is observed. Sensitivities of the individual parameters are calculated identifying those parameters which have the greatest effect on model output. Sensitivity analysis can be performed and implemented in the calibration process to increase calibration efficiency, removing the insensitive parameters from the adjustment process, with an objective of increasing calibration efficiency.

\subsubsection{Adjustable parameters}

The calibration of a model is achieved through the optimization of the model parameters in order to match observation data. If the measured field data are not reproduced or matched within an acceptable range, the model requires further adjustment. The hydraulic parameters' upper and lower bounds are conservative in order to appropriately permit all realistic parameter configurations. Upper and lower parameter bounds are based on the typical range of parameter values from the Wellington Regional Council flow model calibration and those specified by Freeze and Cherry (1977).

The calibration process tested the hydraulic parameters adjusting them accordingly in response to the relative change in the objective function. The estimated hydraulic flow and transport parameters were:

1. Drainage porosity

2. Hydraulic conductivities

3. Storage coefficient 
These parameters were adjusted as they are first-order parameters. Second-order parameters, such as diffusion, were not adjusted as they did not have significant influence on model output.

The GWRC bounds were defined after considering groundwater pump test data and plausible ranges for the type of material contained within each zone (Gyopari and McAllister, 2010a). Neither porosity (ne) nor storativity were adjusted in the GWRC calibration. The hydraulic conductivity parameters, lumping longitudinal and transverse horizontal conductivities, were the only parameters set as adjustable.

Table 6.9 Wellington Regional Council FEFLOW model flow parameter bounds. $\boldsymbol{K}$ is the hydraulic conductivity in the principal $\boldsymbol{x y z}$ directions. Porosity $n e$, and storage coefficient $S \boldsymbol{s}(\mathrm{m} / \mathrm{s})$.

\begin{tabular}{lcccc}
\hline & ne & Kxy & Kzz & Ss \\
\hline Lower bound & $2.28 \mathrm{E}-02$ & $3.85 \mathrm{E}-08$ & $1.29 \mathrm{E}-09$ & $7.24 \mathrm{E}-06$ \\
Upper bound & 0.1 & $4.73 \mathrm{E}-03$ & $2.70 \mathrm{E}-05$ & $1.32 \mathrm{E}-04$ \\
\hline
\end{tabular}

The initial bounds for the Middle Valley flow and transport model were devised from a combination of the GWRC bounds and values specified by Freeze and Cherry (Table 6.10) (1977).

Table 6.10 Ground Water (GW) flow and transport model parameter bounds (m/s).

\begin{tabular}{ccccc}
\hline & Porosity & Kxy & Kzz & Ss \\
\hline Lower bound & $2.00 \mathrm{E}-02$ & $3.85 \mathrm{E}-8$ & $1.29 \mathrm{E}-9$ & $7.24 \mathrm{E}-06$ \\
Upper bound & $6.00 \mathrm{E}-01$ & $4.73 \mathrm{E}-03$ & $2.70 \mathrm{E}-05$ & $1.32 \mathrm{E}-04$ \\
\hline
\end{tabular}

A revised set of parameter bounds were devised following the first calibration round. The upper porosity bound was reduced from 0.6 to 0.4 as it was postulated to be more realistic considering the geological makeup of the Wairarapa (Begg et al, 2005), and the calibration was tending to increase porosities to the highest bound in order to slow the movement of tritium (and allowing it to decay) to match the observed concentrations. 
Hydraulic conductivities were also revised. The lower bounds of both horizontal and vertical hydraulic conductivity were lowered by four orders of magnitude, given the silt and clay presence in the Wairarapa aquitards, also the potential presence of marine silt (Begg et al, 2005). Upper bounds of both horizontal and vertical hydraulic conductivity were also changed, raised by two and three orders of magnitude, respectively. These were increased, as the former bounds were considered too low for the highly conductive Q1 gravels. Both revisions used values as specified by Freeze and Cherry (1977) and Domenico and Schwartz, (1990).

Table 6.11 Revised Ground Water (GW) flow and transport model parameter bounds $(\mathrm{m} / \mathrm{s})$.

\begin{tabular}{ccccc}
\hline & Porosity & Kxy & Kzz & Ss \\
\hline Lower bound & $2.00 \mathrm{E}-02$ & $5.00 \mathrm{E}-12$ & $2.5 \mathrm{E}-13$ & $7.24 \mathrm{E}-06$ \\
Upper bound & $4.00 \mathrm{E}-01$ & $3.00 \mathrm{E}-01$ & $3.00 \mathrm{E}-02$ & $1.32 \mathrm{E}-04$ \\
\hline
\end{tabular}

\subsubsection{Gauss-Marquardt-Levenberg parameter estimation scheme}

The calibration procedure utilized the localized Gauss-Marquardt-Levenberg parameter-estimation process (Fig. 6.13). It is an iterative process with an initial best guess of the parameter set whereby each model run is started with a new estimate of parameters. The parameter set is tested against the objective function and a reduction is indicative of a better set of parameters, an increase indicates a less optimal set. The method is both efficient and robust and has proven successful when dealing with initially inaccurate models (Doherty and Hunt, 2010).

The method however does have inherent problems, primarily the fact that the method finds only a local minimum, not a (preferential) global minimum. Therefore a globalized Monte Carlo approach was utilized to sample from the entire range of (specified) parameter values which the localized (Gauss-Marquardt-Levenberg method) may not effectively sample. The Gauss-Marquardt-Levenberg method can then locally optimize and refine parameterisations based on the Monte-Carlo assessed sets of "reasonable" parameters. 


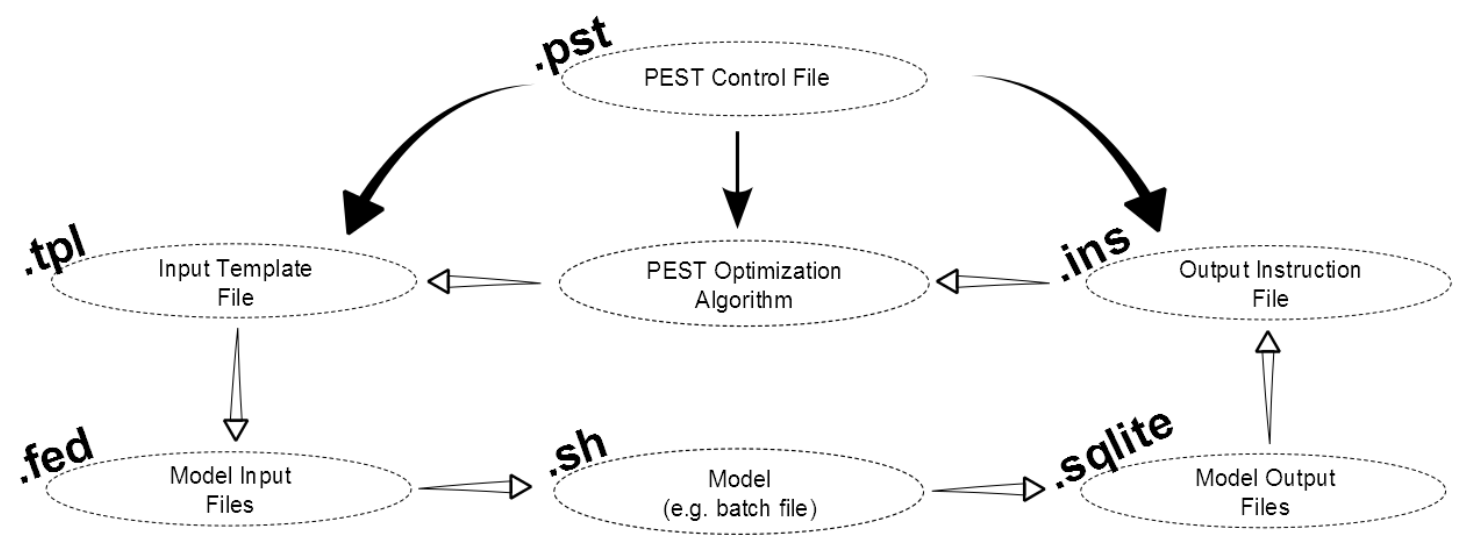

Fig. 6.13 Schematic of PEST optimization process. PEST run will cycle for at least the number of adjustable parameters, until an objective function minimum is achieved. Bold type indicates typical file extension.

\subsubsection{Monte Carlo Method}

Monte Carlo methods use algorithms to repeatedly randomly sample a problem to obtain a full range of results (Fig. 6.14). The Middle Valley parameters were estimated in the transient flow and transport model to test for, and obtain, appropriate parameters for porosity, hydraulic conductivity, and storativity. The parameter performance was evaluated in the same way as the Gauss-Marquardt-Levenberg scheme, comparing observed data to simulated data, the model output confirming the accuracy (or inaccuracy) of the randomly assigned parameters. 


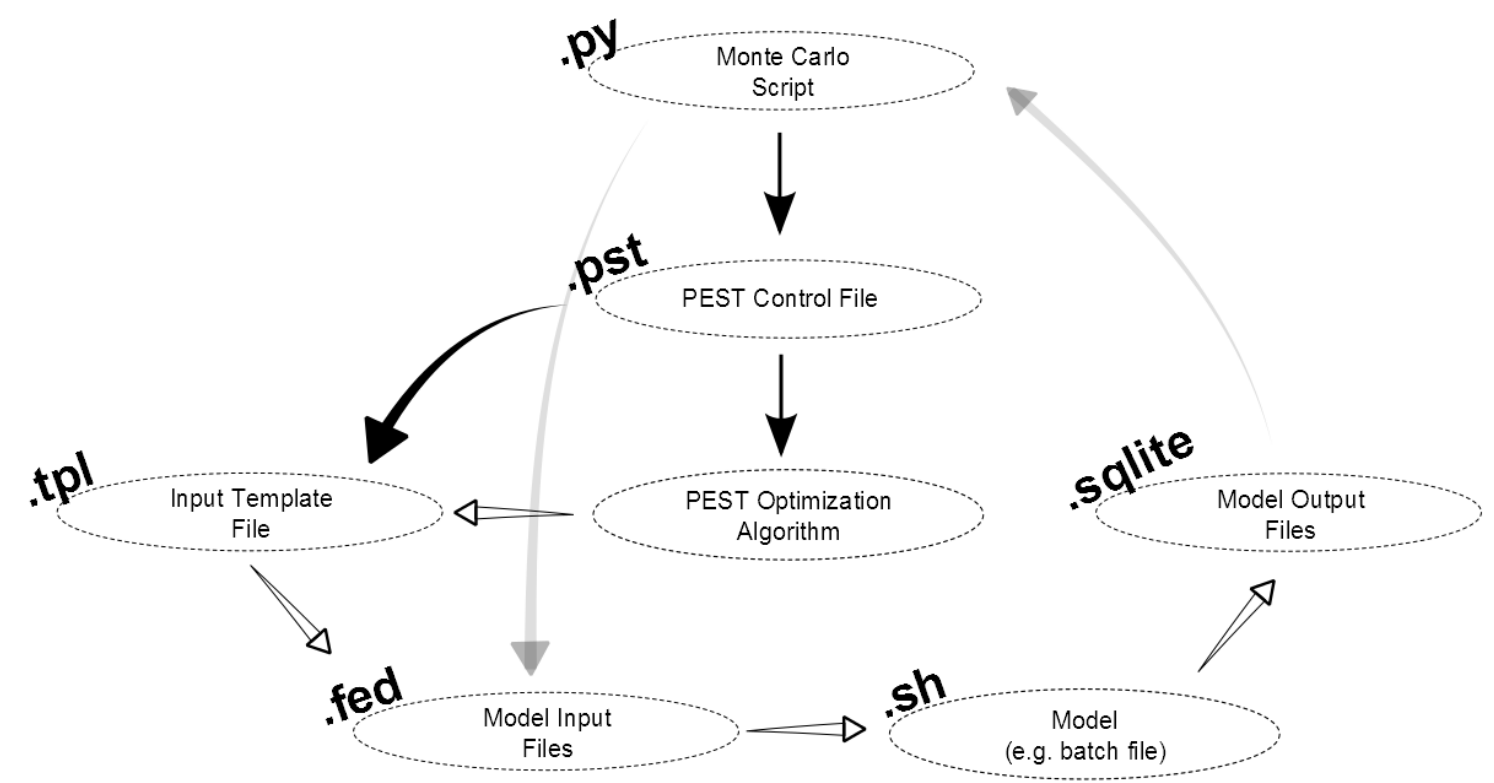

Fig. 6.14 Monte Carlo calibration process schematic. Bold type indicates an example of the file extension used. The process runs for a specified number of stochastic model runs, for example, 3000 .

A classic Monte Carlo calibration is implemented through the generation of random parameter values to sample the domain of the Middle Valley. Stochastically sampling the entire region would involve a considerable number of parameters and results. In order to increase calibration efficiency it was advantageous to define realistic parameter bounds, from known regional geology estimates, from which to randomly sample. This was aimed at achieving the optimal hydraulic parameters within the critical and realistic range of hydraulic parameter possibilities in the Middle Valley groundwater domain (Frenkel and Smit, 1996). The Monte Carlo method was initiated using a custom python code and the generation of a model run via the PEST software (see Appendix G). The process uses the Middle Valley PEST control file containing the adjustable hydraulic parameters and observed tritium and head data. A new Middle Valley PEST control file is constructed with randomly assigned parameters from a specified range for each parameter group. The model is then simulated once with the model output saved to a database file and the process is restarted with another random simulation output for comparison in the database. The objective function is then evaluated from each run of 3000 simulations, and the lowest objective function is evaluated as the best performing and most accurate parameter set. 


\subsection{Direct age simulation}

Age was directly simulated throughout the Middle Valley over a 15 year period. Age was derived in both transient mean-age and age distribution forms. Once the model has been calibrated to match observed tritium and head data the direct age simulation can be run to simulate age throughout the Middle Valley. In order to calculate the age within the domain, the system requires a reference from which the age is measured.

\subsubsection{Boundary conditions}

Groundwater age is defined as (or assumed to be) zero at its starting location. Rainfall recharge is a key recharge component with a groundwater water (particle) age of zero on the surface. Dirichlet-type mass transport boundary conditions were specified as zero (0.0) on nodes across the top slice (Fig. 6.15). This excluded river and spring sections, as it was unjustifiable considering they would already have an inherent age from existing water particles.

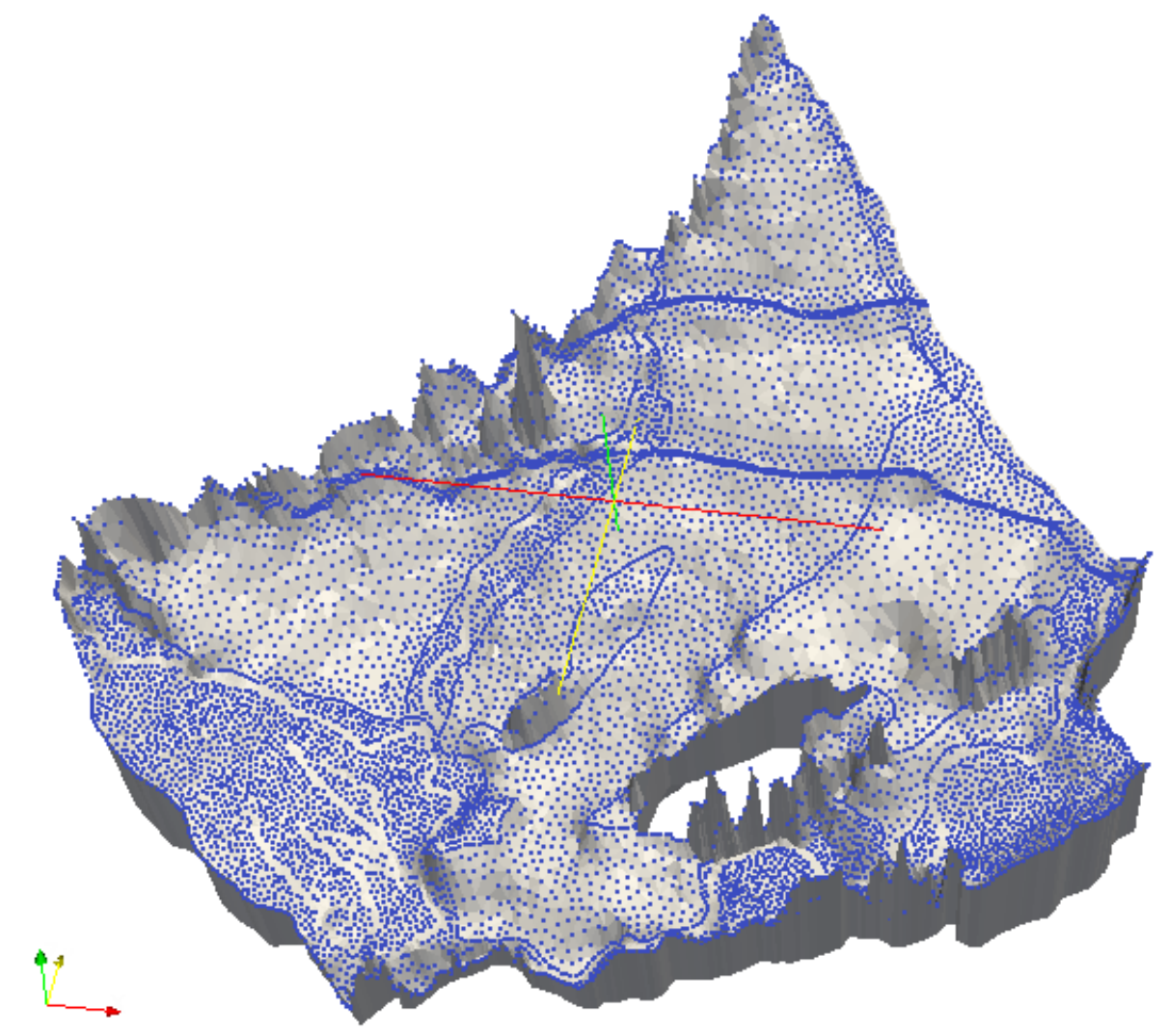

Fig. 6.15 Zero age mass transport boundary conditions assigned across the top slice. Blue nodes indicate Dirichlet-type boundary conditions specified as zero. 


\subsubsection{Transient mean-age initial conditions}

Initial conditions were simulated from a full 15 year model run and applied at the start of the period 1992-2007. Age conditions for the $1^{\text {st }}$ July 1992 were derived from a simulated period representative of 1977-1992. The 1977-1992 simulation assumed the rainfall recharge, transfer rates between rivers, and spring outflows were statistcally similar to available data for 1992-2007. This was justified given the 15 year period would have covered a wide range of hydrological conditions. In order to account for the limited abstraction pressures over 1977-1992, the abstracting wells were removed from the domain.

\subsubsection{Transient groundwater age distributions initial conditions}

Transient groundwater age distributions were simulated using the TMLTGT numerical scheme. As with the mean-age simulations, a representative initial condition was required. To generate initial conditions an initial 5D age state was generated from a full 15 year model run, given that a steady state is not necessarily a proper representation of an initial state for systems exhibiting a transient state (Cornaton, 2012). The TMLTG initial condition used the assumptions made for the mean-age initial condition (see Section 6.4.2). The resulting final state of the 5D age probability density function was used as the initial age distribution for the $1^{\text {st }}$ of July 1992 . The result of this pre-conditioning was used as the initial age distribution for the $1^{\text {st }}$ of July 1992 . An initial condition is required given the age distribution throughout the Middle Valley on the $1^{\text {st }}$ of July 1992 would have been $\neq 0$ (Fig. 6.16). 

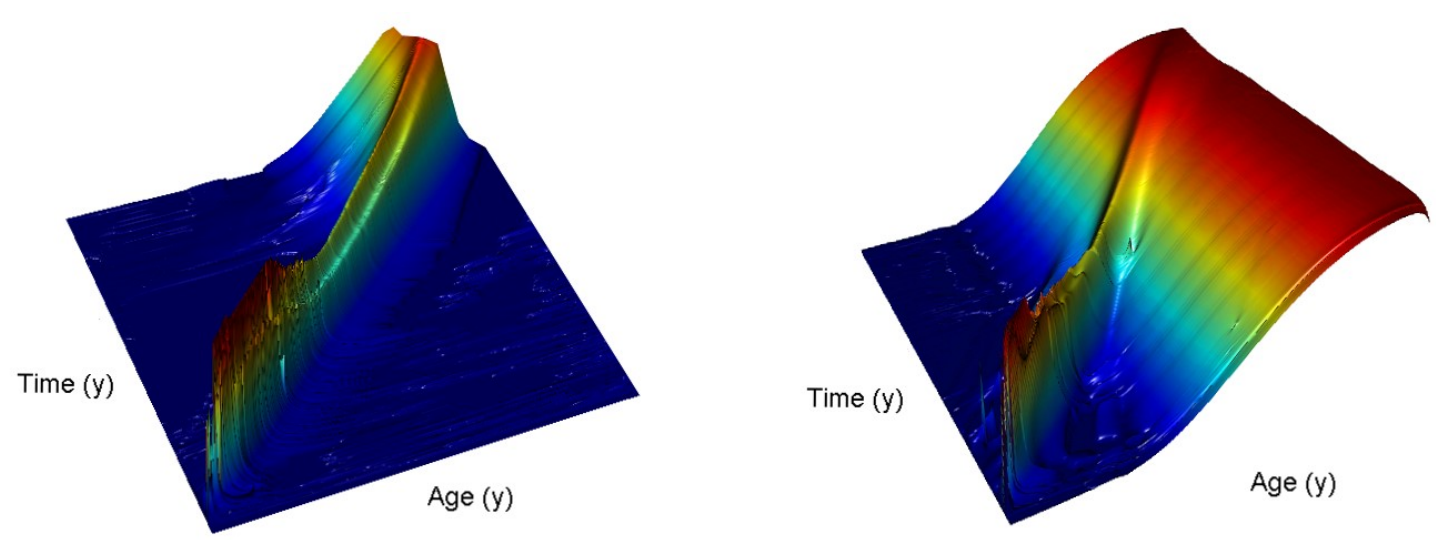

Fig. 6.16 TMLTG example. Left figure shows age distribution without an initial age distribution, right figure shows age distribution with a supplied initial condition. Scale is not indicated as it is merely an example; however the maximum age and time are 15 years.

\subsection{Assumptions and limitations}

Several assumptions are made on the properties of water, tritium, media and the model domain:

1. The model is assumed to be fully saturated and hence only simulates saturated flow and transport (i.e. no vadose zone);

2. Fluid viscosity is assumed to be constant (1.124E-03 kg/m.s), implying temperature is also constant and therefore hydraulic conductivities are not affected;

3. Bulk density is assumed to be constant $\left(1750 \mathrm{~kg} / \mathrm{m}^{3}\right)$, hence there is no density dependence;

4. Fluid compressibility is assumed as a constant $\left(4.4 \mathrm{E}-10 \mathrm{~m} \cdot \mathrm{s}^{2} / \mathrm{kg}\right)$;

5. Horizontal hydraulic directional conductivities (longitudinal and transverse) are assumed to be equal $\left(K_{x}=K_{y}\right)$;

6. Tortuosity (how winding the average flow path is through the media) is assumed to be isotropic; and

7. Tritium decay is governed by the simple first-order rate law $(1.78 \mathrm{E}-9$ per second). 


\subsection{Middle Valley model methodology summary}

The Middle Valley transient flow and transport model utilized measured and inferred data to implement field appropriate hydraulic parameters for the direct simulation of age throughout the domain. The primary objectives were to simulate groundwater age by:

1. Utilizing an existing flow model to implement transport processes, and calibrate hydraulic parameters to measured and inferred tritium data.

2. Directly simulating age information in the form of both the transient mean-age and specific point age distributions. This was possible due to the recent implementation of the TMLTGT within the Ground Water (GW) software.

The methodology combined a range of widely used tools to implement an informative age simulation. One must stress the risks of relying solely on the calculation of the mean age, given at a specified time many different age distributions exist at points within an aquifer which can have the same mean and variance. This does not claim the mean-age is always misleading, but instead shows the advantage of assessing both (1) the mean age and (2) distribution of ages. For example, young water particles shown in the simulated age distribution indicate the potential for contamination and environmental risks (e.g. pollution and drinking water susceptibility) (Cornaton, 2012; Cornaton and Perrochet, 2006). 


\section{Chapter 7}

\section{Tritium calibration and directly simulated age results}

Prediction is ubiquitous in science as a test of understanding: to the extent that a phenomenon is understood, it can be predicted, and vice versa.

Frank Evison (1999)

Groundwater age has been estimated throughout the Middle Valley catchment using a transient numerical flow and transport model. The simulation of groundwater age provides new options for effective resource management especially at the regional management scale. The ability to evaluate, for example:

1. The mean-age evolution across an entire basin in both space and time. This indicates the effect of rainfall variability, increased abstraction pressures, and delineate zones where applied solutes are more or less suitable for application.

2. The transient groundwater age distribution at nodal points throughout the Middle Valley at points in time. This indicates recharge and abstractive influence as well as groundwater drinking water vulnerabilities. For example, any age distribution showing young water particles (less than one year old) would indicate the potential for water contamination, especially pertinent to drinking water supplies for municipal and domestic users.

This chapter is divided into eight sections. Section one presents a comparison and evaluation of the hydraulic head simulations from the FEFLOW and Ground Water (GW) Middle Valley flow models, and where available, a comparison to field measurements. 
This is followed by section two where initial conditions of the transport model are explained, including the tritium data and spin-up required pre-1992 to set the starting concentrations. Section three then presents the results of the calibration. This includes the inferred tritium concentrations, sensitivity analysis of the model parameters, the optimized values of the adjustable model parameters, the match of the model to the observed calibration data, and the results from the Gauss-Marquardt-Levenberg method and classical Monte Carlo method. Section four summarizes the Middle Valley model performance and results compared to the simulated results from the FEFLOW flow model and available field data. Following this section five presents the results of the probabilistic capture zone evaluation for the 110 pumping wells implemented in the model. This was evaluated to estimate the impact abstraction pressures have on simulated and field groundwater age distributions (Zinn and Konikow, 2007). The results of the direct age simulations are shown in section six, providing age information in both the transient mean age form and specific temporal point age distribution evolution over a 15 year period. Section seven summarizes the results of the direct age simulation and its applicability to water management.

\subsection{Simulated and observed hydraulic head data}

Simulated hydraulic heads were compared from both the different models, FEFLOW and Groundwater (GW), in addition to field measurements of hydraulic head (Fig. 7.1). The differences between the simulated hydraulic heads are evaluated at identical nodes in the spatial domain (often corresponding to consented bores) (Fig. 7.2 and Fig. 7.3). Any comparison of simulations between different software implementations will have minor differences due to the different solvers and numerical variation of each individual code. However, assuming the models are implemented using the same domains, boundary conditions, parameterizations, process representations, etc., simulated output from both FEFLOW and Ground Water (GW) should follow similar patterns. For the purposes of this dissertation, the models were considered to exhibit concerning discrepancies when simulations indicated hydraulic head differences of more than one metre, and extreme discrepancies where differences were more than 
two metres. This was evaluated Field data was subject to availability and not available for all wells over the entire period.

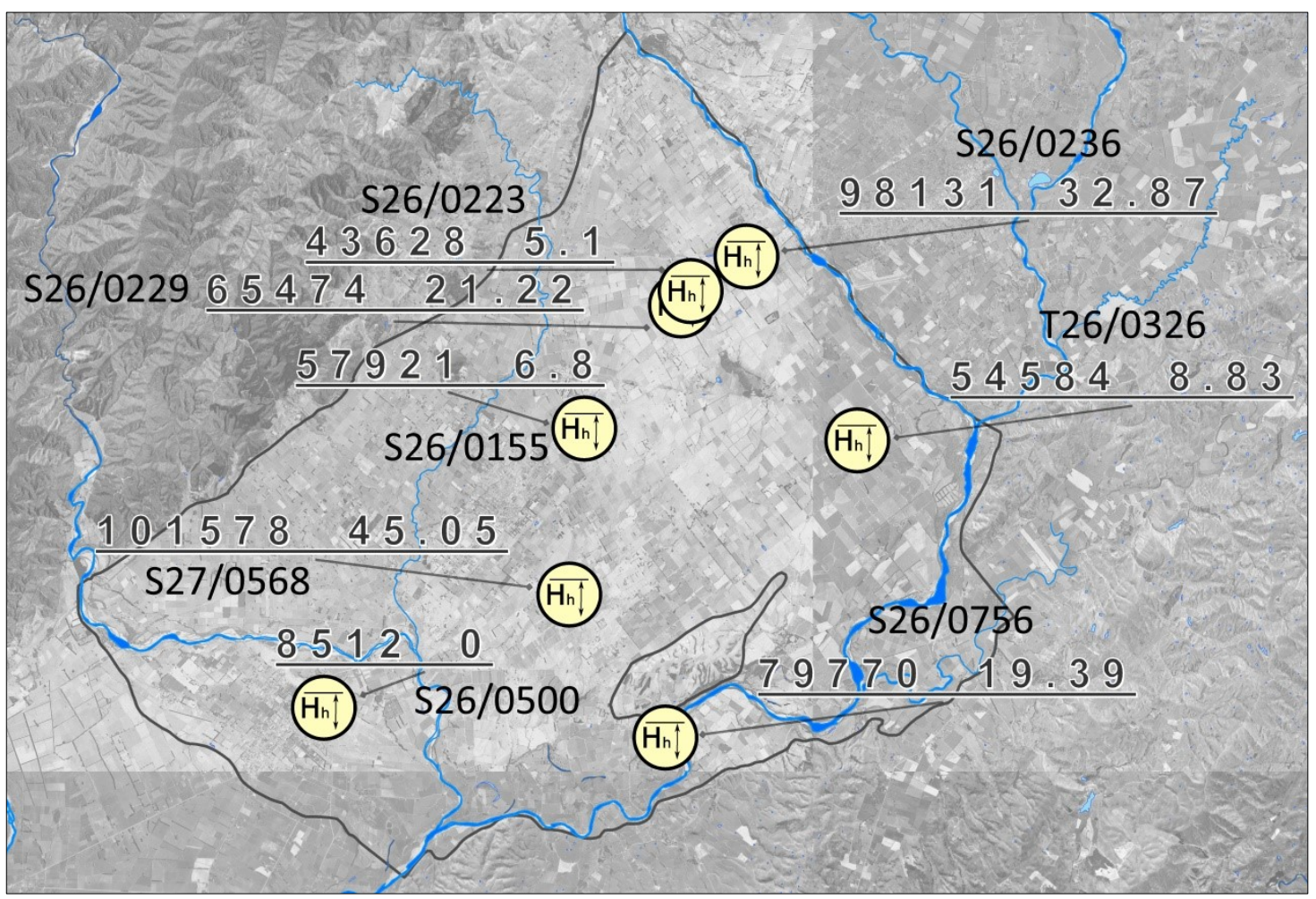

Fig. 7.1 Observation nodes to compare hydraulic head differences between models and field data. Node is indicated on the left and well node depth (metres) below ground surface on right. 

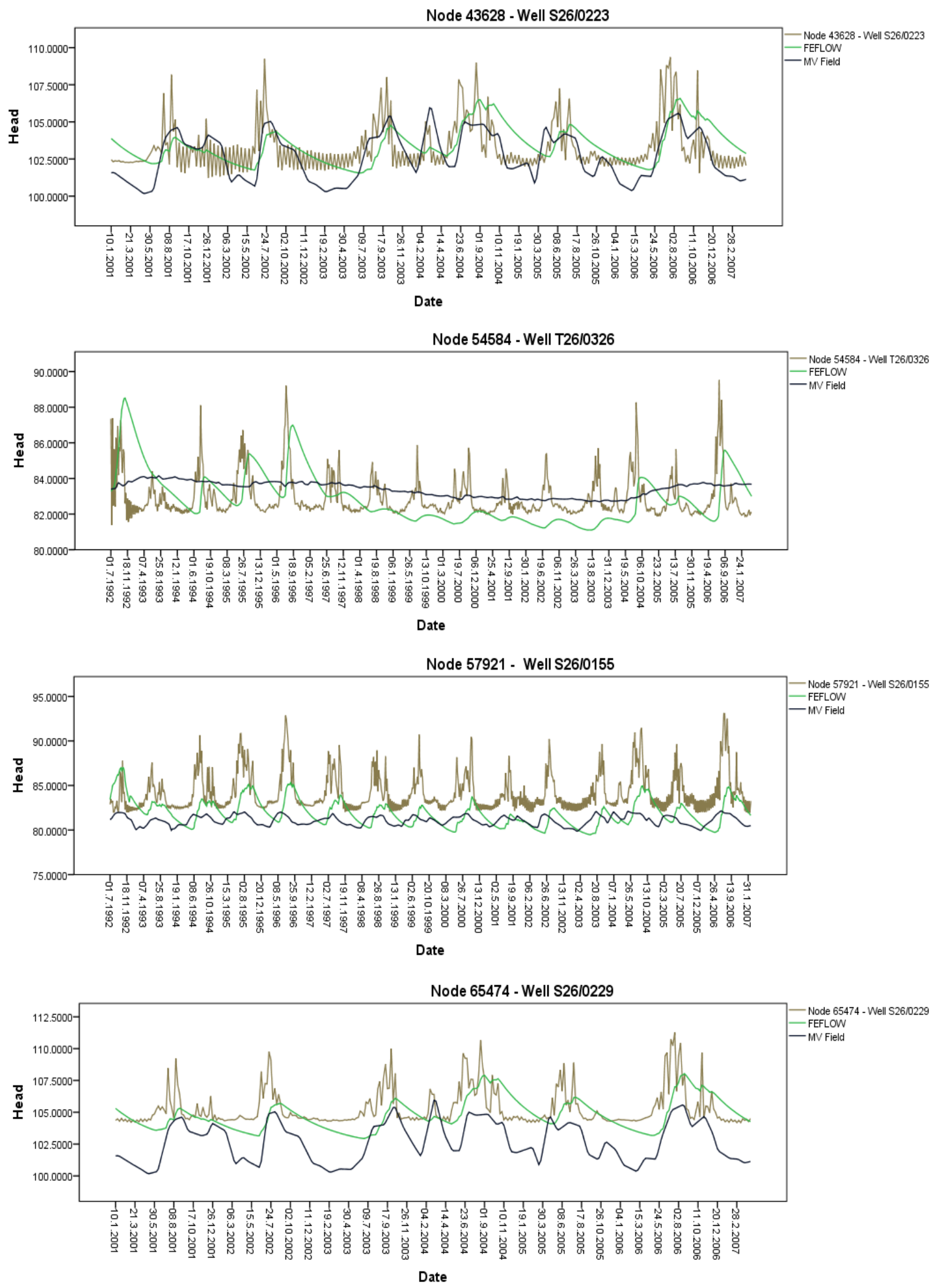

Fig. 7.2 Head comparison between Ground Water (GW) (brown), FEFLOW (green) simulations and Middle Valley field data (Blue) for nodes one to four. 

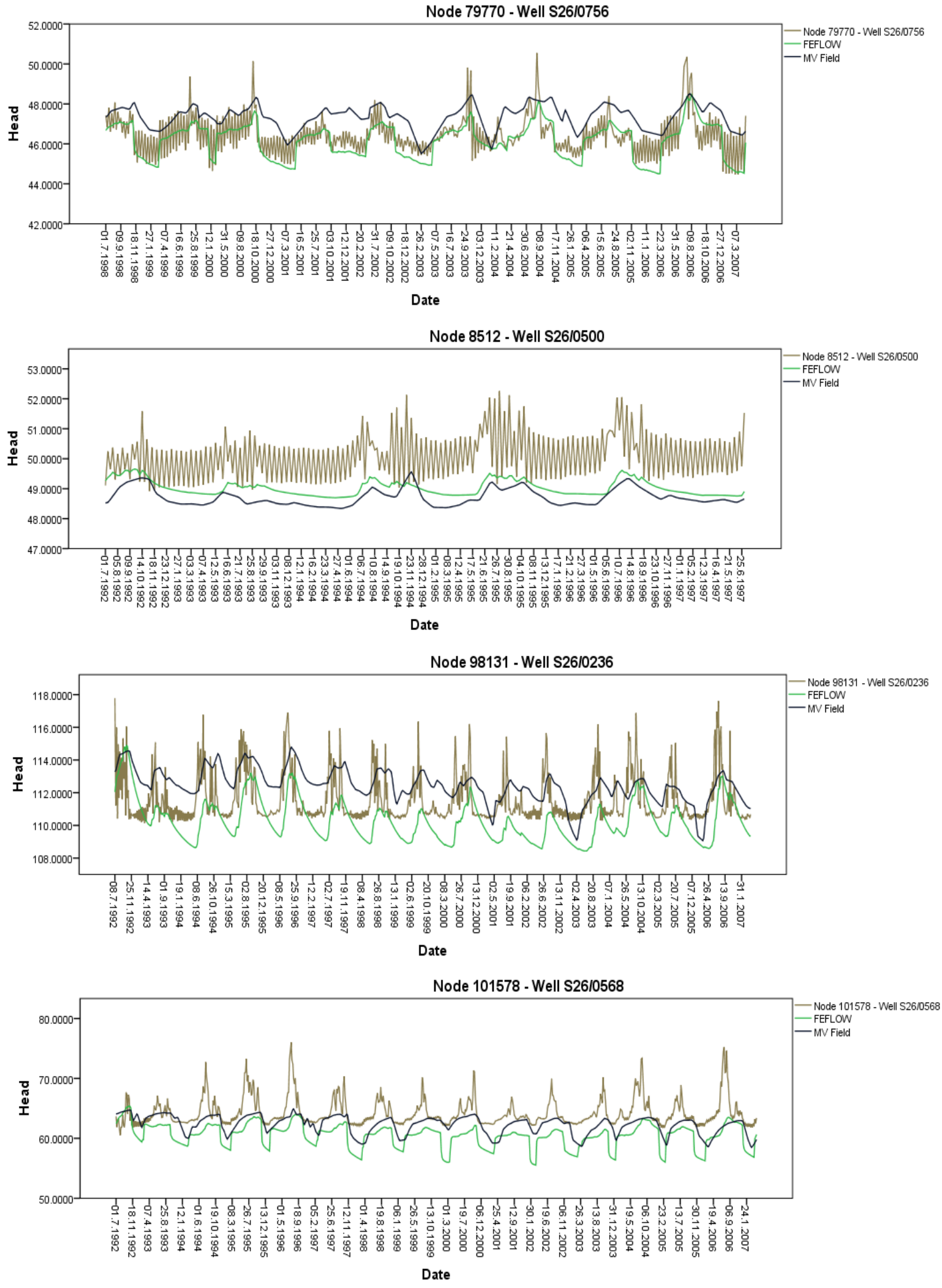

Fig. 7.3 Head comparison between Ground Water (GW) (brown), FEFLOW (green) simulations and Middle Valley field data (Blue) for nodes five to eight. 
Results indicated some significant differences between the two software codes (Fig. 7.1 and Table 7.1). The head difference $\left(H_{d}\right)$ for the simulated heads in the Ground Water (GW) model to compare with the FEFLOW model had to equate to within \pm 1 metre average hydraulic head difference throughout the simulation. This was evaluated using the sum of the square root of the squared difference of the FEFLOW $\left(x_{i}\right)$ and Ground Water (GW) $\left(y_{i}\right)$ simulated heads, divided by the amount of timesteps $(n)$ (e.g. 773 fixed weekly time steps over the simulated period):

$$
H_{D}=\frac{\sum_{i=1}^{t_{s}} \sqrt{\left(\hat{x}_{i}-\hat{y}_{i}\right)^{2}}}{t_{s}}
$$

where:

$$
\begin{gathered}
H_{D}=\text { average nodal head difference }(\mathrm{m}) \\
t_{S}=\text { time-steps in simulation }
\end{gathered}
$$

$\hat{x}_{i}=$ simulated FEFLOW head corresponding to the $i$ th observed head $(\mathrm{m})$ $\hat{y}_{i}=$ simulated Ground Water (GW) head corresponding to the $i$ th observed head $(\mathrm{m})$

Overall $12.5 \%$ of the Ground Water (GW) flow output had a mean difference of less than a metre, $62.5 \%$ was $>1$ metre and $<2 \mathrm{~m}$, and $25 \%$ was $>2$ metres relative to the FEFLOW simulation. Simulated heads in Ground Water (GW) compared to field data also indicated some significant differences, although $37.5 \%$ of the simulated data performed better in the Middle Valley Ground Water (GW) model than the FEFLOW model (according to the available field data). The maximum difference between measured hydraulic heads and simulated heads (at a single point in time) in the FEFLOW flow simulations was 12.92 metres, while the largest difference was 13.13 metres in the Ground Water (GW) model simulations. 
Table 7.1 Statistical differences between Ground Water (GW), FEFLOW and field simulations/data. Bold type indicates $>2 \mathrm{~m}$, italic type indicates $<2 \mathrm{~m}$ but $>1 \mathrm{~m}$ difference.

\begin{tabular}{|c|c|c|c|c|c|}
\hline Well & Comparison & $\begin{array}{l}\text { Sum of the } \\
\text { hydraulic } \\
\text { head } \\
\text { difference } \\
\text { (m) }\end{array}$ & $\begin{array}{c}\text { Average } \\
\text { nodal head } \\
\text { difference } \\
(\mathrm{m})\end{array}$ & $\begin{array}{l}\text { Observations } \\
\text { per group } \\
\left(\boldsymbol{t}_{\boldsymbol{s}}\right)\end{array}$ & $\begin{array}{c}\text { Maximum } \\
\text { difference } \\
\text { (m) }\end{array}$ \\
\hline \multirow[t]{3}{*}{ S26/0223 } & GW vs FEFLOW & 1075.68 & 1.39 & 773 & 6.59 \\
\hline & GW vs Field & 431.83 & 1.32 & 328 & 6.03 \\
\hline & FEFLOW vs Field & 394.94 & 1.20 & 328 & 2.96 \\
\hline \multirow[t]{3}{*}{ T26/0326 } & GW vs FEFLOW & 1028.63 & 1.33 & 773 & 6.97 \\
\hline & GW vs Field & 821.51 & 1.06 & 773 & 5.88 \\
\hline & FEFLOW vs Field & 885.63 & 1.15 & 773 & 4.88 \\
\hline \multirow[t]{3}{*}{ S26/0155 } & GW vs FEFLOW & 1920.62 & 2.48 & 773 & 9.89 \\
\hline & GW vs Field & 2362.80 & 3.09 & 765 & 11.16 \\
\hline & FEFLOW vs Field & 1015.48 & 1.33 & 765 & 5.07 \\
\hline \multirow[t]{3}{*}{ S26/0229 } & GW vs FEFLOW & 951.96 & 1.23 & 773 & 5.15 \\
\hline & GW vs Field & 859.45 & 2.62 & 328 & 7.06 \\
\hline & FEFLOW vs Field & 716.23 & 2.18 & 328 & 4.42 \\
\hline \multirow[t]{3}{*}{ S26/0756 } & GW vs FEFLOW & 499.24 & 0.65 & 773 & 3.50 \\
\hline & GW vs Field & 439.07 & 1.03 & 427 & 3.28 \\
\hline & FEFLOW vs Field & 504.33 & 1.18 & 427 & 2.42 \\
\hline \multirow[t]{3}{*}{ S26/0500 } & GW vs FEFLOW & 970.00 & 1.25 & 773 & 3.46 \\
\hline & GW vs Field & 366.68 & 1.40 & 262 & 3.27 \\
\hline & FEFLOW vs Field & 82.39 & 0.31 & 262 & 0.83 \\
\hline \multirow[t]{3}{*}{ S26/0236 } & GW vs FEFLOW & 1202.27 & 1.56 & 773 & 5.91 \\
\hline & GW vs Field & 1138.25 & 3.47 & 772 & 4.54 \\
\hline & FEFLOW vs Field & 1664.67 & 5.08 & 772 & 3.69 \\
\hline \multirow[t]{3}{*}{ S26/0568 } & GW vs FEFLOW & 2930.90 & 3.79 & 773 & 12.92 \\
\hline & GW vs Field & 1622.19 & 2.10 & 773 & 13.13 \\
\hline & FEFLOW vs Field & 1477.08 & 1.91 & 773 & 6.10 \\
\hline
\end{tabular}

\subsubsection{Discrepancies between models}

The difference between simulated heads between the FEFLOW and Ground Water (GW) flow models were considerable. Specifically, the FEFLOW simulations exhibited much smoother simulations. 
The reason the FEFLOW model exhibited a 'delayed' effect is due to the fact the FEFLOW model had implemented a "phreatic" layer. In the FEFLOW model the model stratigraphy remains constant but variably saturated elements can be present due to the simulation of a phreatic layer on the top of the model surface (Diersch, 2009). Any rainfall recharge must pass through the variably saturated (substrate containing water and air) elements before reaching the water table, creating a dampening effect on vertical water movement (Fig. 7.2 and Fig. 7.3). Therefore, hydraulic heads have a much smaller range in the FEFLOW and field observations, compared to the confined Ground Water (GW) simulations (Table 7.1). For the FEFLOW model implementation, the unconstrained phreatic layer additionally incorporated an extra parameter, drain fillable porosity (also known as specific yield) which is applied to the unconfined 'phreatic' layer. This is exemplified by running both models as confined simulations (Fig. 7.4):
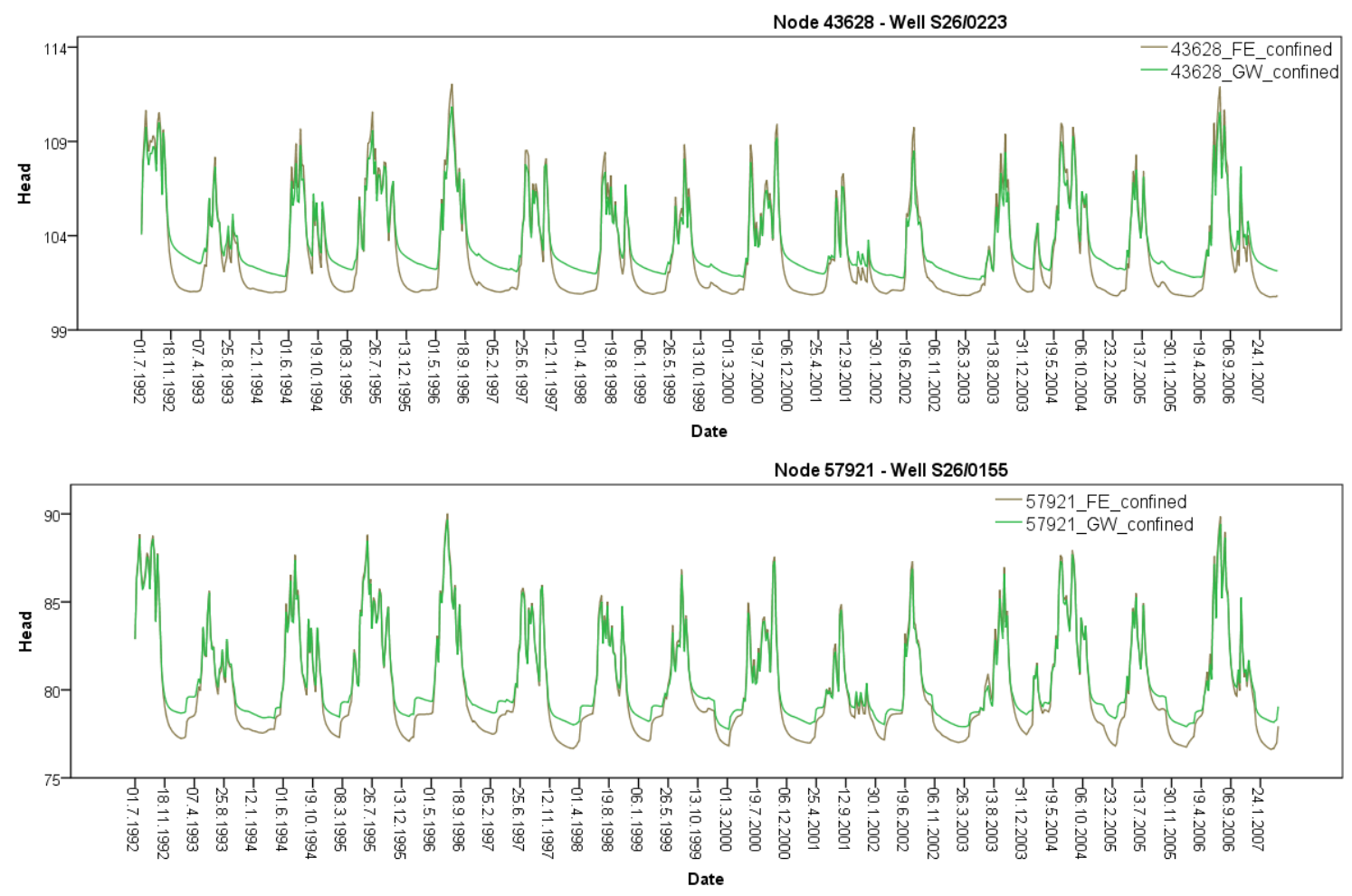

Fig. 7.4 Comparative heads between confined FEFLOW and confined Ground Water (GW) simulations. 
Specific storage is treated differently in unconfined aquifers. For a confined aquifer the storage coefficient is:

$$
S_{s}=S / b
$$

Where $S$ is the storage coefficient and $b$ is the thickness of the aquifer (see Section 2.2.6). However this does not apply for variably saturated aquifer sections, where the specific yield is:

$$
S_{s}=S y / b
$$

$S y$ is the specific yield and $b$ is the thickness of the saturated portion of the aquifer. $S y$ is the ratio of the volume which drains from the aquifer under gravity per unit volume of aquifer material. Specific yield is less than or equal to the cumulative porosity of the aquifer material, typical values for unconfined gravel aquifers are $0.25 \pm 0.1$ (Freeze and Cherry, 1977). Specific yield was estimated and applied to the FEFLOW model (Fig. 7.5).

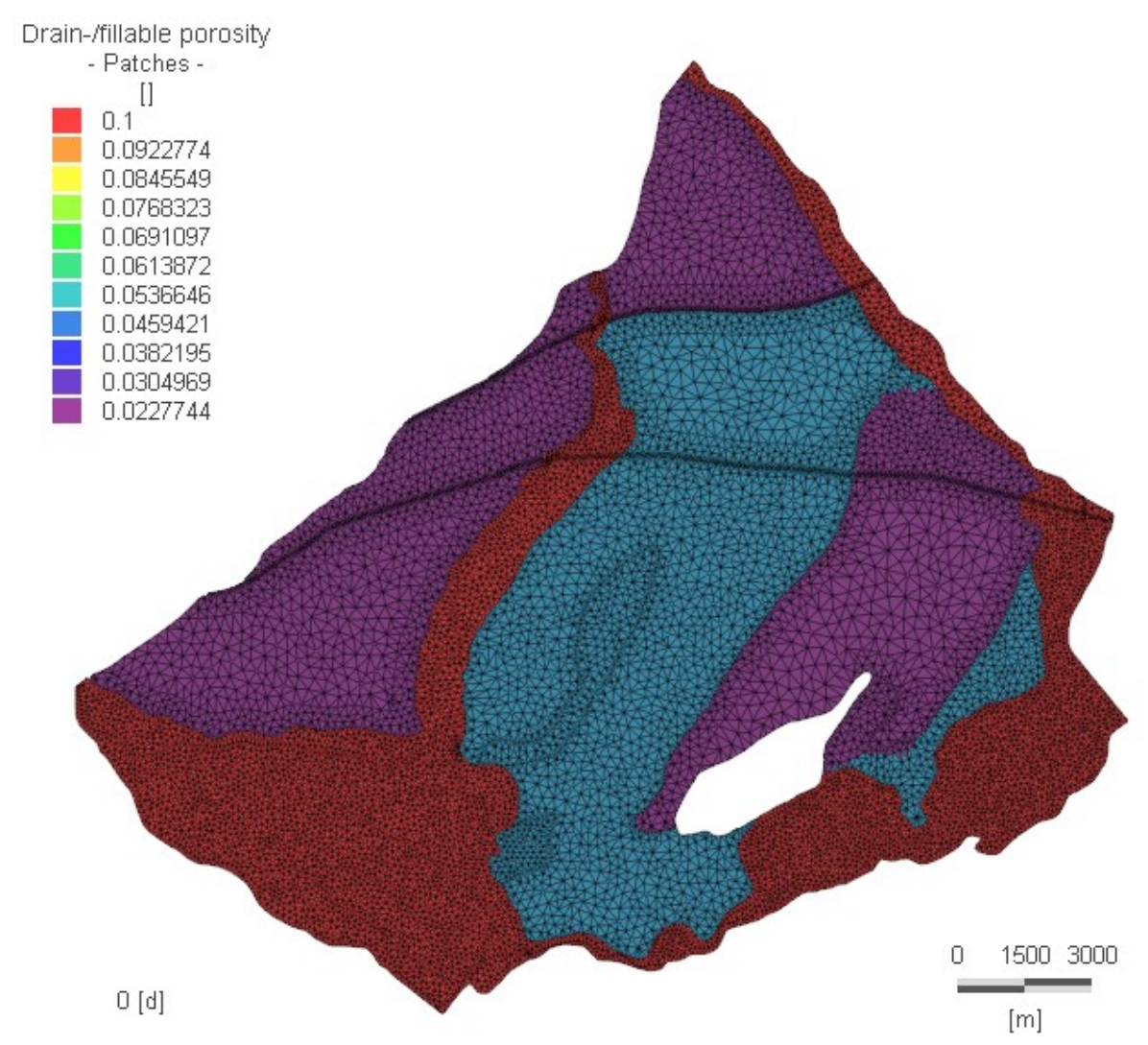

Fig. 7.5 Specific yield (drain fillable porosity) assigned uniformly (layers 1-9) throughout the FEFLOW model. 
Higher values can be seen on the Q1 and Q2 gravel sections. The Middle Valley Ground Water (GW) model could not simulate all of the flow processes represented in the FEFLOW model. Specifically, the versions of Ground Water (GW) provided turned out to have an incomplete implementation of the phreatic method and variably saturated processes for simulations in three spatial dimensions, hence could only simulate a confined groundwater system. Developers were not able to provide a fix to this bug within the timeframe of this thesis. Therefore, the code could not fully reproduce the FEFLOW setup provided by Greater Wellington, which included an unconstrained phreatic zone on the top layer in addition to the saturated layer below. However, the use of Groundwater (GW) remained fundamental to this dissertation, as the FEFLOW software does not yet have the direct simulation of age built into the code.

\subsubsection{Phreatic unconfined aquifer}

In order to achieve comparable results in the Ground Water (GW) model a phreatic simulation was required. The calculation of the variably saturated zone is highly simplified when applying the "phreatic layer" in FEFLOW or Ground Water (GW). In each element which is partially saturated, the partial saturation is calculated by dividing the saturated thickness of the element by the total thickness of the element. Conductivity values in all directions are then linearly reduced by multiplying them with the partial saturation of the element. For entirely dry elements (i.e. where the hydraulic head is below the element bottom), a residual water depth is applied for the calculation of the partial saturation and reduced conductivity (Cornaton, 2007). Groundwater recharge is applied on the top of the model in phreatic mode and therefore has to pass the partially saturated/dry elements before reaching the water table. The unconfined storage term (specific yield) is only applied to the 'phreatic' layer, i.e. the top layer. Therefore it is only applicable when the water table fluctuates within the first layer, i.e. a thin variably saturated zone (Diersch, 2009).

The phreatic water table implementation in Ground Water (GW) was not achievable in this dissertation. Attempts were made to implement it; however, the resulting model output was static (i.e. the numbers were constant) indicating a problem with the phreatic simulation in the Middle Valley Ground Water (GW) model. 
Due to this problem, results and comparisons between software are presented in a confined domain.

\subsubsection{Constraints on type-three boundaries}

Another problem was identified within the Ground Water (GW) model. The third-type Cauchy boundary conditions did not correctly simulate nodes assigned specific constraints. Nodes were unconstrained in the Ground Water (GW) model, despite the specified constraints not allowing any inflows on the assigned spring nodes throughout the model (Fig. 7.6). Hence, these nodes are simulating inflow, where they should not. However, the amount of inflow to the model domain equates to $<2 \%$ of the total fluid budget, at any given time during the simulation.

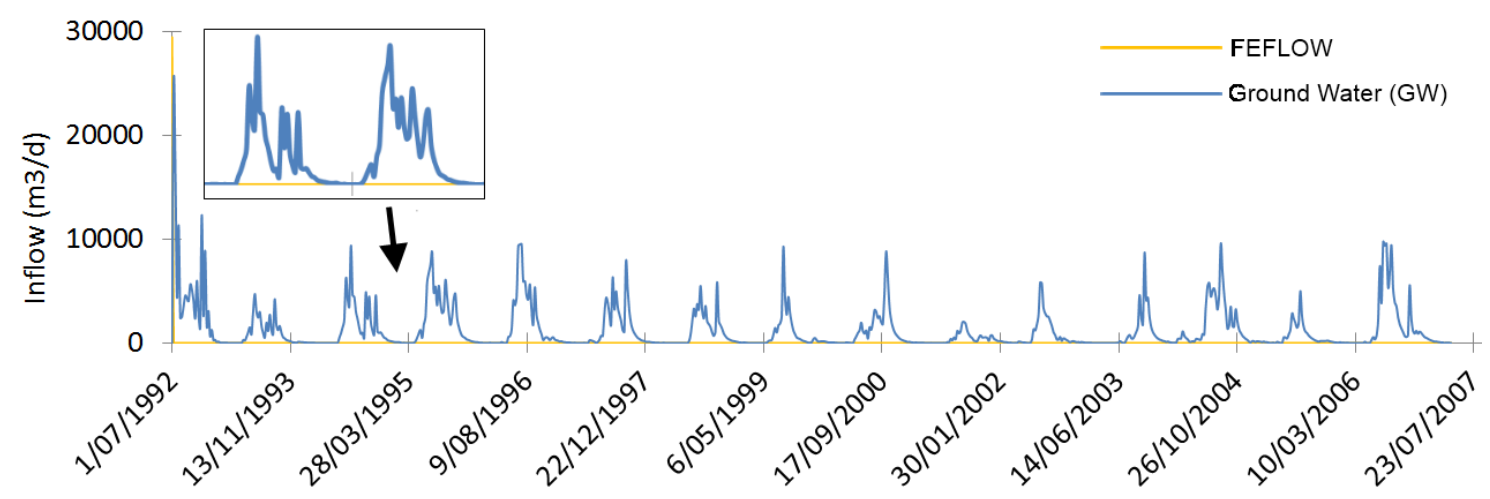

Fig. 7.6 Constraints applied to spring nodes in FEFLOW and Ground Water (GW) confined models. Inflow can be seen in the GW spring nodes.

\subsubsection{Boundary condition modifications}

Modifying the boundary conditions was postulated to abate the problems with the Cauchy boundary conditions (Table 7.2). Given the problems associated with the thirdtype boundary conditions, first-type and forth-type were investigated for their applicability. Third-type boundary conditions were changed in two ways:

1. Cauchy conditions ( $3^{\text {rd }}$ type) to Dirichlet conditions ( $1^{\text {st }}$ type): the fixed hydraulic head was extrapolated from a full (15 year) FEFLOW model run and applied as a type-one boundary with each node assigned a specific varying hydraulic head time-series;

2. Cauchy conditions ( $3^{\text {rd }}$ type) to Well conditions ( $4^{\text {th }}$ type): the flux was extrapolated from a full (15 year) FEFLOW model run and applied as a type-four 
boundary with each node assigned a specific varying time-series $(<0$ treated as an injection well while $>0$ is equivalent to a pumping well, in $\mathrm{m}^{3} / \mathrm{s}$ ).

Table 7.2 Statistical differences in head relative to boundary condition reassignment: from third-type Cauchy conditions (BC3), to first-type (BC1) and forth-type (BC4).

\begin{tabular}{|c|c|c|c|c|c|}
\hline Well & Comparison & $\begin{array}{l}\text { Sum of } \\
\text { the } \\
\text { hydraulic } \\
\text { head } \\
\text { difference } \\
\text { (m) }\end{array}$ & $\begin{array}{c}\text { Average } \\
\text { nodal } \\
\text { head } \\
\text { difference } \\
\text { (m) }\end{array}$ & $\begin{array}{l}\text { Observations } \\
\text { per group } \\
\left(\boldsymbol{t}_{\boldsymbol{s}}\right)\end{array}$ & $\begin{array}{c}\text { Max } \\
\text { Difference } \\
\text { (m) }\end{array}$ \\
\hline \multirow[t]{3}{*}{ S26/0223 } & GW_BC1 vs FEFLOW & 901.20 & 1.17 & 773 & 5.10 \\
\hline & $G W \_B C 3$ vs FEFLOW & 1075.68 & 1.39 & 773 & 6.59 \\
\hline & GW_BC4 vs FEFLOW & 3512.49 & 4.54 & 773 & 7.31 \\
\hline \multirow[t]{3}{*}{ T26/0326 } & GW_BC1 vs FEFLOW & 1947.54 & 2.52 & 773 & 8.89 \\
\hline & GW_BC3 vs FEFLOW & 1028.63 & 1.33 & 773 & 6.97 \\
\hline & GW_BC4 vs FEFLOW & 1214.70 & 1.57 & 773 & 4.08 \\
\hline \multirow[t]{3}{*}{ S26/0155 } & $G W \_B C 1$ vs FEFLOW & 1621.53 & 2.10 & 773 & 5.57 \\
\hline & GW_BC3 vs FEFLOW & 1920.62 & 2.48 & 773 & 9.89 \\
\hline & GW_BC4 vs FEFLOW & 946.42 & 1.22 & 773 & 3.38 \\
\hline \multirow[t]{3}{*}{ S26/0229 } & GW_BC1 vs FEFLOW & 908.03 & 1.17 & 773 & 5.57 \\
\hline & $G W \_B C 3$ vs FEFLOW & 951.96 & 1.23 & 773 & 5.15 \\
\hline & GW_BC4 vs FEFLOW & 3646.00 & 4.72 & 773 & 7.54 \\
\hline \multirow[t]{3}{*}{ S26/0756 } & GW_BC1 vs FEFLOW & 271.64 & 0.35 & 773 & 1.61 \\
\hline & $G W \_B C 3$ vs FEFLOW & 499.24 & 0.65 & 773 & 3.50 \\
\hline & GW_BC4 vs FEFLOW & 4125.43 & 5.34 & 773 & 7.85 \\
\hline \multirow[t]{3}{*}{ S26/0500 } & GW_BC1 vs FEFLOW & 56.18 & 0.07 & 773 & 0.36 \\
\hline & $G W \_B C 3$ vs FEFLOW & 970.00 & 1.25 & 773 & 3.46 \\
\hline & GW_BC4 vs FEFLOW & 3714.93 & 4.81 & 773 & 6.93 \\
\hline \multirow[t]{3}{*}{ S26/0236 } & GW_BC1 vs FEFLOW & 680.32 & 0.88 & 773 & 3.83 \\
\hline & $G W \_B C 3$ vs FEFLOW & 1202.27 & 1.56 & 773 & 5.91 \\
\hline & GW_BC4 vs FEFLOW & 4702.70 & 6.08 & 773 & 9.15 \\
\hline \multirow[t]{3}{*}{ S26/0568 } & GW_BC1 vs FEFLOW & 898.73 & 1.16 & 773 & 6.92 \\
\hline & GW_BC3 vs FEFLOW & 2930.90 & 3.79 & 773 & 12.92 \\
\hline & GW_BC4 vs FEFLOW & 4702.70 & 6.08 & 773 & 9.15 \\
\hline
\end{tabular}


Results indicated that type-one conditions performed the best out of the eight wells compared. Type-one conditions were not used in the direct age simulation however as they are not a transfer type condition, and cannot be used for predictive purposes. Given the problems with the phreatic implementation, and the minor impact constraints have on the global fluid budget (i.e. \%2), type-three conditions were used as in the FEFLOW model.

Variably saturated processes occur in the Middle Valley groundwater system and should be simulated as such, or as a "phreatic surface" to abate the differences between hydraulic heads in FEFLOW. However, such implementation would be extremely time consuming due to the complexities involved with parameterizing and implementing variably saturated zone processes, beyond the scope of this thesis.

\subsection{Initial tritium transport conditions}

Initial transport conditions were derived from the pre-1992 simulation conditioning (see Section 6.2.4). The tritium distribution in groundwater is controlled by the atmospheric input (see Section 3.1.1) and the hydrogeologic parameters. Initial conditions were derived after a 15 year tritium simulation period using the atmospheric tritium input from $2 / 7 / 1977$ to $30 / 06 / 1992$. This was assessed as a long enough spin-up period given the dynamic nature of the catchment (see Fig. 6.5). The resulting tritium distribution suggested relatively fast advective flow and transport processes within the simulated Middle Valley reservoirs. Some zones can be seen to have significantly low tritium concentrations, for example, the base of the domain/groundwater system and parts of the Parkvale groundwater zone (Fig. 7.7). This is due to the zone exhibiting a history of significant faulting events, contributing to the zone containing sections of lower hydraulically conductive media. Slowing the movement of water also slows the movement of the tritium, leaving it longer to decay in the subsurface. Atmospheric tritium concentrations have decreased from the tailend of the bomb peak in 1977 to approximate background levels in 1992, 1.9 TU. 


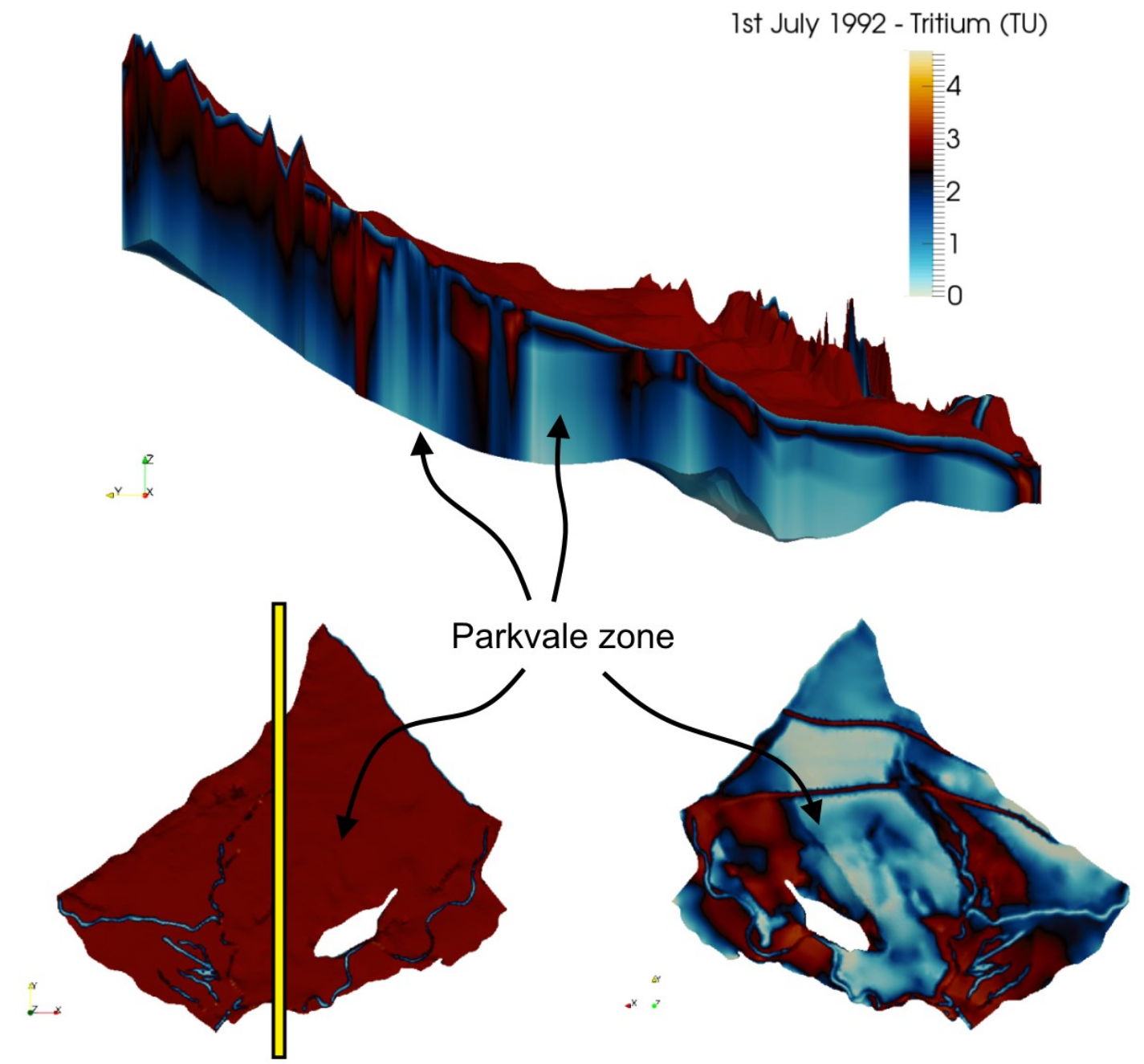

Fig. 7.7 Initial tritium distribution on the $1^{\text {st }}$ July 1992 . The (top) clip runs north to south through the middle of the catchment, indicated by the yellow line in the smaller left figure and the bottom concentrations in the right figure

\subsection{Calibration}

Calibration was performed to estimate the hydraulic parameters controlling the flow of water and transport of water particles (i.e. age) within the model domain. The calibration utilized time-varying observed head, measured tritium concentrations, and inferred tritium concentration derived from $\mathrm{SiO}_{2}$ concentrations (Fig. 7.8). Calibration was performed by adjusting the flow and transport parameters, i.e. porosity, hydraulic conductivity and storativity. Two methods were used in the calibration, the first being the Gauss-Marquardt-Levenberg parameter estimation scheme, the second being a classical Monte Carlo scheme. 


\subsubsection{Calibration data}

Observed field data are critical in the calibration of a model. Measured data gives a comparative base for model output and adjustment of the flow and transport parameters to conform (as much as possible) to the reality of the system being modelled. In addition to measured hydraulic head and tritium data an inferred tritium dataset from measured silica concentrations utilized 27 observed measurements of both tritium and silica. This resulted in 190 additional tritium measurements spread throughout the Middle Valley over a broader time range in the calibration phase. Inferred concentrations were assigned much lower weights relative to their inferred error (Fig. 7.8) as each observation is assigned a weight relative to the inverse of the known error associated with the measurement (see Section 6.3.2). Weighting of observational data is critical, albeit subjective, component when calibrating a model.

\subsubsection{Inferred tritium data}

Silica was used to infer tritium concentrations (see Appendix M). It was selected due to it having the most statistically significant correlation to observed tritium concentrations in the Wairarapa, as well as the most field measurements taken alongside tritium measurements (27 measurements). Inferred tritium concentrations were derived from data extending from 2003 - 2007 (see Appendix D). The equation below shows the results of fitting a linear regression model to describe the relationship between the dependent variable tritium (TR) and the independent variable silica $\left(\mathrm{SiO}_{2}\right)$ :

$$
\mathrm{TR}=2.346-0.049 \times \mathrm{SiO}_{2}
$$

\subsubsection{Inferred tritium justification and calibration weighting}

Tritium concentrations inferred from measured silica concentrations provided additional assistance during the calibration phase (Table 7.3). However, given the values were not as reliable as measured tritium concentrations, the inferred concentrations were assigned lower weights relative to their inferred source (Fig. 7.8). 
Each measurement should be assigned a weight relative to the inverse of the known error associated with the measurement (see Section 6.3.2). Weighting of observational data is a critical, albeit subjective, component when calibrating a model (Doherty, 2010). The weighting of tritium concentrations was based on the known or estimated error of measurement (see Eq. 6-2, Eq. 6-3 and Table 6.8). The reliability of any inferred tritium concentration is questionable, given the crude linear inference and the fact it is not measured field data. However, an attempt is made to weight inferred tritium data from the $95.0 \%$ confidence intervals upper and lower limits of the measured tritium and silica regression analysis (see Section 6.3.2.2).

Table 7.3 Tritium calibration weighting range.

\begin{tabular}{ccc}
\hline & Inferred Tritium from SiO2 & Measured Tritium \\
\hline Highest weight & 1.06 & 25 \\
Lowest weight & 0.48 & 16.67 \\
Observations & 190 & 6 \\
\hline
\end{tabular}

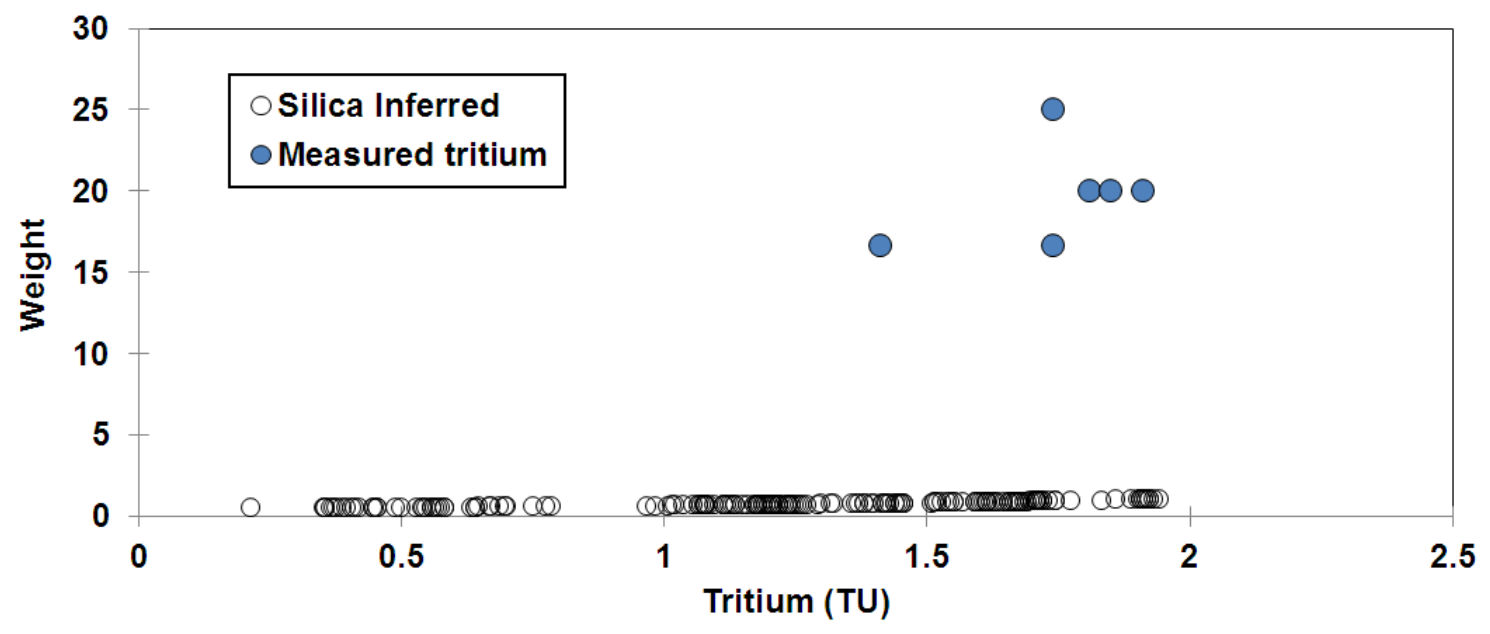

Fig. 7.8 Measured tritium concentrations (6) and tritium concentrations inferred from $\mathrm{SiO} 2$ concentrations (190) compared against assigned weights. 


\subsubsection{Inferred tritium data sensitivity analysis}

Sensitivity analysis was performed adjusting only the vertical hydraulic conductivity parameters with a) measured and inferred tritium concentrations, and b) only measured concentrations (i.e. the six measured tritium concentrations).

Results indicated that the calibration was improved by the inclusion of inferred tritium concentrations, and that they did not adversely or unjustifiably give excessive emphasis on the inferred tritium concentrations over the measured concentrations. Therefore, the weighting regime utilized the inferred concentrations to enhance parameter optimization, particularly the temporal distribution of tritium concentrations.

\subsubsection{Parameter sensitivity analysis}

Model parameters were assessed for their individual sensitivities in response to changes in hydraulic parameters. The Jacobian analysis enabled parameter estimation where appropriate with significance placed on the estimated parameter of greatest influence (see Section 6.3.3). Results indicated 60 out of the 220 adjustable parameters (27.2\%) had the greatest effect on the observation data. The sensitivities were applied in the localized Gauss-Marquardt-Levenberg parameter-estimation process by fixing the 140 insensitive parameters as static, and the 60 sensitive parameters as adjustable. This was an attempt to focus the calibration process towards adjustment of only those parameters that exerted strongest control on the model's ability to simulate the observation data, in an attempt to increase the accuracy and efficiency of the calibration.

\subsubsection{Localized Gauss-Marquardt-Levenberg parameter estimation scheme}

The Localized Gauss-Marquardt-Levenberg parameter estimation scheme was utilized in the initial calibration of the Middle Valley flow and transport model. The method was used within the PEST software (Doherty, 2010). The calibration estimated the model parameters based on the measured and inferred information available for the Middle Valley groundwater system. 
Initially, porosity was calibrated as the only adjustable parameter given porosities proportionality, although not direct, to hydraulic conductivity. Porosity was postulated to be the controlling parameter on simulated tritium transport, in addition to the computational benefits of using a single parameter. All 55 porosity parameters were set as adjustable and tested for relative effect on the simulated tritium output.

The simulated results did not match the measured tritium concentration values. Tritium values were around $50 \%$ higher than the measured field data, indicating further adjustment of the model parameters was needed to match tritium in water through the Middle Valley's aquifers. The simulated tritium objective function was 1101.79 from 196 comparative tritium data concentrations, and this was used as a baseline for calibration of the transport model.

Parameter adjustment was extended to the two horizontal hydraulic conductivities and the storativity coefficients. This resulted in 165 adjustable parameters, as horizontal hydraulic conductivity in both longitudinal and transverse directions is assumed to be equal, and therefore grouped in the calibration process ( $\mathrm{Kxx}=\mathrm{Kyy})$. Kzz was initially fixed with the respective values from the GWRC FEFLOW flow model. A sensitivity analysis was performed prior to optimization indicating 46 of the 165 parameters had the most effect on the simulated heads and tritium transport. After 276 estimation runs, the identified optimal set of parameters reduced the overall objective function (heads and tritium) to 2926.39, with a contribution of 612.32 from the tritium dataset and 2314.06 from the head dataset. The simulated tritium error was reduced by forty-four percent, and the hydraulic head calibration improved by forty-two percent. Calibration was further extended to include the 55 vertical hydraulic conductivity parameters resulting in 220 porosity, hydraulic conductivity and storativity parameters. Following an additional three Gauss-Marquardt-Levenberg parameter estimation calibration runs, the Monte Carlo method was utilized. 


\subsubsection{Classical Monte Carlo method}

The inherent problem with the Gauss-Marquardt-Levenberg parameter estimation scheme is that it tends to reach a localized parameter solution; therefore, it may not find anything approaching the "true" global best fit. In order to be more robust a classical Monte Carlo scheme was also used to sample the global range of the Middle Valley's flow and transport parameters. The method was implemented to reduce the inadequacies of localized parameter estimation from the Gauss-Marquardt-Levenberg scheme.

The outcome of 3000 Middle Valley simulations, with randomly assigned parameter values within certain predefined bounds for the 220 possibilities concluded with a best combined (tritium and head) objective function of 3426.678 (phi). Direct use of the Monte Carlo sampling scheme produced a less good fit than that obtained by using the Gauss-Marquardt-Levenberg scheme. However, combining the two methods enabled a new (stochastically derived) starting point for the calibration (via PEST) to resume.

Following this combined implementation of the calibration process, an overall improvement in the model calibration error was achieved reducing the total objective function from 9939.25 to 2480.41 , a $75 \%$ reduction (Fig. 7.9). This consisted of a relative error contribution of 2197.634 from the hydraulic head observation group and 282.78 from the observed tritium data. Compared to the original starting flow model calibration, negating any transport, a 54\% reduction of the flow model calibration error was achieved, and a $74 \%$ improvement in the simulated tritium concentrations from the initial starting point of the calibration process. 

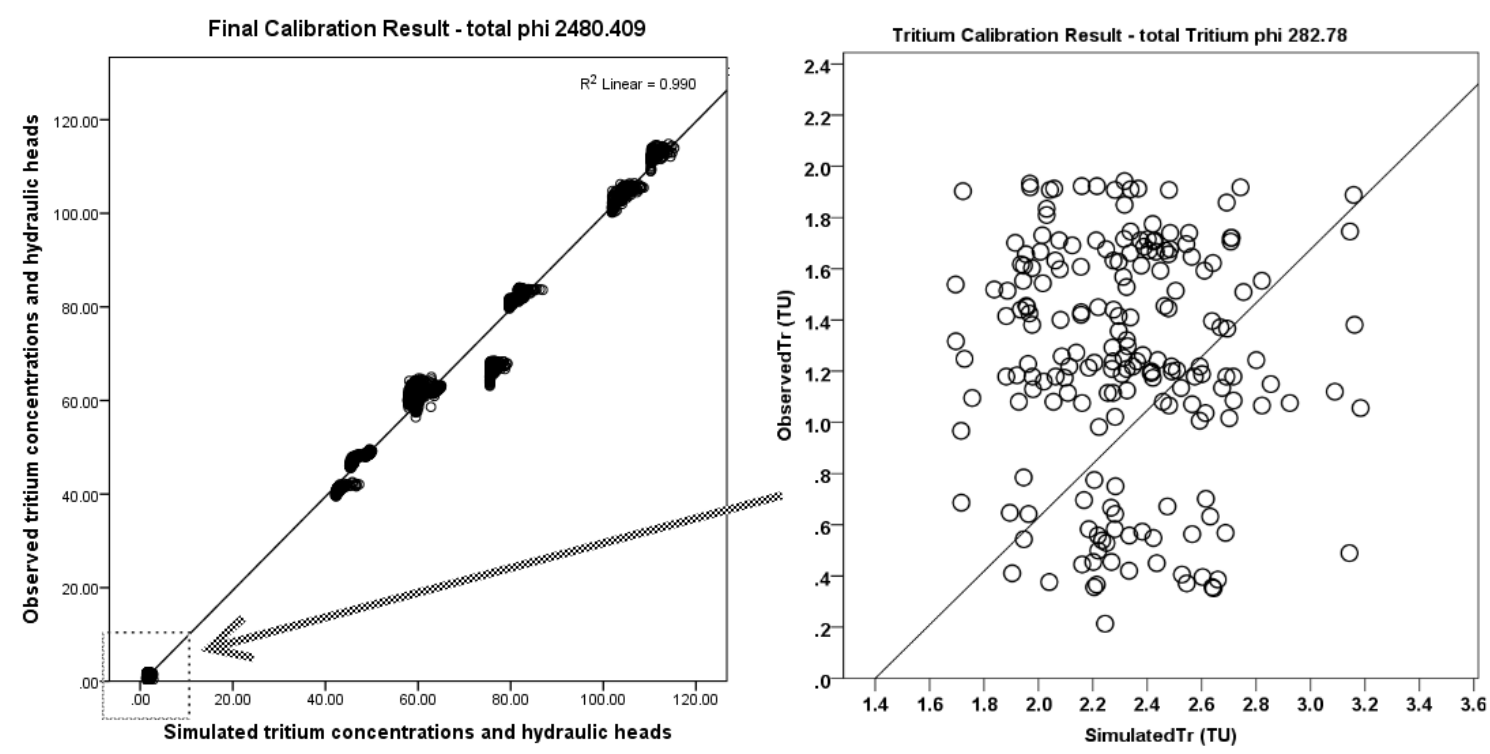

Fig. 7.9 Final model calibration result showing all observed and simulated data used in the calibration. Final phi of 2480.409 ( $n=4524)$. No significant correlation shown in the right tritium calibration result.

\subsubsection{Porosity sensitivity analysis}

Resulting parameters however required additional assessment. The final calibration phase estimated porosities exceeding expected (and realistic) values for the geological composition within the Middle Valley substrate. 23 parameters were assigned porosities of between 0.4 and 0.6; values typical of fine material such as clay (see section 2.2.1). This was an attempt, by the calibration, to slow the model's transport processes and reach an 'ideal' value, irrespective of the reality of the geology within the Middle Valley. To make the parameterisation more consistent with the conceptual understanding of the hydrogeology, the respective unrealistic porosity values were adjusted to a maximum of 0.4 , keeping within a realistic range for fine sands and gravels spread throughout the Middle Valley domain (Fig. 7.10) (see Appendix B). 

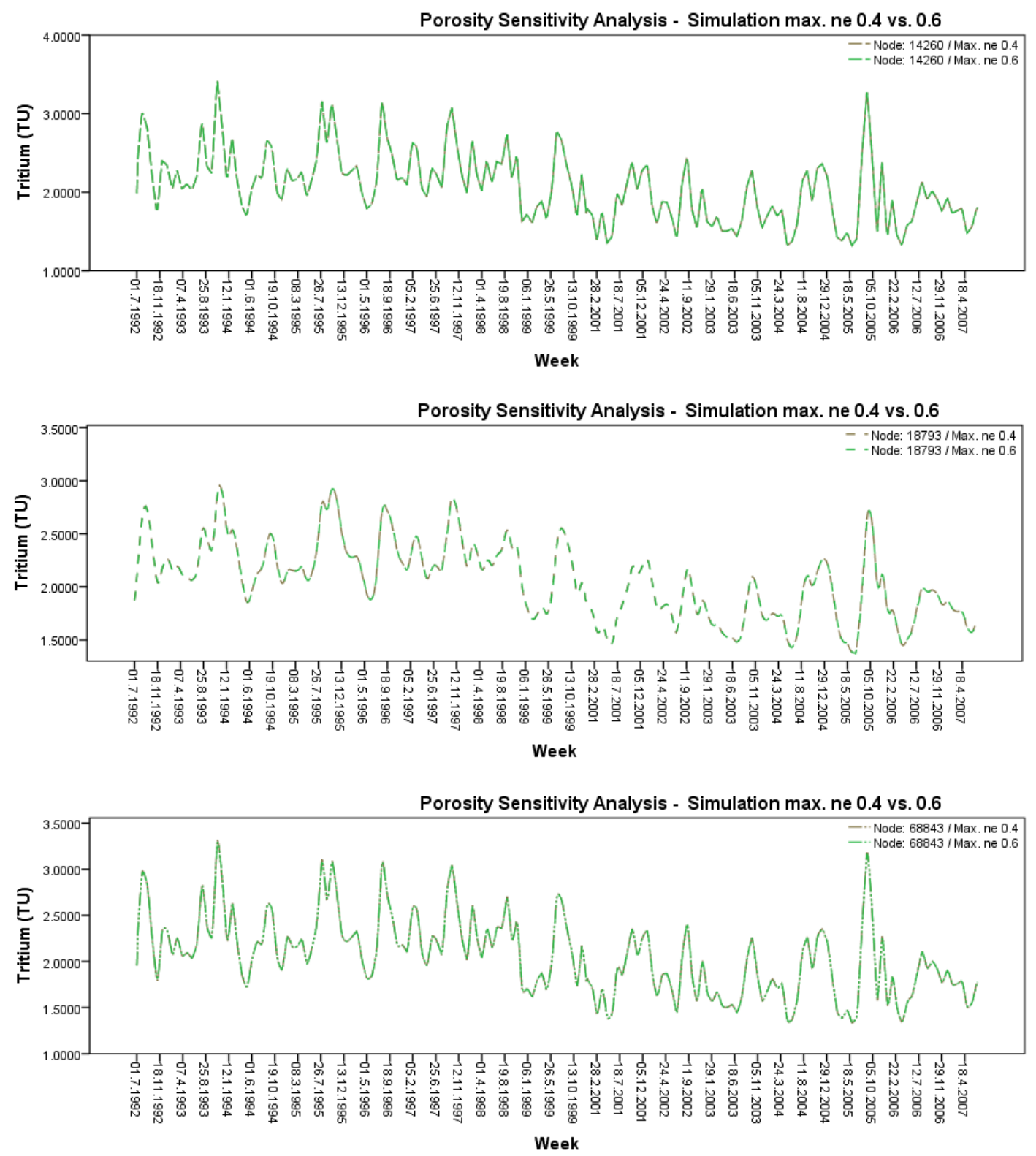

Fig. 7.10 Porosity sensitivity analysis for three nodes in the Middle Valley.

The effect of this change was assessed performing a sensitivity analysis between the two parameter sets. Tritium concentrations simulated were derived from the 19922007 period. For one of the simulations, the 23 scaled parameters adjusted back to a maximum of 0.4 , with the second simulation using the calibrated parameters 23 of which were assigned porosities of $>0.4$ but $\leq 0.6$. The resulting simulations indicated the adjusted parameters had little effect on the simulated tritium concentrations migration through the subsurface of the Middle Valley; hence the adjusted porosities $(\leq 0.4)$ were applied for the direct age simulation. 


\subsubsection{Calibration summary}

Model parameters govern the flow of water and transport of particles within a simulated system. Representative parameters of the simulated system are required to simulate field conditions exhibited in the real groundwater system. The large number of hydrogeologic parameters creates a situation whereby several unique configurations can produce similar results, and hence the problem of a non-unique solution, and over-determined problem. When estimating model parameters several approaches can help the approximation of model parameters, and the reduction of error, when comparing to the available field data. The calibration of the Middle Valley model was achieved using both the localized Gauss-Marquardt-Levenberg parameterestimation process and a classical Monte Carlo method. Initially the Gauss-MarquardtLevenberg method achieved a significant improvement on the Middle Valley flow calibration; however, the localized nature of the scheme prompted the investigation of a stochastically assigned set of parameters via a classical Monte Carlo sampling regime (Table 7.4). The combination of these two methods increased the robustness of the calibration and improved the goodness of fit for both flow and transport outputs.

Table 7.4 Parameter bounds from best parameter sets of FEFLOW and Ground Water (GW) models.

\begin{tabular}{cccccc}
\hline Code & Value & Kxx & Kyy & Kzz & Ss \\
\hline FEFLOW & Minimum & $3.85 \mathrm{E}-08$ & $3.85 \mathrm{E}-08$ & $1.29 \mathrm{E}-09$ & $7.24 \mathrm{E}-06$ \\
Ground Water (GW) & Minimum & $5.21 \mathrm{E}-05$ & $5.21 \mathrm{E}-05$ & $3.34 \mathrm{E}-08$ & $1.25 \mathrm{E}-05$ \\
FEFLOW & Maximum & $4.73 \mathrm{E}-03$ & $4.73 \mathrm{E}-03$ & $2.70 \mathrm{E}-05$ & $1.32 \mathrm{E}-04$ \\
Ground Water (GW) & Maximum & $4.73 \mathrm{E}-03$ & $4.73 \mathrm{E}-03$ & $2.70 \mathrm{E}-05$ & $1.32 \mathrm{E}-04$ \\
\hline
\end{tabular}

Calibrated parameters were representative of dynamic zones within the Middle Valley (see Section 5.1). Comparisons between investigated zones show calibrated values are within the range of hydraulic conductivities and storativity value3s (see Table 5.6). 
The groundwater sediments contain a heterogeneous collection of basin-fill late

Quaternary (i.e. the past 0.5 - 1.0 million years) fluvio-glacial sediments (Gyopari and McAllister, 2010a). For example, the principal aquifers, the Q1 shallow gravel aquifers (i.e. Waiohine, Ruamahanga and Mangatarere rivers floodplains) and the Q4 and Q6 aquifers in the Parkvale sub-basin (see Fig. 4.16 and Fig. 7.11). A comparison between parameter values assigned by GRWC indicated the model parameters have reduced parameter bounds by several orders of magnitude at the lower end (see Table 6.9 Table 6.11). This difference was caused by the calibration process attempting to slow the transport of tritium (i.e. decreasing hydraulic conductivities) to match observed concentrations. The simulation of a phreatic water table or variably saturated zone would slow vertical flow and transport. It is postulated that this would create a wider range of parameter values, extending to the lower ranges of hydraulic conductivity to the values of the deeper Q5 + Q7 silts/clay aquitards (see Table 6.11).

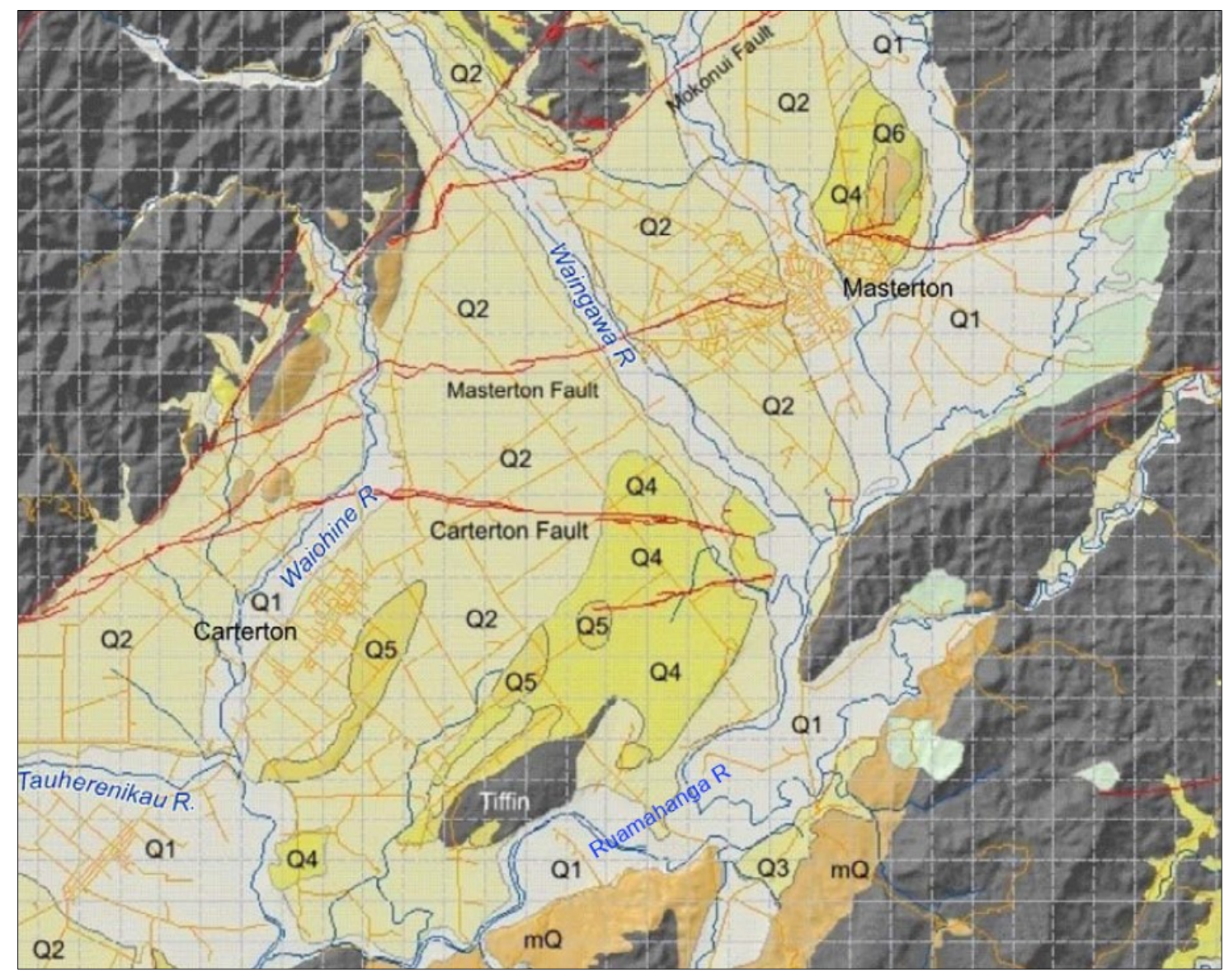

Fig. 7.11 Upper and Middle Valley catchment geology. Middle Valley is bounded by the Waingawa and Ruamahanga Rivers. Source: Begg et al (2005). 


\subsection{Middle Valley transient flow and transport model performance}

The global fluid budget was compared to the estimated steady state and transient water balance for the GWRC FEFLOW flow model (Table 7.5). Rainfall recharge is much greater in the Middle Valley than simulated groundwater abstractions (Fig. 7.12).

A maximum of $1,500,000 \mathrm{~m}^{3} /$ day recharges the Middle Valley domain compared to a maximum of $80,000 \mathrm{~m}^{3} /$ day abstracted for irrigation bores. The abstraction maximum is roughly $5 \%$ of the maximum rainfall input to the system, however, irrigation abstraction pressures have an effect (sometimes significant) on the distribution of ages and mixing within the respective aquifer from which they withdraw from (e.g. Bethke and Johnson, 2002 and Zinn and Konikow, 2007).

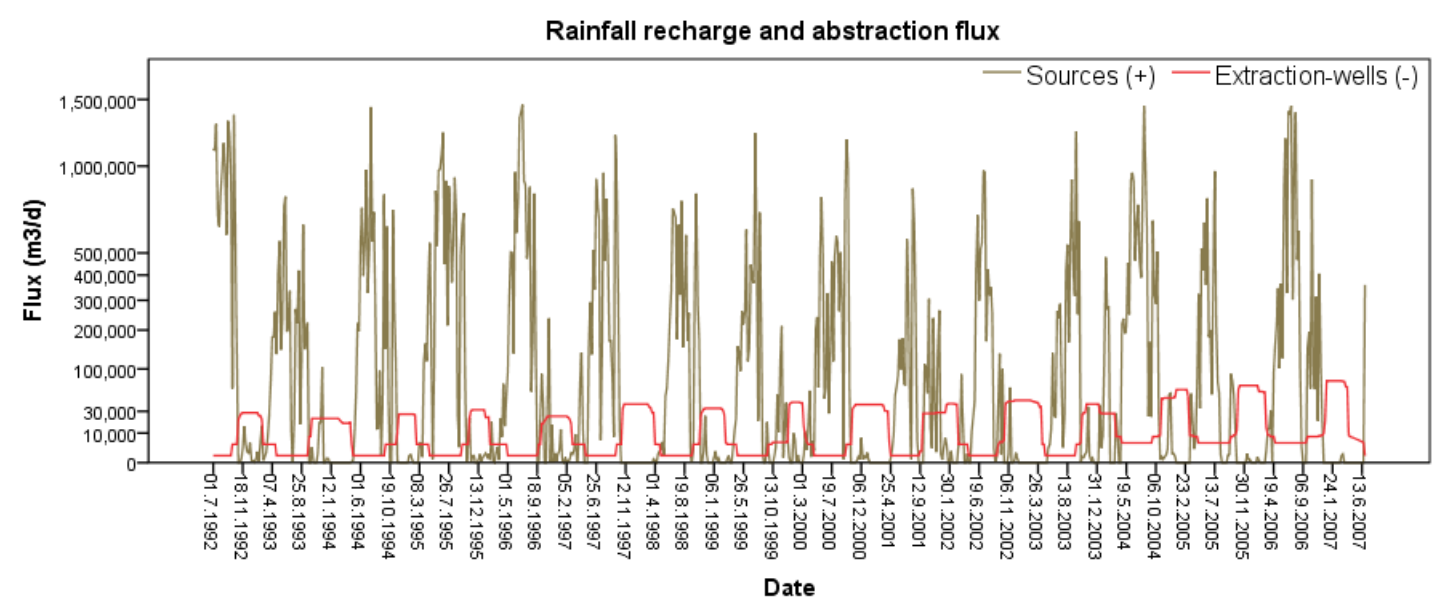

Fig. 7.12 Recharge sources and abstraction withdrawals from the Middle Valley catchment. Sources are positive (inputs) and extractions are negative (outputs).

Compared to the steady state water balance the results indicated a relatively good match of the rainfall recharge and abstraction from irrigation bores, however the groundwater recharge and discharge from rivers (transfer boundaries) were significantly higher in the transient Ground Water (GW) simulation (Table 7.6). This difference is due to the transient nature of the model and natural variation of climatic processes, rainfall, river recharge and discharge (Fig. 7.13). 
Transient model comparisons between the global fluid budgets indicated some discrepancies but were assessed as acceptable differences for the direct simulation of age (Table 7.7$)$. On the $25^{\text {th }}$ of January during the dry summer season the model simulations showed a relatively balanced flux in the respective models, however river recharge was significantly higher and the river base flow significantly lower in the Ground Water (GW) model. This was attributed to the FEFLOW model incorporating a phreatic zone, which was not done in the Ground Water (GW) model (see section 7.1.2).

Table 7.5 Estimated steady state water balance for the Middle Valley catchment. Source: Gyopari and McAllister (2010a).

\begin{tabular}{|c|c|c|}
\hline & $\ln \left(\mathrm{m}^{3} /\right.$ day $)$ & Out $\left(\mathrm{m}^{3} /\right.$ day $)$ \\
\hline Rainfall recharge & 190,000 & - \\
\hline River flow gain/groundwater discharge & - & 170,000 \\
\hline River flow loss/groundwater recharge & 143,000 & - \\
\hline Springs and diffuse evapo-transpiration & - & 140,000 \\
\hline \multirow[t]{2}{*}{ Abstraction } & - & 20,000 \\
\hline & 333,000 & 331,000 \\
\hline
\end{tabular}

Table 7.6 Global fluid budget comparison between transient Ground Water (GW) model and steady state FEFLOW model.

\begin{tabular}{|c|c|c|}
\hline & $\begin{array}{c}\text { Ground Water (GW) } \\
\text { Transient } \\
\left(\mathrm{m}^{3} / \text { day average) }\right.\end{array}$ & $\begin{array}{c}\text { FEFLOW } \\
\text { Steady-state }\left(\mathrm{m}^{3} / \text { day }\right)\end{array}$ \\
\hline Rainfall recharge & 190,192 & 190,000 \\
\hline River flow gain/groundwater discharge & 395,510 & 170,000 \\
\hline - $\quad$ Rivers (54.77\%) & 216,616 & - \\
\hline - $\quad$ Springs (41.24\%) & 163,116 & - \\
\hline - Wells (3.99\%) & 15,778 & - \\
\hline River flow loss/groundwater recharge & 212,494 & 143,000 \\
\hline - $\quad$ Rivers (99.38\%) & 211,186 & - \\
\hline - $\quad$ Springs $(0.62 \%)$ & 1,307 & - \\
\hline - Wells (0\%) & 0 & - \\
\hline Abstraction & 15,843 & 20,000 \\
\hline
\end{tabular}


A comparison of the winter flux on the $19^{\text {th }}$ of July 2005 showed a close match between flux in via rainfall recharge and river recharge, as well as the flux out from abstraction bores and spring discharges. However, the river base flow was $60 \%$ greater in the Ground Water (GW) simulation. It is acknowledged that groundwater fluxes within the model require improvement relative to the reality of the Middle Valley groundwater transfers, however due to time constraints and software limitations; the direct simulation of age and capture zone delineation was performed accordingly with the best available parameters and current resources.

Table 7.7 Transient model comparisons.

\begin{tabular}{|c|c|c|c|c|}
\hline & \multicolumn{2}{|c|}{ FEFLOW } & \multicolumn{2}{|c|}{ Ground Water (GW) } \\
\hline & $\begin{array}{l}\text { Flux In } \\
\left(\mathrm{m}^{3} / \text { day }\right)\end{array}$ & $\begin{array}{l}\text { Flux Out } \\
\left(\mathrm{m}^{3} / \text { day }\right)\end{array}$ & $\begin{array}{l}\text { Flux In } \\
\left(\mathrm{m}^{3} / \text { day }\right)\end{array}$ & $\begin{array}{l}\text { Flux Out } \\
\left(\mathrm{m}^{3} / \text { day) }\right.\end{array}$ \\
\hline 25 January 2005 - summer & & & & \\
\hline Rainfall recharge & 0 & & 0 & \\
\hline River recharge & 114,000 & & 276,138 & \\
\hline Abstraction & & 49,000 & & 60,686 \\
\hline River base flow & & 225,000 & & 142,145 \\
\hline Spring discharge & & 108,000 & & 97,560 \\
\hline Change in storage & 268, & 000 & 24, & 89 \\
\hline Total & 382,000 & 382,000 & 276,138 & 276,102 \\
\hline 19 July 2005 - winter & & & & \\
\hline Rainfall recharge & 388,000 & & 388,298 & \\
\hline River recharge & 137,000 & & 157,844 & \\
\hline Abstraction & & 4,000 & & 4,439 \\
\hline River base flow & & 159,000 & & 263,351 \\
\hline Spring discharge & & 201,000 & & 177,562 \\
\hline Change in storage & 161, & 000 & & 18 \\
\hline Total & 525,000 & 525,000 & 546,142 & 533,970 \\
\hline
\end{tabular}




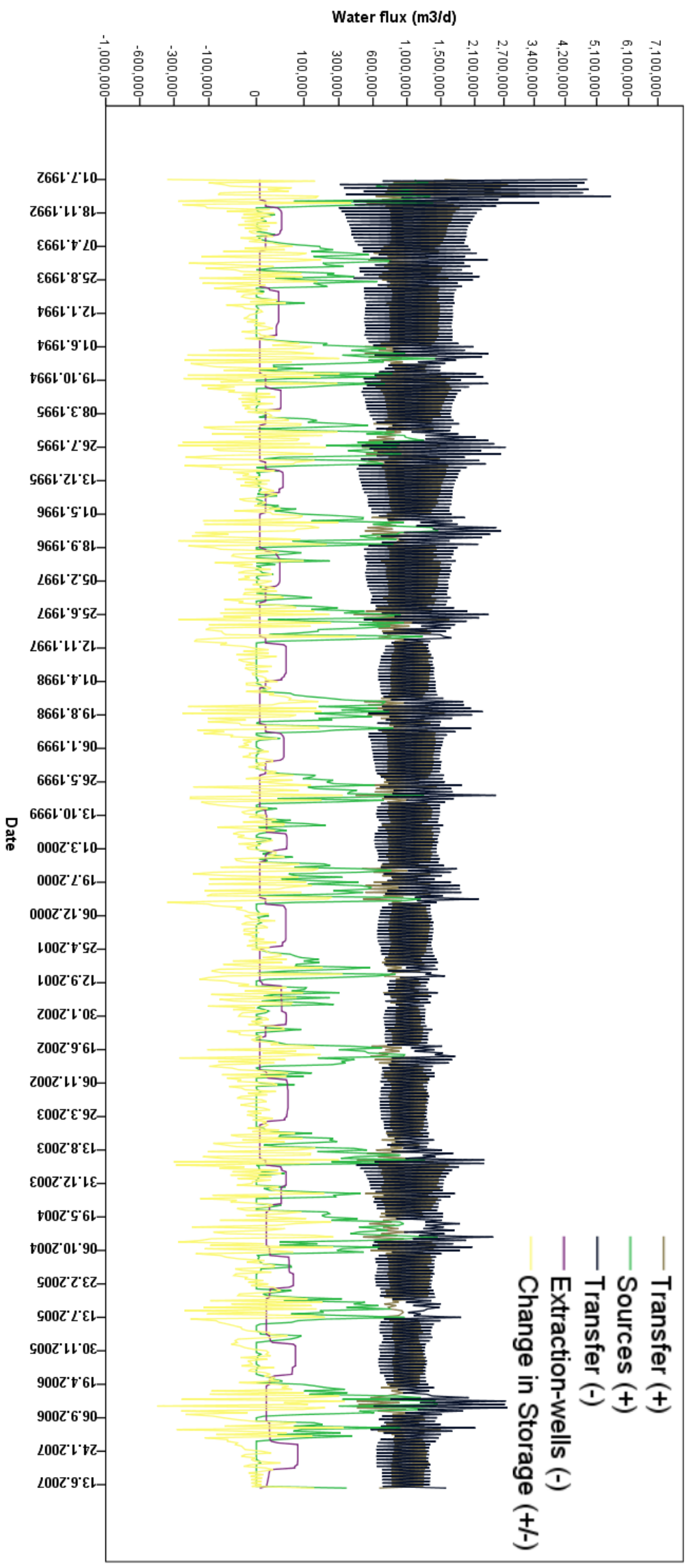

Fig. 7.13 Fluid budget showing transfer in, sources, transfer out, abstractions and overall change in storage $\left(\mathrm{m}^{3} / \mathrm{d}\right)$. 


\subsection{Capture zone evaluation}

A capture zone consists of the up-gradient and down-gradient areas that will flow into a pumping well (Fetter, 1994). Capture zones are important to delineate in order to identify if land use activities are affecting the groundwater quality from within the well's capture zone (Fig. 7.14). Subsequently, identification of the area from which the problematic solute (e.g. nitrate) can confirm the point source of the pollution of the groundwater, resolving ambiguities relating to the source(s) of groundwater quality problems and improving remediation efforts (if required).

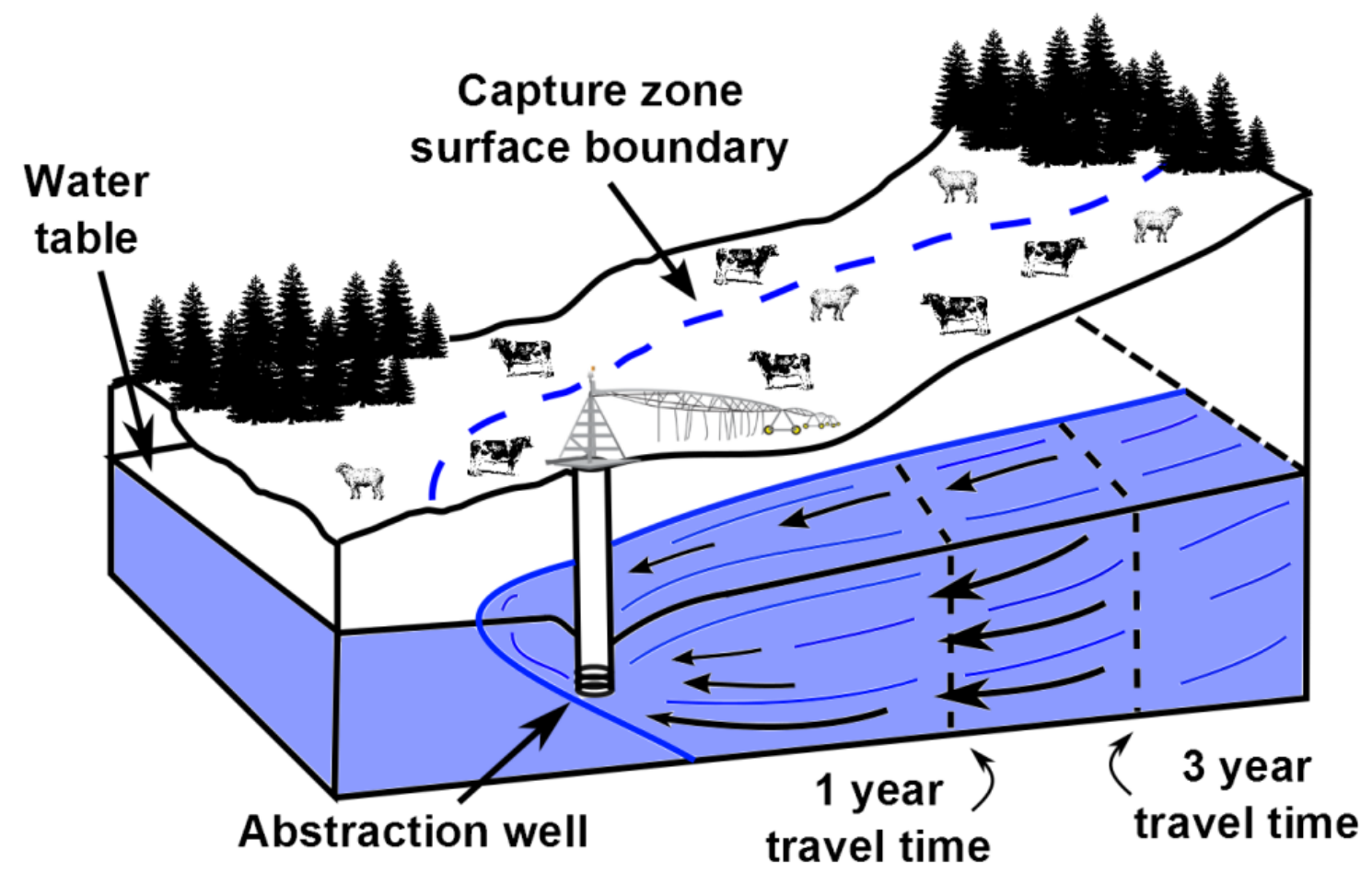

Fig. 7.14 Capture zone schematic indicating arbitrary capture zone and groundwater travel times the irrigation abstraction well. Modified from the Ministry of Environment (British Columbia) (2004).

A probabilistic approach was used estimating the probability of a water particle exiting the system (see Section 6.2.5). This estimates the probability that a water particle would be affected by the abstracting well and the evolution of the probability over the simulation. A pumping well would be expected to show fluctuating age distributions proportional to the pumping rate. The total abstractive flux is relatively minimal in terms of the total fluid budget in the Middle Valley, $1 \%$ of the total fluid budget (see Tab. B-5), however the advective and dispersive impact on water particles, and therefore age, can be significant (e.g. Zinn and Konikow, 2007). 
Additionally, the abstracted water flux out of the system creates an older distribution of ages in the aquifer, and a younger distribution in the confining aquitard (providing there is one present), a process known as the paradox of groundwater age (Bethke and Johnson, 2002). Evaluating the capture zones on the Middle Valley domain was performed in order to:

1. Delineate the capture zones of the simulated pumping wells, in order to assess the specific points of interest, for the temporal age distribution analysis, and;

2. Test if the probabilities of the particle capture were affected by seasonal variations and climatic events in the Middle Valley (see Section 4.4).

Results are shown for six specific points in time and an initial state was generated from a single 15-year transient model run (Fig. 7.15).

The capture zones show some seasonal influence with the pumping wells capture zones extending in the summer irrigation season (Fig. 7.15 and Appendix 0). Interestingly, some areas do not show any pumping influence, for example parts of the West and East Taratahi, Parkvale and Middle Ruamahanga groundwater zones (see Fig. 4.11). In these cases, a monitoring bore with a low probability of capture is potentially missing groundwater quality issues. Capture zones can be seen to extend in the drought affected seasons, for example, the 1/7/1992 and the 25/3/1998 figures (Fig. 7.15 and Table 7.8). The Masterton and Carterton faults are also observed as a flow barrier, most prominent in the $23 / 12 / 1992$ figure and the primary river sections split the Middle Valley groundwater flow divides (e.g. the Mangatarere Stream and Ruamahanga Rivers). Overall abstraction pressure from irrigation bores has an influence on the water balance and groundwater age distribution in the Middle Valley catchment. Capture zone work can be extended to assess the current network of monitoring and drinking water bores, to assess the current network of monitoring and drinking water bores (ensuring the are capturing regional land-use, for example). 

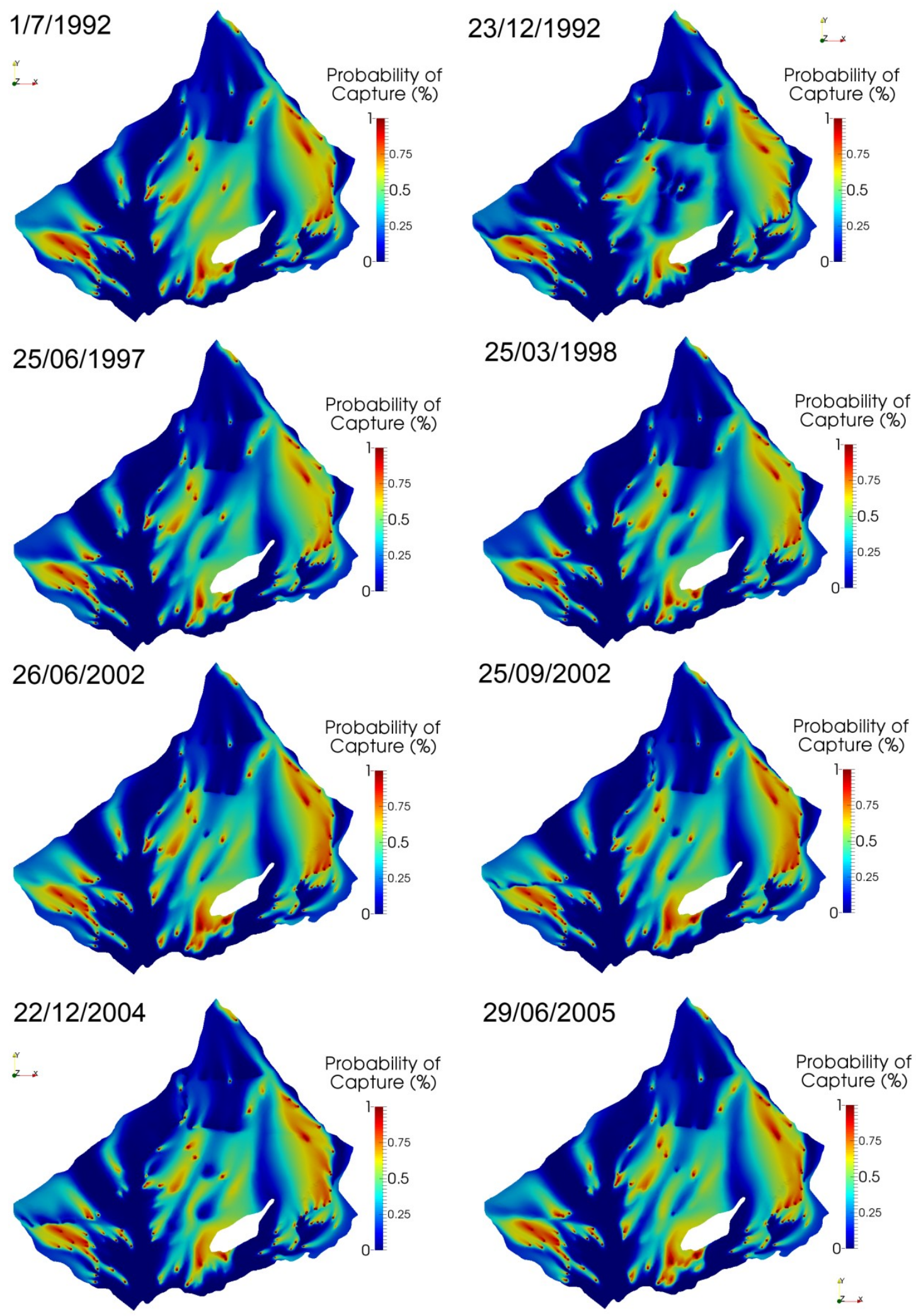

Fig. 7.15 Capture zone probabilities of all simulated pumping wells in the Middle Valley model. 110 wells in total are simulated with varying pumping rates, well distribution indicated by dark red squares. Individual (larger) figures are located in Appendix $\mathrm{O}$. 


\subsection{Direct age simulation}

The direct simulation of age throughout an entire reservoir enables regional analysis of groundwater resources. Using the calibrated model groundwater age can be directly simulated throughout the Middle Valley incorporating natural groundwater dispersion, diffusion, and mixing processes. Groundwater age was simulated over 15 years with an initial state derived from a single 15-year model run. Specific model fluxes and historical climatic events are outlined for the assessment of both the transient meanage and point age distributions (Table 7.8). For the respective specifics on the climatic and modelled information, see Sections 5.2 and 5.3. The influence of both recharge and abstraction will be demonstrated through both mean-age and age distributions.

Table 7.8 Abstraction and climatic events, modelled and historical.

\begin{tabular}{|c|c|c|c|}
\hline & Modelled (annual) & Historical (seasons) & Historical (specific) \\
\hline $\begin{array}{l}\text { Above-average } \\
\text { rainfall influx }\end{array}$ & $\begin{array}{c}1992,1995 \\
1996,2004,2006\end{array}$ & $\begin{array}{l}\text { Spring 1998, spring } \\
2000 \text {, summer } 2004\end{array}$ & $\begin{array}{l}\text { 7-9 March 1994, October } \\
\text { 1998, October 2000, } 12 \\
\text { February 2004, March } \\
\text { 2005, 4-7 July } 2006 .\end{array}$ \\
\hline $\begin{array}{l}\text { Below-average } \\
\text { rainfall influx }\end{array}$ & $\begin{array}{c}1993,1999 \\
2002,2003,2005\end{array}$ & $\begin{array}{c}1992 \text { (winter), } \\
\text { 1997/98, 2000/01, } \\
2007\end{array}$ & \\
\hline $\begin{array}{l}\text { Abstraction for } \\
\text { irrigation }\end{array}$ & $1992-2007$ & $1992-2007$ & \\
\hline
\end{tabular}

\subsubsection{Mean age simulations}

Age measurements are often presented as an average value representative of the various ages of the particles in a given sample or zone and this mean age can indicate catchment-wide age related groundwater characteristics (Kazemi et al, 2006). For example, age can signal an aquifer's renewal time as well as the general speed of the groundwater flow and recharge rates. These characteristics can then be applied to the management of land use activities and water allocation policies depending on the ages exhibited, for example young ages throughout a shallow unconfined aquifer would indicate a sensitive area prone to contamination from intensive farming or industrial zones. Different seasons are typically associated with particular climatic conditions with winter months delivering consistent, and sometimes heavy, precipitation events. 
The flux in and out of the catchment's aquifers is largely governed by the transfers between river beds and shallow aquifers, rainfall recharge and groundwater abstractions, respectively (Fig. 7.13). At the start of the simulation the top boundaries are assigned an age of zero and water progresses through the domain ageing relative to river, rainfall recharge renewal and abstraction pressures (see Fig. 6.4). The mean water age is calculated in days. Mean-age shows interesting changes across the Middle Valley domain, for example, the dynamic changes from rainfall recharge and extended drought periods (Fig. 7.16).

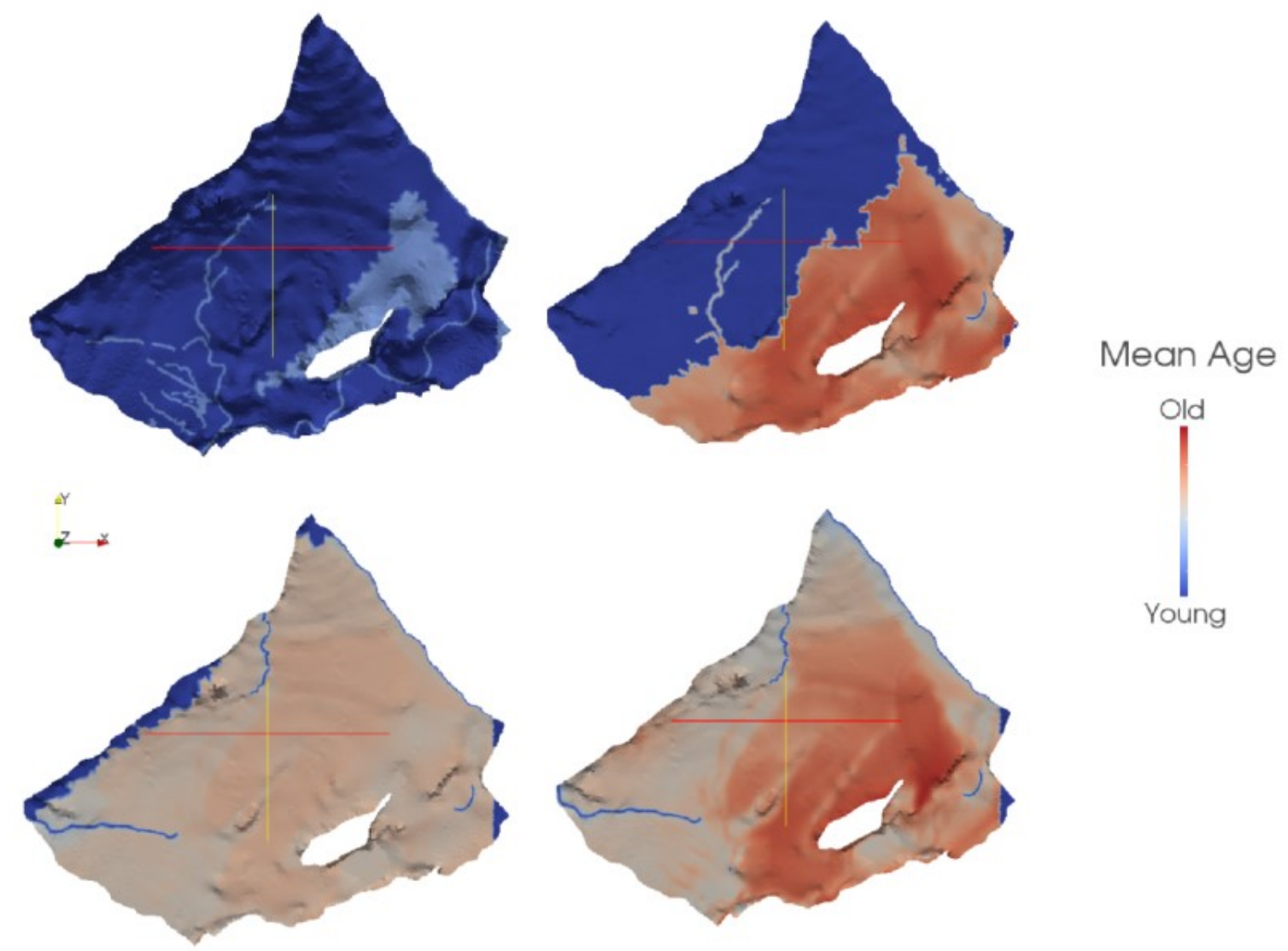

Fig. 7.16 Mean-age example, variable recharge over different seasons creates a transient age conditions across the Middle Valley plain, exemplified by directly simulating the mean-age. Top-left is during winter (i.e. consistent rainfall), top-right is a rainfall event during a dry summer, bottom-left and right are during a progressively dry summer, respectively.

The first mean-age comparison (Fig. 7.17) shows the mean-age throughout the domain in the middle of the first irrigation season. Prior to the 6/01/1993 simulated time-step, rainfall recharge had 'renewed' the bulk water mass throughout the domain and over the drier summer months the mean-age has been progressively increasing. 
Significant decrease in precipitation and subsequent groundwater recharge allows the water particles within the system to gradually increase as there is limited input (renewal). Increases in abstraction pressures from the irrigation season create mixing and diffusive exchanges between aquitards and aquifers; however given the abstractive flux is much less compared to the overall mass balance the effects of this are less pronounced in the mean-age simulations. The Middle Valley can be seen to have several groundwater zones exhibiting an older mean-water age, including East Taratahi, Carterton, Parkvale and some small areas within the Middle Ruamahanga zone (see Fig. 4.11). This indicates slower movement of water and such areas would potentially suit farming and/or water abstraction. Overall the system is showing an increasing groundwater age with the exception of the primary river water channels and the bounding western ranges.

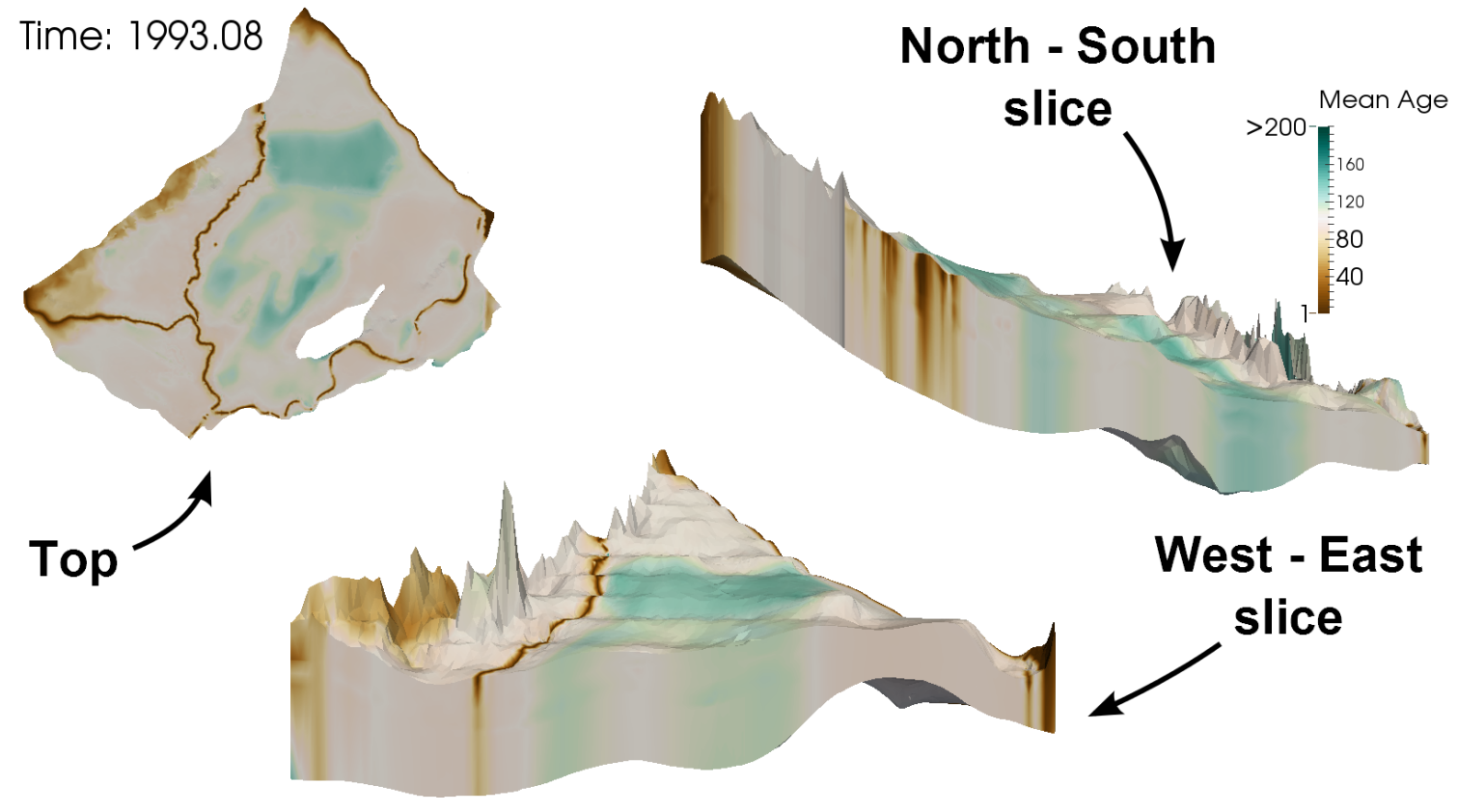

Fig. 7.17 Mean age distribution on the 6/01/1993 during summer and the peak of irrigation season. Figures in clockwise order: 1) top slice, 2) model clipped north-south, and 3) model clipped from west-east.

The next time-step is taken from the 17/03/1993 (Fig. 7.18). The summer has been relatively dry and most of the domain has a mean age of $>120$ days, the only areas with any relatively young water are the sections of the Mangatarere Stream, Ruamahanga, Waiohine and Waingawa Rivers. 
This is typical of a summer in the Wairarapa, and Middle Valley, whereby water within the subsurface of the domain has relatively low recharge and abstraction pressures from widespread irrigation across the valley plains. Most groundwater zones are exhibiting an older water age throughout the system. This does again exclude the primary water channels; however, sections of the Mangatarere Stream and Ruamahanga River appear to show an older mean age towards the middle and bottom of the model domain (see Fig. 4.11).

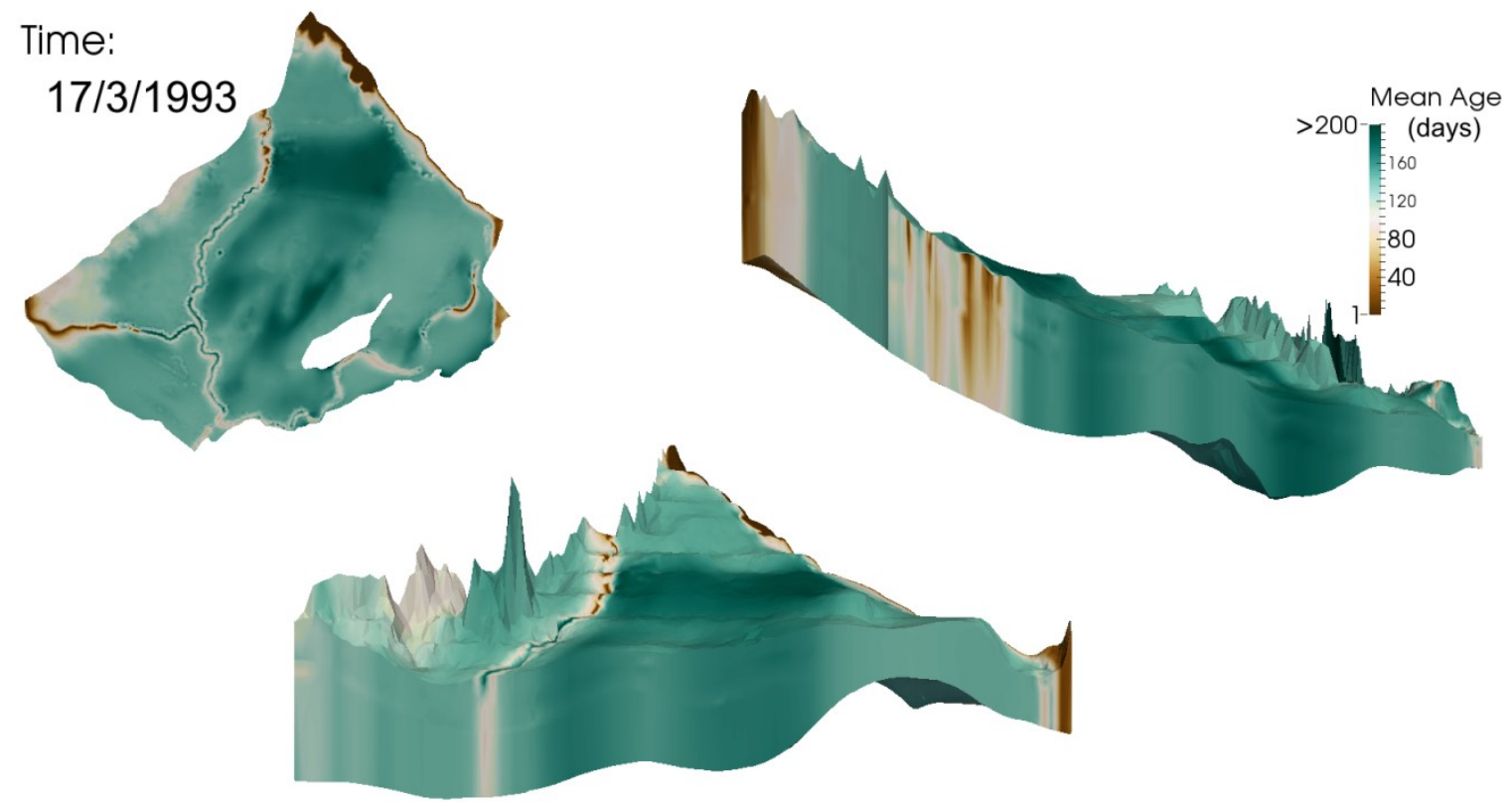

Fig. 7.18 Mean age distribution on the $17 / 03 / 1993$ at the end of the summer and irrigation season.

Rainfall and subsequent groundwater recharge has a significant influence on the groundwater age in the Middle Valley (Fig. 7.19). A prolonged rainfall event occurred across the Middle Valley prior to the 17/08/1994 having a substantial effect on the water particles within the domain and reducing the catchments mean age. A large percentage of the domain is affected by the rainfall recharge and much of the western boundary has been 'renewed'. The speed of this recharge highlights the dynamic nature of the Middle Valley groundwater system and potential sensitivity to applied solutes at the surface. There are some less conductive areas exhibiting an older mean age, the aforementioned East Taratahi, Carterton, Parkvale and the Middle Ruamahanga sub-zones. 


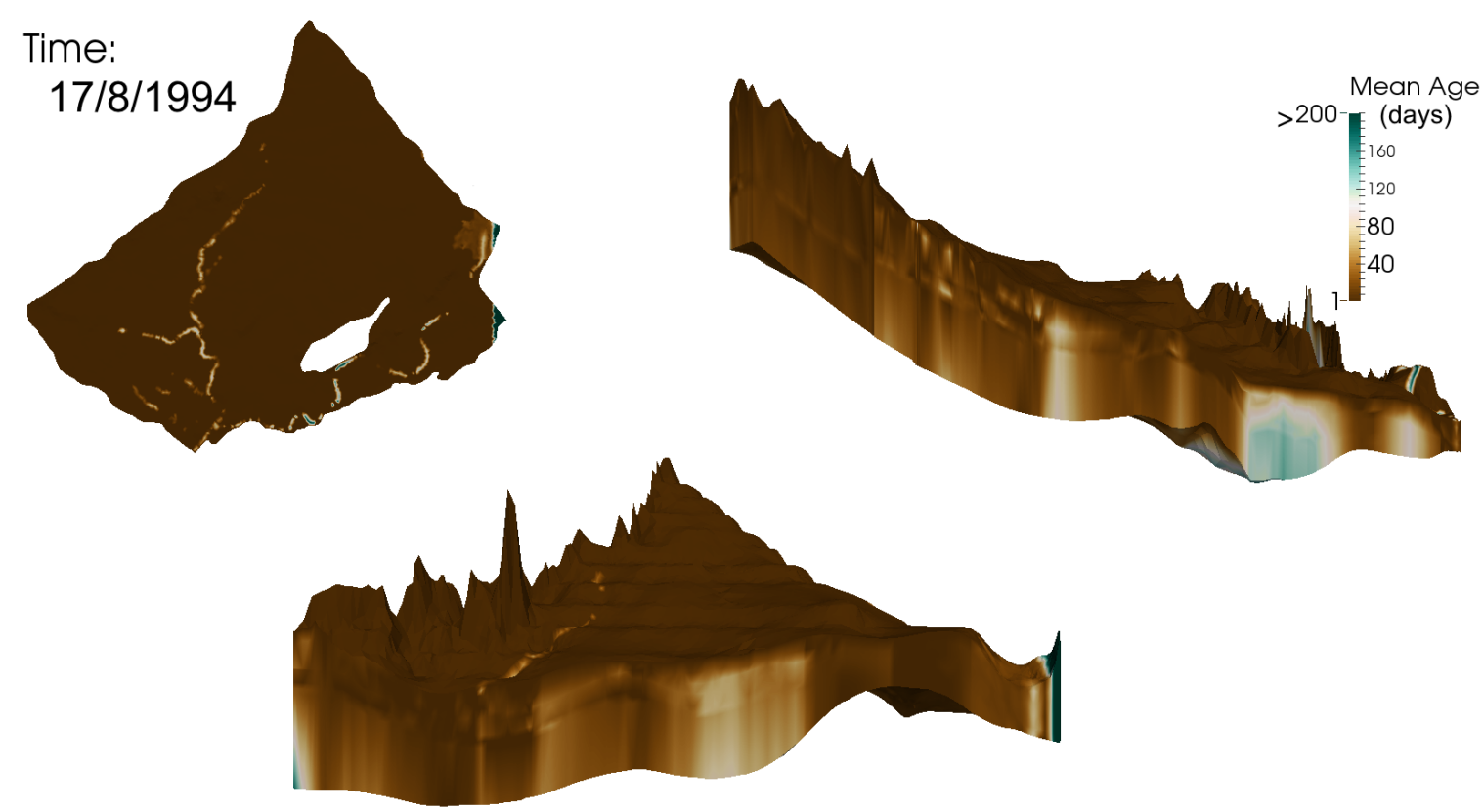

Fig. 7.19 Mean age distribution on the 17/08/1994 in the middle of winter with a high amount of rainfall and groundwater recharge.

The dominant dry climate of the Wairarapa is exemplified by the effect of a significant drought (historical and simulated) over the 1997/98 summer months (Fig. 7.20). The paradox of groundwater age is shown to exist during drought events in the Middle Valley whereby the effect of the confining layers, and older water restricted by the aquitards which they are housed within, is drawn out by the influence of widespread abstraction pressures (Bethke and Johnson, 2002). The overall effect on groundwater age is a shift towards a domain dominated by older water, as there is limited to no recharge percolating through to the subsurface, renewing the bulk water mass.

Between the 22/10/1997 and the 18/03/1998 the simulated recharge was $0 \mathrm{~m}^{3}$ while abstractions collectively totalled $800,408 \mathrm{~m}^{3}$ resulting in a deficit of $-110,926 \mathrm{~m}^{3}$ in the total fluid budget over a five month period. This was the most significant drought in the 15 year simulation period although the region frequently experiences dry summers with limited rainfall and increasing reliance on aquifer abstractions. 


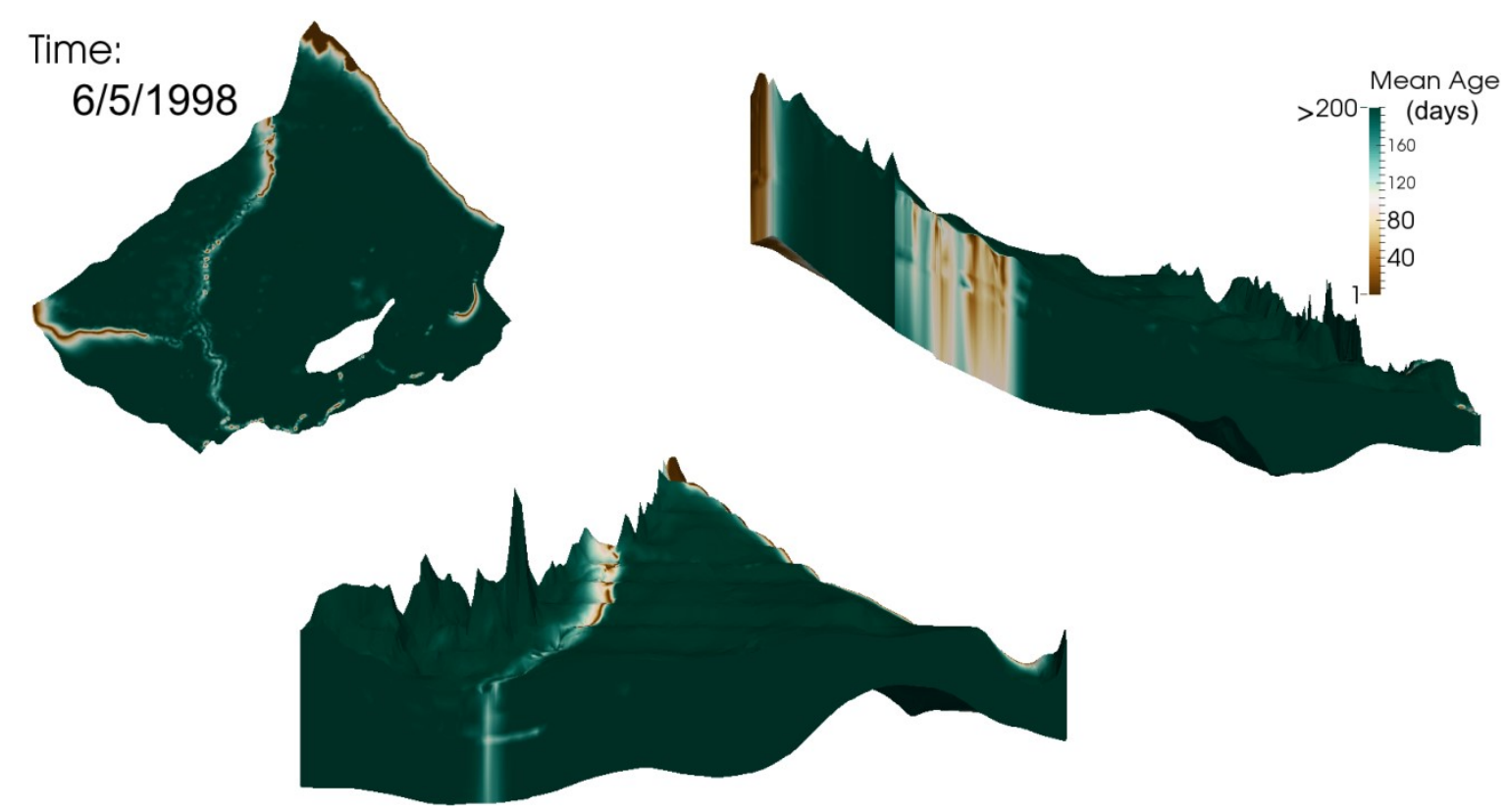

Fig. 7.20 Mean age distribution on the 06/05/1998. This was following an extended classified drought over the 1997/98 summer months.

Groundwater renewal in the simulated Middle Valley system is relatively fast. This is exemplified by the regional age renewal following extended drought conditions (Fig. 7.21). The eastern divide catchments (e.g. Ruamahanga, Waingawa and Waiohine) drain through the Middle Valley system via their incised river channels. The water transfer between the connected river beds and shallow aquifers has a significant impact on the age distribution throughout the groundwater system, directly beneath the river sections and extending throughout adjacent aquifers. This can be seen in the Waiohine River and Mangatarere Stream in Fig. 7.22. 


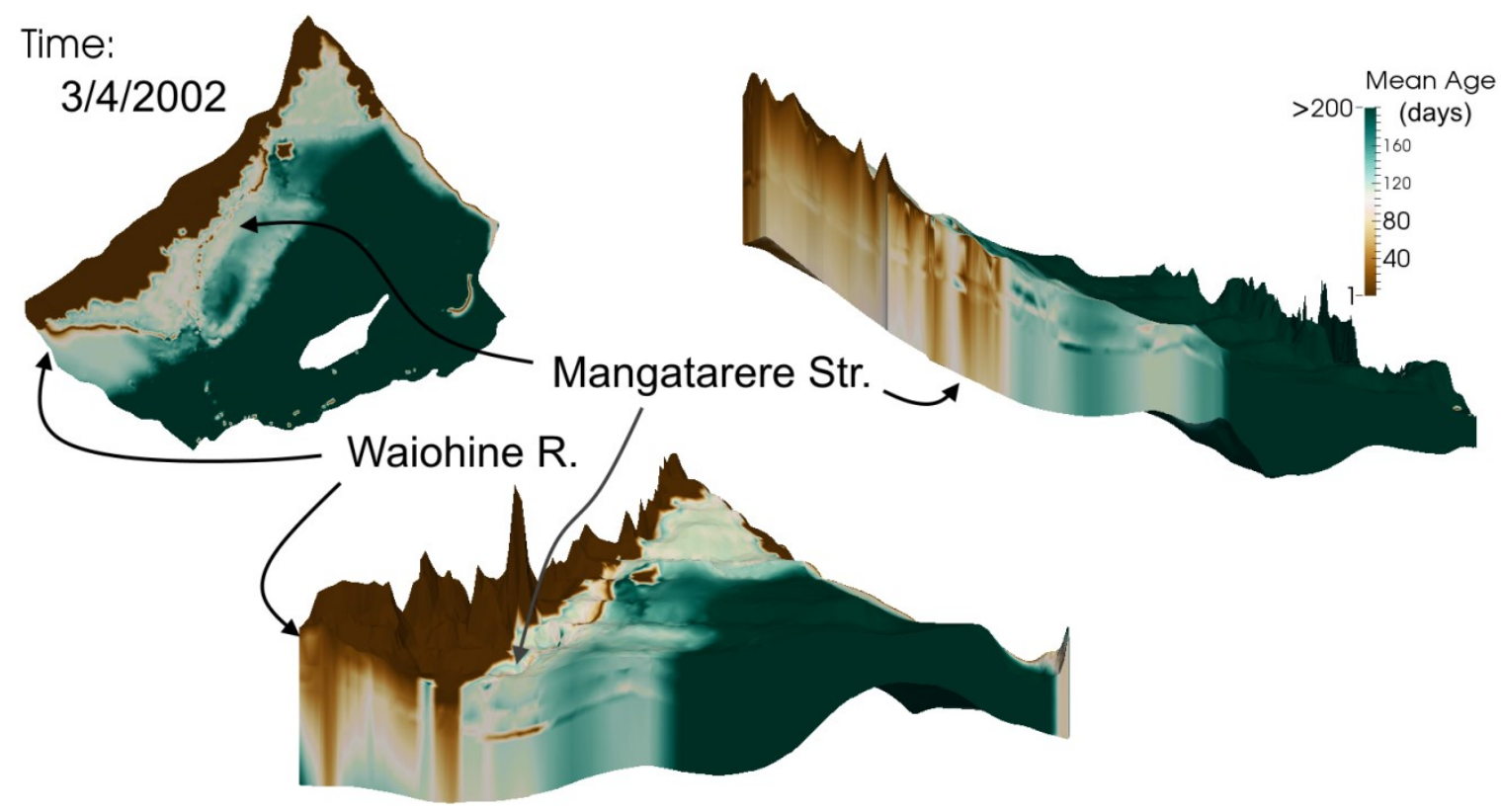

Fig. 7.21 Mean age distribution on the 03/04/2002. This was the result of a relatively wet summer with the following year recording above average mean annual rainfall.

The dynamic nature of the Middle Valley groundwater system is best shown over the final simulated summer and following winter seasons of 2006/07 (Fig. 7.22, Fig. 7.23 and Fig. 7.24). Initially, after significant spring rainfall, the summer season began with a relatively young age distributed throughout the domain, with the exception of several northern and central Q2 material zones (Fig. 7.22). Following the relatively wet winter, a typically dry summer season ensued for roughly half a year, with slight rainfall relief over the month of March (Fig. 7.23) and recharge percolating through the connected sections of the Mangatarere Stream, Ruamahanga and Waiohine rivers. Several zones are shown to be significantly less hydraulically conductive exhibiting an older meanage throughout the simulated 15 year period. These zones include the Parkvale, Fern Hill, East and West Taratahi zones (see Fig. 4.11). The final figure shows the simulated mean-age distribution on the $11 / 07 / 2007$ where heavy rainfall has fallen over $80 \%$ of the catchment and recharged a substantial volume of the subsurface reservoirs, after persistent winter rainfall. 

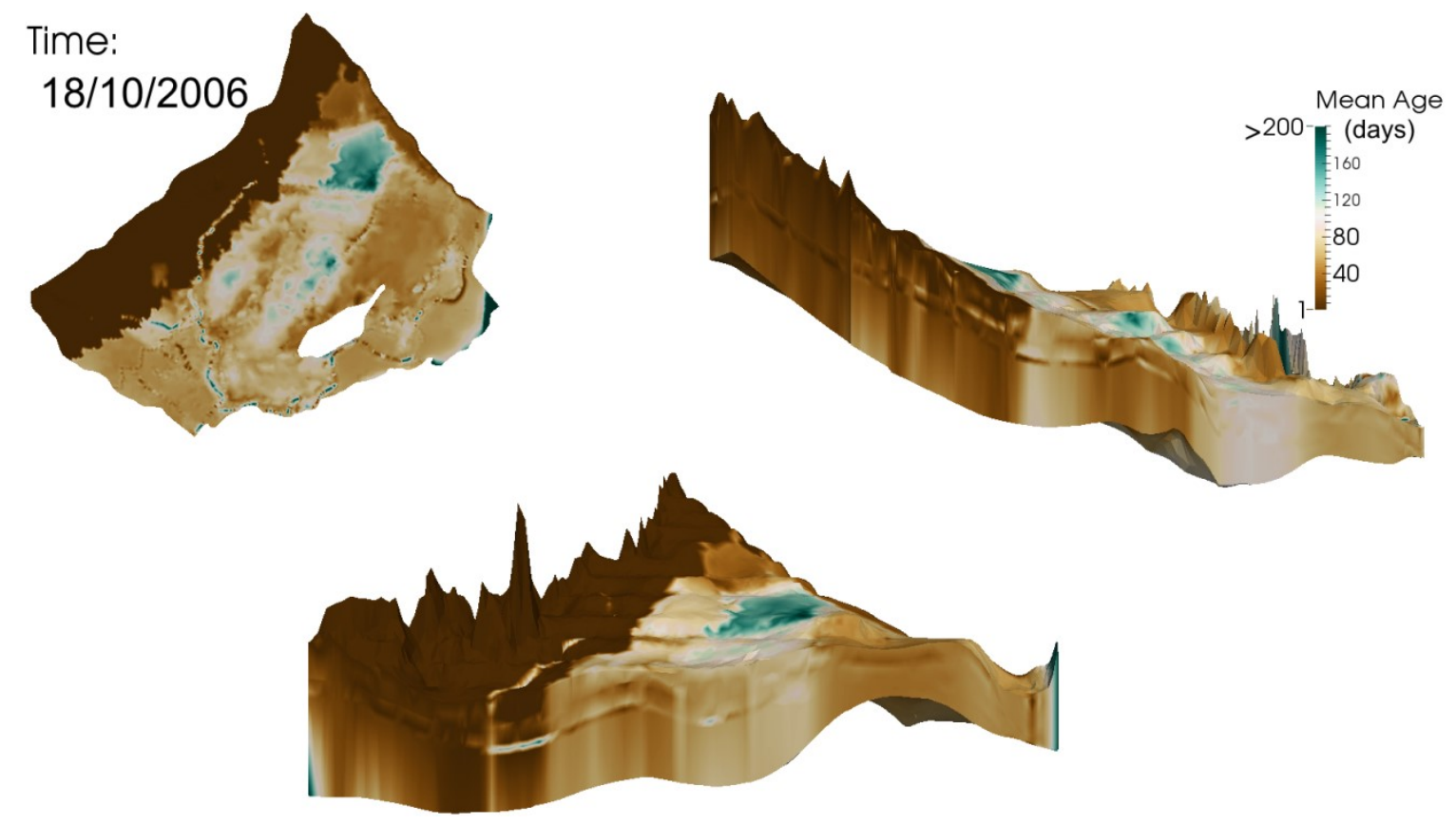

Fig. 7.22 Beginning of 2006/07 summer on the 18/10/2006 after significant spring rainfall.

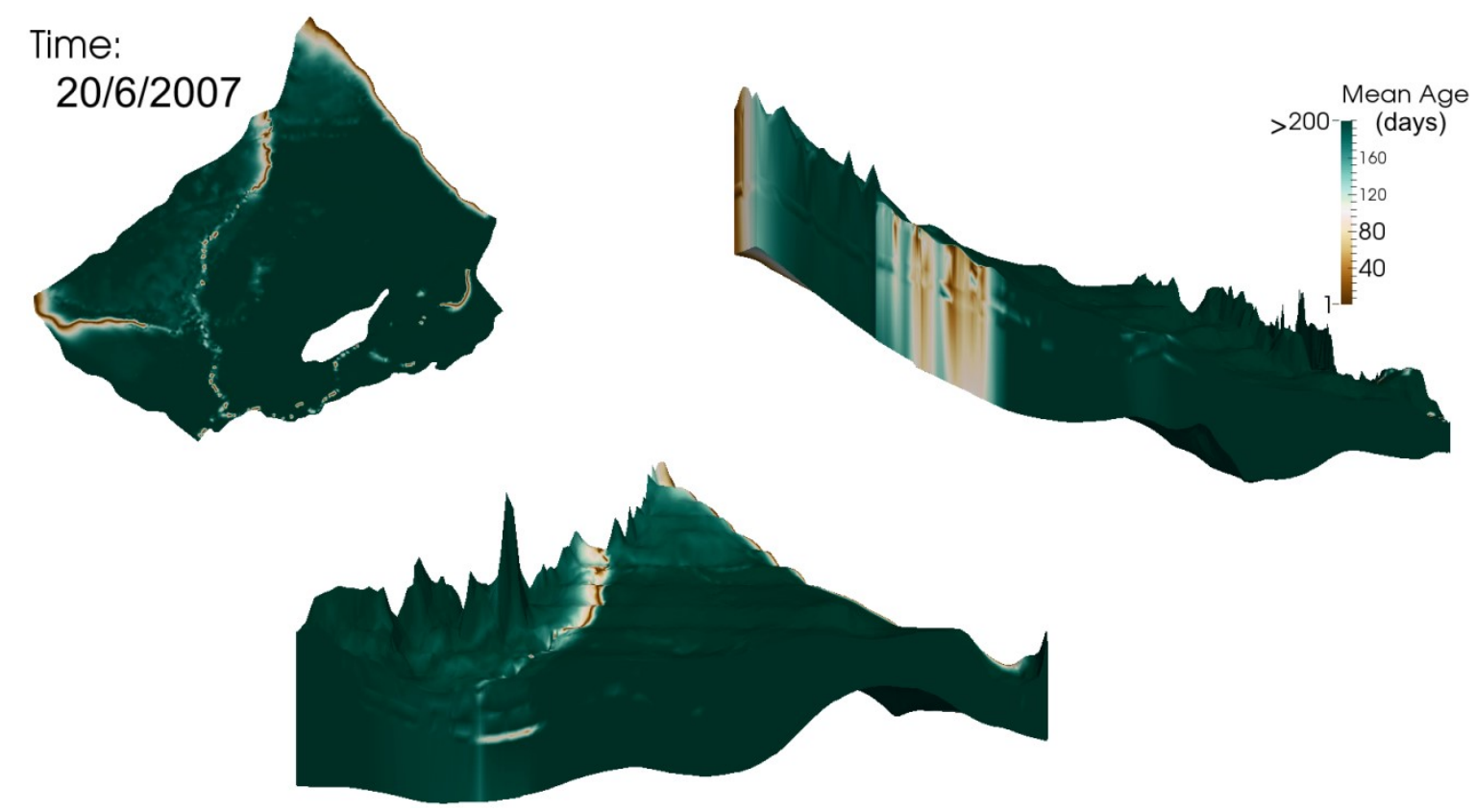

Fig. 7.23 Mean-age distribution on the 20/06/2007 in late summer/autumn. A relatively old water age is spread throughout the domain. 


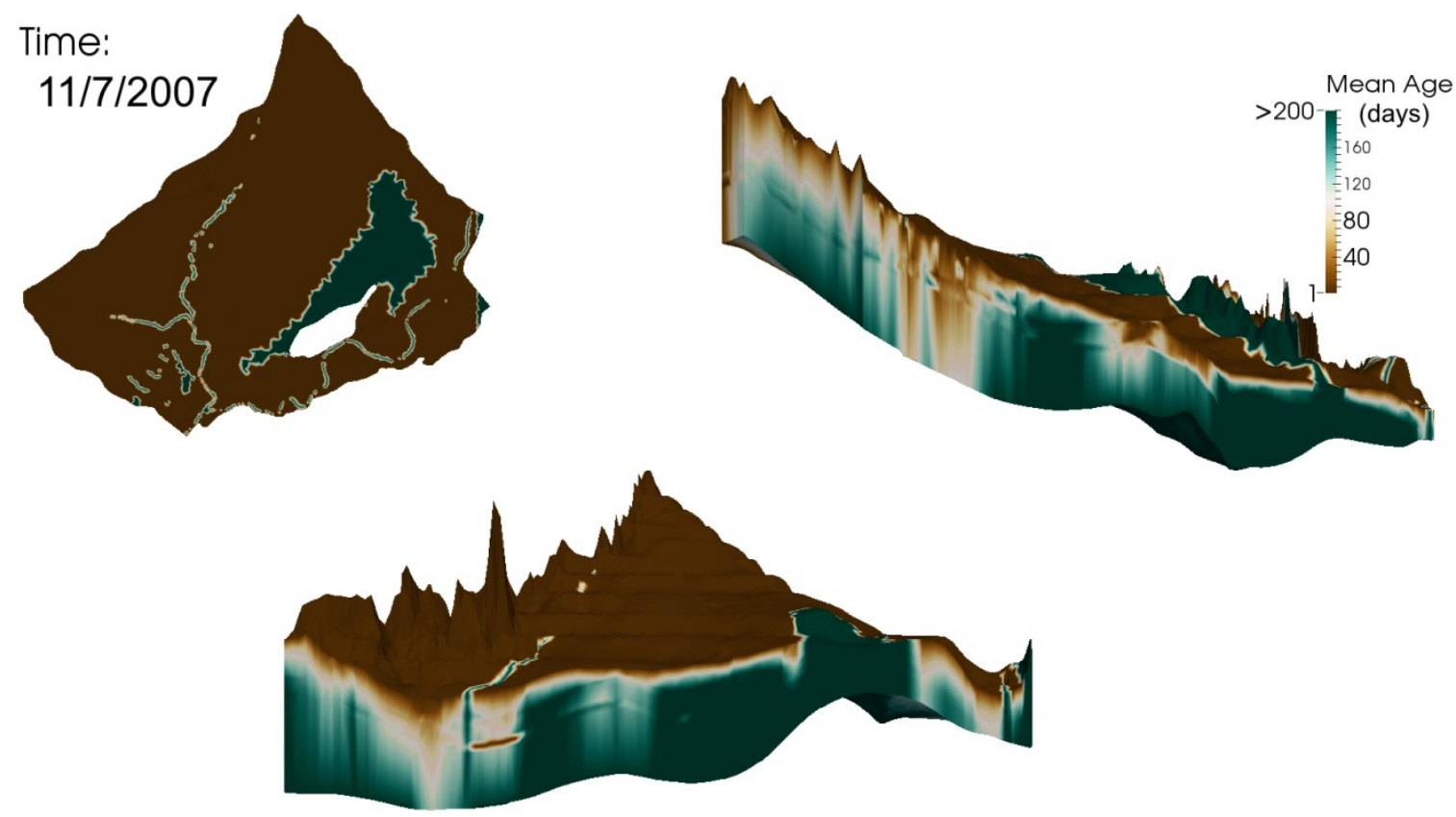

Fig. 7.24 Mean-age on the $11 / 07 / 2007$. The rainfall and subsequent recharge is shown to quickly change the mean-age throughout the upper sections of the domain and lower hydraulically conductive aquifers.

\subsubsection{Mean-age conclusions}

Mean-age water is a valuable tool for water resource management. The evolution and effect of simulated recharge and abstraction pressures following a robust calibration of the model parameters enables age to be quantified and visually assessed for environmental risk and sustainability. It is especially relevant, in dynamic system like the Wairarapa, as the simulated age is derived incorporating the effects of dispersion, diffusion, and mixing. The entire Middle Valley domain can be simulated under a range of rainfall, recharge and abstraction pressures and has demonstrated the relatively fast speed of water and solute transport through the saturated sections of the Middle Valley groundwater system. The East Taratahi, Carterton, Parkvale and Middle Ruamahanga zones exhibited a predominantly older mean age than adjacent zones indicating they contained less hydraulically conductive media (see Fig. 4.11). These areas are assessed as being more suitable for nutrient application, depending on the fluctuating depth to the water table, and aquifers from these regions would be expected to derive older water more suitable as drinking water sources (Ministry of Health (2005). 
Mean-age however, while providing important and informative information for water management, does not account for the full distribution of potential ages within a sample of water. The sole reliance on mean-age assessment, especially drinking water supplies, can give a false representation of the potential reality of contaminated water attributable to a small percentage of young water particles containing toxic and/or harmful solutes. These solutes are spread throughout a sample or aquifer by hydrodynamic processes and hence, the specific age distribution can resolve any ambiguities and risk where water and pollution security is essential (Cornaton, 2012).

\subsubsection{Transient age distributions}

The distribution of ages within a water sample can indicate important information on water resources, potential contamination and age related groundwater characteristics. The importance of a groundwater age distribution is due to the fact water is a collection of individual particles, each with a specific 'groundwater' age, and additionally by the risk of young contaminated water (i.e. water age of $<1$ year). Any contaminated water with harmful solutes travelling within can adversely affect drinking water supplies and those who utilize the well and/or aquifer as their source of water. Given the Middle Valley system is relatively dynamic, specific points throughout the domain were selected to simulate the transient age distribution. An initial state for the transient age distributions was created running a prior simulation for a full 15 year period, essentially creating a maximum age of 15 years within the domain and resolving and ambiguous age information from a simulation assuming and unrealistic uniform zero a throughout the domain in 1992. Information garnered from this newly implemented numerical technique provides important information for water resource management in the Middle Valley of the Wairarapa. Age distributions can be generated from any node within the model, 10 bores from the Middle Valley are evaluated here (Fig. 7.25). The transient age distribution time and age units are in shown in years and the scale of the graphs indicate the proportion of the groundwater age at each point in time (\%, i.e. the probability density function's integral over the entire space is equal to one) (Fig. 7.26 - Fig. 7.35). 


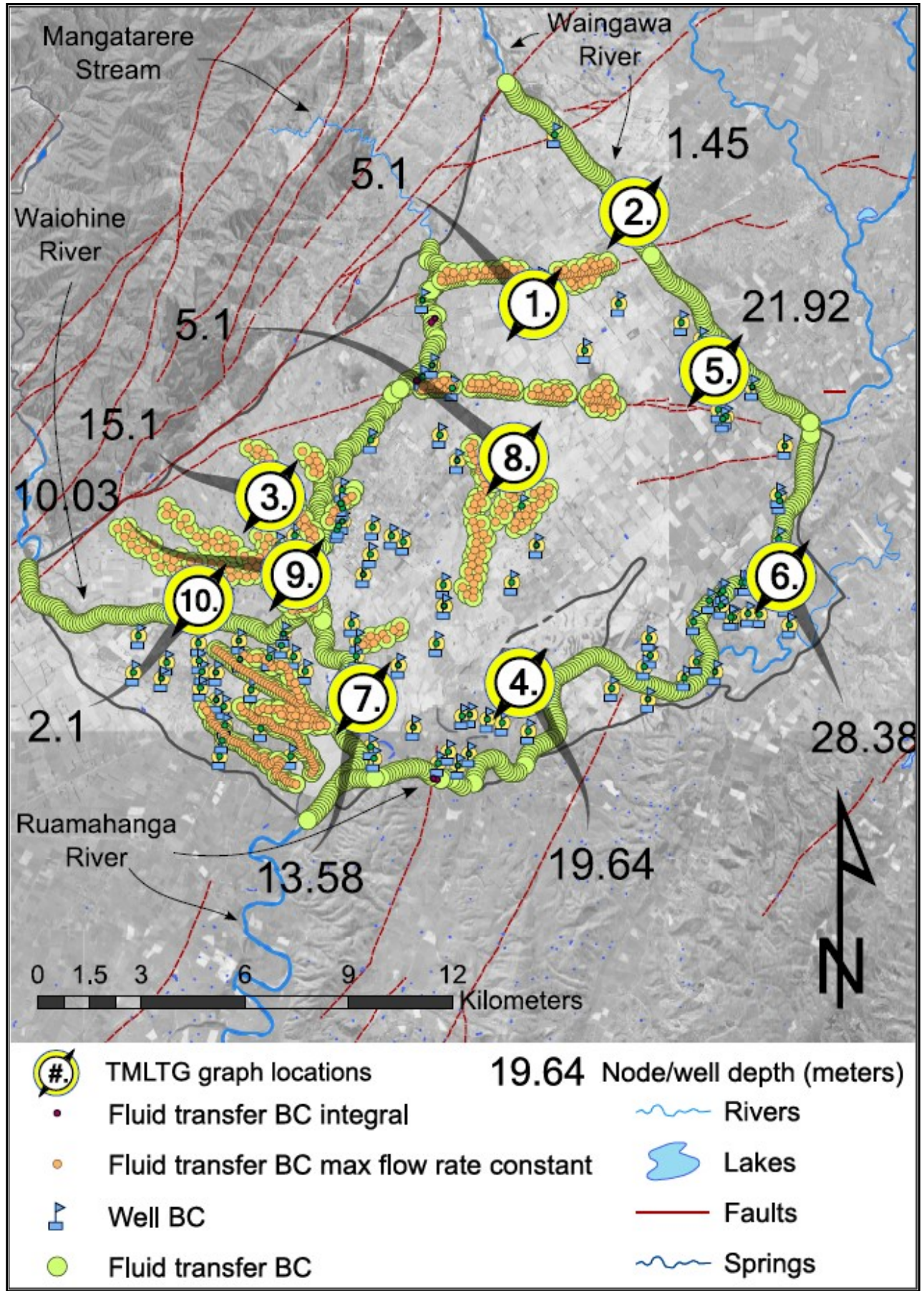

Fig. 7.25 Locations of simulated temporal age evolution. Numbers correspond to nodes and wells within the Middle Valley domain.

The risks posed by dissolved contaminants is concerning given the development and expansion throughout the Wairarapa. For example, industrial developments, pastoral land-use specifically the widespread increase of dairying and rural septic systems. The implementation of the TMLTGT enables the simulated age distribution, throughout the entire Middle Valley domain, to be quantified and assessed for potential risks to water quality and quantity. 
The first age distribution example is the northern node 43628 corresponding to the well S26/0223. The well is located at a depth of 5.1 metres and is a state of the environment (SOE) monitoring bore for GWRC. The bore is located within Q2 gravels between both the Masterton and Carterton faults. The age distribution indicates a relatively steady age distribution with a predominant age of six years. Given the depth of the well a younger age would be expected, however the proximity to the faults and their inherent flow barrier nature creates an older distribution of water ages within this zone and adjacent aquifers. Older water particles are also present within the node indicating an older water source in close proximity, presumably the faulted sections of the Masterton fault zone. The well shows minimal pumping influence but some small age variations can be seen, presumably from minimal abstractions, throughout the age distribution. The well is assumed to be a dedicated monitoring bore with minimal pumping. 


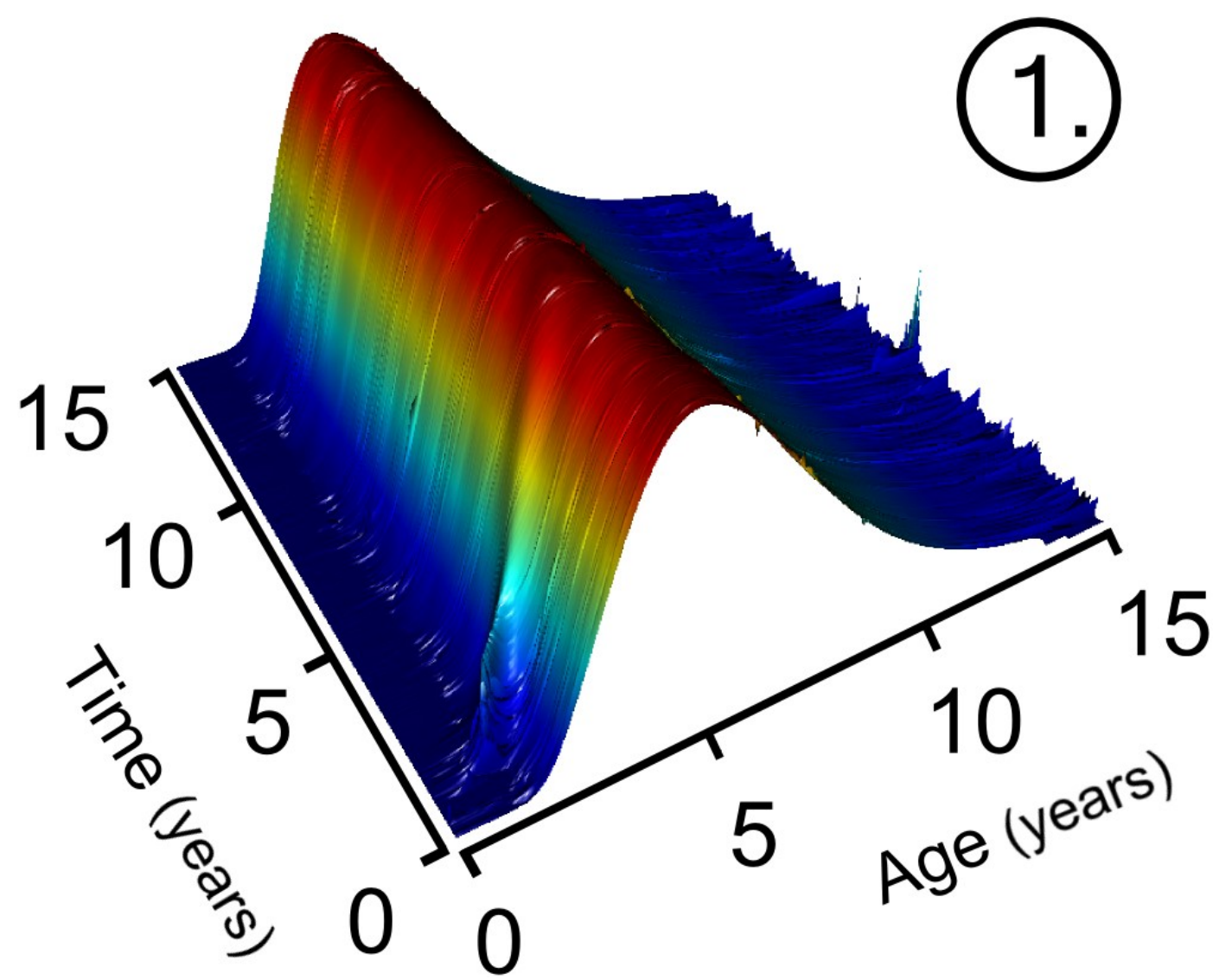

Fig. 7.26 First age distribution. Node 43628/Well S26/0223 located at a depth of 5.1 metres in the Northern section of the domain.

The second age distribution shows a node located in close proximity to a river with a predominantly young water age (Fig. 7.27). The well is located on the true right-hand side of the Waingawa River running south-east towards the eastern boundary of the Middle Valley domain at a shallow depth of around two metres ${ }^{7}$. The simulated age distribution provides confidence in the simulated output given the node (14260) is in relatively close proximity to the Waingawa River, roughly 250 metres north. Given this, and the fact it is located within young Q1 gravels, older particles of water would not be expected to be of any significant proportion during the simulation. The node is simulating pumping rates of the S26/0298 well in the Wairarapa. The simulated abstraction pressures can be seen in the above figure as the taller red spikes, representing a younger overall water age abstracted over the irrigation seasons, indicative of quick withdrawal of adjacent young/river water from the Waingawa system. As the abstraction period duration extends, into the dry summer climate, older

\footnotetext{
${ }^{7}$ True-right, looking down the river in the direction of flow.
} 
water is seen to be drawn from a presumed underlying confining layer. This age distribution is what would be expected; given the relatively minimal rainfall recharge and cone of abstraction resulting from the irrigation pressures (see Zinn and Konikow, 2007). Drinking water from this bore would require chemistry analysis and potentially treatment given its dominant age of $<1$ year.

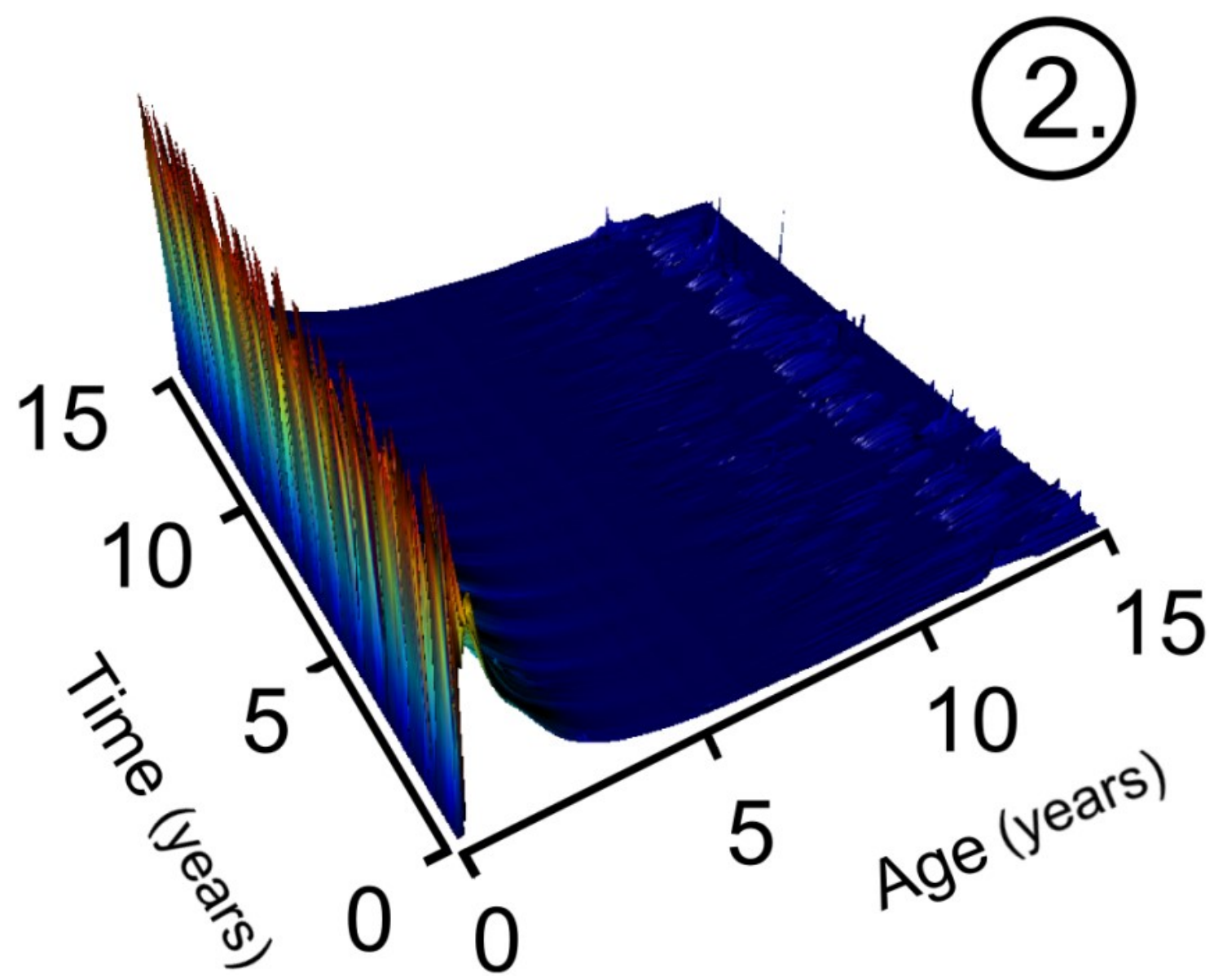

Fig. 7.27 Second TMLTG age distribution. Node 14260/Well S26/0298 located at a depth of 1.45 metres in the Northern section of the domain. The age and time units are shown in years.

The third TMLTG example shows an irrigation bore in Q2 gravels adjacent to the Tararua Ranges (Fig. 7.28). The well (S26/0400) is located near the Waiohine River (south) and Mangatarere Stream (east) and extended Q1 gravel systems. The age distribution initially shows a young portion of water entering the node. This is incorporated to the bulk nodal age mass (around eight years) after four years, however the presence (if not a spin-up condition) indicates some influence of a younger water source and caution if the bore was used as a drinking water supply. 
This is attributed to the proximity to the adjacent surface water channels and Tararua ranges rainfall recharge/runoff. The node also shows pumping influence (wavy abnormalities throughout the 15 year simulation) however these appear minimal and/or the age is not significantly affected by current pumping rates. Given this, the current abstractions from the bore are assessed as sustainable as recharge to the bore maintains a relatively constant mean age of around eight years.

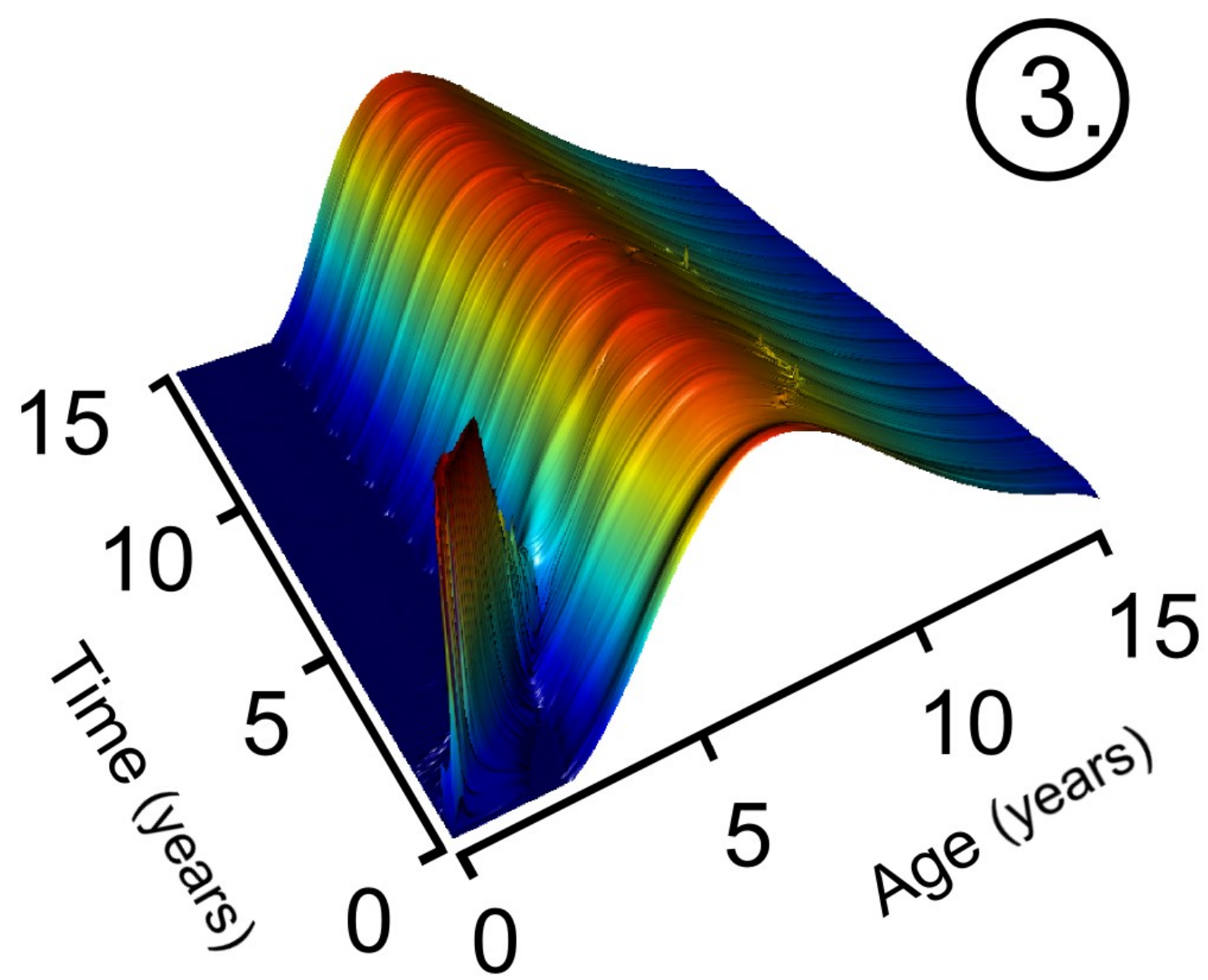

Fig. 7.28 Third TMLTG age distribution. Node 68843 located at a depth of 15.14 metres in the Western section of the domain. The age and time units are shown in years.

The forth example is another SOE monitoring bore located south of Tiffen Hill on Q2 gravels 400 metres from the Ruamahanga River to the east (Fig. 7.29). The well (S26/0756) is regularly pumped and the influence is much more pronounced than previous examples as the strong wavy pattern throughout the 15 year duration. Older water is drawn into the bore in the irrigation season (i.e. spring/summer). 
The water around the node is at a relatively constant predominant age of around 15 years, expected given its depth, but somewhat surprising given its proximity to the Ruamahanga River. The well does not appear to be significantly affected by pumping pressures and recharge maintains the predominant age at around 15 years throughout the simulation, apart from a younger parcel of water (six years old) appearing in 1998. Water utilized for drinking water from this bore would be assessed as safe using the simulated TMLTG distribution.

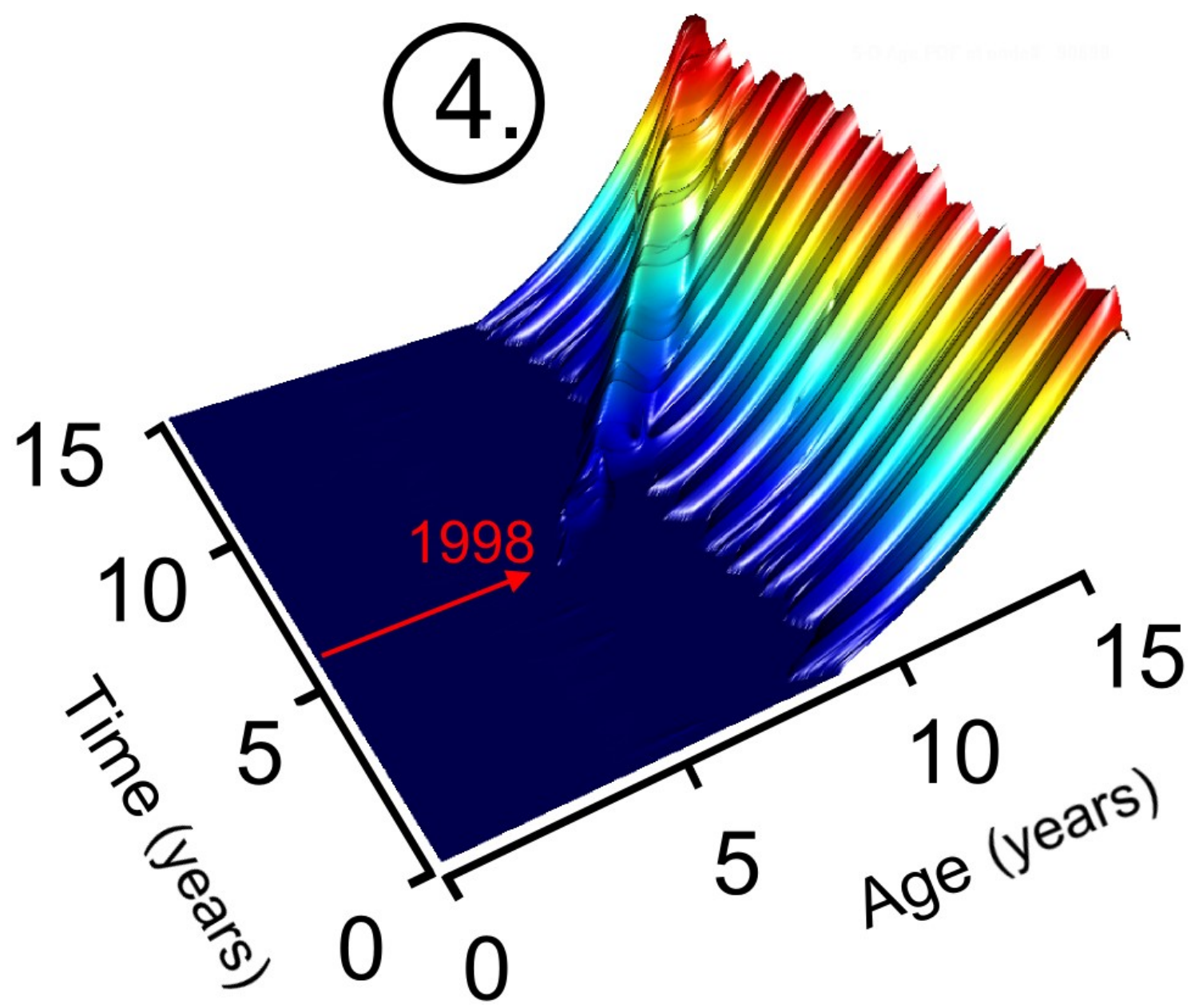

Fig. 7.29 Forth age distribution. Node 90690 located at a depth of 19.64 metres in the Southern section of the domain. The age and time units are shown in years.

The fifth age distribution is taken from a bore located next to the Waingawa River at a relatively deep depth (Fig. 7.30). The node (79786) is a pumping well in the Middle Valley model and shows a strong influence from its proximity to the Waingawa River. A predominant age of around 4-5 years is indicated with older and younger water particles present throughout the simulation. 
The well exhibits noticeable age changes directly attributed to the pumping of the bore, although it does not show any strong pattern and older water particles could be drawn in from an aquitard beneath the aquifer the well is contained in. Again, due to constant recharge, the wells pumping rates appear to be sustainable with no discernible risk apparent to the supply of water in the bore. Any drinking water from the well would pose some risk with a small percentage of younger particles ( $<1$ year) observed throughout the simulation.

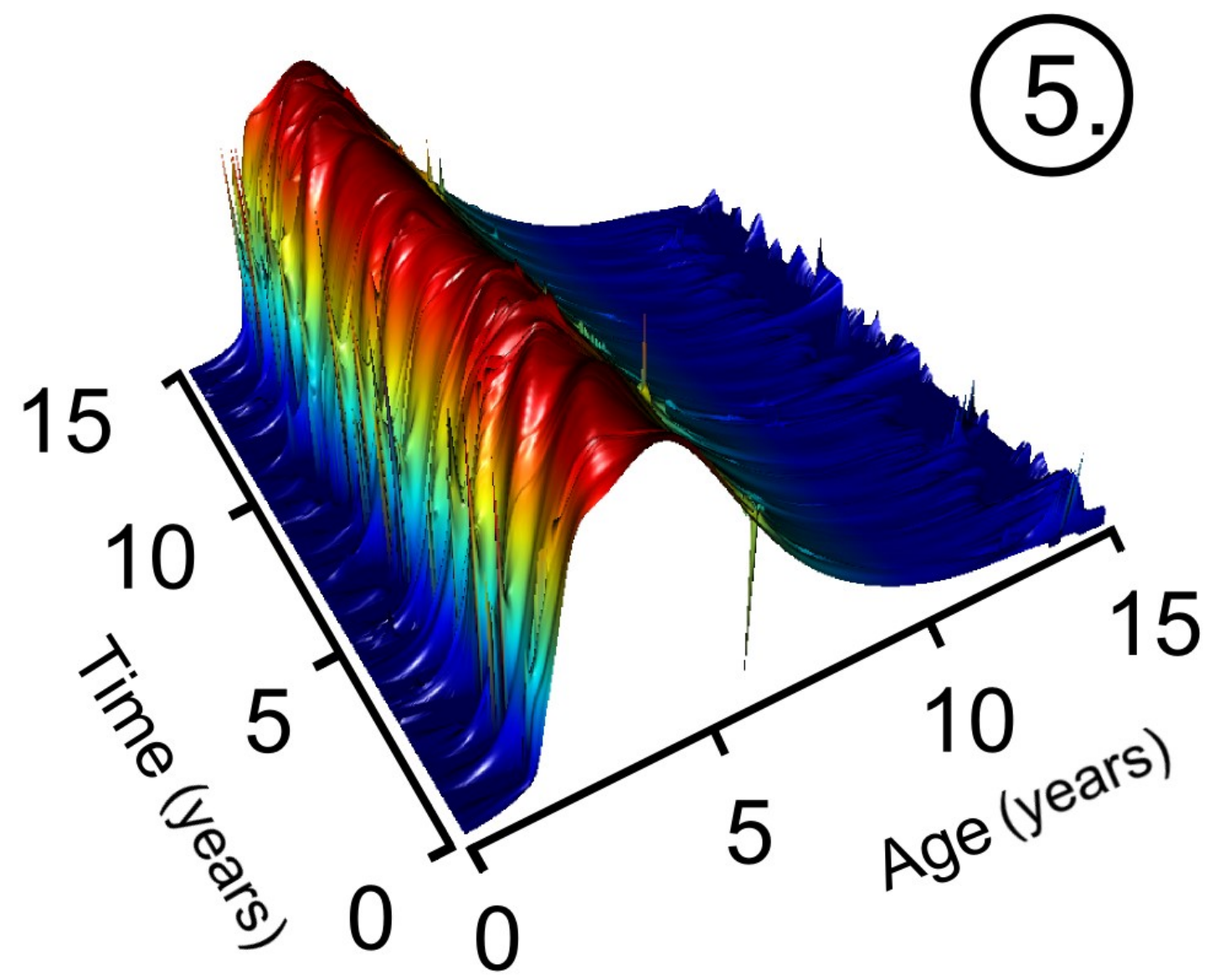

Fig. 7.30 Fifth age distribution. Node 79786 located at a depth of 21.92 metres in the Eastern section of the domain. The age and time units are shown in years.

The sixth age distribution is the node 79766. The node corresponds to the well S26/0658 and is situated at a depth of 28 metres to the east of the Tiffen Hill. The well is located on the youngest Q1 gravels recently out lain by the Ruamahanga River's channel migration. The age evolution shows a predominant age of around five years, however, the age shows an interesting bi-modal distribution (Fig. 7.31). 
This dual peak development could be due to abstractive pressures, visible as the uneven strokes on both peaks and younger water particles entering the node throughout the simulation. The major modes have predominant water ages of four years and 10 years respectively. This split is postulated to be caused by increasing abstraction pressure drawing in older water from an adjacent or underlying material zone with a relatively older water age mass within it. In this example, caution would also be stressed relying on a mean-age assessment, given the mean-age would be increased following the older water mass entering the well area and given a somewhat false indication of a relatively old water mass being constantly abstracted.

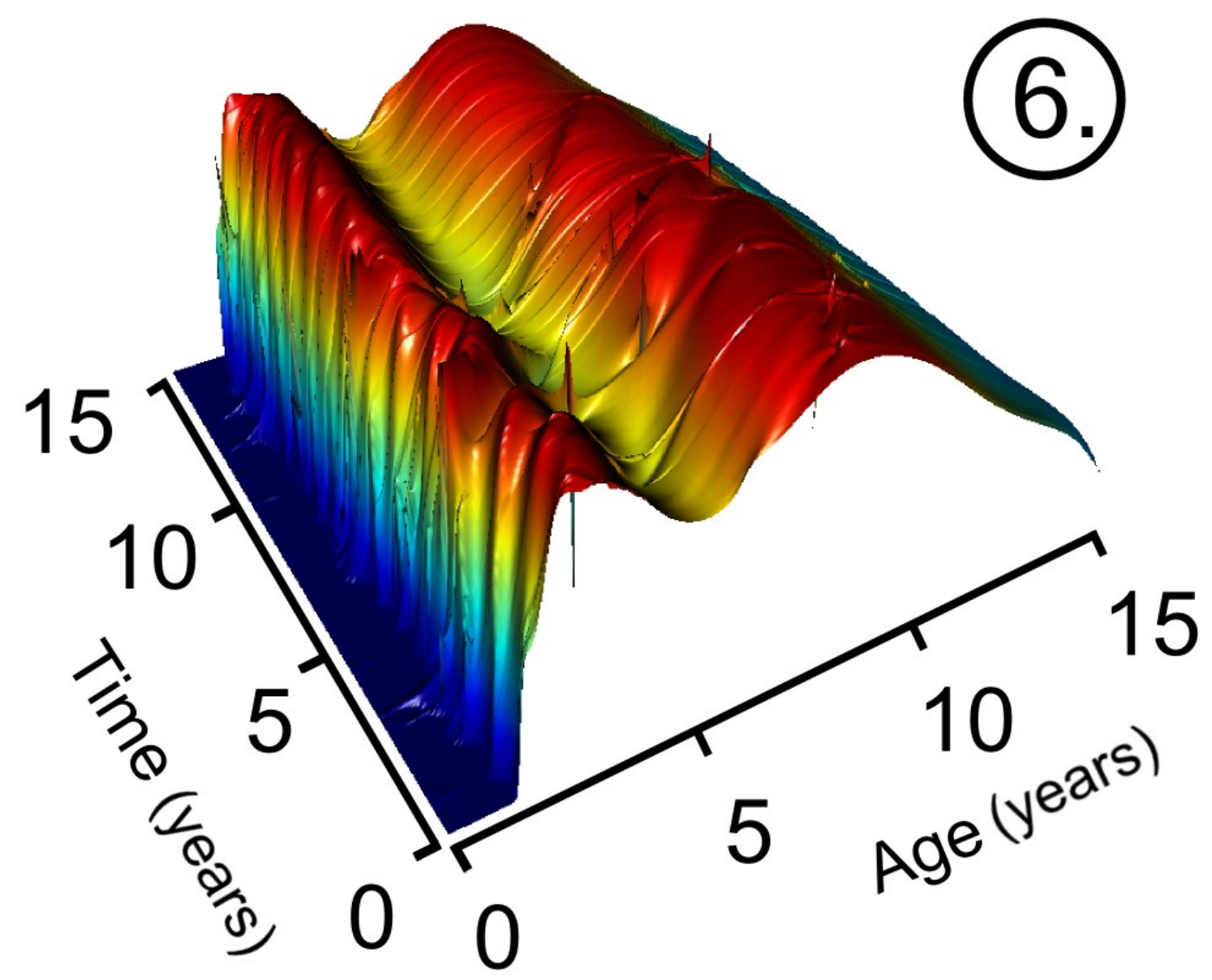

Fig. 7.31 Sixth age distribution. Node 79766 located at a depth of 28.38 metres in the Eastern section of the domain. The age and time units are shown in years.

The seventh age distribution shows a bore located at the confluence of all the major surface water channels running through the Middle Valley (Fig. 7.25). The bore is at a depth of 13.58 metres and exhibits a relatively young age distribution of predominately young water $<1$ year of age in the Q1 gravels. 
Initially, an older age is present at the node indicating a mean age of around five years, although a significant portion is young water presumably from either the Ruamahanga or Waiohine Rivers (Fig. 7.32). Between 1993 and 1998 there is an ambiguous age distribution present, which could potentially be resolved by extending the TMLTG to a 30 or 45 year simulation. Overall, the bore exhibits very young water and would be of concern if being used as a drinking water supply.

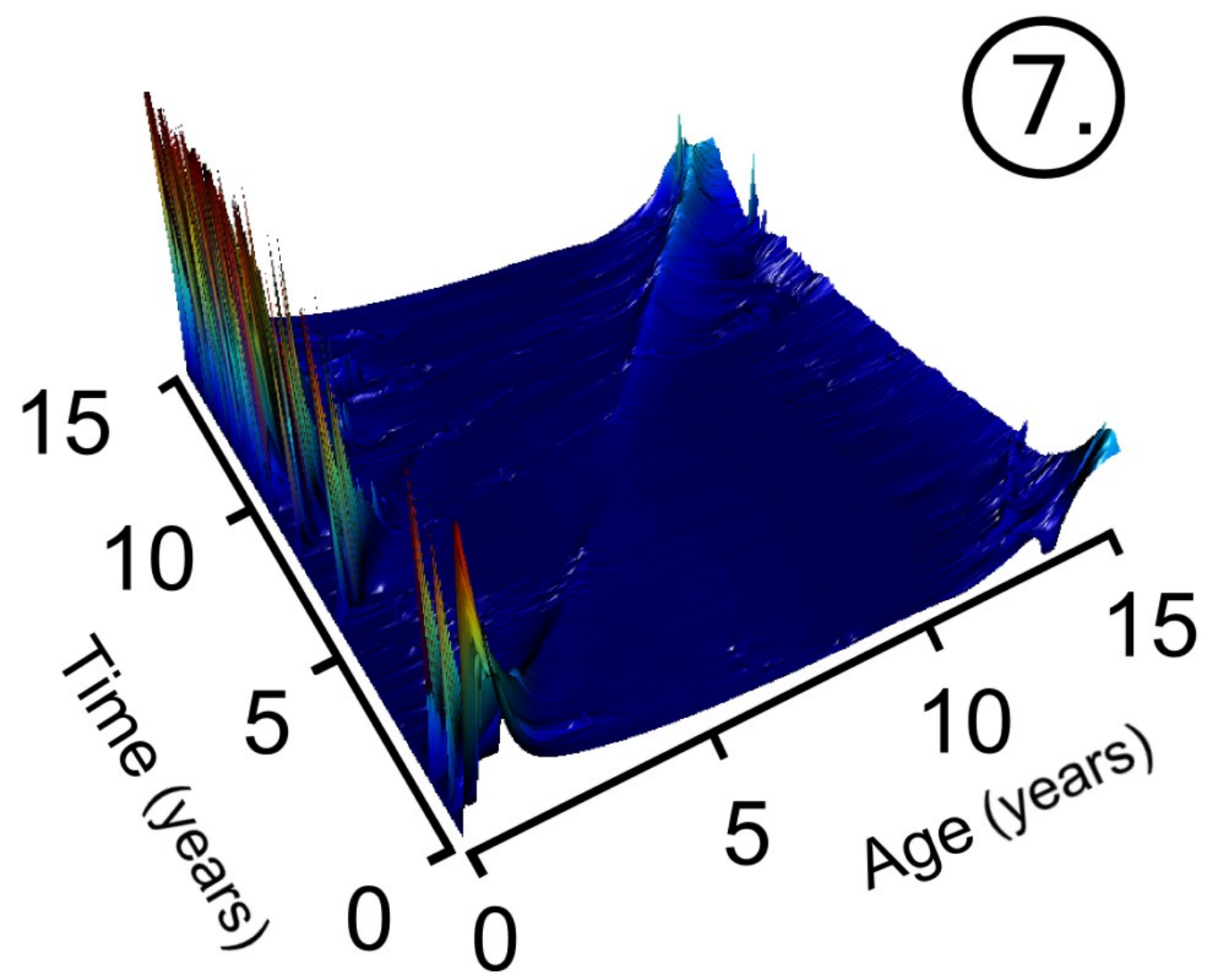

Fig. 7.32 Seventh age distribution. Node 76597 located at a depth of 13.58 metres in the Southern section of the domain. The age and time units are shown in years.

The eighth temporal age evolution is taken from node 36105 located within Q2 river deposits (Fig. 7.33). The node is located 5.1 metres beneath the surface in the middle of the Parkvale spring system (see Fig. 4.14). Initially, the well shows a portion of young water $<1$ year old with a much older bulk water mass dominating the distribution. Again, contamination here is a risk; especially if the bore is used for a domestic or municipal water supply. Generally, the well exhibits a relatively safe age, although young water does appear at times (e.g. in the first five years). 
This young water in the early years of the simulation could be the result of a spin-up error, although several simulations were performed (totalling 45 years) with the young water still appearing in the distribution. Given this, it is postulated that the young water is derived from heavy or otherwise unusual rainfall recharge or an adjacent bore or spring. The younger bulk water mass which enters at the start progressively ages throughout the simulation and an evenly spread mode is evident after around 10 years of the nodes water age development. The node approaches a close to steady state situation with a mean age of 11 years from 2002-2007. Given the simulated age distribution and confirmation by water chemistry analysis, the well appears to be generally safe and at low risk of contamination, contrary to the expected outcome looking only at local geology and bore depth (i.e. Q2 gravels and 5 metres deep). However caution should be indicated given the occasional presence of young water.

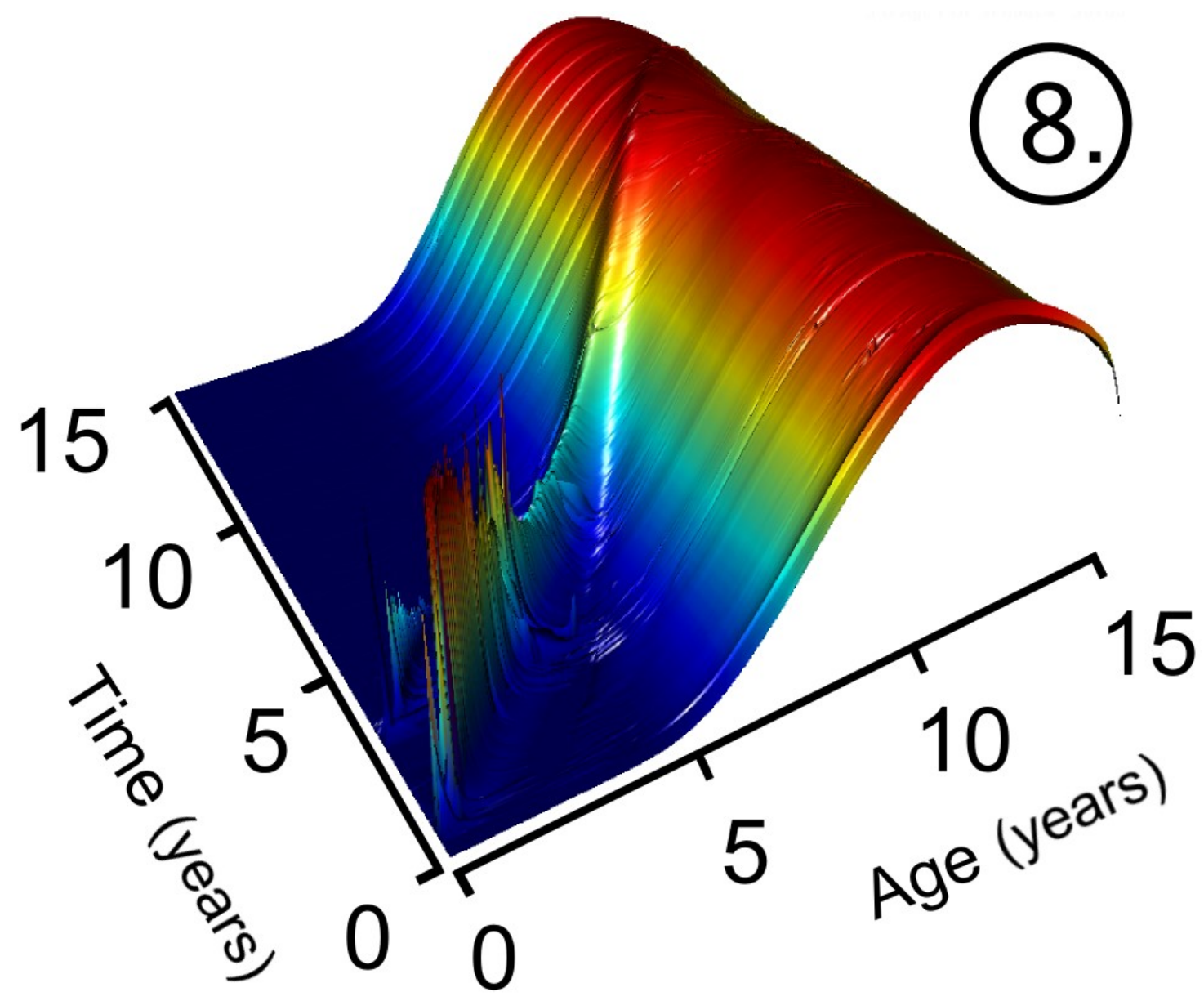

Fig. 7.33 Eighth age distribution: Node 36105 located at a depth of 5.1 metres in the centre of the domain. The age and time units are shown in years. 
The ninth age distribution evaluates a western well located north of the Waiohine River system (Fig. 7.34). This node is located at depth of 10 metres on the sixth slice of the model on the boundaries of Q2 and Q1 gravels. The simulated age distribution shows the bulk water mass of an estimated eight year age. Younger water particles regularly enter the node presumably from the Waiohine River and/or Mangatarere Stream. In this case, a mean age assessment would potentially misrepresent the reality of younger water present and potentially harmful solutes or pathogens such as e-coli, given the distribution of ages within the node.

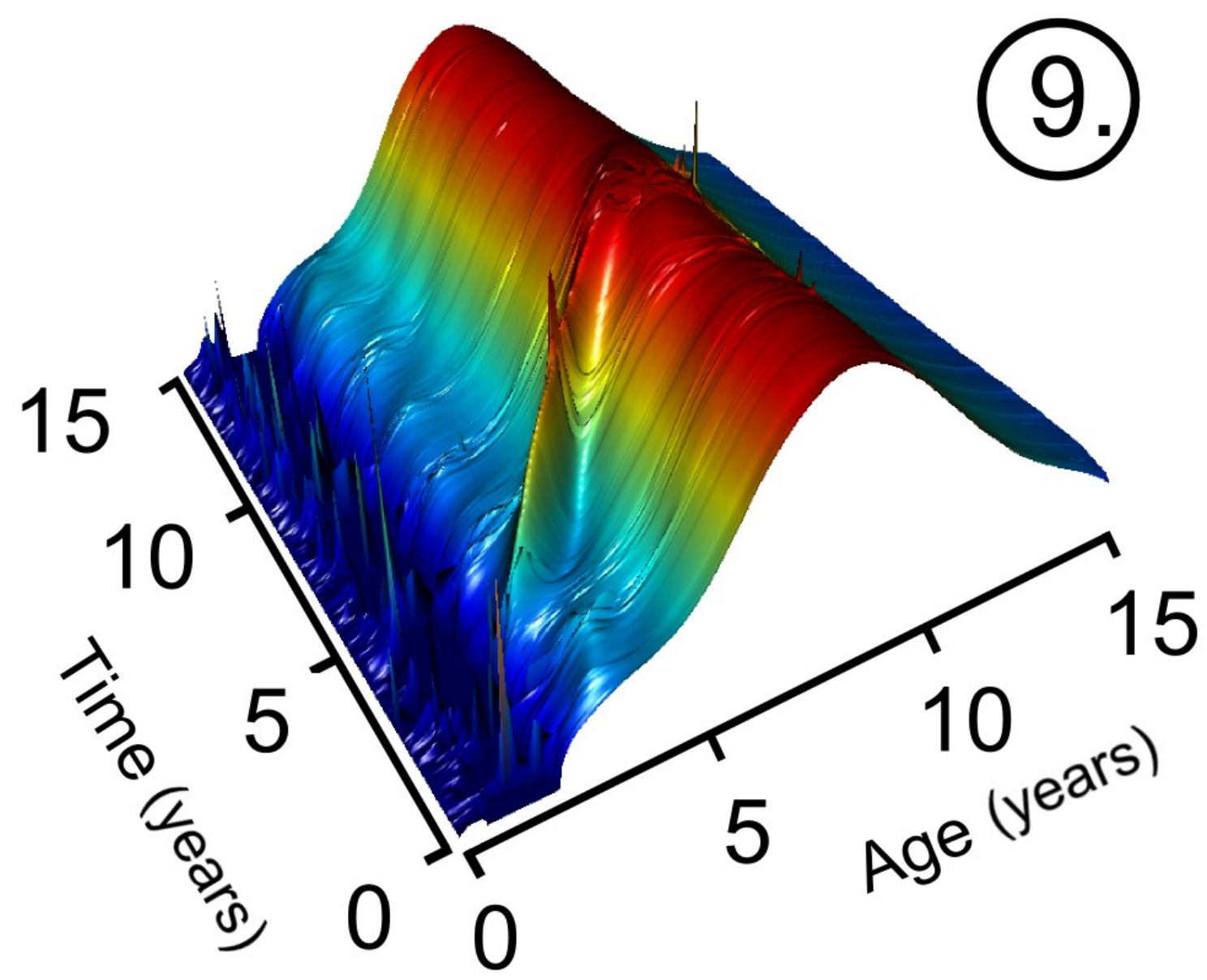

Fig. 7.34 Ninth age distribution. Node 62286 located at a depth of $10.03 \mathrm{~m}$ in the Western section of the domain. The age and time units are shown in years.

The tenth age evolution displays an abstraction well in close proximity to a river in hydraulically conductive gravels (Fig. 7.35). This example shows a vulnerable drinking water well, to pathogenic bacteria and/or viruses potentially present in water $<1$ years of age. 
This is a perfect example of a mean-age assessment giving a false assumption of older (potentially) contaminant-free drinking water, hence the importance of the age distribution. Given the nodes relatively shallow depth and proximity to a surface water channel, the risks are evident, but it does indicate the potential for drinking water contamination of young water to unconfined aquifers. Contaminants may not be present in the young water at this point in time, but given the historical land-use in the Wairarapa, and projected increases in agriculture productivity and irrigation abstractions, contamination is a real risk to the Wairarapa groundwater system. 

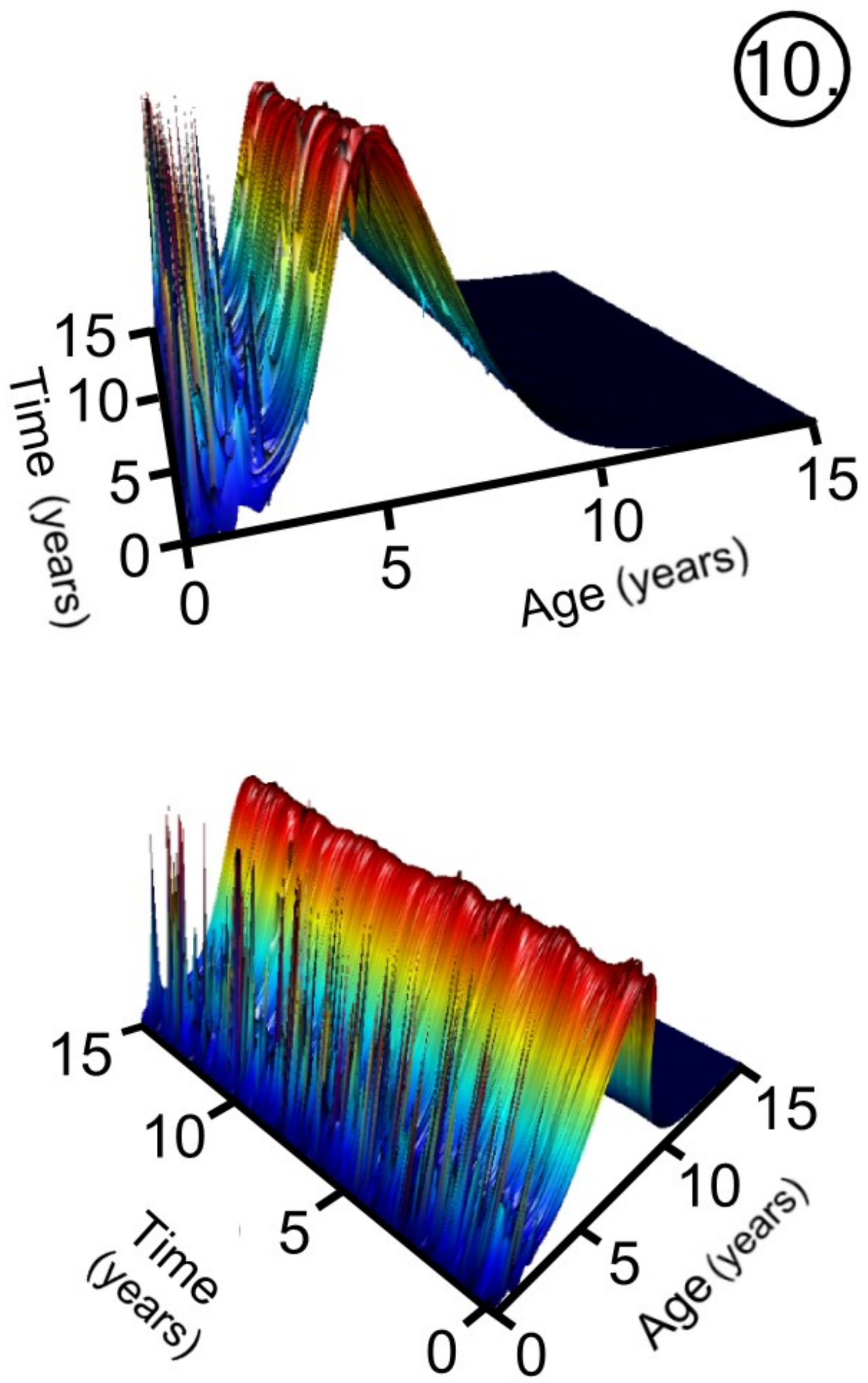

Fig. 7.35 Tenth TMLTG age distribution: Node 14262, located at a depth of 2.1 metres in the Western section of the domain. The age and time units are shown in years. 


\subsubsection{Middle Valley groundwater age summary}

Evaluating the transient distribution of groundwater ages allows for important insights into flow and transport processes. Specifically rainfall and river recharge influence, potential for and identification of drinking water contamination and abstractive aquifer pressures affecting age. Relatively constant rainfall recharge has a significant effect on the age distribution and renewal of the bulk groundwater age. The transient age distributions are shown to be relatively constant in most of the examples. After the initial spin-up is reached (see Fig. 6.16), the rainfall recharge and mixing within the system, prevent much of the groundwater reaching any significantly old age. Examples exhibiting this include three, eight and nine of the TMLTGs. In a more arid climate, for example, South Australia, simulated ages would be expected to show a wider range, providing a long enough time scale was simulated. The influence of rainfall and river recharge exemplifies the potential for contamination of drinking water supplies.

The age distribution can help abate problems with mean-age assessments. A mean-age assessment would have given a false assumption of older (potentially) contaminantfree drinking water on examples three, seven, eight, nine and ten. The risks posed to dynamic water catchments, such as the Wairarapa and many others in New Zealand, from surface activities are of concern and require appropriate monitoring and management. Abstractive pressures also require management. The transient age distributions shown for the Middle Valley indicate strong abstraction influences where pumping is shown to influence the age around and inside the simulated bore. Local geology has a profound influence on age when water is drawn in from surrounding layers of older or younger ages. These pumping influences are seen in examples two, three, four, five, six and ten.

\subsection{Direct age simulation summary}

The information garnered from the direct simulation of age can be implemented in the management of regional surface and subsurface water resources. The resulting age information can be applied at both the regional scale and specific point scale where clarification is required to evaluate the potential health risks, aquifer characteristics and the sustainable allocation of groundwater. 
Increasing intensive land-use in New Zealand, in this case the Wairarapa, has significantly increased the risk of water contamination for both surface and groundwater resources. Use of both mean-age and specific point age distribution information seems an effective way of managing these increasing environmental risks and can be applied to use information contained in flow models already constructed by various water authorities throughout New Zealand and internationally .

The simulated age shows important variances in the groundwater age over a timescale where groundwater resources have been increasingly utilized and modified from a seminatural state. The mean-age shows the speed and dynamic nature of the system, the influence of a significant period of low rainfall, and the subsequent reliance on groundwater irrigation resources. The Middle Valley system is prone to shortages in rainfall recharge over the summer months having a profound effect on the age distribution in drought periods. Conversely, high precipitation events, typically in winter months, cycle younger water through the domain via surface and river recharge. The age throughout the system, and over a given timescale, enables further clarification on the potential for groundwater vulnerabilities and adverse effects resulting from the land-use and abstractive processes causing significant concern in the Wairarapa. The direct simulation of age can be applied to important catchments nationally and globally. 


\title{
Chapter 8
}

\section{Conclusions and recommendations}

\author{
I can foretell the way of celestial bodies, but can say nothing \\ about the movement of a small drop of water.
}

Galileo Galilei

This dissertation has described a numerical modelling-based investigation into the time-varying changes in groundwater flow, transport and subsurface water age. The aim of this research was to determine groundwater age information, in both transient mean-age and transient age distribution forms, at a regional scale. To achieve simulations representative of the actual Middle Valley catchment, the model was calibrated to observed and inferred tritium concentrations, and hydraulic head data taken over the 15 year simulation period (1992-2007). Age information throughout the subsurface was able to be extrapolated following extensive work on the flow and transport processes and parameters within the Middle Valley domain. The following conclusions were drawn from the results and analysis of the dissertation, and recommendations for future study are described.

The final chapter is divided into two sections. The first section covers the overall conclusions and discussions starting with the importance of groundwater age and the mean-age and transient age distribution results and their applicability in regional groundwater management. The calibration is then discussed, outlining the problems and potential improvements for future studies. The chapter concludes with potential avenues for future research and recommendations. 


\subsection{Conclusions and discussion}

\subsubsection{Overall conclusions}

The specific novelty of this dissertation was the application of transient groundwater age distributions in a real world catchment. This allowed the distribution of water particle ages at specific nodal points to be simulated and evaluated throughout the domain in both time and space. Results indicated the Middle Valley was sensitive to recharge and abstraction pressures. The simulated mean-age exhibited considerable seasonal changes as well as responding to specific drought and flood events occurring during the simulation period. The transient age distributions suggested several points where a mean-age assessment would misrepresent the potential for water contamination by water particles < one year of age. Contamination would have resulted from a smaller fraction of water particles in the simulated nodal distribution more likely to contain contaminants and pathogens (e.g. nitrate and e-coli). It was assumed for the purpose of this analysis that older water particles greater than one year of age are subjected to the subsurface environment for long enough to not be of considerable threat.

The results demonstrated an existing flow model could be converted and coupled with a transport model for the direct simulation of age. The transient flow and transport model can be simulated with any specific solute, and has extracted mean-age and specific point age distribution information. The specific point age distributions can be evaluated from any point within the simulated Middle Valley domain. A significant problem however was the inability of the Ground Water (GW) model to simulate an unsaturated or variably saturated zone. This created large differences between modelled (i.e. FEFLOW and Ground Water (GW)), and observed hydraulic heads. Although this technical problem impacted on the reliability of the specific results presented in this dissertation, this is merely a short-term issue that will be resolved as the software implementing these techniques evolves in the future. The direct simulation of age has widespread implications for future application of coupled flow and transport models in regional groundwater management. 
Confined models are widely used for regional groundwater management and this dissertation showed that they can be adapted to simulate groundwater age. Adapting a prior-developed model reduces 1) time and 2) financial costs associated with the development of conceptual and numerical models.

The existence, and need for the simulation of flow and transport through the upper variably saturated portion of the subsurface is a significant source of the models error. Simulated tritium concentrations were exhibiting significant differences, in addition to hydraulic head differences, between the observed tritium data. The variably saturated zone is a complex, variable zone, often simulated separately or in one- or twodimensions. This is due to the fact that incorporating the variably saturated section adds significant complexity posing a combination of problems including: instability and excessively long simulation times. This is especially problematic calculating variably saturated flow and transport in a regional-scale three-dimensional model. The variably saturated zone was not simulated in the Middle Valley model due to time constraints and numerical instability running both phreatic and variably saturated simulations.

\subsubsection{Model calibration}

Tritium measurements enabled calibration of the transport model and the subsequent direct age simulation. The conservative nature of the tritium isotope, known atmospheric inputs and the tritium data (six observed and 190 inferred concentrations) enabled the refinement of parameters, improving the relative error in the flow output and the migration of tritium through the catchment. The limited tritium dataset was useful, and provided encouraging age results; however additional observed field measurements (spatially and temporally) would have significantly contributed in the calibration phase. Hydrochemical inferred tritium concentrations from measured silica concentrations were utilized as a result of this shortage. Given that hydrochemistry is routinely measured, and widely available, measured silica concentrations were utilized to infer tritium measurements for this dissertation. A regression model was developed and weighted against the estimated error of the inferred data, to provide extra constraint within the calibration process. 
This extended the tritium dataset from six measurements in 2005 to 196 measurements between 2003 and 2007. Given this, the transient transport model calibration was enhanced by the inclusion of the inferred tritium data.

The calibration phase utilized the both Guass-Marquard-Levenberg method and a classical Monte Carlo method. This was an attempt to survey the wide-range of hydraulic parameters to find a reasonable fit within the physical ranges of the Middle Valley catchment. The combination of these two techniques provided an extra degree of confidence in the calibrated estimations, and a significant reduction in the simulation flow and transport model error, for the direct simulation of age. This was indicated by the overall reduction of the error between simulated and observed heads and tritium concentrations.

Simulated tritium exhibited higher concentrations at observation points in the model than the measured field data. This indicated the water and tritium were cycling too fast through the model. Simulated hydraulic heads and tritium concentration were proposed to be complicated by the variably saturated zone, causing a lag on the water flow and transport processes in the Middle Valley groundwater system.

Improvements to the calibration method could be achieved by:

I. Incorporating the variably saturated upper sections of the Middle Valley in the simulated transient flow of water and transport of tritium and water particle age, either via a phreatic, free-forming or variably saturated model;

II. A larger dataset of spatio-temporal groundwater tritium data, or an alternative solute, to compare results obtained by different solute transport processes; although tritium's conservative nature makes it the most suitable;

III. Better constraints and investigations on the transfer rates and controls on the river boundary conditions. The water movement between the surface and groundwater was not modified from the FEFLOW conversion, and could be potentially improved numerically in the simulations. This could be implemented in a separate and/or coupled river model; 
IV. Calculating the return flow and solute mass from irrigation and surface water storage lakes. For example, the effect of older water withdrawn from deeper aquifers and its subsequent effect on age and tritium concentrations in the subsurface. This could be considerable given the widespread development of irrigation and storage lakes across New Zealand's agricultural regions. Examples include the Wairarapa Water Use Project or Rangitata South Irrigation scheme.

\subsubsection{The direct simulation of age}

The direct simulation of age results indicated solute-sensitive zones and zones with less sensitivity to climatic variations and groundwater abstractions. Capture zones were also estimated for all pumping wells implemented within the Middle Valley domain. The results indicated the transient probability of particles exiting the subsurface as abstracted water, from very low probabilities and reduced capture zones in the winter months, to very high probabilities and extended capture zones during the dry summers. These results were applied when assessing the mean-age and point age distributions with the simulated influence of pumping visible in the transient age distribution results.

Improvements to this method could be achieved by:

- Extending the model to present time (i.e. 2012/13) with additional data collated from rainfall, abstraction, tritium and river water flux data;

- Improvements mentioned in the calibration method summary (section 8.1.2): Incorporating variably saturated processes (I.), implementing yearly, ideally monthly, tritium measurements (across catchments throughout New Zealand) (II.), further investigation of surface water transfer (III.), return flow and solute mass from irrigation and storage lakes (IV.).

\subsection{Avenues for future research}

Although this research provided important age information and improved the estimates inferred from the model output, there are still many avenues for research in the Wairarapa and other groundwater systems throughout New Zealand. 
This research investigated the flow and transport within the Middle Valley using a numerical groundwater model with inherent limitations and assumptions which provide further options for improving simulated output and conforming to the hydrogeologic reality.

There are numerous unknowns in the subsurface and specific research avenues for the Middle Valley, and groundwater modelling in general, which include:

I. The variably saturated zone. Variably saturated flow and transport processes are complex, as well as computationally demanding, but are a reality and are significantly affect the flow of water and transport of solutes (and age) to the saturated zone. Due to the non-linear nature and complexities, this is typically not generally included in regional three-dimensional models;

II. Accurately simulating surface water fluxes and groundwater interactions between streams, rivers and lakes within the Middle Valley model, given that surface water flux between shallow aquifers is a large component of the system storage, mass transport and water age. This could be achieved incorporating river discharge data from the various monitoring stations and implementing the data in a separate and/or coupled river model;

III. The effect on tritium and potential recharge of abstracted water in heavily irrigated areas. This would be interesting given the variable tritium concentrations within water continuously abstracted from subsurface systems. Given abstraction is typically a small proportion of the model budget it is assumed results would be negligible. However, calculating the concentrations of tritium returned to the water table following abstraction could have implications for the use of tritium in groundwater models;

IV. The relationship between hydrochemical constituents and groundwater age. If a reliable relationship exists, this could potentially resolve problems where tritium data is scarce. However, given tritium's conservative properties, tritium data would still be required and is one of the most reliable groundwater tracers. 
The variably saturated zone is one of the major challenges in hydrogeology, specifically catchment scale modelling (Dogan and Motz, 2005; Fetter, 1993). Groundwater modelling tends to ignore variably saturated processes. However, variably saturated sections are present in most, if not all porous material. The pore spaces of this section are partially inhabited by water with the remaining free pore space taken up by air. Although the concepts of Darcy's law and hydraulic head are the same as in the saturated zone, in the variably saturated zone the hydraulic conductivity $(\boldsymbol{K})$ is no longer a material constant and is a variable, depending on the volumetric water content. The pore water pressure also changes with volumetric water content (Fitts, 2002). The variably saturated zone can influence the flow of water and transport of solutes significantly, particularly the timing between the water and/or solutes migration between the surface and saturated zone, as exemplified in the saturated model's tritium transport simulations. The simulation of this zone is difficult and leads to numerical instability and is not within the scope of this dissertation.

Accounting for surface water mixing is important for a robust transport simulation (Gusyev et al, 2012). Solute concentrations in surface water channels can be affected by various processes, not all of which are accounted for by the advective-dispersive equation. However, given the complexities, further calculations and constraints are required for a more robust solution. This dissertation does not attempt to quantify these interactions due to the scope of the research, however, the topic is of current interest in hydrogeological modelling (e.g. Baalousha, 2012; Gusyev et al, 2012) and is a potentially important flux in dynamic groundwater systems such as the Wairarapa.

\subsubsection{Recommendations}

- Implement the "phreatic layer" as defined in section 7.1.2, and/or variably saturated zone dynamics using the Richard's equation and additional models of variably saturated processes (e.g. Brooks and Corey, 1966; Haverkamp et al, 1977; Van Genuchten, 1980, 1982); 
- Retrospectively, using both the FEFLOW and Groundwater (GW) software in unison could achieve better results. For example, using the FEFLOW model simulating both flow and transport and calibrating (using PEST and/or a Monte Carlo method(s)) with the functioning "phreatic layer" in FEFLOW. Groundwater age estimates could be then gained in FEFLOW 6.2 (mean-age), or both mean-age and point age distributions simulated in Ground Water (GW), using the FEFLOW flow model output for the Ground Water (GW) transport model simulation(s);

- Apply the TMLTG to drinking water bores and SOE wells throughout Greater Wellington's network of models, including the Kapiti, Lower Hutt and Wairarapa (Upper, Middle and Lower Valleys). This would help evaluate potential drinking water bore vulnerabilities;

- Evaluate capture zones for the current network of monitoring bores and drinking water bores (GWRC, 2012a; 2012b). The current groundwater quality network of 71 State of the Environment sites can be simulated to evaluate if the current network is sufficiently capturing land-use processes across the Greater Wellington region. This can be achieved using Greater Wellington's network of models, including the Kapiti, Lower Hutt and Wairarapa (Upper, Middle and Lower Valleys) and using the probabilistic capture zone assessment as used in section 7.5 .

Results from the calibration of the model to tritium indicated the simulated water (and tritium) were travelling too rapidly through the model domain. Although the simulated error was improved following further calibration, it is proposed the model should include three-dimensional transient variably saturated flow and transport processes. This was postulated to be the source of error between simulated and observed tritium and the reason the calibration attempted to assign high porosity values. The variably saturated zone in the Middle Valley is variable with an average depth of around four metres. This would presumably slow the vertical transport of both water and solutes to the the Middle Valley groundwater system. 
Overall, the simulated age throughout the Wairarapa indicated a dynamic groundwater system significantly affected by climatic changes (seasonal and extended) and abstraction pressures, which are increasing due to surface water allocation constraints. Given the hydraulic connections between several surface and subsurface water systems in the Wairarapa, surface water shortfalls cannot be completely met by groundwater as they are inherently connected. A solution proposed and applied in New Zealand are irrigation schemes diverting water from flood conditions to large storage lakes. Such a system is currently being assessed for development in the Wairarapa (i.e. the Wairarapa Water Use Project). 


\section{References}

Airey, S., Puentener, R. and Rebergen, A. (2000). Lake Wairarapa wetlands action plan 2000-2010. Department of Conservation, Wellington. 68pp.

Annear, L. C., and Wairarapa Catchment Board and Regional Water Board. (1989). Wairarapa ground water study. Masterton, N.Z: Wairarapa Catchment Board and Regional Water Board.

Baalousha, H. M. (2012). Characterisation of groundwater-surface water interaction using field measurements and numerical modelling: a case study from the Ruataniwha Basin, Hawke's Bay, New Zealand. Applied Water Science, 1-10.

Barford, N. C. (1985). Experimental measurements: precision, error and truth.Chichester: Wiley, 1985, 2nd ed., 1.

Bassinot, F. C., Labeyrie, L. D., Vincent, E., Quidelleur, X., Shackleton, N. J., \& Lancelot, Y. (1994). The astronomical theory of climate and the age of the BrunhesMatuyama magnetic reversal. Earth and Planetary Science Letters,126(1), 91108.

Bear, J. (1972). Dynamics of fluids in porous media. Courier Dover Publications.

Bear, J., \& Cheng, A. H. D. (2010). Modelling groundwater flow and contaminant transport. Dordrecht, Heidelberg, London, New York: Springer.

Begg, J., Brown, L., Gyopari, M. and Jones, A. (2005). A review of Wairarapa geology with a groundwater bias. Institute of Geological and Nuclear Sciences client report 2005/159.

Bennett, G. D. (1976). Introduction to groundwater hydraulics. Chapter B-2, Techniques of Water-Resources Investigation of the US Geological Survey. 
Bernoulli, D. (1738). Danielis Bernoulli... Hydrodynamica, sive De viribus et motibus fluidorum commentarii. Opus academicum ab auctore, dum Petropoli ageret, congestum. Sumptibus Johannis Reinholdi Dulseckeri.

Bethke, C. M., and Johnson, T. M. (2002). Paradox of groundwater age. Geology, 30(4), 385-388.

Bethke, C. M., and Johnson, T. M. (2008). Groundwater age and groundwater age dating. Annu. Rev. Earth Planet. Sci., 36, 121-152.

Beven, K., \& Freer, J. (2001). Equifinality, data assimilation, and uncertainty estimation in mechanistic modelling of complex environmental systems using the GLUE methodology. Journal of hydrology, 249(1), 11-29.

Beyer, M., Morgenstern, U. and Jackson, B. (2013). Review of dating techniques for young groundwater ( $<100$ years) in New Zealand. Unpublished paper. Victoria University of Wellington.

Black, R. (2007). Drought talks fail to reach farmers - July 4. Straight Furrow.

Boffa Miskell Ltd, (2010). Wairarapa Landscape Study 2010. Landscape Character Description Report August 2010. Report produced by Boffa Miskell Limited for Wellington Regional Council.

Broers, H. P. (2004). The spatial distribution of groundwater age for different geohydrological situations in the Netherlands: implications for groundwater quality monitoring at the regional scale. Journal of Hydrology, 299(1), 84-106.

Brooks, R.H., and Corey, A.T. (1966). Properties of porous media affecting fluid flow. Journal of the Irrigation and Drainage Division, Proc. American Society of Civil Engineers, 92(IR2), 61-88.

Brun, M., Lallemand, A., Quinson, J. F., \& Eyraud, C. (1977). A new method for the simultaneous determination of the size and shape of pores: the thermoporometry. Thermochimica Acta, 21(1), 59-88. 
Busenberg, E., and Plummer, L. N. (2000). Dating young groundwater with sulfur hexafluoride: Natural and anthropogenic sources of sulfur hexafluoride. Water Resources Research, 36(10), 3011-3030.

Busenberg, E., and Plummer, L. N. (2008). Dating groundwater with trifluoromethyl sulfurpentafluoride (SF5CF3), sulfur hexafluoride (SF6), CF3CI (CFC-13), and CF2Cl2 (CFC-12). Water Resources Research, 44(2), W02431.

Butcher, G. (1996a). Ground Water Resources of the Lower Wairarapa Valley. Report prepared for Wellington Regional Council. Professional Ground Water and Environmental Services, April 1996. 69p.

Butcher, G. (1996b). Ground Water Resources of the Ruamahanga River Floodplain Martinborough to Pukeo. Wellington Regional Council.

Butcher, G. (1996c). Safe Yield Estimates for Identified Aquifers in the Wairarapa Valley. Wellington Regional Council.

Butcher, G. (1997). Te Ore Ore Plains Ground Water Study: Wellington Regional Council.

Butcher, G. (2000). Evaluation of Rainfall Recharge to the Aquifers of the Te Ore Ore Plains, Masterton: Wellington Regional Council.

Butcher, G. (2001a). Ground Water Resources of the Martinborough Terraces Ground Water Zone: Wellington Regional Council. 278.

Butcher, G. (2001b). Ground Water Resources of the Huangarua Ground Water Zone. Wellington Regional Council.

Butcher, G. (2001c). Ground Water Resources of the Battersea Ground Water Zone. Greater Wellington Regional Council.

Butcher, G. (2004). Ground Water Resources of the Parkvale Ground Water Zone. Greater Wellington Regional Council. 
Butcher, G.M. (2007a). Spring discharge from the 'Greytown' aquifer. Report prepared for Greater Wellington Regional Council by Professional Groundwater and Environmental Services Ltd (Draft).

Carslaw, H. S., and Jaeger, J. C. (1959). Heat conduction in solids. Clarendon Press, Oxford.

Cape, C. D., Lamb, S. H., Vella, P., Wells, P. E., and Woodward, D. J. (1990). Geological structure of Wairarapa Valley, New Zealand, from seismic reflection profiling. Journal of the Royal Society of New Zealand, 20(1), 85-105.

Castro, M. C., and Goblet, P. (2005). Calculation of ground water ages-a comparative analysis. Ground water, 43(3), 368-380.

Cook, P. G., and Herczeg, A. L. (Eds.). (2000). Environmental tracers in subsurface hydrology (Vol. 529). Boston: Kluwer Academic Publishers.

Cornaton, F. J. (2007). Ground water: a 3-D ground water and surface water flow, mass transport and heat transfer finite element simulator, reference manual. 398 pp. University of Neuchâtel, Neuchâtel, Switzerland.

Cornaton, F. J. (2012), Transient water age distributions in environmental flow systems: The time-marching Laplace transform solution technique, Water Resour. Res., 48, W03524, doi:10.1029/2011WR010606.

Cornaton, F.J. and Perrochet, P. (2006). Groundwater age, life expectancy and transit time distributions in advective-dispersive systems: 1 . Generalized reservoir theory. Advances in Water Resources, 29, p. 1267-1291.

Darcy, H. P. G. (1856). Dètermination des lois d'ècoulement de l'eau à travers le sable. Les Fontaines Publiques de la Ville de Dijon. Paris: Dalmont.

Daughney, C.J. (2007). Multivariate statistical methods for assessment of groundwater chemistry between the Waingawa and Waiohine Rivers, Wairarapa Valley, GNS Science Report, 2007/19, 39p. 
Daughney, C. J., Guggenmos, M. R., McAlister, D., Jackson, B. M., and Begg, J. (2009a). Assessment of groundwater and surface water chemistry in the Upper and Lower Wairarapa Valley. GNS Science Report 2009/21. July 2009.

Daughney, C.J., Morgenstern, U., van der Raaij, R.W., Reeves, R.R. (2009b). Discriminant analysis for estimation of groundwater age from hydrochemistry and well construction: application to New Zealand aquifers. Hydrogeology Journal, 18(2): 417-428, 541.

Daughney, C. J., Morgenstern, U., van der Raaij, R., and Reeves, R. R. (2010). Discriminant analysis for estimation of groundwater age from hydrochemistry and well construction: application to New Zealand aquifers. Hydrogeology Journal, 18(2), 417-428.

Daughney, C. J., Raiber, M., Moreau-Fournier, M., Morgenstern, U., \& van der Raaij, R. (2012). Use of hierarchical cluster analysis to assess the representativeness of a baseline groundwater quality monitoring network: comparison of New Zealand's national and regional groundwater monitoring programs. Hydrogeology journal, 20(1), 185-200.

Davis, S. N. (1969). Porosity and permeability of natural materials, in Flow through Porous Media, R. J. M. De Wiest, ed., Academic Press, New York, 54-89.

De Marsily, G. (1986). Quantitative hydrogeology. Paris School of Mines, Fontainebleau.

Diersch, H. J. G. (2002). FEFLOW reference manual. Institute for Water Resources Planning and Systems Research Ltd, 278.

Diersch, H. J. G. (2009). FEFLOW reference manual. DHI-WASY GmbH.

Dogan, A., \& Motz, L. H. (2005). Saturated-unsaturated 3D groundwater model. I: Development. Journal of Hydrologic Engineering, 10(6), 492-504.

Doherty, J. (2010). PEST, Model-independent parameter estimation-User manual (5th ed., with slight additions): Brisbane, Australia, Watermark Numerical Computing. 
Doherty, J. E., \& Hunt, R. J. (2010). Approaches to highly parameterized inversion: a guide to using PEST for groundwater-model calibration. US Department of the Interior, US Geological Survey.

Domenico, P. A., \& Schwartz, F. W. (1990). Physical and chemical hydrology. Text Book.

Duncan, M., and Woods, R. (2004). Flow regimes. Freshwaters of New Zealand, 7-1.

Eberts, S. M., Böhlke, J. K., Kauffman, L. J., and Jurgens, B. C. (2012). Comparison of particle-tracking and lumped-parameter age-distribution models for evaluating vulnerability of production wells to contamination. Hydrogeology Journal, 1-20.

Engelhardt, I., Prommer, H., Moore, C., Schulz, M., Schüth, C., \& Ternes, T. A. (2013). Suitability of temperature, hydraulic heads, and acesulfame to quantify wastewater - related fluxes in the hyporheic and riparian zone. Water Resources Research, 49(1), 426-440.

Engesgaard, P., and Molson, J. (2005). Direct simulation of ground water age in the Rabis Creek Aquifer, Denmark. Ground Water, 36(4), 577-582.

Eriksson, E. (1958). The Possible Use of Tritium for Estimating Groundwater Storage. Tellus, 10(4), 472-478.

Etcheverry, D., and Perrochet, P. (2000). Direct simulation of groundwater transit-time distributions using the reservoir theory. Hydrogeology Journal, 8(2), 200-208.

Evison, F. (1999). On the existence of earthquake precursors. Annals of Geophysics, 42(5).

Ferris, J.G., Knowles, D. B., Brown, R. H., \& Stallman, R. W. (1962). Theory of aquifer tests(pp. 69-174). US Government Printing Office.

Fetter, C. W. (1993). Contaminant Hydrogeology Macmillan. New York, NY, 458.

Fetter, C.W. (1994). Applied Hydrogeology, third edition. Prentice Hall, Englewood Cliffs, NJ. 691p. 
Fitts, C. R. (2002). Groundwater science. Academic Press.

Freeze, R. A. (1971). Three-Dimensional, Transient, Saturated-Unsaturated Flow in a Groundwater Basin. Water Resources Research, 7(2), 347-366.

Freeze, R. A., and Cherry, J. A. (1977). Groundwater. Prentice-Hall.

Galilei, G. (1632). Dialogue Concerning the Two Chief World Systems - Ptolemaic \& Copernican. Galileo Galilei.

Gallagher, M., \& Doherty, J. (2007). Parameter estimation and uncertainty analysis for a watershed model. Environmental Modelling \& Software, 22(7), 1000-1020.

Gelhar, L. W., Welty, C., and Rehfeldt, K. R. (1992). A critical review of data on fieldscale dispersion in aquifers. Water resources research, 28(7), 1955-1974.

Ginn, T. R. (1999). On the distribution of multicomponent mixtures over generalized exposure time in subsurface flow and reactive transport: Foundations, and formulations for groundwater age, chemical heterogeneity, and biodegradation. Water Resources Research, 35(5), 1395-1407.

Goode, D. J. (1996). Direct simulation of groundwater age. Water Resources Research, 32(2), 289-296.

Gordon, M. (2013). River data personally given to author. Greater Wellington Regional Council, 2013.

Gordon, M., Tidswell, S., Thompson, M., and Mzila, D. (2012). Annual hydrology monitoring report for the Wellington region, 2010/11. Greater Wellington Regional Council.

Greater Wellington Regional Council (GWRC). (2007). Flooding Hazard - Wairarapa. GW/EM-G-07/266. November 2007.

Greater Wellington Regional Council. (2012a). Air, land and water in the Wellington region - state and trends Wairarapa Valley sub-region. GW/EMI-G-12/152. June 2012. 
Greater Wellington Regional Council. (2012b). Groundwater quality in the Wellington region - State and trends. Environmental Monitoring and Investigations Department. GW/EMI-T-12/140. March 2012.

Guggenmos, M. (2010). Groundwater and Surface Water Interaction, Wairarapa Valley, New Zealand: A Thesis Submitted to the Victoria University of Wellington in Fulfilment of the Requirements for the Degree of Master of Science (Masters dissertation, Victoria University of Wellington).

Guggenmos, M. R., Daughney, C. J., Jackson, B. M., and Morgenstern, U. (2011). Regional-scale identification of groundwater-surface water interaction using hydrochemistry and multivariate statistical methods, Wairarapa Valley, New Zealand. Hydrology and Earth System Sciences, 15(11), 3383.

Gundel, A., Weiler, M., and Schirmer, M. (2013, April). Spatial and temporal simulation of groundwater age distributions of a small mountainous catchment. In EGU General Assembly Conference Abstracts (Vol. 15, p. 685).

Gunn, I.; Butcher, G.; Stewart, M.K. (1987). Groundwater studies on the Wairarapa Plains using isotopic and chemical data. In: Smith, D.K. (Comp.) Proceedings of the Groundwater Chemistry Workshop. Auckland Regional Water Board, Auckland, Technical Publication 41, Pp. 139-155.

Gusyev, M. A., Abrams, D., Toews, M. W., Morgenstern, U., \& Stewart, M. K. (2014). Simulated tritium concentrations in river waters of the western Lake Taupo catchment, New Zealand with MODPATH particle tracking. Hydrology and Earth System Sciences Discussions, 11, 3083-3109.

Gusyev, M.A.; Tschritter, C.; Moreau-Fournier, M.; Daughney, C.J. (2011). Capture zone delineation for National Groundwater Monitoring Programme sites in the Southland region. Lower Hutt: GNS Science. GNS Science report 2011/31. 54 p.

Gusyev, M. A., Toews, M., Morgenstern, U., Stewart, M., Daughney, C., and Hadfield, J. (2012). Calibration of a transient transport model to tritium measurements in 
rivers and streams in the Western Lake Taupo catchment, New Zealand. Hydrol. Earth Syst. Sci. Discuss, 9, 9743-9765.

Gyopari, M.C. and McAlister, D. (2010a). Wairarapa Valley groundwater resource investigation - Middle Valley catchment hydrogeology and modelling. November 2010, 112p.

Gyopari, M.C. and McAlister, D. (2010b). Wairarapa Valley groundwater resource investigation - Upper Valley catchment hydrogeology and modelling. November 2010, 112p.

Gyopari, M.C. and McAlister, D. (2010c). Wairarapa Valley groundwater resource investigation - Lower Valley catchment hydrogeology and modelling. November 2010, 112p.

Hadfield, J. C., Morgenstern, U., Piper, J. J., Brebbia, C. A., and Kungolos, A. (2007). Delayed impacts of land-use via groundwater on Lake Taupo, New Zealand. In 4th International Conference on Sustainable Water Resources Management, Kos, Greece, May 2007. (pp. 293-303). WIT Press.

Haitjema, H. M., \& Kelson, V. A. (1994). GFLOW user's manual. Indianapolis, Indiana: Haitjema Software LLC.

Haitjema, H. M. (1985). Modeling Three-Dimensional Flow in Confined Aquifers by Superposition of Both Two-and Three-Dimensional Analytic Functions. Water Resources Research, 21(10), 1557-1566.

Harbaugh, A. W. (2005). MODFLOW-2005, the US Geological Survey modular groundwater model: The ground-water flow process (pp. 6-A16). Reston, VA, USA: US Department of the Interior, US Geological Survey.

Harbaugh, A. W., Banta, E. R., Hill, M. C., and McDonald, M. G. (2000). MODFLOW-2000, the US Geological Survey modular ground-water model: User guide to modularization concepts and the ground-water flow process (p. 121). Reston: US Geological Survey. 
Harding, J. S., Mosley, P., Pearson, C., and Sorrell, B. (2004). Freshwaters of New Zealand. New Zealand Hydrological Society.

Harkness, M. (2000). Predicting rainfall droughts in the Wairarapa using the Southern Oscillation Index. Wellington Regional Council Technical Publication WRC/RINV-T-00/15.

Haverkamp, R., Vauclin, M., Touma, J., Wierenga, P. J., \& Vachaud, G. (1977). A comparison of numerical simulation models for one-dimensional infiltration.Soil Science Society of America Journal, 41(2), 285-294.

Heath, D.A., (1979). Holocene Marine Shorelines of the Wairarapa. Unpub. thesis BSc(Hons) in Geology, Department of Geology, Victoria University of Wellington, Wellington, New Zealand.

Hedenquist, J. W., Goff, F., Phillips, F. M., Elmore, D., and Stewart, M. K. (1990). Groundwater dilution and residence times, and constraints on chloride source, in the Mokai geothermal system, New Zealand, from chemical, stable isotope, tritium, and 36Cl data. Journal of Geophysical Research, 95(B12), 19365-19.

Herrera, P. A., and Beckie, R. D. (2012). An assessment of particle methods for approximating anisotropic dispersion. International Journal for Numerical Methods in Fluids.

Heslop, I., (1995). The Upper Ruamahanga River and Floodplain Investigation - Phase 1 - Issues. Greater Wellington Regional Council - Wairarapa Division, Masterton. Hicks, S.R. and Woodward, D.J. (1978). Gravity models of the Wairarapa region, New Zealand. New Zealand Journal of Geology and Geophysics 21 (5): 538-544.

Hughes, B. and Gyopari, M. (2011). Wairarapa Valley groundwater resource investigation. Greater Wellington Regional Council, May 2011.

Jones, A. G., and Baker, T. (2005). Groundwater monitoring technical report. Greater Wellington Regional Council. 
Jones, A. G., and Gyopari, M. C. (2006). Regional conceptual and numerical modelling of the Wairarapa groundwater basin. Greater Wellington Regional Council.

Jurgens, B. C., Böhlke, J. K., and Eberts, S. M. (2012). TracerLPM (Version 1): An Excel Workbook ${ }^{\circledR}$ for Interpreting Groundwater Age Distributions from Environmental Tracer Data.

Kazemi, G. A., Lehr, J. H., and Perrochet, P. (2006). Groundwater age. WileyInterscience.

Keenan L. (2009). Instream flow assessment for the Papawai Stream. Greater Wellington Technical Publication GW/EMI-T-09/332.

Keenan, L. and Gordon, M. (2008). Annual hydrology monitoring report for the Wellington Region, 2008/2009, Greater Wellington Regional Council Wellington.

Kidston, J., Renwick, J. A., \& McGregor, J. (2009). Hemispheric-scale seasonality of the Southern Annular Mode and impacts on the climate of New Zealand. Journal of Climate, 22(18), 4759-4770.

Knowles, I. M., Fraser, T. J., and Daly, M. J. (2003). White clover: loss in drought and subsequent recovery. Legumes for dryland pastures. Grassland Research and Practice Series, 11, 37-41.

Konikow, L. F., and Grove, D. B. (1977). Derivation of equations describing solute transport in ground water.

Kreft, A., and Zuber, A. (1978). On the physical meaning of the dispersion equation and its solutions for different initial and boundary conditions. Chemical Engineering Science, 33(11), 1471-1480.

Leach, B.F., (1981). The Prehistory of the Southern Wairarapa. Journal of the Royal Society of New Zealand 11(1), 11-33. 
Levin, L., Naegler, T., Heinz, R., Osusko, D., Cuevas, E., Engel, A., ... and Zimov, S. A. (2010). The global SF6 source inferred from long-term high precision atmospheric measurements and its comparison with emission inventories. Atmospheric Chemistry and Physics, 10, 2655-2662.

Lindgren, R.J., Houston, N.A., Musgrove, M., Fahlquist, L.S., and Kauffman, L.J. (2011) Simulations of groundwater flow and particle-tracking analysis in the zone of contribution to a public-supply well in San Antonio, Texas: U.S. Geological Survey Scientific Investigations Report 2011-5149, 93 p.

Lubczynski, M.W, and Gurwin, J. (2005). Integration of various data sources for transient groundwater modelling with spatio-temporally variable fluxesSardon study case, Spain. Journal of hydrology, 306(1), 71-96.

Maiss, M., Brenninkmeijer, C.A.M. (1998). Atmospheric SF6: Trends, sources and prospects. Environmental Science and Technology. 32, 3077-3086.

Małoszewski, P., \& Zuber, A. (1982). Determining the turnover time of groundwater systems with the aid of environmental tracers: 1 . Models and their applicability. Journal of hydrology, 57(3), 207-231.

Małoszewski, P., and Zuber, A. (1996). Lumped parameter models for the interpretation of environmental tracer data. Manual on mathematical models in isotope hydrology. IAEA-TECDOC-910, 9-59.

Małoszewski, P., and Zuber, A. (1991). Influence of matrix diffusion and exchange reactions on radiocarbon ages in fissured carbonate aquifers. Water Resources Research, 27(8), 1937-1945.

Małoszewski, P., and Zuber, A. (1993). Principles and practice of calibration and validation of mathematical models for the interpretation of environmental tracer data in aquifers. Advances in Water Resources, 16, 173-190.

Manzer, L. E. (1990). The CFC-ozone issue: Progress on the development of alternatives to CFCs. Science(Washington), 249(4964), 31-35. 
McAlister, D., and Tidswell, S. (2007). Annual groundwater monitoring report for the Wellington region, 2006/07.

Meharg, A. A. (2005). Venomous Earth: How arsenic caused the world's worst mass poisoning (p. 256). Houndmills,, England: Macmillan.Sanford, W. (2011). Calibration of models using groundwater age. Hydrogeology Journal, 19(1), 1316.

Ministry of Environment (British Columbia) (2004). Well Protection Toolkit Step 2 (electronic resource). $24 \mathrm{p}$.

Ministry of Health (2005). Drinking-water standards for New Zealand 2005 (Revised 2008). Available online at:

\section{http://www.health.govt.nz/system/files/documents/publications/drinking-} water-standards-2008 $0 . p d f$

Mitchell, J., Webber, J. B. W., \& Strange, J. H. (2008). Nuclear magnetic resonance cryoporometry. Physics Reports, 461(1), 1-36.

Modica, E., Buxton, H. T., and Plummer, L. N. (1998). Evaluating the source and residence times of groundwater seepage to streams, New Jersey Coastal Plain. Water Resources Research, 34(11), 2797-2810.

Morgan M. and Hughes B. (2001). Wellington. In Groundwaters of New Zealand, M.R. Rosen and P.A. White (eds). New Zealand Hydrological Society Inc., Wellington. P397-410.

Morgenstern, U. (2005). Wairarapa Valley groundwater - Residence time, flow pattern, and hydrochemistry trends. Wellington: GNS Science. 36pp.

Morgenstern, U., and Daughney, C. J. (2012). Groundwater age for identification of baseline groundwater quality and impacts of land-use intensification-The National Groundwater Monitoring Programme of New Zealand. Journal of Hydrology. 
Morgenstern, U., Reeves, R., Daughney, C., and Cameron, S. (2004). Groundwater Age, Time Trends in Water Chemistry, and Future Nutrient Load in Lakes Rotorua and Okareka Area. Institute of Geological and Nuclear Sciences.

Morgenstern, U., Reeves, R., Daughney, C., Cameron, S., and Gordon, D. (2005). Groundwater age and chemistry, and future nutrient loads for selected Rotorua lakes catchments. Institute of Geological and Nuclear Sciences.

Morgenstern, U., and Taylor, C. B. (2009). Ultra low-level tritium measurement using electrolytic enrichment and LSC+. Isotopes in Environmental and Health Studies, 45(2), 96-117.

Neupauer, R. M., \& Wilson, J. L. (2001). Adjoint-derived location and travel time probabilities for a multidimensional groundwater system. Water Resources Research, 37(6), 1657-1668.

Neuzil, C. E. (1994). How permeable are clays and shales?. Water resources research, 30(2), 145-150.

Noble, K. E. (1985). Land Use Capability Classification of the Southern Hawke's BayWairarapa Region: A Bulletin to Accompany New Zealand Land Resource Inventory Worksheets. National Water and Soil Conservation Authority.

O’Dea, T.F. Donaldson, I.G., King, M., Martin, G.N., Thorpe, H.R., Wilshere, D.S. and Wilson, D.D. (1980). Wairarapa groundwater study - Report by scientific advisory group. Wairarapa Catchment Board. 89p.

Panday, Sorab, Langevin, C.D., Niswonger, R.G., Ibaraki, Motomu, and Hughes, J.D., (2013). MODFLOW-USG version 1: An unstructured grid version of MODFLOW for simulating groundwater flow and tightly coupled processes using a control volume finite-difference formulation: U.S. Geological Survey Techniques and Methods, book 6, chap. A45, 66 p.

Pearson, C. P. (1992). Analysis of Floods and Low Flows. In M. P. Mosley (Ed.), Waters of New Zealand. Wellington: New Zealand Hydrological Society. 
Pearson, C. P. and Henderson, R. (2004). Floods and Low Flows. In J. S. Harding, M. P. Mosley, C. Pearson and B. Sorrell (Eds.), Chapter 10, Freshwaters of New Zealand. Wellington: New Zealand Hydrological Society.

Plummer, L. N. (2005). Dating of young groundwater. Isotopes in the Water Cycle, 193218.

Plummer, L.N., Böhkle, J.K., and Busenberg, E. (2003). Approaches for ground-water dating, in Lindsey, B.D., Phillips, S.W., Donnelly, C.A., Speiran, G.K., Plummer, L.N., Böhlke, J.K., Focazio, M.J., Burton, W.C., and Busenberg, Eurybiades, Residence times and nitrate transport in groundwater discharging to streams in the Chesapeake Bay Watershed: U.S. Geological Survey Water-Resources Investigations Report 03-4035, p. 12-24.

Plummer, L.N. and Busenberg, E. (1999). Chlorofluorocarbons in P. Cook and A. Herczeg, eds., Environmental Tracers in Subsurface Hydrology: Kluwer Academic Press, in press.

Pollock, D. W. (1994). User's Guide for MODPATH/MODPATH-PLOT, Version 3: A Particle Tracking Post-processing Package for MODFLOW, the US: Geological Survey Finite-difference Ground-water Flow Model. US Department of Interior.

Reddy, M. M., Schuster, P., Kendall, C., and Reddy, M. B. (2006). Characterization of surface and ground water $\delta 180$ seasonal variation and its use for estimating groundwater residence times. Hydrological processes, 20(8), 1753-1772.

Reeves, R. R., Morgenstern, U., Daughney, C. J., Stewart, M. K., and Gordon, D. (2008). Identifying leakage to groundwater from Lake Rerewhakaaitu using isotopic and water quality data. Journal of Hydrology (New Zealand), 47(2), 85.

Reeves, R., and Rosen, M. (2002). Effect of logging on groundwater flow and hydrochemistry in the Waimarino catchment, Lake Taupo, New Zealand.Journal of Hydrology(New Zealand), 41(2), 145-174. 
Reimer, P. J., Brown, T. A., and Reimer, R. W. (2004). Discussion: reporting and calibration of post-bomb 14C data. Radiocarbon, 46(3), 1299-1304.

Richards, L. A. (1931). Capillary conduction of liquids through porous mediums.Physics, 1(5), 318-333.

Rigby, M., Mühle, J., Miller, B. R., Prinn, R. G., Krummel, P. B., Steele, L. P., ... and Elkins, J. W. (2010). History of atmospheric SF6 from 1973 to 2008.Atmos. Chem. Phys, 10(21), 10-305.

Rosen, M. R. (2001). Hydrochemistry of New Zealand's aquifers. In Groundwaters of New Zealand, M.R. Rosen and P.A. White (eds). New Zealand Hydrological Society Inc., Wellington. p77-110.

Rushton, K. R., Eilers, V. H. M., and Carter, R. C. (2006). Improved soil moisture balance methodology for recharge estimation. Journal of Hydrology, 318(1), 379-399.

Sanford, W. (2011). Calibration of models using groundwater age. Hydrogeology Journal, 19(1), 13-16.

Spalding, D. B. (1958). A note on mean residence-times in steady flows of arbitrary complexity. Chemical Engineering Science, 9(1), 74-77.

Stewart, M. K. (2012). A 40-year record of carbon-14 and tritium in the Christchurch groundwater system, New Zealand: dating of young samples with carbon14. Journal of Hydrology, 430, 50-68.

Stewart, M. K., and Fahey, B. D. (2010). Runoff generating processes in adjacent tussock grassland and pine plantation catchments as indicated by mean transit time estimation using tritium. Hydrology and Earth System Sciences, 14(6), 1021-1032.

Stewart, M. K., Fahey, B. D., and Davie, T. J. A. (2005). New light on streamwater sources in the Glendhu experimental catchments, East Otago, New Zealand. In International Water Conference (NZHS, NZSSS and IAH (Australian Chapter). 
Stewart, M. K., Hong, T., Cameron, S., Daughney, C., Tait, T., and Thomas, T. (2003). Investigation of groundwater in the Upper Motueka River Catchment. Institute of Geological and Nuclear Sciences Limited.

Stewart, M. K., Mehlhorn, J., and Elliott, S. (2007). Hydrometric and natural tracer (180, silica, $3 \mathrm{H}$ and SF6) evidence for a dominant groundwater contribution to Pukemanga Stream, New Zealand. Hydrol. Process, 21(24), 3340-3356.

Stewart, M., and Morgenstern, U. (2001). Age and source of groundwater from isotope tracers. Groundwaters of New Zealand (Eds. Rosen MR. and White PW.), The Caxton Press, Christchurch, 161-184.

Stewart, M. K., Stevens, G., Thomas, J. T., van der Raaij, R., and Trompetter, V. (2011). Nitrate sources and residence times of groundwater in the Waimea Plains, Nelson. Journal of Hydrology (New Zealand), 50(2), 313.

Stewart, M. K. and Taylor, C. B (1981). Environmental isotopes in New Zealand hydrology. 1. Introduction: The role of oxygen 18 , deuterium and tritium in hydrology, N.Z. J. Sci., 24, 295-311.

Stewart, M. K., and Thomas, J. T. (2007). A conceptual model of flow to the Waikoropupu Springs, NW Nelson, New Zealand, based on hydrometric and tracer $(180, \mathrm{Cl}, 3 \mathrm{H}$ and CFC) evidence. Hydrology and Earth System Sciences Discussions Discussions, 4(3), 1215-1264.

Stewart, M., Van der Raaij, R., and Trompetter, V. (2002). Age and source of Canterbury Plains groundwater. Environment Canterbury.

Strack, O. D., \& Haitjema, H. M. (1981). Modeling double aquifer flow using a comprehensive potential and distributed singularities: 1 . Solution for homogeneous permeability. Water Resources Research, 17(5), 1535-1549.

Sudicky, E. A. (1989). The Laplace transform Galerkin technique: A time-continuous finite element theory and application to mass transport in groundwater. Water Resour. Res, 25(8), 1833-1846. 
Tait, A., Bell, R., Burgess, S., Gorman, R., Gray, W., Larsen, H., Mullan, B., Reid, S.,Sansom, J., Thompson, C., Wratt, D and Harkness, M. (2002). Meteorological Hazards and the Potential Impacts of Climate Change in Wellington Region - A scoping study. NIWA Client Report WLG2002/19. (No. WRC/RP-T-02/16): Greater Wellington Regional Council.

Tait, A., and Woods, R. (2007). Spatial interpolation of daily potential evapotranspiration for New Zealand using a spline model. Journal of Hydrometeorology, 8(3), 430-438.

Taylor, C. B., Brown, L. J., Cunliffe, J. J., and Davidson, P. W. (1992). Environmental tritium and 0-18 applied in a hydrological study of the Wairau Plain and its contributing mountain catchments, Marlborough, New Zealand. Journal of Hydrology, 138(1), 269-319.

Taylor, C. B., and Fox, V. J. (1996). An isotopic study of dissolved inorganic carbon in the catchment of the Waimakariri River and deep ground water of the North Canterbury Plains, New Zealand. Journal of Hydrology, 186(1), 161-190.

Taylor, C. B., Wilson, D. D., Brown, L. J., Stewart, M. K., Burden, R. J., and Brailsford, G. W. (1989). Sources and flow of north Canterbury plains groundwater, New Zealand. Journal of hydrology, 106(3), 311-340.

The Wairarapa/Tararua Drought Recovery Committee (TWTDRC). (2008). A Resource for Drought Management - Lessons from the Eastern Drought of 1997/1998. Released April 2008.

Therrien, R., McLaren, R. G., Sudicky, E. A., \& Panday, S. M. (2010). HydroGeoSphere: A three-dimensional numerical model describing fully-integrated subsurface and surface flow and solute transport. Groundwater Simulations Group, University of Waterloo, Waterloo, ON.

Todd, D. K., \& Mays, L. W. (2005). Groundwater hydrology edition. Wiley, New Jersey. 
Van der Raaij, R. W. (2003). Age dating of New Zealand groundwaters using sulphur hexafluoride. MSc in Physical Geography, School of Earth Sciences, Victoria University of Wellington.

Van der Raaij, R. W. (2013). Tracer data personally given to author. Unpublished raw data. GNS Science, 2013.

Van Genuchten, M. T. (1980). A closed-form equation for predicting the hydraulic conductivity of unsaturated soils. Soil Science Society of America Journal, 44(5), 892-898.

Van Genuchten, M. T. (1982). A comparison of numerical solutions of the onedimensional unsaturated-saturated flow and mass transport equations.Advances in Water Resources, 5(1), 47-55.

van Leeuwen, M., te Stroet, C. B., Butler, A. P., \& Tompkins, J. A. (1998). Stochastic determination of well capture zones. Water Resources Research,34(9), 22152223.

Veitch, J. (1995). A model of innovation. In Riley, B., (ed.), Kiwi Ingenuity: A Book of New Zealand Ideas and Inventions, AIT Press, New Zealand, pp. 151-158.

Viner, A. B. (Ed.). (1987). Inland waters of New Zealand (Vol. 241). Science Information Pub. Centre, Dept. of Scientific and Industrial Research.

Vogel, J.C. (1967). Investigation of groundwater flow with radiocarbon: Isotopes in hydrology, proceedings from Conference on Isotopes in Hydrology, Vienna, International Atomic Energy Agency, p. 355-368.

Wairarapa Engineering Lifelines Association, (2003). Wairarapa Engineering Lifelines Project - Risk to lifelines from natural hazards. Masterton.

Wallis, I., Moore, C., Post, V., Wolf, L., Martens, E., \& Prommer, H. (2014). Using predictive uncertainty analysis to optimise tracer test design and data acquisition. Journal of Hydrology, 515, 191-204. 
Watts, L. (2004). The 15-16 February 2004 storm in the Wellington Region: hydrology and meteorology. (No. GW/RINV-G-04/91). Wellington: Greater Wellington Regional Council.

Watts, L. (2005). Hydrological monitoring technical report. (No. GW $\backslash$ RINV-T-05/88). Wellington: Greater Wellington Regional Council.

Watts, L., and Gordon, M. (2006). The 4 - 7 July 2006 storms in the Wellington region: hydrology and meteorology. (No. WGN_DOCS-\#352907-V1). Wellington: Greater Wellington Regional Council.

Weaver, W. (1948). Science and complexity. American scientist, 36(4), 536-544.

Webb, T. (2008). Soil data overlying Southern Wairarapa aquifers. Unpublished technical notes prepared for Greater Wellington Regional Council.

Weissmann, G. S., Zhang, Y., LaBolle, E. M., and Fogg, G. E. (2002). Dispersion of groundwater age in an alluvial aquifer system. Water Resources Research, 38(10), 1198.

White, P.A. (2001). Groundwater resources in New Zealand. In: Rosen, M.R.,White, P.A. (eds.) Groundwaters of New Zealand. Wellington: New Zealand Hydrological Society, 47-75.

Zuber, A. (1986). Mathematical models for the interpretation of environmental radioisotopes in groundwater systems. Handbook of environmental isotope geochemistry, 2, 1-59.

Zuber, A., and Małoszewski, P. (2001). Lumped-parameter models. Environmental Isotopes in the Hydrological Cycle. Vol. 6. Modelling.UNESCO/IAEA, Tech. Doc. Hydrol, 39, 5-35.

Zuber, A., Różański, K., Kania, J., and Purtschert, R. (2011). On some methodological problems in the use of environmental tracers to estimate hydrogeologic parameters and to calibrate flow and transport models. Hydrogeology Journal, 19(1), 53-69. 
Zuber, A., Witczak, S., Różański, K., Śliwka, I., Opoka, M., Mochalski, P. and Duliński, M. (2005). Groundwater dating with $3 \mathrm{H}$ and SF6 in relation to mixing patterns, transport modelling and hydrochemistry. Hydrological processes,19(11), 22472275. 


\section{Appendix A}

\section{Middle Valley zonation}

\section{Model boundary conditions and domain}

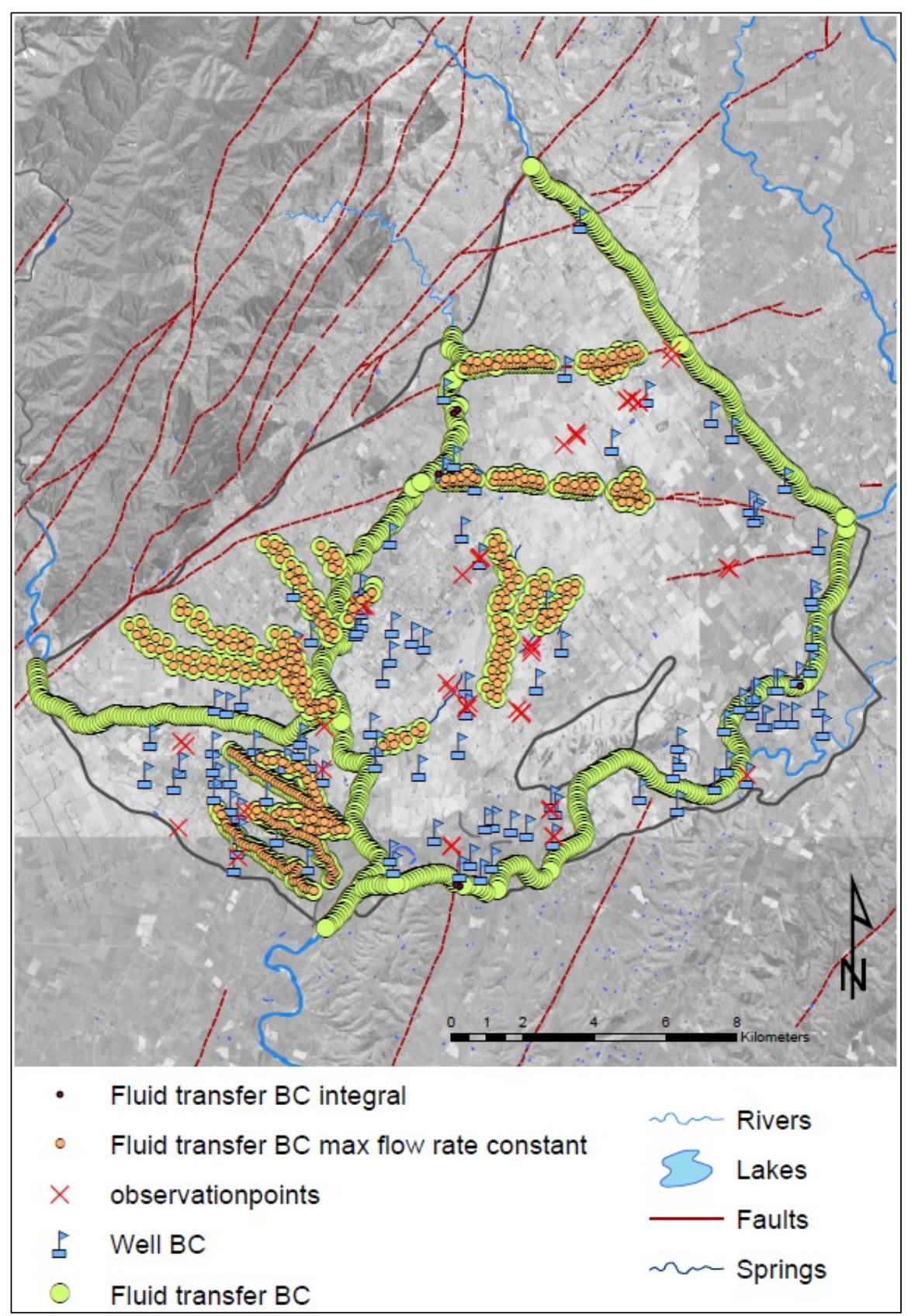

Figure A-1 Model boundary conditions and domain. 
Model zonation north to south

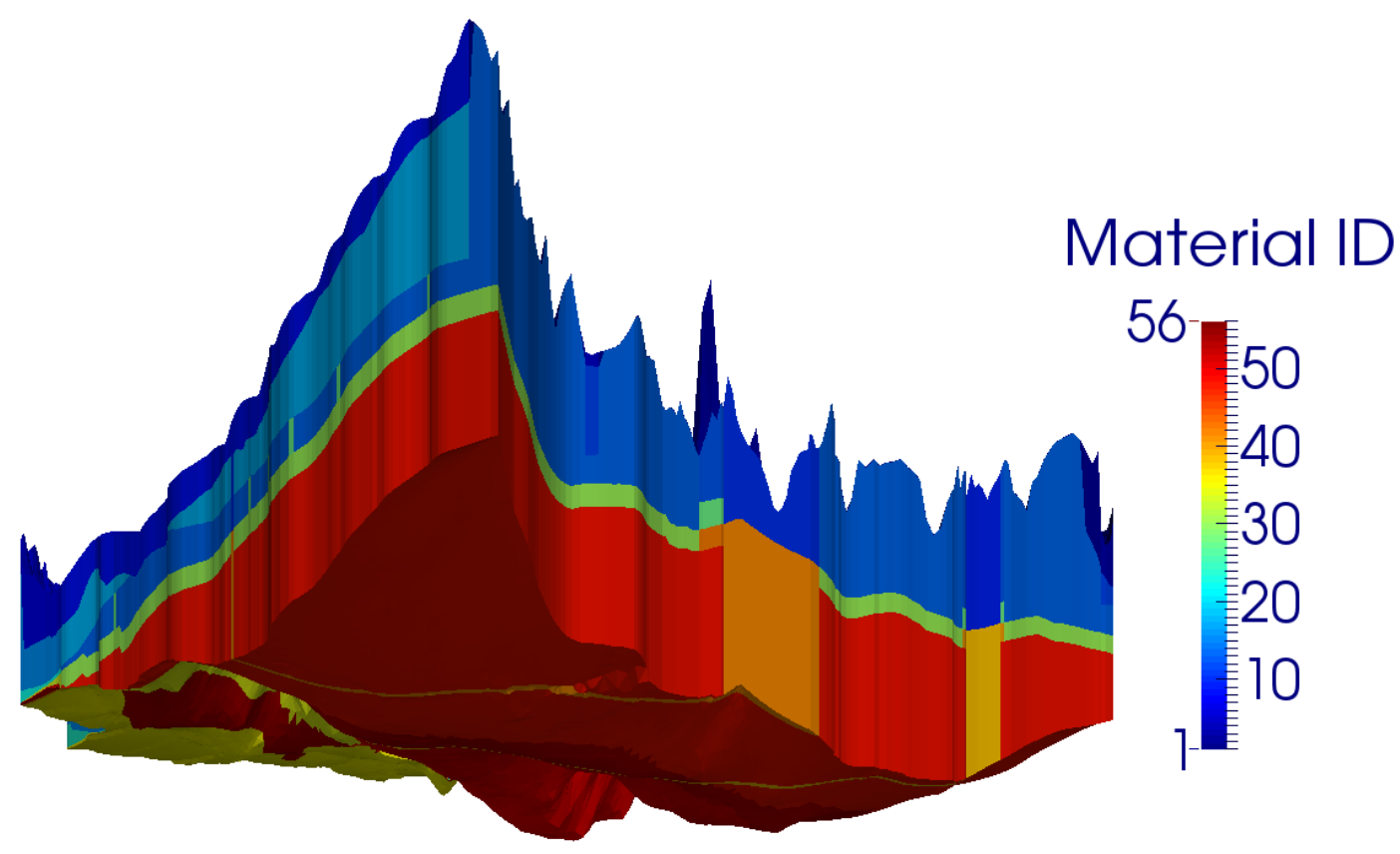

Figure A-2 Zonation of the Middle Valley model domain looking north to south.

\section{Zonation east to west}

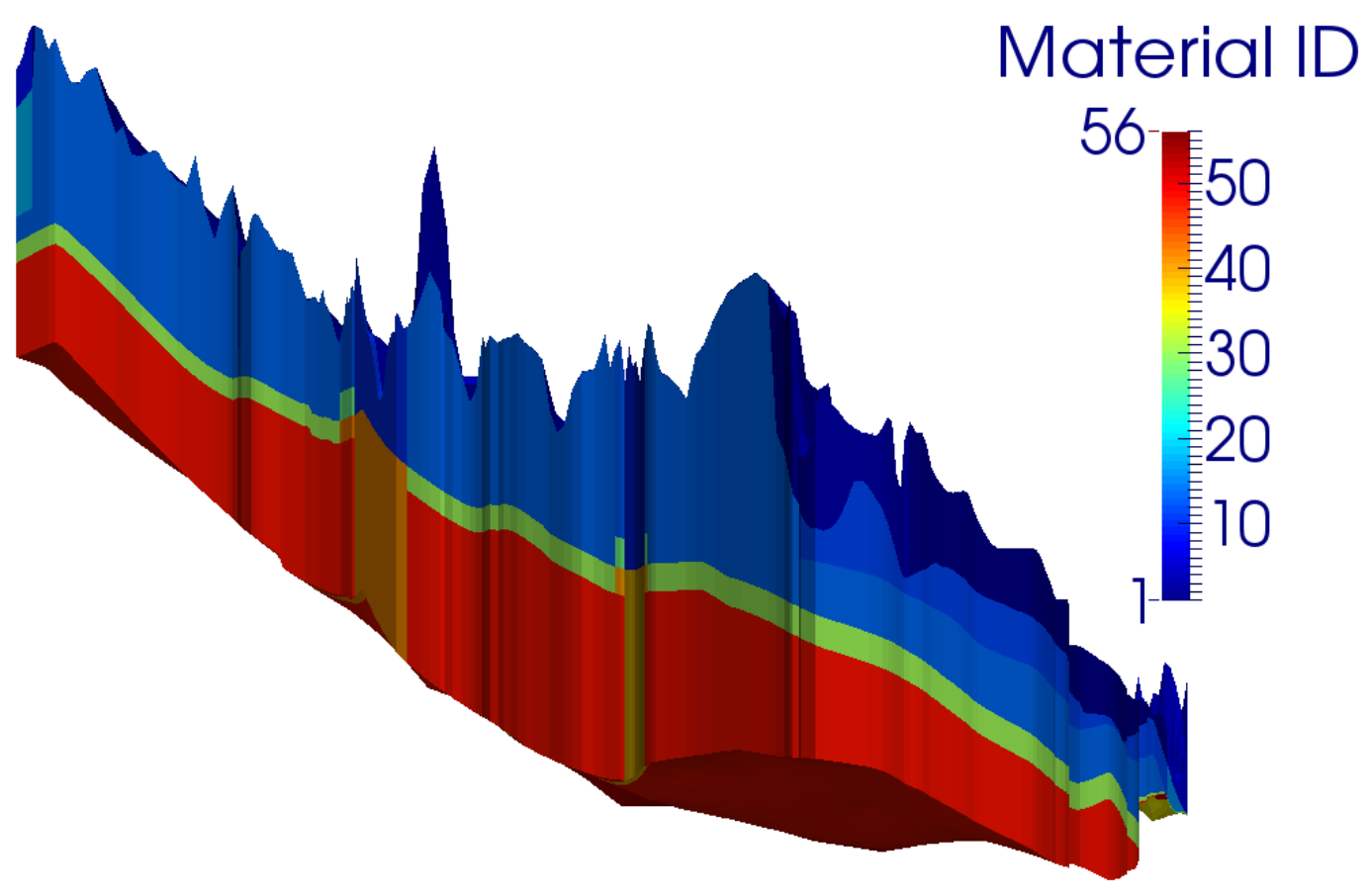

Figure A-3 Zonation of the Middle Valley model looking from the southern perspective. 
Model zonation east to west

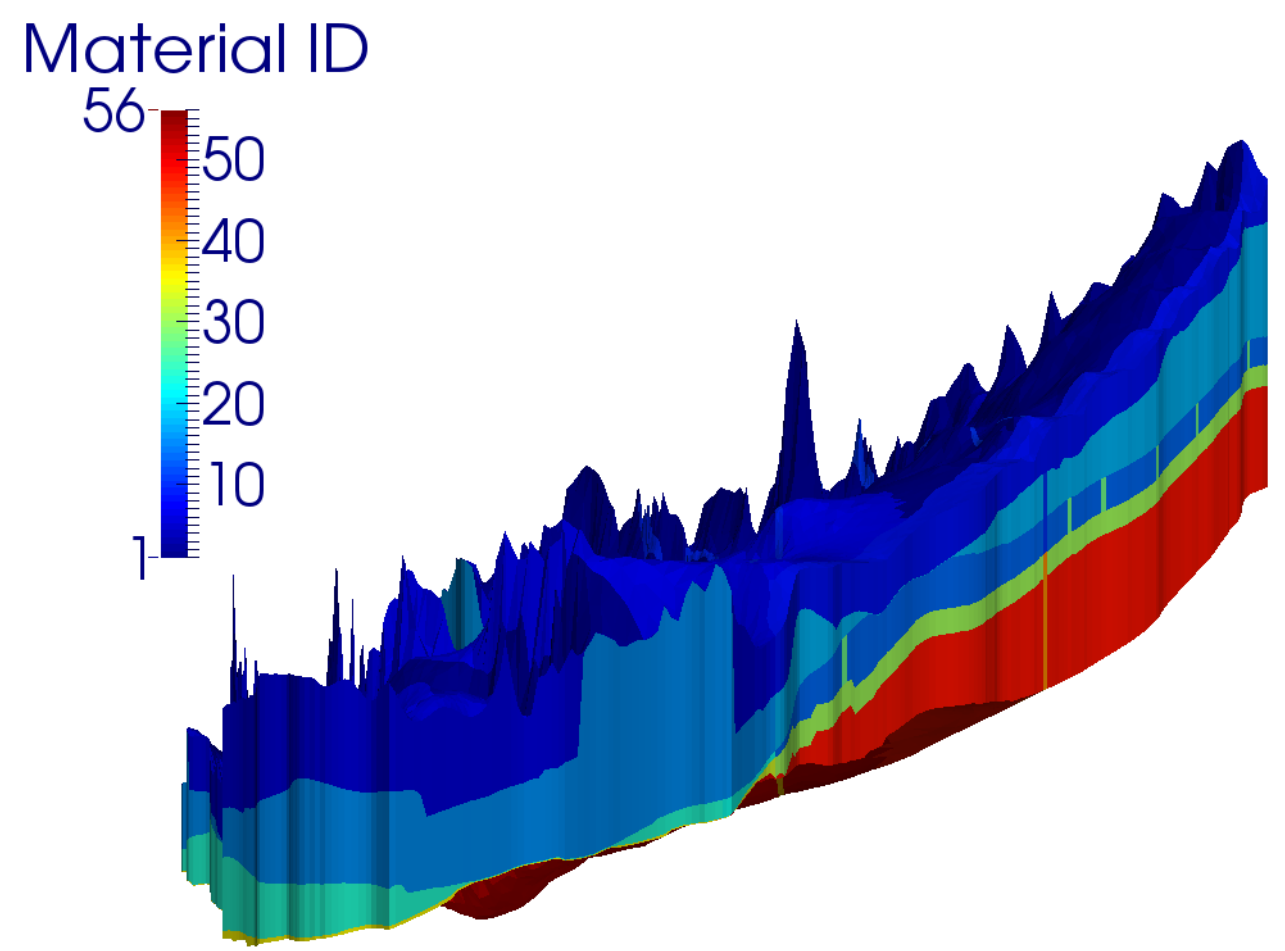

Figure A-4 Zonation of the Middle Valley model from east to west from the northern perspective.

Model zonation south to north

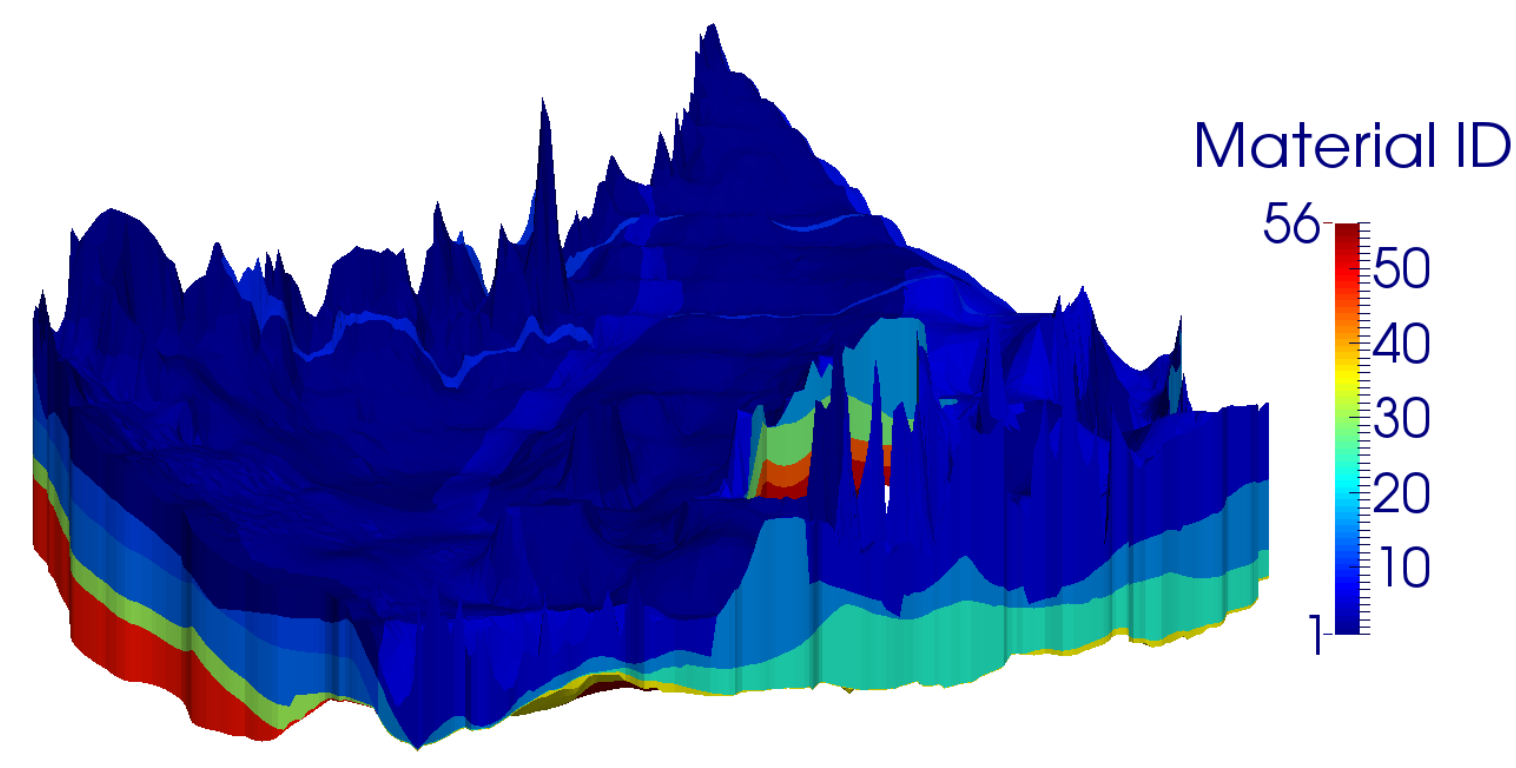

Figure A-5 Zonation of the Middle Valley model looking south to north. 
Model zonation lower layer

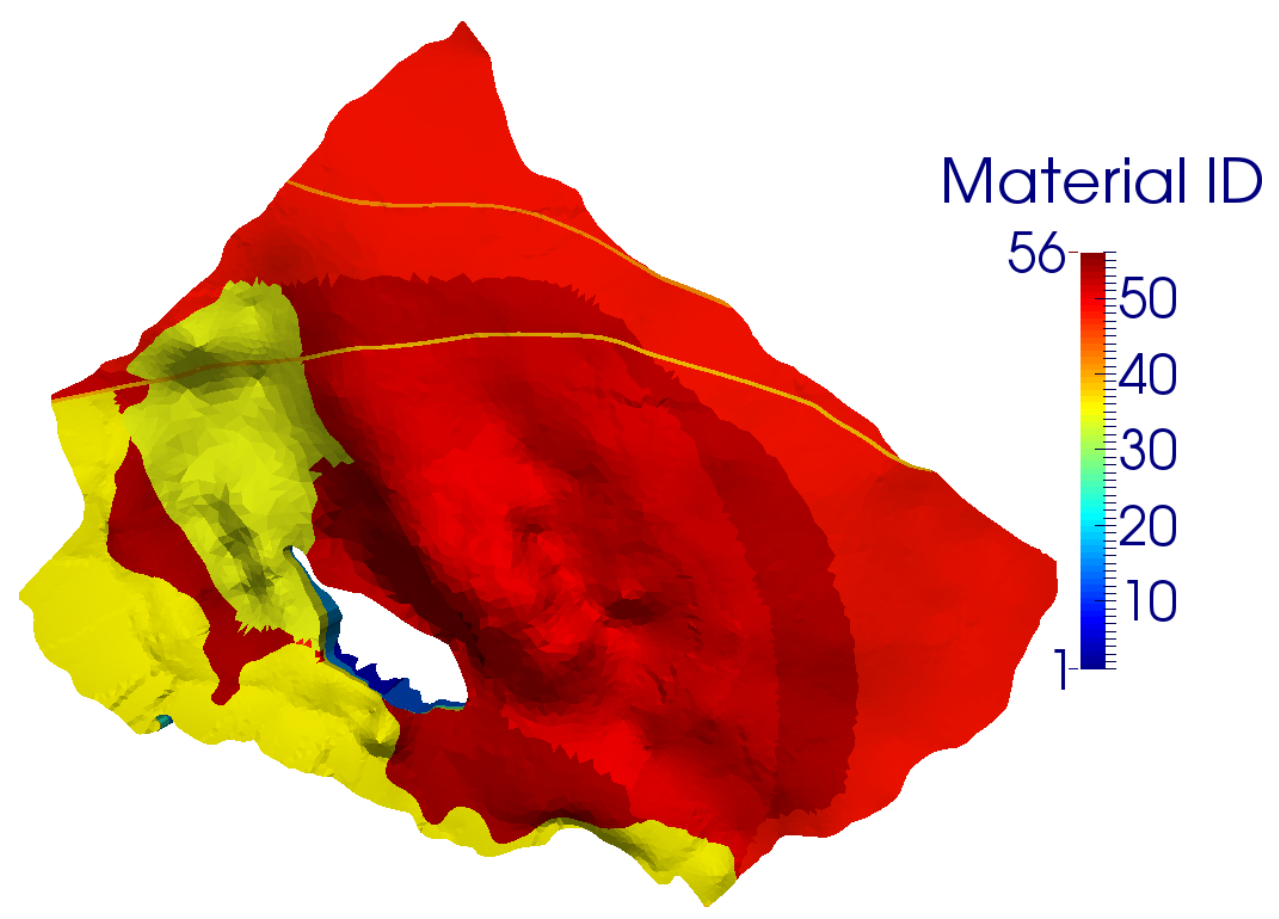

Figure A-6 Bottom layer of the model.

Model zonation upper layer

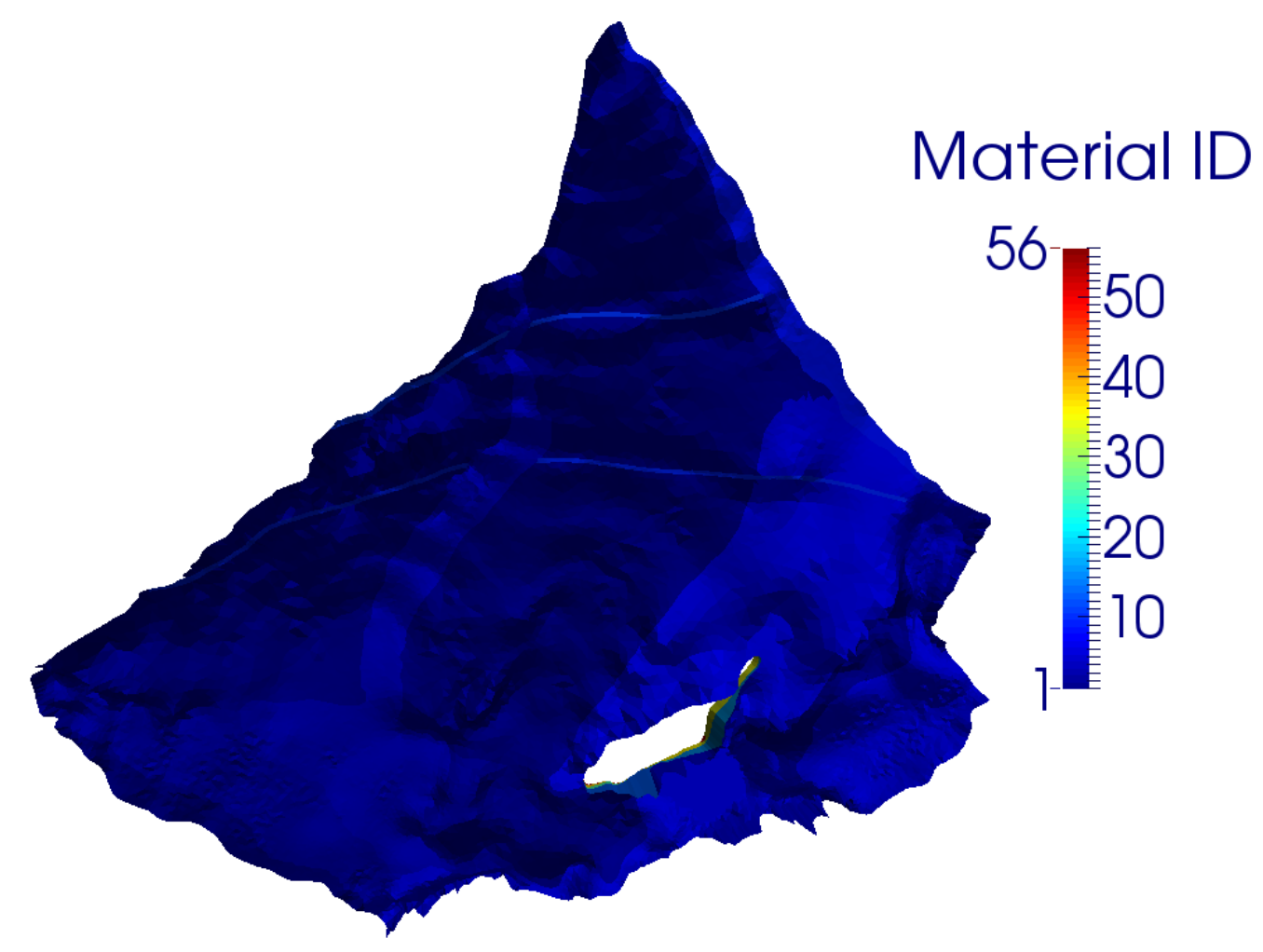

Figure A-7 Top layer of the model. 


\section{Appendix B}

\section{Middle Valley model parameters and fluid budget}

There are nine detailed flow parameters. MatID is the material class identifier, ne is the drainage porosity, $\mathrm{K} 11, \mathrm{~K} 22, \mathrm{~K} 33$ are the conductivities in their three principal directions and Ss is the storage coefficient $(\mathrm{K} 12, \mathrm{~K} 13, \mathrm{~K} 23$ are unused and represent conductivities by means of the three Euler angles, phi, theta and psi, see Cornaton, 2007). There are nine detailed transport parameters. MatID is the material class identifier, poro is porosity, aL, aTh, aTv and Dm are the coefficients of longitudinal dispersivity, transverse horizontal dispersivity, transverse vertical dispersivity, and molecular diffusion, respectively, and where Lambda is the decay constant, and K1 is the equilibrium distribution coefficient for the adsorption isotherm of Henry, or the first adsorption parameter for the Freundlich or Langmuir isotherms, K2 being the second adsorption parameter for these two nonlinear isotherms (Cornaton, 2007).

Final flow and transport parameter values

Tab. B-1 Final flow parameter values.

\begin{tabular}{cccccc}
\hline \multicolumn{6}{c}{ FLOW PARAMETERS } \\
\hline Mat ID & ne & Kx & Ky & Kz & Ss \\
\hline 1 & 0.27 & $2.69 \mathrm{E}-03$ & $2.69 \mathrm{E}-03$ & $2.65 \mathrm{E}-05$ & $9.04 \mathrm{E}-05$ \\
2 & 0.40 & $8.65 \mathrm{E}-04$ & $8.65 \mathrm{E}-04$ & $3.68 \mathrm{E}-06$ & $8.37 \mathrm{E}-05$ \\
\hline 3 & 0.32 & $3.49 \mathrm{E}-03$ & $3.49 \mathrm{E}-03$ & $2.70 \mathrm{E}-05$ & $4.93 \mathrm{E}-05$ \\
4 & 0.10 & $1.47 \mathrm{E}-03$ & $1.47 \mathrm{E}-03$ & $2.68 \mathrm{E}-05$ & $9.15 \mathrm{E}-05$ \\
\hline 5 & 0.40 & $2.38 \mathrm{E}-03$ & $2.38 \mathrm{E}-03$ & $2.42 \mathrm{E}-05$ & $8.29 \mathrm{E}-05$ \\
6 & 0.36 & $4.73 \mathrm{E}-03$ & $4.73 \mathrm{E}-03$ & $1.95 \mathrm{E}-05$ & $1.21 \mathrm{E}-04$ \\
\hline 7 & 0.03 & $5.60 \mathrm{E}-04$ & $5.60 \mathrm{E}-04$ & $2.73 \mathrm{E}-06$ & $1.86 \mathrm{E}-05$ \\
8 & 0.26 & $3.40 \mathrm{E}-03$ & $3.40 \mathrm{E}-03$ & $2.70 \mathrm{E}-05$ & $4.57 \mathrm{E}-05$ \\
\hline 9 & 0.40 & $3.29 \mathrm{E}-03$ & $3.29 \mathrm{E}-03$ & $1.41 \mathrm{E}-05$ & $1.34 \mathrm{E}-05$ \\
10 & 0.40 & $4.73 \mathrm{E}-03$ & $4.73 \mathrm{E}-03$ & $2.70 \mathrm{E}-05$ & $1.25 \mathrm{E}-05$ \\
\hline 11 & 0.25 & $3.15 \mathrm{E}-03$ & $3.15 \mathrm{E}-03$ & $1.77 \mathrm{E}-05$ & $9.71 \mathrm{E}-05$ \\
\hline
\end{tabular}




\begin{tabular}{|c|c|c|c|c|c|}
\hline Mat ID & ne & Kx & Ky & Kz & Ss \\
\hline 12 & 0.38 & 2.12E-04 & $2.12 \mathrm{E}-04$ & $1.58 \mathrm{E}-06$ & $3.00 \mathrm{E}-05$ \\
\hline 13 & 0.27 & $3.54 \mathrm{E}-03$ & $3.54 \mathrm{E}-03$ & 2.70E-05 & $1.32 \mathrm{E}-04$ \\
\hline 14 & 0.13 & $3.83 \mathrm{E}-03$ & $3.83 \mathrm{E}-03$ & 1.60E-06 & 4.55E-05 \\
\hline 15 & 0.40 & $4.73 \mathrm{E}-03$ & 4.73E-03 & $2.18 \mathrm{E}-05$ & $3.32 \mathrm{E}-05$ \\
\hline 16 & 0.14 & $1.45 \mathrm{E}-03$ & $1.45 \mathrm{E}-03$ & 2.44E-05 & 7.97E-05 \\
\hline 17 & 0.40 & 2.99E-03 & 2.99E-03 & 1.97E-05 & 5.25E-05 \\
\hline 18 & 0.33 & $1.04 \mathrm{E}-03$ & $1.04 \mathrm{E}-03$ & 2.37E-05 & $4.12 \mathrm{E}-05$ \\
\hline 19 & 0.33 & $1.24 \mathrm{E}-03$ & $1.24 \mathrm{E}-03$ & 1.70E-05 & $1.32 \mathrm{E}-04$ \\
\hline 20 & 0.40 & $1.16 \mathrm{E}-03$ & 1.16E-03 & $2.48 \mathrm{E}-05$ & $1.03 \mathrm{E}-04$ \\
\hline 21 & 0.40 & $1.58 \mathrm{E}-03$ & $1.58 \mathrm{E}-03$ & 2.70E-05 & $1.32 \mathrm{E}-04$ \\
\hline 22 & 0.23 & $1.75 \mathrm{E}-03$ & $1.75 \mathrm{E}-03$ & $1.82 \mathrm{E}-05$ & $9.81 \mathrm{E}-05$ \\
\hline 23 & 0.40 & 1.81E-03 & $1.81 \mathrm{E}-03$ & 2.37E-05 & $9.24 \mathrm{E}-05$ \\
\hline 24 & 0.40 & $3.42 \mathrm{E}-03$ & $3.42 \mathrm{E}-03$ & 2.51E-05 & 1.27E-04 \\
\hline 25 & 0.40 & $3.16 \mathrm{E}-03$ & 3.16E-03 & $2.23 \mathrm{E}-05$ & 8.67E-05 \\
\hline 26 & 0.36 & $1.15 \mathrm{E}-03$ & $1.15 \mathrm{E}-03$ & 2.61E-05 & 1.17E-04 \\
\hline 27 & 0.10 & $1.56 \mathrm{E}-03$ & $1.56 \mathrm{E}-03$ & 2.61E-05 & $1.34 \mathrm{E}-05$ \\
\hline 28 & 0.07 & $9.50 \mathrm{E}-04$ & $9.50 \mathrm{E}-04$ & 7.50E-07 & $9.14 \mathrm{E}-05$ \\
\hline 29 & 0.40 & 3.12E-03 & $3.12 \mathrm{E}-03$ & 9.37E-06 & $3.08 \mathrm{E}-05$ \\
\hline 30 & 0.40 & 3.91E-03 & $3.91 \mathrm{E}-03$ & 2.60E-05 & 3.57E-05 \\
\hline 31 & 0.14 & 4.16E-04 & 4.16E-04 & 3.30E-06 & $1.32 \mathrm{E}-04$ \\
\hline 32 & 0.06 & 4.73E-03 & 4.73E-03 & 3.34E-08 & $1.22 \mathrm{E}-04$ \\
\hline 33 & 0.20 & $1.96 \mathrm{E}-03$ & $1.96 \mathrm{E}-03$ & 2.07E-06 & $1.28 \mathrm{E}-04$ \\
\hline 34 & 0.40 & $3.81 \mathrm{E}-03$ & 3.81E-03 & 1.51E-05 & $4.26 \mathrm{E}-05$ \\
\hline 35 & 0.21 & 4.73E-03 & 4.73E-03 & $2.55 \mathrm{E}-05$ & 5.31E-05 \\
\hline 36 & 0.40 & 8.79E-04 & 8.79E-04 & 2.39E-05 & 4.73E-05 \\
\hline 37 & 0.19 & $3.85 \mathrm{E}-03$ & $3.85 \mathrm{E}-03$ & 8.91E-06 & 3.90E-05 \\
\hline 38 & 0.40 & 3.33E-03 & 3.33E-03 & 1.97E-05 & $3.60 \mathrm{E}-05$ \\
\hline 39 & 0.33 & $9.70 \mathrm{E}-04$ & $9.70 \mathrm{E}-04$ & $1.73 \mathrm{E}-05$ & $6.28 \mathrm{E}-05$ \\
\hline 40 & 0.40 & 3.64E-03 & $3.64 \mathrm{E}-03$ & 1.93E-05 & $2.30 \mathrm{E}-05$ \\
\hline 41 & 0.40 & $1.03 \mathrm{E}-03$ & $1.03 \mathrm{E}-03$ & 7.30E-06 & 7.09E-05 \\
\hline 42 & 0.22 & $3.08 \mathrm{E}-03$ & $3.08 \mathrm{E}-03$ & $2.58 \mathrm{E}-05$ & $3.63 \mathrm{E}-05$ \\
\hline 43 & 0.40 & 2.37E-03 & 2.37E-03 & 1.30E-05 & $5.06 \mathrm{E}-05$ \\
\hline 44 & 0.37 & $5.21 \mathrm{E}-05$ & 5.21E-05 & 6.60E-06 & 8.59E-05 \\
\hline 45 & 0.11 & $2.52 \mathrm{E}-03$ & $2.52 \mathrm{E}-03$ & $1.21 \mathrm{E}-05$ & 4.90E-05 \\
\hline
\end{tabular}




\begin{tabular}{cccccc}
\hline Mat ID & ne & Kx & Ky & Kz & Ss \\
\hline 46 & 0.06 & $2.22 \mathrm{E}-03$ & $2.22 \mathrm{E}-03$ & $1.26 \mathrm{E}-05$ & $6.16 \mathrm{E}-05$ \\
47 & 0.25 & $2.33 \mathrm{E}-03$ & $2.33 \mathrm{E}-03$ & $1.45 \mathrm{E}-05$ & $9.19 \mathrm{E}-05$ \\
48 & 0.33 & $8.01 \mathrm{E}-04$ & $8.01 \mathrm{E}-04$ & $7.99 \mathrm{E}-06$ & $1.49 \mathrm{E}-05$ \\
\hline 49 & 0.40 & $1.79 \mathrm{E}-03$ & $1.79 \mathrm{E}-03$ & $1.57 \mathrm{E}-05$ & $1.32 \mathrm{E}-04$ \\
\hline 50 & 0.21 & $5.91 \mathrm{E}-04$ & $5.91 \mathrm{E}-04$ & $9.57 \mathrm{E}-06$ & $1.32 \mathrm{E}-04$ \\
\hline 51 & 0.40 & $4.68 \mathrm{E}-03$ & $4.68 \mathrm{E}-03$ & $6.93 \mathrm{E}-06$ & $7.39 \mathrm{E}-05$ \\
\hline 52 & 0.20 & $2.72 \mathrm{E}-03$ & $2.72 \mathrm{E}-03$ & $1.53 \mathrm{E}-05$ & $1.08 \mathrm{E}-04$ \\
\hline 53 & 0.40 & $3.59 \mathrm{E}-03$ & $3.59 \mathrm{E}-03$ & $3.19 \mathrm{E}-06$ & $8.65 \mathrm{E}-05$ \\
\hline 54 & 0.40 & $2.74 \mathrm{E}-03$ & $2.74 \mathrm{E}-03$ & $5.26 \mathrm{E}-06$ & $9.83 \mathrm{E}-05$ \\
\hline 55 & 0.32 & $4.73 \mathrm{E}-03$ & $4.73 \mathrm{E}-03$ & $1.31 \mathrm{E}-06$ & $4.99 \mathrm{E}-05$ \\
\hline 56 (rsl) & 0.00 & 0.00 & 0.00 & 0.00 & 0.00 \\
\hline & & & & & \\
\hline Maximum & 0.40 & $4.73 \mathrm{E}-03$ & $4.73 \mathrm{E}-03$ & $2.70 \mathrm{E}-05$ & $1.32 \mathrm{E}-04$ \\
\hline Minimum & 0.03 & $5.21 \mathrm{E}-05$ & $5.21 \mathrm{E}-05$ & $3.34 \mathrm{E}-08$ & $1.25 \mathrm{E}-05$ \\
\hline Mean & 0.30 & - & - & - & - \\
\hline Geomean & - & $1.95 \mathrm{E}-03$ & $1.95 \mathrm{E}-03$ & $1.09 \mathrm{E}-05$ & $6.11 \mathrm{E}-05$ \\
\hline
\end{tabular}

Tab. B-2 Final transport parameter values.

\begin{tabular}{cccccc}
\hline \multicolumn{7}{c}{ TRANSPORT PARAMETERS } \\
\hline MatID & ne & aL & aTh & aTv & decay (Tritium) \\
1 & 0.27 & 1 & 0.1 & 0.05 & $1.78 \mathrm{E}-09$ \\
$\ldots$ & (see flow parameters) & (aL -decay uniformly applied to all & $(1-55)$ MatIDs) \\
56 & 0.00 & 0 & 0 & 0 & 0 \\
\hline
\end{tabular}

FEFLOW - Ground Water (GW) original conversion with 102 material zones (including recharge spreading layer)

Tab. B-3 Ground Water (GW) original converted flow parameters, with 102 material zones.

\begin{tabular}{|c|c|c|c|c|c|c|c|c|}
\hline \multicolumn{9}{|c|}{ MV 102} \\
\hline FLOW P & RAMETERS & $(K x x)$ & & (Кyу) & & & (Kzz) & \\
\hline MatID & ne & K11 & K12 & K22 & K13 & K23 & K33 & Ss \\
\hline 1 & $1.00 \mathrm{E}-01$ & $5.32 \mathrm{E}-04$ & 0 & 5.32E-04 & 0 & 0 & 2.70E-05 & $1.32 \mathrm{E}-04$ \\
\hline 2 & 5.00E-02 & 4.00E-04 & 0 & 4.00E-04 & 0 & 0 & 5.79E-06 & $1.32 \mathrm{E}-04$ \\
\hline
\end{tabular}




\begin{tabular}{|c|c|c|c|c|c|c|c|c|}
\hline MatID & ne & K11 & K12 & $K 22$ & K13 & K23 & K33 & Ss \\
\hline 3 & $1.00 \mathrm{E}-01$ & 3.71E-03 & 0 & 3.71E-03 & 0 & 0 & 2.70E-05 & $1.32 \mathrm{E}-04$ \\
\hline 4 & 1.00E-01 & 4.73E-03 & 0 & 4.73E-03 & 0 & 0 & $2.70 \mathrm{E}-05$ & $1.32 \mathrm{E}-04$ \\
\hline 5 & $2.28 \mathrm{E}-02$ & 4.00E-04 & 0 & 4.00E-04 & 0 & 0 & 5.79E-06 & $1.32 \mathrm{E}-04$ \\
\hline 6 & 1.00E-01 & $3.38 \mathrm{E}-03$ & 0 & 3.38E-03 & 0 & 0 & 2.70E-05 & 1.32E-04 \\
\hline 7 & $1.00 \mathrm{E}-01$ & 3.80E-03 & 0 & 3.80E-03 & 0 & 0 & 2.70E-05 & $1.32 \mathrm{E}-04$ \\
\hline 8 & $2.28 \mathrm{E}-02$ & $2.31 \mathrm{E}-04$ & 0 & 2.31E-04 & 0 & 0 & 5.79E-06 & $1.32 \mathrm{E}-04$ \\
\hline 9 & $1.00 \mathrm{E}-01$ & 3.13E-03 & 0 & 3.13E-03 & 0 & 0 & 2.70E-05 & $1.32 \mathrm{E}-04$ \\
\hline 10 & 5.00E-02 & 4.73E-03 & 0 & 4.73E-03 & 0 & 0 & 2.70E-05 & $1.32 \mathrm{E}-04$ \\
\hline 11 & $2.28 \mathrm{E}-02$ & 2.07E-05 & 0 & 2.07E-05 & 0 & 0 & 1.16E-06 & $1.32 \mathrm{E}-04$ \\
\hline 12 & $2.28 \mathrm{E}-02$ & 3.90E-06 & 0 & 3.90E-06 & 0 & 0 & 5.79E-06 & 1.32E-04 \\
\hline 13 & 5.00E-02 & 2.07E-05 & 0 & 2.07E-05 & 0 & 0 & 1.16E-06 & 1.32E-04 \\
\hline 14 & 5.00E-02 & 3.38E-03 & 0 & 3.38E-03 & 0 & 0 & 2.70E-05 & $1.32 \mathrm{E}-04$ \\
\hline 15 & $1.00 \mathrm{E}-01$ & 2.07E-05 & 0 & 2.07E-05 & 0 & 0 & 1.16E-06 & $1.32 \mathrm{E}-04$ \\
\hline 16 & 5.00E-02 & 2.31E-04 & 0 & 2.31E-04 & 0 & 0 & 5.79E-06 & $1.32 \mathrm{E}-04$ \\
\hline 17 & $1.00 \mathrm{E}-01$ & 1.16E-04 & 0 & 1.16E-04 & 0 & 0 & 9.11E-06 & 1.32E-04 \\
\hline 18 & 5.00E-02 & $6.94 \mathrm{E}-04$ & 0 & 6.94E-04 & 0 & 0 & 2.66E-06 & $1.32 \mathrm{E}-04$ \\
\hline 19 & $2.28 \mathrm{E}-02$ & 1.16E-04 & 0 & 1.16E-04 & 0 & 0 & 2.66E-06 & $1.32 \mathrm{E}-04$ \\
\hline 20 & $1.00 \mathrm{E}-01$ & $6.94 \mathrm{E}-04$ & 0 & 6.94E-04 & 0 & 0 & $9.11 \mathrm{E}-06$ & $1.32 \mathrm{E}-04$ \\
\hline 21 & $1.00 \mathrm{E}-01$ & 3.80E-03 & 0 & 3.80E-03 & 0 & 0 & 9.11E-06 & $1.32 \mathrm{E}-04$ \\
\hline 22 & $2.28 \mathrm{E}-02$ & 2.31E-04 & 0 & 2.31E-04 & 0 & 0 & 9.36E-07 & 1.32E-04 \\
\hline 23 & 1.00E-01 & 3.13E-03 & 0 & 3.13E-03 & 0 & 0 & 9.11E-06 & $1.32 \mathrm{E}-04$ \\
\hline 24 & $2.28 \mathrm{E}-02$ & 6.94E-04 & 0 & 6.94E-04 & 0 & 0 & 2.66E-06 & $1.32 \mathrm{E}-04$ \\
\hline 25 & 5.00E-02 & 1.16E-04 & 0 & 1.16E-04 & 0 & 0 & 9.11E-06 & $1.32 \mathrm{E}-04$ \\
\hline 26 & 1.00E-01 & 3.90E-06 & 0 & 3.90E-06 & 0 & 0 & 5.79E-06 & 1.32E-04 \\
\hline 27 & $1.00 \mathrm{E}-01$ & 3.90E-06 & 0 & 3.90E-06 & 0 & 0 & $9.11 \mathrm{E}-06$ & $1.32 \mathrm{E}-04$ \\
\hline 28 & $5.00 \mathrm{E}-02$ & $2.31 \mathrm{E}-04$ & 0 & 2.31E-04 & 0 & 0 & 9.36E-07 & $1.32 \mathrm{E}-04$ \\
\hline 29 & 5.00E-02 & 6.94E-04 & 0 & 6.94E-04 & 0 & 0 & 9.11E-06 & $1.32 \mathrm{E}-04$ \\
\hline 30 & 1.00E-01 & 1.16E-04 & 0 & 1.16E-04 & 0 & 0 & 2.66E-06 & $1.32 \mathrm{E}-04$ \\
\hline 31 & 5.00E-02 & 3.85E-08 & 0 & 3.85E-08 & 0 & 0 & $1.01 \mathrm{E}-08$ & $1.32 \mathrm{E}-04$ \\
\hline 32 & 1.00E-01 & 3.85E-08 & 0 & 3.85E-08 & 0 & 0 & 5.79E-08 & 1.32E-04 \\
\hline 33 & $1.00 \mathrm{E}-01$ & 3.85E-08 & 0 & 3.85E-08 & 0 & 0 & 1.01E-08 & $1.32 \mathrm{E}-04$ \\
\hline 34 & 1.00E-01 & 1.16E-05 & 0 & 1.16E-05 & 0 & 0 & $1.01 \mathrm{E}-08$ & $1.32 \mathrm{E}-04$ \\
\hline 35 & $1.00 \mathrm{E}-01$ & 3.80E-03 & 0 & 3.80E-03 & 0 & 0 & 2.66E-06 & $1.32 \mathrm{E}-04$ \\
\hline 36 & $1.00 \mathrm{E}-01$ & 3.80E-03 & 0 & 3.80E-03 & 0 & 0 & 1.16E-06 & 1.32E-04 \\
\hline 37 & $1.00 \mathrm{E}-01$ & 1.16E-05 & 0 & 1.16E-05 & 0 & 0 & $1.28 \mathrm{E}-08$ & $1.32 \mathrm{E}-04$ \\
\hline 38 & $5.00 \mathrm{E}-02$ & $1.16 \mathrm{E}-05$ & 0 & 1.16E-05 & 0 & 0 & $1.01 \mathrm{E}-08$ & $1.32 \mathrm{E}-04$ \\
\hline 39 & 5.00E-02 & 1.16E-04 & 0 & 1.16E-04 & 0 & 0 & 2.66E-06 & $1.32 \mathrm{E}-04$ \\
\hline 40 & 5.00E-02 & 3.85E-08 & 0 & $3.85 \mathrm{E}-08$ & 0 & 0 & 1.16E-06 & 1.32E-04 \\
\hline 41 & 5.00E-02 & 1.16E-05 & 0 & 1.16E-05 & 0 & 0 & 5.79E-08 & $1.32 \mathrm{E}-04$ \\
\hline 42 & $2.28 \mathrm{E}-02$ & 1.16E-05 & 0 & 1.16E-05 & 0 & 0 & 5.79E-08 & $1.32 \mathrm{E}-04$ \\
\hline 43 & $1.00 \mathrm{E}-01$ & 1.16E-05 & 0 & 1.16E-05 & 0 & 0 & 5.79E-08 & $1.32 \mathrm{E}-04$ \\
\hline 44 & $1.00 \mathrm{E}-01$ & 3.85E-08 & 0 & $3.85 \mathrm{E}-08$ & 0 & 0 & 1.16E-06 & $1.32 \mathrm{E}-04$ \\
\hline 45 & $2.28 \mathrm{E}-02$ & 1.16E-05 & 0 & 1.16E-05 & 0 & 0 & $1.28 \mathrm{E}-08$ & $1.32 \mathrm{E}-04$ \\
\hline 46 & $2.28 \mathrm{E}-02$ & $3.85 E-08$ & 0 & 3.85E-08 & 0 & 0 & 5.79E-08 & 1.32E-04 \\
\hline 47 & $5.00 \mathrm{E}-02$ & $3.85 E-08$ & 0 & $3.85 \mathrm{E}-08$ & 0 & 0 & 5.79E-08 & $1.32 \mathrm{E}-04$ \\
\hline
\end{tabular}




\begin{tabular}{|c|c|c|c|c|c|c|c|c|}
\hline MatID & ne & K11 & K12 & K22 & K13 & K23 & K33 & Ss \\
\hline 48 & $2.28 \mathrm{E}-02$ & 3.85E-08 & 0 & $3.85 E-08$ & 0 & 0 & $1.01 \mathrm{E}-08$ & $1.32 \mathrm{E}-04$ \\
\hline 49 & $5.00 \mathrm{E}-02$ & 3.85E-08 & 0 & $3.85 E-08$ & 0 & 0 & 2.66E-06 & $1.32 \mathrm{E}-04$ \\
\hline 50 & $5.00 \mathrm{E}-02$ & $1.16 \mathrm{E}-05$ & 0 & 1.16E-05 & 0 & 0 & $1.28 \mathrm{E}-08$ & $1.32 \mathrm{E}-04$ \\
\hline 51 & $2.28 \mathrm{E}-02$ & 3.85E-08 & 0 & $3.85 E-08$ & 0 & 0 & 1.29E-09 & 1.32E-04 \\
\hline 52 & $2.28 \mathrm{E}-02$ & 1.16E-04 & 0 & $1.16 \mathrm{E}-04$ & 0 & 0 & 1.16E-06 & $1.32 \mathrm{E}-04$ \\
\hline 53 & $1.00 \mathrm{E}-01$ & $3.85 \mathrm{E}-08$ & 0 & $3.85 \mathrm{E}-08$ & 0 & 0 & 2.66E-06 & $1.32 \mathrm{E}-04$ \\
\hline 54 & 1.00E-01 & 1.16E-04 & 0 & 1.16E-04 & 0 & 0 & 1.16E-07 & $2.29 \mathrm{E}-05$ \\
\hline 55 & $5.00 \mathrm{E}-02$ & $1.21 \mathrm{E}-03$ & 0 & $1.21 \mathrm{E}-03$ & 0 & 0 & 9.11E-06 & $7.24 \mathrm{E}-06$ \\
\hline 56 & $1.00 \mathrm{E}-01$ & $4.63 \mathrm{E}-04$ & 0 & $4.63 E-04$ & 0 & 0 & 4.68E-06 & 5.00E-05 \\
\hline 57 & $2.28 \mathrm{E}-02$ & $1.16 \mathrm{E}-04$ & 0 & 1.16E-04 & 0 & 0 & $1.16 \mathrm{E}-07$ & $2.29 \mathrm{E}-05$ \\
\hline 58 & $1.00 \mathrm{E}-01$ & $1.21 \mathrm{E}-03$ & 0 & $1.21 \mathrm{E}-03$ & 0 & 0 & 9.11E-06 & $7.24 \mathrm{E}-06$ \\
\hline 59 & $1.00 \mathrm{E}-01$ & $3.80 \mathrm{E}-03$ & 0 & 3.80E-03 & 0 & 0 & $1.16 \mathrm{E}-07$ & 2.29E-05 \\
\hline 60 & $2.28 \mathrm{E}-02$ & 2.31E-04 & 0 & 2.31E-04 & 0 & 0 & 9.36E-07 & 2.29E-05 \\
\hline 61 & $1.00 \mathrm{E}-01$ & 3.80E-03 & 0 & $3.80 \mathrm{E}-03$ & 0 & 0 & 1.16E-06 & 5.00E-05 \\
\hline 62 & $1.00 \mathrm{E}-01$ & 4.13E-04 & 0 & 4.13E-04 & 0 & 0 & $1.06 \mathrm{E}-05$ & 3.50E-05 \\
\hline 63 & $5.00 \mathrm{E}-02$ & $1.16 \mathrm{E}-04$ & 0 & 1.16E-04 & 0 & 0 & 1.16E-07 & $2.29 \mathrm{E}-05$ \\
\hline 64 & 5.00E-02 & 4.63E-04 & 0 & 4.63E-04 & 0 & 0 & 1.16E-06 & 5.00E-05 \\
\hline 65 & $5.00 \mathrm{E}-02$ & $4.63 E-04$ & 0 & $4.63 E-04$ & 0 & 0 & 4.68E-06 & 5.00E-05 \\
\hline 66 & $2.28 \mathrm{E}-02$ & 4.63E-04 & 0 & 4.63E-04 & 0 & 0 & 4.68E-06 & 5.00E-05 \\
\hline 67 & $1.00 \mathrm{E}-01$ & 2.07E-05 & 0 & 2.07E-05 & 0 & 0 & 1.16E-06 & 2.29E-05 \\
\hline 68 & $1.00 \mathrm{E}-01$ & 4.63E-04 & 0 & & 0 & 0 & 1.16E-06 & \\
\hline 69 & $2.28 \mathrm{E}-02$ & 4.13E-04 & 0 & 4.13E-04 & 0 & 0 & $1.06 \mathrm{E}-05$ & 3.50E-05 \\
\hline 70 & $1.00 \mathrm{E}-01$ & 3.80E-03 & 0 & 3.80E-03 & 0 & 0 & 1.16E-06 & 2.29E-05 \\
\hline 71 & $2.28 \mathrm{E}-02$ & $1.21 \mathrm{E}-03$ & 0 & $1.21 \mathrm{E}-03$ & 0 & 0 & 9.11E-06 & $7.24 \mathrm{E}-06$ \\
\hline 72 & $5.00 \mathrm{E}-02$ & 4.13E-04 & 0 & 4.13E-04 & 0 & 0 & $1.06 \mathrm{E}-05$ & $2.29 \mathrm{E}-05$ \\
\hline 73 & $2.28 \mathrm{E}-02$ & 2.07E-05 & 0 & 2.07E-05 & 0 & 0 & $1.16 \mathrm{E}-06$ & 2.29E-05 \\
\hline 74 & $2.28 \mathrm{E}-02$ & 3.90E-06 & 0 & 3.90E-06 & 0 & 0 & 5.79E-06 & $2.29 \mathrm{E}-05$ \\
\hline 75 & $5.00 \mathrm{E}-02$ & 4.13E-04 & 0 & 4.13E-04 & 0 & 0 & 1.16E-07 & 2.29E-05 \\
\hline 76 & $5.00 \mathrm{E}-02$ & 2.07E-05 & 0 & 2.07E-05 & 0 & 0 & 1.16E-06 & 2.29E-05 \\
\hline 77 & & & 0 & & 0 & 0 & & 3.50E-05 \\
\hline 78 & $1.00 \mathrm{E}-01$ & $3.90 \mathrm{E}-06$ & 0 & $3.90 E-06$ & 0 & 0 & 5.79E-06 & 2.29E-05 \\
\hline 79 & $1.00 \mathrm{E}-01$ & $3.90 E-06$ & 0 & 3.90E-06 & 0 & 0 & 9.11E-06 & 2.29E-05 \\
\hline 80 & $2.28 \mathrm{E}-02$ & 4.95E-04 & 0 & 4.95E-04 & 0 & 0 & 5.05E-06 & 3.50E-05 \\
\hline 81 & $2.28 \mathrm{E}-02$ & $4.95 E-04$ & 0 & 4.95E-04 & 0 & 0 & 1.16E-06 & 2.29E-05 \\
\hline 82 & $5.00 \mathrm{E}-02$ & 4.95E-04 & 0 & 4.95E-04 & 0 & 0 & 5.05E-06 & 7.24E-06 \\
\hline 83 & $5.00 \mathrm{E}-02$ & $2.31 \mathrm{E}-04$ & 0 & 2.31E-04 & 0 & 0 & 9.36E-07 & 5.00E-05 \\
\hline 84 & $5.00 \mathrm{E}-02$ & 2.31E-04 & 0 & 2.31E-04 & 0 & 0 & $9.36 \mathrm{E}-07$ & 2.29E-05 \\
\hline 85 & $1.00 \mathrm{E}-01$ & 1.16E-04 & 0 & 1.16E-04 & 0 & 0 & 5.04E-07 & 2.29E-05 \\
\hline 86 & $5.00 \mathrm{E}-02$ & $2.31 \mathrm{E}-04$ & 0 & 2.31E-04 & 0 & 0 & 5.04E-07 & 7.24E-06 \\
\hline 87 & $1.00 \mathrm{E}-01$ & $1.16 \mathrm{E}-04$ & 0 & $1.16 \mathrm{E}-04$ & 0 & 0 & 5.04E-07 & 5.00E-05 \\
\hline 88 & $2.28 \mathrm{E}-02$ & $1.16 \mathrm{E}-04$ & 0 & 1.16E-04 & 0 & 0 & 5.04E-07 & 2.29E-05 \\
\hline 89 & $1.00 \mathrm{E}-01$ & 2.31E-04 & 0 & 2.31E-04 & 0 & 0 & 5.04E-07 & 7.24E-06 \\
\hline 90 & $1.00 \mathrm{E}-01$ & $3.80 \mathrm{E}-03$ & 0 & 3.80E-03 & 0 & 0 & 5.04E-07 & 2.29E-05 \\
\hline 91 & $1.00 \mathrm{E}-01$ & $1.16 \mathrm{E}-04$ & 0 & $1.16 \mathrm{E}-04$ & 0 & 0 & 5.04E-07 & 3.50E-05 \\
\hline 92 & $5.00 \mathrm{E}-02$ & $1.16 \mathrm{E}-04$ & 0 & 1.16E-04 & 0 & 0 & $5.04 \mathrm{E}-07$ & $2.29 \mathrm{E}-05$ \\
\hline
\end{tabular}




\begin{tabular}{ccccccccc}
\hline MatID & ne & K11 & K12 & K22 & K13 & K23 & K33 & Ss \\
93 & $5.00 \mathrm{E}-02$ & $1.16 \mathrm{E}-04$ & 0 & $1.16 \mathrm{E}-04$ & 0 & 0 & $1.16 \mathrm{E}-06$ & $5.00 \mathrm{E}-05$ \\
94 & $5.00 \mathrm{E}-02$ & $1.16 \mathrm{E}-04$ & 0 & $1.16 \mathrm{E}-04$ & 0 & 0 & $5.04 \mathrm{E}-07$ & $5.00 \mathrm{E}-05$ \\
95 & $2.28 \mathrm{E}-02$ & $1.16 \mathrm{E}-04$ & 0 & $1.16 \mathrm{E}-04$ & 0 & 0 & $5.04 \mathrm{E}-07$ & $5.00 \mathrm{E}-05$ \\
96 & $1.00 \mathrm{E}-01$ & $1.16 \mathrm{E}-04$ & 0 & $1.16 \mathrm{E}-04$ & 0 & 0 & $1.16 \mathrm{E}-06$ & $5.00 \mathrm{E}-05$ \\
97 & $2.28 \mathrm{E}-02$ & $1.16 \mathrm{E}-04$ & 0 & $1.16 \mathrm{E}-04$ & 0 & 0 & $5.04 \mathrm{E}-07$ & $3.50 \mathrm{E}-05$ \\
98 & $2.28 \mathrm{E}-02$ & $2.31 \mathrm{E}-04$ & 0 & $2.31 \mathrm{E}-04$ & 0 & 0 & $5.04 \mathrm{E}-07$ & $7.24 \mathrm{E}-06$ \\
99 & $5.00 \mathrm{E}-02$ & $1.16 \mathrm{E}-04$ & 0 & $1.16 \mathrm{E}-04$ & 0 & 0 & $5.04 \mathrm{E}-07$ & $3.50 \mathrm{E}-05$ \\
100 & $2.28 \mathrm{E}-02$ & $1.16 \mathrm{E}-04$ & 0 & $1.16 \mathrm{E}-04$ & 0 & 0 & $1.16 \mathrm{E}-06$ & $2.29 \mathrm{E}-05$ \\
101 & $5.00 \mathrm{E}-02$ & $1.16 \mathrm{E}-04$ & 0 & $1.16 \mathrm{E}-04$ & 0 & 0 & $5.04 \mathrm{E}-07$ & $7.24 \mathrm{E}-06$ \\
102 & 0 & 0 & 0 & 0 & 0 & 0 & 0 & 0 \\
\hline
\end{tabular}

Change in FEFLOW parameters relative to Tritium calibration assigned values

Tab. B-4 Flow parameter changes from original FEFLOW values.

\begin{tabular}{rcccc}
\hline Mat ID & change ne & change Kxy & change Kzz & change Ss \\
\hline 1 & $6.9000 \mathrm{E}-02$ & $2.1580 \mathrm{E}-03$ & $-5.0000 \mathrm{E}-07$ & $-4.1600 \mathrm{E}-05$ \\
2 & $2.0000 \mathrm{E}-01$ & $4.6500 \mathrm{E}-04$ & $-2.1100 \mathrm{E}-06$ & $-4.8300 \mathrm{E}-05$ \\
3 & $1.1500 \mathrm{E}-01$ & $-2.2000 \mathrm{E}-04$ & $0.0000 \mathrm{E}+00$ & $-8.2700 \mathrm{E}-05$ \\
4 & $-9.7000 \mathrm{E}-02$ & $-3.2600 \mathrm{E}-03$ & $-2.0000 \mathrm{E}-07$ & $-4.0500 \mathrm{E}-05$ \\
5 & $2.0000 \mathrm{E}-01$ & $-1.0000 \mathrm{E}-03$ & $-2.8000 \mathrm{E}-06$ & $-4.9100 \mathrm{E}-05$ \\
6 & $1.5900 \mathrm{E}-01$ & $9.3000 \mathrm{E}-04$ & $-7.5000 \mathrm{E}-06$ & $-1.1000 \mathrm{E}-05$ \\
7 & $-1.6550 \mathrm{E}-01$ & $3.2900 \mathrm{E}-04$ & $-3.0600 \mathrm{E}-06$ & $-1.1340 \mathrm{E}-04$ \\
8 & $6.0000 \mathrm{E}-02$ & $2.7000 \mathrm{E}-04$ & $0.0000 \mathrm{E}+00$ & $-8.6300 \mathrm{E}-05$ \\
9 & $2.0000 \mathrm{E}-01$ & $3.2693 \mathrm{E}-03$ & $1.2940 \mathrm{E}-05$ & $-1.1860 \mathrm{E}-04$ \\
10 & $2.0000 \mathrm{E}-01$ & $4.7261 \mathrm{E}-03$ & $2.1210 \mathrm{E}-05$ & $-1.1950 \mathrm{E}-04$ \\
11 & $5.3000 \mathrm{E}-02$ & $3.0340 \mathrm{E}-03$ & $8.5900 \mathrm{E}-06$ & $-3.4900 \mathrm{E}-05$ \\
12 & $1.7500 \mathrm{E}-01$ & $-4.8200 \mathrm{E}-04$ & $-1.0800 \mathrm{E}-06$ & $-1.0200 \mathrm{E}-04$ \\
13 & $6.6000 \mathrm{E}-02$ & $3.4240 \mathrm{E}-03$ & $2.4340 \mathrm{E}-05$ & $0.0000 \mathrm{E}+00$ \\
14 & $-6.6000 \mathrm{E}-02$ & $3.1360 \mathrm{E}-03$ & $-7.5100 \mathrm{E}-06$ & $-8.6500 \mathrm{E}-05$ \\
15 & $2.0000 \mathrm{E}-01$ & $9.3000 \mathrm{E}-04$ & $1.2690 \mathrm{E}-05$ & $-9.8800 \mathrm{E}-05$ \\
16 & $-6.0000 \mathrm{E}-02$ & $1.2190 \mathrm{E}-03$ & $2.3464 \mathrm{E}-05$ & $-5.2300 \mathrm{E}-05$ \\
17 & $2.0000 \mathrm{E}-01$ & $-1.4000 \mathrm{E}-04$ & $1.0590 \mathrm{E}-05$ & $-7.9500 \mathrm{E}-05$ \\
18 & $1.2500 \mathrm{E}-01$ & $1.0361 \mathrm{E}-03$ & $1.4590 \mathrm{E}-05$ & $-9.0800 \mathrm{E}-05$ \\
19 & $1.2900 \mathrm{E}-01$ & $1.2400 \mathrm{E}-03$ & $1.6990 \mathrm{E}-05$ & $0.0000 \mathrm{E}+00$ \\
\hline 20 & $2.0000 \mathrm{E}-01$ & $1.1600 \mathrm{E}-03$ & $2.4742 \mathrm{E}-05$ & $-2.9000 \mathrm{E}-05$ \\
21 & $2.0000 \mathrm{E}-01$ & $1.5684 \mathrm{E}-03$ & $2.6990 \mathrm{E}-05$ & $0.0000 \mathrm{E}+00$ \\
22 & $3.2000 \mathrm{E}-02$ & $-2.0500 \mathrm{E}-03$ & $1.5540 \mathrm{E}-05$ & $-3.3900 \mathrm{E}-05$ \\
23 & $2.0000 \mathrm{E}-01$ & $-1.9900 \mathrm{E}-03$ & $2.2540 \mathrm{E}-05$ & $-3.9600 \mathrm{E}-05$ \\
24 & $2.0000 \mathrm{E}-01$ & $3.4084 \mathrm{E}-03$ & $2.5087 \mathrm{E}-05$ & $-5.0000 \mathrm{E}-06$ \\
25 & $2.0000 \mathrm{E}-01$ & $3.1600 \mathrm{E}-03$ & $2.1140 \mathrm{E}-05$ & $-4.5300 \mathrm{E}-05$ \\
26 & $1.6200 \mathrm{E}-01$ & $1.1384 \mathrm{E}-03$ & $2.6042 \mathrm{E}-05$ & $-1.5000 \mathrm{E}-05$ \\
27 & $-1.0240 \mathrm{E}-01$ & $1.5600 \mathrm{E}-03$ & $2.3440 \mathrm{E}-05$ & $-1.1860 \mathrm{E}-04$ \\
\hline & & & & \\
\hline
\end{tabular}




\begin{tabular}{|c|c|c|c|c|}
\hline Mat ID & change ne & change Kxy & change Kzz & change Ss \\
\hline 28 & $-1.2600 \mathrm{E}-01$ & 9.4996E-04 & 7.4871E-07 & $-4.0600 \mathrm{E}-05$ \\
\hline 29 & $2.0000 \mathrm{E}-01$ & $3.0040 \mathrm{E}-03$ & $8.2100 \mathrm{E}-06$ & $-1.0120 \mathrm{E}-04$ \\
\hline 30 & $2.0000 \mathrm{E}-01$ & $3.7940 \mathrm{E}-03$ & $2.5884 \mathrm{E}-05$ & $1.2800 \mathrm{E}-05$ \\
\hline 31 & $-6.0000 \mathrm{E}-02$ & $-7.9400 \mathrm{E}-04$ & $-5.8100 \mathrm{E}-06$ & $1.2476 \mathrm{E}-04$ \\
\hline 32 & $-1.3520 \mathrm{E}-01$ & $4.2670 \mathrm{E}-03$ & $-4.6466 \mathrm{E}-06$ & 7.2000E-05 \\
\hline 33 & $-3.0000 \mathrm{E}-03$ & $-1.8400 \mathrm{E}-03$ & $1.9540 \mathrm{E}-06$ & $1.0510 \mathrm{E}-04$ \\
\hline 34 & $2.0000 \mathrm{E}-01$ & 3.5790E-03 & $1.4164 \mathrm{E}-05$ & $1.9700 \mathrm{E}-05$ \\
\hline 35 & $5.0000 \mathrm{E}-03$ & $9.3000 \mathrm{E}-04$ & $2.4340 \mathrm{E}-05$ & $3.1000 \mathrm{E}-06$ \\
\hline 36 & $2.0000 \mathrm{E}-01$ & $4.6600 \mathrm{E}-04$ & $1.3300 \mathrm{E}-05$ & $1.2300 \mathrm{E}-05$ \\
\hline 37 & $-1.0000 \mathrm{E}-02$ & $3.3870 \mathrm{E}-03$ & 7.7500E-06 & $-1.1000 \mathrm{E}-05$ \\
\hline 38 & $2.0000 \mathrm{E}-01$ & 3.3093E-03 & $1.8540 \mathrm{E}-05$ & $1.3100 \mathrm{E}-05$ \\
\hline 39 & $1.3300 \mathrm{E}-01$ & $-2.8300 \mathrm{E}-03$ & $1.6140 \mathrm{E}-05$ & $3.9900 \mathrm{E}-05$ \\
\hline 40 & $2.0000 \mathrm{E}-01$ & $3.2270 \mathrm{E}-03$ & $8.7000 \mathrm{E}-06$ & $1.0000 \mathrm{E}-07$ \\
\hline 41 & $2.0000 \mathrm{E}-01$ & $1.0261 \mathrm{E}-03$ & $1.5100 \mathrm{E}-06$ & 4.8000E-05 \\
\hline 42 & $1.8000 \mathrm{E}-02$ & 2.6670E-03 & $2.5684 \mathrm{E}-05$ & $1.3400 \mathrm{E}-05$ \\
\hline 43 & $2.0000 \mathrm{E}-01$ & $2.3661 \mathrm{E}-03$ & $3.8900 \mathrm{E}-06$ & $2.7700 \mathrm{E}-05$ \\
\hline 44 & $1.6900 \mathrm{E}-01$ & $-4.4290 \mathrm{E}-04$ & $1.5500 \mathrm{E}-06$ & $5.0900 \mathrm{E}-05$ \\
\hline 45 & $-9.5000 \mathrm{E}-02$ & $2.0250 \mathrm{E}-03$ & $1.0940 \mathrm{E}-05$ & $2.6100 \mathrm{E}-05$ \\
\hline 46 & $-1.3530 \mathrm{E}-01$ & $1.7250 \mathrm{E}-03$ & $7.5500 \mathrm{E}-06$ & $5.4360 \mathrm{E}-05$ \\
\hline 47 & 4.9000E-02 & 2.0990E-03 & $1.3564 \mathrm{E}-05$ & 4.1900E-05 \\
\hline 48 & $1.2700 \mathrm{E}-01$ & $6.8500 \mathrm{E}-04$ & 7.4860E-06 & $-8.0000 \mathrm{E}-06$ \\
\hline 49 & $2.0000 \mathrm{E}-01$ & $1.5590 \mathrm{E}-03$ & 1.5196E-05 & $1.2476 \mathrm{E}-04$ \\
\hline 50 & 7.0000E-03 & $4.7500 \mathrm{E}-04$ & $9.0660 \mathrm{E}-06$ & $8.2000 \mathrm{E}-05$ \\
\hline 51 & $2.0000 \mathrm{E}-01$ & $8.8000 \mathrm{E}-04$ & $6.4260 \mathrm{E}-06$ & $5.1000 \mathrm{E}-05$ \\
\hline 52 & $1.0000 \mathrm{E}-03$ & $2.6040 \mathrm{E}-03$ & $1.4796 \mathrm{E}-05$ & 7.3000E-05 \\
\hline 53 & $2.0000 \mathrm{E}-01$ & $3.4740 \mathrm{E}-03$ & $2.0300 \mathrm{E}-06$ & $3.6500 \mathrm{E}-05$ \\
\hline 54 & $2.0000 \mathrm{E}-01$ & $2.6240 \mathrm{E}-03$ & 4.1000E-06 & $7.5400 \mathrm{E}-05$ \\
\hline 55 & $1.1700 \mathrm{E}-01$ & $4.6140 \mathrm{E}-03$ & $8.0600 \mathrm{E}-07$ & $4.2660 \mathrm{E}-05$ \\
\hline 56 & $0.0000 \mathrm{E}+00$ & $0.0000 \mathrm{E}+00$ & $0.0000 E+00$ & $0.0000 E+00$ \\
\hline
\end{tabular}


Tab. B-5 Water balance of the Middle Valley simulation in $\mathrm{m}^{3}$ /d (July 1992 - July 2007)

\begin{tabular}{|c|c|c|c|c|c|}
\hline Period & $\begin{array}{c}\text { Transfer (in) } \\
\mathrm{m}^{3}\end{array}$ & $\begin{array}{c}\text { Sources (in) } \\
\mathrm{m}^{3}\end{array}$ & $\begin{array}{l}\text { Transfer } \\
\text { (out) } \mathrm{m}^{3}\end{array}$ & $\begin{array}{l}\text { Extraction } \\
\text { (wells) } \mathrm{m}^{3}\end{array}$ & $\begin{array}{c}\text { Change in } \\
\text { Storage }(+/-) \mathrm{m}^{3}\end{array}$ \\
\hline 1/07/1992 - 28/4/1993 & 57186981 & 15990763 & 73544845 & 514508 & -387004 \\
\hline 29/4/1993 - 2/03/1994 & 47661716 & 6060602 & 53141470 & 488144 & -82489 \\
\hline 3/03/1994 - 4/01/1995 & 45781968 & 10486726 & 55588869 & 324985 & 11465 \\
\hline 5/01/1995 - 8/11/1995 & 44215825 & 14823140 & 58187788 & 280345 & 22645 \\
\hline 9/11/1995 - 11/09/1996 & 44061887 & 13214908 & 56384474 & 413459 & 162292 \\
\hline 12/09/1996 - 16/07/1997 & 46915831 & 4480416 & 50656718 & 530878 & -73330 \\
\hline 17/07/1997 - 20/05/1998 & 44392611 & 5747329 & 49416247 & 863781 & -66923 \\
\hline 21/05/1998 - 24/03/1999 & 44194701 & 8011456 & 51302784 & 593972 & -36699 \\
\hline 25/03/1999 - 26/01/2000 & 44174940 & 6556311 & 50208232 & 293917 & -3403 \\
\hline $27 / 01 / 2000-29 / 11 / 2000$ & 42539501 & 9235587 & 51056133 & 498591 & -1232 \\
\hline $30 / 11 / 2000-3 / 10 / 2001$ & 43840581 & 3609410 & 46669457 & 778663 & 45932 \\
\hline 4/10/2001 - 7/08/2002 & 42216009 & 6694003 & 47789567 & 741854 & 163191 \\
\hline $8 / 08 / 2002-11 / 06 / 2003$ & 44499830 & 1127818 & 44553953 & 1103729 & -138930 \\
\hline $12 / 06 / 2003-14 / 04 / 2004$ & 43715295 & 7662946 & 50298658 & 785048 & -59001 \\
\hline $15 / 04 / 2004-16 / 02 / 2005$ & 41350685 & 13009672 & 52970608 & 989018 & -38421 \\
\hline $17 / 02 / 2005-21 / 12 / 2005$ & 42643875 & 5626799 & 47253602 & 895047 & 29061 \\
\hline $22 / 12 / 2005-25 / 10 / 2006$ & 41332282 & 13387069 & 53083789 & 883764 & 129437 \\
\hline 26/10/2006 - 27/06/2007 & 35530304 & 1293772 & 36409454 & 1267159 & 23775 \\
\hline Total $\left(\mathrm{m}^{3}\right)$ & 796254822 & 147018727 & $\begin{array}{c}92851664 \\
8\end{array}$ & 12246862 & - \\
\hline Average $\left(\mathrm{m}^{3} / \mathrm{d}\right)$ & $1,030,083$ & 190,192 & $1,201,186$ & 15,843 & - \\
\hline Proportion of total & $42 \%$ & $8 \%$ & $49 \%$ & $1 \%$ & - \\
\hline
\end{tabular}




\section{Appendix C}

\section{Transient FEFLOW flow model figures}

Layer depth
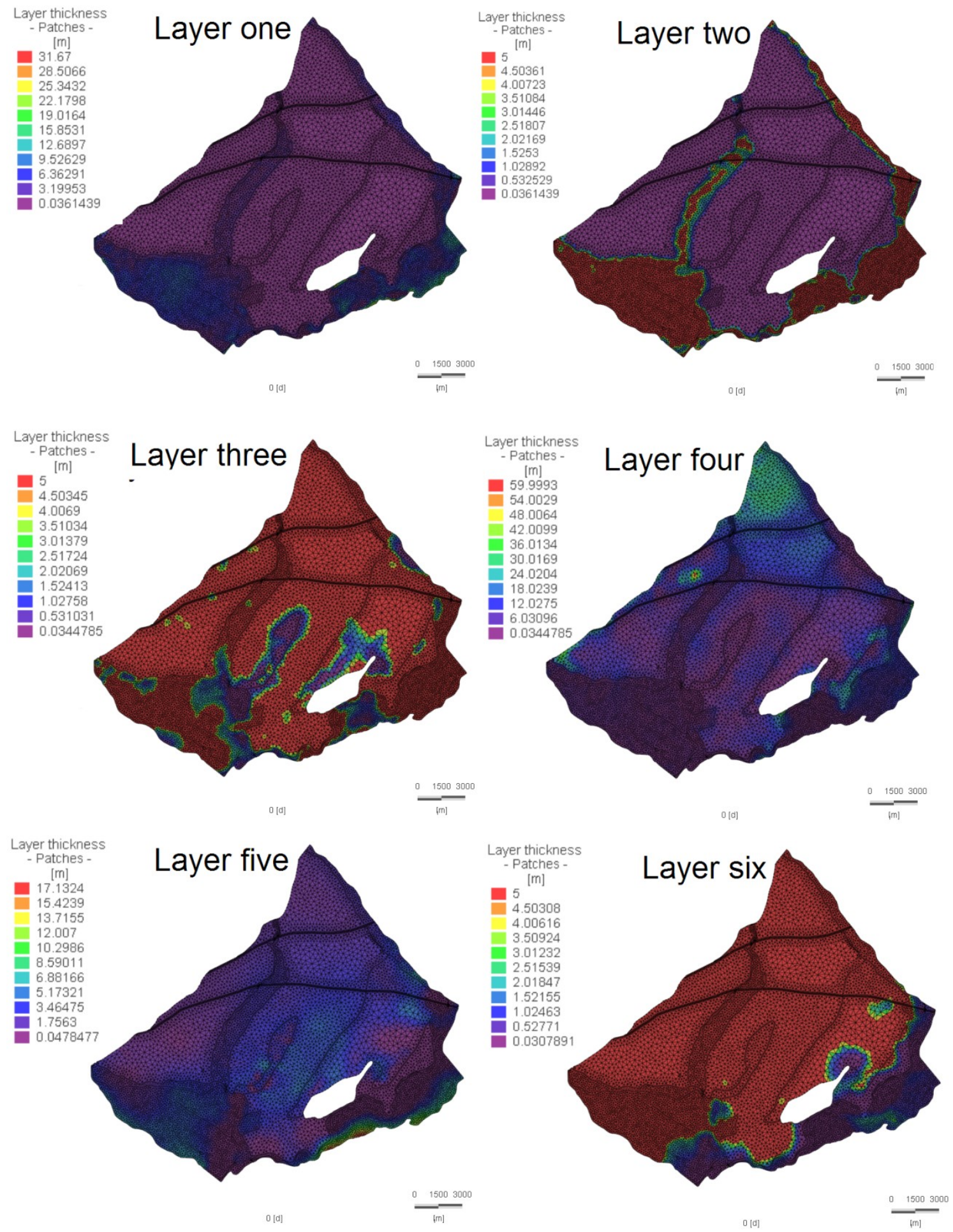

Figure C-1 Model's layer depths (one-six). 

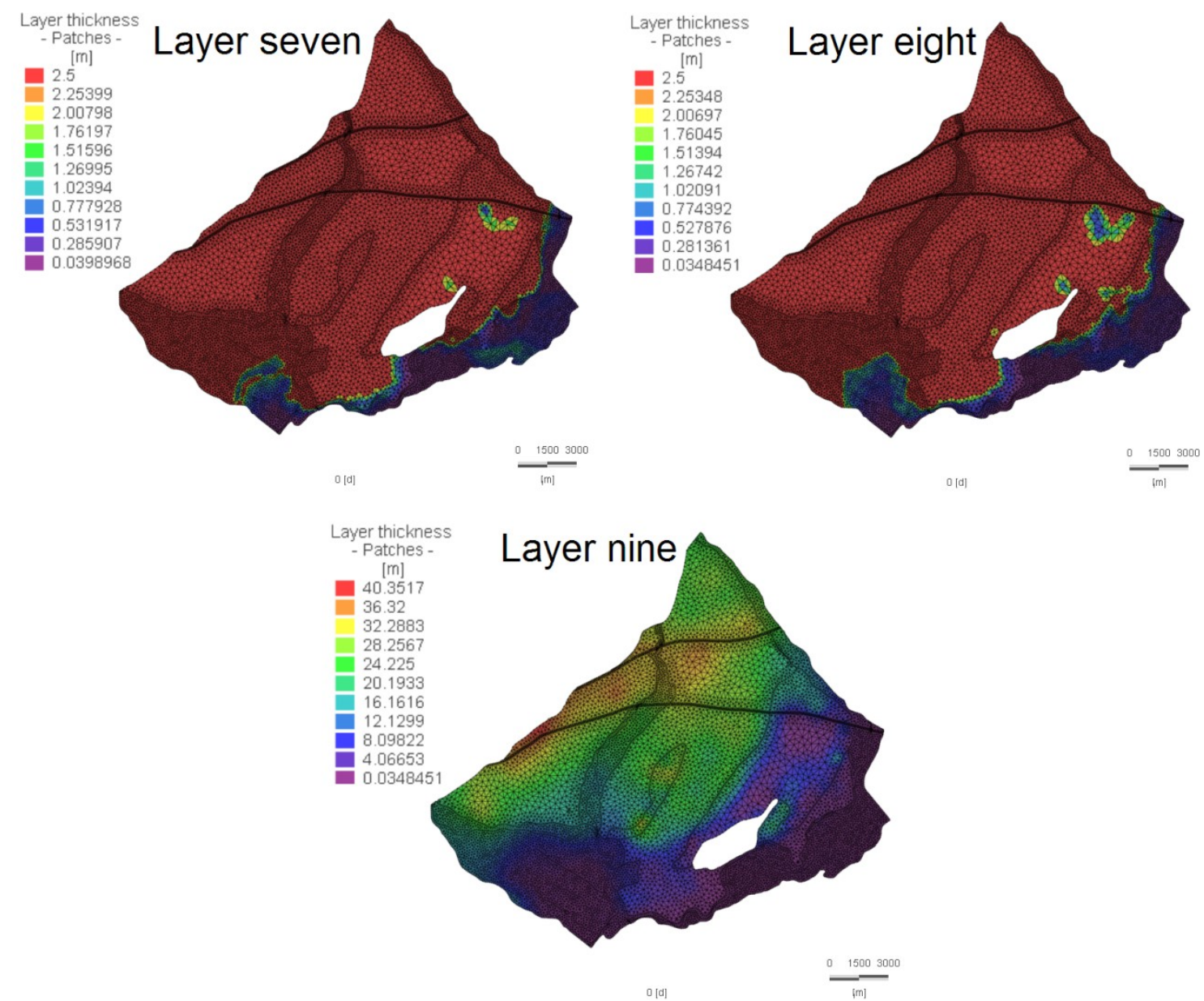

Figure C-2 Model's layer depths (seven-nine). 


\section{Elevation}

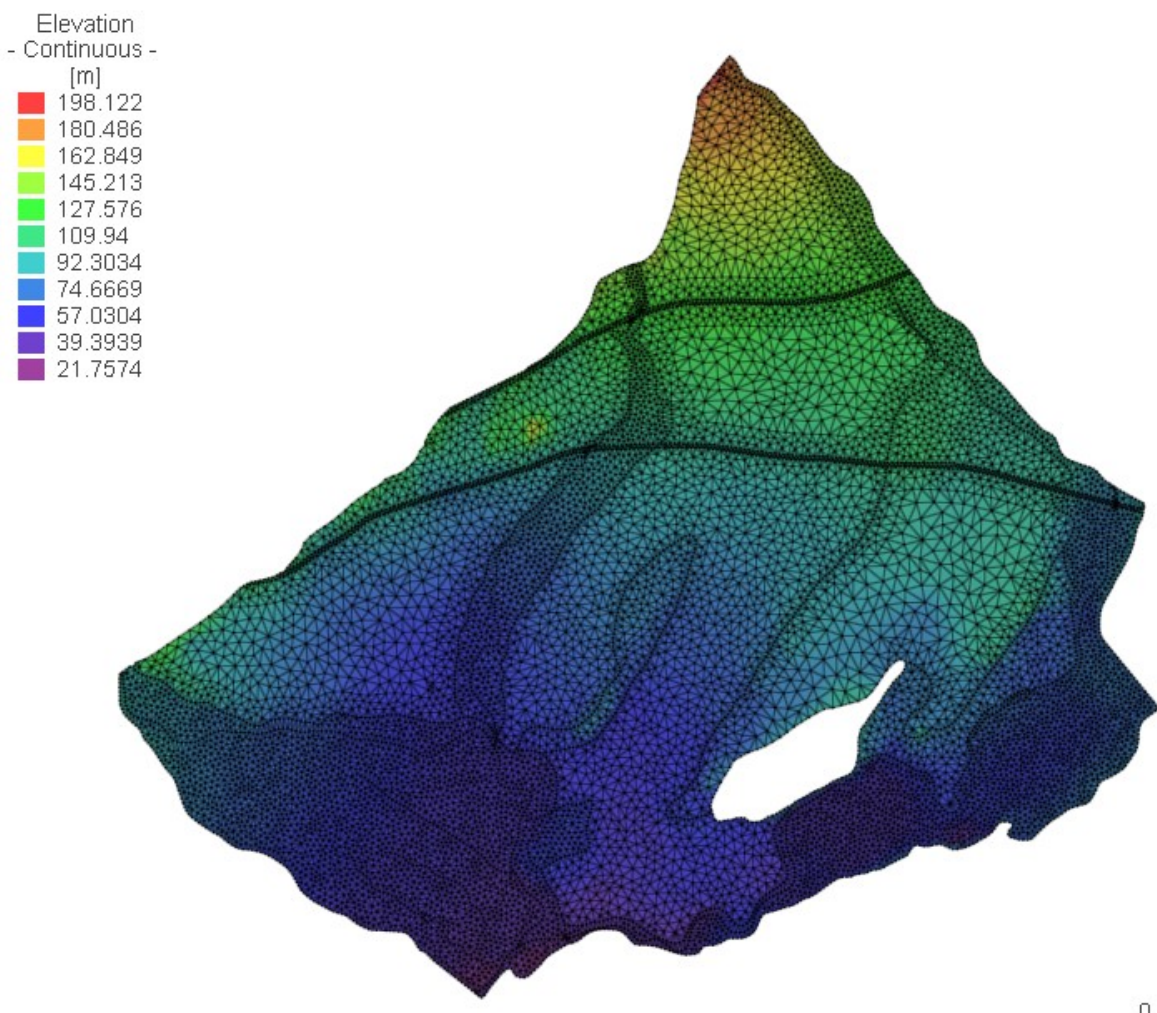

Figure C-3 Layer one elevations.

0 [d]

$[\mathrm{m}]$

$$
\begin{gathered}
\text { Elevation } \\
\text { - Continuous - } \\
\text { [m] } \\
143.907 \\
131.172 \\
118.438 \\
105.704 \\
92.9696 \\
80.2354 \\
67.5011 \\
54.7669 \\
42.0327 \\
29.2984 \\
16.5642
\end{gathered}
$$

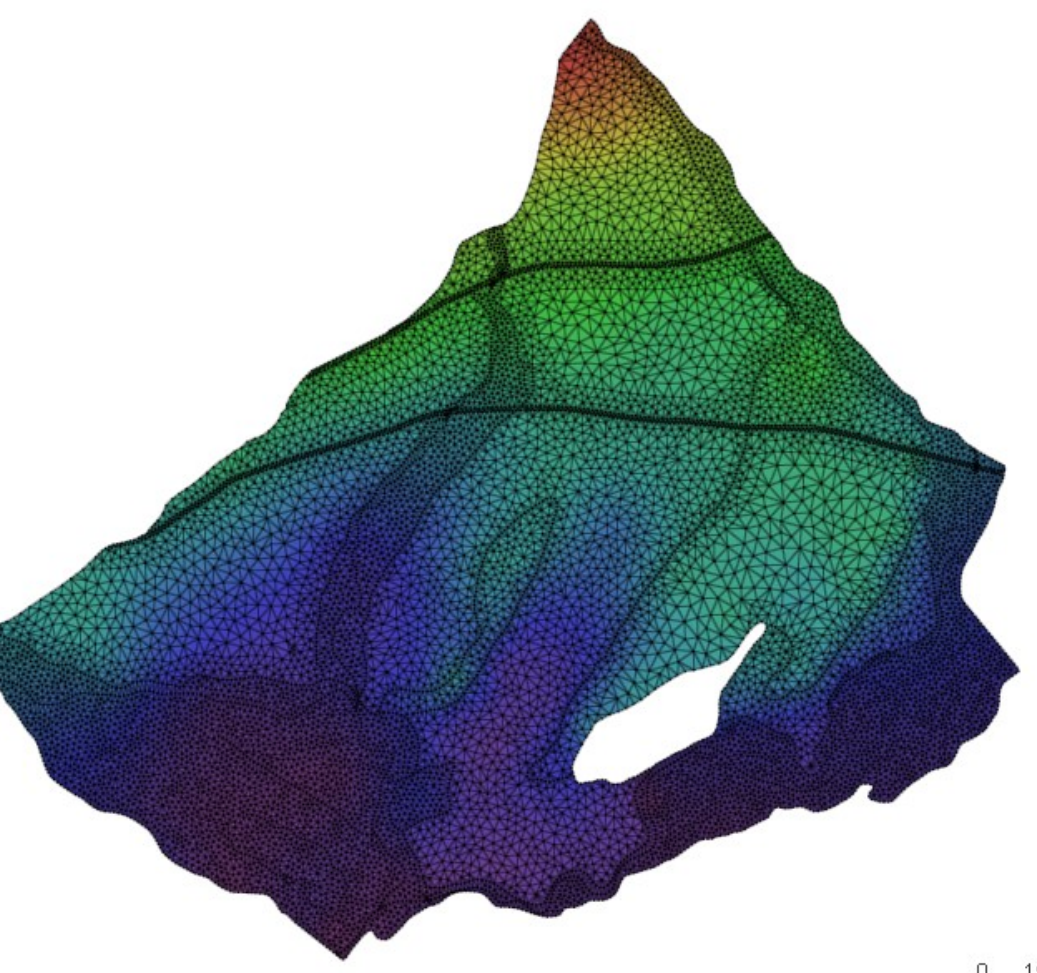

0 [d]

Figure C-4 Layer nine elevations. 


\section{Appendix D}

\section{Tritium Data}

Tritium, SF6, CFC and from the Middle Valley

Tab. D-1 Tritium, sulphur hexaflouride

\begin{tabular}{cccccccc}
\hline Well Depth & TR 2005scale & pH & SF6 & C-11 & C-12 & MRT [y] & SiO2 (g/m3) \\
\hline 46 & 0.043 & & 0.23 & 0.72 & 1 & 150 & \\
9.5 & 1.92 & 5.9 & 5.94 & 272 & 595 & 1 & 9.1 \\
13 & 1.74 & 5.81 & 5.24 & 442 & 2263 & 1.5 & \\
& 1.91 & 5.54 & 6.18 & 3121 & 772 & 1 & 12.2 \\
& 1.81 & 6.03 & 6.37 & 1431 & 917 & 2 & 10.4 \\
9 & 1.85 & 6.07 & 5.93 & 259 & 716 & 1 & 8.2 \\
& 1.72 & 6.05 & 5.39 & 237 & 565 & 1.5 & 12.5 \\
54 & 1.08 & 6.22 & 1.45 & 5.3 & 253 & 40 & 32.3 \\
5 & 1.63 & 5.98 & 6.31 & 203 & 562 & 32 & 17.4 \\
20 & 1.83 & 5.8 & 5.06 & 204 & 550 & 40 & 14.3 \\
27 & 1.41 & 5.9 & 2.71 & 112 & 20000 & 40 & 28 \\
75 & -0.015 & 6.84 & 0 & 7.5 & 25 & 150 & \\
21 & 1.74 & 5.75 & 3.86 & 1050 & 6200 & 40 & 26.6 \\
\hline
\end{tabular}

Tritium and silica measurements: Morgenstern (2005)

Tab. D-2 Tritium and silica measurements

\begin{tabular}{lcccccccc}
\hline Well_ID & TR & sigTR & SiO2 & Easting & Northing & Wairarapa_ID & well depth & pH \\
\hline S26/0911 & 1.85 & 0.05 & 8.2 & 2717612 & 6012423 & $4 \mathrm{G} / 237 / 9 / \mathrm{DI}$ & 9 & 6.07 \\
S26/0043 & 1.92 & 0.04 & 9.1 & 2729310 & 6026190 & $2 \mathrm{I} / 31 / 9.5(14) / I$ & 9.5 & 5.9 \\
S27/0070 & 1.82 & 0.05 & 9.1 & 2707531 & 6004827 & $5 \mathrm{E} / 58 / 15 / \mathrm{P}$ & 14.6 & 6.3 \\
S26/0395 & 1.81 & 0.05 & 10.4 & 2717500 & 6010730 & $4 \mathrm{G} / 139 / 0 / \mathrm{N}$ & & 6.03 \\
S27/0396 & 1.65 & 0.04 & 11 & 2715880 & 5997683 & $6 \mathrm{G} / 27 / 17 / \mathrm{P}$ & 17 & 6.96 \\
& 1.87 & 0.05 & 11 & & & & & 6.11 \\
S27/0330 & 1.64 & 0.04 & 12 & 2707788 & 6002140 & $6 \mathrm{E} / 63 / 20 / \mathrm{I}$ & 20 & 6.3 \\
S26/0244 & 1.91 & 0.05 & 12.2 & 2727780 & 6023410 & $3 \mathrm{II} / 27 / 0 / \mathrm{N}$ & & 5.54 \\
T26/0430 & 1.72 & 0.04 & 12.5 & 2732160 & 6024730 & $3 \mathrm{~J} / 74 / 0 / \mathrm{S}$ & & 6.05 \\
S27/0136 & 1.83 & 0.06 & 14.3 & 2712259 & 6008074 & $5 \mathrm{~F} / 49 / 20 / \mathrm{DI}$ & 20 & 5.8 \\
S27/0202 & 1.66 & 0.05 & 15 & 2715481 & 6008251 & $5 \mathrm{G} / 48 / 4.8 / \mathrm{IR}$ & 4.8 & 5.76 \\
\hline
\end{tabular}




\begin{tabular}{|ccccccccc}
\hline Well_ID & TR & SigTR & SiO2 & Easting & Northing & Wairarapa_ID & well depth & pH \\
\hline S27/0148 & 1.78 & 0.05 & 16 & 2712250 & 6008767 & & 8.55 & 5.54 \\
\hline T26/0517 & 1.63 & 0.06 & 17.4 & 2737500 & 6023500 & $3 \mathrm{~K} / 5 / 5 / \mathrm{I}$ & 5 & 5.98 \\
\hline R28/0012 & 0.72 & 0.03 & 18 & 2689300 & 5977370 & $9 \mathrm{~A} / 2 / 30.5 / D$ & 30.5 & 7.37 \\
\hline S27/0009 & 1.53 & 0.04 & 18 & 2703932 & 6005196 & $5 \mathrm{D} / 12 / 10.5 / D$ & 10.5 & 6.18 \\
\hline S26/0658 & 1.45 & 0.05 & 21 & 2720650 & 6016483 & $4 \mathrm{H} / 47 / 8 / \mathrm{DS}$ & 8 & 5.7 \\
\hline S27/0156 & 0.728 & 0.033 & 23 & 2713432 & 6004513 & $5 \mathrm{~F} / 67 / 21 / \mathrm{I}$ & 20.7 & 6.85 \\
\hline S27/0344 & 1.22 & 0.04 & 23.9 & 2713369 & 5999061 & $6 \mathrm{~F} / 13 / 16.5 / \mathrm{I}$ & 16.5 & 6.4 \\
\hline & 1.49 & 0.04 & 24 & 2720567 & 6016099 & & & 6.1 \\
\hline S27/0595 & 0.279 & 0.023 & 26.1 & 2691376 & 5981438 & $8 \mathrm{~B} / 6 / 44 / \mathrm{IR}$ & 44 & 7.36 \\
\hline S26/0824 & 1.74 & 0.04 & 26.6 & 2720512 & 6016098 & $4 \mathrm{H} / 66 / 21 / \mathrm{P}$ & 21 & 5.75 \\
\hline & 1.27 & 0.04 & 27 & 2720496 & 6015995 & $4 \mathrm{H} / 90 / 27 / \mathrm{P}$ & 27.4 & 6.4 \\
\hline S26/0705 & 1.41 & 0.06 & 28 & 2720489 & 6016012 & $4 \mathrm{H} / 90 / 27 / \mathrm{P}$ & 27 & 5.9 \\
\hline S27/0571 & 0.984 & 0.033 & 28.5 & 2717180 & 5994736 & $7 \mathrm{G} / 5 / 32 / \mathrm{I}$ & 32 & 6.48 \\
\hline S27/0609 & 1.05 & 0.04 & 30.4 & 2696850 & 5983880 & $8 \mathrm{C} / 2 / 91 / \mathrm{DS}$ & 91 & 7.04 \\
\hline S26/0576 & 0.478 & 0.026 & 33 & 2723470 & 6014244 & $4 \mathrm{H} / 62 / 32 / \mathrm{N} ?$ & 31.5 & 6.9 \\
\hline S27/0389 & 0.192 & 0.021 & 36.5 & 2717227 & 5995514 & $6 \mathrm{G} / 20 / 18 / \mathrm{I}$ & 18 & 6.97 \\
\hline
\end{tabular}

\section{Hydrochemistry dataset}

Tab. D-3 Hydrochemistry dataset

\begin{tabular}{|c|c|c|c|c|c|c|c|c|}
\hline Site Name & Easting & Northing & Time & $\begin{array}{l}\text { Conduc } \\
\text { tivity }\end{array}$ & $\mathrm{pH}$ & Silica & $\begin{array}{c}\text { Sulphat } \\
\text { e }\end{array}$ & $\begin{array}{c}\text { Total } \\
\text { Hardness }\end{array}$ \\
\hline S26/0911 & 2717612 & 6012423 & $\begin{array}{r}3 / 05 / 2005 \\
15: 30\end{array}$ & 95 & 6.3 & 8.2 & 5 & 26 \\
\hline S26/0705 & 2720489 & 6015999 & $\begin{array}{r}9 / 10 / 2003 \\
10: 45\end{array}$ & 177 & 6.7 & 26.2 & 9.1 & 35 \\
\hline S26/0824 & 2720564 & 6016101 & $\begin{array}{r}9 / 10 / 2003 \\
10: 55\end{array}$ & 177 & 6.7 & 26 & 8.9 & 35 \\
\hline S26/0299 & 2728370 & 6023590 & $\begin{array}{r}9 / 10 / 2003 \\
14: 09\end{array}$ & 175 & 6.1 & 12.2 & 10.5 & 44 \\
\hline S26/0762 & 2725720 & 6011070 & $\begin{array}{r}15 / 10 / 2003 \\
10: 00\end{array}$ & 358 & 6.6 & 24.9 & 0.7 & 83 \\
\hline S26/0568 & 2723504 & 6013642 & $\begin{array}{r}15 / 10 / 2003 \\
10: 30\end{array}$ & 270 & 7.1 & 38.5 & $<0.5$ & 88 \\
\hline S26/0576 & 2723479 & 6014255 & $\begin{array}{r}15 / 10 / 2003 \\
11: 00\end{array}$ & 211 & 6.9 & 37.7 & 1.3 & 56 \\
\hline S26/0756 & 2725937 & 6010018 & $\begin{array}{r}15 / 10 / 2003 \\
11: 35\end{array}$ & 241 & 6.6 & 19.6 & 6.5 & 82 \\
\hline S26/0457 & 2717675 & 6012051 & $\begin{array}{r}15 / 10 / 2003 \\
13: 15\end{array}$ & 100 & 6.2 & 9.3 & 6.3 & 30 \\
\hline S26/0705 & 2720489 & 6015999 & $\begin{array}{r}12 / 12 / 2003 \\
9: 50\end{array}$ & 167 & 6.6 & 27.2 & 9.1 & 37 \\
\hline S26/0824 & 2720564 & 6016101 & $\begin{array}{r}12 / 12 / 2003 \\
10: 15\end{array}$ & 181 & 6.5 & 24.3 & 9.6 & 43 \\
\hline S26/0299 & 2728370 & 6023590 & $\begin{array}{r}12 / 12 / 2003 \\
11: 00\end{array}$ & 161 & 6.2 & 12.7 & 7.4 & 43 \\
\hline
\end{tabular}




\begin{tabular}{|c|c|c|c|c|c|c|c|c|}
\hline Site Name & Easting & Northing & Time & $\begin{array}{c}\text { Conduc } \\
\text { tivity }\end{array}$ & $\mathrm{pH}$ & Silica & $\begin{array}{c}\text { Sulphat } \\
\text { e }\end{array}$ & $\begin{array}{c}\text { Total } \\
\text { Hardness }\end{array}$ \\
\hline S26/0299 & 2728370 & 6023590 & $\begin{array}{r}22 / 03 / 2004 \\
13: 30\end{array}$ & 163 & 6 & 13 & 16.8 & 39 \\
\hline S26/0705 & 2720489 & 6015999 & $\begin{array}{r}26 / 03 / 2004 \\
9: 30\end{array}$ & 161 & 6.4 & 25 & 8.9 & 38 \\
\hline S26/0824 & 2720564 & 6016101 & $\begin{array}{r}26 / 03 / 2004 \\
10: 00\end{array}$ & 176 & 6.3 & 22.4 & 9.5 & 45 \\
\hline S26/0576 & 2723479 & 6014255 & $\begin{array}{r}30 / 03 / 2004 \\
11: 00\end{array}$ & 212 & 7.2 & 31.9 & 1.7 & 61 \\
\hline S26/0762 & 2725720 & 6011070 & $\begin{array}{r}30 / 03 / 2004 \\
11: 45\end{array}$ & 327 & 6.8 & 22.5 & 1.1 & 83 \\
\hline S26/0568 & 2723504 & 6013642 & $\begin{array}{r}30 / 03 / 2004 \\
12: 20\end{array}$ & 261 & 7.4 & 33.4 & $<0.500$ & 90 \\
\hline S26/0756 & 2725937 & 6010018 & $\begin{array}{r}30 / 03 / 2004 \\
13: 00\end{array}$ & 255 & 6.8 & 18.2 & 8.9 & 92 \\
\hline S26/0457 & 2717675 & 6012051 & $\begin{array}{r}30 / 03 / 2004 \\
14: 20\end{array}$ & 95 & 6.6 & 8.6 & 5.6 & 30 \\
\hline S26/0299 & 2728370 & 6023590 & $\begin{array}{r}10 / 06 / 2004 \\
13: 25\end{array}$ & 139 & 5.9 & 12.9 & 9.6 & 37 \\
\hline S26/0705 & 2720489 & 6015999 & $\begin{array}{r}10 / 06 / 2004 \\
13: 45\end{array}$ & 167 & 6.4 & 25.8 & 9.4 & 38 \\
\hline S26/0824 & 2720564 & 6016101 & $\begin{array}{r}10 / 06 / 2004 \\
14: 00\end{array}$ & 182 & 6.2 & 23.7 & 10.1 & 46 \\
\hline S26/0457 & 2717675 & 6012051 & $\begin{array}{r}11 / 06 / 2004 \\
15: 00\end{array}$ & 87 & 6.4 & 8.6 & 6.2 & 26 \\
\hline S26/0762 & 2725720 & 6011070 & $\begin{array}{r}17 / 06 / 2004 \\
10: 20\end{array}$ & 325 & 6.6 & 23 & $<0.500$ & 75 \\
\hline S26/0756 & 2725937 & 6010018 & $\begin{array}{r}17 / 06 / 2004 \\
11: 00\end{array}$ & 265 & 6.6 & 18.6 & 8.2 & 90 \\
\hline S26/0576 & 2723479 & 6014255 & $\begin{array}{r}17 / 06 / 2004 \\
11: 00\end{array}$ & 209 & 6.9 & 33.5 & 0.9 & 58 \\
\hline S26/0568 & 2723504 & 6013642 & $\begin{array}{r}17 / 06 / 2004 \\
11: 30\end{array}$ & 267 & 7.3 & 36.2 & $<0.500$ & 90 \\
\hline S26/0705 & 2720489 & 6015999 & $\begin{array}{r}22 / 09 / 2004 \\
10: 43\end{array}$ & 169 & 6.5 & 27 & 9.9 & 35 \\
\hline S26/0824 & 2720564 & 6016101 & $\begin{array}{r}22 / 09 / 2004 \\
11: 10\end{array}$ & 180 & 6.4 & 24.6 & 10.1 & 42 \\
\hline S26/0299 & 2728370 & 6023590 & $\begin{array}{r}22 / 09 / 2004 \\
12: 00\end{array}$ & 143 & 6.1 & 12.7 & 10 & 36 \\
\hline $\begin{array}{c}\text { S26/0705 } \\
\text { NGMP }\end{array}$ & 2720489 & 6015999 & $\begin{array}{r}22 / 09 / 2004 \\
12: 00\end{array}$ & & 6.6 & 26 & 8.8 & \\
\hline S26/0762 & 2725720 & 6011070 & $\begin{array}{r}4 / 10 / 2004 \\
10: 15\end{array}$ & 343 & 6.9 & 25.6 & 0.5 & 74 \\
\hline S26/0756 & 2725937 & 6010018 & $\begin{array}{r}4 / 10 / 2004 \\
10: 50\end{array}$ & 301 & 6.8 & 19.9 & 13.6 & 97 \\
\hline S26/0568 & 2723504 & 6013642 & $\begin{array}{r}4 / 10 / 2004 \\
11: 30\end{array}$ & 270 & 7.3 & 39.4 & $<0.500$ & 82 \\
\hline S26/0576 & 2723479 & 6014255 & $\begin{array}{r}4 / 10 / 2004 \\
12: 20\end{array}$ & 208 & 7.1 & 36.1 & 1.3 & 52 \\
\hline S26/0457 & 2717675 & 6012051 & $\begin{array}{r}4 / 10 / 2004 \\
15: 20\end{array}$ & 100 & 6.4 & 9.9 & 6.9 & 28 \\
\hline
\end{tabular}




\begin{tabular}{|c|c|c|c|c|c|c|c|c|}
\hline Site Name & Easting & Northing & Time & $\begin{array}{l}\text { Conduc } \\
\text { tivity }\end{array}$ & $\mathrm{pH}$ & Silica & $\begin{array}{l}\text { Sulphat } \\
\text { e }\end{array}$ & $\begin{array}{c}\text { Total } \\
\text { Hardness }\end{array}$ \\
\hline T26/0332 & 2732246 & 6019123 & $\begin{array}{r}21 / 10 / 2004 \\
9: 30\end{array}$ & 205 & 6.2 & 39.8 & 14.8 & 46 \\
\hline S26/0223 & 2726219 & 6021005 & $\begin{array}{r}21 / 10 / 2004 \\
10: 30\end{array}$ & 207 & 6.1 & 16.1 & 15.5 & 56 \\
\hline S26/0705 & 2720489 & 6015999 & $\begin{array}{r}7 / 12 / 2004 \\
9: 45\end{array}$ & 165 & 6.4 & 26 & 9.5 & 38 \\
\hline S26/0824 & 2720564 & 6016101 & $\begin{array}{r}7 / 12 / 2004 \\
9: 55\end{array}$ & 175 & 6.3 & 23.7 & 9.3 & 45 \\
\hline $\begin{array}{c}\text { S26/0705 } \\
\text { NGMP }\end{array}$ & 2720489 & 6015999 & $\begin{array}{r}7 / 12 / 2004 \\
12: 00\end{array}$ & & $\begin{array}{r}6.5 \\
3\end{array}$ & 25 & 9 & \\
\hline T26/0332 & 2732246 & 6019123 & $\begin{array}{r}10 / 12 / 2004 \\
8: 40\end{array}$ & 200 & 6.2 & 40.5 & 12.8 & 48 \\
\hline S26/0299 & 2728370 & 6023590 & $\begin{array}{r}10 / 12 / 2004 \\
9: 10\end{array}$ & 129 & 6.1 & 13.2 & 11.3 & 38 \\
\hline S26/0223 & 2726219 & 6021005 & $\begin{array}{r}10 / 12 / 2004 \\
12: 00\end{array}$ & 217 & 6 & 16.9 & 12.4 & 63 \\
\hline S26/0457 & 2717675 & 6012051 & $\begin{array}{r}17 / 12 / 2004 \\
9: 05\end{array}$ & 86 & 6.6 & 8.8 & 6.1 & 27 \\
\hline S26/0568 & 2723504 & 6013642 & $\begin{array}{r}18 / 01 / 2005 \\
9: 45\end{array}$ & 265 & 7.1 & 36.5 & $<0.500$ & 91 \\
\hline S26/0576 & 2723479 & 6014255 & $\begin{array}{r}18 / 01 / 2005 \\
10: 10\end{array}$ & 211 & 6.9 & 34.6 & 2.7 & 56 \\
\hline S26/0762 & 2725720 & 6011070 & $\begin{array}{r}18 / 01 / 2005 \\
10: 50\end{array}$ & 342 & 6.6 & 23.1 & 0.7 & 77 \\
\hline S26/0756 & 2725937 & 6010018 & $\begin{array}{r}18 / 01 / 2005 \\
11: 25\end{array}$ & 298 & 6.6 & 21.4 & 13.1 & 114 \\
\hline S26/0439 & 2717510 & 6016900 & $\begin{array}{r}18 / 01 / 2005 \\
12: 10\end{array}$ & 173 & 6.4 & 22.9 & 11.2 & 47 \\
\hline S26/0400 & 2718695 & 6015416 & $\begin{array}{r}27 / 01 / 2005 \\
7: 45\end{array}$ & 180 & 7.2 & 40.4 & 0.8 & 51 \\
\hline S26/0467 & 2719290 & 6015570 & $\begin{array}{r}27 / 01 / 2005 \\
8: 10\end{array}$ & 153 & 6.3 & 20.8 & 10.8 & 33 \\
\hline S26/0846 & 2717921 & 6011212 & $\begin{array}{r}27 / 01 / 2005 \\
11: 15\end{array}$ & 97 & 6.7 & 15.3 & 3.7 & 30 \\
\hline S26/0117 & 2721500 & 6018500 & $\begin{array}{r}27 / 01 / 2005 \\
12: 00\end{array}$ & 155 & 6 & 16.6 & 10 & 43 \\
\hline T26/0332 & 2732246 & 6019123 & $\begin{array}{r}15 / 03 / 2005 \\
9: 15\end{array}$ & 218 & 6.4 & 40.2 & 11.5 & 45 \\
\hline S26/0223 & 2726219 & 6021005 & $\begin{array}{r}15 / 03 / 2005 \\
9: 30\end{array}$ & 214 & 6.1 & 16.9 & 9.3 & 53 \\
\hline S26/0299 & 2728370 & 6023590 & $\begin{array}{r}15 / 03 / 2005 \\
10: 15\end{array}$ & 134 & 6.2 & 13.8 & 10.9 & 33 \\
\hline S26/0824 & 2720564 & 6016101 & $\begin{array}{r}16 / 03 / 2005 \\
9: 20\end{array}$ & 185 & 6.7 & 26.6 & 9.6 & 39 \\
\hline S26/0705 & 2720489 & 6015999 & $\begin{array}{r}23 / 03 / 2005 \\
8: 50\end{array}$ & 166 & 6.5 & 28 & 10.3 & 37 \\
\hline S26/0576 & 2723479 & 6014255 & $\begin{array}{r}23 / 03 / 2005 \\
10: 00\end{array}$ & 199 & 7.2 & 33.7 & 2.3 & 52 \\
\hline S26/0568 & 2723504 & 6013642 & $\begin{array}{r}23 / 03 / 2005 \\
10: 40\end{array}$ & 264 & 7.2 & 38.4 & $<0.500$ & 85 \\
\hline
\end{tabular}




\begin{tabular}{|c|c|c|c|c|c|c|c|c|}
\hline Site Name & Easting & Northing & Time & $\begin{array}{l}\text { Conduc } \\
\text { tivity }\end{array}$ & $\mathrm{pH}$ & Silica & $\begin{array}{c}\text { Sulphat } \\
\text { e }\end{array}$ & $\begin{array}{c}\text { Total } \\
\text { Hardness }\end{array}$ \\
\hline S26/0762 & 2725720 & 6011070 & $\begin{array}{r}23 / 03 / 2005 \\
11: 35\end{array}$ & 311 & 6.9 & 23.7 & $<0.500$ & 71 \\
\hline $\begin{array}{c}\text { S26/0705 } \\
\text { NGMP }\end{array}$ & 2720489 & 6015999 & $\begin{array}{r}23 / 03 / 2005 \\
12: 00\end{array}$ & 172 & $\begin{array}{r}6.3 \\
8\end{array}$ & 23 & 9.2 & \\
\hline S26/0756 & 2725937 & 6010018 & $\begin{array}{r}23 / 03 / 2005 \\
12: 15\end{array}$ & 278 & 6.8 & 22.3 & 11.2 & 96 \\
\hline S26/0117 & 2721500 & 6018500 & $\begin{array}{r}23 / 03 / 2005 \\
13: 20\end{array}$ & 144 & 6 & 16.4 & 10.5 & 35 \\
\hline S26/0457 & 2717675 & 6012051 & $\begin{array}{r}23 / 03 / 2005 \\
13: 45\end{array}$ & 78 & 6.4 & 9 & 5.2 & 23 \\
\hline S26/0467 & 2719290 & 6015570 & $\begin{array}{r}23 / 03 / 2005 \\
14: 00\end{array}$ & 142 & 6.3 & 20.9 & 10.7 & 27 \\
\hline S26/0439 & 2717510 & 6016900 & $\begin{array}{r}23 / 03 / 2005 \\
14: 55\end{array}$ & 173 & 6.5 & 24.8 & 11.4 & 45 \\
\hline S26/0846 & 2717921 & 6011212 & $\begin{array}{r}8 / 04 / 2005 \\
13: 25\end{array}$ & 96 & 6.7 & 14.2 & 3.3 & 28 \\
\hline S26/0395 & 2717581 & 6010704 & $\begin{array}{r}3 / 05 / 2005 \\
16: 00\end{array}$ & 102 & 6.3 & 10.4 & 4.9 & 28 \\
\hline S26/0244 & 2727780 & 6023410 & $\begin{array}{r}3 / 05 / 2005 \\
17: 30\end{array}$ & 117 & 5.9 & 12.2 & 9.4 & 26 \\
\hline S26/0299 & 2728370 & 6023590 & $\begin{array}{r}8 / 07 / 2005 \\
13: 25\end{array}$ & 110 & 6.1 & 13.1 & 10.3 & 28 \\
\hline T26/0332 & 2732246 & 6019123 & $\begin{array}{r}8 / 07 / 2005 \\
13: 55\end{array}$ & 207 & 6.2 & 40 & 12.5 & 48 \\
\hline S26/0223 & 2726219 & 6021005 & $\begin{array}{r}8 / 07 / 2005 \\
14: 45\end{array}$ & 191 & 5.9 & 16.8 & 13.7 & 47 \\
\hline S26/0762 & 2725720 & 6011070 & $\begin{array}{r}11 / 07 / 2005 \\
14: 35\end{array}$ & 327 & 6.7 & 23.7 & $<0.500$ & 76 \\
\hline S26/0756 & 2725937 & 6010018 & $\begin{array}{r}11 / 07 / 2005 \\
15: 10\end{array}$ & 319 & 6.6 & 18.9 & 14.1 & 113 \\
\hline S26/0576 & 2723479 & 6014255 & $\begin{array}{r}11 / 07 / 2005 \\
15: 40\end{array}$ & 210 & 7.1 & 34.5 & 1.8 & 59 \\
\hline S26/0568 & 2723504 & 6013642 & $\begin{array}{r}11 / 07 / 2005 \\
16: 10\end{array}$ & 269 & 7.2 & 37.5 & $<0.500$ & 88 \\
\hline S26/0467 & 2719290 & 6015570 & $\begin{array}{r}20 / 07 / 2005 \\
10: 30\end{array}$ & 143 & 6.5 & 19.2 & 8 & 29 \\
\hline S26/0439 & 2717510 & 6016900 & $\begin{array}{r}20 / 07 / 2005 \\
11: 10\end{array}$ & 170 & 6.5 & 22.9 & 10 & 48 \\
\hline S26/0457 & 2717675 & 6012051 & $\begin{array}{r}20 / 07 / 2005 \\
11: 45\end{array}$ & 83 & 6.5 & 8.8 & 4.2 & 27 \\
\hline S26/0117 & 2721500 & 6018500 & $\begin{array}{r}20 / 07 / 2005 \\
16: 00\end{array}$ & 144 & 6.1 & 15.2 & 8.2 & 39 \\
\hline S26/0705 & 2720489 & 6015999 & $\begin{array}{r}27 / 07 / 2005 \\
9: 40\end{array}$ & 166 & 6.5 & 27.7 & 10.4 & 40 \\
\hline S26/0824 & 2720564 & 6016101 & $\begin{array}{r}27 / 07 / 2005 \\
9: 55\end{array}$ & 173 & 6.5 & 25.7 & 11.1 & 45 \\
\hline $\begin{array}{c}\text { S26/0705 } \\
\text { NGMP }\end{array}$ & 2720489 & 6015999 & $\begin{array}{r}27 / 07 / 2005 \\
12: 00\end{array}$ & & $\begin{array}{r}6.1 \\
9\end{array}$ & 26 & 9.1 & \\
\hline S26/0846 & 2717921 & 6011212 & $\begin{array}{r}2 / 08 / 2005 \\
15: 40\end{array}$ & 96 & 7.2 & 13.8 & 3.2 & 29 \\
\hline
\end{tabular}




\begin{tabular}{|c|c|c|c|c|c|c|c|c|}
\hline Site Name & Easting & Northing & Time & $\begin{array}{l}\text { Conduc } \\
\text { tivity }\end{array}$ & $\mathrm{pH}$ & Silica & $\begin{array}{l}\text { Sulphat } \\
\text { e }\end{array}$ & $\begin{array}{c}\text { Total } \\
\text { Hardness }\end{array}$ \\
\hline S26/0299 & 2728370 & 6023590 & $\begin{array}{r}21 / 09 / 2005 \\
13: 55\end{array}$ & 118 & 6.1 & 13 & 9.8 & 35 \\
\hline T26/0332 & 2732246 & 6019123 & $\begin{array}{r}21 / 09 / 2005 \\
14: 35\end{array}$ & 205 & 6.2 & 40.1 & 11.9 & 50 \\
\hline S26/0223 & 2726219 & 6021005 & $\begin{array}{r}21 / 09 / 2005 \\
15: 10\end{array}$ & 197 & 6 & 17 & 11.6 & 55 \\
\hline S26/0762 & 2725720 & 6011070 & $\begin{array}{r}23 / 09 / 2005 \\
11: 03\end{array}$ & 325 & 6.7 & 23.5 & $<0.500$ & 80 \\
\hline S26/0756 & 2725937 & 6010018 & $\begin{array}{r}23 / 09 / 2005 \\
11: 48\end{array}$ & 309 & 6.7 & 19.8 & 12.4 & 112 \\
\hline S26/0576 & 2723479 & 6014255 & $\begin{array}{r}23 / 09 / 2005 \\
12: 25\end{array}$ & 207 & 7.1 & 34.8 & 1.5 & 60 \\
\hline S26/0568 & 2723504 & 6013642 & $\begin{array}{r}23 / 09 / 2005 \\
13: 02\end{array}$ & 266 & 7.3 & 36.9 & $<0.500$ & 90 \\
\hline S26/0467 & 2719290 & 6015570 & $\begin{array}{r}23 / 09 / 2005 \\
13: 55\end{array}$ & 143 & 6.3 & 19.3 & 8.9 & 29 \\
\hline S26/0439 & 2717510 & 6016900 & $\begin{array}{r}23 / 09 / 2005 \\
14: 32\end{array}$ & 170 & 6.5 & 23.7 & 10.4 & 47 \\
\hline S26/0117 & 2721500 & 6018500 & $\begin{array}{r}23 / 09 / 2005 \\
15: 10\end{array}$ & 138 & 6.1 & 14.7 & 9.2 & 36 \\
\hline S26/0846 & 2717921 & 6011212 & $\begin{array}{r}12 / 10 / 2005 \\
12: 15\end{array}$ & 97 & 6.6 & 13.7 & 3.3 & 30 \\
\hline S26/0457 & 2717675 & 6012051 & $\begin{array}{r}12 / 10 / 2005 \\
14: 54\end{array}$ & 75 & 6.5 & 8.7 & 4.9 & 23 \\
\hline S26/0705 & 2720489 & 6015999 & $\begin{array}{r}18 / 10 / 2005 \\
8: 26\end{array}$ & 165 & 6.4 & 25.8 & 9.7 & 40 \\
\hline S26/0824 & 2720564 & 6016101 & $\begin{array}{r}18 / 10 / 2005 \\
8: 40\end{array}$ & 176 & 6.3 & 23.2 & 10.1 & 47 \\
\hline S26/0299 & 2728370 & 6023590 & $\begin{array}{r}12 / 12 / 2005 \\
13: 24\end{array}$ & 117 & 6.1 & 12.9 & 10.8 & 33 \\
\hline T26/0332 & 2732246 & 6019123 & $\begin{array}{r}12 / 12 / 2005 \\
13: 53\end{array}$ & 202 & 6.2 & 39.6 & 10.9 & 48 \\
\hline S26/0223 & 2726219 & 6021005 & $\begin{array}{r}12 / 12 / 2005 \\
14: 35\end{array}$ & 154 & 6.1 & 14.9 & 9.2 & 42 \\
\hline S26/0117 & 2721500 & 6018500 & $\begin{array}{r}13 / 12 / 2005 \\
9: 34\end{array}$ & 137 & 6.1 & 14.5 & 8.4 & 36 \\
\hline S26/0467 & 2719290 & 6015570 & $\begin{array}{r}13 / 12 / 2005 \\
10: 16\end{array}$ & 141 & 6.3 & 18.4 & 8.4 & 30 \\
\hline S26/0439 & 2717510 & 6016900 & $\begin{array}{r}13 / 12 / 2005 \\
10: 52\end{array}$ & 172 & 6.5 & 22.9 & 10.2 & 49 \\
\hline S26/0576 & 2723479 & 6014255 & $\begin{array}{r}13 / 12 / 2005 \\
11: 27\end{array}$ & 210 & 6.9 & 32.4 & 2.4 & 64 \\
\hline S26/0762 & 2725720 & 6011070 & $\begin{array}{r}13 / 12 / 2005 \\
12: 21\end{array}$ & 333 & 6.6 & 23.4 & $<0.500$ & 82 \\
\hline S26/0756 & 2725937 & 6010018 & $\begin{array}{r}13 / 12 / 2005 \\
12: 50\end{array}$ & 286 & 6.7 & 22.2 & 8 & 98 \\
\hline S26/0457 & 2717675 & 6012051 & $\begin{array}{r}16 / 12 / 2005 \\
8: 46\end{array}$ & 69 & 6.3 & 8.9 & 3.9 & 21 \\
\hline S26/0705 & 2720489 & 6015999 & $\begin{array}{r}12 / 01 / 2006 \\
8: 43\end{array}$ & 166 & 6.4 & 26.9 & 10.3 & 37 \\
\hline
\end{tabular}




\begin{tabular}{|c|c|c|c|c|c|c|c|c|}
\hline Site Name & Easting & Northing & Time & $\begin{array}{c}\text { Conduc } \\
\text { tivity }\end{array}$ & $\mathrm{pH}$ & Silica & $\begin{array}{l}\text { Sulphat } \\
\text { e }\end{array}$ & $\begin{array}{c}\text { Total } \\
\text { Hardness }\end{array}$ \\
\hline S26/0824 & 2720564 & 6016101 & $\begin{array}{r}12 / 01 / 2006 \\
9: 03\end{array}$ & 176 & 6.3 & 24.6 & 10.7 & 42 \\
\hline S26/0568 & 2723504 & 6013642 & $\begin{array}{r}12 / 01 / 2006 \\
9: 36\end{array}$ & 269 & 7.1 & 36 & $<0.500$ & 91 \\
\hline S26/0846 & 2717921 & 6011212 & $\begin{array}{r}12 / 01 / 2006 \\
11: 15\end{array}$ & 94 & 6.6 & 13.6 & 3.4 & 28 \\
\hline $\begin{array}{c}\text { S26/0705 } \\
\text { NGMP }\end{array}$ & 2720489 & 6015999 & $\begin{array}{r}12 / 01 / 2006 \\
12: 00\end{array}$ & & $\begin{array}{r}7.8 \\
2\end{array}$ & 27 & 9.2 & \\
\hline S26/0457 & 2717675 & 6012051 & $\begin{array}{r}14 / 03 / 2006 \\
11: 58\end{array}$ & 72 & 6.4 & 8.9 & 3.9 & 22 \\
\hline S26/0705 & 2720489 & 6015999 & $\begin{array}{r}15 / 03 / 2006 \\
7: 40\end{array}$ & 163 & 6.3 & 25.7 & 9.5 & 39 \\
\hline S26/0824 & 2720564 & 6016101 & $\begin{array}{r}15 / 03 / 2006 \\
9: 48\end{array}$ & 173 & 6.2 & 23.3 & 9.7 & 46 \\
\hline $\begin{array}{c}\text { S26/0705 } \\
\text { NGMP }\end{array}$ & 2720489 & 6015999 & $\begin{array}{r}15 / 03 / 2006 \\
12: 00\end{array}$ & 164 & $\begin{array}{r}6.5 \\
7\end{array}$ & 24 & 9.4 & \\
\hline S26/0223 & 2726219 & 6021005 & $\begin{array}{r}16 / 03 / 2006 \\
10: 34\end{array}$ & 136 & $\begin{array}{r}6.4 \\
9\end{array}$ & 14.5 & 8.8 & 36 \\
\hline S26/0299 & 2728370 & 6023590 & $\begin{array}{r}16 / 03 / 2006 \\
11: 48\end{array}$ & 101 & 6.7 & 13.3 & 11.1 & 27 \\
\hline S26/0762 & 2725720 & 6011070 & $\begin{array}{r}22 / 03 / 2006 \\
10: 38\end{array}$ & 330 & 6.7 & 25 & $<0.500$ & 85 \\
\hline S26/0756 & 2725937 & 6010018 & $\begin{array}{r}22 / 03 / 2006 \\
11: 35\end{array}$ & 286 & 6.7 & 22.1 & 10 & 105 \\
\hline T26/0332 & 2732246 & 6019123 & $\begin{array}{r}22 / 03 / 2006 \\
13: 04\end{array}$ & 199 & 6.3 & 43.3 & 11.6 & 49 \\
\hline S26/0846 & 2717921 & 6011212 & $\begin{array}{r}30 / 03 / 2006 \\
13: 40\end{array}$ & 93 & 6.8 & 13.7 & 3.5 & 30 \\
\hline S26/0568 & 2723504 & 6013642 & $\begin{array}{r}7 / 04 / 2006 \\
10: 50\end{array}$ & 270 & 7.1 & 36.3 & 0.5 & 102 \\
\hline S26/0439 & 2717510 & 6016900 & $\begin{array}{r}7 / 04 / 2006 \\
11: 40\end{array}$ & 175 & 6.4 & 23.5 & 10.4 & 52 \\
\hline S26/0467 & 2719290 & 6015570 & $\begin{array}{r}7 / 04 / 2006 \\
12: 25\end{array}$ & 133 & 6.3 & 18.8 & 9.1 & 27 \\
\hline S26/0117 & 2721500 & 6018500 & $\begin{array}{r}7 / 04 / 2006 \\
13: 00\end{array}$ & 135 & 6.2 & 15 & 8.5 & 33 \\
\hline T26/0332 & 2732246 & 6019123 & $\begin{array}{r}15 / 06 / 2006 \\
14: 29\end{array}$ & 200 & 6.3 & 38.4 & 12.8 & 46 \\
\hline S26/0299 & 2728370 & 6023590 & $\begin{array}{r}15 / 06 / 2006 \\
15: 04\end{array}$ & 100 & 6.2 & 12.8 & 11 & 26 \\
\hline S26/0223 & 2726219 & 6021005 & $\begin{array}{r}15 / 06 / 2006 \\
15: 40\end{array}$ & 177 & 6 & 15.8 & 12.2 & 46 \\
\hline S26/0762 & 2725720 & 6011070 & $\begin{array}{r}20 / 06 / 2006 \\
10: 16\end{array}$ & 321 & 6.7 & 23.1 & $<0.500$ & 78 \\
\hline S26/0756 & 2725937 & 6010018 & $\begin{array}{r}20 / 06 / 2006 \\
11: 00\end{array}$ & 276 & 6.7 & 20.1 & 8.8 & 95 \\
\hline S26/0568 & 2723504 & 6013642 & $\begin{array}{r}20 / 06 / 2006 \\
11: 49\end{array}$ & 265 & 7.3 & 36.7 & $<0.500$ & 91 \\
\hline S26/0117 & 2721500 & 6018500 & $\begin{array}{r}20 / 06 / 2006 \\
12: 52\end{array}$ & 130 & 6.1 & 14.6 & 8.4 & 35 \\
\hline
\end{tabular}




\begin{tabular}{|c|c|c|c|c|c|c|c|c|}
\hline Site Name & Easting & Northing & Time & $\begin{array}{c}\text { Conduc } \\
\text { tivity }\end{array}$ & $\mathrm{pH}$ & Silica & $\begin{array}{c}\text { Sulphat } \\
\text { e }\end{array}$ & $\begin{array}{c}\text { Total } \\
\text { Hardness }\end{array}$ \\
\hline S26/0467 & 2719290 & 6015570 & $\begin{array}{r}20 / 06 / 2006 \\
13: 33\end{array}$ & 125 & 6.4 & 18.9 & 9.9 & 26 \\
\hline S26/0439 & 2717510 & 6016900 & $\begin{array}{r}20 / 06 / 2006 \\
14: 11\end{array}$ & 166 & 6.5 & 21.3 & 12.1 & 47 \\
\hline S26/0705 & 2720489 & 6015999 & $\begin{array}{r}26 / 06 / 2006 \\
9: 21\end{array}$ & 166 & 6.6 & 25 & 10 & 40 \\
\hline S26/0824 & 2720564 & 6016101 & $\begin{array}{r}26 / 06 / 2006 \\
9: 48\end{array}$ & 169 & 6.4 & 22.4 & 10.5 & 44 \\
\hline $\begin{array}{c}\text { S26/0705 } \\
\text { NGMP }\end{array}$ & 2720489 & 6015999 & $\begin{array}{r}26 / 06 / 2006 \\
12: 00\end{array}$ & & $\begin{array}{r}6.3 \\
9\end{array}$ & 26 & 9.2 & \\
\hline S26/0576 & 2723479 & 6014255 & $\begin{array}{r}30 / 06 / 2006 \\
9: 47\end{array}$ & 217 & 7.2 & 34.1 & 2.2 & 63 \\
\hline S26/0846 & 2717921 & 6011212 & $\begin{array}{r}4 / 07 / 2006 \\
14: 06\end{array}$ & 94 & 6.5 & 12.8 & 3.5 & 29 \\
\hline T26/0332 & 2732246 & 6019123 & $\begin{array}{r}4 / 09 / 2006 \\
13: 27\end{array}$ & 212 & 6.4 & 39.1 & 12.4 & 49 \\
\hline S26/0223 & 2726219 & 6021005 & $\begin{array}{r}4 / 09 / 2006 \\
14: 05\end{array}$ & 184 & 6 & 15.3 & 11 & 51 \\
\hline S26/0299 & 2728370 & 6023590 & $\begin{array}{r}4 / 09 / 2006 \\
14: 41\end{array}$ & 132 & 6.1 & 11.6 & 11.7 & 38 \\
\hline S26/0762 & 2725720 & 6011070 & $\begin{array}{r}5 / 09 / 2006 \\
9: 43\end{array}$ & 345 & 6.7 & 23.8 & 0.9 & 91 \\
\hline S26/0756 & 2725937 & 6010018 & $\begin{array}{r}5 / 09 / 2006 \\
10: 18\end{array}$ & 314 & 6.7 & 18.1 & 13 & 119 \\
\hline S26/0568 & 2723504 & 6013642 & $\begin{array}{r}5 / 09 / 2006 \\
11: 12\end{array}$ & 268 & 7.3 & 35.8 & $<0.500$ & 98 \\
\hline S26/0576 & 2723479 & 6014255 & $\begin{array}{r}5 / 09 / 2006 \\
11: 44\end{array}$ & 220 & 7.1 & 34 & 2.4 & 66 \\
\hline S26/0117 & 2721500 & 6018500 & $\begin{array}{r}5 / 09 / 2006 \\
12: 36\end{array}$ & 170 & 6.1 & 14 & 7.3 & 50 \\
\hline S26/0439 & 2717510 & 6016900 & $\begin{array}{r}5 / 09 / 2006 \\
13: 19\end{array}$ & 169 & 6.6 & 22 & 11.3 & 52 \\
\hline S26/0467 & 2719290 & 6015570 & $\begin{array}{r}5 / 09 / 2006 \\
14: 01\end{array}$ & 136 & 6.6 & 18.3 & 8.6 & 31 \\
\hline S26/0457 & 2717675 & 6012051 & $\begin{array}{r}7 / 09 / 2006 \\
10: 10\end{array}$ & 105 & 6.5 & 8.9 & 4.9 & 35 \\
\hline S26/0824 & 2720564 & 6016101 & $\begin{array}{r}20 / 09 / 2006 \\
9: 39\end{array}$ & 170 & 6.5 & 23.4 & 10.8 & 43 \\
\hline S26/0705 & 2720489 & 6015999 & $\begin{array}{r}20 / 09 / 2006 \\
9: 53\end{array}$ & 165 & 6.5 & 25.9 & 10.1 & 39 \\
\hline $\begin{array}{c}\text { S26/0705 } \\
\text { NGMP }\end{array}$ & 2720489 & 6015999 & $\begin{array}{r}20 / 09 / 2006 \\
12: 00\end{array}$ & & $\begin{array}{r}6.3 \\
2\end{array}$ & 25 & 9.2 & \\
\hline S26/0846 & 2717921 & 6011212 & $\begin{array}{r}5 / 10 / 2006 \\
11: 46\end{array}$ & 97 & 6.7 & 12.9 & 3 & 30 \\
\hline T26/0332 & 2732246 & 6019123 & $\begin{array}{r}5 / 12 / 2006 \\
12: 07\end{array}$ & 218 & 6.1 & 40.4 & 12.6 & 52 \\
\hline S26/0299 & 2728370 & 6023590 & $\begin{array}{r}5 / 12 / 2006 \\
13: 23\end{array}$ & 109 & 6 & 12.5 & 11.7 & 30 \\
\hline S26/0223 & 2726219 & 6021005 & $\begin{array}{r}5 / 12 / 2006 \\
15: 50\end{array}$ & 207 & 5.8 & 16.1 & 11.7 & 59 \\
\hline
\end{tabular}




\begin{tabular}{|c|c|c|c|c|c|c|c|c|}
\hline Site Name & Easting & Northing & Time & $\begin{array}{c}\text { Conduc } \\
\text { tivity }\end{array}$ & $\mathrm{pH}$ & Silica & $\begin{array}{c}\text { Sulphat } \\
\text { e }\end{array}$ & $\begin{array}{c}\text { Total } \\
\text { Hardness }\end{array}$ \\
\hline S26/0824 & 2720564 & 6016101 & $\begin{array}{r}7 / 12 / 2006 \\
8: 13\end{array}$ & 174 & 6.3 & 23.3 & 10.1 & 46 \\
\hline S26/0705 & 2720489 & 6015999 & $\begin{array}{r}7 / 12 / 2006 \\
8: 42\end{array}$ & 167 & 6.4 & 25.7 & 9.4 & 40 \\
\hline $\begin{array}{c}\text { S26/0705 } \\
\text { NGMP }\end{array}$ & 2720489 & 6015999 & $\begin{array}{r}7 / 12 / 2006 \\
12: 00\end{array}$ & & $\begin{array}{r}6.2 \\
6\end{array}$ & 25 & 9 & \\
\hline S26/0762 & 2725720 & 6011070 & $\begin{array}{r}12 / 12 / 2006 \\
9: 13\end{array}$ & 352 & 6.7 & 23.8 & 0.6 & 84 \\
\hline S26/0756 & 2725937 & 6010018 & $\begin{array}{r}12 / 12 / 2006 \\
9: 48\end{array}$ & 342 & 6.6 & 18.2 & 16.6 & 119 \\
\hline S26/0568 & 2723504 & 6013642 & $\begin{array}{r}12 / 12 / 2006 \\
10: 40\end{array}$ & 272 & 7.3 & 36.3 & $<0.500$ & 91 \\
\hline S26/0576 & 2723479 & 6014255 & $\begin{array}{r}12 / 12 / 2006 \\
11: 06\end{array}$ & 218 & 7.1 & 34.6 & 1.8 & 63 \\
\hline S26/0467 & 2719290 & 6015570 & $\begin{array}{r}12 / 12 / 2006 \\
12: 07\end{array}$ & 148 & 6.5 & 18.1 & 8.1 & 30 \\
\hline S26/0439 & 2717510 & 6016900 & $\begin{array}{r}12 / 12 / 2006 \\
12: 42\end{array}$ & 169 & 6.6 & 21.8 & 10.5 & 47 \\
\hline S26/0117 & 2721500 & 6018500 & $\begin{array}{r}12 / 12 / 2006 \\
13: 47\end{array}$ & 158 & 6.2 & 14 & 7.9 & 42 \\
\hline S26/0457 & 2717675 & 6012051 & $\begin{array}{r}14 / 12 / 2006 \\
8: 32\end{array}$ & 82 & 6.5 & 8.7 & 5.4 & 27 \\
\hline S26/0846 & 2717921 & 6011212 & $\begin{array}{r}14 / 12 / 2006 \\
9: 32\end{array}$ & 100 & 6.8 & 13.4 & 3.6 & 31 \\
\hline S26/0457 & 2717675 & 6012051 & $\begin{array}{r}6 / 03 / 2007 \\
9: 15\end{array}$ & 75 & 6.6 & 8.4 & 4.1 & 23 \\
\hline S26/0223 & 2726219 & 6021005 & $\begin{array}{r}6 / 03 / 2007 \\
13: 35\end{array}$ & 195 & 6 & 16.3 & 10 & 50 \\
\hline S26/0299 & 2728370 & 6023590 & $\begin{array}{r}6 / 03 / 2007 \\
14: 05\end{array}$ & 107 & 6.1 & 12.9 & 11.1 & 27 \\
\hline T26/0332 & 2732246 & 6019123 & $\begin{array}{r}6 / 03 / 2007 \\
14: 36\end{array}$ & 213 & 6.2 & 38.6 & 11.6 & 47 \\
\hline S26/0576 & 2723479 & 6014255 & $\begin{array}{r}7 / 03 / 2007 \\
8: 49\end{array}$ & 218 & 7.3 & 31.7 & 3.5 & 67 \\
\hline S26/0568 & 2723504 & 6013642 & $\begin{array}{r}7 / 03 / 2007 \\
9: 22\end{array}$ & 265 & 7.5 & 35.8 & $<0.500$ & 99 \\
\hline S26/0467 & 2719290 & 6015570 & $\begin{array}{r}7 / 03 / 2007 \\
10: 04\end{array}$ & 134 & 6.7 & 18.4 & 9.6 & 31 \\
\hline S26/0439 & 2717510 & 6016900 & $\begin{array}{r}7 / 03 / 2007 \\
10: 38\end{array}$ & 172 & 6.6 & 22.6 & 10.5 & 50 \\
\hline S26/0117 & 2721500 & 6018500 & $\begin{array}{r}7 / 03 / 2007 \\
11: 15\end{array}$ & 141 & 6.4 & 14.8 & 8.9 & 39 \\
\hline S26/0762 & 2725720 & 6011070 & $\begin{array}{r}7 / 03 / 2007 \\
12: 00\end{array}$ & 342 & 6.7 & 23.7 & 1 & 87 \\
\hline S26/0756 & 2725937 & 6010018 & $\begin{array}{r}7 / 03 / 2007 \\
12: 29\end{array}$ & 292 & 6.8 & 22.7 & 8.2 & 105 \\
\hline S26/0846 & 2717921 & 6011212 & $\begin{array}{r}19 / 03 / 2007 \\
13: 32\end{array}$ & 100 & 6.8 & 13.9 & 3.2 & 29 \\
\hline S26/0705 & 2720489 & 6015999 & $\begin{array}{r}26 / 03 / 2007 \\
9: 32\end{array}$ & 167 & 6.9 & 25.4 & 9.6 & 42 \\
\hline
\end{tabular}




\begin{tabular}{|c|c|c|c|c|c|c|c|c|}
\hline Site Name & Easting & Northing & Time & $\begin{array}{c}\text { Conduc } \\
\text { tivity }\end{array}$ & $\mathrm{pH}$ & Silica & $\begin{array}{c}\text { Sulphat } \\
\text { e }\end{array}$ & $\begin{array}{c}\text { Total } \\
\text { Hardness }\end{array}$ \\
\hline S26/0824 & 2720564 & 6016101 & $\begin{array}{r}26 / 03 / 2007 \\
10: 00\end{array}$ & 175 & 7 & 22.9 & 10.2 & 48 \\
\hline $\begin{array}{c}\text { S26/0705 } \\
\text { NGMP }\end{array}$ & 2720489 & 6015999 & $\begin{array}{r}26 / 03 / 2007 \\
12: 00\end{array}$ & 164 & $\begin{array}{r}6.3 \\
4\end{array}$ & 25 & 9.5 & \\
\hline T26/0332 & 2732246 & 6019123 & $\begin{array}{r}13 / 06 / 2007 \\
15: 33\end{array}$ & 208 & 6.2 & 39.3 & 11.7 & 46 \\
\hline S26/0223 & 2726219 & 6021005 & $\begin{array}{r}13 / 06 / 2007 \\
16: 09\end{array}$ & 167 & 5.9 & 14.9 & 8.2 & 42 \\
\hline S26/0568 & 2723504 & 6013642 & $\begin{array}{r}19 / 06 / 2007 \\
10: 00\end{array}$ & 273 & 7 & 36.6 & $<0.500$ & 86 \\
\hline S26/0762 & 2725720 & 6011070 & $\begin{array}{r}19 / 06 / 2007 \\
10: 44\end{array}$ & 318 & 6.6 & 23.6 & $<0.500$ & 69 \\
\hline S26/0756 & 2725937 & 6010018 & $\begin{array}{r}19 / 06 / 2007 \\
11: 19\end{array}$ & 305 & 6.6 & 18.7 & 12.9 & 103 \\
\hline S26/0467 & 2719290 & 6015570 & $\begin{array}{r}19 / 06 / 2007 \\
12: 23\end{array}$ & 131 & 6.4 & 19.6 & 9 & 26 \\
\hline S26/0439 & 2717510 & 6016900 & $\begin{array}{r}19 / 06 / 2007 \\
13: 01\end{array}$ & 171 & 6.4 & 24.1 & 10.5 & 47 \\
\hline S26/0117 & 2721500 & 6018500 & $\begin{array}{r}19 / 06 / 2007 \\
13: 31\end{array}$ & 125 & 5.8 & 15.1 & 8.5 & 29 \\
\hline S26/0846 & 2717921 & 6011212 & $\begin{array}{r}20 / 06 / 2007 \\
13: 31\end{array}$ & 96 & 6.4 & 13.6 & 3.2 & 27 \\
\hline S26/0705 & 2720489 & 6015999 & $\begin{array}{r}28 / 06 / 2007 \\
9: 50\end{array}$ & 168 & 6.2 & 24.7 & 9.9 & 41 \\
\hline S26/0824 & 2720564 & 6016101 & $\begin{array}{r}28 / 06 / 2007 \\
10: 14\end{array}$ & 175 & 6 & 22.5 & 10.4 & 47 \\
\hline $\begin{array}{c}\text { S26/0705 } \\
\text { NGMP }\end{array}$ & 2720489 & 6015999 & $\begin{array}{r}28 / 06 / 2007 \\
12: 00\end{array}$ & & $\begin{array}{r}6.6 \\
6\end{array}$ & 25 & 8.9 & \\
\hline
\end{tabular}

\section{Tritium calibration dataset}

Bold rows indicate field measured tritium data. The additional (non-bold) are data inferred from the field tritium measurements and observed hydrochemistry measurements of silica through multivariate regression.

Tab. D-4 Tritium dataset for the calibration of the Middle Valley model

\begin{tabular}{rccrccrrr}
\hline num & group & type & location & name & date & simtime & value & weight \\
\hline 1 & S26/0155 & node & 79761 & $\mathrm{~S} 26 / 0155 / 1$ & $3 / 05 / 2005$ & 4689 & 1.74 & 16.66667 \\
2 & S26/0117 & node & 28302 & $\mathrm{~S} 26 / 0117 / 1$ & $27 / 01 / 2005$ & 4593 & 1.528759 & 0.821646 \\
3 & S26/0117 & node & 28302 & $\mathrm{~S} 26 / 0117 / 2$ & $23 / 03 / 2005$ & 4648 & 1.538612 & 0.826046 \\
4 & $\mathrm{~S} 26 / 0117$ & node & 28302 & $\mathrm{~S} 26 / 0117 / 3$ & $20 / 07 / 2005$ & 4767 & 1.597727 & 0.853471 \\
5 & $\mathrm{~S} 26 / 0117$ & node & 28302 & $\mathrm{~S} 26 / 0117 / 4$ & $23 / 09 / 2005$ & 4832 & 1.622358 & 0.865443 \\
6 & $\mathrm{~S} 26 / 0117$ & node & 28302 & $\mathrm{~S} 26 / 0117 / 5$ & $13 / 12 / 2005$ & 4913 & 1.632211 & 0.870326 \\
\hline
\end{tabular}




\begin{tabular}{|c|c|c|c|c|c|c|c|c|}
\hline num & group & type & Iocation & name & date & simtime & value & weight \\
\hline 7 & S26/0117 & node & 28302 & S26/0117/6 & $7 / 04 / 2006$ & 5028 & 1.60758 & 0.85822 \\
\hline 8 & S26/0117 & node & 28302 & S26/0117/7 & $20 / 06 / 2006$ & 5102 & 1.627285 & 0.867877 \\
\hline 9 & S26/0117 & node & 28302 & S26/0117/8 & $5 / 09 / 2006$ & 5179 & 1.656842 & 0.882779 \\
\hline 10 & S26/0117 & node & 28302 & S26/0117/9 & $12 / 12 / 2006$ & 5277 & 1.656842 & 0.882779 \\
\hline 11 & S26/0117 & node & 28302 & S26/0117/10 & $7 / 03 / 2007$ & 5362 & 1.617432 & 0.863021 \\
\hline 12 & S26/0117 & node & 28302 & S26/0117/11 & $19 / 06 / 2007$ & 5466 & 1.602653 & 0.855839 \\
\hline 13 & S26/0223 & node & 43628 & S26/0223/1 & $21 / 10 / 2004$ & 4496 & 1.553391 & 0.832736 \\
\hline 14 & S26/0223 & node & 43628 & S26/0223/2 & $10 / 12 / 2004$ & 4545 & 1.51398 & 0.815133 \\
\hline 15 & S26/0223 & node & 43628 & S26/0223/3 & $15 / 03 / 2005$ & 4640 & 1.51398 & 0.815133 \\
\hline 16 & S26/0223 & node & 43628 & S26/0223/4 & $8 / 07 / 2005$ & 4755 & 1.518907 & 0.817292 \\
\hline 17 & S26/0223 & node & 43628 & S26/0223/5 & 21/09/2005 & 4830 & 1.509054 & 0.812985 \\
\hline 18 & S26/0223 & node & 43628 & S26/0223/6 & $12 / 12 / 2005$ & 4912 & 1.612506 & 0.860614 \\
\hline 19 & S26/0223 & node & 43628 & S26/0223/7 & $16 / 03 / 2006$ & 5006 & 1.632211 & 0.870326 \\
\hline 20 & S26/0223 & node & 43628 & S26/0223/8 & $15 / 06 / 2006$ & 5097 & 1.568169 & 0.839535 \\
\hline 21 & S26/0223 & node & 43628 & S26/0223/9 & $4 / 09 / 2006$ & 5178 & 1.592801 & 0.851116 \\
\hline 22 & S26/0223 & node & 43628 & S26/0223/10 & $5 / 12 / 2006$ & 5270 & 1.553391 & 0.832736 \\
\hline 23 & S26/0223 & node & 43628 & S26/0223/11 & 6/03/2007 & 5361 & 1.543538 & 0.828264 \\
\hline 24 & S26/0223 & node & 43628 & S26/0223/12 & $13 / 06 / 2007$ & 5460 & 1.612506 & 0.860614 \\
\hline 25 & S26/0244 & node & 11787 & S26/0244/1 & $3 / 05 / 2005$ & 4689 & 1.91 & 20 \\
\hline 26 & S26/0244 & node & 11787 & S26/0244/2 & $3 / 05 / 2005$ & 4689 & 1.745515 & 0.930719 \\
\hline 27 & S26/0299 & node & 33620 & S26/0299/1 & $9 / 10 / 2003$ & 4117 & 1.745515 & 0.930719 \\
\hline 28 & S26/0299 & node & 33620 & S26/0299/2 & $12 / 12 / 2003$ & 4181 & 1.720884 & 0.916888 \\
\hline 29 & S26/0299 & node & 33620 & S26/0299/3 & $22 / 03 / 2004$ & 4282 & 1.706105 & 0.908785 \\
\hline 30 & S26/0299 & node & 33620 & S26/0299/4 & $10 / 06 / 2004$ & 4362 & 1.711031 & 0.91147 \\
\hline 31 & S26/0299 & node & 33620 & S26/0299/5 & $22 / 09 / 2004$ & 4466 & 1.720884 & 0.916888 \\
\hline 32 & S26/0299 & node & 33620 & S26/0299/6 & $10 / 12 / 2004$ & 4545 & 1.696252 & 0.903462 \\
\hline 33 & S26/0299 & node & 33620 & S26/0299/7 & $15 / 03 / 2005$ & 4640 & 1.666695 & 0.88786 \\
\hline 34 & S26/0299 & node & 33620 & S26/0299/8 & $8 / 07 / 2005$ & 4755 & 1.701179 & 0.906115 \\
\hline 35 & S26/0299 & node & 33620 & S26/0299/9 & 21/09/2005 & 4830 & 1.706105 & 0.908785 \\
\hline 36 & S26/0299 & node & 33620 & S26/0299/10 & $12 / 12 / 2005$ & 4912 & 1.711031 & 0.91147 \\
\hline 37 & S26/0299 & node & 33620 & S26/0299/11 & $16 / 03 / 2006$ & 5006 & 1.691326 & 0.900823 \\
\hline 38 & S26/0299 & node & 33620 & S26/0299/12 & $15 / 06 / 2006$ & 5097 & 1.715957 & 0.914171 \\
\hline 39 & S26/0299 & node & 33620 & S26/0299/13 & $4 / 09 / 2006$ & 5178 & 1.775073 & 0.947878 \\
\hline 40 & S26/0299 & node & 33620 & S26/0299/14 & $5 / 12 / 2006$ & 5270 & 1.730736 & 0.922371 \\
\hline 41 & S26/0299 & node & 33620 & S26/0299/15 & 6/03/2007 & 5361 & 1.711031 & 0.91147 \\
\hline 42 & S26/0395 & node & 20248 & S26/0395/1 & $3 / 05 / 2005$ & 4689 & 1.81 & 20 \\
\hline 43 & S26/0395 & node & 20248 & S26/0395/2 & $3 / 05 / 2005$ & 4689 & 1.834188 & 0.984166 \\
\hline 44 & S26/0400 & node & 79763 & S26/0400/1 & $27 / 01 / 2005$ & 4593 & 0.356307 & 0.502873 \\
\hline 45 & S26/0439 & node & 76179 & S26/0439/1 & $18 / 01 / 2005$ & 4584 & 1.218404 & 0.703586 \\
\hline 46 & S26/0439 & node & 76179 & S26/0439/2 & $23 / 03 / 2005$ & 4648 & 1.124805 & 0.674363 \\
\hline 47 & S26/0439 & node & 76179 & S26/0439/3 & $20 / 07 / 2005$ & 4767 & 1.218404 & 0.703586 \\
\hline 48 & S26/0439 & node & 76179 & S26/0439/4 & $23 / 09 / 2005$ & 4832 & 1.178994 & 0.690978 \\
\hline 49 & S26/0439 & node & 76179 & S26/0439/5 & $13 / 12 / 2005$ & 4913 & 1.218404 & 0.703586 \\
\hline 50 & S26/0439 & node & 76179 & S26/0439/6 & $7 / 04 / 2006$ & 5028 & 1.188847 & 0.694087 \\
\hline 51 & S26/0439 & node & 76179 & S26/0439/7 & $20 / 06 / 2006$ & 5102 & 1.297224 & 0.730233 \\
\hline
\end{tabular}




\begin{tabular}{|c|c|c|c|c|c|c|c|c|}
\hline num & group & type & location & name & date & simtime & value & weight \\
\hline 52 & S26/0439 & node & 76179 & S26/0439/8 & $5 / 09 / 2006$ & 5179 & 1.262741 & 0.718331 \\
\hline 53 & S26/0439 & node & 76179 & S26/0439/9 & $12 / 12 / 2006$ & 5277 & 1.272593 & 0.721692 \\
\hline 54 & S26/0439 & node & 76179 & S26/0439/10 & $7 / 03 / 2007$ & 5362 & 1.233183 & 0.708433 \\
\hline 55 & S26/0439 & node & 76179 & S26/0439/11 & $19 / 06 / 2007$ & 5466 & 1.159289 & 0.684842 \\
\hline 56 & S26/0457 & node & 14732 & S26/0457/1 & $15 / 10 / 2003$ & 4123 & 1.888377 & 1.01996 \\
\hline 57 & S26/0457 & node & 14732 & S26/0457/2 & $30 / 03 / 2004$ & 4290 & 1.922861 & 1.044125 \\
\hline 58 & S26/0457 & node & 14732 & S26/0457/3 & $11 / 06 / 2004$ & 4363 & 1.922861 & 1.044125 \\
\hline 59 & S26/0457 & node & 14732 & S26/0457/4 & $4 / 10 / 2004$ & 4478 & 1.858819 & 1.00012 \\
\hline 60 & S26/0457 & node & 14732 & S26/0457/5 & $17 / 12 / 2004$ & 4552 & 1.913008 & 1.037105 \\
\hline 61 & S26/0457 & node & 14732 & S26/0457/6 & $23 / 03 / 2005$ & 4648 & 1.903156 & 1.030178 \\
\hline 62 & S26/0457 & node & 14732 & S26/0457/7 & 20/07/2005 & 4767 & 1.913008 & 1.037105 \\
\hline 63 & S26/0457 & node & 14732 & S26/0457/8 & $12 / 10 / 2005$ & 4851 & 1.917935 & 1.040603 \\
\hline 64 & S26/0457 & node & 14732 & S26/0457/9 & $16 / 12 / 2005$ & 4916 & 1.908082 & 1.03363 \\
\hline 65 & S26/0457 & node & 14732 & S26/0457/10 & $14 / 03 / 2006$ & 5004 & 1.908082 & 1.03363 \\
\hline 66 & S26/0457 & node & 14732 & S26/0457/11 & $7 / 09 / 2006$ & 5181 & 1.908082 & 1.03363 \\
\hline 67 & S26/0457 & node & 14732 & S26/0457/12 & $14 / 12 / 2006$ & 5279 & 1.917935 & 1.040603 \\
\hline 68 & S26/0457 & node & 14732 & S26/0457/13 & $6 / 03 / 2007$ & 5361 & 1.932713 & 1.051242 \\
\hline 69 & S26/0467 & node & 26611 & S26/0467/1 & $27 / 01 / 2005$ & 4593 & 1.321856 & 0.73898 \\
\hline 70 & S26/0467 & node & 26611 & S26/0467/2 & $23 / 03 / 2005$ & 4648 & 1.31693 & 0.737214 \\
\hline 71 & S26/0467 & node & 26611 & S26/0467/3 & $20 / 07 / 2005$ & 4767 & 1.400676 & 0.768432 \\
\hline 72 & S26/0467 & node & 26611 & S26/0467/4 & $23 / 09 / 2005$ & 4832 & 1.39575 & 0.766523 \\
\hline 73 & S26/0467 & node & 26611 & S26/0467/5 & $13 / 12 / 2005$ & 4913 & 1.440086 & 0.784057 \\
\hline 74 & S26/0467 & node & 26611 & S26/0467/6 & $7 / 04 / 2006$ & 5028 & 1.420381 & 0.776166 \\
\hline 75 & S26/0467 & node & 26611 & S26/0467/7 & $20 / 06 / 2006$ & 5102 & 1.415455 & 0.774218 \\
\hline 76 & S26/0467 & node & 26611 & S26/0467/8 & $5 / 09 / 2006$ & 5179 & 1.445013 & 0.786054 \\
\hline 77 & S26/0467 & node & 26611 & S26/0467/9 & $12 / 12 / 2006$ & 5277 & 1.454865 & 0.790081 \\
\hline 78 & S26/0467 & node & 26611 & S26/0467/10 & $7 / 03 / 2007$ & 5362 & 1.440086 & 0.784057 \\
\hline 79 & S26/0467 & node & 26611 & S26/0467/11 & $19 / 06 / 2007$ & 5466 & 1.380971 & 0.760851 \\
\hline 80 & S26/0568 & node & 79739 & S26/0568/1 & $15 / 10 / 2003$ & 4123 & 0.449906 & 0.518946 \\
\hline 81 & S26/0568 & node & 79739 & S26/0568/2 & $30 / 03 / 2004$ & 4290 & 0.701146 & 0.567646 \\
\hline 82 & S26/0568 & node & 79739 & S26/0568/3 & $17 / 06 / 2004$ & 4369 & 0.56321 & 0.539833 \\
\hline 83 & S26/0568 & node & 79739 & S26/0568/4 & $4 / 10 / 2004$ & 4478 & 0.40557 & 0.511206 \\
\hline 84 & S26/0568 & node & 79739 & S26/0568/5 & $18 / 01 / 2005$ & 4584 & 0.548431 & 0.537013 \\
\hline 85 & S26/0568 & node & 79739 & S26/0568/6 & 23/03/2005 & 4648 & 0.454832 & 0.51982 \\
\hline 86 & S26/0568 & node & 79739 & S26/0568/7 & $11 / 07 / 2005$ & 4758 & 0.499169 & 0.527825 \\
\hline 87 & S26/0568 & node & 79739 & S26/0568/8 & $23 / 09 / 2005$ & 4832 & 0.528726 & 0.5333 \\
\hline 88 & S26/0568 & node & 79739 & S26/0568/9 & $12 / 01 / 2006$ & 4943 & 0.573063 & 0.541728 \\
\hline 89 & S26/0568 & node & 79739 & S26/0568/10 & $7 / 04 / 2006$ & 5028 & 0.558284 & 0.538889 \\
\hline 90 & S26/0568 & node & 79739 & S26/0568/11 & $20 / 06 / 2006$ & 5102 & 0.538579 & 0.53515 \\
\hline 91 & S26/0568 & node & 79739 & S26/0568/12 & $5 / 09 / 2006$ & 5179 & 0.582915 & 0.543638 \\
\hline 92 & S26/0568 & node & 79739 & S26/0568/13 & $12 / 12 / 2006$ & 5277 & 0.558284 & 0.538889 \\
\hline 93 & S26/0568 & node & 79739 & $S 26 / 0568 / 14$ & $7 / 03 / 2007$ & 5362 & 0.582915 & 0.543638 \\
\hline 94 & S26/0568 & node & 79739 & S26/0568/15 & $19 / 06 / 2007$ & 5466 & 0.543505 & 0.53608 \\
\hline 95 & S26/0576 & node & 14228 & S26/0576/1 & $15 / 10 / 2003$ & 4123 & 0.489316 & 0.526025 \\
\hline 96 & S26/0576 & node & 14228 & S26/0576/2 & $30 / 03 / 2004$ & 4290 & 0.77504 & 0.583759 \\
\hline
\end{tabular}




\begin{tabular}{|c|c|c|c|c|c|c|c|c|}
\hline num & group & type & location & name & date & simtime & value & weight \\
\hline 97 & S26/0576 & node & 14228 & S26/0576/3 & $17 / 06 / 2004$ & 4369 & 0.69622 & 0.566603 \\
\hline 98 & S26/0576 & node & 14228 & S26/0576/4 & $4 / 10 / 2004$ & 4478 & 0.568137 & 0.540779 \\
\hline 99 & S26/0576 & node & 14228 & S26/0576/5 & $18 / 01 / 2005$ & 4584 & 0.642031 & 0.555383 \\
\hline 100 & S26/0576 & node & 14228 & S26/0576/6 & $23 / 03 / 2005$ & 4648 & 0.686367 & 0.56453 \\
\hline 101 & S26/0576 & node & 14228 & S26/0576/7 & $11 / 07 / 2005$ & 4758 & 0.646957 & 0.556384 \\
\hline 102 & S26/0576 & node & 14228 & S26/0576/8 & $23 / 09 / 2005$ & 4832 & 0.632178 & 0.55339 \\
\hline 103 & S26/0576 & node & 14228 & S26/0576/9 & $13 / 12 / 2005$ & 4913 & 0.750409 & 0.578287 \\
\hline 104 & S26/0576 & node & 14228 & S26/0576/10 & $30 / 06 / 2006$ & 5112 & 0.666662 & 0.560427 \\
\hline 105 & S26/0576 & node & 14228 & S26/0576/11 & $5 / 09 / 2006$ & 5179 & 0.671588 & 0.561447 \\
\hline 106 & S26/0576 & node & 14228 & S26/0576/12 & $12 / 12 / 2006$ & 5277 & 0.642031 & 0.555383 \\
\hline 107 & S26/0576 & node & 14228 & S26/0576/13 & $7 / 03 / 2007$ & 5362 & 0.784892 & 0.585976 \\
\hline 108 & S26/0705 & node & 12970 & S26/0705/1 & $9 / 10 / 2003$ & 4117 & 1.055837 & 0.654337 \\
\hline 109 & S26/0705 & node & 12970 & S26/0705/2 & $12 / 12 / 2003$ & 4181 & 1.006575 & 0.640746 \\
\hline 110 & S26/0705 & node & 12970 & S26/0705/3 & $26 / 03 / 2004$ & 4286 & 1.114953 & 0.671427 \\
\hline 111 & S26/0705 & node & 12970 & S26/0705/4 & $10 / 06 / 2004$ & 4362 & 1.075542 & 0.659936 \\
\hline 112 & S26/0705 & node & 12970 & S26/0705/5 & 22/09/2004 & 4466 & 1.016427 & 0.643419 \\
\hline 113 & S26/0705 & node & 12970 & S26/0705/6 & $7 / 12 / 2004$ & 4542 & 1.06569 & 0.657125 \\
\hline 114 & S26/0705 & node & 12970 & S26/0705/7 & $23 / 03 / 2005$ & 4648 & 0.967164 & 0.630273 \\
\hline 115 & S26/0705 & node & 12970 & S26/0705/8 & $12 / 05 / 2005$ & 4698 & 1.41 & 16.66667 \\
\hline 116 & S26/0705 & node & 12970 & S26/0705/9 & $27 / 07 / 2005$ & 4774 & 0.981943 & 0.63416 \\
\hline 117 & S26/0705 & node & 12970 & S26/0705/10 & $18 / 10 / 2005$ & 4857 & 1.075542 & 0.659936 \\
\hline 118 & S26/0705 & node & 12970 & S26/0705/11 & $12 / 01 / 2006$ & 4943 & 1.021353 & 0.644764 \\
\hline 119 & S26/0705 & node & 12970 & S26/0705/12 & $15 / 03 / 2006$ & 5005 & 1.080469 & 0.661351 \\
\hline 120 & S26/0705 & node & 12970 & S26/0705/13 & $26 / 06 / 2006$ & 5108 & 1.114953 & 0.671427 \\
\hline 121 & S26/0705 & node & 12970 & S26/0705/14 & $20 / 09 / 2006$ & 5194 & 1.070616 & 0.658527 \\
\hline 122 & S26/0705 & node & 12970 & S26/0705/15 & $7 / 12 / 2006$ & 5272 & 1.080469 & 0.661351 \\
\hline 123 & S26/0705 & node & 12970 & S26/0705/16 & 26/03/2007 & 5381 & 1.095247 & 0.665632 \\
\hline 124 & S26/0705 & node & 12970 & S26/0705/17 & $28 / 06 / 2007$ & 5475 & 1.129731 & 0.67584 \\
\hline 125 & S26/0756 & node & 12957 & S26/0756/1 & $15 / 10 / 2003$ & 4123 & 1.380971 & 0.760851 \\
\hline 126 & S26/0756 & node & 12957 & S26/0756/2 & $30 / 03 / 2004$ & 4290 & 1.449939 & 0.788063 \\
\hline 127 & S26/0756 & node & 12957 & S26/0756/3 & $17 / 06 / 2004$ & 4369 & 1.430234 & 0.780091 \\
\hline 128 & S26/0756 & node & 12957 & S26/0756/4 & $4 / 10 / 2004$ & 4478 & 1.366192 & 0.755263 \\
\hline 129 & S26/0756 & node & 12957 & S26/0756/5 & $18 / 01 / 2005$ & 4584 & 1.292298 & 0.728509 \\
\hline 130 & S26/0756 & node & 12957 & S26/0756/6 & $23 / 03 / 2005$ & 4648 & 1.247962 & 0.713348 \\
\hline 131 & S26/0756 & node & 12957 & S26/0756/7 & $11 / 07 / 2005$ & 4758 & 1.415455 & 0.774218 \\
\hline 132 & S26/0756 & node & 12957 & S26/0756/8 & $23 / 09 / 2005$ & 4832 & 1.371119 & 0.757116 \\
\hline 133 & S26/0756 & node & 12957 & S26/0756/9 & $13 / 12 / 2005$ & 4913 & 1.252888 & 0.715001 \\
\hline 134 & S26/0756 & node & 12957 & S26/0756/10 & $22 / 03 / 2006$ & 5012 & 1.257814 & 0.716662 \\
\hline 135 & S26/0756 & node & 12957 & S26/0756/11 & $20 / 06 / 2006$ & 5102 & 1.35634 & 0.751583 \\
\hline 136 & S26/0756 & node & 12957 & S26/0756/12 & $5 / 09 / 2006$ & 5179 & 1.454865 & 0.790081 \\
\hline 137 & S26/0756 & node & 12957 & S26/0756/13 & $12 / 12 / 2006$ & 5277 & 1.449939 & 0.788063 \\
\hline 138 & S26/0756 & node & 12957 & S26/0756/14 & $7 / 03 / 2007$ & 5362 & 1.228257 & 0.70681 \\
\hline 139 & S26/0756 & node & 12957 & S26/0756/15 & 19/06/2007 & 5466 & 1.425308 & 0.778124 \\
\hline 140 & S26/0762 & node & 36911 & S26/0762/1 & $15 / 10 / 2003$ & 4123 & 1.119879 & 0.672892 \\
\hline 141 & S26/0762 & node & 36911 & S26/0762/2 & $30 / 03 / 2004$ & 4290 & 1.238109 & 0.710064 \\
\hline
\end{tabular}




\begin{tabular}{|c|c|c|c|c|c|c|c|c|}
\hline num & group & type & location & name & date & simtime & value & weight \\
\hline 142 & S26/0762 & node & 36911 & $\mathrm{~S} 26 / 0762 / 3$ & $17 / 06 / 2004$ & 4369 & 1.213478 & 0.701985 \\
\hline 143 & S26/0762 & node & 36911 & S26/0762/4 & $4 / 10 / 2004$ & 4478 & 1.085395 & 0.662772 \\
\hline 144 & S26/0762 & node & 36911 & S26/0762/5 & $18 / 01 / 2005$ & 4584 & 1.208552 & 0.700391 \\
\hline 145 & S26/0762 & node & 36911 & S26/0762/6 & $23 / 03 / 2005$ & 4648 & 1.178994 & 0.690978 \\
\hline 146 & S26/0762 & node & 36911 & S26/0762/7 & $11 / 07 / 2005$ & 4758 & 1.178994 & 0.690978 \\
\hline 147 & S26/0762 & node & 36911 & S26/0762/8 & 23/09/2005 & 4832 & 1.188847 & 0.694087 \\
\hline 148 & S26/0762 & node & 36911 & S26/0762/9 & $13 / 12 / 2005$ & 4913 & 1.193773 & 0.695653 \\
\hline 149 & S26/0762 & node & 36911 & S26/0762/10 & $22 / 03 / 2006$ & 5012 & 1.114953 & 0.671427 \\
\hline 150 & S26/0762 & node & 36911 & S26/0762/11 & $20 / 06 / 2006$ & 5102 & 1.208552 & 0.700391 \\
\hline 151 & S26/0762 & node & 36911 & S26/0762/12 & $5 / 09 / 2006$ & 5179 & 1.174068 & 0.689434 \\
\hline 152 & S26/0762 & node & 36911 & S26/0762/13 & $12 / 12 / 2006$ & 5277 & 1.174068 & 0.689434 \\
\hline 153 & S26/0762 & node & 36911 & S26/0762/14 & $7 / 03 / 2007$ & 5362 & 1.178994 & 0.690978 \\
\hline 154 & S26/0762 & node & 36911 & S26/0762/15 & $19 / 06 / 2007$ & 5466 & 1.18392 & 0.692529 \\
\hline 155 & S26/0824 & node & 77563 & S26/0824/1 & $9 / 10 / 2003$ & 4117 & 1.06569 & 0.657125 \\
\hline 156 & S26/0824 & node & 77563 & S26/0824/2 & $12 / 12 / 2003$ & 4181 & 1.149436 & 0.681815 \\
\hline 157 & S26/0824 & node & 77563 & S26/0824/3 & $26 / 03 / 2004$ & 4286 & 1.243036 & 0.711702 \\
\hline 158 & S26/0824 & node & 77563 & S26/0824/4 & $10 / 06 / 2004$ & 4362 & 1.178994 & 0.690978 \\
\hline 159 & S26/0824 & node & 77563 & S26/0824/5 & $22 / 09 / 2004$ & 4466 & 1.134658 & 0.677324 \\
\hline 160 & S26/0824 & node & 77563 & S26/0824/6 & $7 / 12 / 2004$ & 4542 & 1.178994 & 0.690978 \\
\hline 161 & S26/0824 & node & 77563 & S26/0824/7 & $16 / 03 / 2005$ & 4641 & 1.036132 & 0.648832 \\
\hline 162 & S26/0824 & node & 77563 & S26/0824/8 & $12 / 05 / 2005$ & 4698 & 1.74 & 25 \\
\hline 163 & S26/0824 & node & 77563 & S26/0824/9 & $27 / 07 / 2005$ & 4774 & 1.080469 & 0.661351 \\
\hline 164 & S26/0824 & node & 77563 & S26/0824/10 & $18 / 10 / 2005$ & 4857 & 1.203625 & 0.698804 \\
\hline 165 & S26/0824 & node & 77563 & S26/0824/11 & $12 / 01 / 2006$ & 4943 & 1.134658 & 0.677324 \\
\hline 166 & S26/0824 & node & 77563 & S26/0824/12 & $15 / 03 / 2006$ & 5005 & 1.198699 & 0.697225 \\
\hline 167 & S26/0824 & node & 77563 & S26/0824/13 & $26 / 06 / 2006$ & 5108 & 1.243036 & 0.711702 \\
\hline 168 & S26/0824 & node & 77563 & S26/0824/14 & 20/09/2006 & 5194 & 1.193773 & 0.695653 \\
\hline 169 & S26/0824 & node & 77563 & S26/0824/15 & $7 / 12 / 2006$ & 5272 & 1.198699 & 0.697225 \\
\hline 170 & S26/0824 & node & 77563 & S26/0824/16 & 26/03/2007 & 5381 & 1.218404 & 0.703586 \\
\hline 171 & S26/0824 & node & 77563 & S26/0824/17 & $28 / 06 / 2007$ & 5475 & 1.238109 & 0.710064 \\
\hline 172 & S26/0846 & node & 79725 & S26/0846/1 & $27 / 01 / 2005$ & 4593 & 1.592801 & 0.851116 \\
\hline 173 & S26/0846 & node & 79725 & S26/0846/2 & $8 / 04 / 2005$ & 4664 & 1.64699 & 0.877755 \\
\hline 174 & S26/0846 & node & 79725 & S26/0846/3 & $2 / 08 / 2005$ & 4780 & 1.666695 & 0.88786 \\
\hline 175 & S26/0846 & node & 79725 & S26/0846/4 & $12 / 10 / 2005$ & 4851 & 1.671621 & 0.890423 \\
\hline 176 & S26/0846 & node & 79725 & S26/0846/5 & $12 / 01 / 2006$ & 4943 & 1.676547 & 0.893 \\
\hline 177 & S26/0846 & node & 79725 & S26/0846/6 & $30 / 03 / 2006$ & 5020 & 1.671621 & 0.890423 \\
\hline 178 & S26/0846 & node & 79725 & S26/0846/7 & $4 / 07 / 2006$ & 5116 & 1.715957 & 0.914171 \\
\hline 179 & S26/0846 & node & 79725 & S26/0846/8 & $5 / 10 / 2006$ & 5209 & 1.711031 & 0.91147 \\
\hline 180 & S26/0846 & node & 79725 & S26/0846/9 & $14 / 12 / 2006$ & 5279 & 1.6864 & 0.898201 \\
\hline 181 & S26/0846 & node & 79725 & S26/0846/10 & $19 / 03 / 2007$ & 5374 & 1.661768 & 0.885312 \\
\hline 182 & S26/0846 & node & 79725 & S26/0846/11 & 20/06/2007 & 5467 & 1.676547 & 0.893 \\
\hline 183 & S26/0911 & node & 17745 & S26/0911/1 & $3 / 05 / 2005$ & 4689 & 1.85 & 20 \\
\hline 184 & S26/0911 & node & 17745 & S26/0911/2 & $3 / 05 / 2005$ & 4689 & 1.942566 & 1.058455 \\
\hline 185 & T26/0332 & node & 44227 & T26/0332/1 & $21 / 10 / 2004$ & 4496 & 0.385865 & 0.50784 \\
\hline 186 & T26/0332 & node & 44227 & T26/0332/2 & $10 / 12 / 2004$ & 4545 & 0.351381 & 0.502054 \\
\hline
\end{tabular}




\begin{tabular}{rcccccccc}
\hline num & group & type & location & name & date & simtime & value & weight \\
187 & $\mathrm{~T} 26 / 0332$ & node & 44227 & $\mathrm{~T} 26 / 0332 / 3$ & $15 / 03 / 2005$ & 4640 & 0.366159 & 0.504518 \\
188 & $\mathrm{~T} 26 / 0332$ & node & 44227 & $\mathrm{~T} 26 / 0332 / 4$ & $8 / 07 / 2005$ & 4755 & 0.376012 & 0.506173 \\
189 & $\mathrm{~T} 26 / 0332$ & node & 44227 & $\mathrm{~T} 26 / 0332 / 5$ & $21 / 09 / 2005$ & 4830 & 0.371086 & 0.505344 \\
190 & $\mathrm{~T} 26 / 0332$ & node & 44227 & $\mathrm{~T} 26 / 0332 / 6$ & $12 / 12 / 2005$ & 4912 & 0.395717 & 0.509517 \\
191 & $\mathrm{~T} 26 / 0332$ & node & 44227 & $\mathrm{~T} 26 / 0332 / 7$ & $22 / 03 / 2006$ & 5012 & 0.213445 & 0.480173 \\
192 & $\mathrm{~T} 26 / 0332$ & node & 44227 & $\mathrm{~T} 26 / 0332 / 8$ & $15 / 06 / 2006$ & 5097 & 0.454832 & 0.51982 \\
193 & $\mathrm{~T} 26 / 0332$ & node & 44227 & $\mathrm{~T} 26 / 0332 / 9$ & $4 / 09 / 2006$ & 5178 & 0.420348 & 0.51376 \\
194 & $\mathrm{~T} 26 / 0332$ & node & 44227 & $\mathrm{~T} 26 / 0332 / 10$ & $5 / 12 / 2006$ & 5270 & 0.356307 & 0.502873 \\
195 & $\mathrm{~T} 26 / 0332$ & node & 44227 & $\mathrm{~T} 26 / 0332 / 11$ & $6 / 03 / 2007$ & 5361 & 0.44498 & 0.518074 \\
196 & $\mathrm{~T} 26 / 0332$ & node & 44227 & $\mathrm{~T} 26 / 0332 / 12$ & $13 / 06 / 2007$ & 5460 & 0.410496 & 0.512055 \\
\hline
\end{tabular}




\section{Appendix E}

\section{Tritium Monthly Measurements 1977-2007}

Tab. E-1 Tritium Monthly Measurements 1977-2007

\begin{tabular}{|c|c|c|c|c|c|c|c|c|c|}
\hline Year & Month & Tritium & Sig & Mean & Year & Month & Tritium & Sig & Mean \\
\hline 1977 & 1 & 8.21336 & 0.4 & 8.292334 & 1992 & 1 & 2.371285 & 0.08 & 2.096922 \\
\hline 1977 & 2 & 8.726349 & 0.4 & 8.292005 & 1992 & 2 & 1.979259 & 0.07 & 2.096838 \\
\hline 1977 & 3 & 13.78985 & 0.6 & 8.291677 & 1992 & 3 & 1.675445 & 0.09 & 2.096755 \\
\hline 1977 & 4 & 5.073515 & 0.3 & 8.291348 & 1992 & 4 & 1.645986 & 0.08 & 2.096672 \\
\hline 1977 & 5 & 6.287356 & 0.3 & 8.291019 & 1992 & 5 & 1.959429 & 0.08 & 2.096589 \\
\hline 1977 & 6 & 5.171812 & 0.3 & 8.29069 & 1992 & 6 & 1.988741 & 0.08 & 2.096506 \\
\hline 1977 & 7 & 6.99746 & 0.3 & 6.23751 & 1992 & 7 & 2.321739 & 0.18 & 2.282554 \\
\hline 1977 & 8 & 6.789932 & 0.3 & 6.237263 & 1992 & 8 & 3.046549 & 0.23 & 2.282463 \\
\hline 1977 & 9 & 7.302834 & 0.3 & 6.237015 & 1992 & 9 & 2.830926 & 0.23 & 2.282373 \\
\hline 1977 & 10 & 7.805828 & 0.3 & 6.236768 & 1992 & 10 & 2.20392 & 0.08 & 2.282282 \\
\hline 1977 & 11 & 7.095029 & 0.3 & 6.236521 & 1992 & 11 & 1.704298 & 0.06 & 2.282192 \\
\hline 1977 & 12 & 6.078393 & 0.3 & 6.236273 & 1992 & 12 & 2.409429 & 0.07 & 2.282101 \\
\hline 1978 & 1 & 9.028245 & 0.4 & 6.235902 & 1993 & 1 & 2.340728 & 0.16 & 2.281965 \\
\hline 1978 & 2 & 5.377266 & 0.3 & 6.235655 & 1993 & 2 & 2.027245 & 0.08 & 2.281875 \\
\hline 1978 & 3 & 3.857665 & 0.3 & 6.235408 & 1993 & 3 & 2.291577 & 0.09 & 2.281784 \\
\hline 1978 & 4 & 4.163351 & 0.3 & 6.235161 & 1993 & 4 & 2.036877 & 0.08 & 2.281694 \\
\hline 1978 & 5 & 5.376626 & 0.4 & 6.234913 & 1993 & 5 & 2.105342 & 0.12 & 2.281603 \\
\hline 1978 & 6 & 4.971949 & 0.4 & 6.234666 & 1993 & 6 & 2.026924 & 0.08 & 2.281513 \\
\hline 1978 & 7 & 5.070398 & 0.4 & 6.066721 & 1993 & 7 & 2.20309 & 0.09 & 2.379338 \\
\hline 1978 & 8 & 7.200863 & 0.5 & 6.06648 & 1993 & 8 & 2.937337 & 0.11 & 2.379243 \\
\hline 1978 & 9 & 9.232521 & 0.6 & 6.06624 & 1993 & 9 & 2.320404 & 0.08 & 2.379149 \\
\hline 1978 & 10 & 8.413492 & 0.5 & 6.065999 & 1993 & 10 & 2.232199 & 0.07 & 2.379055 \\
\hline 1978 & 11 & 7.40713 & 0.5 & 6.065759 & 1993 & 11 & 3.465646 & 0.18 & 2.37896 \\
\hline 1978 & 12 & 6.41071 & 0.3 & 6.065518 & 1993 & 12 & 2.858555 & 0.09 & 2.378866 \\
\hline 1979 & 1 & 5.522745 & 0.2 & 6.065157 & 1994 & 1 & 2.114422 & 0.07 & 2.378724 \\
\hline 1979 & 2 & 6.015609 & 0.3 & 6.064917 & 1994 & 2 & 2.711442 & 0.1 & 2.37863 \\
\hline 1979 & 3 & 5.029244 & 0.2 & 6.064676 & 1994 & 3 & 2.172983 & 0.09 & 2.378536 \\
\hline 1979 & 4 & 4.831827 & 0.3 & 6.064436 & 1994 & 4 & 1.820535 & 0.06 & 2.378441 \\
\hline 1979 & 5 & 4.042797 & 0.2 & 6.064195 & 1994 & 5 & 1.693227 & 0.07 & 2.378347 \\
\hline 1979 & 6 & 3.648233 & 0.2 & 6.063955 & 1994 & 6 & 2.05528 & 0.07 & 2.378253 \\
\hline 1979 & 7 & 4.634058 & 0.2 & 5.255219 & 1994 & 7 & 2.231359 & 0.08 & 2.211785 \\
\hline 1979 & 8 & 6.112771 & 0.3 & 5.255011 & 1994 & 8 & 2.172552 & 0.09 & 2.211698 \\
\hline 1979 & 9 & 4.633691 & 0.2 & 5.254802 & 1994 & 9 & 2.671546 & 0.1 & 2.21161 \\
\hline 1979 & 10 & 7.295309 & 0.3 & 5.254594 & 1994 & 10 & 2.573586 & 0.11 & 2.211522 \\
\hline 1979 & 11 & 6.703532 & 0.3 & 5.254386 & 1994 & 11 & 1.986377 & 0.09 & 2.211434 \\
\hline 1979 & 12 & 4.140252 & 0.2 & 5.254177 & 1994 & 12 & 1.888451 & 0.1 & 2.211347 \\
\hline
\end{tabular}




\begin{tabular}{|c|c|c|c|c|c|c|c|c|c|}
\hline Year & Month & Tritium & Sig & Mean & Year & Month & Tritium & Sig & Mean \\
\hline 1980 & 1 & 6.012866 & 0.3 & 5.253865 & 1995 & 1 & 2.318841 & 0.07 & 2.211215 \\
\hline 1980 & 2 & 5.224086 & 0.3 & 5.253657 & 1995 & 2 & 2.142641 & 0.08 & 2.211128 \\
\hline 1980 & 3 & 4.928188 & 0.3 & 5.253448 & 1995 & 3 & 2.162123 & 0.1 & 2.21104 \\
\hline 1980 & 4 & 5.125112 & 0.3 & 5.25324 & 1995 & 4 & 2.259867 & 0.11 & 2.210952 \\
\hline 1980 & 5 & 3.942238 & 0.3 & 5.253032 & 1995 & 5 & 1.936952 & 0.08 & 2.210865 \\
\hline 1980 & 6 & 4.336289 & 0.3 & 5.252823 & 1995 & 6 & 2.161866 & 0.1 & 2.210777 \\
\hline 1980 & 7 & 3.941925 & 0.2 & 4.267134 & 1995 & 7 & 2.416107 & 0.11 & 2.396544 \\
\hline 1980 & 8 & 4.040313 & 0.3 & 4.266965 & 1995 & 8 & 3.188744 & 0.14 & 2.396449 \\
\hline 1980 & 9 & 5.518257 & 0.3 & 4.266795 & 1995 & 9 & 2.582193 & 0.11 & 2.396354 \\
\hline 1980 & 10 & 5.320966 & 0.2 & 4.266626 & 1995 & 10 & 3.16893 & 0.12 & 2.396258 \\
\hline 1980 & 11 & 5.51782 & 0.3 & 4.266457 & 1995 & 11 & 2.670011 & 0.07 & 2.396163 \\
\hline 1980 & 12 & 4.433786 & 0.3 & 4.266288 & 1995 & 12 & 2.229811 & 0.1 & 2.396068 \\
\hline 1981 & 1 & 5.024659 & 0.3 & 4.266034 & 1996 & 1 & 2.210119 & 0.1 & 2.395926 \\
\hline 1981 & 2 & 2.758527 & 0.2 & 4.265865 & 1996 & 2 & 2.278484 & 0.11 & 2.395831 \\
\hline 1981 & 3 & 4.433171 & 0.3 & 4.265696 & 1996 & 3 & 2.337065 & 0.07 & 2.395736 \\
\hline 1981 & 4 & 3.644907 & 0.3 & 4.265527 & 1996 & 4 & 1.98496 & 0.1 & 2.395641 \\
\hline 1981 & 5 & 2.955213 & 0.2 & 4.265357 & 1996 & 5 & 1.789326 & 0.09 & 2.395546 \\
\hline 1981 & 6 & 3.644618 & 0.2 & 4.265188 & 1996 & 6 & 1.847919 & 0.06 & 2.395451 \\
\hline 1981 & 7 & 3.348976 & 0.2 & 3.713423 & 1996 & 7 & 2.150932 & 0.1 & 2.375802 \\
\hline 1981 & 8 & 4.629283 & 0.3 & 3.713276 & 1996 & 8 & 3.19694 & 0.13 & 2.375708 \\
\hline 1981 & 9 & 4.629099 & 0.4 & 3.713129 & 1996 & 9 & 2.688452 & 0.12 & 2.375614 \\
\hline 1981 & 10 & 3.841015 & 0.2 & 3.712981 & 1996 & 10 & 2.483053 & 0.1 & 2.375519 \\
\hline 1981 & 11 & 4.628732 & 0.3 & 3.712834 & 1996 & 11 & 2.140815 & 0.1 & 2.375425 \\
\hline 1981 & 12 & 3.840711 & 0.3 & 3.712687 & 1996 & 12 & 2.189606 & 0.1 & 2.375331 \\
\hline 1982 & 1 & 3.052691 & 0.2 & 3.712466 & 1997 & 1 & 2.091731 & 0.1 & 2.37519 \\
\hline 1982 & 2 & 5.21891 & 0.4 & 3.712319 & 1997 & 2 & 2.638995 & 0.11 & 2.375096 \\
\hline 1982 & 3 & 3.446313 & 0.2 & 3.712172 & 1997 & 3 & 2.580248 & 0.11 & 2.375001 \\
\hline 1982 & 4 & 2.363092 & 0.2 & 3.712024 & 1997 & 4 & 2.042616 & 0.1 & 2.374907 \\
\hline 1982 & 5 & 2.756832 & 0.2 & 3.711877 & 1997 & 5 & 1.935033 & 0.09 & 2.374813 \\
\hline 1982 & 6 & 2.756723 & 0.1 & 3.71173 & 1997 & 6 & 2.316084 & 0.09 & 2.374719 \\
\hline 1982 & 7 & 4.922524 & 0.3 & 3.721428 & 1997 & 7 & 2.218271 & 0.1 & 2.364853 \\
\hline 1982 & 8 & 4.823882 & 0.2 & 3.72128 & 1997 & 8 & 2.042292 & 0.08 & 2.364759 \\
\hline 1982 & 9 & 4.725248 & 0.2 & 3.721133 & 1997 & 9 & 2.853232 & 0.11 & 2.364665 \\
\hline 1982 & 10 & 3.642234 & 0.1 & 3.720985 & 1997 & 10 & 3.077851 & 0.12 & 2.364571 \\
\hline 1982 & 11 & 2.854611 & 0.1 & 3.720838 & 1997 & 11 & 2.57943 & 0.1 & 2.364477 \\
\hline 1982 & 12 & 4.232531 & 0.3 & 3.72069 & 1997 & 12 & 2.208061 & 0.07 & 2.364384 \\
\hline 1983 & 1 & 3.444879 & 0.2 & 3.720469 & 1998 & 1 & 1.983229 & 0.08 & 2.364243 \\
\hline 1983 & 2 & 4.92106 & 0.3 & 3.720321 & 1998 & 2 & 2.706072 & 0.05 & 2.364149 \\
\hline 1983 & 3 & 2.657267 & 0.2 & 3.720174 & 1998 & 3 & 2.217523 & 0.08 & 2.364056 \\
\hline 1983 & 4 & 3.149229 & 0.2 & 3.720026 & 1998 & 4 & 2.012298 & 0.07 & 2.363962 \\
\hline 1983 & 5 & 2.755466 & 0.2 & 3.719879 & 1998 & 5 & 2.412708 & 0.08 & 2.363868 \\
\hline 1983 & 6 & 2.558545 & 0.2 & 3.719731 & 1998 & 6 & 2.109815 & 0.07 & 2.363774 \\
\hline 1983 & 7 & 3.542461 & 0.2 & 3.473579 & 1998 & 7 & 2.392982 & 0.06 & 2.031593 \\
\hline 1983 & 8 & 4.034309 & 0.3 & 3.473442 & 1998 & 8 & 2.35382 & 0.06 & 2.031513 \\
\hline 1983 & 9 & 4.722906 & 0.4 & 3.473304 & 1998 & 9 & 2.754153 & 0.08 & 2.031432 \\
\hline
\end{tabular}




\begin{tabular}{|c|c|c|c|c|c|c|c|c|c|}
\hline Year & Month & Tritium & Sig & Mean & Year & Month & Tritium & Sig & Mean \\
\hline 1983 & 10 & 2.558139 & 0.2 & 3.473166 & 1998 & 10 & 2.158311 & 0.06 & 2.031352 \\
\hline 1983 & 11 & 3.837057 & 0.3 & 3.473029 & 1998 & 11 & 2.500026 & 0.06 & 2.031271 \\
\hline 1983 & 12 & 3.541758 & 0.2 & 3.472891 & 1998 & 12 & 1.611281 & 0.05 & 2.03119 \\
\hline 1984 & 1 & 2.459408 & 0.2 & 3.472684 & 1999 & 1 & 1.718597 & 0.05 & 2.03107 \\
\hline 1984 & 2 & 4.623504 & 0.2 & 3.472547 & 1999 & 2 & 1.601357 & 0.04 & 2.030989 \\
\hline 1984 & 3 & 3.738004 & 0.2 & 3.472409 & 1999 & 3 & 1.816101 & 0.07 & 2.030909 \\
\hline 1984 & 4 & 2.950939 & 0.2 & 3.472271 & 1999 & 4 & 1.884374 & 0.07 & 2.030828 \\
\hline 1984 & 5 & 2.852461 & 0.2 & 3.472133 & 1999 & 5 & 1.649982 & 0.07 & 2.030748 \\
\hline 1984 & 6 & 2.852348 & 0.2 & 3.471996 & 1999 & 6 & 2.030667 & 0.08 & 2.030667 \\
\hline 1984 & 7 & 2.852235 & 0.1 & 3.393176 & 1999 & 7 & 2.792056 & 0.1 & 2.069636 \\
\hline 1984 & 8 & 4.130659 & 0.2 & 3.393041 & 1999 & 8 & 2.655277 & 0.07 & 2.069554 \\
\hline 1984 & 9 & 4.622221 & 0.2 & 3.392907 & 1999 & 9 & 2.323275 & 0.07 & 2.069472 \\
\hline 1984 & 10 & 2.655213 & 0.2 & 3.392772 & 1999 & 10 & 2.079151 & 0.06 & 2.06939 \\
\hline 1984 & 11 & 1.966746 & 0.2 & 3.392638 & 1999 & 11 & 1.669112 & 0.05 & 2.069308 \\
\hline 1984 & 12 & 5.211671 & 0.3 & 3.392503 & 1999 & 12 & 2.235154 & 0.06 & 2.069226 \\
\hline 1985 & 1 & 3.834775 & 0.3 & 3.392301 & 2000 & 1 & 1.668946 & 0.05 & 2.069103 \\
\hline 1985 & 2 & 4.129594 & 0.3 & 3.392167 & 2000 & 2 & 2.352047 & 0.07 & 2.069021 \\
\hline 1985 & 3 & 3.047913 & 0.2 & 3.392032 & 2000 & 3 & 1.766405 & 0.05 & 2.068939 \\
\hline 1985 & 4 & 3.047792 & 0.2 & 3.391898 & 2000 & 4 & 1.454055 & 0.05 & 2.068857 \\
\hline 1985 & 5 & 2.162863 & 0.2 & 3.391763 & 2000 & 5 & 1.844332 & 0.06 & 2.068775 \\
\hline 1985 & 6 & 3.04755 & 0.2 & 3.391629 & 2000 & 6 & 1.951597 & 0.06 & 2.068693 \\
\hline 1985 & 7 & 2.752517 & 0.2 & 2.929465 & 2000 & 7 & 1.414852 & 0.04 & 1.78564 \\
\hline 1985 & 8 & 3.44051 & 0.2 & 2.929348 & 2000 & 8 & 2.741776 & 0.07 & 1.785569 \\
\hline 1985 & 9 & 3.440373 & 0.2 & 2.929232 & 2000 & 9 & 2.263583 & 0.06 & 1.785499 \\
\hline 1985 & 10 & 2.850482 & 0.2 & 2.929116 & 2000 & 10 & 2.019582 & 0.06 & 1.785428 \\
\hline 1985 & 11 & 3.440101 & 0.2 & 2.929 & 2000 & 11 & 1.473163 & 0.05 & 1.785357 \\
\hline 1985 & 12 & 3.341679 & 0.2 & 2.928884 & 2000 & 12 & 2.087712 & 0.07 & 1.785286 \\
\hline 1986 & 1 & 2.653529 & 0.2 & 2.92871 & 2001 & 1 & 1.78518 & 0.05 & 1.78518 \\
\hline 1986 & 2 & 3.341348 & 0.2 & 2.928593 & 2001 & 2 & 1.707072 & 0.05 & 1.785109 \\
\hline 1986 & 3 & 2.751589 & 0.1 & 2.928477 & 2001 & 3 & 1.375358 & 0.045 & 1.785038 \\
\hline 1986 & 4 & 2.358412 & 0.1 & 2.928361 & 2001 & 4 & 1.775214 & 0.05 & 1.784968 \\
\hline 1986 & 5 & 2.161792 & 0.1 & 2.928245 & 2001 & 5 & 1.345988 & 0.05 & 1.784897 \\
\hline 1986 & 6 & 2.554743 & 0.1 & 2.928129 & 2001 & 6 & 1.433713 & 0.05 & 1.784826 \\
\hline 1986 & 7 & 2.849408 & 0.2 & 2.711851 & 2001 & 7 & 1.999316 & 0.06 & 1.989563 \\
\hline 1986 & 8 & 2.456289 & 0.2 & 2.711743 & 2001 & 8 & 1.833446 & 0.06 & 1.989484 \\
\hline 1986 & 9 & 3.438669 & 0.2 & 2.711636 & 2001 & 9 & 2.125933 & 0.007 & 1.989406 \\
\hline 1986 & 10 & 2.84907 & 0.2 & 2.711528 & 2001 & 10 & 2.398894 & 0.07 & 1.989327 \\
\hline 1986 & 11 & 3.045436 & 0.2 & 2.711421 & 2001 & 11 & 2.018501 & 0.07 & 1.989248 \\
\hline 1986 & 12 & 2.4559 & 0.2 & 2.711313 & 2001 & 12 & 2.281694 & 0.06 & 1.989169 \\
\hline 1987 & 1 & 2.848674 & 0.2 & 2.711152 & 2002 & 1 & 2.34981 & 0.08 & 1.989051 \\
\hline 1987 & 2 & 2.652109 & 0.2 & 2.711044 & 2002 & 2 & 1.803724 & 0.06 & 1.988972 \\
\hline 1987 & 3 & 3.044893 & 0.2 & 2.710937 & 2002 & 3 & 1.589164 & 0.06 & 1.988893 \\
\hline 1987 & 4 & 2.357243 & 0.2 & 2.710829 & 2002 & 4 & 1.881574 & 0.05 & 1.988814 \\
\hline 1987 & 5 & 2.258935 & 0.2 & 2.710722 & 2002 & 5 & 1.871751 & 0.06 & 1.988735 \\
\hline 1987 & 6 & 2.258845 & 0.2 & 2.710614 & 2002 & 6 & 1.666962 & 0.04 & 1.988656 \\
\hline
\end{tabular}




\begin{tabular}{|c|c|c|c|c|c|c|c|c|c|}
\hline Year & Month & Tritium & Sig & Mean & Year & Month & Tritium & Sig & Mean \\
\hline 1987 & 7 & 2.160549 & 0.1 & 2.563197 & 2002 & 7 & 1.393954 & 0.03 & 1.735131 \\
\hline 1987 & 8 & 3.240695 & 0.2 & 2.563095 & 2002 & 8 & 2.115217 & 0.05 & 1.735062 \\
\hline 1987 & 9 & 3.731561 & 0.2 & 2.562993 & 2002 & 9 & 2.475777 & 0.06 & 1.734994 \\
\hline 1987 & 10 & 3.535023 & 0.2 & 2.562892 & 2002 & 10 & 1.764165 & 0.04 & 1.734925 \\
\hline 1987 & 11 & 2.552971 & 0.2 & 2.56279 & 2002 & 11 & 1.530182 & 0.05 & 1.734856 \\
\hline 1987 & 12 & 2.356495 & 0.2 & 2.562689 & 2002 & 12 & 2.085643 & 0.06 & 1.734787 \\
\hline 1988 & 1 & 1.865448 & 0.1 & 2.562536 & 2003 & 1 & 1.617739 & 0.03 & 1.734684 \\
\hline 1988 & 2 & 3.043505 & 0.2 & 2.562435 & 2003 & 2 & 1.559205 & 0.03 & 1.734615 \\
\hline 1988 & 3 & 1.767126 & 0.1 & 2.562333 & 2003 & 3 & 1.695568 & 0.04 & 1.734546 \\
\hline 1988 & 4 & 2.159735 & 0.1 & 2.562231 & 2003 & 4 & 1.500616 & 0.05 & 1.734478 \\
\hline 1988 & 5 & 2.257815 & 0.2 & 2.56213 & 2003 & 5 & 1.500556 & 0.04 & 1.734409 \\
\hline 1988 & 6 & 2.061402 & 0.1 & 2.562028 & 2003 & 6 & 1.53947 & 0.05 & 1.73434 \\
\hline 1988 & 7 & 3.141059 & 0.2 & 2.620821 & 2003 & 7 & 1.432235 & 0.04 & 1.705042 \\
\hline 1988 & 8 & 3.239089 & 0.2 & 2.620717 & 2003 & 8 & 1.646518 & 0.05 & 1.704974 \\
\hline 1988 & 9 & 3.238961 & 0.2 & 2.620614 & 2003 & 9 & 2.084858 & 0.05 & 1.704907 \\
\hline 1988 & 10 & 3.042539 & 0.2 & 2.62051 & 2003 & 10 & 2.279614 & 0.05 & 1.704839 \\
\hline 1988 & 11 & 2.747991 & 0.1 & 2.620406 & 2003 & 11 & 1.82167 & 0.05 & 1.704772 \\
\hline 1988 & 12 & 2.257189 & 0.1 & 2.620302 & 2003 & 12 & 1.539104 & 0.05 & 1.704704 \\
\hline 1989 & 1 & 2.649586 & 0.1 & 2.620146 & 2004 & 1 & 1.694862 & 0.05 & 1.704603 \\
\hline 1989 & 2 & 2.551352 & 0.1 & 2.620042 & 2004 & 2 & 1.831158 & 0.06 & 1.704535 \\
\hline 1989 & 3 & 2.158751 & 0.1 & 2.619938 & 2004 & 3 & 1.694728 & 0.05 & 1.704467 \\
\hline 1989 & 4 & 2.060544 & 0.1 & 2.619834 & 2004 & 4 & 1.772576 & 0.05 & 1.7044 \\
\hline 1989 & 5 & 2.158579 & 0.1 & 2.61973 & 2004 & 5 & 1.314771 & 0.04 & 1.704332 \\
\hline 1989 & 6 & 2.158494 & 0.1 & 2.619626 & 2004 & 6 & 1.37315 & 0.05 & 1.704265 \\
\hline 1989 & 7 & 2.648955 & 0.2 & 2.335005 & 2004 & 7 & 1.587338 & 0.05 & 1.84 \\
\hline 1989 & 8 & 2.845062 & 0.2 & 2.334913 & 2004 & 8 & 2.142334 & 0.07 & 1.84 \\
\hline 1989 & 9 & 2.648745 & 0.1 & 2.33482 & 2004 & 9 & 2.278574 & 0.05 & 1.84 \\
\hline 1989 & 10 & 2.942934 & 0.2 & 2.334727 & 2004 & 10 & 1.86 & 0.04 & 1.84 \\
\hline 1989 & 11 & 2.550441 & 0.2 & 2.334635 & 2004 & 11 & 2.31 & 0.08 & 1.84 \\
\hline 1989 & 12 & 2.15798 & 0.1 & 2.334542 & 2004 & 12 & 2.36 & 0.07 & 1.84 \\
\hline 1990 & 1 & 2.35402 & 0.2 & 2.334403 & 2005 & 1 & 2.2 & 0.05 & 1.84 \\
\hline 1990 & 2 & 1.961606 & 0.1 & 2.334311 & 2005 & 2 & 1.77 & 0.04 & 1.84 \\
\hline 1990 & 3 & 1.569222 & 0.1 & 2.334218 & 2005 & 3 & 1.42 & 0.04 & 1.84 \\
\hline 1990 & 4 & 2.35374 & 0.1 & 2.334126 & 2005 & 4 & 1.38 & 0.05 & 1.84 \\
\hline 1990 & 5 & 2.353647 & 0.1 & 2.334033 & 2005 & 5 & 1.49 & 0.04 & 1.84 \\
\hline 1990 & 6 & 1.6671 & 0.1 & 2.333941 & 2005 & 6 & 1.32 & 0.03 & 1.84 \\
\hline 1990 & 7 & 2.35346 & 0.2 & 2.431909 & 2005 & 7 & 1.41 & 0.05 & 1.9 \\
\hline 1990 & 8 & 3.137822 & 0.2 & 2.431812 & 2005 & 8 & 2.5 & 0.05 & 1.9 \\
\hline 1990 & 9 & 2.451327 & 0.1 & 2.431716 & 2005 & 9 & 3.31 & 0.06 & 1.9 \\
\hline 1990 & 10 & 3.333672 & 0.2 & 2.43162 & 2005 & 10 & 2.46 & 0.06 & 1.9 \\
\hline 1990 & 11 & 2.353087 & 0.1 & 2.431523 & 2005 & 11 & 1.45 & 0.04 & 1.9 \\
\hline 1990 & 12 & 2.156911 & 0.1 & 2.431427 & 2005 & 12 & 2.42 & 0.04 & 1.9 \\
\hline 1991 & 1 & 2.450889 & 0.1 & 2.431282 & 2006 & 1 & 1.4 & 0.03 & 1.9 \\
\hline 1991 & 2 & 1.960634 & 0.1 & 2.431186 & 2006 & 2 & 1.9 & 0.05 & 1.9 \\
\hline 1991 & 3 & 2.156611 & 0.1 & 2.431089 & 2006 & 3 & 1.45 & 0.05 & 1.9 \\
\hline
\end{tabular}




\begin{tabular}{cccccccccc}
\hline Year & Month & Tritium & Sig & Mean & Year & Month & Tritium & Sig & Mean \\
1991 & 4 & 2.156526 & 0.1 & 2.430993 & 2006 & 4 & 1.32 & 0.05 & 1.9 \\
1991 & 5 & 2.35248 & 0.1 & 2.430896 & 2006 & 5 & 1.58 & 0.05 & 1.9 \\
1991 & 6 & 2.254371 & 0.1 & 2.4308 & 2006 & 6 & 1.63 & 0.05 & 1.9 \\
1991 & 7 & 2.254282 & 0.1 & 2.097462 & 2006 & 7 & 1.88 & 0.05 & 1.82 \\
1991 & 8 & 2.450209 & 0.1 & 2.097379 & 2006 & 8 & 2.14 & 0.06 & 1.82 \\
1991 & 9 & 2.646121 & 0.1 & 2.097296 & 2006 & 9 & 1.9 & 0.06 & 1.82 \\
1991 & 10 & 2.254013 & 0.1 & 2.097213 & 2006 & 10 & 2.02 & 0.05 & 1.82 \\
1991 & 11 & 1.861937 & 0.1 & 2.097129 & 2006 & 11 & 1.91 & 0.06 & 1.82 \\
1991 & 12 & 2.116645 & 0.07 & 2.097046 & 2006 & 12 & 1.75 & 0.05 & 1.82 \\
& & & & & 2007 & 1 & 1.93 & 0.05 & 1.82 \\
& & & & & 2007 & 2 & 1.73 & 0.05 & 1.82 \\
& & & & & 2007 & 3 & 1.76 & 0.05 & 1.82 \\
& & & & & 2007 & 4 & 1.8 & 0.05 & 1.82 \\
& & & & & 2007 & 5 & 1.47 & 0.05 & 1.82 \\
& & & & & 2007 & 6 & 1.56 & 0.05 & 1.82 \\
& & & & & 2007 & 7 & 1.81 & 0.05 & 1.92 \\
& & & & & 2007 & 8 & 2.32 & 0.06 & 1.92 \\
& & & & & 2007 & 9 & 2.29 & 0.05 & 1.92 \\
& & & & & 2007 & 10 & 2.29 & 0.06 & 1.92 \\
& & & & & 11 & 1.69 & 0.04 & 1.92 \\
& & & & & & & & & \\
\end{tabular}




\section{Appendix F}

\section{Yearly Atmospheric Tritium 1940-2012}

Tab. F-1 Yearly atmospheric tritium measurements from Kaitoke, Upper Hutt, Wellington, New Zealand.

\begin{tabular}{|c|c|c|c|}
\hline Year & Tritium & Year & Tritium \\
\hline 1940 & 1.49 & 1977 & 8.29 \\
\hline 1941 & 1.49 & 1978 & 6.24 \\
\hline 1942 & 1.49 & 1979 & 6.07 \\
\hline 1943 & 1.49 & 1980 & 5.25 \\
\hline 1944 & 1.49 & 1981 & 4.27 \\
\hline 1945 & 1.51 & 1982 & 3.71 \\
\hline 1946 & 1.50 & 1983 & 3.72 \\
\hline 1947 & 1.50 & 1984 & 3.47 \\
\hline 1948 & 1.50 & 1985 & 3.39 \\
\hline 1949 & 1.50 & 1986 & 2.93 \\
\hline 1950 & 1.50 & 1987 & 2.71 \\
\hline 1951 & 1.50 & 1988 & 2.56 \\
\hline 1952 & 1.49 & 1989 & 2.62 \\
\hline 1953 & 1.49 & 1990 & 2.33 \\
\hline 1954 & 1.49 & 1991 & 2.43 \\
\hline 1955 & 1.49 & 1992 & 2.09 \\
\hline 1956 & 4.99 & 1993 & 2.28 \\
\hline 1957 & 4.99 & 1994 & 2.38 \\
\hline 1958 & 7.38 & 1995 & 2.21 \\
\hline 1959 & 8.06 & 1996 & 2.39 \\
\hline 1960 & 9.06 & 1997 & 2.38 \\
\hline 1961 & 9.95 & 1998 & 2.36 \\
\hline 1962 & 9.35 & 1999 & 2.03 \\
\hline 1963 & 15.31 & 2000 & 2.07 \\
\hline 1964 & 25.54 & 2001 & 1.79 \\
\hline 1965 & 38.14 & 2002 & 1.99 \\
\hline 1966 & 32.96 & 2003 & 1.74 \\
\hline 1967 & 31.85 & 2004 & 1.71 \\
\hline 1968 & 27.96 & 2005 & 1.85 \\
\hline 1969 & 27.06 & 2006 & 1.9 \\
\hline 1970 & 30.31 & 2007 & 1.82 \\
\hline 1971 & 23.07 & 2008 & 1.92 \\
\hline 1972 & 22.27 & 2009 & 2.11 \\
\hline 1973 & 14.44 & 2010 & 2.1 \\
\hline 1974 & 10.18 & 2011 & 1.9 \\
\hline 1975 & 10.77 & 2012 & 1.9 \\
\hline 1976 & 8.42 & & \\
\hline
\end{tabular}




\section{Appendix G}

\section{Classical Monte Carlo python script}

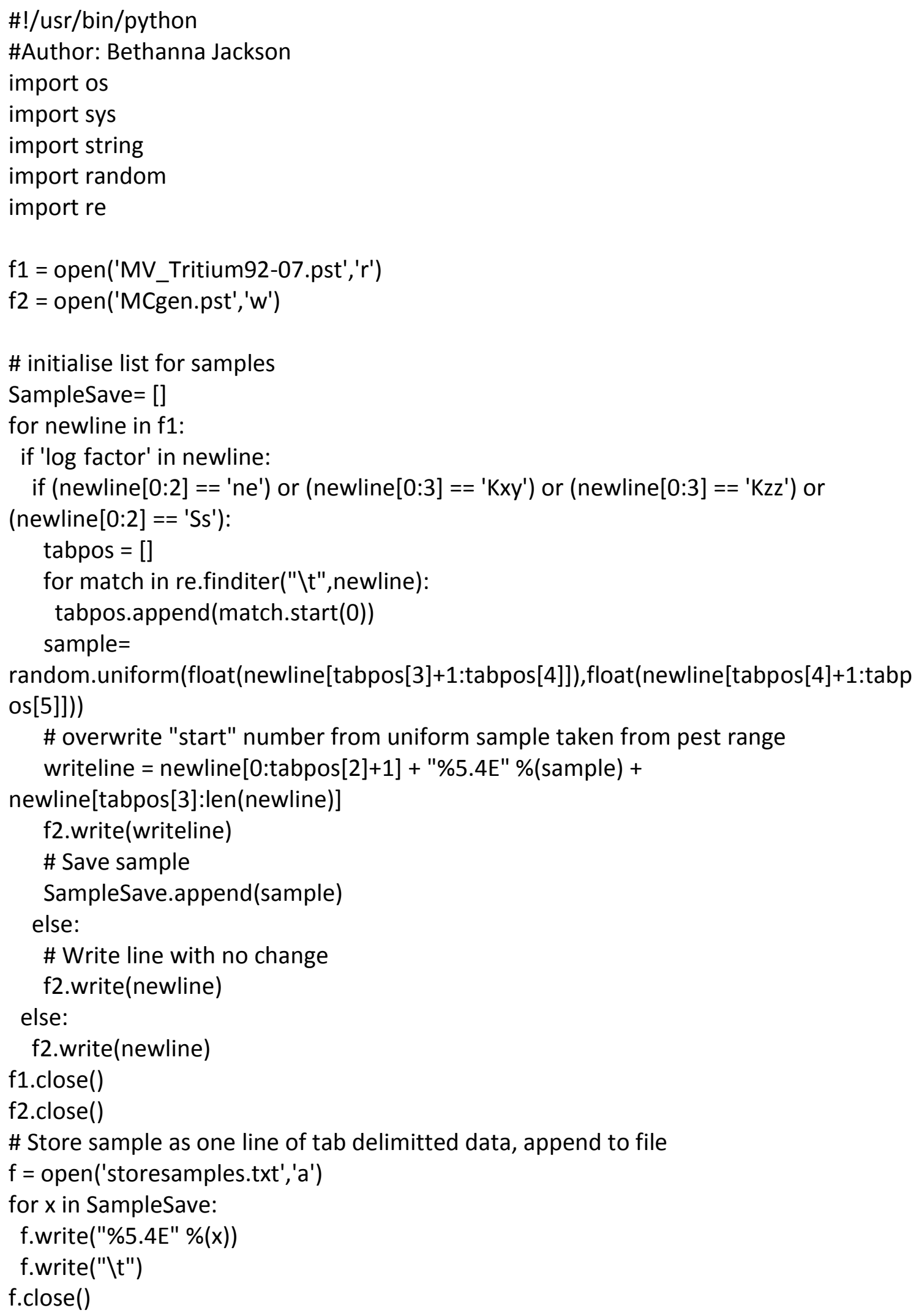




\section{Appendix $\mathrm{H}$}

\section{Recharge spreading layer python script}

"'"'Add Recharge Spreading Layer to GW Model

MV:

189666 3D elements over 18 layers

10537 3D elements per layer

Author: Mike Toews

Date: $20 / 8 / 2012$

"'"!"

import numpy as np

import sys

sys.path.append(r'I:\Groundwater\Python\GroundWater')

from gw import fed, misc

sys.path.append(r'l:\Groundwater\Python')

import feflow

from hashlib import md5

prefix $=r^{\prime} \mathrm{C}: \backslash g w \backslash$ Tritium55'

fem_name $=r^{\prime} C: \backslash g w \backslash$ Tritium55 $\backslash M V_{\text {_Tritium92-07' }}$

\# Read whole FED file

$f=$ fed.FedFile(verbose=True)

f.read(fem_name + '.fed')

fil=r'C: \gw \Tritium55\MV_Tritium92-07'

\# powerid file

pow $=$ misc. PowerFile()

pow.read(r'C:\gw\Tritium55\powerid.txt')

\# FEFLOW file

fem $=$ feflow.FEM(verbose=True)

fem.read(fil+ '.fem', only=['MMLIST','DIMENS','CLASS'])

rech $=$ fem.mmlist $[(2,3)]$

\# Convert from $10-4 \mathrm{~m} / \mathrm{d}$ into $\mathrm{m} / \mathrm{s}$

rech.data $/=$ float $(60 * 60 * 24 * 10000)$ 


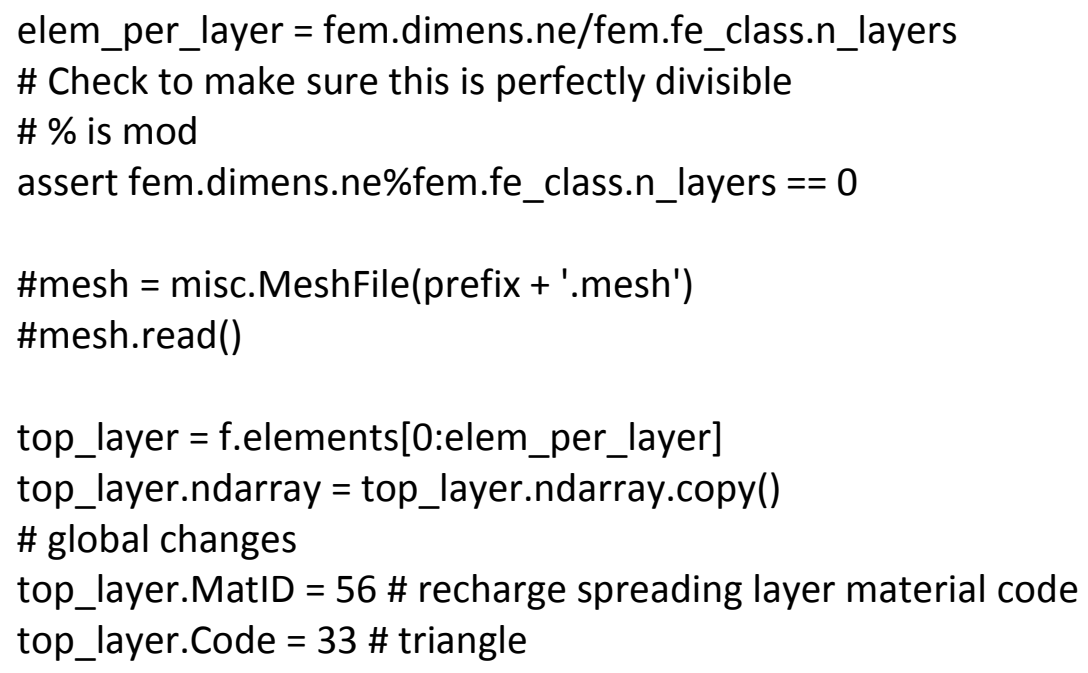

\# Source sink for flow, copy from original FED file

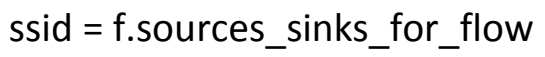

\# Store these to find unique recharge time series hashes prev_ssids $=\{\}$

for $\mathrm{i}$ in range(len(top_layer)):

\# Copy only the top three nodes (for the triangle), ignore the others top_layer.Nodes[i] = top_layer.Nodes[i][0:3]

\# Determine hash for recharge time series

rech_values $=$ rech.data[i]

hash = md5(rech_values).hexdigest()

if hash not in prev_ssids:

\# Add new power series

ps = misc.PowerSeries(len(rech.time))

ps. Time $=$ rech.time

ps.Value $=$ rech_values

ps.cyclic $=$ True

ps. method $=2$ \# linear?

\# make a new power ID by adding 1 to the last

ps.ID = pow[-1].ID + 1

pow.power_series.append(ps)

\# Add source sink for flow

ss = fed.SourcesSinksForFlow(1)

\# increment new ID

ss.SSID $=$ cur_ssid $=$ ssid.SSID $[-1]+1$

ss.Value $=$ ps.ID +500000

ssid.append(ss)

\# archive hash for later

prev_ssids[hash] $=$ cur_ssid

else: \# otherwise, we've already made this power series, get the id cur_ssid = prev_ssids[hash]

top_layer.SSID[i] = cur_ssid 
\# Offset the IDs

top_layer.Elem $=n p$. arange $($ len(top_layer $))+$ len $($ f.elements $)+1$

\# Write the files

pow.write(r'C: \gw\Tritium55\MV_Tritium92-07\poweridle.txt')

\# Other files that we can piece together manually top_layer.write_part(r'C: \gw \Tritium55 \MV_Tritium92-

07\recharge_spreading_layer.fed.part')

ssid.write_part(r'C: \gw\Tritium55 \MV_Tritium92-07\sources_sinks_for_flow.fed.part') 


\title{
Appendix I
}

\section{Observations and simulated data matching script}

\author{
\#!/usr/bin/python \\ "'"'"Match Tritium observations and simulated concentrations \\ This module file is a *module* so it can be used to filter-out \\ bad observations, so they can have a zero weight. \\ "'"!" \\ import re \\ import os \\ import sys \\ import numpy as np \\ import shutil
}

from gw import dat, misc

def get_obs(group):

"'"'Read observations from obs_fname""'"

\# Return data type

obs_dtype $=$ np.dtype $([$

('num', 'i'),

('group', 'S10'),

('type', 'S10'),

('location', '|S20'),

('name', '|S2O'),

('date', '|S10'),

('simtime', 'd'),

('value', 'd'),

('weight', 'd'),

])

obs_fname = 'observed_' + group + '.tab'

with open(obs_fname, ' $r$ ') as fp:

header $=$ tuple(fp.readline().split())

if header != obs_dtype.names:

sys.exit("Headers don't match\nfound: \%s\nexpected: \%s" \%

(header, obs_dtype.names))

dat $=$ np.genfromtxt $\left(f p\right.$, dtype=obs_dtype, delimiter $\left.=' \backslash t^{\prime}\right)$

return dat

\# Get prefix from main.sup file 
if not os.path.isfile('main.sup'):

sys.exit("Cannot find 'main.sup' in current directory")

with open('main.sup', 'r') as fp:

prefix $=f p \cdot \operatorname{read}() \cdot \operatorname{strip}()$

\# Find observation groups in current directory, based on files

obs_groups $=$ []

for fname in os.listdir('.'):

res = re.findall( $r^{\prime \wedge}$ observed_( $\left.\mid w+\right) . t a b \$ '$, fname $)$

if res:

obs_groups.append(res[0])

continue

if not obs_groups:

sys.exit('No observed_*.tab files found')

\# Return data type

match_dtype $=$ np.dtype $([$

('pest_name', '|S20'),

('pest_value', 'd'),

('num', 'i'),

('location', '|S20'),

('name', ' 'S20'),

('type', '|S10'),

('weight', 'd'),

('observed', 'd'),

('simulated', 'd'),

('residule', 'd'),

('index0', 'i'),

('quality', 'B'), \# "quality" of simulated data

])

def get_matches(obs_data, group):

"'"'Get simulations from node and zone files using simtime from observations

The returned data structure has the same number of rows as input obs.

"'"!"

\# Prepare paired simulated data to return

match_data $=$ np.zeros(len(obs_data), match_dtype)

match_data['num'] = obs_data['num'].copy()

match_data['location'] = obs_data['location'].copy()

match_data['name'] = obs_data['name'].copy()

match_data['type'] = obs_data['type'].copy()

match_data['weight'] = obs_data['weight'].copy()

match_data['observed'] = obs_data['value'].copy() 


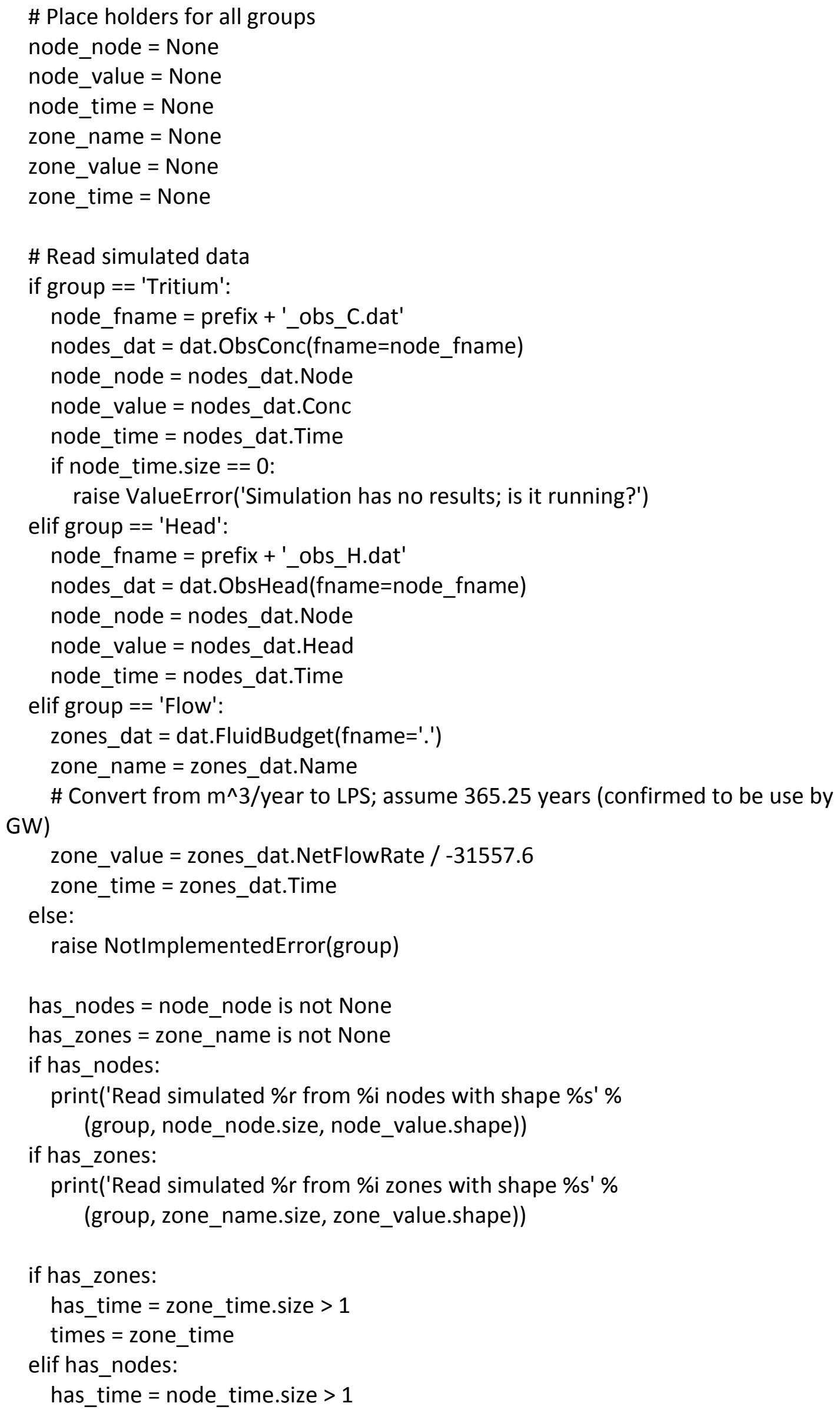


times $=$ node_time

else:

raise Exception('Simulated data from nodes or zones not found')

if has_time:

print('There are \%i simulated times between \%s and \%s' \%

(times.size, times.min(), times.max()))

\# Check Time dimension, make sure it can be interpolated

if has_nodes:

assert np.all(np.diff(node_time) $>0$ )

if has_zones:

assert np.all(np.diff(zone_time) $>0$ )

def assess_quality(v):

if $\mathrm{v} \cdot \min ()==\mathrm{v} \cdot \max ()==0.0$ :

return 1

elif v.std() > 20:

return 2

elif $v \cdot \min ()>=0.0$ and $v \cdot \max ()>0.0$ :

return 9

elif $v \cdot \min ()<0.0$ and (v.mean() $>0.0$ or np.median(v) $>0.0$ ):

return 5

elif v. $\min ()<0.0$ :

return 3

raise ValueError('What? \%s \%s \%s \%s \%s' \%

(v.min(), np.median(v), v.mean(),

v.std(), v.max()))

\# Find observed data in simulated time series

unused_rows $=[]$

nan_rows $=$ []

missing_nodes $=$ set ()

missing_zones $=$ set ()

\# export observed time series

ts_names $=[]$

ts_data $=\{\}$

for obs, mat in zip(obs_data, match_data):

\# get times and values from the observation types

times $=$ values $=$ None

unused $=$ False

if obs['type'] == 'node':

assert has_nodes, has_nodes

node $=$ int(obs['location'])

sel $=$ np. where $($ node_node $==$ node $)[0]$

if len(sel) $==0$ :

missing_nodes.add(node)

continue 


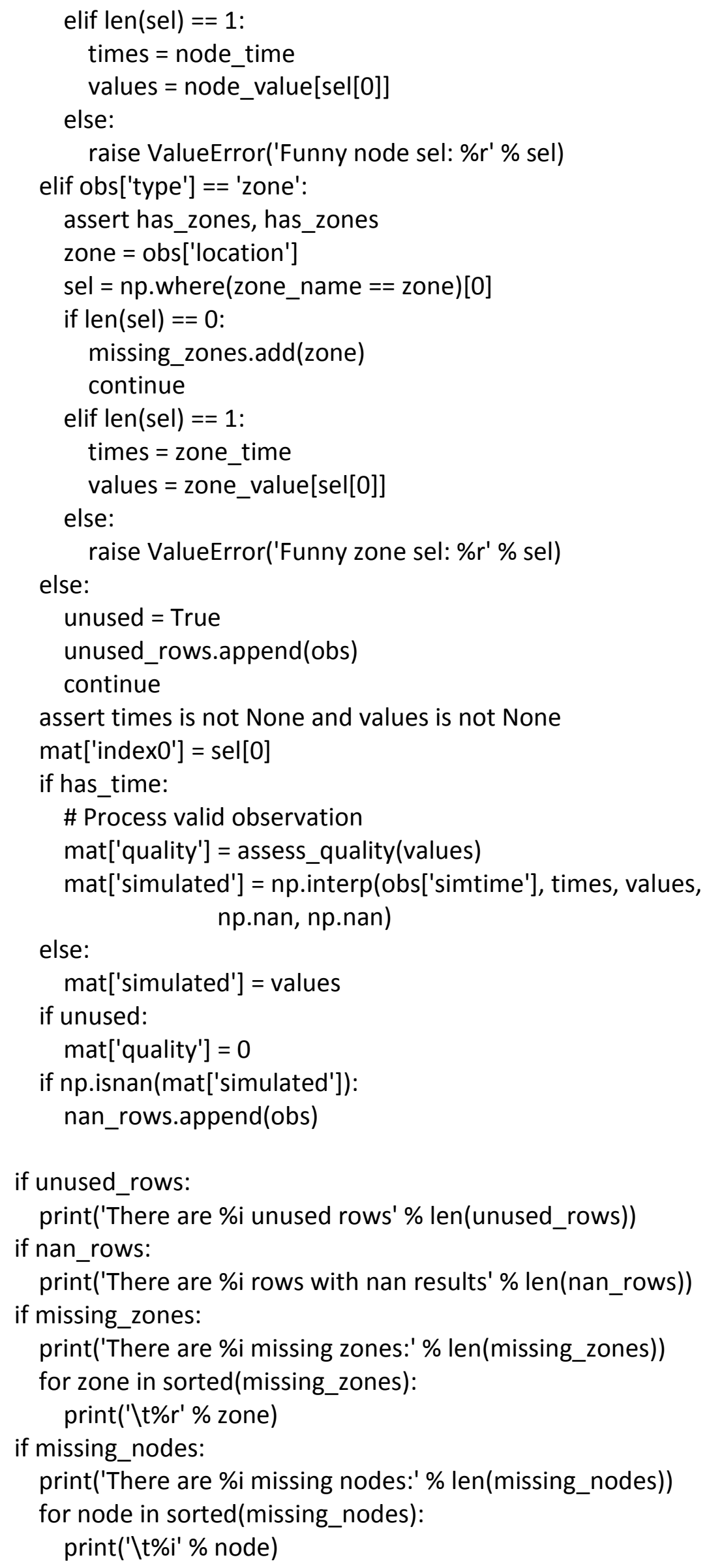




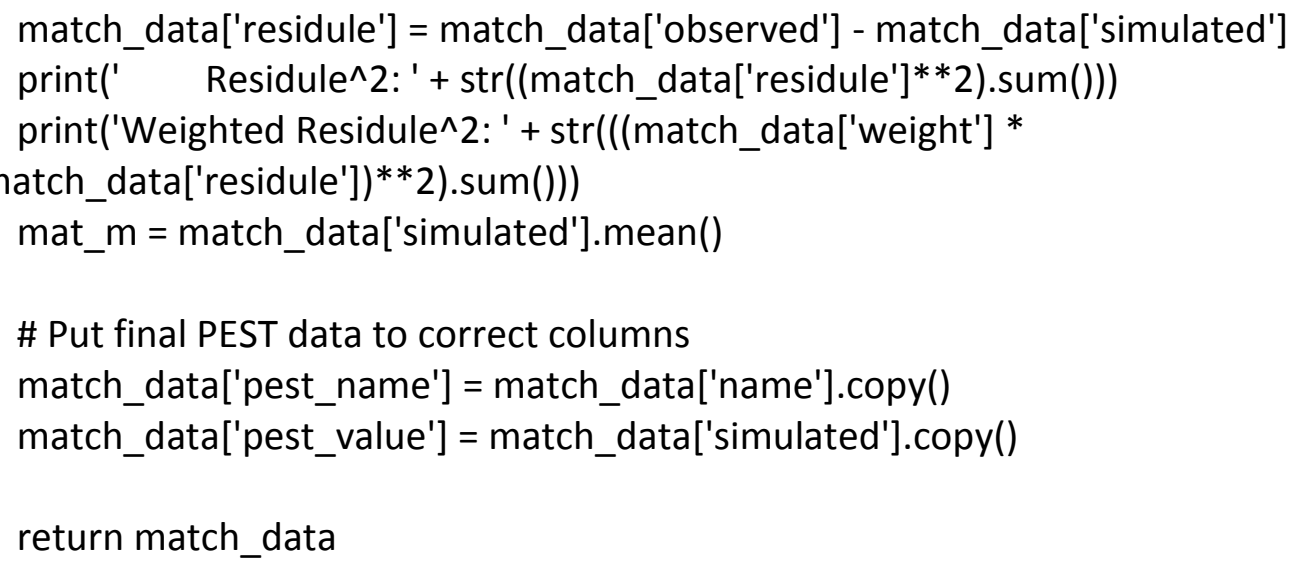

if $\_$name__ == '_main__':

for group in obs_groups:

match_data = get_matches(get_obs(group), group)

fname_prefix = 'matched_' + group

fname_tab $=$ fname_prefix + '.tab'

\# Make a TAB file for PEST to read simulated results

with open(fname_tab, ' $w$ ') as fp:

fp.write('\t'.join(match_dtype.names) + '\n')

for row in match_data:

fp.write('\t'.join ([str(x) for $x$ in row]) + '\n')

print 'Wrote ' + fname_tab

\# Copy a backup for convenience, since PEST deletes the original TAB file fname_bak = fname_prefix + '.bak.tab'

shutil.copy(fname_tab, fname_bak)

print('Finnished matching data') 


\section{Appendix J}

\section{Lumped Parameter Models}

Lumped parameter models use environmental tracer data to estimate the flow and age of water in groundwater systems (Jurgens et al, 2012; Małoszewski and Zuber, 1982). Age can be inferred from tracer concentration samples analysed from an abstraction point in the system. These are related to the inputs of the tracer through recharge processes and travel time through the subsurface to an abstraction point. When modelling the flow and transport of water and solutes, respectively, hydrogeological systems are often simplified to approximate behaviour under certain assumptions, for example steady state flow and isotropic conditions in the subsurface environment. A lumped-parameter model ignores spatial variations of parameters (such as rainfall) and the system is described by adjustable (fitted) parameters (Zuber and Małoszewski, 2001). Lumped parameter models were developed in the 1950s and have been applied to the interpretation of environmental tracer data (Małoszewski and Zuber, 1982; Vogel, 1967). The models correspond to different assumed, simplified configurations of groundwater flow from an input source in the aquifer (recharge area) to the output point(s) in the aquifer (often a well or spring), and are represented mathematically as transit-time distribution functions or exit-age distribution functions $[\boldsymbol{g}(\boldsymbol{t})]$ (Małoszewski and Zuber, 1982).

For example, a steady state tracer concentration is calculated from the tracer input history at the input region of the aquifer using the exit age distribution function and the decay function for the tracer (e.g. biodegradation or radioactive decay): 


$$
C_{\text {out }}(t)=\int_{-\infty}^{t} C_{\text {in }}\left(t^{\prime}\right) e^{-\lambda\left(t-t^{\prime}\right)} g\left(t-t^{\prime}\right) d t^{\prime} \quad \mathrm{J}-1
$$

where:

$$
C_{\text {out }}(t)=\text { outlet concentration }
$$

$C_{i n}\left(t^{\prime}\right)=$ concentration of the tracer at input at time $t^{\prime}$

$$
t=\text { sample date }
$$

$t^{\prime}=$ date when the water parcel entered the system

$\lambda=$ decay constant, fractional loss per unit of time

$g(t)=$ transit-time distribution functions or exit-age distribution function $t-t^{\prime}=$ age of the water parcel.

The mean age of a sample is derived from the exit-age distribution function which describes the tracer concentrations in the sample:

$$
\tau_{s}=\int_{-\infty}^{t}\left(t-t^{\prime}\right) g\left(t-t^{\prime}\right) d t
$$

this can be approximated numerically by:

$$
\tau_{s}=\sum_{i=1}^{\infty} t_{i} X_{i}(\Delta t)
$$

where:

$$
t_{i}=\text { age of the water parcel }\left(t-t^{\prime}\right)
$$

$X_{i}=$ fraction of the sample represented by a water parcel corresponding to a known age increment $\Delta t=$ time step (or age increment) 
Typically the mean age of the sample is not equal to the mean age of the entire aquifer, however the exponential mixing model (EMM), or exponential piston-flow model (EPM) can derive results where the mean age of a sample also corresponds to the mean age of the aquifer sampled (Jurgens et al, 2012). Four lumped parameter models are described below, some terms are not repeated, and are referenced in the above section (3.2.1).

Lumped parameter models assume that tracers are injected and present in the fluid flux where they behave conservatively (except for known decay or degradation) and travel with the water. This implies that the mean age estimated by tracer concentrations is equal to the mean age of water exiting the system (Małoszewski and Zuber, 1982). In some cases the tracer travel time and water travel time may differ and this can cause inaccurate estimates of the age distribution and mean age of a sample $\left(\tau_{s}\right)$. This is because some tracers are affected by diffusion, sorption, and geochemical exchange. This is most-likely when using certain tracers which are not part of the water molecule. Hence large differences can occur between the water ages and tracer ages (Jurgens et al, 2012).

\section{The Piston-Flow Model}

The piston-flow model assumes that a tracer travels from the recharge area (initial entry point) through the system to an outlet point (well) without any hydrodynamic dispersion or mixing within the system (Zuber and Małoszewski, 2001). The piston-flow model assumes the concentration of a tracer changes only due to the radioactive decay, thus, it applies strictly to situations where water has been separated from its recharge source and left undisturbed since inception underground, i.e. minimal mixing (Figure J-1). This model is useful for confined aquifers and river recharge where the tracer travel time is relatively short (Jurgens et al, 2012). 
The exit-age distribution function of the piston-flow model is:

$$
\operatorname{PFM}_{\mathrm{g}\left(t-t^{\prime}\right)}=\delta\left(t-t^{\prime}-\tau_{s}\right)
$$

where $\delta$ is a Dirac delta function. The piston-flow model is calculated by using the formula:

$$
\begin{gathered}
C_{\text {out }}(t)=C_{\text {in }}\left(t-\tau_{s}\right) e^{\left(-\lambda-\tau_{s}\right)} \\
\text { for } t=\tau_{s} ; 0 \text { for } t \neq \tau_{s}
\end{gathered}
$$
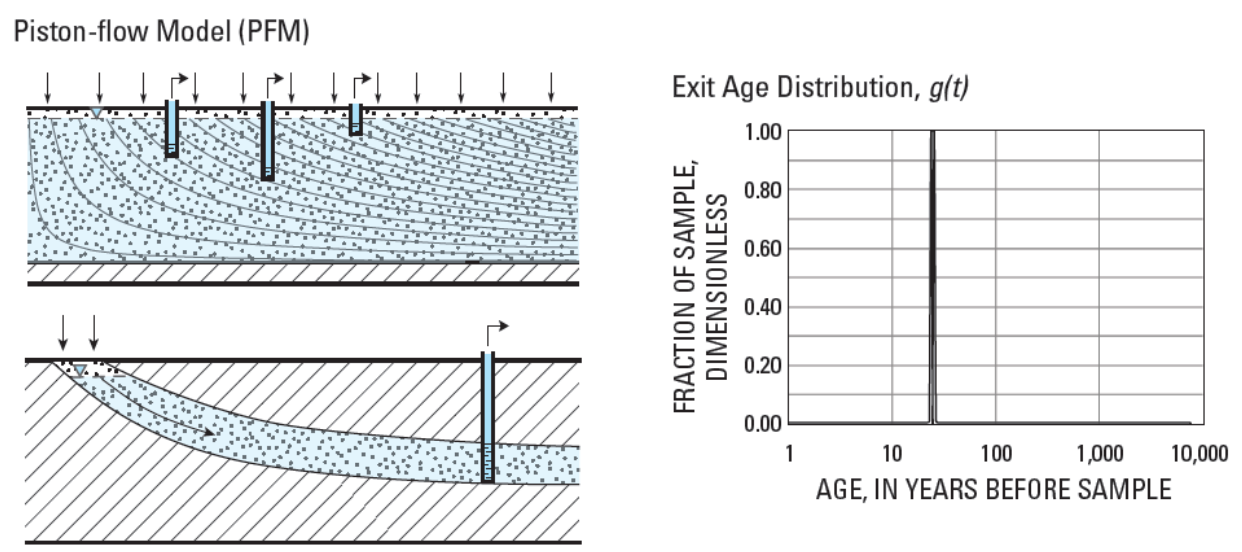

Figure J-1 Example figure of where the piston-flow model could be ideally applied. The top left figure shows an unconfined aquifer receiving recharge on top with several wells at shallow depths. The bottom left figure shows a confined aquifer receiving a small amount of recharge, this travels through the system with minimal mixing. Graph shows the sampled age distribution after the tracer travelled along a single travel path exiting with uniform mean age of 25 years at the abstraction point (modified from Jurgens et al, 2012).

Piston flow age (or apparent age) is purely a function of flow speed (i.e. negating hydrodynamic dispersion or mixing, which may, or may not be justified). Modified groundwater systems often have mixed flow fields and a sample from a bore will usually have a distribution of ages as a direct result of the advective and dispersive processes associated with abstraction and a heterogeneous subsurface (Jurgens et al, 2012). 


\section{The Exponential Mixing Model}

The exponential model introduced by Eriksson (1958) describes fully-mixed systems and assumes that the exponential distribution of transit times corresponds to the likely situation of decreasing permeability at greater depths in the aquifer. The exponential mixing model can be applied to unconfined, homogeneous aquifers of constant thickness, and which receive uniform recharge (Figure J-2). This tends to create a logarithmic increase in groundwater age from the water table (zero), to very old ages at the base of the aquifer (Jurgens et al, 2012; Vogel, 1967). The exponential mixing model is suitable for wells that are screened through the whole aquifer, or aquifers that discharge to streams and springs. It does not apply where longitudinal and transverse dispersion occurs along the advective flow line and where any mixing occurs only at the bore or spring discharge point, not the aquifer. The exit-age distribution function of the exponential mixing model (EMM) is:

$$
\operatorname{EMM}_{g\left(t-t^{\prime}\right)}=\frac{1}{\tau_{s}} e^{\left(\frac{t-t^{\prime}}{\tau_{s}}\right)}
$$

The exponential mixing model is calculated by using the following closed form solution of the convolution integral for each age increment $(\Delta t)$ starting from the sample date minus the age increment and stepping backwards in time until the output concentration does not change by more than $10^{-6}$ (Jurgens et al, 2012):

$$
\left.C_{\text {out }}(t)=\sum_{t^{\prime}=-\infty}^{t-\Delta t} C_{\text {in }}\left(t^{\prime}\right) \frac{1}{\tau_{s}} \frac{1}{\frac{1}{\tau_{s}}+\lambda}\left[e^{\left[-\left(\frac{1}{\tau_{s}}+\lambda\right)\left(t-t^{\prime}-\Delta t\right)\right.}\right] e^{\left[-\left(\frac{1}{\tau_{s}}+\lambda\right)\left(t-t^{\prime}\right)\right]}\right]
$$


Exponential Mixing Model (EMM)

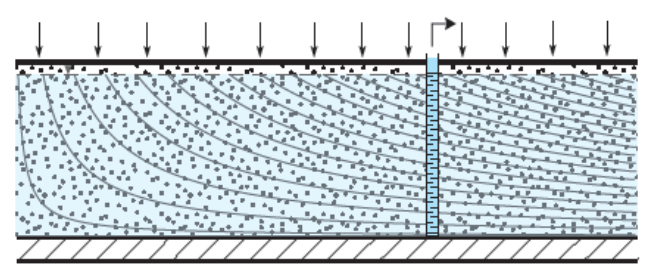

Exit Age Distribution, $g(t)$

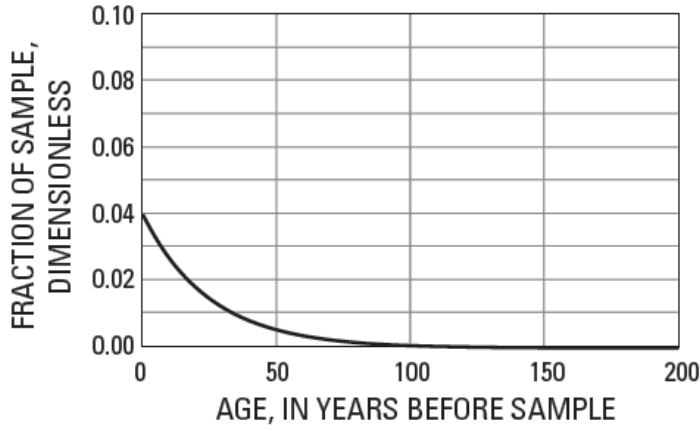

Figure J-2 Example figure of where the exponential mixing model could be ideally applied. The left figure shows an unconfined aquifer receiving equal recharge with the sample taken from a well screened throughout the entire aquifer thickness. Any mixing is assumed to occur only in the well, and not in the aquifer, hence a fairly uniform flow speed. The straight down arrows represent recharge, and the arrow bent at a right angle is the sample point. The graph shows the exit-age frequency distribution expected from exponential mixing of the tracer in the well which has a mean age of 25 years (modified from Jurgens et al, 2012).

The exponential model could be deemed suitable for unconfined aquifers and localized rain recharge (Małoszewski and Zuber, 1982). Real groundwater systems exhibit a combination of these two models exhibiting rainfall recharge, dynamic subsurface flow and variable discharge to wells and river outlet points.

\section{The Exponential Piston-Flow Model}

The exponential piston-flow model is appropriate where there are two sections of flow in a series. Essentially one portion is exponential flow that receives the input (rainfall), with the second lower piston-flow section receiving minimal, if any recharge (Figure $\mathrm{J}-3)$. Constant thickness of the aquifer and saturated flow is assumed and exponential flow occurs first followed by piston-flow. 


$$
\begin{aligned}
& \begin{aligned}
\operatorname{EPM}_{g\left(t-t^{\prime}\right)} & =\frac{n}{\tau_{s}} e^{\left[\frac{n\left(\left(t-t^{\prime}\right)\right)}{\tau_{s}}+n-1\right]}, \text { for } t \geq \tau_{s}\left(1-\frac{1}{n}\right) ; 0
\end{aligned} \\
& \text { where: } n \text { is } \frac{\text { total volume }}{\text { exponential volume }}=\frac{x^{*}+x}{x}=\frac{x^{*}}{x}+1 \\
& =\text { EPM ratio }+1
\end{aligned}
$$

The exponential piston-flow model has two parameters:

1. Mean age; and

2. The exponential piston-flow model ratio, this is the ratio of piston-flow to exponential parts $\left(x^{*} / x\right)$.

The exponential piston-flow model ratio is used to calculate the $\boldsymbol{n}$ parameter, defined by Małoszewski and Zuber (1982) and shown in the above equation. This age distribution in the exponential-piston flow model ranges from completely exponential (EPM ratio $=0$ ) to almost completely piston-flow (EPM ratio = 5) (Jurgens et al, 2012). The model has an advantage over the stand-alone exponential model as it can show a (more realistic) delay in the shortest flow lines (Zuber and Małoszewski, 2001).

$$
\begin{gathered}
\sum_{t^{\prime}=-\infty} C_{\text {out }}(t) \\
\text { in } \\
\text { for } \left.\left.\left.t \geq t^{\prime}\right) \frac{n}{\tau_{s}} \frac{1}{\frac{n}{\tau_{s}}+\lambda}\left[e^{\left[-\left(\frac{n}{\tau_{s}}+\lambda\right)\left(t-t^{\prime}-\Delta t\right)+n-1\right.}\right]\right]\left[-e^{\left[-\left(\frac{n}{\tau_{s}}+\lambda\right)\left(t-t^{\prime}\right)+n-1\right.}\right]\right] \\
\end{gathered}
$$


Exponential Piston-Flow Model (EPM)

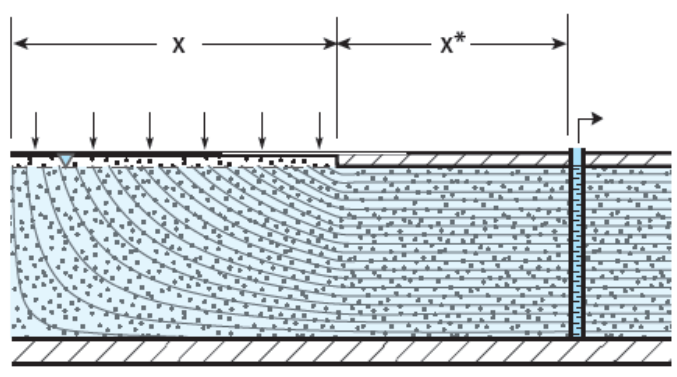

Exit Age Distribution, $g(t)$

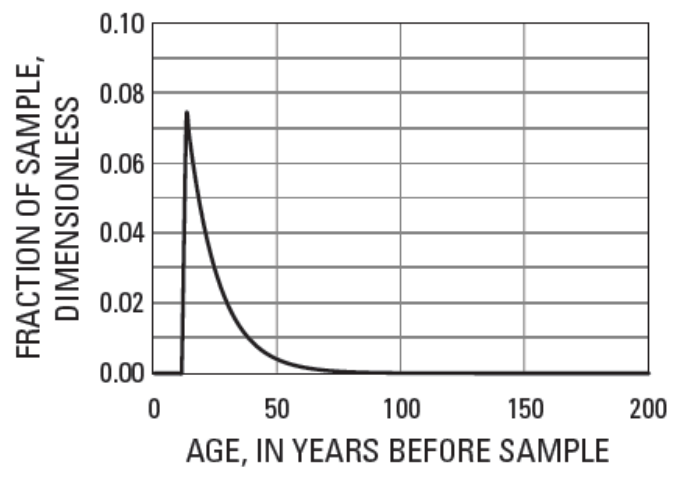

Figure J-3 Example figure of where the exponential piston-flow model could be ideally applied. The left figure shows a partially confined aquifer with a recharge area $(\mathbf{x})$, a confined section $\left(\mathbf{x}^{*}\right)$, and an abstracting well. The rightangled arrow is where the tracer exits the system (via the well). The graph of the right shows the exit-age distribution expected from the exponential pistonflow tracer transport from the recharge area with an exponential piston-flow ratio of one, and a mean age of 25 years (modified from Jurgens et al, 2012).

\section{The Dispersion Model}

The dispersion model is based on a solution to a one-dimensional advection dispersion equation for a semi-infinite medium with an instantaneous injection and detection of the tracer in the fluid flux (Figure J-4) (Kreft and Zuber, 1978; Małoszewski and Zuber, 1982). The dispersion model is flexible and can be applied to multiple groundwater systems in order to approximate age-distributions. Two parameters are used:

1. Mean-age; and

2. The dispersion parameter, this is the ratio of the dispersion coefficient to the velocity and outlet position (Jurgens et al, 2012). 


$$
D M_{g\left(t-t^{\prime}\right)}=\frac{1}{\tau_{s}} \frac{1}{\sqrt{4 \pi D P \frac{t-t^{\prime}}{\tau_{s}}}} e^{\left(-\frac{\left(1-\frac{t-t^{\prime}}{\tau_{s}}\right)^{2}}{4 D P \frac{t-t^{\prime}}{\tau_{s}}}\right)}
$$

where:

$$
D P=\text { dispersion parameter }=\frac{\text { Dispersion coefficient }(D)}{v x}
$$

The dispersion parameter (DP) is the inverse of the Peclet number, i.e. the ratio of the dispersion coefficient (D) to the velocity (v) and outlet position $(\boldsymbol{x})$. The dispersion parameter describes the width and height of the age distribution which is primarily a measure of the relative importance of mixing (dispersion) to advection (Zuber and Małoszewski, 2001). Higher values move the peak towards younger age parcels and lower values tend to show narrower age distributions with the taller peak centred on or near the mean age (Jurgens et al, 2012; Małoszewski and Zuber, 1996).

$$
\begin{gathered}
C_{\text {out }}(t)=\frac{1}{\sqrt{4 \pi D P}} e^{\left(\frac{1}{2 D P}\right)} \sum_{t^{\prime}=-\infty}^{t-\Delta t} C_{i n}\left(t^{\prime}\right) \int_{x_{2}}^{x_{1}} x^{-\frac{3}{2}} e^{\left(-a x-\frac{b}{x}\right)} d x \\
\text { where: } \mathrm{a}=\lambda \tau_{s}+\frac{1}{4 D P}, \quad b=\frac{1}{4 D P}, \\
x=\frac{t-t^{\prime}}{\tau_{s}}, \quad x_{1}=\frac{t-t^{\prime}}{\tau_{s}}, \\
x_{2}=\frac{t-t^{\prime}-\Delta t}{\tau_{s}} .
\end{gathered}
$$



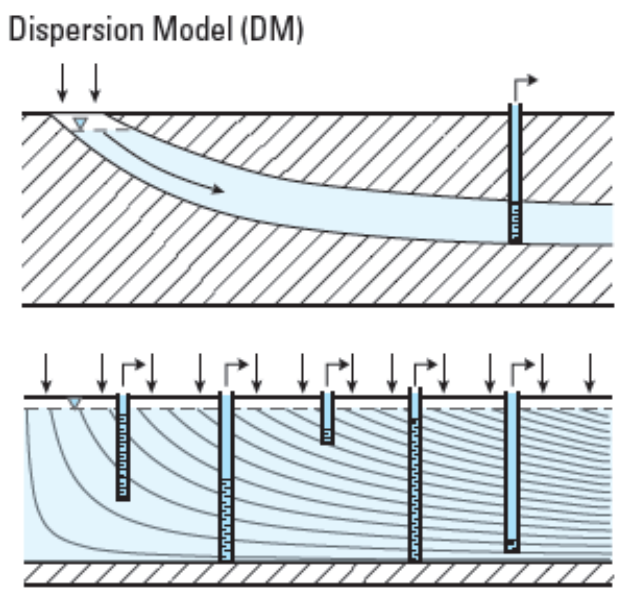

Exit Age Distribution, $g(t)$
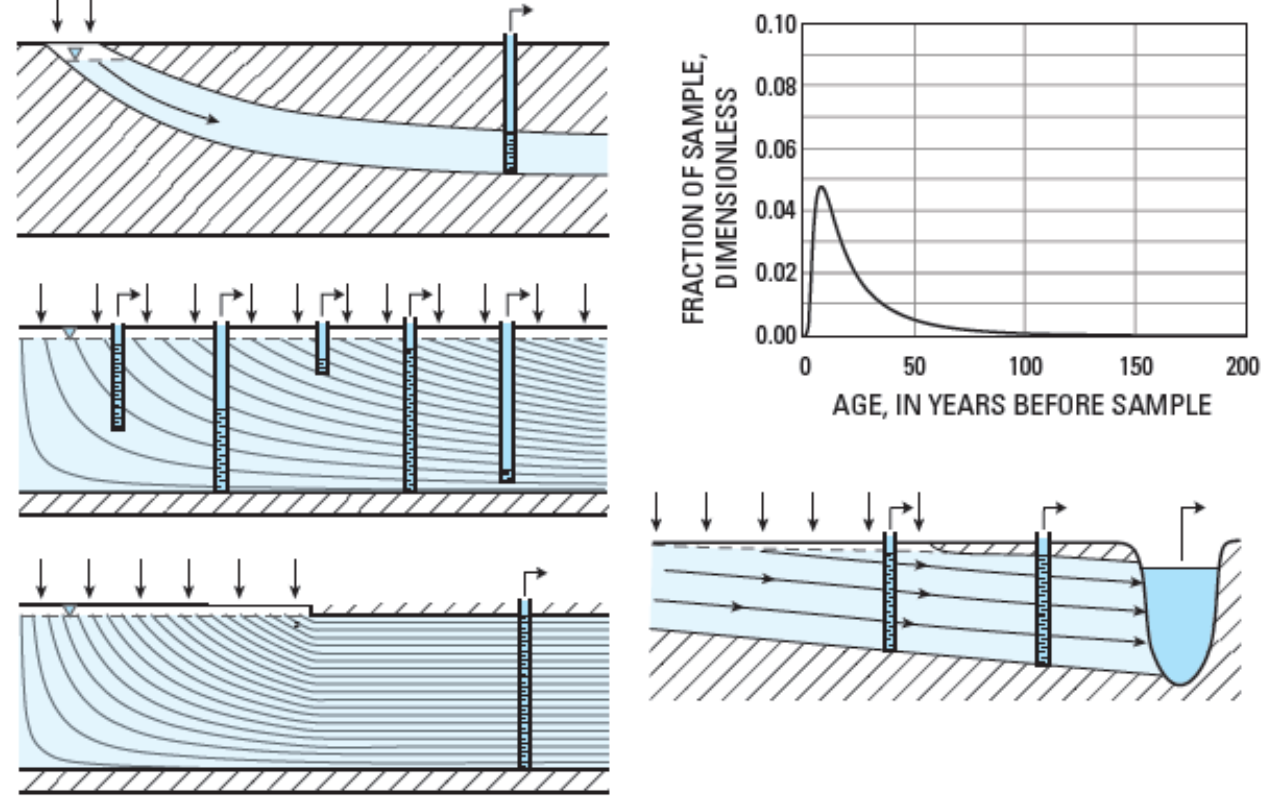

Figure J-4 Four groundwater systems where the dispersion model could be applied. Mixing occurs due to fluctuations in flow velocity and a heterogeneous subsurface. Right-angled arrows are sample points and straight arrows represent recharge. The graph (top right) shows the abstracted age frequency distribution with a dispersion parameter of 0.5 and a mean age of 25 years (modified from Jurgens et al, 2012). 


\section{Appendix K}

\section{Particle Tracking}

\section{Calculating the velocity field}

Particle tracking often uses cellular volumetric fluxes (i.e. the finite difference method) from a groundwater flow model combined with effective porosity to calculate linear velocity (Pollock, 1994). Particle path lines are simulated by tracking the particles from one cell to another until they reach the desired point in the system. The $x, y$, and $z$ components of linear velocity are used to create a velocity field using linear interpolation of the components between the cell faces of the bounding cells. In steady state simulations an analytical expression for the flow path in each cell is calculated by direct integration of the velocity components. The calculated time the particle takes is an average travel time for the advection of a conservative solute/tracer (e.g. tritium) or a particle of water, without any other transport processes (i.e. dispersion, diffusion, degradation) affecting the solute concentrations. The simulations depend on porosity values in the model domain, and the accuracy is dependent on these values being similar to the actual hydrogeological system under investigation (Lindgren et al, 2011).

The partial differential equation describing conservation of mass in a steady state, three-dimensional groundwater flow system can be expressed as:

$$
\begin{aligned}
& \frac{\partial}{\partial x}\left(n v_{x}\right)+\frac{\partial}{\partial y}\left(n v_{y}\right)+\frac{\partial}{\partial z}\left(n v_{z}\right)=\mathrm{W} \\
& \text { where: } \\
& v_{x}=\text { average linear groundwater velocity, three components, also } v_{y} \text {, and } v_{z}(\mathrm{~m} / \mathrm{s}) \\
& n=\text { porosity }(\%) \\
& \mathrm{W}=\text { is the volume of water created or consumed by sources or sinks per unit }\left(\mathrm{m}^{3}\right)
\end{aligned}
$$


This equation (Eq. K-1) calculates water flowing into and out of the cell. Figure K-1 shows a finite cell representing a portion of the simulated aquifer system, inflows $\left(v_{x_{1}}, v_{y_{1}}, v_{z_{1}}\right)$ and outflows $\left(q_{x_{2}}, q_{y_{2}}, q_{z_{2}}\right)$ across the six faces. The average linear velocity of each of the six components is calculated by dividing the volume flow rate across the face by the cross sectional area and the porosity of the material in the cell (Pollock, 1994).

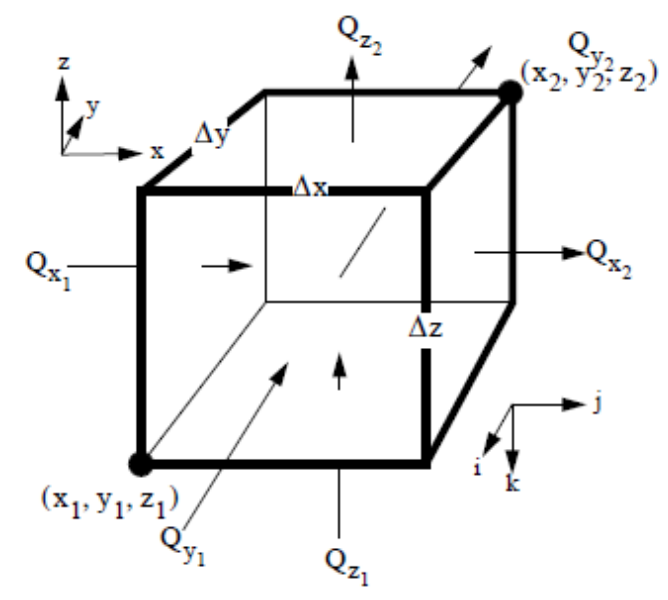

Figure K-1 Finite difference cell showing inflow and outflow components ( $x$-y$z)$ and the average linear velocity component across each face in cell (i-j-k). Source: Pollock (1994).

$$
v_{x_{1}}=\frac{\mathrm{Q}_{x_{1}}}{(n \Delta x \Delta y \Delta z)}
$$

where:

$Q=$ volume flow rate across a cell face $\left(\mathrm{m}^{3} / \mathrm{s}\right)$

$\Delta x \Delta y \Delta z=$ dimensions of the cell in the $\mathrm{x}, \mathrm{y}$, and $\mathrm{z}$ directions $\left(\mathrm{m}^{3}\right)$

note: five more analogous equations for each face (i.e. $v_{x_{1},} v_{y_{1}, . .} v_{y_{2},} v_{z_{2}}$ ) 
If flow to internal sources or sinks within the cell is specified as $Q_{s}$, a mass balance equation for the cell can be derived:

$$
\begin{aligned}
\frac{\left(n v_{x_{2}}-n v_{x_{1}}\right)}{\Delta x} & +\frac{\left(n v_{y_{2}}-n v_{y_{1}}\right)}{\Delta y}+\frac{\left(n v_{z_{2}}-n v_{z_{1}}\right)}{\Delta z} \\
& =\frac{\mathrm{Q}_{s}}{\Delta x \Delta y \Delta z}
\end{aligned}
$$

where:

$$
\mathrm{Q}_{s}=\text { flow to internal sources or sinks within the cell }\left(\mathrm{m}^{3} / \mathrm{s}\right)
$$

The left side of Eq. K-3 is the net volume rate of outflow per cell volume; the right side is the net volume rate of production per cell volume attributed to internal sources and sinks. If each of the flow terms in Eq. K-3 is substituted with Darcy's law it would yield a set of algebraic equations expressed in terms of heads and nodes (centred in each cell). The solution of that set would yield the values of head at each node point. With the head solution solved, the intercell flow rates can be calculated from Darcy's law using the head values from each node (Pollock, 1994).

To simulate the path lines the main components of the velocity vector must be computed at every point in the flow field based on flow rates from the finite difference model. Pollock (1994) uses linear interpolation to compute the principal velocity components at points within a cell. There are three components (two more, $y$ and $z$, which are analogous, in addition to Eq. K-4 replacing $x$ with $y$ and then $z$ respectively.

$$
v_{x}=\mathrm{A}_{x}\left(x-x_{1}\right)+v_{x_{1}}
$$

$A_{x}, A_{y}$, and $A_{z}$ are constants that correspond to the components of the velocity gradient within the cell (Eq. K-5):

$$
\mathrm{A}_{\mathrm{x}}=\frac{\left(v_{x_{2}}-v_{x_{1}}\right)}{\Delta x}
$$


Linear interpolation produces a continuous velocity vector field within each cell that identically satisfies the differential conservation of mass equation (Eq. K-1) everywhere within the cell. That point can be shown by seeing that when the linear velocity component functions Eq. K-5 are substituted into Eq. K-1, the three derivatives on the left side of Eq. K-1 become constants that are identically equal to the three terms on the left side of Eq. K-3 (assuming porosity is uniform/equal, e.g. $0.1 \%)$. Linear interpolation of all (six) faces/velocity components results in a velocity vector field within the cell that automatically satisfies Eq. K-1 at every point inside the cell (it is assumed that internal sources or sinks are uniformly distributed within the cell). Given the velocity vector field within each cell satisfies the differential mass balance equation Eq. K-1 assures that path lines will distribute water throughout the flow field in a way that is consistent with the overall movement of water in the system as indicated by the solution of the finite difference flow equations (Pollock, 1994).

\section{Calculating particle transport time}

The particle tracking method evaluates movement of particle $(p)$ through a threedimensional finite difference cell. The rate of change in the particle's x-direction of velocity as it travels through the cell is (the left side is the time rate of change in the $x$ part of velocity simulated at the point of the particle):

$$
\left(\frac{d v_{x}}{d t}\right) \mathrm{p}=\left(\frac{d v_{x}}{d x}\right)\left(\frac{d x}{d t}\right) \mathrm{p}
$$

where:

$\mathrm{P}$ is used to indicate the term has been calculated at the point/location of the

$$
\text { particle }\left(x-y-z \text { coordinates, } x_{p}, y_{p}, y_{z}\right)
$$

$\left(\frac{d x}{d t}\right) \mathrm{p}=$ the time rate of change of the $\mathrm{x}$-location of the particle 
As in Eq. K-6, the term $\left(\frac{d x}{d t}\right) \mathrm{p}$ is by definition:

$$
v_{x_{p}}=\left(\frac{d x}{d t}\right) \mathrm{p}
$$

In K-7, $v_{x_{p}}$ is the x-part of the velocity for the particle. If Eq. K-4 is differentiated (for $\mathrm{x})$, it yields an extra relation:

$$
\left(\frac{d v_{x}}{d t}\right)=\mathrm{A}_{x}
$$

Substituting the equations K-7 and Eq. K-8 into Eq. K-6:

$$
\left(\frac{d v_{x}}{d t}\right)_{\mathrm{p}}=A_{x} v_{p}
$$

Analogous equations are derived for the $y$ and $z$ directions. These equations can all be rearranged to form:

$$
\left(\frac{1}{v_{x_{p}}}\right) d\left(v_{x_{p}}\right)=A_{x} d t
$$

Eq. K-10 can be integrated and evaluated between times $t_{1}$ and $t_{2}$ :

$$
\ln \left(\frac{v_{x_{p}}\left(t_{2}\right)}{v_{x_{p}}\left(t_{1}\right)}\right)=A_{x} \Delta t
$$

where:

$$
\Delta t=t_{2}-t_{1}
$$

If the exponential of each side of Eq. K-11 is taken, substituting Eq. K-4 for $v_{x_{p}}\left(t_{2}\right)$, and rearranging, results in Eq. K-11 with analogous equations for the $y$ and $z$ directions. 


$$
x_{p}\left(t_{2}\right)=x_{1}+\left(\frac{1}{\mathrm{~A}_{x}}\right)\left\{v_{x_{p}}\left(t_{1}\right) \exp \left(\mathrm{A}_{\mathrm{x}} \Delta t\right)-v_{x_{1}}\right\} \quad \mathrm{K}-12
$$

The velocity of the particle at time $t_{1}$ are known functions of the particles location, and the location of the particle at any future time $\left(t_{2}\right)$ can be evaluated from Eq. K-12 (Pollock, 1994). 


\section{Appendix L}

\section{Additional tracers}

\section{Chlorofluorocarbons}

Chlorofluorocarbons (CFCs) are entirely man-made stable organic compounds containing carbon, chlorine, hydrogen and fluorine (Kazemi et al, 2006).

Chlorofluorocarbons were released into the atmospheric and hydrological systems as a result of worldwide industrial production in the 1930s (Höhener et al, 2003; van der Raaij, 2003). The three most abundant chlorofluorocarbons are CFC-12 ( $\left.\mathrm{CF}_{2} \mathrm{Cl}_{2}\right), \mathrm{CFC}-11$ $\left(\mathrm{CFCl}_{3}\right)$, and $\mathrm{CFC}-113\left(\mathrm{CF}_{2} \mathrm{ClCFCL}_{2}\right)$ all of which are used as tracers in atmospheric, oceanic, and hydrological studies. The atmospheric lifetimes of CFC-11, CFC-12, and CFC-113 are estimated at 45, 87, and 100 years respectively (Plummer and Busenberg, 1999).

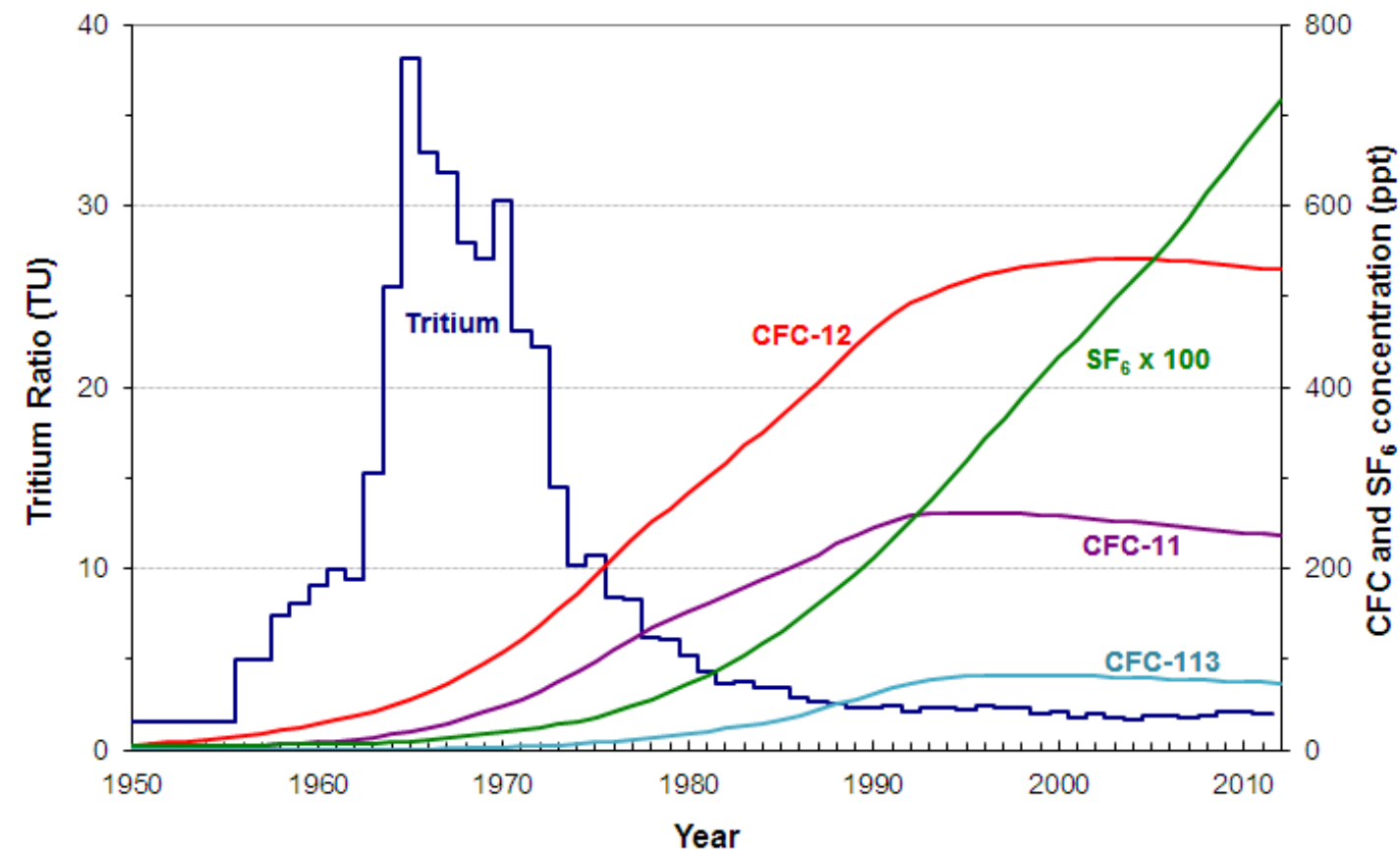

Figure L-1 History of Tritium, CFC-12, SF 6 , CFC-11 and CFC-113 concentrations in the atmosphere in the Southern Hemisphere. Source: van der Raaji, 2013. 
CFC concentrations in New Zealand rain have gradually increased over the past 60 years (Stewart et al, 2007). Atmospheric concentrations increased from zero in 1940, to current concentrations:

1. CFC-11: $236.22\left(\mathrm{ppt}^{8}\right)$,

2. CFC-12: 530.05 (ppt), and

3. CFC-113 74.19 (ppt).

Chlorofluorocarbons were used as refrigerants, solvents, and propellants in numerous household and industrial products. They have since been succeeded by less harmful compounds as they contributed to a pronounced reduction of the ozone layer in the Earth's stratosphere. This was recognized in the late 1970s and attributed to the industrial production of chlorofluorocarbons and other ozone-depleting substances (ODS), such as Methyl Bromide $\left(\mathrm{CH}_{3} \mathrm{Br}\right)$, and Halon $1211\left(\mathrm{CF}_{2} \mathrm{ClBr}\right)$. Alternatives were developed in the late 1970s after chlorofluorocarbons were proved to be damaging the stratospheric ozone layer. Hydrochlorofluorocarbons (HCFCs) are less stable in the lower atmosphere and hence break down before reaching the ozone layer, but are attributed to significantly more chlorine build up in the stratosphere than prior estimates. Hydrofluorocarbons (HFCs) do not contain any chlorine and have shorter lifetimes. The hydrofluorocarbon HFC-134a has since usurped CFC-12 use in car air conditioners. Hydrocarbon refrigerants are now used in air conditioners worldwide which have better performance properties than the formerly used chlorofluorocarbons as well as having lower environmental impacts (Manzer, 1990).

CFC concentrations are currently sufficient for hydrological investigations of young water post-1970 (van der Raaij, 2003). However, as worldwide production has significantly reduced, the atmospheric input no longer exists and chlorofluorocarbons will eventually become redundant as tracers. Dating is possible due to the fact (1) chlorofluorocarbons atmospheric concentrations over the past 70 years are known, (2) the Henry's law solubility's in water are known, and (3) atmospheric and young water concentrations are high enough to be accurately measured (Plummer and Busenberg, 1999).

\footnotetext{
${ }^{8}$ Parts per trillion
} 
Groundwater age process rates can be calculated via the time-dependent source function, relating measured concentrations in groundwater back to historical atmospheric concentration data.

Chlorofluorocarbons have been used extensively for groundwater dating in New Zealand (Morgenstern and Daughney, 2012). They are suitable for dating groundwater from the present to around 60 year old water, which is representative of a large portion of New Zealand's shallow groundwater systems (van der Raaij, 2003). Chlorofluorocarbons have also been used to estimate the age of the groundwater in the Rotorua Lakes region (Morgenstern et al, 2004); Taupo (Reeves and Rosen, 2002), Hawkes Bay (Baalousha, 2012), the Canterbury Plains (Stewart et al, 2002), the South Island's West Coast (Baker, 2004), and Otago (Stewart et al, 2005; Stewart and Fahey, 2010).

\section{Sulphur Hexafluoride}

Sulphur hexafluoride $\left(\mathrm{SF}_{6}\right)$ is a colourless, nontoxic, and odourless inert gas. $\mathrm{SF}_{6}$ is produced naturally in the environment and has a steady state value of $0.054 \pm 0.009$ ppt (Busenberg and Plummer, 2000). However the majority of $\mathrm{SF}_{6}$ released into the atmosphere is of anthropogenic origin with relatively well-known production rates (Levin et al, 2010; van der Raaij, 2003). Production began in 1953 for use in the electric power, semiconductor, and footwear industries. $\mathrm{SF}_{6}$ is a very stable molecule with a long atmospheric lifetime of between 1,935 and 3,200 years with a known atmospheric history (Busenberg and Plummer, 2000; Levin et al, 2010; Rigby et al, 2010). It is largely unaffected by soil processes and biodegradation and has a lack of natural sinks (Harden et al, 2003). It additionally has a lower risk of urban contamination, compared to shallow chlorofluorocarbon dating, and has a low solubility in water making it an ideal hydrological age tracer (Maiss and Brenninkmeijer, 1998; Busenberg and Plummer, 2000). 


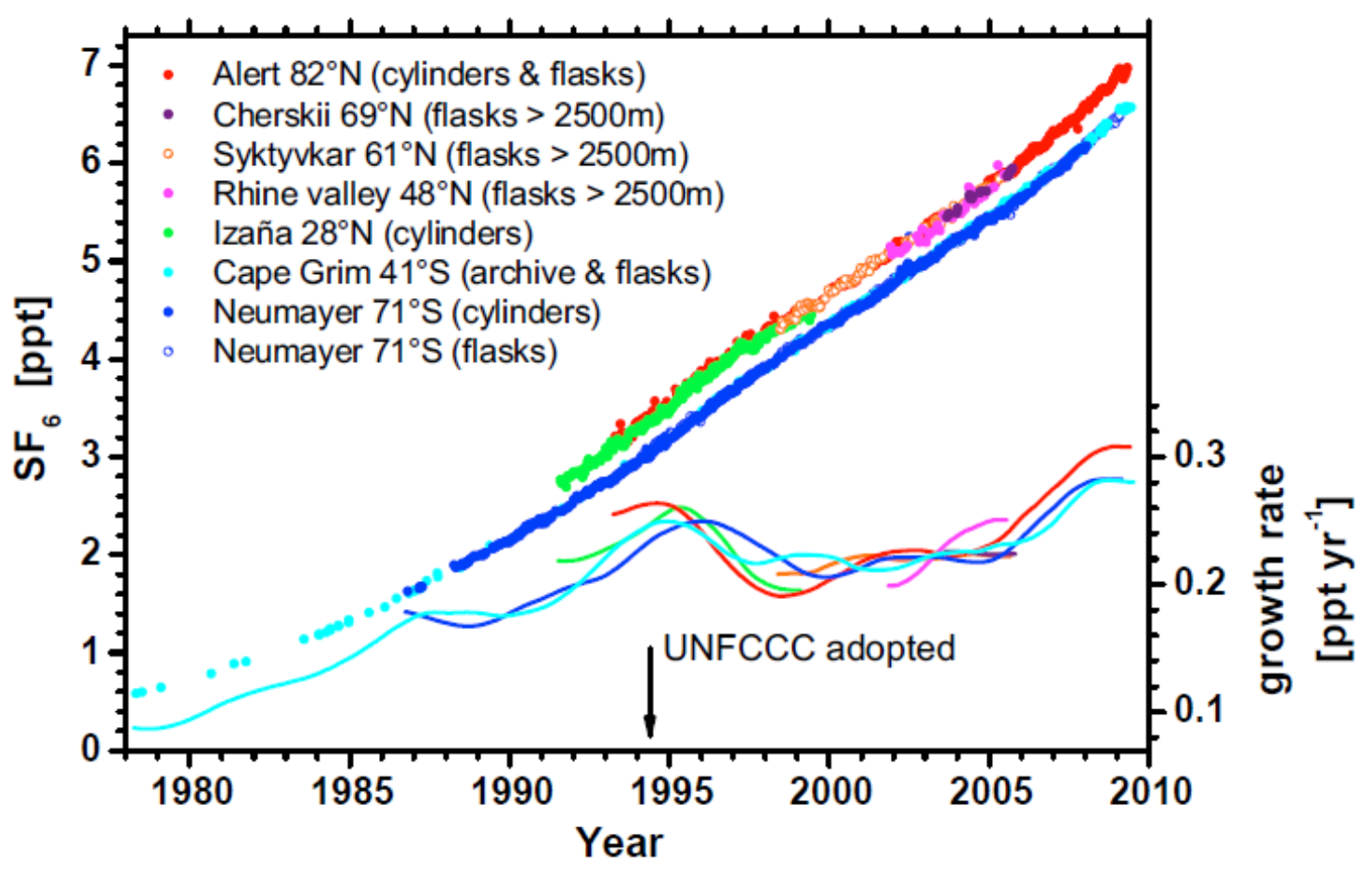

Figure L-2 Global observations of tropospheric SF6 (parts per trillion) observed in Northern and Southern hemispheres. Source: Levin et al, 2010.

$\mathrm{SF}_{6}$ concentrations in rain have increased significantly over the past 60 years.

Concentrations of $\mathrm{SF}_{6}$ in air have rapidly increased from an estimated 0.02 to over 7 parts per trillion over the past 45 years, an increase of about 0.2 parts per trillion per year (Kazemi et al, 2006; Levin et al, 2010). Uncertainties exist when estimating age from $\mathrm{SF}_{6}$ concentrations in any groundwater recharged pre-1970, as no measurements of atmospheric concentrations of sulphur hexafluoride were taken pre-1970. However, estimates have been reconstructed from pre-1970 industrial production data by the United States Geological Survey, for any such application (Busenberg and Plummer, 2008; Plummer et al, 2003). Given the steady increasing and well-known concentrations of $\mathrm{SF}_{6}$ in the atmosphere, $\mathrm{SF}_{6}$ is an increasingly utilized tracer to infer groundwater age.

$\mathrm{SF}_{6}$ has been extensively applied to infer groundwater age over the past 15 years throughout New Zealand (Daughney et al, 2010; Morgenstern and Daughney, 2012). Studies have used age inferred from $\mathrm{SF}_{6}$ in the Waikato (Stewart et al, 2007), Rotorua (Reeves et al, 2008), Taupo (Gusyev et al, 2012), Hawke's Bay (Baalousha, 2012), the Wairarapa Valley (Guggenmos et al, 2011), Nelson (Stewart et al, 2011), 
and Canterbury (Stewart et al, 2002). $\mathrm{SF}_{6}$ is often measured in conjunction with other age-dating tracers (Gusyev et al, 2012; Stewart et al, 2002, 2007), and has become a widely used groundwater age dating tool (Busenberg and Plummer, 2008, 2010; Stewart et al, 2007; Zuber et al, 2005).

\section{Oxygen-18}

Oxygen-18 $\left({ }^{18} \mathrm{O}\right)$ is a natural, stable isotope of oxygen and one of the environmental tracers used in groundwater age assessment. The primary uses of ${ }^{18} \mathrm{O}$ are when investigating water movement, distribution within groundwater reservoirs, and specifically, recharge contributions from rainfall. Seasonal variations of oxygen-18 concentrations in water occur due to variable precipitation, runoff, and recharge events. Stable isotopic variability enables estimates of surface and groundwater mean residence time (Reddy et al, 2006). ${ }^{18} \mathrm{O}$ concentrations in water are not affected by interaction with rocks (at ambient temperature), and are therefore useful for estimating recharge sources provided there are differences in the oxygen-18 concentrations of any potential recharge sources (Stewart and Thomas, 2007). Estimating mean residence times in aquifers with oxygen-18 is limited to shallow dynamic aquifers as seasonal oxygen-18 variations become less accurate with increasing depth (Reddy et al, 2006). Seasonal variations of oxygen-18 in water have been used to investigate small catchments with residence times of weeks to 2-4 years (Zuber et al, 2011) and were used on a $9 \mathrm{~km}^{2}$ catchment to estimate mean residence times of between 1-16 years (Reddy et al, 2006).

\section{Radiocarbon}

Radiocarbon is a radioactive isotope of carbon $\left({ }^{14} \mathrm{C}\right)$ and an environmental tracer for dating groundwater systems of relatively old age, ranging from 2,000, to 30,000 years (Zuber et al, 2011). Dating is achieved through the radioactive decay of ${ }^{14} \mathrm{C}$ in the sample. Like tritium, radiocarbon is produced by cosmic ray spallation in the atmosphere, and increased significantly (roughly doubling) following numerous nuclear bomb tests from 1955-1980 (Reimer et al, 2004). The radioactive half-life of radiocarbon-14 is 5,730 \pm 40 years (Cutnell and Johnson, 2005). 
Isotope exchange interactions between dissolved and solid carbonates complicates analysis and must be accounted for, however, many authors think the ${ }^{14} \mathrm{C}$ method is unsuitable in fractured carbonate groundwater zones, or gravel aquifers rich in carbonates (Małoszewski and Zuber, 1991). Ambiguities of ${ }^{14} \mathrm{C}$ are resolved through additional tracer measurements (e.g. tritium); either measured or estimated, and it is primarily utilized when dating very old groundwater reservoirs (Reimer et al, 2004). 


\section{Appendix M}

\section{Silica-inferred Tritium data statistics}

A relationship between dissolved groundwater constituents is inferred given the natural hydrochemical evolution of groundwater, which becomes enriched with various solutes, as the tritium concentration decreases due to radioactive decay. Inferred tritium concentrations were derived by fitting a linear regression model (Tab. M-1). Two hydrochemical constituents were found to have the most statistically significant correlation (i.e. $>0.6 \mathrm{R}^{2}$ ) to observed tritium concentrations and Silica $\left(\mathrm{SiO}_{2}\right)$ was used as it had the most measurements alongside tritium measurements.

Tab. M-1 Regression relationship between tritium and silica.

\begin{tabular}{lccc}
\hline Parameter & Estimate & Standard Error & T-Statistic \\
\hline Tritium (Constant) & 2.346 & 0.165 & 14.24 \\
SiO2 & -0.049 & 0.008 & -6.26 \\
\hline
\end{tabular}

Figure M-1 shows the fitted linear regression model. Since the P-value in the ANOVA is less than 0.05 , there is a statistically significant relationship between the variables at the $95.0 \%$ confidence level (Tab. M-2). The standard error of the estimate shows the standard deviation of the residuals to be 0.33 .

- $\quad$ R-squared $=61 \%$

- Standard Error of Est. $=0.33$

- Mean absolute error $=0.23$

Tab. M-2 Analysis of Variance (Tritium and Silica, $\mathrm{n}=27$ )

\begin{tabular}{lccccc}
\hline Source & Sum of Squares & Df & Mean Square & F-Ratio & P-Value \\
\hline Model & 4.24 & 1 & 4.24 & 39.18 & 0.0 \\
Residual & 2.70 & 25 & 0.12 & & \\
Total (Corr.) & 6.94 & 26 & & & \\
\hline
\end{tabular}



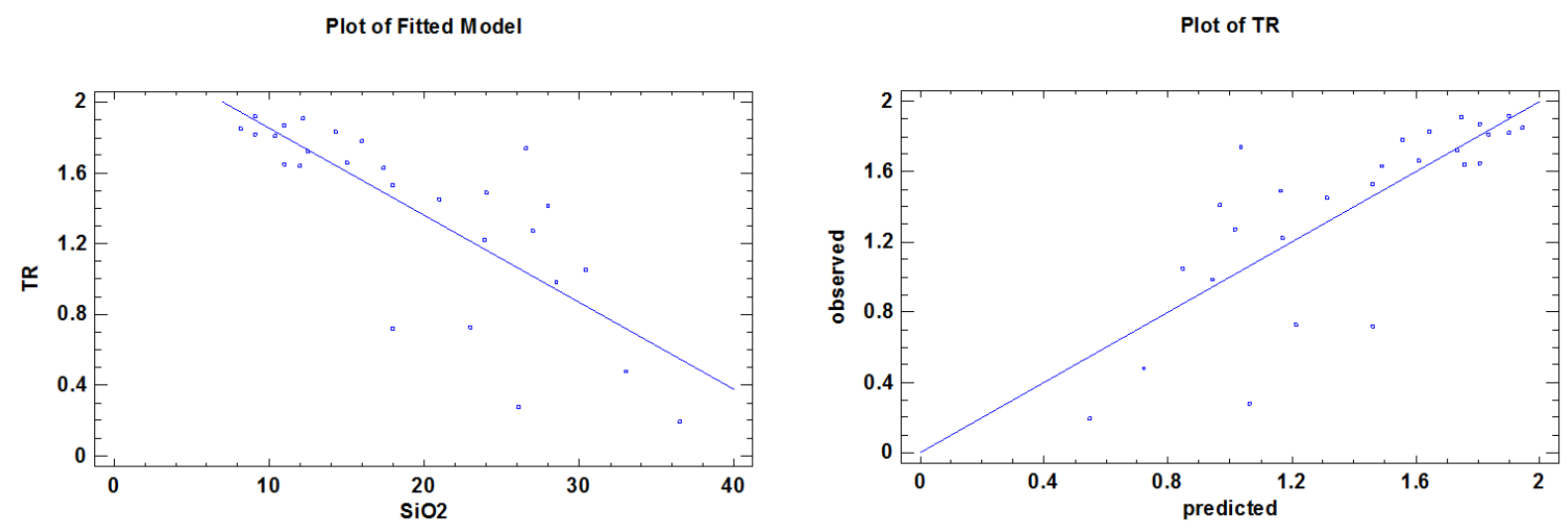

Residual Plot

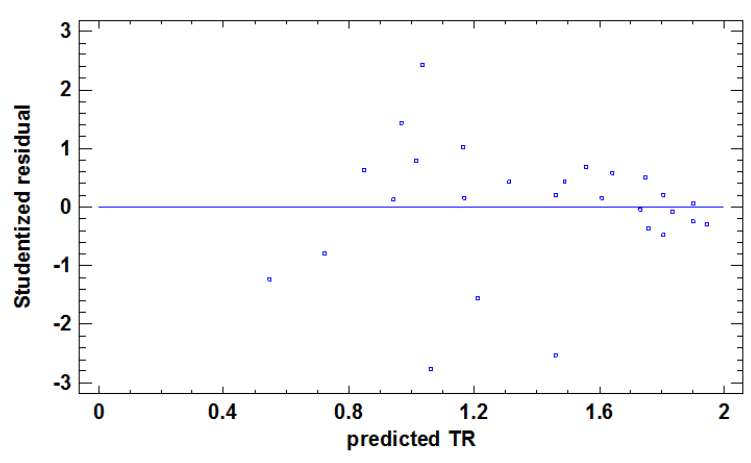

Figure M-1 Plots of the linear regression model showing the measured tritium and silica relationship, observed tritium against predicted tritium, and the residual plot of the predicted tritium. 27 observations were used. 


\section{Appendix N}

\section{Extended Wairarapa Hydrochemistry Information}

\section{Groundwater and surface water interaction}

The first stage involved evaluating the unique groundwater chemistry for each hydrostratigraphic unit based on all the wells that were assumed to abstract from each unit. Differences in each unit's hydrochemistry were apparent but subtle. The chemistry signals from Unit 1 indicated a proportionally larger amount of river recharge, while Units 2 and 6 showed a higher proportion of rainfall recharge. Units 2, 4 and 5 all have similar chemistry suggesting that recharge falls from Unit 2, to Unit 4, to Unit 5. Reduction of oxygen levels is apparent between Unit 4 to Unit 5, and Unit 7 has the least oxygen content as well as the most chemically evolved water indicating that Unit 7 is the oldest. Chemistry analysis confirms the assumptions (by Wellington Regional Council) that recharge moves down through the overlying layers. The Greater Wellington Regional Council conceptual model was confirmed to be generally consistent through the measured hydrochemistry (Daughney, 2007).

The second stage used hierarchal cluster analysis to obtain an independent comparison to Wellington Regional Council's conceptual hydrostratigraphy. Hierarchal cluster analysis restructured the monitoring wells based on major ion concentrations without any consideration of the well or assumed geologic unit. The two major hydrochemical categories ( $A$ and $B$ ) and nine subcategories ( $A 1, A 2$ and $B 1-B 7)$ defined by hierarchal cluster analysis were again generally consistent with the original Wellington Regional Council conceptual hydrostratigraphy. Subcategories A1, A2, B1, B2, B3, B5 and B7 appear to correspond to the hydrochemical expectation for Units 1, $6,4,3,5,2$ and 7, respectively. Elevated concentrations of potassium, sulphate, and nitrate suggest the influence of local land use processes in the hydrochemistry of subcategories B4 and B6 (Daughney, 2007). 
The final third stage used discriminant analysis to assess the likelihood that a well taps into each Wellington Regional Council defined unit, based on ion concentration and well depth. Again this generally agreed with the Wellington Regional Council conceptual hydrostratigraphy with discriminant analysis prediction matching the assumed unit for $75 \%$ of the monitoring wells $(n=99)$. Discriminant analysis failed to classify correctly in several areas (Daughney, 2007):

4. Near the confluence of the Mangatere and Waiohine Rivers, suggesting older sediments are closer to the surface.

5. Along a line almost parallel to the Tararua Ranges, the edges of the Q2 to Q4 fan gravels are closer to the Tararua Ranges.

6. A few shallow sites in the Parkvale sub-region thought to be caused by local land influence, not subsurface processes.

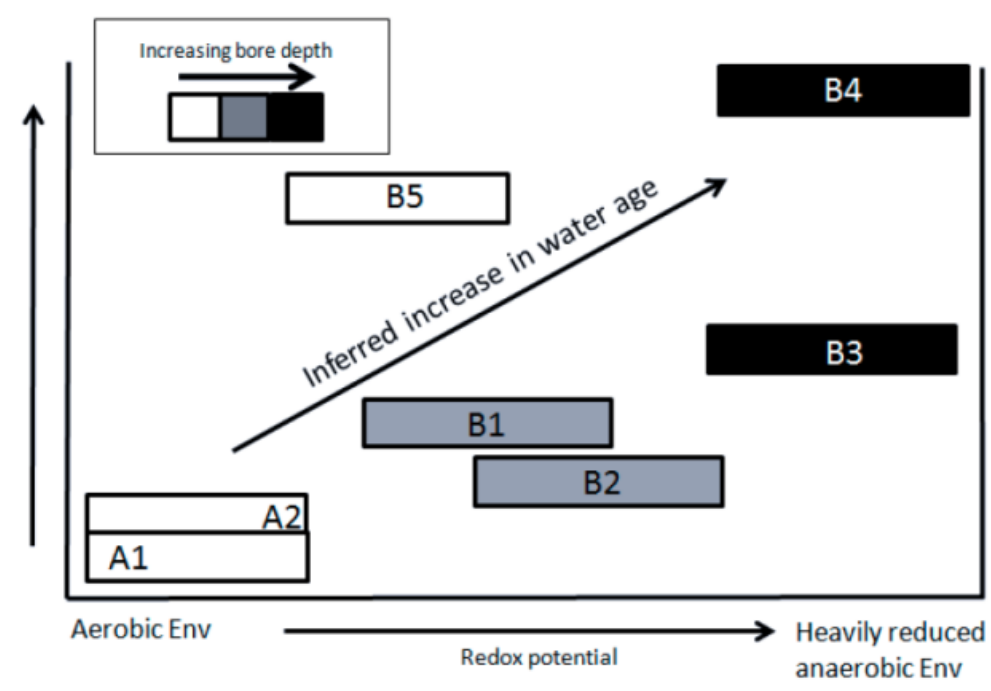

Figure N-1 Simplified diagram of the differences between the seven devised hydrochemical clusters. Source: Guggenmos et al (2011). 


\section{Appendix 0}

\section{Capture Zone Figures}

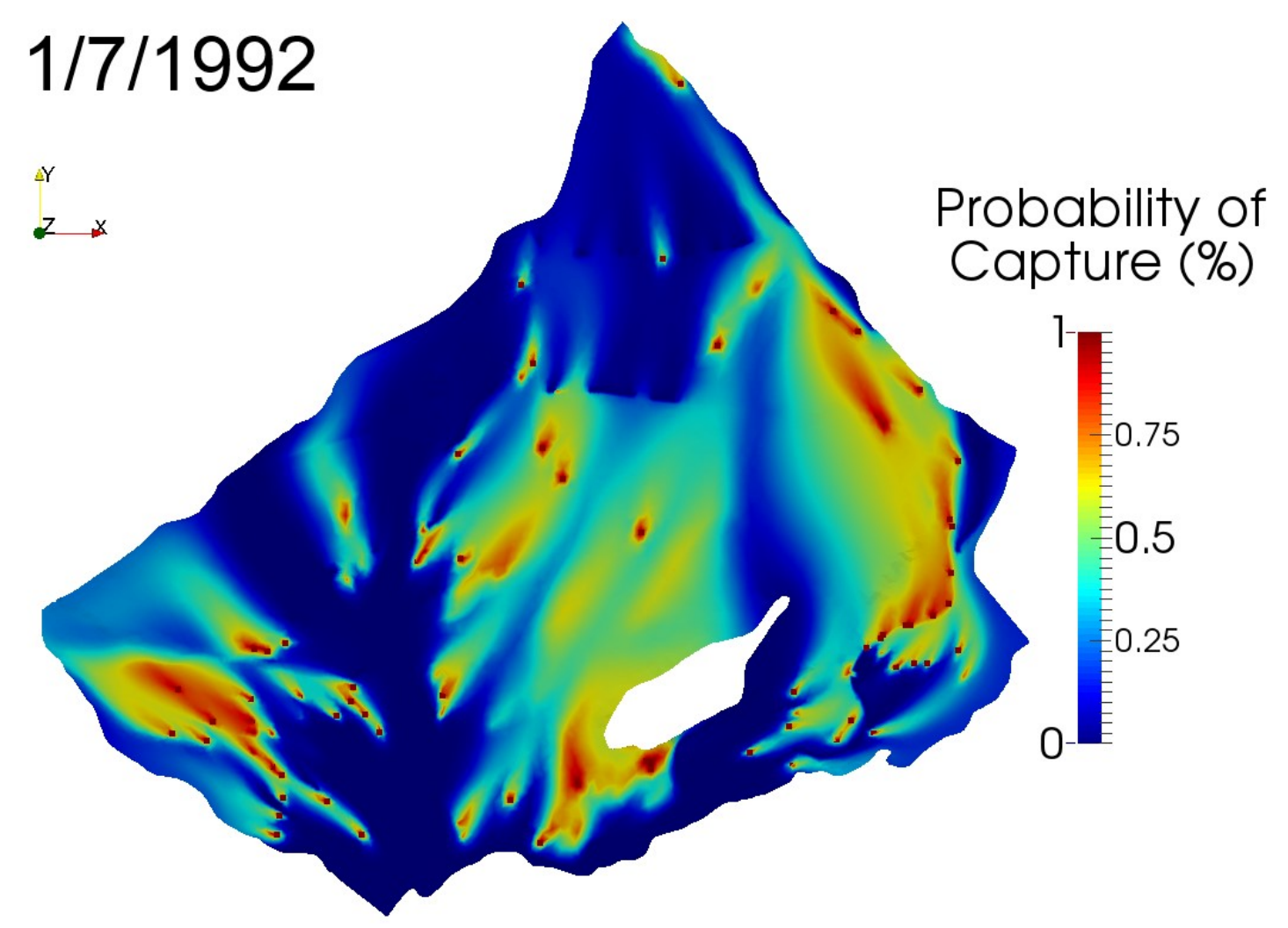

Figure 0-1 Capture zone analysis on the $1^{\text {st }}$ of July 1992. 

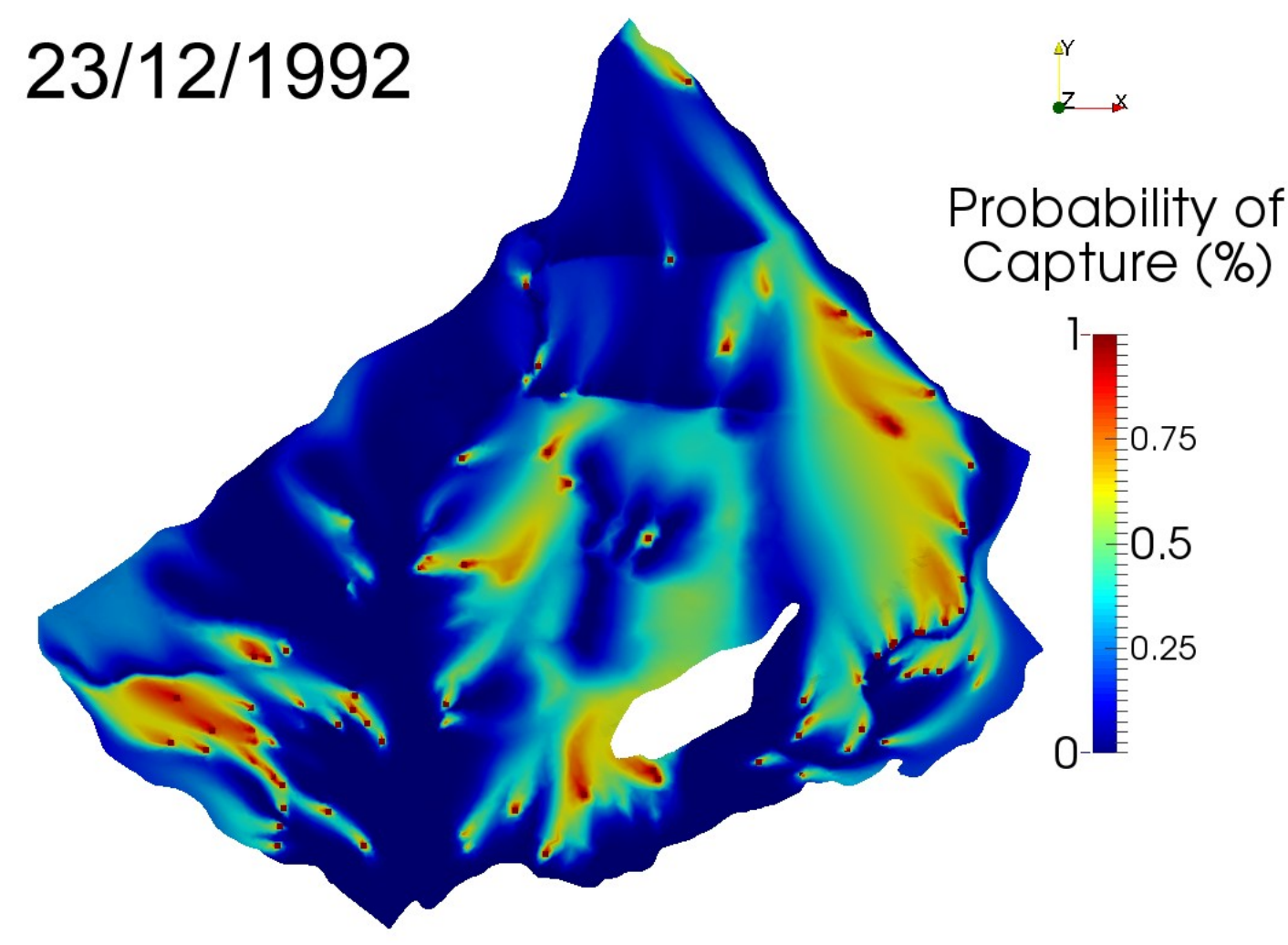

Figure 0-2 Capture zone analysis on the $23^{\text {rd }}$ of December 1992.

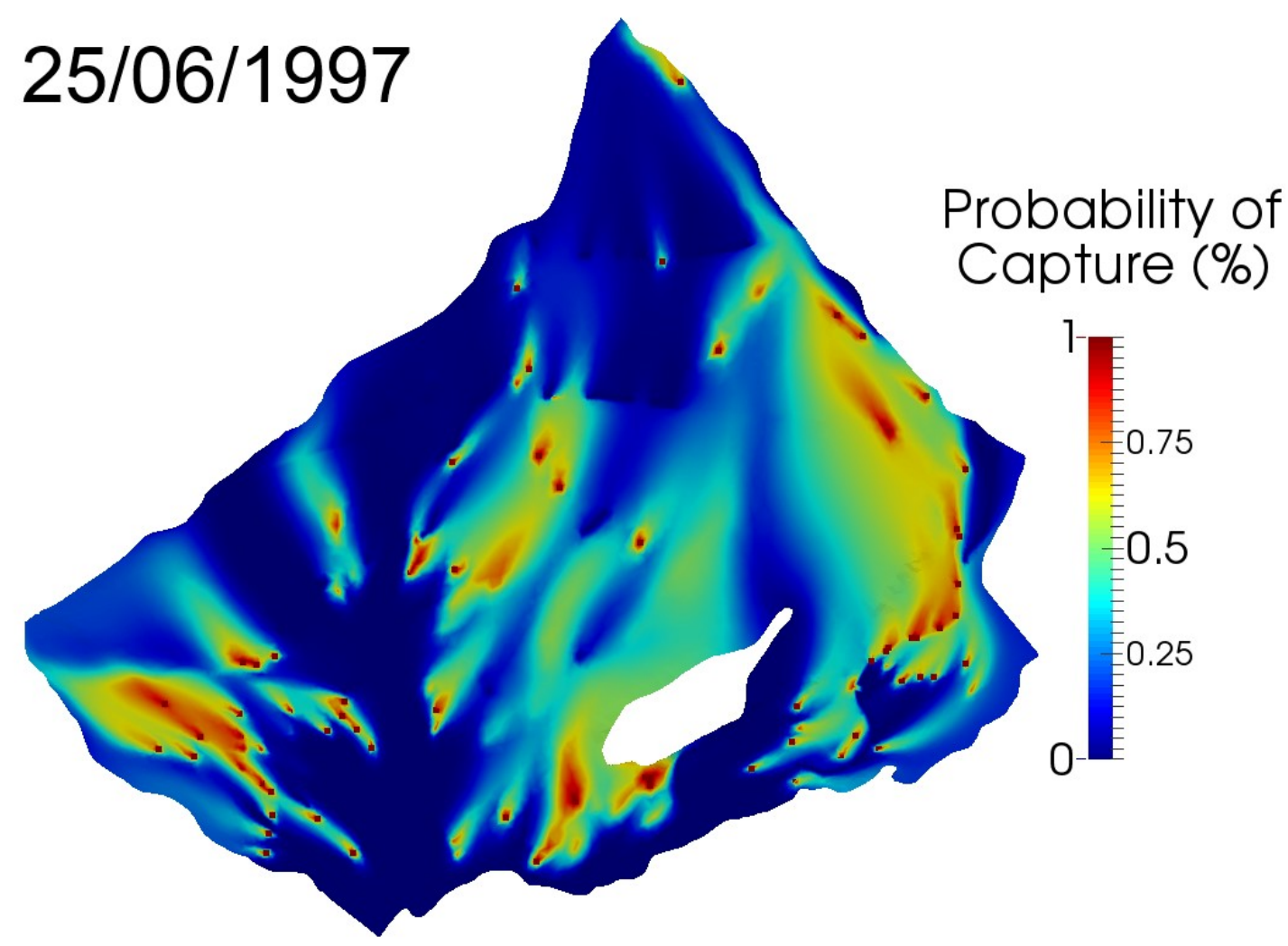

Figure 0-3 Capture zone analysis on the $25^{\text {th }}$ of June 1997. 


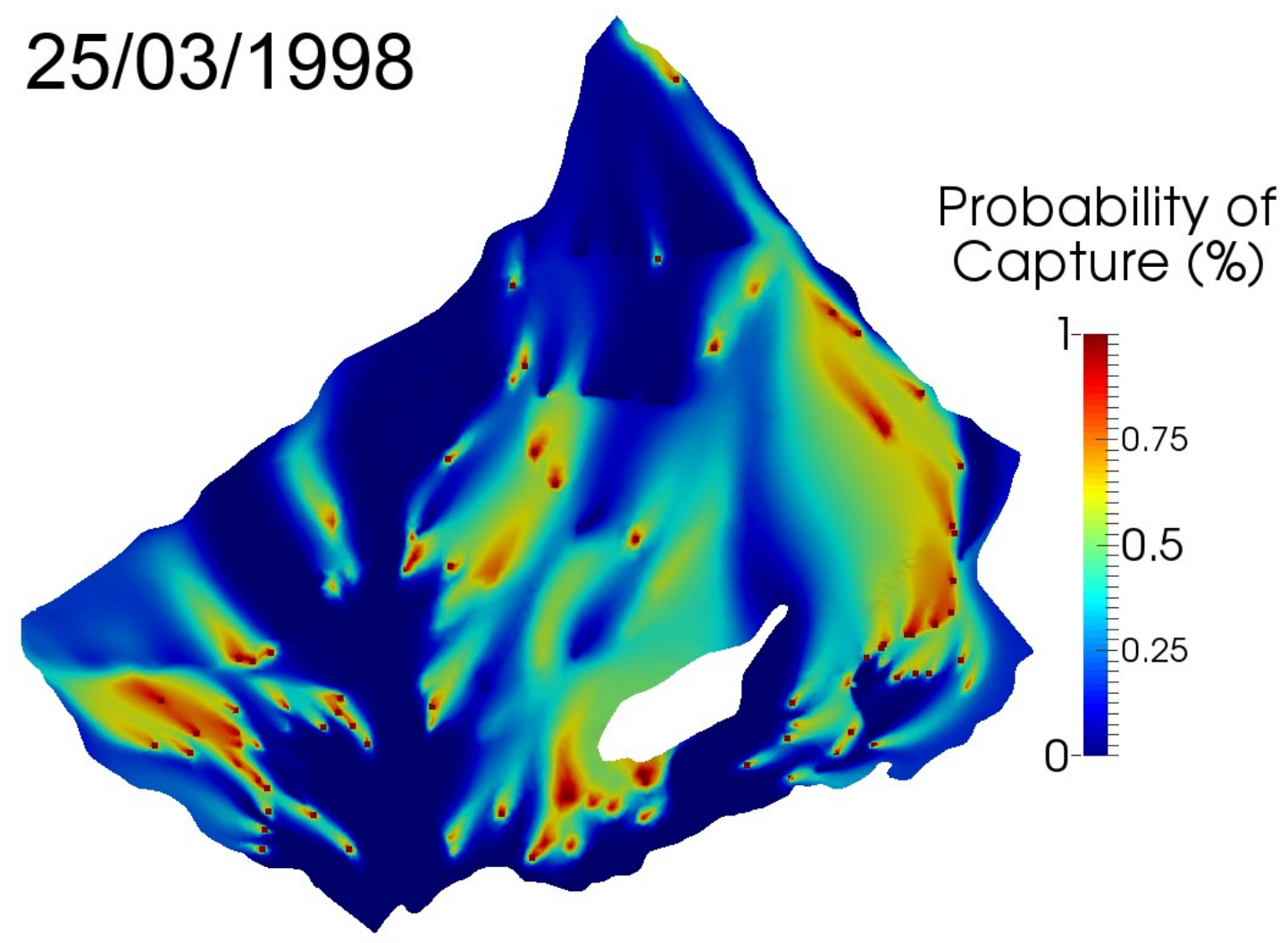

Figure O-4 Capture zone analysis on the $25^{\text {th }}$ of March 1998.

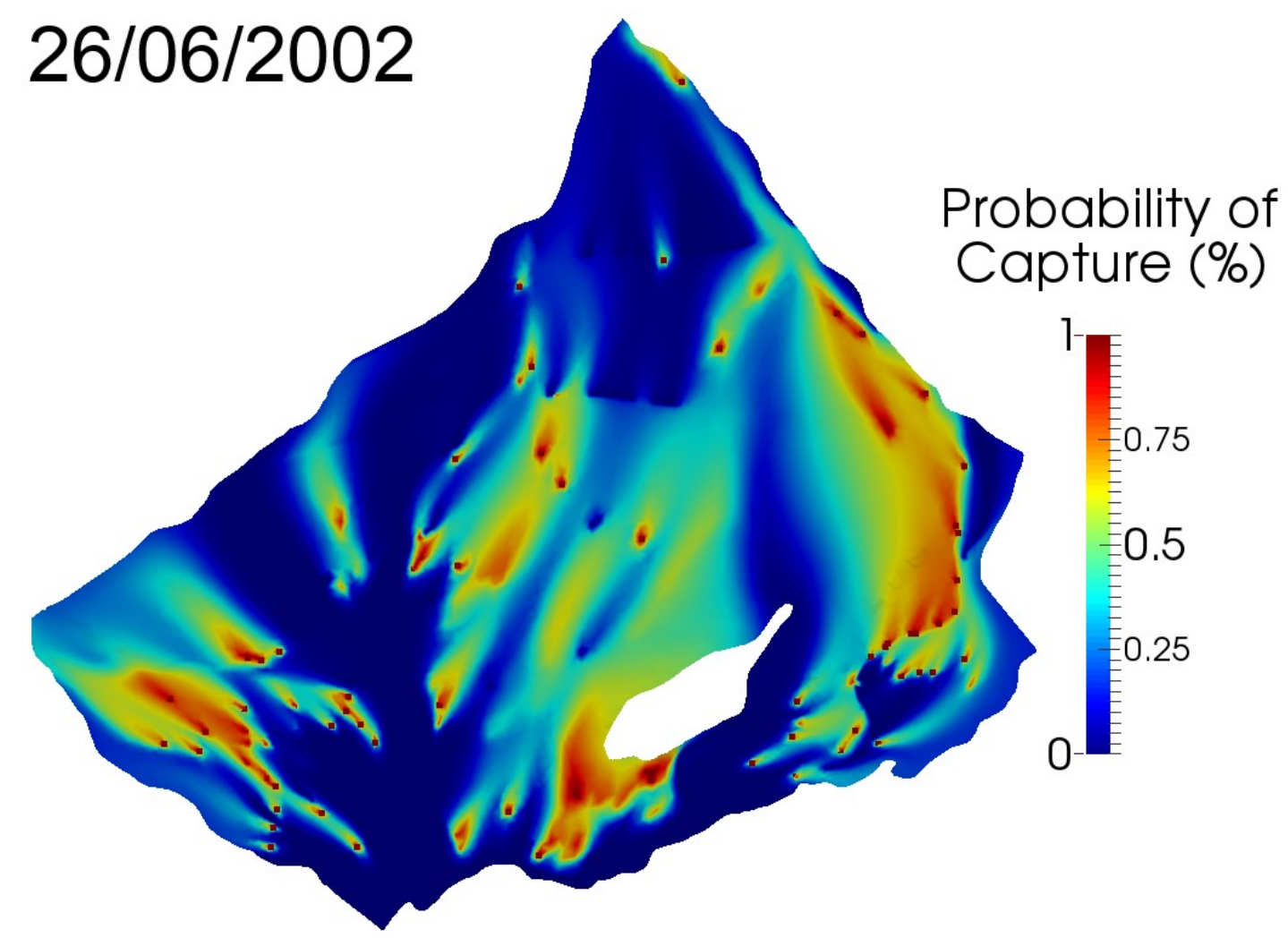

Figure 0-5 Capture zone analysis on the $26^{\text {th }}$ of June 2002. 


\section{$25 / 09 / 2002$}

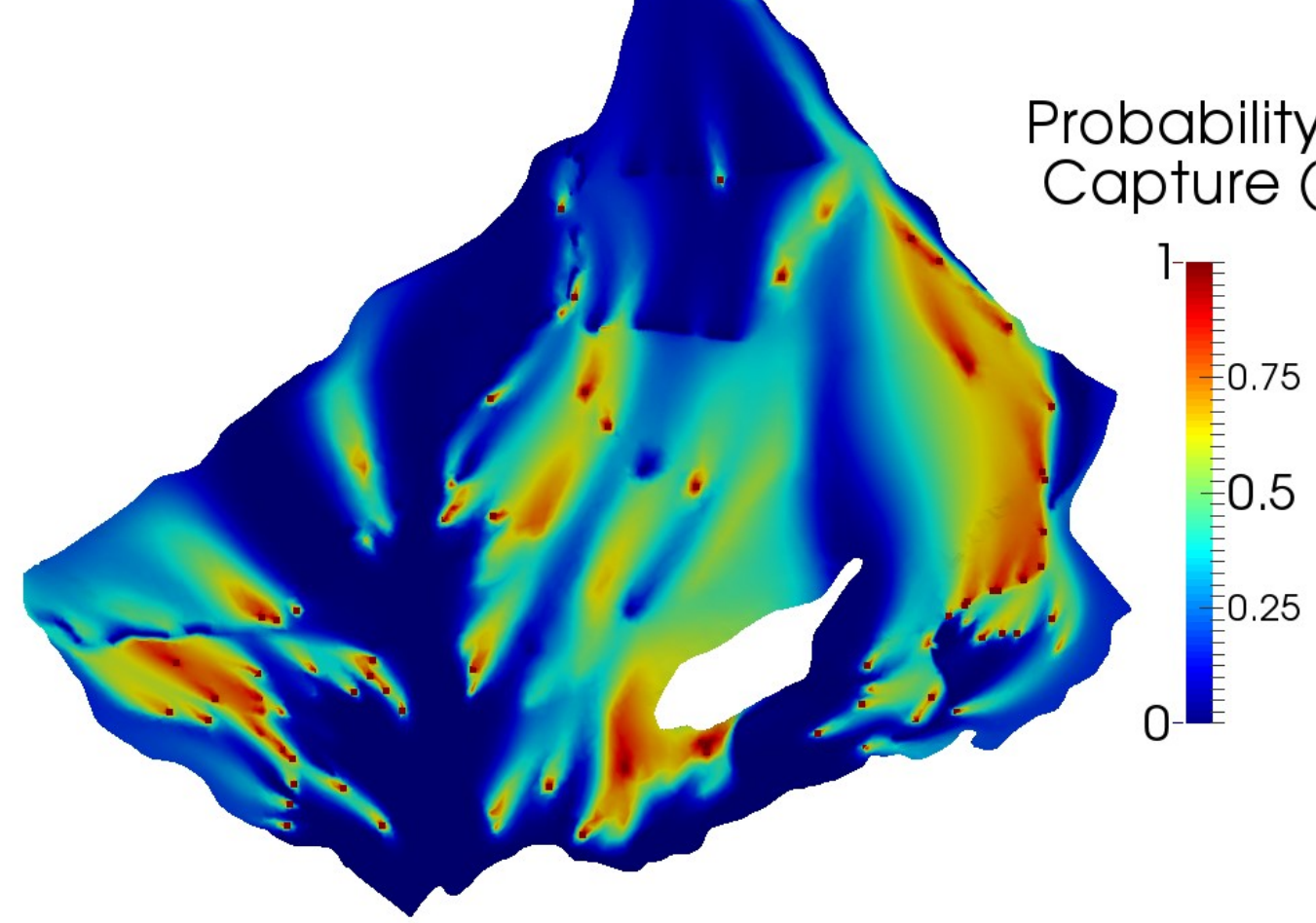

Figure 0-6 Capture zone analysis on the $25^{\text {th }}$ of September 2002.

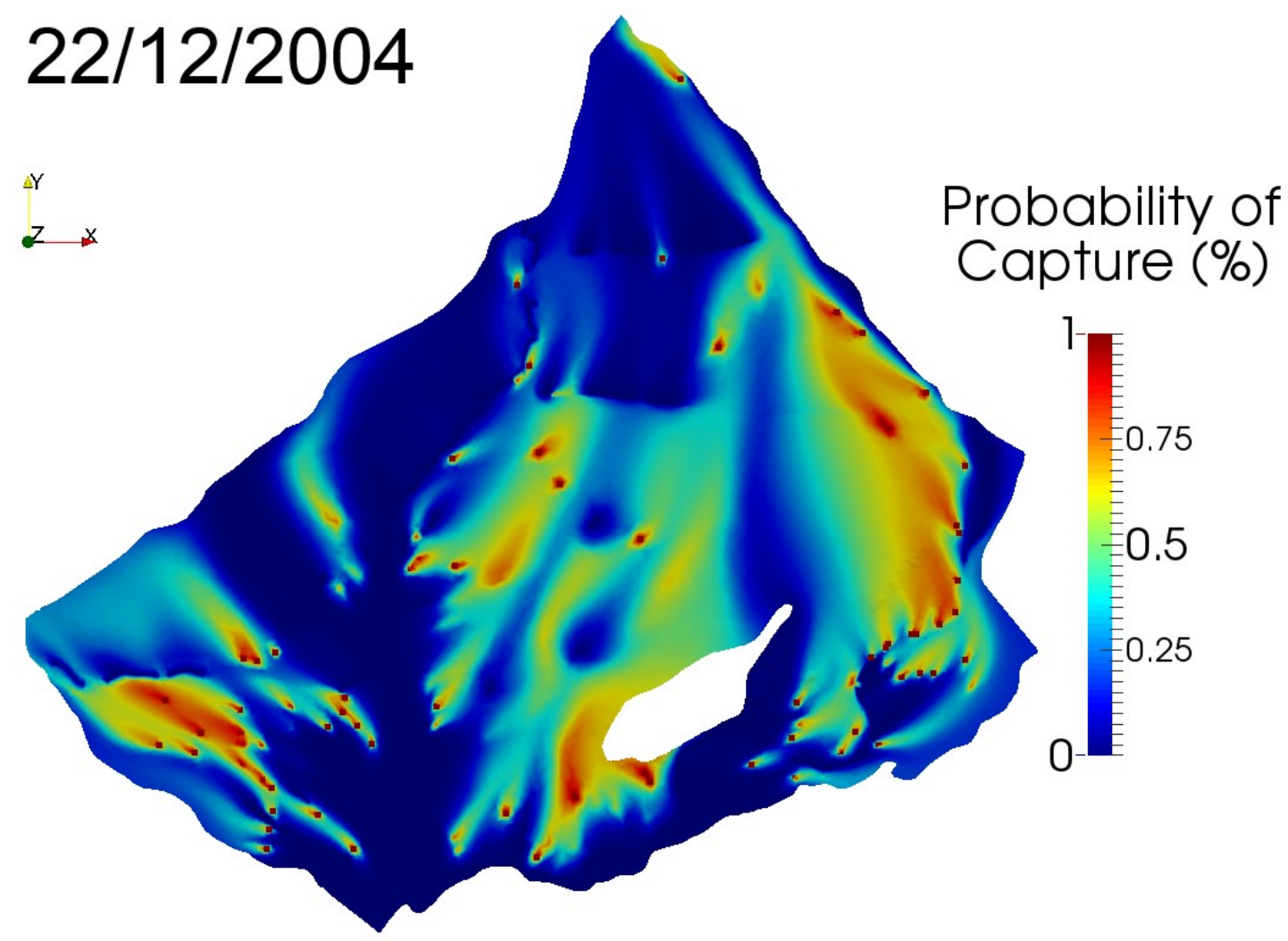

Figure 0-7 Capture zone analysis on the $22^{\text {nd }}$ of December 2004. 


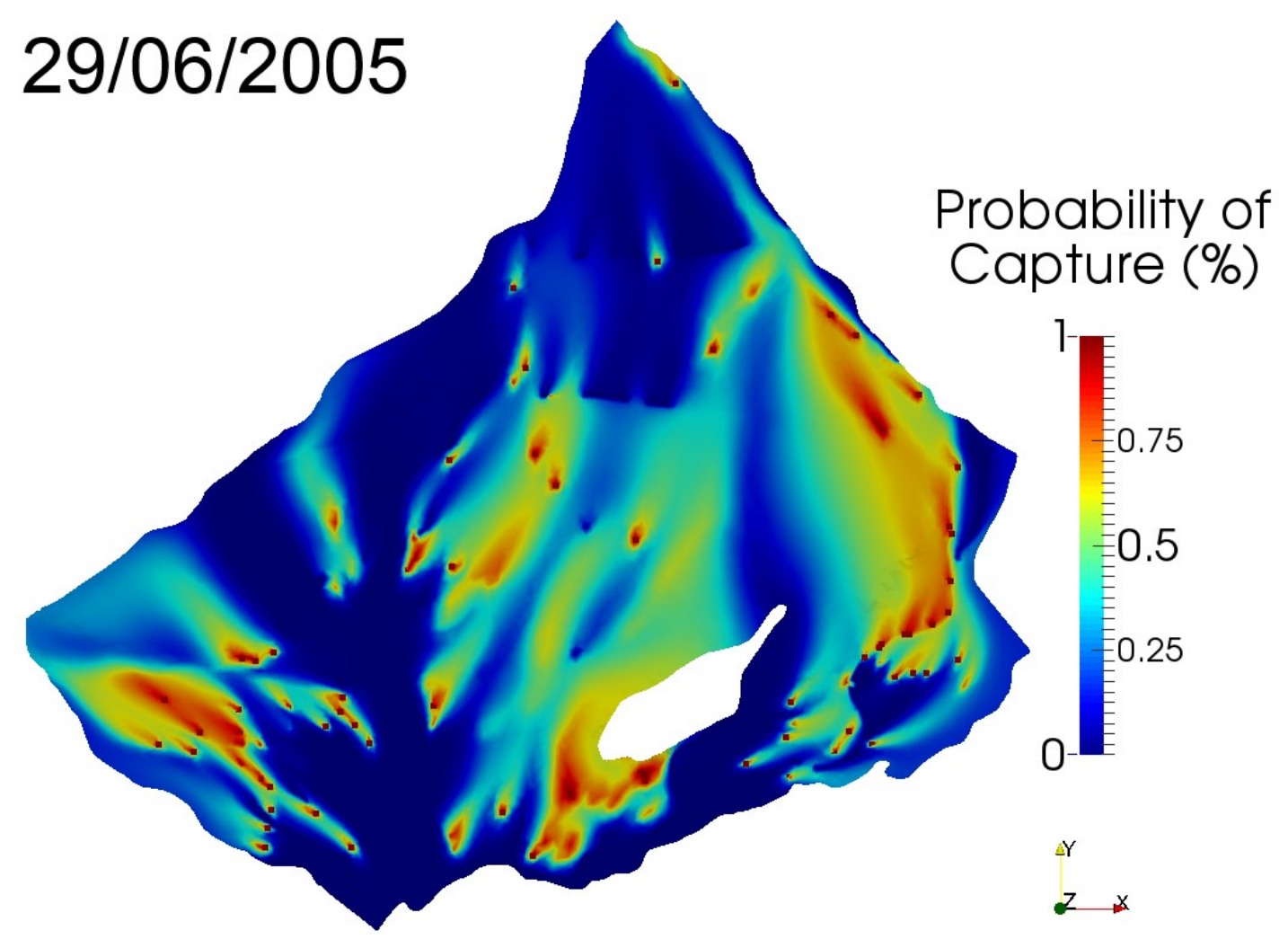

Figure 0-8 Capture zone analysis on the $29^{\text {th }}$ of June 2005. 